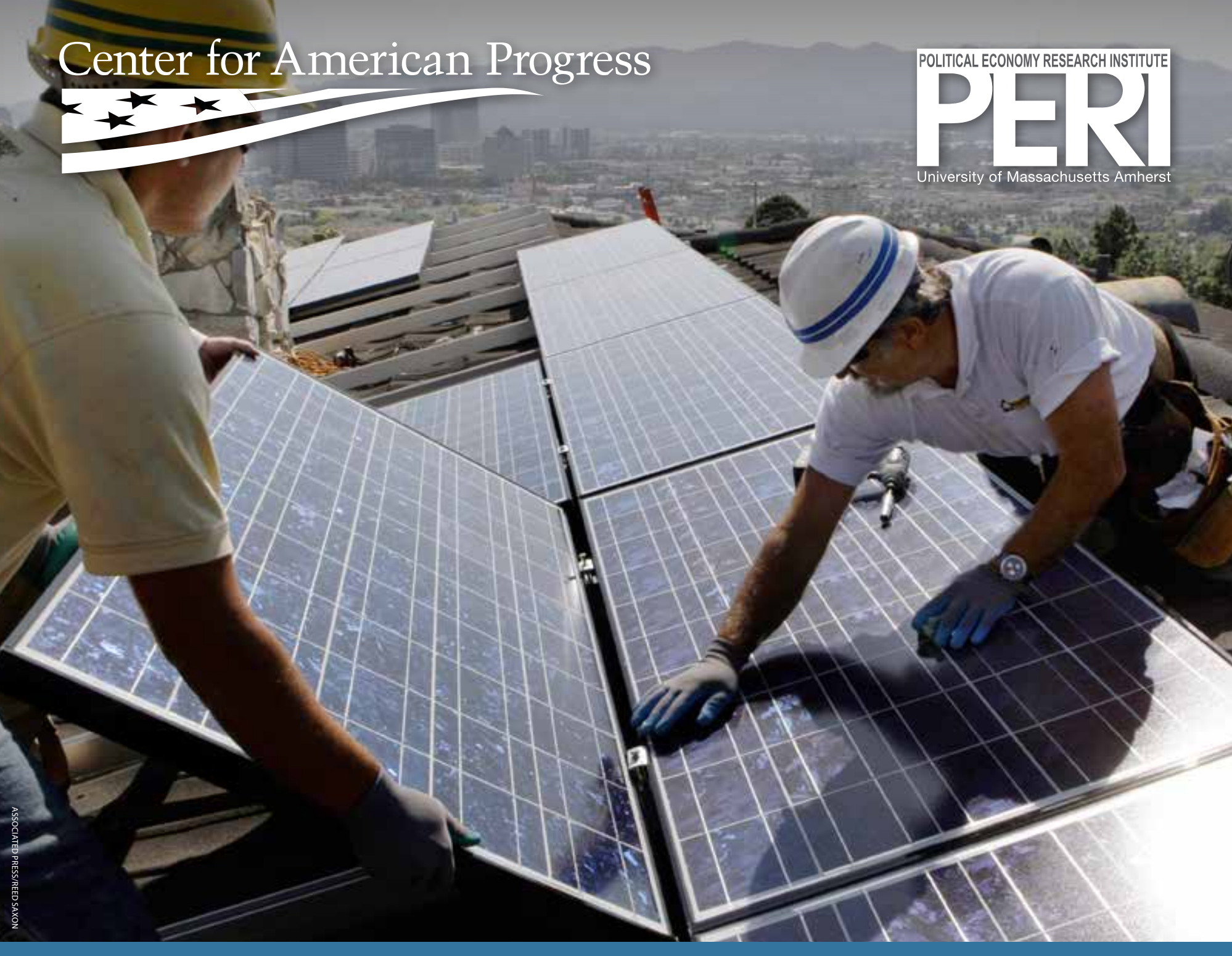

\title{
Green Growth
}

A U.S. Program for Controlling Climate Change and Expanding Job Opportunities

Robert Pollin, Heidi Garrett-Peltier, James Heintz, and Bracken Hendricks September 2014 
Center for American Progress

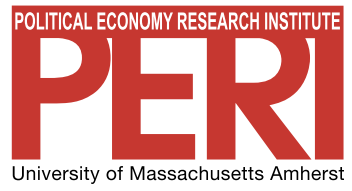

\section{Green Growth}

\section{A U.S. Program for Controlling Climate Change and Expanding Job Opportunities}

Robert Pollin, Heidi Garrett-Peltier, James Heintz, and Bracken Hendricks

September 2014 


\section{Contents}

\section{Summary}

9 Chapter 1: Introduction

37 Chapter 2: Prospects for energy efficiency

98 Chapter 3: Prospects for clean renewable energy

142 Chapter 4: Oil, coal, natural gas, and nuclear power

174 Chapter 5: Carbon dioxide emissions levels under alternative scenarios

198 Chapter 6: Employment effects of the clean energy investment framework

236 Chapter 7: Macroeconomic issues with clean energy investments

267 Chapter 8: Advancing a workable clean energy policy agenda

\section{Appendices}

326 Appendix 1: Public transportation and energy efficiency

334 Appendix 2: Auto fuel-economy standards and energy consumption

337 Appendix 3: Explanation of the ElA's Extended Policies case

343 Appendix 4: Methodology for estimating the employment effects of alternative energy industry expenditures

368 Appendix 5: Estimating fiscal impacts of clean energy public policy programs

\section{References}

396 Index

404 Acknowledgments and About the authors 


\section{List of Tables}

91 Table 2.17: Estimates of direct rebound effects from two recent survey papers

Table 1.1: Conversion factors in standard energy units

Table 2.1: Comparative energy use and emissions levels for the United States and other advanced economies

Table 2.2: Energy consumption in the United States by economic sector Table 2.3: Energy consumption in buildings, 2010 and 2030 Reference case

Table 2.4: Main sources of energy-efficiency investments:

'Technoeconomic potential' Residential - electricity

Table 2.5: Main sources of energy-efficiency investments:

'Technoeconomic potential' Residential - natural gas

Table 2.6: Main sources of energy-efficiency investments:

'Technoeconomic potential' Commercial - electricity

Table 2.7: Main sources of energy-efficiency investments:

'Technoeconomic potential' Commercial - natural gas

Table 2.8: Prospects for energy efficiency in buildings: EIA 2030 Reference case vs. the National Academy of Science's technoeconomic cases

Table 2.9: Sources of energy saving in U.S. pulp and paper industry

Table 2.10: Sources of energy saving in U.S. iron and steel industry

67 Table 2.11: Range of estimates of economic potential for energy-efficiency improvements in industry

8 Table 2.12: Overall costs of energy-efficiency investments in industry from 2011 through 2030

2 Table 2.13: Energy use by transportation mode

5 Table 2.14: Estimated retail-price increase, gasoline savings, and reductions in greenhouse gas emissions of advanced vehicles (relative to baseline-average gasoline vehicles, 2005 models)

9 Table 2.15: Overall costs to reduce transportation-sector energy consumption from 28 to 20 Q-BTUs in 2030

83 Table 2.16: Summary of efficiency investments needed to reduce total U.S. energy consumption from EIA 2030 Reference case of 104.3 Q-BTUs to 70 Q-BTUs in 2030

2 Table 3.1: U.S. renewable energy consumption by categories in 2010 
Table 3.2: EIA Reference case projection of 2030 U.S. renewable energy consumption Table 3.3: EIA Reference case projection of 2035 U.S. renewable energy consumption Table 3.4: Alternative estimates for renewable energy generation

Table 3.5: Greenhouse gas emissions reductions for alternative biofuels and biomass energy sources

Table 3.6: 2035 projections for wind, solar, and geothermal energy supply in EIA Low-Cost Renewable Technology case

Table 3.7: Summary of clean renewable supply potential from 2030 through 2035

Table 3.8: Estimated average levelized costs of electricity from renewable energy sources

Table 3.9: Range for total system levelized costs for electricity from renewable energy sources

Table 3.10: Average levelized costs of renewables versus fossil fuels and nuclear Table 3.11: Range for total system levelized costs for conventional electricity sources

Table 3.12: Total levelized costs for clean renewables in 2030 based on EIA Reference case cost figures

Table 3.13: Total levelized costs for renewables in 2030 based on EIA Low-Cost Renewable Technology case

Table 3.14: Total levelized costs for producing 15.4 Q-BTUs of electricity powered by a combination of coal, natural gas, and nuclear energy (2010 prices)

Table 3.15: Comparison of total levelized costs for generating 15.4 Q-BTUs of electricity through Alternative Renewable and Nonrenewable cases

Table 3.16: Renewable energy capital expenditures for electricity generation: Annual levelized costs and present values

7able 3.17: Capital expenditures for estimated clean renewable capacity expansion from 2010 through 2030

Table 4.1: Estimated U.S. overall oil demand in 2030

Table 4.2: Coal-fired electricity capacity: Alternative projections

Table 4.3: Coal-fired electricity consumption: Alternative projections

Table 4.4: Natural gas-fired electricity capacity: Alternative projections

Table 4.5: Natural gas-fired electricity consumption: Alternative projections

7 Table 4.6: Nuclear-powered electricity capacity: Alternative projections

8 Table 4.7: Nuclear-powered electricity consumption: Alternative projections 
161 Table 4.8: Electricity generation from all nonrenewable energy sources: Alternative projections

166 Table 4.9: Total levelized costs for electricity generation from alternative energy sources

177 Table 5.1: $\mathrm{CO}_{2}$ emissions levels from alternative fossil fuel energy sources

179 Table 5.2: Weighted averages of U.S. emissions for oil, coal, and natural gas

182 Table 5.3: Summary of investment requirements under 2030 PERI/CAP scenario

187 Table 5.4: Features of Aggressive Reference case for U.S. energy consumption in 2030

188 Table 5.5: Alternative U.S. energy consumption scenarios for 2030

191 Table 5.6: CO emissions generated by alternative U.S. energy scenarios

194 Table 5.7: 2030 side case 1: 100 percent fuel switch from coal to natural gas off of Aggressive Reference case assumptions

Table 5.8: 2030 side case 2: Natural gas partially replaces nuclear power under PERI/CAP case

Table 5.9: 2030 side case 3: Natural gas fully replaces nuclear power under PERI/CAP case

Table 6.1: Employment creation through energy-efficiency capital expenditures in buildings and industry

210 Table 6.2: Job creation through buildings and industry efficiency investments

211 Table 6.3: Job creation through renewable energy capital investments

212 Table 6.4: Job creation through renewable energy operations and maintenance expenditures

213 Table 6.5: Job creation through capital expenditures to produce a net expansion of 11.8 Q-BTUs of clean renewable energy

214 Table 6.6: Job creation through operations and maintenance of 15.4 Q-BTUs of clean renewable energy by 2030 to 2035

215 Table 6.7: Summary of job creation for achieving a 70 Q-BTU economy with 15.4 Q-BTUs of clean renewable energy by 2030 to 2035

216 Table 6.8: Job creation within nonrenewable energy sectors: New capital expenditures and operations and maintenance for coal, natural gas, nuclear power, and oil

218 Table 6.9: Net change in employment through transferring funds from nonrenewable to clean energy sector spending

226 Table 6.10: Occupations with large growth potential through green investments 
Table 6.11: Breakdown of job creation by formal educational credential levels

Table 6.12: Bioenergy operations and maintenance: Job creation breakdown by formal educational credential levels

Table 6.13: Bioenergy operations and maintenance: Occupations with large growth potential

Table 7.1: Comparison of alternative U.S. GDP growth forecasts under baseline and with cap-and-trade legislation

Table 7.2: Projected clean energy investments as share of U.S. economy

Table 7.3: Expenditure allocation for all ARRA clean energy appropriations from U.S. Council of Economic Advisers, January 2010

Table 7.4: Estimates of direct job creation through ARRA clean energy projects within the U.S. Department of Energy

Table 7.5: Estimate of total job creation on DOE-funded ARRA projects

Table 7.6: ARRA clean energy 1705 loan guarantee program: Recipients of guarantees from 2009 through 2013

Table 8.1: A clean energy policy agenda for achieving the U.S. 20-year $\mathrm{CO}_{2}$ emission reduction target

Table 8.2: Summary of average annual sources of revenues/net savings and expenditures from clean energy projects

Table A1.1: U.S. energy consumption in 2011 through alternative transportation modes

Table A1.2: Employment creation through investments in public transportation

Table A1.3: Employment creation through doubling public bus transportation availability in 20 years

Table A2.1: Age range for entire U.S. auto fleet in 2001

Table A2.2: Calculations for estimating the average fuel economy level for U.S. light-duty vehicles as of 2030

Table A3.1: Alternative U.S. energy consumption scenarios for 2030 including ElA's extended policies case

Table A3.2: $\mathrm{CO}_{2}$ emissions generated by alternative U.S. energy scenarios

Table A4.1: Composition of energy industries using input-output model

Table A4.2: Change in U.S. output multipliers for alternative energy sectors, 1995-2007

Table A4.3: Possible impacts on employment from varying rates of GDP growth and labor productivity growth 


\section{Contents}

366 Table A4.4: U.S. average annual GDP growth and labor productivity growth over various time periods

373 Table A5.1: Federal and state green bank programs: Estimating annual program costs over 20 years

375 Table A5.2: Federal loan guarantee program for clean energy investments: Estimating annual costs for 20-year program

377 Table A5.3: Estimated 20-year public budgetary impacts through policies supporting $\$ 200$ billion annual U.S. clean energy investment program

381 Table A5.4: Summary of average annual sources of revenues/net savings and expenditures from clean energy projects 


\section{Contents}

\section{List of Figures}

5 Figure S.1: $\mathrm{CO}_{2}$ emissions generated by alternative U.S. energy scenarios

38 Figure 2.1: U.S. energy consumption from 1970 through 2010

51 Figure 2.2: Residential electricity savings potential for 2030 based on National Academy of Sciences 'Technoeconomic' cases

52 Figure 2.3: Residential natural gas savings potential for 2030 based on National Academy of Sciences 'Technoeconomic' cases

52 Figure 2.4: Commercial electricity savings potential for 2030 based on National Academy of Sciences 'Technoeconomic' cases

53 Figure 2.5: Commercial natural gas savings potential for 2030 based on National Academy of Sciences 'Technoeconomic' cases

189 Figure 5.1: Alternative U.S. energy-consumption scenarios for 2030

192 Figure 5.2: $\mathrm{CO}_{2}$ emissions generated by alternative U.S. energy scenarios

225 Figure 6.1: Job creation through \$1 million in spending: Clean energy investments versus fossil fuels 
Summary 


\section{Summary}

The question for policymakers, and all other citizens, is no longer whether humans are changing our climate. The question now is, how we can stabilize an already-changing climate in a way that promotes economic prosperity? While recently established domestic policies have made strides toward a lower carbon future, such measures are stepping stones. They prescribe the initial path but will not lead to the final goal of achieving the reductions in greenhouse gas emissions necessary to help stabilize global temperatures. Effectively mitigating climate change requires identifying exactly how the United States will transform its energy economy to attain international goals to help protect our climate.

This report quantifies the level of investment required for the United States to align emissions reductions with international goals in an economically beneficial and technically feasible manner. The specific emissions-reduction goal we explore in this study is what the Intergovernmental Panel on Climate Change, or IPCC, has proposed for the world as a whole: reducing greenhouse gas emissions by 40 percent from 2005 levels by 2035. ${ }^{1}$ To do its part to meet this goal, the United States must reduce its carbon dioxide emissions from energy-based sources by 40 percent, to 3,200 million metric tons, or mmt, over roughly the next 20 years. The proposals in this report put the United States on this track to effectively mitigate global climate change.

The report covers three areas of analysis. It first describes the need for a substantial new wave of mostly private investment in advanced energy technology and higher performing buildings, as well as significant public and private investment needed to build dramatically more efficient infrastructure. Second, it outlines how the United States can and must reduce its use of fossil fuels by 40 percent within the next 20 years, as the window of opportunity to stabilize our changing climate is small and closing rapidly. Third, the report shows that stabilizing the climate requires bold actions that we term the PERI-CAP scenario. In addition to this analysis, the report outlines flexible policy options that can be utilized to take the needed actions. Notably, the report finds that this investment agenda will not only protect our climate but will also generate 2.7 million net new jobs. 


\section{Findings}

\section{Greater clean energy investment is vital to the nation's welfare and economy}

The report finds that the investment needed to stabilize our climate and improve our economy amounts to about $\$ 200$ billion annually in both public and private resources. Average net public expenditures would comprise roughly one quarter of that total, averaging $\$ 55$ billion per year, which falls within the $\$ 44$ billion to $\$ 60$ billion per year range that the United States has devoted to clean energy investments in recent years. ${ }^{2}$ If a successful carbon tax or cap were implemented as part of this plan, it would also yield public revenues averaging $\$ 200$ billion per year. ${ }^{3}$

To put the clean energy investment total in perspective, consider the following:

- Public expenditures would comprise 0.3 percent of current U.S. GDP and roughly 1.4 percent of the federal budget.

- Total expenditures - public and private-are roughly 1.2 percent of current U.S. GDP.

- A recent White House Council of Economic Advisors report found that a temperature increase of 3 degrees Celsius above pre-industrial levels would increase economic damages by $\$ 150$ billion, year after year in perpetuity.

- Total expenditures are roughly 40 percent below U.S. oil and gas industry investments for 2013.

Of the $\$ 200$ billion needed for annual investments, $\$ 90$ billion must be invested in raising efficiency standards for the operations of buildings, transportation systems, and industrial equipment. These investments can reduce overall U.S. energy consumption by 30 percent relative to current levels. In most cases, the costs of these energy efficiency investments can be offset within an average of three years, followed by net positive financial gains. The remaining $\$ 110$ billion per year would be invested in renewable energy that generates low to zero emissions-i.e., solar, wind, geothermal, small-scale hydro, and low-emissions bioenergy—which will raise overall U.S. production from these energy sources more than fourfold. Additionally, the U.S. Energy Information Agency, or EIA, estimates that the average cost for producing electricity from most clean renewable sourcesincluding wind, hydro, geothermal, and clean bioenergy — will be at rough cost parity with most nonrenewable sources by 2017.4 
The report finds these investments will yield the following employment benefits:

- 4.2 million overall jobs created both by new investments and expanded levels of operations and maintenance

- 2.7 million net increase in jobs, even after estimated contractions in fossil fuel sectors

- Net employment expansion at all levels of pay in the U.S. labor market and a decrease in the unemployment rate by about 1.5 percentage points-e.g., from 6.5 percent to 5 percent within the 2030 U.S. labor market

We must significantly reduce demand for nonrenewable energy sources, including natural gas

$\mathrm{CO}_{2}$ emissions produced by burning oil, coal, and natural gas to generate energy account for roughly 75 percent of all U.S. and global greenhouse gas emissions. ${ }^{5}$ Reducing U.S. $\mathrm{CO}_{2}$ emissions by 40 percent within 20 years will therefore require major absolute reductions in U.S. consumption of oil, coal, and natural gas - about 60 percent for coal, 40 percent for oil, and 30 percent for natural gas. Based on careful review of currently available technology and economics, this report determines that such a transformed fuel mix, while ambitious, is entirely achievable without undue disruption to the security, reliability, or affordability of the domestic energy system and would provide a net gain to the U.S. economy.

To meet the 20-year emissions-reduction target, the following energy and economic policies are required:

- Reductions in fossil fuel consumption by approximately 60 percent for coal, 40 percent for oil, and 30 percent for natural gas

- Reduction of overall U.S. energy consumption by approximately 30 percent relative to current levels

- Raising overall U.S. energy production from low to zero emissions renewables by more than fourfold.

- Reduction in oil imports to absorb most of the decline in U.S. oil consumption, which will bring a sharp decline in the U.S. trade deficit and favorable macroeconomic effects

- Transitional support for affected communities and workers hardest hit by the reduced U.S. consumption of coal and natural gas. The federal government therefore needs to provide major transitional support for workers and communities that are facing retrenchment in order to promote economic development and job opportunity in these impacted communities and regions. 
- No expansion of nuclear energy supply; despite being an emissions-free source of electricity, nuclear energy is unlikely to experience major expansion in the next two decades, due to public-safety considerations and market concerns. This report concludes that nuclear energy's contribution to the overall U.S. energy mix will therefore remain roughly constant.

\section{These investments are the best path to achieving economically beneficial}

\section{carbon emissions reductions}

The report examines the three distinct pathways for the energy future of the United States: a Reference case of future emissions based on our current actions; an Aggressive Reference case of emissions stemming from substantially more assertive actions based on the current political and policy framework; and finally, the PERI-CAP case, which works backward from the IPCC goal noted earlier to outline a realistic framework of actions needed to achieve success.

The PERI-CAP case may face political challenges. It is not without cost. However, it is also a necessary and feasible way to stabilize the climate. In aggregate it will provide strong net benefits to the U.S. economy.

FIGURE S.1

$\mathrm{CO}_{2}$ emissions generated by alternative U.S. energy scenarios

Emissions are in millions of metric tons, or $\mathrm{mmt}$

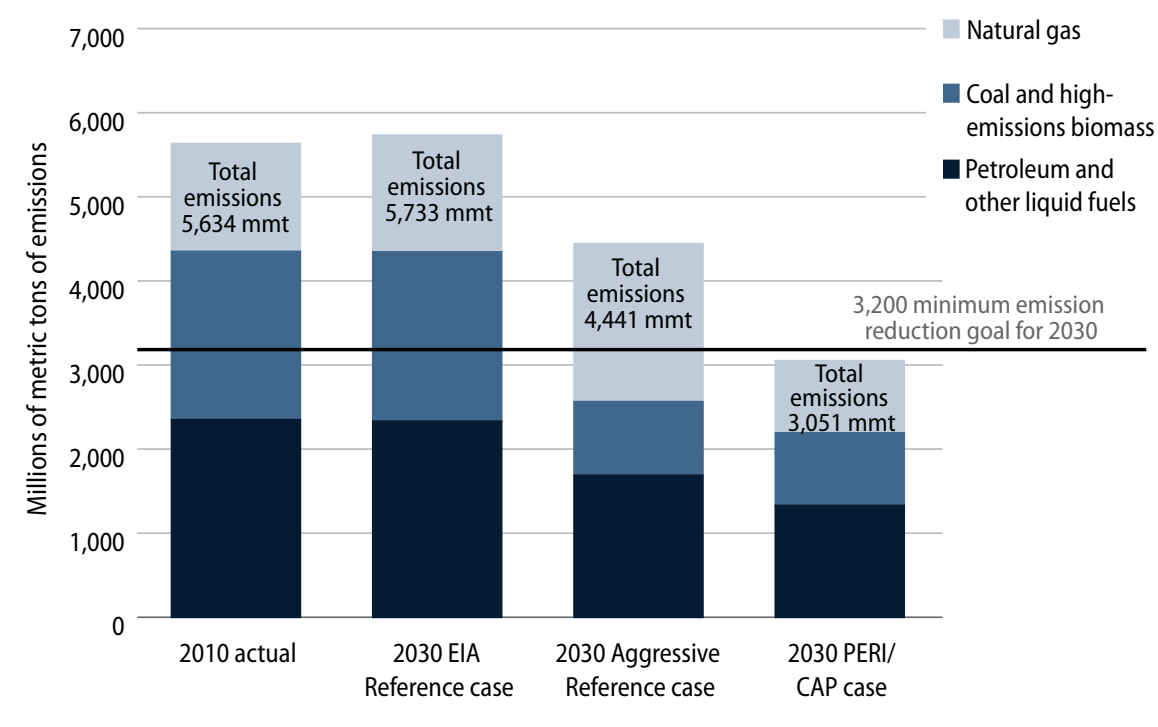

Source: See Table 5.6. 
As Figure S.1 shows, this report found that in the Energy Information Agency's Reference case for U.S. energy consumption in 2030-i.e., what the EIA regards as the most likely U.S. energy-sector conditions in 2030- $\mathrm{CO}_{2}$ emissions are at 5,733 $\mathrm{mmt}$, or roughly 80 percent above the 20 -year IPCC emissions-reduction goal.

The report then constructs a scenario based on the Aggressive Reference casethe full implementation of the best clean energy policies currently considered achievable within the near term without a change in the current political and policy debate. Assuming that these initiatives are all fully and successfully implemented, Figure S. 1 estimates that U.S. $\mathrm{CO}_{2}$ emissions will be at $4,441 \mathrm{mmt}$, or 40 percent above the 3,200 $\mathrm{mmt}$ target level, under this case.

Finally, under the PERI-CAP case, we work backward from the IPCC goal to understand which technologies can produce a sustainable fuel mix within climate limits. We constrain these choices by the best available technical and economic research to ensure that this scenario is achievable using existing technologies under reasonably anticipated market conditions. The clean energy program we developthrough which overall annual U.S. energy consumption falls to 70 quadrillion BTUs within 20 years, with 15 Q-BTUs coming from clean renewable sources and 55 Q-BTUs from nonrenewables-will enable the United States to achieve the $\mathrm{CO}_{2}$ emissions target of no more than $3,200 \mathrm{mmt}$ within 20 years. This is a decline of about 40 percent relative to current emissions levels of about 5,600 $\mathrm{mmt}$.

\section{There are four essential pillars to transforming our energy and environmental future}

Building from existing policies at the federal, state, and municipal levels within the United States, we highlight four pillars, or policy categories, to promote a $\$ 200$ billion annual shift in investment across the U.S. economy. These measures will be most effective when used in concert with each other.

- Market-shaping rules that level the playing field and build demand for new technology within energy, real estate, and financial markets. These include a carbon cap or tax, strict enforcement of the Clean Air Act, renewable energy standards and building codes, vehicle fuel-efficiency standards, and state and local regulation of electricity markets.

- Direct public spending, including government investments in energy efficiency retrofits for publicly owned buildings, major infrastructure systems, renewable energy procurement projects, and expanding federal research and development 
support for efficiency and renewable energy. Such public investment is crucial for setting the platform upon which individual market decisions are made.

- Private investment incentives that manage risk and improve access to capital for private investors at all levels of the economy and thereby make clean energy cheaper and more broadly accessible. These programs include restructuring clean energy production and investment tax credits, implementation of feed-in tariffs, financing green banks, and offering government loan guarantees.

- Regional equity and transitional support for communities and workers, which includes allocating federal government clean energy investment spending equitably among all regions of the country, targeted community-adjustment assistance, extensive worker-training programs, and adjustment-assistance programs for fossil fuel workers. The national clean energy investment program can itself provide a critical base for generating new opportunities among workers and communities that are presently dependent on the fossil fuel industries.

Stabilizing climate change requires a transformational shift in how we construct, finance, and deploy our energy infrastructure. This report quantifies that shift by outlining the challenging but feasible steps that can help restore a climate balance and increase overall U.S. employment in the process. 


\section{Endnotes}

1 Intergovernmental Panel on Climate Change, "Climate Change 2007: Mitigation of Climate Change: Chapter 13: Policies, instruments, and co-operative arrangements" (New York: Cambridge University Press, 2007), p. 776, box 13.7, available at http://www.ipcc.ch/pdf/ assessment-report/ar4/wg3/ar4-wg3-chapter13.pdf.

2 Bloomberg New Energy Finance and Business Council for Sustainable Energy, "Sustainable Energy in America 2013 Factbook" (2013), available at http://www.bcse. org/factbook/pdfs/BCSE_BNEF_Sustainable_Energy_ in_America_2013_Factbook.pdf.

3 Including the carbon tax or cap, the full program would operate, on average, in rough fiscal balance over the 20-year investment cycle-meaning there would be no net increase in government spending. This would be after assuming that 75 percent of the revenues generated by the carbon tax or cap would be returned directly to U.S. taxpayers, while 25 percent would support clean energy public policies.
4 U.S. Energy Information Administration, “Levelized Cost of New Generation Resources in the Annual Energy Outlook 2012," June 25, 2012, available at http://www. eia.gov/forecasts/archive/aeo12/electricity_generation. $\mathrm{cfm}$.

5 Ecofys, “World GHG Emissions Flow Chart 2010” (2010) available at http://www.ecofys.com/files/files/asnecofys-2013-world-ghg-emissions-flow-chart-2010.pdf U.S. Environmental Protection Agency, Inventory of U.S. Greenhouse Gas Emissions and Sinks: 1990-2011 (2013), page 78, table 2-3, available at http://www.epa.gov/ climatechange/Downloads/ghgemissions/US-GHGInventory-2013-Main-Text.pdf. 
Chapter 1

Introduction 


\section{Introduction}

This study develops a transformative clean energy investment program over the next 20 years that will enable the United States to dramatically reduce its overall level of greenhouse gas emissions and thereby allow the country to make a fair contribution to the massive and urgent global project to control climate change. We show that this clean energy program is technologically and financially achievable and will in fact generate widespread and broadly shared economic benefits. We recognize that there are already a wide range of policies in operation in the United States that are making effective contributions toward controlling climate change. The advances achieved by these policies are the result of concerted and successful efforts by large numbers of citizens and policymakers. But we also show that the policy framework in place today is not close to being adequate for meeting the challenges before us.

The starting point of our study is the firm conclusion by the overwhelming majority of climate scientists that greenhouse gas, or GHG, emissions from economic activity is the fundamental cause of global climate change. Moreover, we know that generating energy from fossil fuel sources - by burning oil, coal, and natural gasis by far the largest single source of GHG emissions. This is because burning these fuels releases carbon dioxide, or $\mathrm{CO}_{2}$, into the atmosphere. Our study therefore examines what is required-in terms of raising energy efficiency standards and generating energy from low- or zero-emissions renewable energy sources-in order for the United States to achieve a major reduction in $\mathrm{CO}_{2}$ emissions over the next 20 years. We also establish how much the United States will need to reduce its reliance on oil, coal, and natural gas as energy sources over this 20 -year time period.

Working from this understanding of the necessary changes over the next 20 years in the U.S. energy system, we are then able to provide carefully developed estimates of the level of public and private investments that will be needed to make this new clean energy economy a reality. Crucially, we also show that building a clean energy economy in the United States can be a significant new source of job opportunities in all regions of the country and can contribute toward returning the U.S. economy 
to a healthy long-term economic growth trajectory. That is, we demonstrate in detail that the project of building a clean energy economy in the United States is fully compatible with the equally important purpose of expanding economic opportunities for working people and businesses throughout the country. As Podesta et al. wrote in 2009, building a clean energy economy in the United States "is a fundamentally affirmative agenda, rather than a restrictive one. Moving beyond pollution from fossil fuels will involve exciting work, new opportunities, new products, innovation and stronger communities." This study documents in depth how this "fundamentally affirmative agenda" can be successful in the United States over the next 20 years.

The basics of the program are simple. It entails about $\$ 200$ billion of combined public and private investments in clean energy every year for 20 years. This is a massive amount of money, but it is only about 1.2 percent of current U.S. GDP. ${ }^{2}$ Nevertheless, it is about 3 to 4 times more than the $\$ 44$ billion to $\$ 60$ billion per year that has been devoted to U.S. clean energy investments over the past few years. ${ }^{3}$

The challenge to ramp up investments to $\$ 200$ billion per year over the next 20 years will be formidable. Investments will need to be focused on two areas. The first is to dramatically raise energy efficiency standards in buildings, transportation systems, and industrial processes to reduce the overall level of U.S. energy consumption by 30 percent while still allowing for the U.S. economy to grow at a healthy rate. The second is to expand the U.S. production of zero-to-low emissions renewable energy sources - solar, wind, geothermal, small-scale hydro, and clean bioenergy powerby about 400 percent relative to current levels, or at an average annual rate of about 7.5 percent per year over the next 20 years. This will enable these low-emissions sources - what we term clean renewables throughout this study-to provide about 20 percent of overall U.S. energy supply within 20 years.

It is important to emphasize that the investment in energy efficiency will also produce significant savings. After investors make their upfront efficiency investments, they will be able to operate buildings, cars, trucks, buses, trains, and industrial machinery at significantly lower costs. On average, their upfront investments will be fully returned to them in energy savings within about three to five years. Similarly, once investments are made to create expanded clean renewable energy resources, the costs to consumers of purchasing energy from these sources will be, in most cases, at rough parity or lower than those of oil, coal, natural gas, and nuclear power. 
At every level of government throughout the United States, there are already policies in place aimed at promoting clean energy investments and reducing $\mathrm{CO}_{2}$ emissions. The primary challenge for now is therefore not designing new measures but greatly strengthening the policy framework that already exists. Within this existing policy framework, we develop our agenda within four broad categories: marketshaping rules that promote investments in energy efficiency and renewable energy; direct public spending that invests in infrastructure, procurement, and research and development; private-investment incentives that manage risk and improve access to capital; and transitional support for communities and workers facing retrenchment. We consider 19 separate policy measures in all, including carbon caps and taxes; federal research and development funding in support of advancing efficiency and clean renewable technologies; production and investment tax credits; and a "Superfund" to finance a viable adjustment-assistance program for workers employed in the coal, oil, and natural gas sectors.

We have developed rough estimates as to the fiscal impact of all of our policy proposals deliberately based on high-end cost assumptions for all public policy programs. More specifically, we find that if a carbon cap or tax is implemented along the lines recently outlined by the U.S. Energy Department, ${ }^{4}$ then the overall U.S. clean energy program will be fiscally neutral-there will be no net impact, either positive or negative, on public-sector budgets. This is true even if we assume that 75 percent of the tax revenues from a carbon cap or tax are returned directly to U.S. taxpayers rather than being retained by the federal government for spending on clean energy projects or to support any other government activity. If, alternatively, we consider our full set of policy proposals exclusive of a carbon tax or cap, the remaining programs that we discuss would amount to a net annual cost of about $\$ 50$ billion, or 0.3 percent of current U.S. GDP. That is, operating without a carbon cap or tax, we estimate that about 75 percent of the full $\$ 200$ billion in annual clean energy investments that are needed would come from the private sector and 25 percent would come from public spending.

Working from our overall goal of achieving the 20 -year $\mathrm{CO}_{2}$ emissions-reduction target, we find that the United States needs to sharply reduce its reliance on energy generated from burning oil, coal, and natural gas. We conclude that, by 2030 to 2035 , coal consumption needs to decline by about 60 percent relative to its 2010 level; oil consumption by about 40 percent, including from both domestic sources and imports; and natural gas by about 30 percent. Communities and workers in many 
parts of the country will obviously be significantly impacted by this contraction in U.S. fossil fuel production. This is precisely why effective transition-assistance programs targeted at these impacted regions, communities, and individual workers must be incorporated as a centerpiece of the clean energy policy agenda.

We further demonstrate that there are basically no workable alternatives to something akin to our clean energy investment path if the United States is going to make a serious contribution toward meeting the global challenge of controlling climate change. Thus, over the next 20 years, if the United States were to proceed along an energy path that the U.S. Energy Information Administration considers its most likely trajectory - what the EIA terms its Reference case scenario-U.S. emissions as of 2030 to 2035 will be roughly 80 percent higher than the target figure for emissions reductions established by the Intergovernmental Panel on Climate Change. Moreover, even assuming highly optimistic estimates as to the impact of the Obama administration's current policy agenda for reducing emissions-what we have termed an Aggressive Reference case - the United States will still exceed the IPCC's emissions-reduction target for 2030 to 2035 by nearly 40 percent.

A critical feature of such a clean energy investment program is that it can succeed in dramatically reducing emissions while also expanding employment opportunities in all regions of the country and at all levels of the U.S. labor market. Specifically, we find that this investment program would result in the creation of 4.2 million total new jobs and a net expansion of 2.7 million jobs, even after taking account of the job losses that will result from a contraction in the production of oil, coal, and natural gas. We again give careful attention in our policy discussions to the most effective methods of transition assistance to workers and communities that will be affected by the decline in U.S. fossil fuel production. As such, our study demonstrates that the project of controlling climate change can be fully compatible with the goal of expanding broadly shared economic opportunity and prosperity.

The reason for advancing this highly ambitious clean energy investment program is straightforward. At present, an overwhelming majority of climate scientists contend that our environment faces a severe-and perhaps even existentialthreat if we do not control the changing climatic conditions resulting from the emissions of greenhouse gases generated by human activity. The overwhelming consensus among climate scientists is that achieving these dramatically reduced emissions levels in the United States and equivalently low levels elsewhere in the world is needed to stabilize global mean temperatures at around 3.6 degrees Fahrenheit ( 2 degrees Celsius) above the preindustrial mean global temperature 
of around 56.7 degrees Fahrenheit (13.72 degrees Celsius). If the global mean temperature can be stabilized at around 60.1 degrees Fahrenheit, climate scientists hold that the most severe threats to global ecology resulting from climate change may still be prevented. ${ }^{5}$

As of 2010 total annual global greenhouse gas emissions amounted to about 45,000 million metric tons of carbon dioxide or its equivalent. This includes 33,615 in $\mathrm{CO}_{2}$ emissions from burning oil, coal, and natural gas-equaling about 75 percent of total greenhouse gas emissions. The remaining $\mathrm{CO}_{2}$-equivalent emissions come from methane and nitrous oxide, as well as smaller amounts from hydrofluorocarbons, perfluorocarbons, and sulfur hexafluoride. In order to control climate change, the IPCC estimates that total greenhouse emissions-including both $\mathrm{CO}_{2}$ and $\mathrm{CO}_{2}$ equivalent emissions - will need to fall by about 40 percent as of 2030 , to $27,000 \mathrm{mmt}$, and by 80 percent by 2050 , to about $9,000 \mathrm{mmt}$.

As of 2010 the U.S. economy was consuming a total of about 98 quadrillion BTUs, or Q-BTUs, of energy per year from all energy sources-including oil, natural gas, coal, and nuclear power, as well as from all renewable energy sources. ${ }^{6}$ This translated into about 5,600 million metric tons of $\mathrm{CO}_{2}$ emissions in 2010 from all energy sources, given the existing energy mix in the United States. In addition, the United States emitted roughly another 1,200 metric tons of $\mathrm{CO}_{2}$ from nonenergy sources in 2010, including methane, nitrous oxide, and other less significant sources of greenhouse gases. This amounts to a total of about 6,800 million metric tons of emissions in 2010, or 17 percent of total global emissions. ${ }^{7}$ At the same time, U.S. residents accounted for only about 4.4 percent of global population. ${ }^{8}$ 


\section{Units of Measurement}

By its nature, this study necessarily aims to provide an across-the-board analysis of energy use within the United States economy. We are examining energy consumption for all purposes - that is, for industry, transportation, and for all activities within buildings. We also necessarily take account of all energy sources, including oil, coal, natural gas, nuclear power, and all renewables. We also stress the role of investments in energy efficiency.

Each of these segments of the energy industry operates with its own sets of terms, markets, and ways of measuring activity and output. For example, electricity consumption is typically measured and priced in terms of kilowatt hours or megawatt hours, while crude petroleum is measured and priced as barrels of oil. In retail markets, refined petroleum is priced and sold as gallons of gasoline.

To keep the study grounded in the realities of each specific market segment, it is important to keep in mind these standard units of measurement and terms. At the same time, precisely because this study necessarily considers all segments of the U.S. energy industry as a unified whole, it is also crucial that we make use of terms and units of measurement that can be applied equally across all industry segments.

One standard unit of measurement that applies across all industry segments is the British Thermal Unit, or BTU. BTUs measure the heat content generated by any given energy source. One BTU is roughly equivalent to the energy produced by burning one wooden match. In discussing and comparing energy generation across alternative energy sources and sectors of the economy, we therefore need to work within the framework of BTU measurement. Further, for discussions on general energy use at a large scale, such as for the U.S. economy as a whole, it is convenient to refer to quadrillion BTUs of energy. Throughout this study, we use the acronym Q-BTUs as a shorthand for quadrillion BTUs. At the same time, we also refer, when appropriate, to more industry-specific terms, especially as regards the electricity sector, where the standard units of measurement are kilowatts or megawatts.

As a reference, Table 1.1 presents conversion factors between Q-BTUs, kilowatt hours of electricity, barrels of crude oil, and gallons of gasoline. 
TABLE 1.1

\section{Conversion factors in standard energy units}

Energy units converted to BTU heat rates

\begin{tabular}{|c|c|c|}
\hline Fuel & Units & Approximate heat content \\
\hline \multicolumn{3}{|l|}{ Coal $^{1}$} \\
\hline Production & million BTU per short ton & 20.192 \\
\hline Consumption & million BTU per short ton & 19.847 \\
\hline Coke plants & million BTU per short ton & 26.297 \\
\hline Industrial & million BTU per short ton & 20.433 \\
\hline Residential and commercial & million BTU per short ton & 21.188 \\
\hline Electric power sector & million BTU per short ton & 19.623 \\
\hline Imports & million BTU per short ton & 24.719 \\
\hline Exports & million BTU per short ton & 25.698 \\
\hline Coal coke & million BTU per short ton & 24.800 \\
\hline \multicolumn{3}{|l|}{ Crude oil } \\
\hline Production & million BTU per barrel & 5.800 \\
\hline Imports $^{1}$ & million BTU per barrel & 5.989 \\
\hline \multicolumn{3}{|c|}{ Petroleum products and other liquids } \\
\hline Consumption ${ }^{1}$ & million BTU per barrel & 5.254 \\
\hline Motor gasoline ${ }^{1}$ & million BTU per barrel & 5.100 \\
\hline Jet fuel & million BTU per barrel & 5.670 \\
\hline Distillate fuel oil ${ }^{1}$ & million BTU per barrel & 5.771 \\
\hline Diesel fuel ${ }^{1}$ & million BTU per barrel & 5.762 \\
\hline Residual fuel oil & million BTU per barrel & 6.287 \\
\hline Liquefied petroleum gases ${ }^{1}$ & million BTU per barrel & 3.557 \\
\hline Kerosene & million BTU per barrel & 5.670 \\
\hline Petrochemical feedstocks ${ }^{1}$ & million BTU per barrel & 5.510 \\
\hline Unfinished oils & million BTU per barrel & 6.118 \\
\hline Imports $^{1}$ & million BTU per barrel & 5.337 \\
\hline Exports $^{1}$ & million BTU per barrel & 5.851 \\
\hline Ethanol & million BTU per barrel & 3.561 \\
\hline Biodiesel & million BTU per barrel & 5.359 \\
\hline \multicolumn{3}{|l|}{ Natural gas plant liquids } \\
\hline Production ${ }^{1}$ & million BTU per barrel & 3.674 \\
\hline \multicolumn{3}{|l|}{ Natural gas ${ }^{1}$} \\
\hline Production, dry & BTU per cubic foot & 1,024 \\
\hline Consumption & BTU per cubic foot & 1,024 \\
\hline End-use sectors & BTU per cubic foot & 1,025 \\
\hline Electric power sector & BTU per cubic foot & 1,022 \\
\hline Imports & BTU per cubic foot & 1,025 \\
\hline Exports & BTU per cubic foot & 1,009 \\
\hline Electricity consumption & BTU per kilowatt hour & 3,412 \\
\hline \multicolumn{3}{|c|}{ ' Conversion factor varies from year to year. The value shown is for 2010.} \\
\hline \multicolumn{3}{|c|}{ Note: BTU=British thermal unit. } \\
\hline $\begin{array}{l}\text { Sources: Energy Information Administrat } \\
\text { Administration, Annual Energy Outlook } 20\end{array}$ & $\begin{array}{l}\text { al Energy Review } 2010 \text { (U.S. Depart } \\
\text { epartment of Energy, 2012). }\end{array}$ & f Energy, 2011); Energy Information \\
\hline
\end{tabular}


BOX 1.1

\section{How much energy does one Q-BTU provide?}

Residential energy consumption: One Q-BTU is equal to the total average annual energy consumption for the residences of 10 million U.S. households. This roughly equals the annual residential energy consumption for all households in Pennsylvania and Ohio combined.

Automobile travel: One Q-BTU can provide enough energy for 61 million round-trip automobile trips between New York City and Los Angeles.

Power plants: One Q-BTU is the amount of electricity generated in one year by 408 averaged-sized U.S. power plants. This is about 7 percent of all U.S. power plants. It is approximately equal to the amount of electricity consumed in one year in Michigan, Virginia, and Colorado combined.

Coal Supply: One Q-BTU is roughly equal to the energy contained in 40 million tons of coal. This is the amount of coal that would be loaded onto a freight train that stretches from New York City to Fairbanks, Alaska.

Numbers of calories: One Q-BTU contains just over 250 trillion calories. This is roughly equal to the amount of calories contained in 1 trillion McDonald's hamburgers. If each of the world's 7.1 billion people ate 140 hamburgers - one per day for 20 weeks - this would equal the amount of calories contained in one Q-BTU.23 
The specific goal we explore in this study is for the United States to reduce its $\mathrm{CO}_{2}$ emissions from energy-based sources over roughly the next 20 years - that is, as of the five-year period from 2030 to 2035 - by the percentage that the IPCC has proposed for the world as a whole. This means that the United States needs to reduce its energy-based $\mathrm{CO}_{2}$ emissions by about 40 percent in 20 years. As we discuss in detail later in this study, this translates into a specific goal for the United States of reducing $\mathrm{CO}_{2}$ emissions from its energy sector to the level of no more than 3,200 mmt annually by the period from 2030 to 2035 .

We do not in this study look at the separate set of issues relating to the control of nonenergy based GHG emissions from methane, nitrous oxide, or other greenhouse gas sources, though we of course recognize the critical need for controlling these non- $\mathrm{CO}_{2}$ sources of GHG emissions. Methane is the most significant emissions source other than fossil fuels, accounting for about 9 percent of total U.S. emissions. ${ }^{9}$ At the same time, the largest proportion of methane emissions comes from producing natural gas and coal. This means that a clean energy program that leads to significant reductions in coal and natural gas production will also produce major reductions in methane emissions. ${ }^{10}$

It is certainly true that other countries at all stages of development also need to take dramatic steps over the next generation to make their contributions toward controlling climate change. The most obvious case is China-the only country in the world where total emissions presently exceed those of the United States. But there is also no doubt that the project of dramatically reducing emissions in the United States requires an extensive and detailed analysis on its own.

Precisely because the challenge of controlling climate change is global, it is crucial that the United States commit to taking on the challenge in full within its own borders. It is not adequate for the United States to maintain excessively high emissions within its domestic economy and compensate for these high emissions by helping finance emissions-reduction measures in other lower-income countries. U.S. financial support to reduce emissions in lower-income countries will of course be beneficial, and we encourage the expansion of such programs. But measured on a per-capita basis, $\mathrm{CO}_{2}$ emissions in the United States as of 2010 were 60 times higher than the average for low-income countries as categorized by the World Bank and five times higher than the average for middle-income countries. ${ }^{11}$ Average U.S. emissions per capita were also three times higher than those in China in 2010. ${ }^{12}$ As such, the United States should not undertake any carbonoffset program for low-income countries program as a substitute for dramatically 
lowering emissions in the United States itself. For the United States to do so would constitute an abdication of responsibility, especially given this country's enormous technological and financial resources and capacities.

Of course, we also recognize the centrality of achieving the IPCC's 2050 goal of an 80 -percent reduction in emissions by 2050, both in the United States and the rest of the world, but our focus in this study is the next 20 years. There will be almost no chance for the United States or the world at large to meet its 2050 emissionsreduction targets - and to thereby control climate change-if we do not achieve major advances within the next 20 years.

In this study, we have found that for the United States to have a serious chance of reaching the 2030 to 2035 emissions target, the single most important order of business is for there to be dramatic improvements in energy efficiency throughout the U.S. economy. No matter what additional actions are taken, it will not be possible for the U.S. economy to dramatically cut emissions without a highly aggressive set of initiatives to increase energy efficiency. By our estimates, this entails investing about $\$ 90$ billion per year in various efficiency measures in order to cut overall U.S. energy consumption to 70 Q-BTUs by 2030 to 2035 from its 2010 level of about 100 Q-BTUs. This estimate takes reasonable account of any possible rebound effects-when consumers increase their energy-consumption levels in response to improved energy efficiency.

The second crucial project for the United States to undertake is a major expansion in the use of clean renewable sources of energy, especially solar, wind, and geothermal power since they can produce energy without emitting $\mathrm{CO}_{2}$. This means investing about $\$ 110$ billion per year in new investments. We estimate that this level of investment will enable overall clean renewable production in the United States to rise from its 2010 level of about 3.5 Q-BTUs to 15 Q-BTUs by 2030 to 2035. Overall renewable energy was at about 8 Q-BTUs as of $2010,{ }^{13}$ but more than half of this total supply came from high-emissions bioenergy sources, corn ethanol in particular. Another one-third came from large-scale hydro projects, in which future prospects for expansion are unfavorable. This is why the U.S. clean energy investment project needs to focus on greatly expanding capacity in clean renewables such as solar, wind, and geothermal power, low-emissions bioenergy, and smallscale hydro projects. 
Without major advances in these two critical areas of efficiency and clean renewables, the only other plausible path for significantly reducing greenhouse gas emissions will entail a major increase in our reliance on nuclear power, which is emissionsfree. However, the meltdown of the Fukushima nuclear power plant in Japan in 2011 as a result of the massive 9.0 Richter-scale earthquake and subsequent tsunami provided a dramatic and tragic reminder of the severe public safety risks associated with nuclear power. This recent event will likely result in ongoing strong public opposition to any large-scale expansion of U.S. nuclear power plants, as has been the pattern throughout most of Europe and Asia. The combination of such growing public distrust and serious financial risks has brought investments in nuclear power to a standstill. These obstacles to growth are not likely to diminish in the foreseeable future, and as such, nuclear energy cannot be seen as a reliable source for supplying an increasing supply of low-emissions energy in the United States or elsewhere.

The United States must undertake one further major and critical project, even if something similar to the clean energy investment program that we have developed here advances successfully over the next 20 years: building in resilience and adaptation that can effectively protect people, communities, businesses, and our physical infrastructure against the effects of climate change. The impacts of climate change are already occurring with increasing frequency and force, including droughts, floods, and other severe weather events. Climate scientists have made clear that the current global concentration of atmospheric $\mathrm{CO}_{2}$ is already at a level that has not been seen on this planet for millennia. This means we have already entered uncharted territory in terms of the stability of the global climate. ${ }^{14}$

Examining this parallel project of increasing resilience and adaptation is beyond the scope of this study. ${ }^{15}$ But we note that many of the investments in infrastructure and the built environment we discuss in the context of achieving major advances in energy efficiency and renewables throughout the economy will also contribute toward strengthening resilience and adaptation. These measures include dramatically improving the efficiency of the electricity transmission and distribution grid by creating smart grid operations; expanding smaller-scale, community-based distributed energy generation systems as alternatives to central-station power plants; upgrading building management and automation technologies to dramatically increase building efficiency; and strengthening both public and private transportation networks. 
This study is structured as follows. We begin in Chapter 2 by exploring the ways through which the U.S. economy can achieve major gains in energy efficiencythat is, to reduce overall U.S. energy consumption within 20 years by about 30 percent relative to 2010 levels, while also enabling the U.S. economy to grow at healthy rates. Our overall conclusion is that this will take about $\$ 1.8$ trillion in new investments over roughly 20 years, or about $\$ 90$ billion per year over the 20 -year period. But we also emphasize that these efficiency investments lead to immediate and permanent gains in energy savings, which in turn bring financial savings. For example, with building efficiency investments, we estimate that the average payback period for investments ranges between three and five years.

The U.S. private and public sectors will both need to undertake major investments in all three energy-consuming areas-buildings, industry, and transportation. This includes investments to raise efficiency standards for both existing and new buildings, which entails improving the thermal shell of buildings and improving the functioning of heating, cooling, ventilation, and lighting systems, among other things. Within industry, it includes investments in combined heat-and-power systems and a range of sector-specific efficiency enhancing investments, especially in industries that operate at high levels of energy intensity such as pulp and paper, iron and steel, and chemical manufacturing. Several measures will also be needed in the transportation sector, the single most important of which will be to raise the fuel-efficiency standard for automobiles. The agreement reached in 2011 between the U.S. auto industry and the Obama administration to raise the average fuelefficiency standard for new cars to 54.5 miles per gallon by 2025 will be a cornerstone for achieving the economy's overall efficiency and emissions-reduction goals. It is imperative that this fuel-efficiency standard be implemented in full over the next decade without any revisions that would weaken the agreed-upon standards.

We conclude Chapter 2 by considering the possibility that advances in efficiency may not end up yielding reductions in emissions at all. As noted above, this could result from the rebound effect, in which the efficiencies achieved actually encourage consumers to expand their energy consumption. The economist William Stanley Jevons first described this effect in 1865 , observing that the invention of more efficient steam engines led to more-not less-coal consumption in 19th century Britain. ${ }^{16}$ But we conclude from reviewing the evidence that any rebound effect that is likely to emerge as one byproduct of an economy-wide energy efficiency investment project will not be large enough to significantly reduce the environmental benefits of the investments. Nevertheless, we have factored into our estimates a provision for additional investments that will be needed to counteract the impact 
of rebound effects at levels suggested by the recent research on this question. At the same time, the most effective way to limit any rebound effects is to combine efficiency investments with measures that increase the supply of clean renewable sources while reducing fossil fuel energy consumption. That way, even if energy consumption rises somewhat due to rebound effects, a growing proportion of that consumption will be provided by clean energy sources. The critical initiatives here would therefore include policies to accelerate the integration of clean renewable energy sources into the economy, as well as measures that would directly aim to reduce the use of fossil fuels such as a carbon cap or tax.

Chapter 3 focuses on the project of greatly expanding the supply of energy in the United States coming from clean renewable sources, including solar, wind, geothermal, small-scale hydropower, and low- or zero-emissions bioenergy. As of 2010 as we have discussed above, the United States was producing about 3.5 Q-BTUs of energy from these clean renewable sources. We argue that this figure needs to increase roughly four-fold, to about 15 Q-BTUs as of 2030 to 2035, if the United States is going to achieve its emissions-reduction target. This amounts to an expansion in clean renewable production of about 7.5 percent per year over the next 20 years. We conclude that this goal can be achieved through annual investments to expand clean renewable capacity of about $\$ 110$ billion per year for 20 years. In most cases, the costs to consumers of purchasing clean renewable energy should reach rough parity or be less than those for oil, coal, natural gas, and nuclear energy by 2017.

In advancing this clean renewable investment project, we must recognize that as of 2012 roughly 80 percent of all renewable energy consumed in the United States came from either bioenergy or hydro power. ${ }^{17}$ But significant problems exist with both of these currently dominant renewable sources. The most important problems result from the production of corn ethanol, which is also the single most heavily utilized source of bioenergy at present. Under current methods of refining corn ethanol, total emissions from consuming corn ethanol can be comparable to burning petroleum. Moreover, as we discuss in Chapter 3, relying on corn and other food products as the raw material for producing biofuels can create a major strain on global food supplies, which has contributed to the recent rising trend in global food prices. This problem will only become more severe to the extent that food crops are utilized increasingly for producing bioenergy. ${ }^{18}$ 
With hydro power, the most favorable sites in the United States for building largescale dams are already built out and operating at capacity. Beyond this existing capacity, there are likely to be serious environmental issues resulting from constructing additional large-scale dams. However, we explore the prospects for capturing energy from the roughly 5,000 sites where small-scale hydroelectric plants could be developed at low costs, using only existing technologies. As we will discuss, taking advantage of these small-scale hydro power opportunities could increase hydro-based electricity supply in the United States by as much as 25 percent.

According to the most recent 2012 EIA data, wind power accounted for about 16 percent of all U.S. renewable energy, with solar and geothermal each at around 2 percent. ${ }^{19}$ These three renewable sources combined therefore provided about 20 percent of all renewable energy in the United States, which amounts to about 1.8 percent of all U.S. energy supply that year. ${ }^{20}$ We examine in Chapter 3 what would be needed to make wind, solar, and geothermal, along with clean bioenergy and hydro, a major source of U.S. energy supply. Working with projections on electricity capital costs for renewables from the EIA, we estimate that the total direct capital expenditures (not including financing costs) needed to expand clean renewable capacity to around 15 Q-BTUs will be around $\$ 2.1$ trillion, or roughly $\$ 107$ billion per year for 20 years. We round this estimate up to about $\$ 110$ billion per year. The major investment areas would be clean bioenergy, at around $\$ 40$ billion per year, as well as hydro, wind, and solar PV, all within the range of $\$ 17$ billion to $\$ 23$ billion per year.

Still working with the EIA's cost estimates, we show that the costs for producing electricity from most clean renewable sources_-including wind, hydro, geothermal, and clean bioenergy - will be at rough cost parity with most nonrenewable sources by 2017. The EIA does estimate that natural gas could be supplied more cheaply in the future but only by expanding reliance on hydraulic fracturing for extracting gas from shale rock formations. As we discuss in Chapter 4, this would entail major environmental costs and faces ongoing public opposition.

According to the EIA, solar costs are not likely to be at cost parity with nonrenewables by 2017 under average conditions. But solar costs are coming down the most rapidly of all renewable sources. Moreover, through technical innovations and expanded market opportunities over the next one or two decades, solar promises to become the cleanest, safest, and most abundant renewable energy source in the United States. Overall, then, our conclusion from examining the evidence in Chapter 3 is that a large-scale expansion of clean renewable energy is both critical for the success of achieving the 20-year emissions-reduction targets and is feasible in terms of the investment commitment that will be required. 
In Chapter 4, we examine the future prospects for nonrenewable energy sources, including oil, coal, natural gas, and nuclear power. From our discussions in Chapters 2 and 3, we reached two basic conclusions: the United States is capable of achieving a 30-percent improvement in energy efficiency, bringing total energy consumption down to roughly 70 Q-BTUs by 2030 to 2035; and about 15 Q-BTUs could be economically supplied by clean renewable sources. It follows from these two conclusions that the U.S. economy will still require another 55 Q-BTUs of total energy supply by 2030 to 2035 . By necessity, this supply will come from nonrenewable sources. The central issue we examine in Chapter 4 is how the United States can, as of 2030 to 2035, consume as much as 55 Q-BTUs of nonrenewable energy resources while still bringing energy-based $\mathrm{CO}_{2}$ emissions down to the 20-year target level of no more than 3,200 mmt.

In pursuing this question, the first issue we consider is, what will be the likely level of overall demand for petroleum in 20 years as the primary liquid fuel source? We estimate that overall U.S. oil consumption will be around 21 Q-BTUs in total by 2030 to 2035, with 13 Q-BTUs used in transportation-powering automobiles, trucks, airplanes, and water vessels - and 8 Q-BTUs consumed as petrochemical feedstocks and for other industrial uses. Our estimate for transportation-based oil consumption is less than half the level projected by the EIA in its 2030 Reference case. This difference reflects both our conclusion that the auto fuel-efficiency standard of $54.5 \mathrm{mpg}$ as of 2025 will generate a major reduction in overall oil consumption within 20 years and that the production of clean biofuels as a substitute liquid fuel for petroleum can reach about 6 Q-BTUs within 20 years.

Working with this estimate that by 2030 to 2035 , the maximum practical reductions in petroleum use will still result in annual oil consumption of about 21 Q-BTUs, this means that about 34 Q-BTUs will need to be supplied by some combination of coal, natural gas, and nuclear power. ${ }^{21}$ Chapter 4 therefore also focuses on the critical issues at play with respect to generating electricity through alternative combinations of coal, nuclear power, or natural gas supply.

In considering future prospects for coal, we incorporate the analysis of Deutsche Bank Climate Change advisors' 2011 study in which Deutsche Bank analysts projected that U.S. coal consumption will fall to about 9 Q-BTUs by 2030 . This would represent a decline of nearly 60 percent relative to the 2010 coal-consumption level of 20.8 Q-BTUs. The Deutsche Bank study concluded that this sharp decline in U.S. coal consumption would result because the Environmental Protection Agency would begin to strictly enforce the Clean Air Act as it applied to the high levels of carbon pollution resulting from the combustion of coal. The EPA has the 
authority to proceed with such measures even without Congress passing any new climate legislation. In fact, this 2011 Deutsche Bank analysis is fully consistent with the stated aims of President Obama's June 2013 Climate Action Plan, which gives major prominence to the policy of reducing carbon pollution from U.S. utility plants by utilizing its regulatory authority under the Clean Air Act.

The Deutsche Bank study also provides a useful analysis of prospects for the nuclear sector through 2030. The authors conclude that nuclear power will supply a total of about 8 Q-BTUs of energy in the United States as of 2030. This figure is modestly below the actual 2010 level of U.S. nuclear energy consumption of 8.4 Q-BTUs. As the Deutsche Bank analysts recognize and we discuss further, nuclear power does provide the major benefit among nonrenewables of being an emissions-free source of electricity. At the same time, public-safety considerations and the expenses associated with nuclear energy are also critical. A significant new wave of nuclear power plant construction is therefore unlikely, given the combination of public opposition and very large high-risk financial requirements for such investments. The most likely scenario for nuclear energy moving forward is rather in line with the conclusion of the Deutsche Bank study-that its contribution to the overall U.S. energy mix will remain roughly constant at around 8 Q-BTUs.

Given these major constraints facing both coal and nuclear power, we therefore anticipate that natural gas will become the residual nonrenewable energy source in the United States by 2030 to 2035, for both electricity generation and other less significant uses in buildings and industry. Yet with requirements for oil in 2030 to 2035 reaching about 21 Q-BTUs, and with coal and nuclear power contributing a total of about 17 Q-BTUs to produce electricity, this adds to a total of about 38 Q-BTUs. We have also estimated that clean renewables will supply about 15 Q-BTUs of overall U.S. energy supply as of 2030 to 2035. If overall U.S. energy consumption, including clean renewables, is held to about 70 Q-BTUs, this then leaves about 17 Q-BTUs in total that can be supplied by natural gas.

U.S. natural gas consumption at 17 Q-BTUs by 2030 to 2035 would represent an absolute decline of 31 percent relative to the 2010 level of 24.7 Q-BTUs. We recognize that natural gas development is currently experiencing a significant expansion in production and a decline in prices tied to rapid increases in drilling using hydraulic fracturing technology. Despite these current industry trends, there is simply no scenario through which natural gas consumption in the United States can increase significantly relative to current levels if we are going to achieve our emissions-reduction target, as we examine in detail in Chapter 5. Rather, any significant expansion in natural gas production will almost certainly contribute to the United States failing to reach its emissions-reduction target. 
Chapter 5 explores what $\mathrm{CO}_{2}$ emissions levels would result through three alternative U.S. energy scenarios through 2030 to 2035 . One scenario is what the EIA itself sees as the most likely energy-sector scenario through 2030. Our second scenario is based on developing a range of highly optimistic assessments of the impact on $\mathrm{CO}_{2}$ emissions levels of the Obama administration's current major initiatives around climate change. Our third scenario is based on our own analyses in Chapters 2 through 4 as to the prospects for successfully advancing a major clean energy investment project in the United States over the next 20 years. We reach a major conclusion through this exercise of comparing the three alternative scenarios. It is that the clean energy investment project that we develop in Chapters 2 through 4 is the only path through which the United States can even come close to achieving its 2030 to $2035 \mathrm{CO}_{2}$ emissions-reduction target of $3,200 \mathrm{mmt}$.

We begin the Chapter 5 discussion by reviewing data on the levels of $\mathrm{CO}_{2}$ emissions generated through burning oil, coal, and natural gas to produce energy. These are the underlying figures through which we calculate overall emissions levels generated by any given energy scenario. As we show, on average, emissions are $96 \mathrm{mmt}$ per Q-BTU for coal, $63 \mathrm{mmt}$ per Q-BTU for oil, and $52 \mathrm{mmt}$ per Q-BTU for natural gas. That is, oil generates 34 percent less $\mathrm{CO}_{2}$ than coal, and natural gas generates 46 percent less than coal. Natural gas also generates 17 percent less $\mathrm{CO}_{2}$ than oil per Q-BTU of energy.

Working from these average emissions figures, we then focus on the prospects for reaching the 2030 to $2035 \mathrm{CO}_{2}$ emissions level of no more than 3,200 $\mathrm{mmt}$ through our three alternative scenarios for future U.S. energy consumption. More specifically, the first scenario we consider is the EIA's Reference case, as developed in their 2012 "Annual Energy Outlook." The EIA's Reference case incorporates what the EIA considers to be all of the most likely trajectories through 2030 for U.S. energy production and consumption, as well as the U.S. economy overall.

The second scenario we consider is what we call the PERI/CAP case. This case builds from the conclusions we have developed in Chapters 2 through 4 on prospects for energy efficiency, renewables, and nonrenewables through an ambitious but feasible clean energy investment project. Specifically this PERI/CAP case is the framework through which we anticipate that overall U.S. energy consumption is able to decline to 70 Q-BTUs, with clean renewables providing about 15 Q-BTUs of the total U.S. energy supply. 
For our third scenario, we present what we term an Aggressive Reference case. We developed this scenario as a means of evaluating whether the full set of the Obama administration's current initiatives around climate change are likely to be sufficient for achieving the emissions target of 3,200 $\mathrm{mmt}$, even assuming that these initiatives are fully and successfully implemented. Thus, the Aggressive Reference case assumes that the implementation of the $54.5 \mathrm{mpg}$ automobile fuel-efficiency standard for 2025 will have substantially greater impact on improving energy efficiency than what the EIA estimates in its Reference case. Our Aggressive Reference case also assumes that the administration's June 2013 Climate Change Action Plan will succeed in sharply reducing utility-sector power plant emissions through the full and aggressive enforcement of carbon-pollution standards under the Clean Air Act. This scenario also takes full account of the U.S. military's program to rely on renewable energy to supply 25 percent of its energy needs by 2025 and more generally assumes that domestic clean renewable supply increases three-fold relative to 2010 levels.

We then calculate the emissions levels generated by these three alternative scenarios. What emerges clearly is that the PERI/CAP case is the only one that is capable of achieving the 2030 to $2035 \mathrm{CO}_{2}$ emissions level of no more than 3,200 $\mathrm{mmt}$. The EIA itself recognizes that under its 2030 Reference case, overall $\mathrm{CO}_{2}$ emissions would be 5,733 $\mathrm{mmt}$ - fully 80 percent above the target level of 3,200 $\mathrm{mmt}$. Under the Aggressive Reference case, we estimate the overall level of $\mathrm{CO}_{2}$ emissions to be 4,441 mmt, still 40 percent above the target. But overall $\mathrm{CO}_{2}$ emissions do fall below 3,200 mmt, to 3,051 mmt, under the PERI/CAP case. These findings clearly underscore the scale of the challenge for the United States to make its fair contribution toward controlling global climate change over the next 20 years.

Chapter 5 concludes by considering three additional side cases. The first side case explores the prospect that we can achieve a sufficient reduction in $\mathrm{CO}_{2}$ emissions primarily through a major project of fuel switching from coal to natural gas for producing electricity, given that emissions per Q-BTU from natural gas are nearly half those generated by coal combustion. The widely discussed idea that natural gas can serve effectively as an intermediate term "bridge fuel" as part of the longerterm project of building a low-emissions economy stems from this fact. In this first side case, we therefore modify the assumptions of the Aggressive Reference case, by allowing that coal consumption falls to zero and the difference is covered entirely by expanding natural gas consumption. That is, we create the most favorable possible scenario on behalf of a coal-to-natural-gas fuel-switching approach to emissions reduction. Despite this implausibly favorable scenario, energy-based $\mathrm{CO}_{2}$ emissions remain 26 percent above the 3,200 $\mathrm{mmt}$ target emissions level in this side case. 
In the second and third side cases, we modify the PERI/CAP case, by assuming that nuclear energy falls first to 5 Q-BTUs, then to zero. In both cases, again, the difference is covered entirely by expanding natural gas consumption. We explore these cases in consideration of public-safety concerns about nuclear energy, even while recognizing that nuclear power is a zero-emissions energy source. We find that within the framework of the PERI/CAP case, we can still meet the 3,200 mmt $\mathrm{CO}_{2}$ emissions target when nuclear power is maintained at 5 Q-BTUs rather than 8 Q-BTUs. But when we substitute natural gas for nuclear power entirely within the PERI/CAP case, we cannot lower overall $\mathrm{CO}_{2}$ emissions sufficiently to get below the 3,200 mmt threshold, even while we hold the overall level of U.S. energy consumption at 70 Q-BTUs.

In Chapter 6, we estimate the gains in employment that would result from making the roughly $\$ 200$ billion in annual clean energy investments that are needed for meeting the 2030 to 2035 greenhouse gas emissions-reduction target $-\$ 90$ billion per year in efficiency investments and $\$ 110$ billion per year in clean renewables. We also consider the employment losses that would result from the corresponding retrenchments in the nonrenewable energy sectors.

We begin Chapter 6 by describing our methodology for estimating the employment effects of alternative energy-investment scenarios. In particular, this includes our use of U.S. business survey data and the U.S. input-output model as our basic estimating tools. This is the framework we use for estimating how many U.S. jobs will be created through $\$ 200$ billion in annual investments in energy efficiency and clean renewables over a 20 -year period. We also calculate the gains in employment that would result from the expanded level of spending on operations and maintenance for these clean energy projects.

At the same time, to measure the net employment effects of clean energy investments, we also need to estimate the reductions in employment in the nonrenewable sectors-oil, natural gas, coal, and nuclear power-that would result when production contracts in these sectors. As we have seen, within an overall scenario of operating the U.S. economy at 70 Q-BTUs of total energy consumption, we estimate that demand for all nonrenewable energy sources will be about 55 Q-BTUs. Holding nonrenewable energy production at this level represents a contraction of 34 percent relative to the EIA's 2030 Reference case in which all nonrenewables combined would account for 83.4 Q-BTUs of total U.S. energy consumption. This contraction in nonrenewable energy production will, of course, mean job losses in these nonrenewable sectors. 
Nevertheless, we show in Chapter 6 that the net employment effects of concurrently expanding investments in energy efficiency and clean renewables in the range of $\$ 200$ billion per year while contracting production in the nonrenewable sectors will be to significantly expand job opportunities in the United States economy over the next 20 years. There are two basic reasons for this outcome. The first is that clean energy investments require more employment per unit of activity-i.e., they are more labor intensive than the average spending to maintain our existing nonrenewable sectors. The second is that clean energy investments entail a higher proportion of spending within the domestic U.S. economy-they have a higher level of domestic content - than spending within the nonrenewable sectors at roughly their current proportions.

In addition, there are large differences in the employment impacts of operations and maintenance, or O\&M, activities within the renewable versus the nonrenewable sectors. For the most part, O\&M within the clean renewable sectors generate roughly the same level of employment as those for nonrenewables. But there is one important exception, which is the clean biofuels/biomass sector. This sector requires significantly higher levels of employment than O\&M for both nonrenewables and other renewable sectors.

Within this overall framework, we then estimate that the annual level of employment that will result through advancing the PERI/CAP clean energy investment scenario is 4.2 million jobs. This includes jobs created both by new investments, as well as expanded levels of operations and maintenance in the clean energy sectors. We also find that total net employment-after taking account of job losses in the nonrenewable sectors tied to retrenchment in these sectors-is still at 2.7 million jobs.

We close Chapter 6 by considering the likely impact on the U.S. labor market in 2030 from expanding overall employment by about 2.7 million jobs. One gauge of this impact is that all else equal, it would bring a reduction in unemployment of about 1.5 percentage points. Thus, if the economy were otherwise operating at a 6.5 percent unemployment rate, operating under a clean energy framework as we have described would instead mean that the unemployment rate would be about 5 percent. We also provide a profile of the types of jobs that will be created under the clean energy agenda. As we show, building and operating the clean energy economy in the United States will produce large increases in job opportunities at all levels of credentials and pay. In short, the clean energy investment agenda creates more jobs, better jobs, and a broader distribution of opportunity across wages and skill levels. 
Chapter 7 examines the macroeconomic effects of a clean energy investment project in addition to the employment effects reviewed in Chapter 6. We begin this chapter by reviewing a range of recent macroeconomic forecasting models that have attempted to estimate the effects of cap-and-trade legislation on U.S. GDP growth. The primary purpose of cap-and-trade policies is to lower emissions through restricting production of fossil fuel energy. But limiting the supply of fossil fuel energy will then also raise the market price of these energy sources. With fossil fuel-based energy supply thus restricted and prices increasing as a result, we would expect that, all else equal, the impact of any such measure would be to lower GDP growth, at least moderately. Nevertheless, all of the large-scale macroeconomic forecasting models that we review in Chapter 7-including models produced by strong opponents of cap and trade-find that cap and trade will have a negligible impact on GDP growth. Of course, cap-and-trade policies per se are not the focus of our study (though, in Chapter 8, as discussed below, we do consider cap and trade among a range of policy measures for achieving the emissions-reduction target). Still, these forecasting results provide a useful framework for considering how a clean energy investment program could affect various specific components of overall GDP.

The macroeconomic impacts that we then examine-specifically with regard to the broader clean energy investment project outlined in the PERI/CAP energy scenario-include private investment, labor productivity, energy prices, the U.S. trade balance, and finally, how a decline in emissions could affect overall economic activity by reducing severe weather events. In most cases, consistent with the results of the various econometric forecasting models, we argue that the impact of clean energy investments on these other macro impacts should be modest. But there are also some aspects to the clean energy investment agenda that should yield positive effects on GDP — for example, a reduction in the structural trade deficit and a decline in severe weather events should both generate positive benefits for overall economic growth.

To further inform all such discussions on the macro effects of a clean energy investment agenda, we can now also learn from the experience of the 2009 stimulus package, the American Recovery and Reinvestment Act, or ARRA. The overall two-year $\$ 800$ billion program committed roughly $\$ 90$ billion to various sorts of clean energy investment projects. There is a widespread view-vocally advanced, for example, by many leading Republican political figures - that the clean energy components of ARRA failed as an engine of job creation. However, we show that, in fact, ARRA produced some important positive achievements, as well as some 
unsuccessful results in the clean energy area. First, the clean energy components of ARRA did succeed in creating jobs as anticipated to the extent that funds from the program were actually channeled as planned into the economy. Some problems were encountered with job creation from ARRA clean energy investments. But principally this was due to the money not moving into the economy quickly enough to generate the full positive impact on job creation that had been projected. The fundamental obstacle here was that within a short time framework, the federal government's administrative capacity was not adequate to manage a clean energy investment program that was orders of magnitude larger than any previous such federal initiative. However, to the extent that funds did move successfully throughout the country into supporting clean energy projects, the positive job effects of these investments did result basically as had been predicted.

We also consider in this chapter the specific experience with the closure in 2011 of Solyndra, the Northern California solar energy firm that received roughly $\$ 500$ million in 2009 through the federal loan guarantee program within ARRA. ${ }^{22}$ Critics have argued that Solyndra's failure provided confirmation that large-scale government subsidy programs for clean energy are doomed to failure. However, we evaluate the Solyndra experience as one case within the overall ARRA clean energy loan-guarantee program. Of the 24 firms that received loan guarantees under the same program as Solyndra, 22 of them are still in operation, moving the clean energy industry forward. We also provide further perspectives on the issue by considering previous federal R\&D programs such as those conducted through the Pentagon. Over generations, the Pentagon-based R\&D programs have led to the successful development of several epoch-defining technologies, including the jet engine and the internet. We argue that important lessons can be extracted from these programs in terms of advancing new clean energy technologies successfully through U.S. federal government support.

Chapter 8 develops a set of policy proposals that, in combination, can enable the United States to achieve the 2030 to $2035 \mathrm{CO}_{2}$ emissions-reduction targets through increased capital investment in clean energy. All of the proposed policy measures we discuss in Chapter 8 are currently in operation within the United States at either the federal, state, or municipal levels. Our aim in Chapter 8 is to show how these measures can be most effectively implemented, combined, and brought to scale. 
As mentioned at the outset of this chapter, we develop our policy agenda within four broad categories: market-shaping rules, direct public spending, private investment incentives, and transitional support for communities and workers facing retrenchment. The full set of policies we examine in this chapter vary widely in their approaches. Some entail large-scale public sector involvement, and others require little to no public funding while still providing effective levers to encourage private clean energy investments. As a general principle, all policy measures need to succeed as public/private partnerships. But ultimately, this agenda must be effective in mobilizing private business owners to invest in clean energy. This includes small and large businesses, cooperative and community-based enterprises, as well as individually owned firms and corporations. There is no other way in which the United States can realistically achieve the 20 -year $\mathrm{CO}_{2}$ emissions-reduction target that is essential for controlling climate change. The scale of the energy transformation is simply too large for public-sector resources and programs to tackle alone.

It follows that the first set of challenges in designing an effective clean energy agenda is to identify policy interventions that can best encourage private-sector investments. The policy agenda needs to be correspondingly focused on removing the obstacles that, to date, have held back large-scale private investments. We focus on three basic problems found in both the energy efficiency and renewable sectors: unpredictable demand in their respective markets; a lack of certainty in both the tax code and policy incentives; and unavailable long-term, low-cost financing. What we need are policies capable of both stabilizing and expanding demand for clean energy, reducing uncertainty for private investors, and increasing the supply of affordable financing.

Equally, we need to take seriously the fact that the major contractions in coal, oil, and natural gas production will create uncertainty and hardships for workers and communities whose livelihoods depend on fossil fuels. The provision of major transitional support for workers and communities facing retrenchment therefore needs to be established as a first-order priority. This is true despite the fact that, as we show in Chapter 6, large-scale investments in energy efficiency and renewable energy will be a major new engine of overall job creation, even after taking full account of the job losses in the coal, oil, and natural gas sectors.

As mentioned above, we provide at the end of Chapter 8 rough approximations of the fiscal impacts of these policies, assuming they are designed to operate at a scale capable of supporting the overall $\$ 200$ billion per year clean energy investment project. The program with the greatest fiscal impact is the carbon tax or cap. If a 
tax or cap were designed to operate, for example, at a level outlined in the EIA's 2011 "Annual Energy Outlook," it would on average generate more than $\$ 200$ billion per year in revenues over the 20 -year investment period. In terms of public expenditures, the program of federal production and investment tax credits would provide large-scale financial support for private clean energy investments, probably in the range of $\$ 50$ billion per year if they are to significantly support a major expansion in clean energy investments. By contrast, the regulatory programs we discuss are capable of achieving major impacts without requiring large-scale public expenditures.

It is beyond the scope of this discussion to establish in specific terms the most effective levels at which to set tax rates, subsidies, or regulatory standards with these programs. Our aim here is rather to provide a broad framework for understanding the scale at which these programs will need to operate and the fiscal impacts of operating at scale. As one major overarching point though, even if we were to assume that 75 percent of the revenues from a carbon cap or tax were returned directly to taxpayers, this would still leave roughly $\$ 50$ billion per year to channel into supporting clean energy investments. In addition, the combined annual net savings to the federal, state, and local governments of roughly $\$ 10$ billion from making investments in energy efficiency building retrofits could also be channeled into other areas of clean energy investments.

These two sources of revenues or net savings from clean energy policies could therefore provide about $\$ 60$ billion annually in funding for clean energy spending policies. This figure is roughly equal to our estimate that about $\$ 65$ billion per year on average would be needed to support clean energy expenditure policies. In short, when combined, the clean energy policies that we have discussed here would operate at a rough fiscal balance-again, after assuming that 75 percent of the funds generated by a carbon tax or cap would be distributed directly to U.S. taxpayers.

If we assume that a federal carbon tax or cap is not enacted, but that all the other programs are implemented as we have specified them, this would then imply an average annual level of net federal expenditures of $\$ 55$ billion. The net level of government spending would therefore amount to about 25 percent of the overall $\$ 200$ billion annual clean energy investment program, including both public and private funds for this level of investments. This is equal to about 0.3 percent of U.S. GDP. 
Overall, then, Chapter 8 presents a workable program for achieving the 2030 to $2035 \mathrm{CO}_{2}$ emissions target of 3,200 mmt. Pursuing this policy agenda will also promote expanded job opportunities at all levels of the U.S. economy and will not act as an obstacle to moving the U.S. economy onto a more healthy and stable long-term growth trajectory. Most fundamentally, advancing a transformational clean energy investment agenda will provide a truly viable framework for the United States to make its fair contribution over the next 20 years toward the immense global challenge of controlling climate change. 
1 John D. Podesta, Kate Gordon, Bracken Hendricks, and Benjamin Goldstein, "The Clean-Energy Investment Agenda: A Comprehensive Approach to Building the Low-Carbon Economy" (Washington: Center for American Progress, 2009), available at http://www. americanprogress.org/wp-content/uploads/ issues/2009/09/pdf/clean_energy_investment.pdf.

2 According to the U.S. Bureau of Economic Analysis, GDP in the U.S. was approximately $\$ 17$ trillion in the first half of 2014 . Thus $\$ 200$ billion represents 1.2 percent of this amount. See U.S. Bureau of Economic Analysis, "Table 1.1.5 Gross Domestic Product," http://www.bea.gov/ iTable/iTable.cfm?ReqID=9\&step=1\#reqid=9\&step=3\&is uri $=1 \& 903=5$ (last accessed August 2014)

3 Our source for this estimated range of total clean energy investments in the United States is the Bloomberg New Energy Finance and Business Council for Sustainable Energy, "Sustainable Energy in America 2013 Factbook" (2013), p. 2, available at http://www.bcse.org/factbook/ pdfs/BCSE_BNEF_Sustainable_Energy_in_America 2013_Factbook.pdf. The report writes that "estimated total new investment in U.S. clean energy was $\$ 44.2$ billion in 2012. This amount ... marks a 32 percent decline from 2011"

4 See the "Carbon Price Scenario" in U.S. Energy Information Administration, Annual Energy Outlook 2011 (Washington: U.S. Department of Energy, 2011), available at http://www.eia.gov/forecasts/archive/ aeo11/pdf/0383(2011).pdf.

5 The global mean temperature figures reported in this paragraph are approximations, based on data from the National Aeronautics and Space Administration, or NASA. The most widely accepted position among climate scientists is that global mean temperatures need to be stabilized at no more than about $2{ }^{\circ} \mathrm{C}$ above preindustrial levels. We derived a rough approximation of what these temperature levels are both in Fahrenheit and Celsius, based on NASA's land-ocean global temperature index. Using that index, we approximate the average global mean surface temperature for the year 1880 - the first year for which reliable data are reported-at $13.72^{\circ} \mathrm{C}$. This implies that global average mean surface temperature needs to be stabilized at $15.72^{\circ} \mathrm{C}$. NASA's global mean surface temperature index numbers are presented at U.S. National Aeronautics and Space Administration, "GLOBAL Land-Ocean Temperature Index in 0.01 degrees Celsius, base period: 1951-1980," available at http:// data.giss.nasa.gov/gistemp/tabledata_v3/GLB.Ts+dSST. txt (last accessed July 2012). We realize that climate scientists typically do not discuss climate change in terms of absolute temperature figures, but rather as temperature anomalies relative to a base year, which is generally a mid-20th century figure. We have calculated the reported absolute figures, as approximations, to facilitate understanding of the issues at hand.

6 Throughout this study, we make use of the term Q-BTU to refer to quadrillion British Thermal Units, or BTUs, of energy. This is a commonly used unit of measurement for energy when considering different types of energy sources and industry sectors in a unified or comparative way. We discuss this further in the sidebar on units of measurement, including an explanation of measuring how much energy is provided by one Q-BTU.

7 U.S. Environmental Protection Agency, Inventory of U.S Greenhouse Gas Emissions and Sinks: 1990-2012 (2014) available at http://www.epa.gov/climatechange/ Downloads/ghgemissions/US-GHG-Inventory2014-Main-Text.pdf.
8 The World Bank, "Population, Total," available at http:// data.worldbank.org/indicator/SP.POP.TOTL (last accessed August 2014).

9 U.S. Environmental Protection Agency, Inventory of U.S. Greenhouse Gas Emissions and Sinks: 1990-2012.

10 Robert Horwarth, "A Bridge to Nowhere: Methane Emissions and the Greenhouse Gas Footprint of Natural Gas," Energy Science and Engineering 2 (3) (2014): 107-163, available at http://onlinelibrary.wiley.com/ doi/10.1002/ese3.35/pdf. For alternative perspectives on U.S. methane emissions and proposals to control them, see ICF International, "Economic Analysis of Methane Emission Reduction Opportunities in the U.S. Onshore Oil and Natural Gas Industries" (2014), available at http://www.edf.org/sites/default/files/ methane_cost_curve_report.pdf; The White House, "Fact Sheet: Climate Action Plan-Strategy to Cut Methane Emissions," Press release, March 28, 2014, available at http://www.whitehouse.gov/the-press office/2014/03/28/fact-sheet-climate-action-planstrategy-cut-methane-emissions. We also note that, just in terms of data availability, it is not feasible to focus strictly on the year 2030 in terms of addressing U.S. intermediate $\mathrm{CO}_{2}$ emissions reduction targets. This is because of gaps in the various forecasts for the U.S. energy industry, especially those developed by the U.S Energy Information Agency, or EIA, itself. For example, the EIA in some instances provides forecasts for the years 2025 and 2035, but not 2030. As will be clear, we draw heavily on these forecasts in developing our own analysis. As such, we will refer frequently to the five-year period of 2030-2035 as our target years for reaching the emission reduction targets. But we also continue to fully recognize that 2030, the earliest year in that range, is the most desirable date for the U.S. economy to achieve the target of no more than $4,200 \mathrm{mmt}$ per year of emissions relative to the 2010 level of 5,600.

11 The World Bank, "Table 3.8, World Development Indicators: Energy dependency, efficiency, and carbon dioxide emissions," available at http://wdi.worldbank. org/table/3.8 (last accessed August 2014).

12 The figures on per capita emissions are from the World Bank, "Climate Change," available at http://data. worldbank.org/topic/climate-change (last accessed August 2014). For a full-length discussion of global emissions patterns and related topics that is complimentary to the current study, see Robert Pollin, Heidi Garrett-Peltier, James Heintz, and Shouvik Chakraborty. "Global Green Growth: Clean Energy Industrial Investments and Expanding Job Opportunities" (Vienna, Austria: U.N. Industrial Development Organization, forthcoming).

13 U.S. Energy Information Administration, Annual Energy Outlook 2012: with Projections to 2035 (Washington: U.S Department of Energy, 2012), available at http://www. eia.gov/forecasts/aeo/pdf/0383(2012).pdf.

14 For an excellent, authoritative, and highly accessible discussion on these issues in climate science, see Kerry Emanuel, What We Know About Climate Change, Second edition (Cambridge, MA: MIT Press, 2012).

15 Good discussions on policies for adapting to climate change include, the National Research Council, Adapting to the Impacts of Climate Change (Washington: The National Academies Press, 2010); and M.L. Parry, O.F. Canziani, J.P. Palutikof, P.J. van der Linden, and C.E. Hanson "Contribution of Working Group II to the Fourth Assessment Report of the Intergovernmental Panel on 
Climate Change (Cambridge, U.K.: Cambridge University Press, 2007). In addition, the OECD has produced a wide range of studies that are available at their website: Organisation for Economic Co-operation and

Development, "Adaptation to climate change," available at http://www.oecd.org/env/cc/adaptation.htm (last accessed February 2014).

16 William Stanley Jevons, The Coal Question: An Inquiry Concerning the Progress of the Nation, and the Probable Exhaustion of our Coal-Mines: 3rd edition (London: Macmillan, 1906).

17 U.S. Energy Information Administration, "Annual Energy Outlook 2014" (Washington: U.S. Department of Energy, 2014), available at http://www.eia.gov/forecasts/aeo/ pdf/0383(2014).pdf..Our main reference in this study for all U.S. energy data is the EIA data for 2010, published in the EIA's 2012 Annual Energy Outlook, rather than

2012 data, published in its 2014 Annual Energy Outlook. However, because clean energy production has grown significantly from a very small base between 2010 and 2012, we cite the figures for 2012 in this opening chapter as an initial reference point. As of 2010, bioenergy and hydro accounted for nearly 90 percent of all renewables. The expansion in wind energy supply has been the biggest source for the relative expansion between 2010 and 2012 in wind, solar, and geothermal combined.

18 At the same time, the primary cause of rising global food prices in recent years has been the enormous rise in financial speculation on the commodities futures markets. For extensive discussions on this issue, see Jayati Ghosh, James Heintz, and Robert Pollin, "Speculation on Commodities Futures Markets and Destabilization of Global Food Prices: Exploring Connections," International Journal of Health Services 42 (3) (2012): 465-483 and Manisha Pradhananga, "Financialization of the Commodities Futures Markets and its Effects on Prices," Ph.D. dissertation, University of Massachusetts-Amherst, 2014.

19 U.S. Energy Information Administration, Annual Energy Outlook 2014: with projections to 2040 (Washington: U.S. Department of Energy, 2014), Table A17, available at http://www.eia.gov/forecasts/aeo/pdf/0383(2014).pdf.
20 U.S. Energy Information Administration, "Annual Energy Outlook 2014."This figure was at 14 percent of all renewable energy as of the 2010 data, which was only slightly more than one percent of total U.S. energy supply that year.

21 That is, with 55 Q-BTUs of energy supplied by all non-renewable sources and $21 \mathrm{Q}-\mathrm{BTU}$ s supplied by oil that leaves 34 Q-BTUs (55 Q-BTUs - 21 Q-BTUs = 34 QBTUs) to be supplied by some combination of coal, natural gas, and nuclear power.

22 U.S. Department of Energy, "Projects," available at http:// energy.gov/lpo/projects (last accessed August 2014).

23 U.S. Energy Information Administration, Annual Energy Outlook (2012), for figures on U.S. residential and automobile energy consumption, as well as data on average capacity of U.S. power plants; Additional data on U.S. electrical utility data are from the U.S. Energy Information Administration, Form EIA-923 detailed data," available at http://www.eia.gov/electricity/data/ eia923/ (last accessed July 2014); For electricity consumption by U.S. states, see U.S. Energy Information Administration, Table C9. Electric Power Sector Consumption Estimates (2012), available at http://www. eia.gov/state/seds/sep_sum/html/pdf/sum_btu_eu. pdf; U.S. For data on energy use by automobiles see U.S. National Transportation Research Center, "Transportation Energy Data Book" (Knoxville, TN: Oak Ridge National Laboratory, 2013), available at http:// cta.ornl.gov/data/tedb32/Edition32_Chapter02.pdf. Fo figures on tons of coal per Q-BTU see U.S. Bureau of Land Management, "American Energy for America's Future: The Role of the U.S. Department of the Interior," available at http://www.blm.gov/pgdata/etc/medialib/ $\mathrm{blm} /$ wo/MINERALS_REALTY_AND_RESOURCE_PROTECTION_Par.61407.File.dat/EnergyBro.pdf; For figures on freight train storage capacity, Bob Vance, "Coal Train Fact Check" (Washington: League of Women Voters, 2013), available at http://www.lwv-bf.org/Coal_Train Fact_Check.pdf; Calories per Q-BTU generated through conversion calculator. McDonalds, "McDonalds's USA Nutrition Facts for Popular Menu Items" (2014), available at http://nutrition.mcdonalds.com/ getnutrition/nutritionfacts.pdf. 
Chapter 2

Prospects for energy efficiency 


\section{Introduction}

The United States has made significant advances over the past 40 years in raising energy efficiency standards. As of 2010 the average energy consumption per person was 317 million BTUs. (see Figure 2.1) This figure is about 4 percent lower than the level in 1970 of 331 million BTUs per person. It is also 12 percent lower than the peak level of consumption between 1978 and 1979, at 359 millions of BTUs per person. This is while real per capita GDP in the United States rose from $\$ 21,000$ to $\$ 42,000$ between 1970 and 2010 .

As Figure 2.1 also shows, energy consumption in the United States since 1970 has fallen sharply relative to GDP since 1970. This ratio, which is termed the energyintensity ratio, was at 15.9 thousand BTUs per dollar of GDP in 1970. It stood at

FIGURE 2.1

U.S. energy consumption from 1970 through 2010

Energy consumption per person and per dollar of GDP

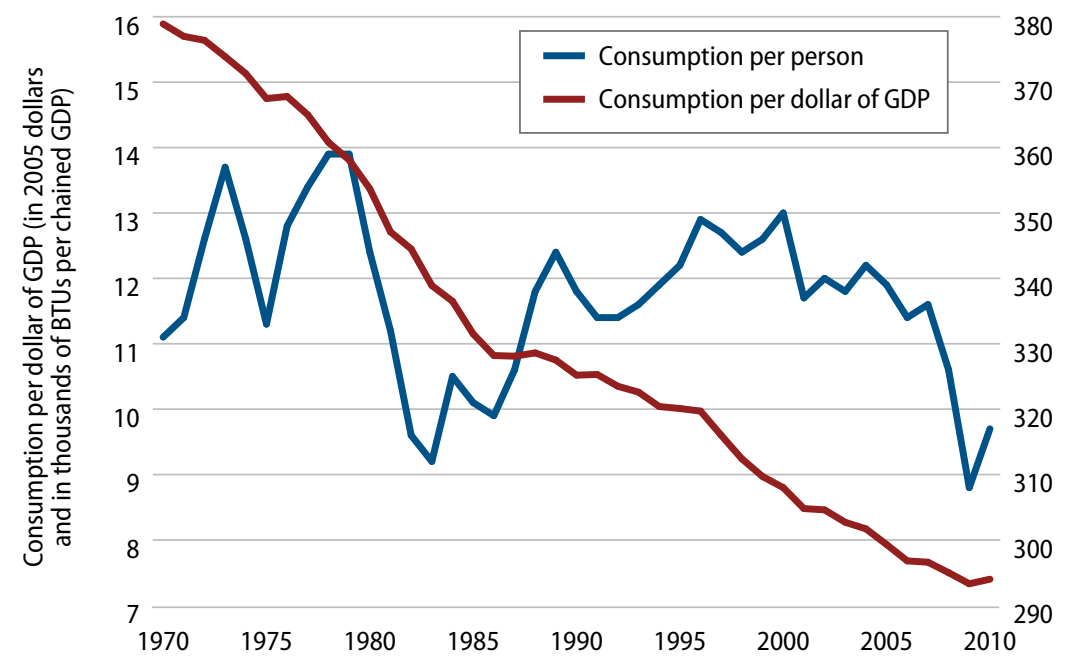

Sources: U.S. Energy Information Agency (EIA), Annual Energy Review 2010, U.S. Department of Energy, 2010, http://www.eia.gov/ totalenergy/data/annual/ 
7.4 thousand BTUs per dollar in 2010. This is a 53 percent decline, equivalent to a 1.9 percent average annual rate of decline over the full 40 -year period.

Such long-term improvements in energy efficiency are impressive. But to consider environmental impacts, we need to focus on the absolute level of greenhouse gas emissions, not simply on improvements in efficiency. This is especially true since gains in efficiency can be offset by an expanding level of economic output, as well as by population growth. Thus, the absolute level of energy consumption of 98 Q-BTUs in 2010 was 45 percent higher than in 1970. This increase in total energy consumption translates into more $\mathrm{CO}_{2}$ emissions. Overall, at 5,634 mmt, carbondioxide emissions in 2010 from energy sources were about 34 percent higher than the 1970 figure of $4,201 \mathrm{mmt}$.

In addition, the level of energy consumption and $\mathrm{CO}_{2}$ emissions is substantially higher in the United States than almost all other advanced economies, as we see in Table 2.1. Measured by BTUs per dollar of GDP, compared to the United States, France consumes 26 percent less energy, Germany 28 percent less, Japan 25 percent less, and the United Kingdom 42 percent less. Among advanced economies, only Canada consumes more energy than the United States-in fact, 48 percent more-in order to produce a dollar of GDP.

The figures on BTUs per person are similar. The average person in the United States consumes roughly twice as much as residents of France, Germany, Japan, and the United Kingdom. Again, in Canada, energy consumption per capita is about 27 percent higher than in the United States.

Finally, in terms of $\mathrm{CO}_{2}$ emissions, we see that France, Germany, Japan, and the United Kingdom are all between 47 percent and 66 percent lower than the United States in per capita emissions. Even Canada is 10.3 percent lower than the United States in this category. The long-term trend in the United States toward rising efficiency levels, coupled with the fact that other advanced economies for the most part already operate at roughly double the U.S. efficiency rate, make clear that the United States could achieve major gains in efficiency over the next 20 years. 
Comparative energy use and emissions levels for the United States and other advanced economies

\begin{tabular}{|c|c|c|c|c|c|c|}
\hline & \multicolumn{2}{|c|}{$\begin{array}{l}\text { BTUs per dollar of GDP, } 2009 \\
\quad \text { (in } 2005 \text { U.S. dollars) }\end{array}$} & \multicolumn{2}{|c|}{ Millions of BTUs per capita, 2009} & \multicolumn{2}{|c|}{$\begin{array}{c}\mathrm{CO}_{2} \text { emissions per capita from } \\
\text { energy sources, metric tons per } \\
\text { capita, } 2010\end{array}$} \\
\hline & $\begin{array}{l}\text { BTUs per } \\
\text { dollar of } \\
\text { GDP }\end{array}$ & $\begin{array}{c}\text { Ratio relative to } \\
\text { United States } \\
\text { (percent) }\end{array}$ & $\begin{array}{c}\text { BTUs } \\
\text { per capita }\end{array}$ & $\begin{array}{l}\text { Ratio relative to } \\
\text { United States } \\
\text { (percent) }\end{array}$ & $\begin{array}{l}\mathrm{CO}_{2} \text { emissions } \\
\text { per capita }\end{array}$ & $\begin{array}{l}\text { Ratio relative to } \\
\text { United States } \\
\text { (percent) }\end{array}$ \\
\hline United States & 7,340 & -- & 308 & -- & 18.1 & -- \\
\hline Canada & 10,847 & +47.8 & 389.5 & +26.5 & 16.2 & -10.3 \\
\hline France & 5,435 & -26.0 & 169.2 & -45.1 & 6.2 & -65.5 \\
\hline Germany & 5,296 & -27.9 & 163.5 & -46.9 & 9.6 & -46.7 \\
\hline Japan & 5,501 & -25.1 & 162.1 & -47.4 & 9.2 & -49.2 \\
\hline United Kingdom & 4,251 & -42.1 & 143.0 & -53.6 & 8.5 & -53.0 \\
\hline
\end{tabular}

Source: U.S. Energy Information Administration, "International Energy Statistics," available at http://www.eia.gov/cfapps/ipdbproject/IEDIndex3.cfm (last accessed September 2013).

In fact, this conclusion is built into the Energy Information Administration's Reference case projection for energy consumption, as of both 2030 and 2035. Focusing on the Reference case projection for 2030, the EIA projects that U.S. energy consumption as of 2030 will be 104.3 Q-BTUs, which is an increase of only 6.1 Q-BTUs relative to the 2010 level of 98.2 Q-BTUs. ${ }^{1}$

Table 2.2 shows the actual level of total U.S. economic consumption for 2010 and the EIA's Reference case projection for 2030, broken down by major energyconsuming sectors such as buildings, industry, and transportation. As the table shows, the EIA projects that the relative levels of consumption for the three sectors remains fairly stable through 2030 - with buildings accounting for about 40 percent of the total both in 2010 and 2030, and industry and transportation each accounting for roughly 30 percent both in 2010 and 2030.

The EIA's overall projected increase in consumption, from 98.2 to 104.3 Q-BTUs between 2010 and 2030, amounts to an average annual increase of only 0.3 percent, a significant improvement from the 0.9 percent annual increase in energy use between 1970 and 2010. The EIA also forecasts U.S. GDP growth to be at 2.5 percent annually between 2010 and 2035 . 
TABLE 2.2

Energy consumption in the United States by economic sector

2010 actual and EIA 2030 Reference case projections

\begin{tabular}{lcc}
\hline Energy source & 2010 actual consumption, in Q-BTUs & EIA 2030 Reference case, in Q-BTUs \\
\hline Buildings & 40.3 & 43.4 \\
& $(41 \%$ of 2010 total $)$ & $(41.6 \%$ of 2030 total $)$ \\
Industry & 30.3 & 32.9 \\
& $(30.9 \%$ of 2010 total $)$ & $(31.5 \%$ of 2030 total $)$ \\
Transportation & 27.6 & 28.0 \\
Total & $(28.1 \%$ of 2010 total $)$ & $(26.9 \%$ of 2030 total $)$
\end{tabular}

Source: Energy Information Administration, Annual Energy Outlook 2012 (U.S. Department of Energy, 2012).

But here is precisely where the major source of concern with $\mathrm{CO}_{2}$ emissions becomes evident. That is, despite the EIA's forecasted slow rate of increase in energy consumption through 2030 and beyond, the U.S. economy will still emit about 5,600 $\mathrm{mmt}$ of $\mathrm{CO}_{2}$ into the atmosphere from energy-based sources in 2030, according to the EIA's 2030 Reference case. This figure is 75 percent higher than the 20-year emissions-reduction target of 3,200 $\mathrm{mmt}$ of $\mathrm{CO}_{2}$ emissions from all energy-based sources.

As we will review below, the National Academy of Sciences, or NAS, and others have developed scenarios for energy-efficiency investments that can deliver gains beyond the EIA Reference case for 2030. In the most extensive analysis provided by the NAS (2010), it estimated that as of 2030, with sufficient levels of efficiency investments, the U.S. economy could operate with a total level of energy consumption approximately between 82.2 and 87.5 Q-BTUs (2010, p. 262). ${ }^{2}$ The midpoint of these two estimates is thus around 85 Q-BTUs of total energy consumption as of 2030 — or 18 percent below the EIA's Reference case of 104.3 Q-BTUs. This would represent a dramatic improvement in energy efficiency in the U.S. economy-indeed, an absolute decline in the level of energy consumption of 13 percent relative to the actual 2010 level of 98 Q-BTUs. The NAS anticipates that this level of efficiency could be achieved, and the U.S. economy would not experience any significant effects on maintaining its long-run GDP growth path of around 2.5 percent per year.

That said, even with this ambitious agenda to improve energy efficiency by nearly 20 percent relative to the EIA 2030 Reference case, it is still true that operating at a roughly 85 Q-BTU level of consumption and with roughly the 
same mix of energy sources as is currently the case, the U.S. economy would be generating about 4,500 of $\mathrm{CO}_{2}$ by consuming energy, This level of $\mathrm{CO}_{2}$ emissions is still more than 40 percent above the 2030 minimum stabilization target of 3,200 of $\mathrm{CO}_{2}$ emissions.

The most basic question we therefore need to address in this chapter is how to make further improvements in energy efficiency in the United States beyond the types of improvements projected in the NAS study. Indeed, as will become clear through our analysis in this and the following chapters, for the United States to succeed in reaching the goal of 3,200 $\mathrm{mmt}$ in $\mathrm{CO}_{2}$ emissions from energy-based sources, the overall level of energy consumption in the U.S. economy will need to be lowered to about 70 Q-BTUs - that is, to a level that is nearly 30 percent below the actual level for 2010 and about 33 percent below the EIA's Reference case projection for 2030 .

In the remainder of this chapter, we will explore scenarios for reaching a target of 70 Q-BTUs of energy consumption by 2030-2035. We will see from this discussion that the NAS study itself, as well as comparable studies, do provide a basis for showing how this is feasible, both technically and economically, without having to make heroic assumptions about technological breakthroughs or disruptions to overall economic activity. We will review the evidence on these matters and will also provide broad estimates as to the amount of new capital investments that will be necessary to reach this level of efficiency. The chapter then concludes with an evaluation of the rebound effect and other potential obstacles to achieving efficiency goals-even if the efficiency can be shown to be attainable in terms of both technical and financial criteria. 


\section{Energy efficiency in the building sector}

Comparing 2010 and projected 2030 consumption levels

As shown in Table 2.3, overall consumed energy use in operating buildings was 40.3 Q-BTUs in 2010, with 22.1 Q-BTUs in residential and 18.6 in commercial buildings. The amount of delivered energy was 20.4 Q-BTUs, half of the total energy consumed.

TABLE 2.3

Energy consumption in buildings, 2010 and 2030 Reference case

\begin{tabular}{lccc}
\hline & Residential & Commercial & Total \\
\hline 2010 actuals & & & 20.4 \\
Delivered (in Q-BTUs) & 11.7 & 8.6 & 40.3 \\
$\begin{array}{l}\text { Consumed (in Q-BTUs) } \\
\text { Ratio of delivered/ } \\
\text { consumed energy }\end{array}$ & 22.1 & 48.2 & $50.6 \%$ \\
$\begin{array}{l}\text { 2030 Reference case } \\
\text { Delivered (in Q-BTUs) }\end{array}$ & $52.9 \%$ & & \\
Consumed (in Q-BTUs) & 11.7 & 9.9 & 21.6 \\
$\begin{array}{l}\text { Ratio of delivered/ } \\
\text { consumed energy }\end{array}$ & 22.7 & 20.7 & 43.4 \\
& $51.5 \%$ & $47.8 \%$ & $49.8 \%$
\end{tabular}

Source: Energy Information Administration, Annual Energy Outlook 2012 (U.S. Department of Energy, 2012).

Of course, the reason for this large gap between consumed and delivered energy is that the building sector relies far more heavily than transportation or industry on electricity as an energy source. Energy losses in generating electricity are about two-thirds of all energy consumed, with only one-third of energy converted to delivered electricity. This means that when electricity-generated energy is saved at the point of consumption, the overall savings will be three times greater than the savings in consumption itself. As such, the potential for energy-efficiency gains in 
buildings is substantially higher than for the industry and transportation sectors. Correspondingly, the potential for energy savings in industry and transportation will increase if their reliance on electricity as an energy source also increases.

The 2030 Reference case predicts that total energy consumed will be 43.4 Q-BTUs, and total delivered energy will be 21.6 Q-BTUs. That is, the EIA anticipates an increase in energy consumption of only 3.1 Q-BTUs over 20 years at an annual rate of increase of only 0.4 percent for the entire U.S. building sector. Clearly, then, the EIA's main conclusion is that energy use in the building sector will be increasing at a very slow rate, if at all.

In fact, the EIA has varied its explanation as to the main source for this pattern of nearly flat energy consumption in buildings through 2030. In the 2010 edition of its "Annual Energy Outlook," the EIA writes that most of the explanation lies with what it terms "structural change" as opposed to improvements in efficiency. More precisely, as of 2010 the EIA's Reference case estimated that 82 percent of the improvements are from structural change, and only 18 percent are from efficiency improvements. ${ }^{3}$ What this Reference case assumes is that the average annual increases in residential and commercial floor space will grow at only half their projection for GDP growth. That is, the model assumes an average annual GDP growth rate of 2.4 percent, while the average rate of growth in residential floor space in the model is only 1 percent, and that of commercial floor space is 1.3 percent.

The reasons for assuming such slow growth in construction are derived through the EIA's forecasting tool, the NEMS model. From the discussions presented in the AEO and the underlying discussion of the NEMS model, however, it is not clear how the EIA derived this result. ${ }^{4}$ One factor is likely the slump in the construction industry caused by the 2008-2009 financial crisis and Great Recession.

In its 2012 edition of the "Annual Energy Outlook," however, the explanations for the low rate of increase in energy consumption are more focused on various investments in efficiency. ${ }^{5}$ It is not clear that the EIA remains committed to the idea that the growth in floor space will stay low. The main point for our purposes is that if we allow that the EIA remains committed to the idea that "structural change" in the use of buildings is a major factor in slowing the growth of energy use in buildings, that still leaves large additional opportunities for lowering energy consumption through efficiency gains. Moreover, the greatest opportunities for raising efficiency in buildings would result by designing and constructing new 
structures that are much more energy efficient. From this perspective, even if the growth in construction were to accelerate beyond the slow rate assumed in the EIA's 2010 estimating model, it does not follow that the overall level of energy consumption would necessarily rise commensurately.

This becomes clear in the EIA's own assessment in 2010 of the assumptions it uses with its NEMS estimating model. It compares the results of its Reference case for the building sector to alternative scenarios, including the case for using the "Best Available Technology" and even surpassing that level of technological efficiency. The report concludes:

In the Best Available Technology case, with new construction materials and replacement equipment limited to the most energy-efficient available, energy consumption in the buildings sector in 2035 is 8.6 percent lower than the 2009 level and 23 percent lower than in the Reference case, even though total floor space grows by more than 50 percent. Even in 2035, however, not every piece of equipment or every building shell reaches the maximum efficiency that could be achieved as a result of technology improvements, because some long-lived equipment and building shells installed before 2009 still have not been replaced at that point. Surpassing the efficiency levels projected in the Best Available Technology case would require policies designed to increase the rate of stock turnover-for example, by incentivizing or mandating retrofits of existing buildings and replacement of equipment with the most efficient models available.

In short, the EIA itself is considering a scenario in which, through relying on the "Best Available Technology," overall energy consumption in buildings could be as much as 23 percent lower than its own 2030 Reference case, even while floor space is growing by 50 percent. $^{6}$

Moreover, the EIA also is allowing for faster improvements beyond the Best Available Technology case if policies are established that accelerate the rate of building stock turnover. The most important example they provide here are policies to either mandate or incentivize retrofits and new building equipment. In the 2012 edition of its "Annual Energy Outlook," the EIA emphasizes the importance of such policy measures more fully. We focus on precisely these types of policy ideas in our proposals in Chapter 8. 
Consistent with the EIA's assessment of its Best Available Technology case, the National Academy of Sciences study presents extensive evidence showing consumption in buildings could fall by approximately 30 percent or more below the EIA's 2030 Reference case through a wide range of "low-cost" investments in energy efficiency. By low-cost investments, we refer to the NAS measure of the "cost of conserved energy." Low-cost investments are those in which the costs of conservation are below the market price of energy from the relevant energy source. For buildings, the relevant energy threshold is the price of delivered electricity or natural gas.

Tables 2.4 to 2.7 present data from the NAS estimates, with data for residential buildings in Tables 2.4 and 2.5 and for commercial buildings in Tables 2.6 and 2.7. In both cases, we break down the investment and savings potential in terms of electricity or natural gas energy sources. As shown in both sets of tables, major efficiency gains can be attained first through investments in a building's thermal shell—for example, its insulation, windows, and air sealing. These thermal-shell investments are reflected in changes in heating and cooling costs. Further savings can result from investments in improving heating, ventilation, and air conditioning, or HVAC, systems. 
TABLE 2.4

\section{Main sources of energy-efficiency investments: 'Technoeconomic potential' Residential- electricity}

From National Academy of Sciences (2010)

\begin{tabular}{|c|c|c|c|c|c|}
\hline $\begin{array}{l}\text { End use } \\
\text { (electricity) }\end{array}$ & $\begin{array}{l}\text { Savings in } \\
\text { Q-BTUs, } \\
2030^{1}\end{array}$ & $\begin{array}{l}\text { Percent sav- } \\
\text { ings relative to } \\
\text { EIA } 2030 \text { Refer- } \\
\text { ence case }\end{array}$ & $\begin{array}{l}\text { Percent } \\
\text { total } \\
\text { savings in } \\
\text { sector }\end{array}$ & $\begin{array}{l}\text { Cost of conserved } \\
\text { energy (cents per } \\
\text { kilowatt hour, in } \\
2010 \text { dollars) }\end{array}$ & $\begin{array}{l}\text { Efficiency-measure } \\
\text { description }\end{array}$ \\
\hline Lighting & 0.58 & 50 & 13 & 1.2 & $\begin{array}{l}\text { Compact florescent fixtures, halogen- } \\
\text { infrared lamps, and reduced wattage }\end{array}$ \\
\hline Space cooling & 0.30 & 27 & 17 & 5.5 & $\begin{array}{l}\text { Improved efficiency in central and } \\
\text { room air conditioners and variable- } \\
\text { speed refrigeration and } \\
\text { air conditioning }\end{array}$ \\
\hline Color television & 0.23 & 25 & 5 & 0.9 & Reduced standby-power use \\
\hline Water heating & 0.13 & 27 & 8 & 2.1 & $\begin{array}{l}\text { Reduced standby loss in electric- } \\
\text { resistance water heaters, heat-pump } \\
\text { water heaters, and horizontal-axis } \\
\text { clothes washers }\end{array}$ \\
\hline $\begin{array}{l}\text { Personal } \\
\text { computers }\end{array}$ & 0.13 & 57 & 8 & 4.5 & $\begin{array}{l}\text { Energy Star-rated PCs and monitors } \\
\text { that are power-management enabled }\end{array}$ \\
\hline Refrigeration & 0.13 & 31 & 7 & 4.8 & $\begin{array}{l}\text { Best-in-class Energy Star } \\
\text { refrigerator, } 2008\end{array}$ \\
\hline Space heating & 0.10 & 17 & 3 & 3.7 & $\begin{array}{l}\text { Improved heat-pump efficiency after } \\
\text { switching electric furnaces to heat } \\
\text { pump }\end{array}$ \\
\hline $\begin{array}{l}\text { Other } \\
\text { (thermal shell) }\end{array}$ & N/A & Up to 40 & N/A & N/A & $\begin{array}{c}\text { Improved shell—insulation, windows, } \\
\text { and air sealing —in new electric- } \\
\text { heated homes }\end{array}$ \\
\hline $\begin{array}{l}\text { Other } \\
\text { (appliances and } \\
\text { motors) }\end{array}$ & 0.33 & 36 & 39 & 2.3 & $\begin{array}{l}\text { Includes cooking; freezers; dishwash- } \\
\text { ers; clothes washers and dryers; } \\
\text { furnace fans and boiler circulation } \\
\text { pumps; and other uses }\end{array}$ \\
\hline Total & 1.93 & 33 & 100 & 2.8 & N/A \\
\hline
\end{tabular}


TABLE 2.5

\section{Main sources of energy-efficiency investments: Technoeconomic potential Residential- natural gas}

From National Academy of Sciences (2010)

\begin{tabular}{|c|c|c|c|c|c|}
\hline $\begin{array}{l}\text { End use } \\
\text { (electricity) }\end{array}$ & $\begin{array}{l}\text { Savings in } \\
\text { Q-BTUs, } \\
2030^{1}\end{array}$ & $\begin{array}{l}\text { Percent sav- } \\
\text { ings relative to } \\
\text { EIA } 2030 \text { Refer- } \\
\text { ence case }\end{array}$ & $\begin{array}{l}\text { Percent } \\
\text { total } \\
\text { savings in } \\
\text { sector }\end{array}$ & $\begin{array}{l}\text { Cost of conserved } \\
\text { energy (dollars per } \\
\text { millions of BTUs, in } \\
2010 \text { dollars) }\end{array}$ & $\begin{array}{l}\text { Efficiency-measure } \\
\text { description }\end{array}$ \\
\hline Space heating & 1.15 & 30 & 72 & $\$ 5.75$ & $\begin{array}{c}\text { Insulate, seal, and balance ducts and } \\
\text { place the ducts within thermal shell } \\
\text { condensing furnace }\end{array}$ \\
\hline Water heating & 0.35 & 29 & 28 & $\$ 12.33$ & $\begin{array}{l}\text { On-demand water heater; gas water } \\
\text { heater; low-flow plumbing fittings; } \\
\text { Energy Star rated clothes washer; } \\
\text { reduced water-heater tank tempera- } \\
\text { ture; greywater heat exchanger; and } \\
\text { pipe insulation }\end{array}$ \\
\hline Clothes dryers & 0.002 & 3 & Less than 1 & $\$ 3.03$ & NA \\
\hline $\begin{array}{l}\text { Other } \\
\text { (thermal shell) }\end{array}$ & $\mathrm{N} / \mathrm{A}$ & Up to 40 & N/A & N/A & $\begin{array}{l}\text { Air sealing; R-19 floor insulation; R-21 } \\
\text { wall insulation, R-49 attic insulation; } \\
\text { integrated design for new construc- } \\
\text { tion; triple-pane windows; and } \\
\text { insulated attic hatches }\end{array}$ \\
\hline Total & 1.50 & 28 & 100 & $\$ 7.18$ & N/A \\
\hline
\end{tabular}

Source: National Academy of Sciences, "Real Prospects for Energy Efficiency in the United States" (2010), pp. 69, 72-73.

1 Calculated using Energy Information Administration, Annual Energy Outlook 2012 (U.S. Department of Energy, 2012), table A4.

2 Costs from Rich Brown et al., "US Building Sector Energy Efficiency Potential” (Berkeley: Ernest Orlando Berkeley National Laboratory, 2008) were inflated using the GDP implicitprice deflator. See U.S. Bureau of Economic Analysis, Table 1.1.9, "Implicit Price Deflators for Gross Domestic Product." Available at www.bea.gov. 
TABLE 2.6

\section{Main sources of energy-efficiency investments: Technoeconomic potential Commercial- electricity}

From National Academy of Sciences (2010)

\begin{tabular}{|c|c|c|c|c|c|}
\hline $\begin{array}{l}\text { End use } \\
\text { (electricity) }\end{array}$ & $\begin{array}{l}\text { Savings in } \\
\text { Q-BTUs, } \\
2030^{1}\end{array}$ & $\begin{array}{l}\text { Percent sav- } \\
\text { ings relative to } \\
\text { EIA } 2030 \text { Refer- } \\
\text { ence case }\end{array}$ & $\begin{array}{l}\text { Percent } \\
\text { total } \\
\text { savings in } \\
\text { sector }\end{array}$ & $\begin{array}{l}\text { Cost of conserved } \\
\text { energy (cents per } \\
\text { kilowatt hour, in } \\
2010 \text { dollars) }\end{array}$ & $\begin{array}{l}\text { Efficiency-measure } \\
\text { description }\end{array}$ \\
\hline Lighting & 0.47 & 25 & 14 & 5.4 & $\begin{array}{l}\text { T8 lamps and electronic ballasts; } 32 \text { per- } \\
\text { cent combined savings from occupancy } \\
\text { controls; and daylight dimming and } \\
\text { improved lighting design }\end{array}$ \\
\hline Space cooling & 0.39 & 48 & 13 & 2.9 & $\begin{array}{c}\text { Up to } 55 \text { percent savings in existing } \\
\text { buildings from improved shell, HVAC } \\
\text { equipment and controls }\end{array}$ \\
\hline $\begin{array}{l}\text { Office } \\
\text { equipment (PCs) }\end{array}$ & 0.24 & 60 & 6 & 4.1 & $\begin{array}{l}\text { Energy Star-rated PCs and monitors and } \\
\text { power-management enabling software }\end{array}$ \\
\hline $\begin{array}{l}\text { Office } \\
\text { equipment } \\
\text { (not } P C s \text { ) }\end{array}$ & 0.23 & 25 & 6 & 3.3 & Energy Star-rated copiers and printers \\
\hline Ventilation & 0.20 & 45 & 14 & 0.5 & $\begin{array}{l}20 \text { percent savings compared to frozen } \\
\text { efficiency baseline }\end{array}$ \\
\hline Refrigeration & 0.12 & 38 & 7 & 1.4 & $\begin{array}{l}20 \text { percent to } 45 \text { percent savings com- } \\
\text { pared to frozen efficiency baseline }\end{array}$ \\
\hline Space heating & 0.10 & 39 & 3 & 0.5 & $\begin{array}{l}\text { Up to } 55 \text { percent savings in existing } \\
\text { buildings from improved shell, HVAC } \\
\text { equipment and controls }\end{array}$ \\
\hline $\begin{array}{l}\text { Other uses and } \\
\text { thermal shell }\end{array}$ & 0.65 & 35 & 36 & $\$ 1.5$ & $\begin{array}{l}\text { More-efficient motors in ceiling fans, } \\
\text { pool pumps, and other small motors, as } \\
\text { well as up to } 55 \text { percent savings in exist- } \\
\text { ing buildings from improved shell, HVAC } \\
\text { equipment and controls }\end{array}$ \\
\hline Total & 2.40 & 35 & 100 & $\$ 2.8$ & N/A \\
\hline
\end{tabular}

Source: National Academy of Sciences, "Real Prospects for Energy Efficiency in the United States" (2010), pp. 69, 72-73.

1 Calculated using Energy Information Administration, Annual Energy Outlook 2012 (U.S. Department of Energy, 2012), table A4.

2 Costs from Rich Brown et al., "US Building Sector Energy Efficiency Potential” (Berkeley: Ernest Orlando Berkeley National Laboratory, 2008) were inflated using the GDP implicitprice deflator. See U.S. Bureau of Economic Analysis, Table 1.1.9, "Implicit Price Deflators for Gross Domestic Product." Available at www.bea.gov. 
TABLE 2.7

Main sources of energy-efficiency investments:

Technoeconomic potential Commercial-natural gas

From National Academy of Sciences (2010)

\begin{tabular}{|c|c|c|c|c|c|}
\hline $\begin{array}{l}\text { End use } \\
\text { (electricity) }\end{array}$ & $\begin{array}{l}\text { Savings in } \\
\text { Q-BTUs, } \\
2030^{1}\end{array}$ & $\begin{array}{l}\text { Percent sav- } \\
\text { ings relative to } \\
\text { EIA } 2030 \text { Refer- } \\
\text { ence case }\end{array}$ & $\begin{array}{l}\text { Percent } \\
\text { total } \\
\text { savings in } \\
\text { sector }\end{array}$ & $\begin{array}{l}\text { Cost of conserved } \\
\text { energy (dollars per } \\
\text { millions of BTUs, in } \\
2010 \text { dollars) }\end{array}$ & $\begin{array}{l}\text { Efficiency-measure } \\
\text { description }\end{array}$ \\
\hline Space heating & 1.09 & 47 & 68 & $\$ 1.98$ & $\begin{array}{l}\text { Up to } 55 \text { percent savings in existing } \\
\text { buildings from improved shell and } \\
\text { HVAC equipment and controls }\end{array}$ \\
\hline Water heating & 0.16 & 15 & 7 & $\$ 2.4$ & $\begin{array}{l}10 \text { percent savings compared to frozen } \\
\text { efficiency baseline }\end{array}$ \\
\hline Cooking & 0.14 & 31 & 6 & $\$ 7.6$ & $\begin{array}{l}\text { Energy Star-rated fryer and steamer } \\
\text { and more-efficient broilers, griddles, } \\
\text { and ovens }\end{array}$ \\
\hline $\begin{array}{l}\text { Other uses and } \\
\text { thermal shell }\end{array}$ & 0.09 & 20 & 19 & $\$ 1.98$ & $\begin{array}{c}10 \text { percent reduction in miscellaneous } \\
\text { gas use and up to } 55 \text { percent reduction } \\
\text { due to improved shell, equipment, and } \\
\text { controls }\end{array}$ \\
\hline Space cooling & 0.02 & 38 & 1 & $\$ 4.3$ & $\mathrm{~N} / \mathrm{A}$ \\
\hline Total & 1.51 & 35 & 100 & $\$ 2.6$ & N/A \\
\hline
\end{tabular}

Source: National Academy of Sciences, "Real Prospects for Energy Efficiency in the United States" (2010), pp. 70, 72-73.

1 Calculated using Energy Information Administration, Annual Energy Outlook 2012 (U.S. Department of Energy, 2012), table A4.

2 Costs from Rich Brown et al., "US Building Sector Energy Efficiency Potential" (Berkeley: Ernest Orlando Berkeley National Laboratory, 2008) were inflated using the GDP implicitprice deflator. See U.S. Bureau of Economic Analysis, Table 1.1.9, "Implicit Price Deflators for Gross Domestic Product." Available at www.bea.gov. 
In addition, as we see from these tables, major efficiency gains are available through investments in more efficient appliance systems, of which the single most important area is lighting systems. With residential lighting, the NAS estimates savings in the range of 50 percent through use of florescent fixtures and halogeninfrared lamps. With commercial buildings, the NAS estimates lower but still substantial efficiency gains by upgrading lighting systems, in the range of 25 percent relative to the EIA's 2030 Reference case. Similarly large gains are also available by using more efficient equipment, including computers, refrigerators, and televisions.

Figures 2.2 through 2.5 present updated versions of figures from the Brown et al. (2008) and the NAS (2010) studies, which show the costs of conserved energy of various efficiency investments relative to the prices of electricity and natural gas, as of 2010. They also show the total savings potential through investments in these various areas.

FIGURE 2.2

Residential electricity savings potential for 2030 based on National Academy of Sciences 'Technoeconomic' cases

In Q-BTUs

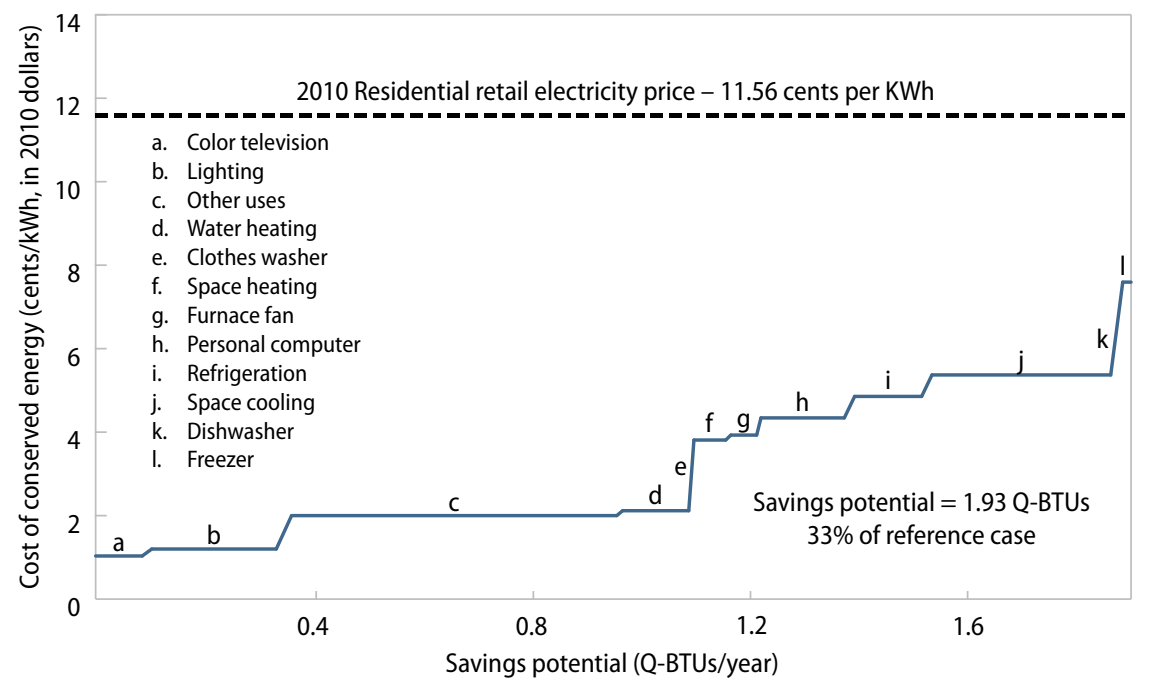

Source: National Academy of Sciences, Real Prospects for Energy Efficiency in the United States (2010), Washington, DC: The National Academies Press. 
FIGURE 2.3

Residential natural gas savings potential for 2030 based on National Academy of Sciences 'Technoeconomic' cases

In Q-BTUs

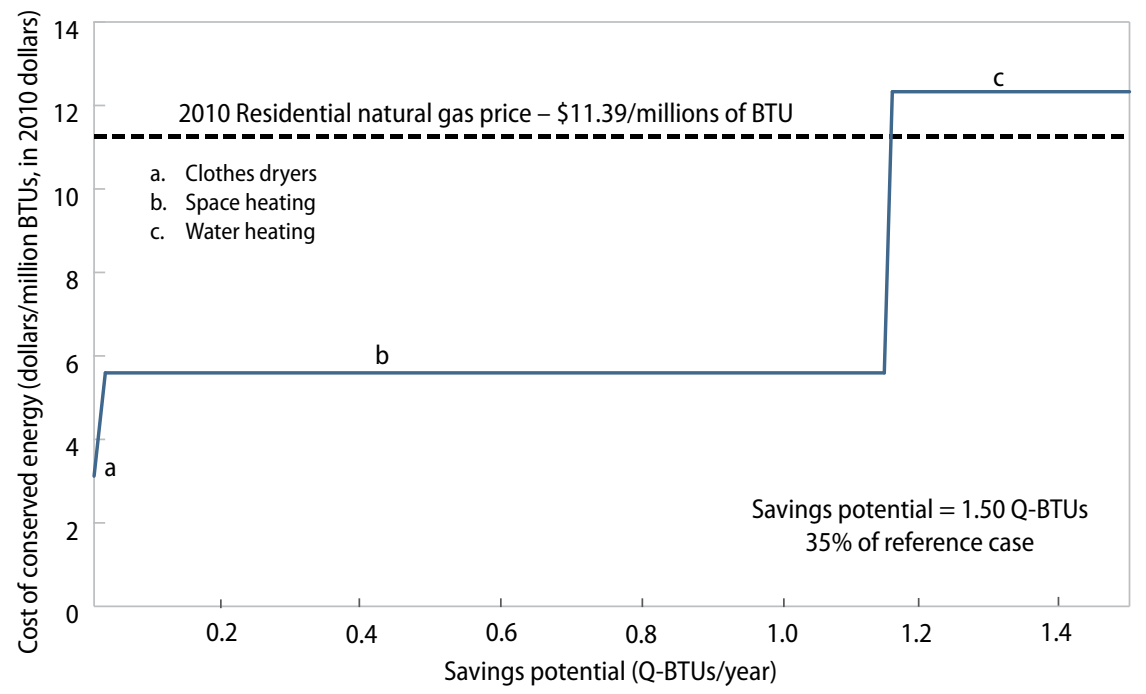

Source: National Academy of Sciences, Real Prospects for Energy Efficiency in the United States (2010), Washington, DC: The National Academies Press.

FIGURE 2.4

Commercial electricity savings potential for 2030 based on National Academy of Sciences 'Technoeconomic' cases

In Q-BTUs

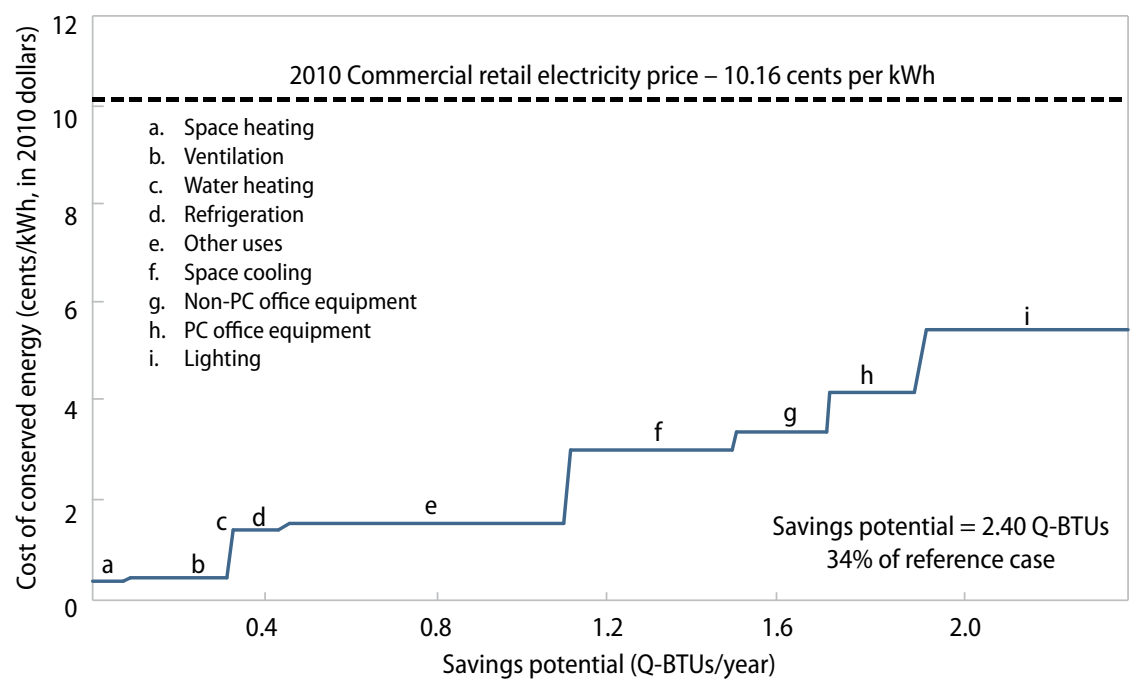

Source: National Academy of Sciences, Real Prospects for Energy Efficiency in the United States (2010), Washington, DC: The National Academies Press. 
FIGURE 2.5

Commercial natural gas savings potential for 2030 based on

National Academy of Sciences 'Technoeconomic' cases

In Q-BTUs

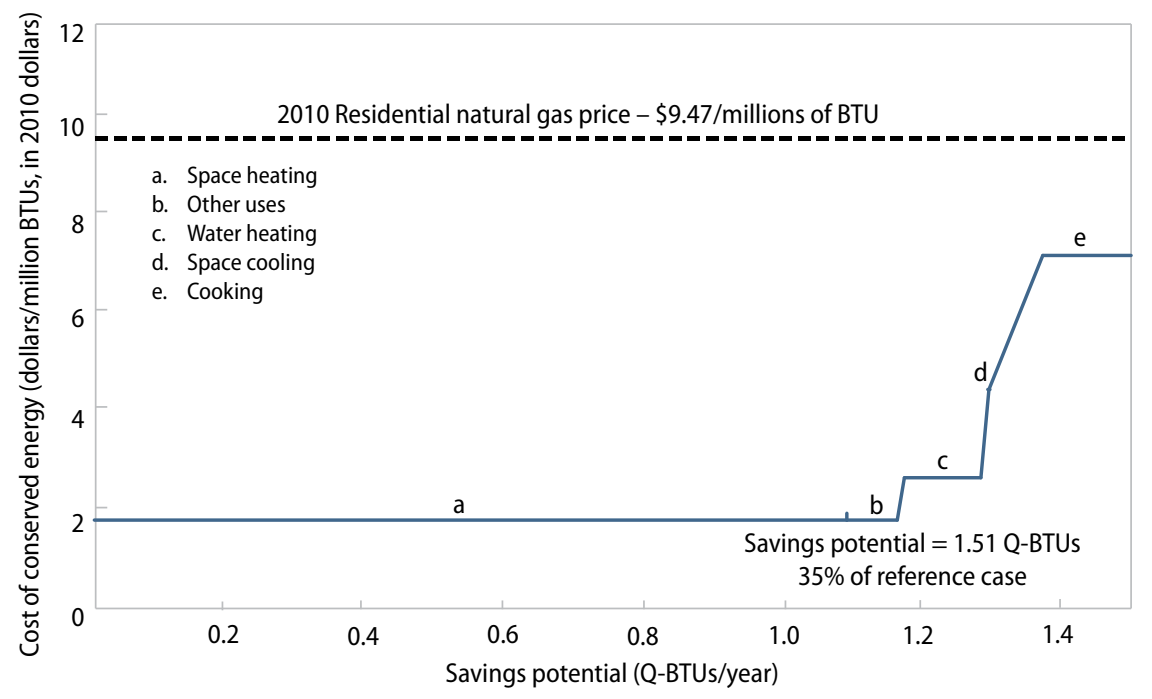

Source: National Academy of Sciences, Real Prospects for Energy Efficiency in the United States (2010), Washington, DC: The National Academies Press.

In Figure 2.2, for example, we see that the cost of conserving energy in lighting is 1.2 cents per kilowatt hour. This compares with the average 2010 residential electricity price of 11.5 cents per kilowatt hour. As Figure 2.2 shows, all of the energy-efficiency investments included in the figure fall well below the 2010 retail price for electricity. Considering Figures 2.3 through 2.5 as a whole, we see that the costs of conserved energy are consistently lower than the retail price of electricity or natural gas. There is only one exception to this situation: the costs of upgrading water-heating systems for residential buildings. In this one case, the cost of conserved energy is $\$ 12.33$ per million BTU of energy, while the 2010 residential natural gas retail price was $\$ 11.30$ per million BTUs. This high price for energy-efficiency investments in residential water heating contrasts sharply with that for similar investments for commercial buildings, in which the costs of conserved energy are only $\$ 2.40$ per million BTUs, while the commercial retail price for natural gas was $\$ 9.47$ per million BTUs. There are several factors producing this large disparity in the energy-efficiency costs in the residential versus commercial water-heating systems, including the economies of scale possible with commercial buildings. ${ }^{7}$ But the main point is that overall large savings are available through energy-efficiency investments in buildings.

Table 2.8 presents figures on the energy savings and investment costs for achieving the "technoeconomic" efficiency gains presented by the NAS. 
TABLE 2.8

Prospects for energy efficiency in buildings: EIA 2030 Reference case vs. the National Academy of Sciences's technoeconomic cases

\begin{tabular}{l|c|c|cc}
\hline A. Energy-saving estimates for 2030 & \multicolumn{2}{l}{$\begin{array}{c}\text { Savings (EIA Reference case versus NAS } \\
\text { technoeconomic cases) }\end{array}$} \\
\hline & $\begin{array}{c}\text { EIA 2030 Reference } \\
\text { case (in Q-BTUs) }\end{array}$ & $\begin{array}{c}\text { NAS technoeconomic } \\
\text { cases (in Q-BTUs) }\end{array}$ & $\begin{array}{c}\text { Savings (in Q-BTUs) } \\
\text { Percent savings }\end{array}$ \\
\cline { 4 - 5 } Residential & 22.68 & 15.76 & 6.91 & 30 \\
Commercial & 20.69 & 13.63 & 7.06 & 34 \\
Total & 43.37 & 29.39 & 13.98 & 32
\end{tabular}

B. Total investment costs and utility-bill savings to achieve NAS-level efficiency

\begin{tabular}{lccc}
\hline $\begin{array}{l}\text { Sector and } \\
\text { energy type }\end{array}$ & $\begin{array}{c}\text { Cumulative capital } \\
\text { investment (in billions) }\end{array}$ & $\begin{array}{c}\text { Annual utility-bill savings in 2030 } \\
\text { (assuming 2010 electricity and } \\
\text { natural-gas prices, in billions) }\end{array}$ & $\begin{array}{c}\text { Simple payback time } \\
\text { (in years) }\end{array}$ \\
\hline Residential & $\$ 142.71$ & $\$ 61.92$ & 2.3 \\
\hline Electricity & $\$ 102.53$ & $\$ 15.44$ & 6.6
\end{tabular}

\begin{tabular}{lccc}
\hline Commercial & & & \\
\hline Electricity & $\$ 120.79$ & $\$ 57.85$ & 2.1 \\
Natural gas & $\$ 28.26$ & $\$ 11.14$ & 2.5 \\
Total & $\$ 394$ & $\$ 146$ & 2.7
\end{tabular}

\begin{tabular}{l|c|c|c}
\hline \multicolumn{2}{c|}{ C. Investment costs per Q-BTU of energy savings in NAS 2030 case versus EIA 2030 Reference case } \\
\hline & Q-BTUs of savings & $\begin{array}{c}\text { Investment costs } \\
\text { (in billions) }\end{array}$ & $\begin{array}{c}\text { Costs per Q-BTU of savings } \\
\text { (in billions) }\end{array}$ \\
\hline Residential & 6.91 & $\$ 245$ & $\$ 35$ \\
Commercial & 7.06 & $\$ 149$ & $\$ 21$ \\
Total & 13.98 & $\$ 394$ & $\$ 28$
\end{tabular}

D. Additional investments to bring 2030 building consumption to 27.5 Q-BTUs

\begin{tabular}{l|c|c}
\hline & $\begin{array}{c}\text { NAS technoeconomic case: Build- } \\
\text { ing energy consumption } \\
\text { at 29.4 Q-BTUs }\end{array}$ & $\begin{array}{c}\text { Additional investments to bring } \\
\text { energy consumption } \\
\text { to 27.5 Q-BTUs }\end{array}$ \\
\hline Total investment costs (in billions) & $\$ 394$ & $\$ 450$ \\
Annual utility-bill savings (in billions) & $\$ 146$ & $\$ 155$ \\
Simple payback time (years) & 2.7 & 2.7
\end{tabular}

Sources: National Academy of Sciences, "Real Prospects for Energy Efficiency in the United States" (2010), Energy Information Administration, Annual Energy Outlook 2012 (U.S. Department of Energy, 2012a). 
To begin with, Panel A shows that the overall estimated savings are about 14 Q-BTUs, or 32 percent relative to the EIA's 2010 Reference case of 43.4 Q-BTUs for 2030. Panel B then shows the investment costs and energy savings in dollars associated with this level of energy savings. As we see, the total investment costs are estimated at $\$ 394$ billion. Over 20 years, this would amount to about $\$ 20$ billion per year. Of the total, $\$ 143$ billion is for residential electricity, $\$ 103$ billion for residential natural gas, $\$ 121$ billion for commercial electricity, and $\$ 28$ billion for commercial natural gas.

As the NAS notes in its 2010 study, the investment figures include:

... both the full add-on cost for new equipment or measures (e.g. attic insulation), and the incremental cost of purchasing an efficient technology (e.g. a high-efficiency boiler) compared with purchasing its conventional-technology equivalent (e.g. a standard boiler). These investments would be made by the individuals and private entities making the purchases.

However, the NAS also makes clear that these figures are direct capital costs. It states, "the costs of programs to support, motivate, or require these improvements are not included." We consider in Chapter 7 the macroeconomic conditions needed to support this level of investment. In Chapter 8, we consider specific policies for encouraging such investments, including the add-on costs for encouraging high levels of both public and private investments in building efficiency.

Based on the roughly 30 percent savings potential for these investments, Panel $B$ then shows the annual utility-bill savings in each of the categories, estimated at $\$ 146$ billion per year. This amounts to a simple payment period of 2.7 years. Working from these estimates, we calculate that the savings over the life of the period until 2030 would amount to more than $\$ 2.6$ trillion, an amount 6.5 times greater than the $\$ 394$ billion in required energy efficiency investments. ${ }^{8}$

Finally, in Panel C, we generate ratios of total costs per Q-BTU of saving. As we see, those costs are about $\$ 35$ billion per Q-BTU in the residential sector and $\$ 21$ billion per Q-BTU in the commercial sector. Including both sectors at the given level of investment, total costs then amount to about $\$ 28$ billion per Q-BTU. 


\section{Environmental effects of building-efficiency investments}

As we have seen, bringing energy consumption down from 43.4 to 29.4 Q-BTUs in 2030 would represent a 32 percent savings. This is obviously a major gain. But achieving even this level of efficiency in buildings will not be adequate to provide a realistic chance of achieving the overall 2030 emissions target of 3,200 $\mathrm{mmt} \mathrm{CO}_{2}$ from all energy sources. As such, we need to consider the possibility of improving energy efficiency in buildings at least another 6 percent, so that total energy consumption in building falls to around 27.5 Q-BTUs in 2030.

It is especially important to seek out these gains for buildings, even more than with industry or transportation. This is because buildings consume electricity more heavily than any other sector of the economy. As we have emphasized above, for every unit of energy saved in consumed energy, overall energy savings will be three times greater in total savings. We therefore now consider further savings possibilities within the building sector.

\section{Further energy-efficiency investment opportunities}

The 2010 NAS study notes that:

The conservation supply curves do not take into account a number of newer technologies and whole-building design approaches. These technologies and approaches add to the energy-savings potential identified in the conservation supply curves. Thus, the panel judges that these supply curves represent lower estimates of energy-saving potential. [emphasis added]

The NAS study highlights seven areas where advanced technologies are "the most promising for further improving the energy efficiency of buildings." These include solid state lighting, advanced cooling systems, lower energy consumption in home electronics, reduced consumption in servers and data centers, advanced window technology, better home construction, and better commercial-building construction.

\section{Solid state lighting}

Lighting accounts for about 18 percent of primary energy use in buildings. Compact Florescent Lighting bulbs, or CFLs, are a major improvement over incandescent lamps. But they contain mercury, are difficult to dim, are not a point light source, and are not "instant on." Light-emitting diodes, or LEDs, do not suffer from these 
disadvantages. The primary issue with LEDs is high costs, but this is decreasing rapidly - the Department of Energy projects that a 1000-lumen LED source that cost around \$9 in 2008 will cost $\$ 2$ in $2015 .{ }^{9}$

\section{Advanced cooling systems}

Cooling systems are responsible for about 10 percent of total U.S. electricity use and 25 percent to 30 percent of total peak electricity demand. Significant potential exists for reducing cooling demand in buildings, using both existing technologies, as well as emerging new technologies. Relying on existing technologies, large efficiency gains are possible through combining measures to reduce building cooling requirements and peak loads. These measures entail investments in highly efficient building envelopes, shading, and reflective surfaces and roofs, as well as reducing heat gains from lights and other equipment, natural ventilation, and thermal storage. At the same time, new technologies are being designed to supplement or replace vapor compression-based cooling with low-energy, thermally driven cooling approaches.

\section{Lower energy consumption in home electronics}

Home electronics includes all products dealing with the processing of information. The NAS finds that at least five strategies exist to reduce the energy use of consumer electronics, but these strategies are not yet widely used. They include improvements in power supplies, which could reduce electricity use in all power modes; redesigning many products to exploit smaller and more efficient circuitry; incorporating an auto-power-down feature in some products, a feature that is already required in new Energy Star specifications for digital adapters but can be utilized much more widely; employing protocols to allow products on a network to operate with a low-power sleep level without losing network connectivity; and finally, designing "power strips" to be used more efficiently in managing energy consumption in clusters of products.

\section{Reduced energy consumption in servers and data centers}

The strategies for improving efficiency in this category include the following: virtualization, which allows data processing to be accomplished with fewer servers; improved microprocessors with higher performance per watt; servers with more efficient power supplies, fans, and microprocessors; more efficient data-storage devices; and more efficient cooling techniques, uninterruptible power supplies, and other "site infrastructure" systems. 


\section{Advanced window technologies}

The window $\mathrm{U}$-value is the primary determinant of winter heat loss. U-values have changed little in mainstream markets since the 1980s. The NAS reports that advances in window technology are now available in niche markets. They currently have higher-than-acceptable cost, but they could have far-reaching implications if they became mainstream products and systems. The first new technology is highly insulating "superwindows" that achieve U values in the range of 0.1-0.2, compared to a typical $U$-value of 0.5 . The second opportunity is a new generation of dynamic products that can reduce cooling loads and control lighting consumption in commercial buildings.

\section{Home construction}

It is possible to construct homes that combine high levels of energy efficiency in the building envelope, heating and cooling systems, and appliances, along with passive and active solar features, in order to approach zero net-energy consumption. ${ }^{10}$ The NAS finds that a growing, if still small, number of homes have cut energy consumption by 50 percent or more relative to typical new homes. In 2005 Congress enacted a tax credit for home builders who were constructing homes that consume at least 50 percent less energy than conventionally built houses. Through 2009, more than 200,000 homebuilders have qualified for this credit.

\section{Commercial-building construction}

Technical innovation in the building sector will continue to drive improvements in building performance, but there is a significant gap between the potential of existing building technologies and the effective adoption of these strategies by the building sector. This gap represents a huge opportunity for improvements in building performance that will generate substantial performance improvements in the near term.

New buildings as complete structures last for many decades, but major energyusing subsystems within such buildings are often redesigned on a five-year or 20 -year cycle. This means improved subsystems could be applied at least partially to existing commercial buildings. The NAS reports that a review of the best-performing new buildings in the country suggests that buildings that achieve energyuse reductions of 50 percent or more below standard practice do so typically on the basis of integrating multiple "state of the shelf" technologies, rather than relying on advanced technologies. This suggests that further efficiency gains are attainable, as new technologies come into more widespread use. 
Overall, there is clearly a wide range of major new opportunities for increased energy efficiency in buildings beyond the "technoeconomic" gains highlighted by the NAS in its 2010 study. Indeed, again, the NAS itself judges that its technoeconomic cases for 2030 represent "lower estimates of energy-saving potential."

The question remains: What is likely to be the range of capital investments necessary to achieve additional improvements in building efficiency in the range of 6 percentthat is, to a point where annual energy consumption in buildings is about 27.5 Q-BTUs in total rather than 29 Q-BTUs? Any attempt at an estimate will inevitably be based on an incomplete foundation of solid evidence, as is the case with virtually all projections of long-term investments and advances in technologies over a 20-year period. For now though, it seems reasonable to conclude that the relationship between efficiency gains and capital improvements will continue to proceed in a roughly linear framework - that is, improvements in efficiency will be approximately proportional to capital investments - as opposed to assuming that in the aggregate, there would be either increasing or decreasing gains in efficiency for any given level of capital expenditures.

There are good reasons to assume there could be significant economies of scale with energy-efficiency investments in buildings - that is, the capital expenditures necessary to achieve efficiency as we move beyond the NAS technoeconomic threshold. These include the following considerations:

\section{- The average cost of conserved energy for electricity use in buildings is less}

than 3 cents per kilowatt hour. At the same time, the market price of electricity in 2010 was 11.6 cents per kilowatt hour for residential customers and 10.2 cents per kilowatt hour for commercial customers. This means there will be lots of space for cost-saving incentives, which should encourage accelerated growth in the next round of efficiency investments.

\section{- The returns on investment in building efficiency are high, but the market} has been held up because financial and market infrastructures remain undeveloped to date. That is, the systems of financing and risk-sharing that enable businesses and homeowners to capture the benefits of high returns without having to carry the full burden of initial financial risk remain immature. Developments in these areas should come rapidly once the initial set of business models, market structures, and financial innovations take hold. 
- The absolute level of efficiency gains attainable in buildings is very high, given that there are already residential and commercial buildings that are carbon neutral. Of course, the costs of getting buildings to the point of carbon neutrality are also high at this point, meaning that before reaching carbon neutrality, we begin to approach a point of diminishing returns on investment. At the same time, as the market for efficiency investments expands, the costs of the best upcoming technologies begin to fall. As the NAS notes, this is certainly true with LED lighting. Similar opportunities are emerging in the other six areas discussed above-cooling, home electronics, servers, and construction of both homes and commercial buildings.

Despite all of these factors suggesting falling costs as the level of investment expands, there have also been many instances of over-optimism in assessing the prospects for clean energy investments in efficiency, as well as other areas. It is important to recognize the perspective advanced by Allcott and Greenstone (2012), who argue that claims for high returns from efficiency investments, especially with respect to residential buildings, have been repeatedly overstated. Their main argument is that such claims are based on engineering evidence, such as that presented in the National Academy of Sciences study that we have reviewed in depth in this chapter. According to Allcott and Greenstone, however, such engineering-based evidence neglects other considerations that are significant and can be decisive in discouraging energy consumers. As they emphasize, these nonengineering issues are especially significant with regard to private homeowners as opposed to commercial-building owners.

While the engineering evidence consistently finds, for example, that investments in building efficiencies will have rapid pay-offs, it is still necessary to obtain financing for a project to proceed. Another issue is the hassle factor involved in undertaking such projects. Considering home-weatherization efficiency programs specifically, Allcott and Greenstone write that "Weatherization takes time, and for most people it is not highly enjoyable: the process requires one or sometimes two home energy audits, a contractor appointment to carry out the work, and sometimes additional follow-up visits and paperwork." Such matters can create serious difficulties for individual homeowners. Commercial buildings are less likely to present comparable levels of difficulties and costs. 
The implication that follows from the Allcott and Greenstone position is not that the engineering information is wrong, but rather that both public policy and private initiatives are needed to tackle the financial issues and the hassle factors that are involved in building-efficiency projects. These policy and business-model challenges are by no means insurmountable, as we discuss in some detail in Chapter 8. Overall, even taking these issues fully into consideration, it is reasonable to assume as a first approximation that, at least with respect to commercial and large multifamily residential buildings (as opposed to private single-family residences), the gains from investments in building efficiency will remain roughly proportional to the level of investment expended.

Based on this assumption, bringing total energy consumption in buildings to 27.5 Q-BTUs in 2030 from the NAS-based technoeconomic case of around 29.4 Q-BTUs would entail an additional level of investment of about $\$ 56$ billion - or a 2 Q-BTU savings multiplied by $\$ 28$ billion/Q-BTU of savings, including both commercial and residential buildings. Adding this amount to the $\$ 394$ billion needed to bring consumption in buildings to 29 Q-BTUs means that the total cost of reaching a 27.5-Q-BTU consumption level in 2030 would be about $\$ 450$ billion, or about $\$ 22.5$ billion per year.

Working with the assumption of linearity between energy-efficiency investments, costs, and savings also implies that energy savings would increase in proportion to the additional level of investments. Since we are increasing investments while reducing energy consumption by about 6 percent, that means that annual utility savings will rise from $\$ 146$ billion to $\$ 155$ billion. The simple payback time would therefore remain 2.9 years.

These estimates on the investment costs and energy savings through bringing overall building energy consumption from the NAS "technoeconomic" case of 29.4 Q-BTUs to 27.5 Q-BTUs are summarized in panel D of Table 2.8. 


\section{Energy efficiency in the industry sector}

As shown in Table 2.2, industrial energy consumption in the United States was 30.3 Q-BTUs in 2010. The EIA's Reference case forecasts that as of 2030, energy consumption will be 32.9 Q-BTUs. As was the case with the building sector, we assume virtually no increase in the level of energy consumed in the industry sector over a 20-year stretch. This then implies that the industrial sector will experience sharp increases in efficiency over these 20 years since the EIA is also projecting industrial output growing by about 1.8 percent annually over this period. ${ }^{11}$

The EIA explains this lack of growth in energy consumption in its 2012 report as:

... reflecting a shift in the share of shipments from energy-intensive manufacturing industries (which include bulk chemicals, petroleum refineries, paper products, iron and steel, food products, aluminum, cement and glass) to other, less energy-intensive industries, such as plastics, computers, and transportation equipment.

The issue explored here is the prospect for significantly greater energy efficiency gains for the industry sector beyond the EIA's Reference case for 2030. Such additional efficiency gains will primarily result from changes in production methods, as opposed to relying on further shifts in the manufacturing industrial composition toward low-energy-intensity industries. The main additional energy-efficiency gains in industrial production are expected to result from two types of initiatives:

- Crosscutting investments: These are investments that are applicable in a wide range of industrial settings. The most important example is combined heat and power, or CHP, systems, which dramatically improve energy efficiency by using waste process heat to generate a productive low-cost energy source.

- Industry-specific investments: This includes a wide range of specific energysaving measures and process improvements, especially in the high-energy-intensity sectors such as chemicals, refining, paper, steel, and food. 
Combined heat and power units transform a fuel into electricity and then use the hot waste gas stream for processes such as space and hot-water heating or industrial and commercial processes. As discussed above, large central-station electrical generators use only about one-third of the energy in fuel to produce electricity, and the rest must be dispersed with cooling towers or transferred to the atmosphere, rivers, lakes, or the ocean. By capturing and converting waste heat, CHP systems achieve effective electrical efficiencies of 50 percent to 80 percent-a tremendous improvement in the efficiency of electricity generation over traditional power plants.

CHP facilities have been commonly established in energy-intensive industries such as food processing, pulp and paper, chemicals, metals, and oil refining. European countries such as Finland and Denmark are among the leaders in terms of installed CHP capacity, with 30 percent to 50 percent of their total electricity generated through CHP technologies. In the United States, as of 2010, 4.2 percent of all electricity was generated through $\mathrm{CHP}$ processes. ${ }^{12}$ For commercial and industrial installations that buy electricity and also use large quantities of natural gas for process heating, $\mathrm{CHP}$ could double energy efficiency and cut costs by half. The sectors of industry where large energy-saving opportunities through CHP technologies look most promising include steel-rolling mills, paper mills, hospitals, and hotels.

CHP offers two additional benefits. Since the electricity is generated on site, there could be a greatly reduced need for transmission and distribution lines, thus saving the expense of building and operating the lines and eliminating the 6 percent to 10 percent loss of electricity during transmission and distribution. Generating electricity on site is also essential to building infrastructure that is more resilient to climate change effects that may already be unavoidable, by eliminating the possibility of power disruptions from transmission or distribution line problems.

In addition to CHP systems, other areas for crosscutting investments in energy efficiency include high-temperature separation technologies and utilizing more energy-efficient materials in production. High-temperature separation processes are integral to a wide range of industrial processes, but they generally consume enormous 
amounts of energy - totaling 4.5 Q-BTUs per year in 2008, or 47 percent of all the energy consumed in manufacturing, according to the 2010 NAS study. New technologies in the areas of distillation and membrane separation offer opportunities for large gains in energy efficiency. With respect to new materials, there are similarly large opportunities for energy-efficiency gains through substituting less energyintensive materials, including nanomaterials for steel in various uses. ${ }^{13}$

\section{Industry-specific investments}

\section{Pulp and paper industry}

Pulp and paper production, which constitutes a majority of the forest products industry, consumes about 2.4 Q-BTUs of energy annually. Drying and the recovery of chemicals are the most energy-intensive parts of the papermaking process. The pulp and paper sector is both capital- and energy-intensive. Energy is the third-largest manufacturing cost for the forest and paper products industry, according to the NAS 2010 study.

The NAS describes a range of areas in pulp and papermaking where major efficiency gains are available. The 2007 McKinsey study summarized in the NAS report quantifies many of these opportunities. The McKinsey study concludes that if the industry were to only accelerate the adoption of proven technologies and processes and were not to incorporate any new technologies into its operations, it could still reduce energy consumption by 25 percent by 2020 . Table 2.9 breaks down these major efficiency opportunities identified by McKinsey.

\section{TABLE 2.9}

Sources of energy saving in U.S. pulp and paper industry

Saving potential as of 2020

\begin{tabular}{lcc}
\hline & $\begin{array}{c}\text { Energy-saving potential } \\
\text { (in Q-BTUs) }\end{array}$ & $\begin{array}{c}\text { Percent of total saving } \\
\text { potential for industry }\end{array}$ \\
\hline Papermaking & 0.18 & 30 \\
Multiprocess improvements & 0.10 & 17 \\
Steam efficiencies & 0.10 & 17 \\
Fiber substitution & 0.08 & 14 \\
Pulping & 0.07 & 12 \\
Other process steps & 0.07 & 11
\end{tabular}

Source: National Academy of Sciences, "Real Prospects for Energy Efficiency in the United States" (2010), p. 212 


\section{Iron and steel}

Energy consumption per ton of steel decreased 27 percent between 1990 and 2008, while $\mathrm{CO}_{2}$ emissions decreased by 16 percent. ${ }^{14}$ Moving beyond these gains, a 2008 McKinsey study finds that along with pulp and paper, the iron and steel industry offers the largest opportunities to reduce energy use in the industrial sector. ${ }^{15}$ McKinsey estimates that overall, through accelerating the adoption of proven technologies and process improvements only-again, without relying on assumptions about the use of new technologies - the industry can reduce its energy consumption by 0.3 Q-BTUs, or 22 percent, by 2020. McKinsey further estimates that investments in many of these proven energy-efficiency technologies will yield internal rates of return in excess of 20 percent. The relevant technologies are listed in Table 2.10 below, along with McKinsey's estimates of the energysaving prospects with each of them as of $2020 .^{16}$

TABLE 2.10

Sources of energy saving in U.S. iron and steel industry

Saving potential as of 2020

\begin{tabular}{lcc}
\hline & $\begin{array}{c}\text { Energy-saving potential } \\
\text { (in Q-BTUs) }\end{array}$ & $\begin{array}{c}\text { Percent of total saving } \\
\text { potential for industry }\end{array}$ \\
\hline Secondary casting & 0.12 & 39 \\
Arc-furnace processes & 0.06 & 19 \\
Blast-furnace processes & 0.03 & 11 \\
Integrated casting & 0.02 & 8 \\
Multiprocess improvements & 0.03 & 10 \\
Other process steps & 0.04 & 13
\end{tabular}

Source: National Academy of Sciences, "Real Prospects for Energy Efficiency in the United States” (2010), p. 218.

Beyond these efficiency opportunities using the best existing technologies, the American Iron and Steel Institute, or AISI, argues that major additional efficiencies can be achieved through what it terms "transformational technologies." In a 2005 report the AISI held that energy use in steel production could be cut by 40 percent within 22 years, from 2003 to 2025, through introducing new methods in melting, heat recovery, integration of refining functions, and direct carbon injection. AISI estimated that the majority of these new technologies would be available before 2020 . 


\section{Petroleum refining and chemical manufacturing}

There is a substantial range of estimates as to the prospects for efficiency gains in the areas of petroleum refining and chemical manufacturing. ${ }^{17}$ With the refining industry, various studies indicate that possible affordable savings by 2020 could be between 10 percent and 20 percent, including all technologies. Considering various specific technologies, the prospects for efficiency gains are higher-perhaps as high as 50 percent or more in some cases.

The Department of Energy found that the largest potential savings are in crude distillation, with possible savings as high as 54 percent for atmospheric distillation. The range of +estimates is wider still for chemical manufacturing, varying between 3 percent and 18 percent of the business-as-usual (BAU) figures for 2020. The new efficiency-enhancing technologies would apply to the production of ethylene, chlorine, ethylene oxide, ammonia, and terephthalic acid.

Beyond these technologies, within the traditional chemical industry, another whole range of possibilities is available through investments in the emerging green chemical industry. Many new opportunities exist in this area, including with products used for building materials, health care, and personal care. For the present discussion, the most significant possibilities are in the area of bioplastics. The vast majority of polymers used to produce plastics are derived from bulk petrochemicals, such as ethylene, propylene, and benzene. However, the polymers used to produce plastics and resins can also be derived from renewable biomass. Although bioplastics and bioresins currently account for a small fraction of the overall plastics market, their growth potential is significant. ${ }^{18} \mathrm{~A}$ recent study from Utrecht University in the Netherlands finds that bio-based polymers could technically substitute up to 90 percent of the polymers currently in use, which are derived from petrochemicals. ${ }^{19}$ Of course, investments in bioplastics do not increase the level of efficiency in energy use in general. Rather, they achieve efficiency gains in environmental terms by replacing fossil fuel feedstocks altogether.

\section{Overall potential for energy-efficiency improvements}

Table 2.11 presents figures taken from the McKinsey study and other research reports, and summarized by the NAS report, projecting the cost-effective energyefficiency savings available in U.S. industry in 2020. The table gives a range of figures by sectors and for all industry. As is shown, the total projected energy efficiency savings in 2020 is between 4.9 and 7.7 Q-BTUs. As the table also shows, this amounts to a percentage savings of between 14 percent and 22 percent. 
TABLE 2.11

Range of estimates of economic potential for energy-efficiency improvements in industry

Savings figures are relative to EIA 2020 Reference case estimates

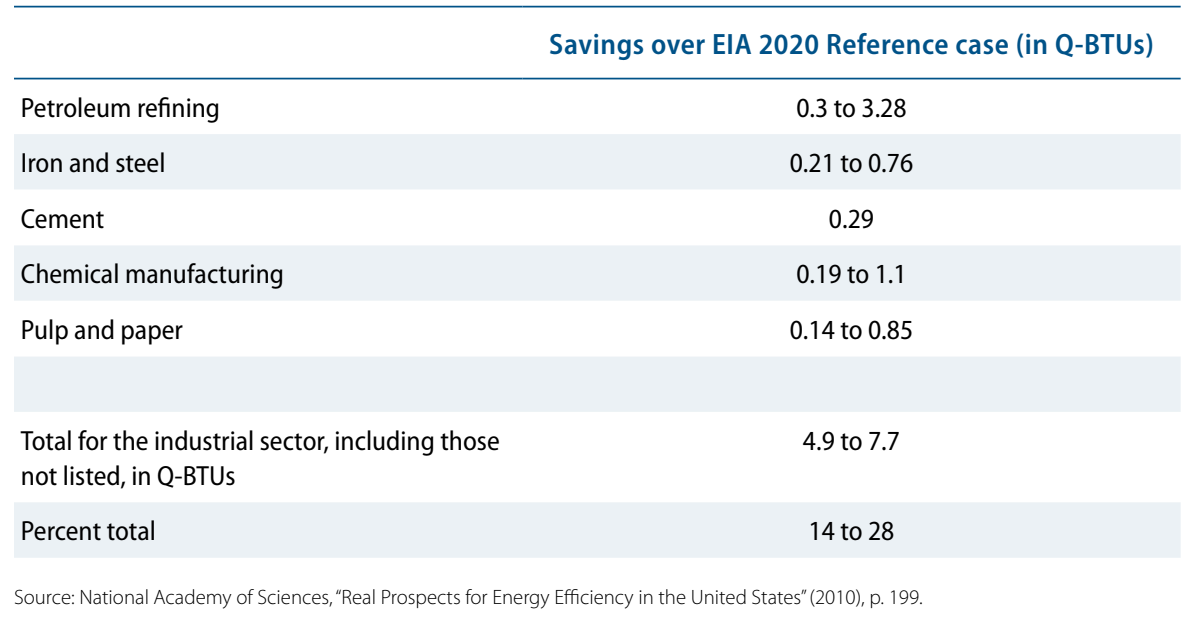

It is important to keep in mind that these projections for the iron and steel industry, as with those for the pulp and paper industry, are projected only through 2020, unlike those reported above on building efficiencies, which are reported through 2030. Unfortunately, we are not aware of any systematic efficiency figures for industry beyond those through 2020. At the same time, there will be more efficiency-investment opportunities available beyond 2020, especially as the industry moves to incorporating new "transformational technologies."

\section{Estimating investment expenditure needs}

The amount of new investment needed to achieve the high-end figure of energy savings in industry of about 7.7 Q-BTUs, as shown in Table 2.11, can be determined by addressing this issue separately for $\mathrm{CHP}$ and non-CHP energy-efficiency investments in industry. Table 2.12 provides a summary of the figures we derive in the following discussion. 
TABLE 2.12

\section{Overall costs of energy-efficiency investments in industry from 2011 through 2030}

Investment requirements to reduce industry energy consumption from 32.9 Q-BTUs (EIA 2030 Reference case) to 22.5 Q-BTUs by $2030=10.4$ Q-BTUs of saving

\begin{tabular}{lccc}
\hline & 2011 to 2020 & Investment periods & 2011 to 2030 totals \\
\hline & & & \\
\hline $\begin{array}{l}\text { Combined Heat and Power (CHP) } \\
\text { investments }\end{array}$ & \$50 billion per Q-BTU & \$50 billion per Q-BTU & \$50 billion per Q-BTU \\
$\begin{array}{l}\text { Costs per Q-BTU of efficiency gains } \\
\text { Q-BTUs of annual energy savings }\end{array}$ & 2.4 & 1.4 & 3.8 \\
$\begin{array}{l}\text { Investment levels } \\
\text { Industry-specific investments }\end{array}$ & $\$ 123$ billion & $\$ 70$ billion & \$193 billion \\
Costs per Q-BTU of efficiency gains & $\$ 16.4$ billion per Q-BTU & $\$ 16.4$ billion per Q-BTU & \$16.4 billion per Q-BTU \\
Q-BTUs of annual energy savings & 5.3 & 1.3 & 6.6 \\
$\begin{array}{l}\text { Investment levels } \\
\text { Total spending for CHP and industry- } \\
\text { specific investments }\end{array}$ & $\$ 210$ billion & $\$ 21.3$ billion & \$108.3 billion
\end{tabular}

Full-period investment levels and energy savings, 2011 to 2030

\begin{tabular}{|c|c|}
\hline Total investment spending & $\begin{array}{c}\$ 301.3 \text { billion } \\
\text { (equals } \$ 193 \text { billion } C H P+\$ 108.3 \text { billion industry-specific investments) } \\
\text { equals } \$ 15 \text { billion per year for } 20 \text { years }\end{array}$ \\
\hline Total Q-BTUs of annual energy saving & $\begin{array}{c}10.4 \\
\text { (EIA 2030 Reference case of 32.9 Q-BTUs } \\
\text { versus industrial efficiency case of 22.5 Q-BTUs) }\end{array}$ \\
\hline Weighted costs per Q-BTU of energy saving & $\begin{array}{c}\text { \$29 billion } \\
\text { (equals } \$ 301.3 \text { billion total investment per } 10.4 \text { Q-BTUs of total energy saving) }\end{array}$ \\
\hline
\end{tabular}

In its 2012 "Annual Energy Outlook," the EIA's Reference case estimates that industrial consumption of energy will total 31.6 Q-BTUs in 2020. If we allow that the high-end saving figure of 7.7 Q-BTUs can be reached by 2020, this would bring industry-based energy consumption down to 23.9 Q-BTUs by 2020. Following the breakdown between CHP and non-CHP investments indicated in Table 2.11, investments in CHP systems would result in 2.4 Q-BTUs of total savings, and the remaining 5.3 Q-BTUs of savings would result from industry-specific efficiency investments. Two research studies provide estimates as to how much capital expenditure will be needed on CHP systems and other areas to achieve this level of energy efficiency savings. 


\section{CHP systems}

The technical supplement to the EIA's 2012 "Annual Energy Outlook" contains estimates of the capital cost of investing in CHP generation. ${ }^{20}$ Based on this analysis, we work with an estimate of $\$ 1,100$ per kilowatt of installed capacity to calculate total investment costs. CHP generation of 2.4 Q-BTUs is equal to 703.4 billion kilowatt hours. Based on the figures from the EIA, we calculate that the stock of installed CHP capacity needed to generate this much electricity is 111.7 gigawatts. This would imply a level of capital expenditure of about $\$ 123$ billion. This amounts to an investment level of about $\$ 50$ billion per Q-BTU of savings.

\section{Other efficiency investments for industry}

The 2000 study by the Interlaboratory Working Group on Energy-Efficient and Clean Energy Technologies, or IWG, contains estimates of the investment costs associated with the non-CHP energy-efficiency savings. In current dollar terms, the cost per Q-BTU saved over the range of energy-efficiency savings detailed in the IWG report is $\$ 16.4$ billion per Q-BTU. ${ }^{21}$ Therefore, to achieve 5.3 Q-BTUs of savings, the total cost of non-CHP investment in current dollars would be approximately $\$ 87$ billion.

Overall, then, obtaining the 7.7 Q-BTUs of energy savings - as reported in Table 2.11 - in 2020 relative to the EIA Reference case estimate would entail a total of $\$ 210$ billion. ${ }^{22}$ These figures are summarized in the first column of the upper panel of Table 2.12. This would amount to about $\$ 21$ billion per year if we did indeed hold to the idea that this level of investment would occur over 10 years, from 2011 to 2020. It also breaks down to about $\$ 26$ billion per Q-BTU of savings as a weighted average, including both $\mathrm{CHP}$ and non-CHP technologies, with investments in CHP systems being far more expensive per unit of energy saved than non-CHP systems.

To meet the $\mathrm{CO}_{2}$ emissions target of $3,200 \mathrm{mmt}$ by $2030-2035$, it is likely to be necessary for the industrial sector to make further advances in efficiency between 2021 and 2030, beyond the 7.7 Q-BTUs that we have described for 2011 to 2020. Specifically, total energy consumption in industry should decline to about 22.5 Q-BTUs by 2030. This would represent a reduction in energy consumption for industry of 31.6 percent relative to the EIA's Reference case for 2030 energy consumption in industry at 32.9 Q-BTUs. ${ }^{23}$ 
The costs of attaining a 22.5 Q-BTU consumption level for industry by 2030, as opposed to the EIA's 32.9 Q-BTU 2030 Reference case figure, will depend on the mix between $\mathrm{CHP}$ and non-CHP investments in industry. This is because the costs of achieving efficiency gains through CHP investments, at around \$50 billion per Q-BTU of savings, are far higher than the figure we have reported for non-CHP investments of about $\$ 16$ billion per Q-BTU. For simplicity's sake, we assume that between 2021 and 2030, investments in energy efficiency in industry are divided evenly between CHP and non-CHP investments. Thus, reducing industrial energy consumption to about 22.5 Q-BTUs in 2030 - to save an additional 2.7 Q-BTUs of saving beyond the 7.7 Q-BTUs achievable through 2020 - would cost about $\$ 91$ billion. In Table 2.12, we show the calculations that derive this figure.

Considering the overall level of investment - combining both the period from 2011 to 2020 and 2021 to 2030 - the total investment level would be about $\$ 301$ billion, as is shown in Table 2.12. This amounts to about $\$ 15$ billion per year for 20 years. 


\section{Energy efficiency in the transportation sector}

\section{EIA Reference case assumptions}

In the Reference case for the transportation sector included in its 2012 "Annual Energy Outlook" report, the EIA estimates that energy consumption in the transportation sector will grow from 27.6 Q-BTUs as of 2010 to 28 Q-BTUs in 2030. That is, the EIA is projecting that there will be essentially no increase at all in energy consumption in the transportation sector between 2010 and 2030. The EIA concurrently projects that U.S. overall GDP will grow at an average annual rate of 2.5 percent over this 20 -year period.

The EIA thus concludes that energy consumption will be virtually flat in the transportation sector from 2010 to 2030 . It summarizes its findings saying, "The slower growth results primarily from improvement in fuel economy for both light-duty vehicles as well as heavy-duty vehicles, as well a relatively modest growth in demand for personal travel." ${ }^{24}$ This is clear in the figures in Table 2.13, which break down total energy consumption in the transportation sector by mode of transportation. We show both actual figures for 2010 and the EIA's Reference case projections for 2030 .

As the table shows, energy consumption in transportation is dominated by light-duty vehicles, or LDVs, such as private automobiles and noncommercial light trucks. In 2010 LDVs accounted for 58 percent of all transportation-based energy consumption, at 16.1 Q-BTUs. This share of total energy consumption basically continues through 2030, where it is projected to be 54 percent of total consumption, according to the EIA forecast. 


\begin{tabular}{|c|c|c|c|c|}
\hline & \multicolumn{2}{|c|}{2010 actual } & \multicolumn{2}{|c|}{ EIA 2030 Reference case } \\
\hline & Q-BTUs & $\begin{array}{l}\text { Percent of total } \\
\text { consumption }\end{array}$ & Q-BTUs & $\begin{array}{l}\text { Percent of total } \\
\text { consumption }\end{array}$ \\
\hline Light-duty vehicles & 16.06 & 58.2 & 15.05 & 53.9 \\
\hline Heavy-duty vehicles & 4.82 & 17.5 & 5.69 & 20.4 \\
\hline Air & 2.52 & 9.1 & 2.76 & 9.9 \\
\hline International shipping & 0.86 & 3.1 & 0.88 & 3.1 \\
\hline Military use & 0.77 & 2.8 & 0.7 & 2.5 \\
\hline Pipeline fuel & 0.65 & 2.3 & 0.68 & 2.4 \\
\hline Commercial light trucks & 0.55 & 2.0 & 0.59 & 2.1 \\
\hline Rail freight & 0.45 & 1.6 & 0.52 & 1.9 \\
\hline Bus transportation & 0.25 & 0.9 & 0.3 & 1.1 \\
\hline Recreational boats & 0.25 & 0.9 & 0.28 & 1.0 \\
\hline Domestic shipping & 0.22 & 0.8 & 0.25 & 0.9 \\
\hline Lubricants & 0.14 & 0.5 & 0.14 & 0.5 \\
\hline Passenger rail & 0.05 & 0.2 & 0.06 & 0.2 \\
\hline Total & 27.63 & 100 & 28.01 & 100 \\
\hline
\end{tabular}

Source: Energy Information Administration, Annual Energy Outlook 2012 (U.S. Department of Energy, 2012), table A-7, p. 146. Note: Totals include electricity-related losses.

Heavy-duty vehicles, or HDVs_-including freight trucking, tractor trailers, heavyduty pickups, vans, and privately operated buses - is the next-biggest consumer of energy in the transportation sector, representing 17 percent of total consumption in 2010 and an anticipated 20 percent in 2030. As such, LDVs and HDVs together account for nearly 75 percent of all transportation-based energy consumption. Air travel is the next-largest energy consumer in transportation, at 9 percent in 2010 and a projected 10 percent in 2030. Cars, various forms of trucks, and airplanes therefore account in total for roughly 85 percent all energy consumption in the sector. Any policy agenda to significantly reduce energy consumption in transportation will thus need to focus on these three categories.

There is a range of strong arguments—-social as well as environmental—for investing significantly in upgrading public bus and passenger rail transportation systems. As Table 2.13 shows, however, these two transportation modes accounted for only about 1 percent of overall transportation-based energy consumption in the United States in 2010. Precisely because this baseline level for public transportation use is 
so low, the scope is necessarily limited for making major absolute gains in overall transportation efficiency by expanding public transportation. What emerges clearly out of these data is that in terms of reducing greenhouse gas emissions over the next 20 years, investments to expand public transportation should be considered as supplemental to a set of higher-priority measures focused on cars and trucks. At the same time, achieving longer-term gains in energy efficiency and social and environmental benefits through public transportation needs to be a major policy priority. This will require a significant and steady investment to expand the program, beginning immediately. A detailed discussion on strategies to promote public transportation can be found in Appendix 1.

The EIA generated its Reference case results for 2030 for transportation by focusing mainly on light- and heavy-duty vehicles. We then must consider possibilities for gains in efficiency beyond the Reference case-that is, the prospects for lowering energy consumption in transportation to around 20 Q-BTUs, or a reduction of roughly one-third relative to the EIA's 2030 Reference case of 28 Q-BTUs. Here again, we will need to focus on opportunities available with cars and trucks, since these are the modes of transportation that are responsible for most of the sector's energy consumption.

\section{Light-duty vehicles}

As we have seen, the EIA Reference case from its 2012 report already shows energy demand for LDV's falling 6 percent between 2010 and 2030, from 16.1 to 15.1 Q-BTUs. The main cause of this reduction is the rise in LDV fuel efficiency. As of 2010 the EIA reports that LDV fuel economy for new cars was 29.2 miles per gallon, or mpg. According to Environmental Protection Agency regulations cited in the EIA report, fuel economy for new cars was originally mandated to rise to $33.8 \mathrm{mpg}$ in 2016 and $35.9 \mathrm{mpg}$ in 2020 . After 2020 the standards had been scheduled to rise further, if moderately, to $37.9 \mathrm{mpg}$ by $2035 .{ }^{25}$ These were the assumptions about fuel economy on which the EIA based its reference-case forecast for LDV energy consumption for 2030.

However, in July 2011 the Obama administration reached an agreement with 13 major automakers to significantly increase fuel efficiency standards for new cars still further, to $54.5 \mathrm{mpg}$ by 2025 . $^{26}$ The automakers that signed onto this agreement include GM, Ford, Chrysler, Toyota, Nissan, Honda, Volvo, Mitsubishi, 
BMW, Mazda, Kia, Jaguar/Land Rover, and Volvo. These companies account for more than 90 percent of the current U.S. auto market. The United Auto Workers union also endorsed this agreement.

Assuming this new standard is implemented for most of the U.S. auto fleet by 2025 , it will represent a near doubling in overall fuel efficiency relative to the 29.2mpg standard prevailing in 2010 . These ambitious deployment gains will entail both changing the mix of vehicles on the road in favor of smaller, lighter cars, as well as further improvements in fuel efficiency within each given vehicle size and class. Yet the 54.5-mpg standard is certainly realistic when seen in a global market context. Both Europe and Japan are already at a 40-mpg standard, and both regions have targets for the equivalent of $60 \mathrm{mpg}$ by $2020 .^{27}$

Assuming that all new cars sold in the United States are at the 54.5-mpg standard by 2025 , this still does not mean that all cars on the road in 2025 will be at that standard. A large fraction of older, vintage cars will be at the previously established 2020 standard of $35.9 \mathrm{mpg}$. Some still-older cars will be operating at still-lower standards. We have developed an estimate as to what the overall level of fuel economy will be in 2030 for the entire LDV auto fleet, given the ratcheting upward of the mandated efficiency standards, which can be found in Appendix 2. The key conclusion from that analysis is the estimate that the total fleet average fuel-economy level will be $42.4 \mathrm{mpg}$ in 2030. According to our estimate, this would generate a 32 percent reduction in fuel consumption relative to what the fuel economy level would be under the EIA's 2030 Reference case. Given that LDV energy consumption is 15.1 Q-BTUs under the EIA's 2030 Reference case, we estimate that this figure will fall to approximately 10 Q-BTUs due to the establishment of the 54.5-mpg standard by 2025.

With fuel economy standards rising so significantly relative to current levels, we need to consider the possibility that this will encourage substantially more driving-for example, a variation on the rebound effect now applied to LDVs. Any such rebound effects will then, of course, reduce benefits in terms of lowering $\mathrm{CO}_{2}$ emissions. Overall, however, we do not think such rebound effects are likely to be significant. Drawing on the recent professional research on this issue that we review later in this chapter, we believe that such rebound effects will at most range between 10 percent and 30 percent of the total energy saved. That figure will be substantially lower still if two sets of policies are implemented: an increase in gasoline prices achieved by setting a price on carbon emissions either through a carbon tax or carbon emissions cap; and an expansion of the availability of transportation alternatives, including high-quality public transit. We discuss both of these issues in detail below. 


\section{Costs of more fuel-efficient automobiles}

To roughly approximate how much more expensive the cars would have to be to reach this higher efficiency standard, we can refer to figures produced by the 2010 National Academy of Sciences study on the additional costs of a range of alternative vehicles-both the 2005 vintage models, as well as those that are capable of becoming available by 2035. (The NAS study does not provide comparable figures for either 2025 or 2030). Table 2.14 reports the results of the NAS survey.

TABLE 2.14

Estimated retail-price increase, gasoline savings, and reductions in greenhouse gas emissions of advanced vehicles (relative to baseline-average gasoline vehicles, 2005 models)

Assume average retail price of $\$ 19,600$ for 2005 model gasoline vehicle

\begin{tabular}{l|cc|cc}
\hline & \multicolumn{2}{|c|}{ Additional retail price above $\$ 19,600$} & \\
\hline Propulsion system & $\begin{array}{c}\text { Additional } \\
\text { retail price (in 2007 } \\
\text { dollars) }\end{array}$ & $\begin{array}{c}\text { Percentage } \\
\text { increase }\end{array}$ & $\begin{array}{c}\text { Reduction in gasoline } \\
\text { consumption } \\
\text { (percent) }\end{array}$ & $\begin{array}{c}\text { Reductions in green- } \\
\text { house gas emissions } \\
\text { (percent) }\end{array}$ \\
\hline Current diesel & $+\$ 1,700$ & +8.8 & 20 & 20 \\
Current hybrid & $+\$ 4,900$ & +25 & 25 & 25 \\
2035 gasoline & $+\$ 2,000$ & +10.2 & 35 & 35 \\
2035 diesel & $+\$ 3,600$ & +18.4 & 45 & 45 \\
2035 hybrid & $+\$ 4,500$ & +23 & 60 & 60 to 70 \\
2035 hydrogen fuel cell & $+\$ 7,300$ & +37.2 & 100 & 55 to 65 \\
2035 plug-in electric & $+\$ 7,800$ & +39.8 & 80 & 50 to 65
\end{tabular}

Source: National Academy of Sciences, "Real Prospects for Energy Efficiency in the United States" (2010), pp. 140, 143

Note: Greenhouse gas emissions from the electricity used in the 2035 plug-in, battery, and hydrogen-fuel-cell vehicles are estimates from the projected baseline-electricitygrid mix in 2035.

To begin with, we see that the more fuel efficient 2005 model cars-diesels and hybrids - were already between 9 percent and 25 percent more expensive than current conventional gasoline models, for which the NAS has assumed a retail price of $\$ 19,600$. They also are between 20 percent and 25 percent more fuel efficient. 
Moving to the NAS estimates for 2035, we see first that the 2035 conventional gasoline cars themselves are projected to be 10 percent more expensive than 2005 model conventional gasoline cars, which would put their price at $\$ 21,500$. The NAS also projects the 2035 model gasoline cars to be 35 percent more efficient than the 2005 model. This would put their fuel efficiency at around $30 \mathrm{mpg}$. The other types of vehicles the NAS assumes will be on the market in 2035 include diesels, hybrid-electrics, hydrogen fuel cells, plug-in electrics, and battery-electrics. The NAS assumes these will sell at retail prices that are between 18 percent and 82 percent higher than the current gasoline vehicles, which then means they will be 8 percent to 66 percent more expensive than a 2035 model gasoline-powered vehicle. The NAS also estimates that these cars will generate between 45 percent and 70 percent fewer $\mathrm{CO}_{2}$ emissions than current gasoline vehicles.

As an illustrative exercise for gauging the costs of rising fuel-efficiency standards from approximately 22 miles per gallon in 2005 (the 2005 level of fuel efficiency being $22.1 \mathrm{mpg}$ ) to approximately $55 \mathrm{mpg}$ in 2030 (the 2025 standard for new cars again being $54.5 \mathrm{mpg}$ ), consider one example of an advanced-vehicle car included in the NAS listings that will be capable of delivering a 55-mpg level of fuel efficiency in its 2035 models: the hybrid-electric car, which the NAS has priced at $\$ 4,500$ more than a 2005 model gasoline-fueled car, and $\$ 2,500$ more than a 2035 model gasoline-powered car. ${ }^{28} \mathrm{We}$ assume that the average drivers continue to travel at the current level of about 14,000 miles per year in their vehicles. We also assume that the price of gasoline will be at $\$ 4 /$ gallon in 2035 , which is the EIA's approximate Reference case retail price for 2035 , expressed in 2010 dollars.

Under this set of assumptions, the average driver in 2035 would pay about $\$ 1,900$ for gasoline per year, with their cars at the 2035 model gasoline-powered car efficiency standard of $30 \mathrm{mpg}$. With a 55-mpg efficiency standard, the driver would instead pay about $\$ 1,000$ per year for gasoline. The drivers with the more efficient cars would therefore save about $\$ 900$ per year in fuel costs. As such, if they paid about $\$ 2,500$ more than price of the standard gasoline-powered car for a hybridelectric car, they would make up those costs in 2.8 years of driving.

In terms of aggregate costs-assuming that in turning over the entire U.S. auto fleet of 250 million cars over the next 20 years, every car will cost $\$ 2,500$ more than it would have otherwise so as to attain an overall fuel-efficiency standard of $42.4 \mathrm{mpg}$ for the entire fleet by 2030 - achieving this gain in fuel efficiency would cost $\$ 625$ billion ( $\$ 2,500$ per car $\mathrm{x} 250$ million cars). With these costs spread out over 20 years, it would amount to about $\$ 31$ billion/year. 
Of course, it is likely that the price of more energy-efficient autos will fall over time, as technologies mature and their market share expands. Moreover, the payback period for purchasing a fuel-efficient car will also fall relative to our estimate of 2.8 years if the price of gasoline rises above the EIA's 2030 Reference case of $\$ 4$ per gallon.

Given this reality of long-term savings, a viable strategy for minimizing the impact of the higher initial purchase price would be for policymakers to devise innovative financing arrangements for purchasing autos that are above a given efficiency threshold. The idea behind such arrangements would be to enable consumers to capture some of the long-term savings through the terms of their auto-financing loans. The government could also subsidize part of the increased price of purchasing a fuel-efficient car in recognition of the social benefits generated by driving such vehicles.

\section{Heavy-duty vehicles}

In contrast with light-duty vehicles, the EIA does not anticipate a reduction in energy consumption with Heavy-Duty Vehicles in its 2030 Reference case, but rather an increase from 4.82 to 5.69 Q-BTUs from 2010 to 2030, an 18 percent increase. However, it will be necessary achieve reductions in HDV consumption in order to reduce overall transportation energy consumption to 20 Q-BTUs total or lower over the next 20 years. The Obama administration did establish the first fuel-economy standards for HDVs in 2011 to be implemented starting in 2014. The June 2013 President's Climate Action Plan also calls for the development of more stringent standards for HDVs to be implemented in 2019. ${ }^{29}$

The EIA is assuming that fuel economy will improve with HDVs from $6.6 \mathrm{mpg}$ in 2010 to about $8 \mathrm{mpg}$ by 2030 and rise to $8.2 \mathrm{mpg}$ by 2035. This implies an average annual improvement in HDV fuel efficiency of 0.9 percent per year. However, the EIA is also assuming that the number of miles traveled by truck will increase by 48 percent through 2035 - a 1.6 percent increase per year, which is why overall energy consumption by HDVs ends up rising by 18 percent in the EIA's Reference case. Further, under the EIAs' Reference case scenario, improvements in HDV fuel efficiency will have mostly ended as of 2018, which also contributes to the rise of energy consumption by HDVs. 
It is critical that HDVs, similar to LDVs, continue to improve efficiency levels beyond 2018. It is also reasonable to assume that they will in fact improve, especially given the Obama administration's recent strong commitment in this area. If we assume that from 2010 to 2035 , HDV fuel-efficiency standards rise by 1.1 percent per year rather than the 0.9 percent rate of improvement built into the EIA's 2030 Reference case (including the slowing of improvements after 2018), this would raise average HDV fuel efficiency by 32 percent from 2010 to 2035 . It is therefore reasonable to expect that, with these improvements in HDV fuel efficiency, overall energy consumption by HDVs will fall by 24 percent relative to the EIA's Reference case prediction of 5.69 Q-BTUs. This 24 percent drop would produce a decline in consumption to 4.3 Q-BTUs, a decline of 1.4 Q-BTUs. This is even if we also allow that the number of miles traveled by HDVs annually would remain as the EIA had assumed, at an average annual increase of 1.6 percent through 2030. But, if we allow that the overall increase in miles traveled falls only modestly relative to the EIA's aggressive assumptions in their Reference case, we could then also assume that total HDV energy consumption would fall by 1.5 Q-BTUSBTUs relative to the EIA's 2030 Reference case.

\section{Prospects with air travel and other transportation modes}

In the 2012 "Annual Energy Outlook," the EIA does not provide a detailed narrative on energy consumption for other transportation modes, which, in combination, account for about 7.2 Q-BTUs of consumption. This is 25 percent of the transportation-sector energy consumption total as of 2010. Air travel alone accounts for about 10 percent of that 25 percent.

Moving forward, it will be important for these additional modes of transportation to achieve even modest efficiency gains beyond the EIA's Reference case. For this discussion, we assume, as part of the economywide initiative to advance energy efficiency, that these sectors will be able to raise efficiency by about 0.4 percent per year over 20 years relative to the EIA Reference case, or about 8 percent overall (while assuming overall levels of travel remain constant). In absolute terms, this would amount to a reduction in consumption of 0.6 Q-BTUs from the EIA's Reference case figure of 7.2 Q-BTUs. 


\section{Overall costs of lowering transportation energy consumption}

We estimate above that reducing the energy consumption of LDVs by 5 Q-BTUs relative to the EIA's 2030 Reference case - that is, lowering LDV consumption in 2030 from about 15 to 10 Q-BTUs - will cost approximately $\$ 625$ billion, with a payback period for these efficiency investments being 2.8 years. To roughly estimate the costs of achieving fuel-efficiency improvements of 2 Q-BTUs with HDVs, and 1 additional Q-BTU for the rest of the transportation sector, it is reasonable as a first approximation to assume that these costs would be proportional to those with LDVs.

With LDVs, we are assuming that the $\$ 625$ billion in costs will achieve a reduction in consumption from 15 to 10 Q-BTUs by 2030, or about $\$ 125$ billion per Q-BTU in improved fuel efficiency. With non-LDV transportation, we are assuming 2030 consumption will fall from the EIA Reference case of 13 Q-BTUs to 10 Q-BTUs, an improvement of 3 Q-BTUs. This implies that the costs of non-LDV transportation efficiency will be $\$ 375$ billion. The overall costs of bringing transportation energy consumption down from the EIA's 2030 Reference case of 28 Q-BTUs to 20 Q-BTUs will therefore be about $\$ 1$ trillion. This is $\$ 50$ billion per year over 20 years. (see Table 2.15)

TABLE 2.15

Overall costs to reduce transportation-sector energy consumption from 28 to 20 Q-BTUs in 2030

\begin{tabular}{lccc}
\hline & $\begin{array}{c}\text { EIA 2030 Reference case } \\
\text { consumption level } \\
\text { (in Q-BTUs) }\end{array}$ & $\begin{array}{c}\text { High-efficiency } \\
\text { consumption level } \\
\text { (in Q-BTUs) }\end{array}$ & $\begin{array}{c}\text { Overall costs to achieve } \\
\text { high-efficiency consump- } \\
\text { tion level (in billions) }\end{array}$ \\
\hline Light-duty vehicles & 15 & 10 & $\$ 625$ \\
All other transportation & 13 & 10 & $\$ 375$ \\
Total & 28 & 20 & $\$ 1000$ \\
& & & $(\$ 1$ trillion)
\end{tabular}

Sources: Energy Information Administration, Annual Energy Outlook 2012 (U.S. Department of Energy, 2012a),.National Academy of Sciences, "Real Prospects for Energy Efficiency in the United States" (2010). 


\section{Expanded use of clean-burning fuels}

One further way to lower $\mathrm{CO}_{2}$ emissions, even with given transportation fuelefficiency standards, is to substitute clean renewable energy sources for fossil fuels, either as a liquid fuel or as a source for electricity. These renewable energy sources could include sustainable biofuels for liquid energy-powered vehicles or any clean renewable source that generates electricity.

We discuss in Chapter 3 the prospects for both expanding the renewable electricity market, as well as the market for clean biofuels directly as a liquid fuel for cars. In particular, we discuss a major opportunity to expand the use of clean biofuels by 2030. This would reduce emissions from the transportation sector further without requiring any additional efficiency gains with LDVs.

\section{Expanding public-transportation use}

The public-transportation sector is very small in the United States in comparison with the use of cars and light personal trucks. As seen in Table 2.13, total energy consumption for buses and passenger rail amounted to just slightly more than 1 percent of the total for the transportation sector. This means that even a major increase in public transportation will generate only a small overall impact on energy savings and greenhouse gas emissions from this sector during this intermediate time frame.

Nevertheless, due to the important long-term structural demand created through infrastructure investment choices, it is critically important to explore the benefits of a major expansion in public transportation. Over time, public transit is capable of emerging throughout the United States as a major mode of transportation, but it currently only operates in the few urban centers that have reliable and extensive public transit systems. In addition, any gains in publictransportation use will carry the additional benefit of reducing traffic congestion. The Association of American Railroads estimated in 2007 that the effects of lower traffic congestion can increase energy efficiency by an additional 77 percent of its direct energy savings. ${ }^{30}$ 


\section{Passenger transit}

The EIA's 2012 annual report makes no reference to increasing the share of public transportation in the overall transportation mix. Similarly, the NAS chapter on energy efficiency in transportation does not attempt to quantify benefits from shifting to public transportation, writing that, "the panel did not analyze the potential for energy efficiency gains in public transit per se." According to the NAS, the basic problem with relying on public transportation both by bus and rail as a means of raising energy efficiency is that the average ridership is too low.

On the other hand, the NAS does also note that public-transit ridership did grow by one-third between 1996 and 2008. In addition, public transit ridership increased even more when gas prices increased in 2007 and 2008. This experience suggests that there are major opportunities available for expanding public transit use once an appropriate set of incentives/disincentives are established. The 2007-2008 data show that any significant increase in the price of gasoline clearly generates strong incentives for shifting away from private-car use to public transportation.

As mentioned above, Appendix 1 contains some strategies for expanding the use of public transportation. In particular, we describe in detail how investments in public transportation of approximately $\$ 130$ billion to $\$ 210$ billion over 20 years would be capable of expanding bus ridership by 85 percent relative to current levels. This would amount to about $\$ 6.5$ billion to $\$ 10.5$ billion per year in public-transportation investments over the next 20 years. This level of investment would dramatically improve the convenience of public transportation, as well as lower the costs to consumers.

Appendix 1 also discusses the range of benefits that could result through major investments in public transportation. These benefits could be quite substantialassuming investments are undertaken in effective ways-including creating opportunities for lower-income households to reduce their transportation expenditures by a significant amount relative to their overall family income. A fall in transportation costs for these households will, in turn, translate directly into a significant improvement in their living standards.

In terms of our projections for achieving energy efficiency through 2030, however, we do not attempt to quantify the impact of public-transportation investments. We assume that there will be no gains in lowering overall transportation energy consumption through public-transportation investments. We operate with this premise so that our overall estimates for energy-efficiency prospects in transportation are erring, if at all, on the side of moderation. 


\section{Rail and waterway freight}

The movement of freight plays a major role in the U.S. economy, accounting for between 6 percent and 7 percent of GDP in total. A report prepared for the Federal Highway Administration, or FHWA, estimates that U.S. freight will grow by about 2 percent per year over the next two to three decades, as the economy expands and domestic and international trade increases. ${ }^{31}$

As with public transportation for passengers, both the EIA and NAS studies give no significant weight to the prospects for raising energy efficiency through shifting away from trucking in favor of rail or waterway freight shipments. This is despite the fact that, as the NAS recognizes, "trucks consume 10 times more energy than rail and waterborne per ton of freight moved." According to the NAS, rail and waterway freight systems face difficulties competing with trucks for shipments with time-sensitive deliveries. The NAS also argues that a shift toward rail would require expensive investments in laying down new tracks, and that such projects would also likely face opposition by nearby residents. Nevertheless, given the large efficiency gains that are possible through rail and waterway freight shipping, it is important to explore new investment possibilities in these sectors, along with those for public transportation for passengers. 


\section{Conclusion}

Table 2.16 brings together our estimates of the investment requirements needed for the building, industry, and transportation sectors, respectively, in order to bring overall energy consumption in the U.S. economy to around 70 Q-BTUs by 2030.

TABLE 2.16

Summary of efficiency investments needed to reduce total U.S. energy consumption from EIA 2030 Reference case of 104.3 Q-BTUs to 70 Q-BTUs in 2030

\begin{tabular}{lccccc}
\hline & $\begin{array}{c}\text { EIA 2030 } \\
\text { Reference case } \\
\text { consumption level } \\
\text { (in Q-BTUs) }\end{array}$ & $\begin{array}{c}\text { Consumption lev- } \\
\text { els for high-effi- } \\
\text { ciency economy } \\
\text { (in Q-BTUs) }\end{array}$ & $\begin{array}{c}\text { Percentage } \\
\text { reduction in } \\
\text { consumption in high- } \\
\text { efficiency case }\end{array}$ & $\begin{array}{c}\text { Investment costs } \\
\text { through 2030 for } \\
\text { high-efficiency } \\
\text { economy }\end{array}$ & $\begin{array}{c}\text { Average } \\
\text { investment costs } \\
\text { per year for } 20 \\
\text { years }\end{array}$ \\
\hline Buildings & 43.4 & 27.5 & -36.8 & $\$ 450$ billion & $\$ 22.5$ billion \\
Industry & 32.9 & 22.5 & -31.6 & $\$ 300$ billion & $\$ 15.0$ billion \\
Transportation & 28.0 & 20 & -28.8 & $\$ 1$ trillion & $\$ 50.0$ billion \\
Total & 104.3 & 70 & -33 & $\$ 1.75$ trillion & $\$ 87.5$ billion
\end{tabular}

Sources: National Academy of Sciences, "Real Prospects for Energy Efficiency in the United States” (2010); Energy Information Administration, Annual Energy Outlook 2012 (U.S. Department of Energy, 2012a).

Costs of increasing public bus ridership by 85 percent by 2030

\begin{tabular}{lcc}
\hline & $\begin{array}{c}\text { Total costs } \\
\text { (in billions) }\end{array}$ & $\begin{array}{c}\text { Costs per year } \\
\text { (in billions) }\end{array}$ \\
\hline $\begin{array}{l}\text { Costs with bus fares at } \\
\$ 1.50 \text { per trip }\end{array}$ & $\$ 130$ & $\$ 6.5$ \\
Costs with bus fares at & $\$ 210$ & $\$ 10.5$ \\
75 cents per trip & & \\
Sources: See Appendix 1 for details. & &
\end{tabular}




\section{Buildings}

We began with the estimate from the NAS study that it would require a level of investment of $\$ 394$ billion over 20 years to reduce energy consumption in buildings to 29.4 Q-BTUs, or about 32 percent below the EIA's 2030 Reference case of 43.4 Q-BTUs. This level of investment, again, includes "both the full add-on cost for new equipment or measures (e.g. attic insulation) and the incremental cost of purchasing an efficient technology compared with purchasing its conventional technology equivalent."

We then assumed that the costs of lowering consumption further to 27.5 Q-BTUs would be proportional to the costs of achieving a 29 Q-BTU level of energy consumption in the building sector. That would then mean that the total costs of reaching a 27.5-Q-BTU level of consumption in the building sector would be $\$ 450$ billion in investments, or $\$ 22.5$ billion per year, to achieve about a 37 percent gain in efficiency relative to the EIA Reference case.

\section{Industry}

To examine how to bring energy consumption in U.S. industry down from the EIA's 2030 Reference case of 32.9 Q-BTUs to 22.5 Q-BTUs-a 32 percent reduction-we divided the sector's overall energy consumption into two broad categories: industry-specific investments and cross-cutting technologies, especially CHP systems. In the interests of simplicity, and erring, if anything, on the side of moderation, we did not include in these calculations any additional cross-cutting efficiency investment areas beyond CHP, such as high-temperature separation technologies.

We showed in Table 2.12 above that overall investment in CHP systems would need to be about $\$ 193$ billion between 2011 and 2030 to reduce U.S. industrial energy consumption by 3.8 Q-BTUs. We also estimated that about $\$ 108$ billion in industry-specific efficiency investments would yield about 6.6 Q-BTUs of savings by 2030 . Overall, then, as is shown in Table 2.16, the investment costs to bring energy consumption in U.S. industry down to 22.5 Q-BTUs would be $\$ 301$ billion. This amounts to about $\$ 15$ billion per year for 20 years. 


\section{Transportation}

We focused our estimate here on the 2025 fuel economy standard of $54.5 \mathrm{mpg}$ by 2025, as accepted by the Obama administration, most of the U.S. auto industry, and the United Auto Workers. Working from the National Academy of Sciences estimate of the incremental retail costs of purchasing a high-efficiency vehicle relative to a standard gasoline-powered car in 2035, we estimate that the cost of replacing the entire U.S. auto fleet with high-efficiency cars in 20 years would be $\$ 625$ billion. This would reduce energy consumption of LDVs from the EIA's 2030 Reference case of about 15 Q-BTUs to 10 Q-BTUs.

We then assumed that HDVs would increase their efficiency by about 24 percent relative to the EIA's Reference case. That would lower energy consumption of HDVs from about 5.6 to 4.3 Q-BTUs. We then assumed that relative to the EIA's 2030 Reference case, an additional 0.5 Q-BTU reduction in energy consumption could be achieved through efficiency measures implemented with all other transportation modes-i.e. air, rail, and water travel, and pipeline fuels. Overall, we estimated that total costs would be roughly $\$ 1$ trillion to reduce energy consumption from the EIA Reference case of about 28 Q-BTUs to 20 Q-BTUsan efficiency gain of 29 percent relative to the EIA Reference case. This would amount to about $\$ 50$ billion in spending per year for 20 years.

We did also give careful attention to the prospects for dramatically expanding public-transportation offerings throughout the United States. Over time, a shift toward significantly increasing public-transportation options will provide a wide range of social, as well as environmental, benefits. However, at present and for the intermediate time frame of this study, because public transportation is now so small a fraction in the overall energy consumption for the transportation sector, we cannot rely on this sector as a significant factor in improving energy-efficiency standards in transportation. But as shown in Table 2.16, our overall level of energy-efficiency investments includes an infusion of between $\$ 130$ billion and $\$ 210$ billion in spending on public bus transportation. To achieve longer-term carbon emission reductions, these infrastructure investments will be required during the 2030 to 2050 time period. This amounts to between $\$ 6.5$ billion and $\$ 10.5$ billion per year. 
Our total spending figure-including all areas of energy-efficiency investments in buildings, industry, and transportation, including public transportation—adds up to around $\$ 1.75$ trillion in order to achieve energy-consumption efficiencies at about 33 percent below the EIA 2030 Reference case of 104 Q-BTUs. This $\$ 1.75$ trillion in new investments would span over 20 years, at a rate of roughly $\$ 87.5$ billion per year for the full 20-year period. The average cost of savings relative to the EIA 2030 Reference case would be about $\$ 50$ billion per Q-BTU ( $\$ 1.75$ trillion in investments/34.3 Q-BTUs of saving). The net result would be to push the level of energy consumption in the United States to about 70 Q-BTUs.

Note that this figure for new energy-efficiency investments is reasonably close to the $\$ 38$ billion per Q-BTU estimated by McKinsey for the United States in its 2008 study, even while the two figures were generated independently of one another. One possible factor as to why our estimated cost per Q-BTU of energy saved is about 30 percent higher that McKinsey's is that our more recent estimate is building off of the most current EIA Reference case estimates for 2030. As we have discussed, these EIA estimates do already themselves incorporate aggressive assumptions as to the potential for energy efficiency. This makes it more expensive to achieve further efficiency gains beyond those already built into the EIA's Reference case. ${ }^{32}$

\section{Total savings}

A key driver in this analysis of energy-efficiency investments is that these investments will be generating substantial savings over time. As we have seen, the NAS estimates the payback period for energy-efficiency investments in buildings at less than three years. From our own rough calculations, we also found that the savings on fuel costs for operating an energy-efficient automobile in 2030 rather than a conventional gasoline-powered model would also produce a full payback in less than three years. We have not yet made similar estimates for the industrial sector, but it is likely that the results will be in the same range as those for buildings and transportation. 
Given such major opportunities for cost savings, we explore in Chapter 8 an issue that we raised briefly in this chapter. It will be crucial to establish, through policy initiatives, various forms of innovative financing packages so that the substantial long-term savings of energy-efficiency investments can be realized more effectively in near-term decision-making by building owners and investors. These benefits can be captured through the use of a range of financing options that enable investors to overcome the first cost barrier of out-of-pocket payments. Such financing packages therefore enable the savings from energy-efficiency investments to be realized more effectively within an investor's ongoing cash flows. 


\section{Potential rebound effects}

In advancing an ambitious agenda for energy efficiency in the United States, it is critical to also examine what is termed the "rebound effect" and the related phenomenon of a "backfire effect." The key question posed with the rebound effect is whether the amount of energy-consuming activities will increase if economic activities that entail the consumption of energy can be accomplished at lower costs due to energy-efficiency gains. This goes hand-in-hand with the question of whether more energy-consuming economic activity powered specifically by fossil fuels takes place because of these efficiency gains, thereby reducing the effectiveness of efficiency investments in lowering greenhouse gas emissions. It is even possible that, in some circumstances, the initial gains in energy efficiency would end up being lower than the subsequent increase in energy consumption. This outcome is what we mean by the "backfire effect." When such a rebound effect exceeds initial reductions in this way, specifically with respect to fossil fuels, the net backfire effect would then mean that improvements in energy efficiency could end up actually producing net increases in greenhouse gas emissions.

The possibility that rebound and backfire effects could occur was first proposed in the economics literature by William Stanley Jevons in his 1865 book, The Coal Question. Jevons wrote that the invention of a more efficient steam engine would ultimately lead to increased coal consumption by way of making the use of coal economically desirable for many uses. He claimed that overall coal consumption would increase even as the coal used for particular applications may decrease. Jevons wrote that, "It is a confusion of ideas to suppose that the economical use of fuel is equivalent to diminished consumption. The very contrary is the truth." ${ }^{33}$

Since Jevons's era, further research on the rebound effect became highly active in the 1980s and 1990s, including the influential contributions by Khazzoom (1980) and Brookes (1990). A large professional literature has subsequently emerged, which we review below, but beyond even the findings of most recent literature, the prospects for rebound effects needs to be examined within a broader context of a given economy's level of development and policy priorities, as we also consider in this section. 
It is important initially to distinguish two broad categories of rebound effects: direct and indirect effects. Direct effects refer to a given activity, such as driving a car or heating a home. The rebound effect here measures how much more consumers engage in such activities due to rising energy efficiency associated with these activities, which in turn yields falling per-unit energy costs-for example, the number of additional miles might people drive as a result of operating more energy-efficient automobiles or how much more they may heat or cool buildings after efficiency investments bring the costs down.

Indirect effects take different forms. These include the following:

- When the costs of energy fall, consumers then are able to spend more on everything else besides directly energy-consuming activities such as driving a car or heating a building. But the remaining goods and services-everything from education, health care, or consumer goods - also make use of energy. When demand for these products rises, it in turn will produce increased demand for energy.

- Businesses experiencing falling energy costs may increase their use of energyintensive equipment in their production processes.

- Investments in energy efficiency involve expenditures on capital goods, which themselves require products that require energy inputs—for example, supplies for building weatherization projects.

- To the extent that energy-efficiency investments encourage faster economic growth, this accelerated overall economic growth rate would mean a higher overall level of energy demand.

There is no doubt that both direct and indirect rebound effects occur. But the first relevant question is not whether they occur, but rather how large they are. A second related question regards the extent to which rebound effects vary, depending on the specific conditions in any given economy, as well as the economy's relevant policy environment. 


\section{Measuring rebound effects}

Major professional reviews of this literature include those by Greening, Greene, and Difiglio (2000), Sorrell (2007), Sorrell et al. (2009), and Gavankar and Geyer (2010). ${ }^{34}$ We draw on the main findings from these literature reviews in what follows.

\section{Direct rebound effects}

Most research into the size of the direct rebound effect has been focused on the household sector in the United States - that is, residential energy use and household transportation. The effect is based on how consumers may change their behavior in response to changing prices. But there are several methodological issues and potential sources of bias in trying to measure the direct rebound effect for households.

To begin with, since direct rebound effects are tied to the idea of demand for energy services, the size and nature of the effect will depend on how "energy services" are defined. But such definitions are subject to substantial variation-for example, with the transportation sector, energy services are frequently defined in terms of number of miles traveled, but this measure does not take into account choices about the types of vehicles driven. Would consumers want bigger cars if such vehicles became more efficient? A consistent measure of "energy services" would have to control for this factor but does not always do so.

Another concern is that many studies assume that changes in demand in response to increases in energy efficiency are equivalent to changes in demand associated with comparable changes in prices. But this may not be the case because changes in energy efficiency may not translate directly into reductions in prices if the efficiency improvements require new investments with additional capital costs. If the demand effect is calculated without taking account of such capital costs, the rebound effect is likely to be overstated.

A third important concern is being able to accurately identify causality. Most studies on the rebound effect assume that when energy efficiency increases, this efficiency increase is the driving factor causing a subsequent rise in energy demand. However, higher demand for energy emerging from independent factors could also cause consumers to respond by investing in energy efficiency-that is, the causality between an increase in energy demand and energy efficiency would be the reverse of the relationship that the rebound effect presupposes. 
Drawing from the literature reviews by Greening, Greene, and Difiglio (2000) and Sorrell et al. (2009), Table 2.17 shows estimates of the direct rebound effect by category of energy services. ${ }^{35}$ As the table shows, these estimates range widely in both studies. Though these two surveys were published nine years apart from one another, they summarize similar sets of conclusions as to the likely range of household rebound effects. Thus, these articles find that for automobiles and heating and cooling systems, the rebound effect is likely to lie in the range of 10 percent to 30 percent relative to the total amount of energy saved. ${ }^{36}$ For home appliances and lighting, the rebound effect is lower and may be close to zero. A zero rebound effect reflects the level of consumer saturation-for example, utilizing more energyefficient laundry or dishwashing machines will likely have little to no impact on the demand for energy services for people to, for example, wash their clothes or dishes more frequently than they are already doing. For such activities, when demand for energy services is near its saturation point, efficiency gains will translate proportionally into reduced energy consumption.

TABLE 2.17

\section{Estimates of direct rebound effects from two recent survey papers}

\begin{tabular}{lcc}
\hline & $\begin{array}{c}\text { Estimated percent range } \\
\text { from survey by Greening } \\
\text { and others (2000) }\end{array}$ & $\begin{array}{c}\text { Estimated likely percent } \\
\text { range from survey by Sorrell } \\
\text { and others (2009) }\end{array}$ \\
\hline $\begin{array}{l}\text { Personal vehicles } \\
\text { Space heating }\end{array}$ & 10 to 30 & 10 to 30 \\
Space cooling & 0 to 50 & 10 to 30 \\
Home appliances & 0 & 1 to 26 \\
Lighting & 5 to 12 & Less than 20
\end{tabular}

Sources: Lorna Greening et al."Energy Efficiency and Consumption: The Rebound Effect: A Survey" (2000); Steve Sorrell et al., "Empirical estimates of the direct rebound effect: A review" (2009).

Note: The survey by Sorrell and others includes the category "other energy services."The estimates for this category are used for home appliances and lighting in this table. The term "likely range" in describing the survey figures is the assessment of these authors' probable ranges for the direct rebound effects based on their literature review.

\section{Indirect rebound effects}

Research on the magnitude of indirect, or economywide, rebound effects are even more limited than those for direct effects. Various methodologies have been utilized in the literature, including consumer expenditure surveys, macro-econometric models, and theoretical general equilibrium models. They have produced a wide range of estimates of the indirect effect, but the results are highly sensitive to the methodology used and the underlying assumptions within the method used. Sorrell 
in 2007 concludes, regarding these studies, that, "while a number of methodological approaches are available to estimate these effects, the limited number of studies to date provides an insufficient basis to draw any general conclusions."

More broadly, in 2009 Sorrell summarizes the overall state of knowledge on rebound effects as follows:

The available evidence for all types of rebound effects is far from comprehensive. The evidence is better for direct effects than indirect effects, but even this focus on a small number of consumer energy services, such as home heating and personal transportation, within developed countries. Both direct and indirect effects appear to vary widely between different technologies, sectors and income groups, and in most cases cannot be quantified with much confidence. However the evidence does not suggest that improvements in energy efficiency routinely lead to economy-wide increases in energy consumption. At the same time, the evidence suggests that economy-wide rebound effects will be at least 10 percent and often higher. Rebound effects therefore need to be factored into policy assessments.

\section{Broader context for considering rebound effects}

As these survey papers all recognize, the size of any rebound effects will depend on the level of development of an economy, the purposes for which energy is being consumed in the economy, and the economic policies being pursued at a given time. For example, in the historical period in Britain described by Jevons, the use of steam engines was growing rapidly as a crucial component of the 19th century industrial revolution. The very purpose of producing more efficient steam engines was to facilitate an accelerated rate of industrialization, powered by coalpowered machinery.

The Jevons case has relevant parallels with developing countries today, including India and China. These are rapidly expanding economies, in which per-capita energy consumption is rising. In these cases, we would expect that increased energy efficiency that produces lower costs for consuming a unit of energy will encourage, for example, more intensive use of automobile travel or household appliances.

Conditions will be different with economies that are already at high GDP levels, such as the United States. In these cases, the per-capita consumption of energyintensive activities is far closer to a saturation point than is true in India or China. 
With household appliances such as dishwashers or laundry machines, for example, it is not likely that use of such equipment on a per-capita basis would rise significantly beyond their current level of use. People do drive more when fuel costs fall due to efficiency gains or any other purpose. But such increases are, again, likely to be relatively modest—nowhere near where we would see a backfire effect—given how much people are already driving, both for business and personal use.

The basic long-term pattern of energy consumption in the United States is relevant here. As we have reviewed above, energy consumption relative to GDP has fallen dramatically in the United States over the past 40 years-from 15.9 thousands of BTUs per dollar of GDP in 1970 to 7.4 thousands in 2010. If large rebound effects were operating in the United States, we would not observe this sharp decline in energy use per dollar of GDP. Of course, as we have seen, it is also the case that, due to both GDP and population growth, the absolute level of U.S. energy consumption has risen in the United States since 1970. But these factors leading to an increasing absolute level of energy consumption in the United States are distinct from any kind of rebound effect, in which efficiency gains that produce falling costs of consuming energy are encouraging greater per capita energy demand.

As for the role of policy, if we consider the case of Britain in the Jevons era, the purpose of improving energy efficiency was precisely to support the greater use of coal-fired power. There was no reason for economic policy to capture the benefits of rising energy efficiency for any other purpose. With the United States today, the overarching purpose of raising energy efficiency is quite distinct. The proximate purpose is to maintain or enhance the benefits of energy-driven machines, while lowering the need for energy inputs to power these machines. The fundamental purpose is, quite simply, to play a major role in fighting climate change.

In the United States today, then, it is logical that the effort to increase energy efficiency would be accompanied by complementary policies that, in combination, can succeed in dramatically reducing $\mathrm{CO}_{2}$ emissions. Thus, in the case of the U.S. economy today, one major complementary policy to promoting energy-efficiency investments would be to set a price on carbon emissions through either a carbon cap or carbon tax. In addition, policies to promote affordable, clean renewable energy would allow for higher levels of energy consumption-including through some limited rebound effects - without leading to increases in $\mathrm{CO}_{2}$ emissions. In short, a policy environment that complements energy-efficiency investments with 
a price on carbon, as well as strong support for renewable energy will purposefully create a much smaller rebound effect than a situation-such as that in Jevons's England - when the drive for energy efficiency was serving the aim of expanding early industrialization. We consider a range of complementary policy measures in detail in Chapter 8.

The comparison that we reviewed earlier with other advanced economies is also relevant here. As we have seen, countries such as Germany, France, Japan, and the United Kingdom are presently operating at efficiency levels roughly twice as high as the United States while maintaining roughly comparable living standards. These countries maintain high prices for fossil fuels, rely much more heavily on public transportation, and are incorporating renewable energy more rapidly into their energy infrastructure. As such, the high levels of energy efficiency have become permanent features of how these economies operate. There is no evidence that large rebound effects have been emerging as a result of the high efficiency standards achieved by these economies.

Our main findings from this discussion are as follows:

1. The weight of evidence derived from the contemporary research literature on the magnitude of the rebound effect - though limited in its scope to datefinds that such effects are most often modest.

2. Over the past 40 years, the U.S. economy has made major advances in reducing energy consumption on a per-capita basis, even as average incomes and overall consumption levels have grown significantly. Similarly, other countries at comparable GDP levels currently operate at energy-efficiency levels that are roughly twice that of the United States. These patterns demonstrate that large gains in energy efficiency are being achieved in advanced economies, despite any countervailing rebound effects.

3. Public policies, such as establishing a price on carbon and supporting the development of a large-scale renewable energy sector-should be advanced along with major energy-efficiency investments, codes, and standards, as complementary features of an overall project to dramatically limit greenhouse gas emissions. To the extent that such policy initiatives are developed along with efficiency investments, their impact will be to mitigate any rebound effects that may have occurred otherwise. 
Considering these three findings, we conclude that any rebound effects that may accompany a major project to increase energy efficiency in the U.S. economy are almost certain to be modest and manageable within the broader scope of the measures contemplated here.

Still, in estimating the total costs of energy efficiency investments to achieve a 70 Q-BTU total consumption level in the United States within 20 years, we do need to take into account the possibility that some relatively modest rebound effects will occur. In terms of overall energy efficiency investment costs, the main impact of a rebound effect will be to raise the efficiency investment requirements - and therefore the investment costs - to bring total consumption down to 70 Q-BTUs. For example, we have concluded in this chapter that about $\$ 88$ billion per year for 20 years will be needed to bring U.S. energy consumption down to 70 Q-BTUs. If a modest rebound effect were operating, we might therefore assume that investment costs would rise to perhaps $\$ 90$ billion to $\$ 95$ billion per year. We consider this issue further, after we have examined the costs of expanding clean renewable energy capacity in the United States. This is the topic to which we now turn. 
1 U.S. Energy Information Administration, Annual Energy Outlook 2012 (U.S. Department of Energy, 2012), available at http://www.eia.gov/forecasts/aeo/ pdf/0383(2012).pdf.

2 Specifically, the NAS estimates a range of efficiency gains relative to the EIA's 2030 Reference case as presented in their 2008 Annual Energy Outlook. In that 2008 Reference case, overall energy consumption in 2030 was estimated at 118 Q-BTUs. The NAS estimated a range of efficiency gains off of this 118 Q-BTU target as being between 30.5 and 35.8 Q-BTUs. This means an overall level of consumption between 82 and 87 Q-BTUs.

3 U.S. Energy Information Administration. Annual Energy Outlook 2010 (U.S. Department of Energy, 2010), p. 32 available at http://www.eia.gov/forecasts/archive/ aeo10/pdf/0383(2010).pdf.

4 The full forecasting model is presented in U.S. Energy Information Administration "Macroeconomic Activity Module." In The National Energy Modeling System: An Overview 2009, available at http://www.eia.gov/oiaf/ aeo/overview/pdf/0581(2009).pdf.

5 U.S. Energy Information Administration, Annual Energy Outlook 2012, p. 25

6 The significance of implementing "Best Available Technologies" in new buildings was also recently emphasized by the highly respected leader in sustainable architecture Edward Mazria. He concludes that energy consumption in buildings as of 2030 could be reduced by more than $8 \mathrm{Q}$-BTUs relative to the EIA Reference case through utilizing best available technologies in new projects and renovations. Stephen Lacey, "This 'Monumental Shift' in the US Building Sector May Surprise You," Greentechmedia, May 9, 2013, available at https://www.greentechmedia.com/articles/ read/federal-data-shows-sweeping-savings-in-energyusage-by-us-building-sector.

7 Because of these economies of scale, the technology for commercial water heating systems is more advanced. Thus, the average lifetime for residential natural gas water-heating systems is 16 years, while that for commercial building systems is 50 years.

8 The simple payback period is calculated as: $(\$ 394$ billion in cumulative capital investments) / ( $\$ 146$ billion in annual utility bill savings) $=2.7$ years payback. To generate the $\$ 2.6$ trillion figure for cumulative saving over 20 years, it was necessary to multiply the annual savings from each efficiency investment by the number of years over which each investment is likely to generate savings. For example, the NAS estimates that investments in residential space heating efficiencies will last 24.5 years, while those for color televisions, freezers, and water heating equipment will last only 11 years. The full set of figures and calculations are available from the authors.

9 U.S. Department of Energy, Successes of the Recovery Act (2012), available at http://energy.gov/sites/prod/files/ RecoveryActSuccess_Jan2012final.pdf.

10 A home with zero net-energy consumption may at times produce more energy than it consumes-for example, through photovoltaic panels on the roof-and at other times it may consume more energy than it produces.
11 The ElA's 2012 Annual Energy Outlook only reports Reference case forecasts for 2025 and 2035, not 2030 for the value of total industrial shipments. U.S. Energy Information Administration, Annual Energy Outlook 2012, p. 181, Table B4. According to the EIA's projections, starting with a 2010 base year, the average annual growth rate for industrial shipments is 2.1 percent through 2025 and 1.6 percent through 2035. We have taken the average of these two growth projections to obtain our roughly estimated for 2010-2030 industrial growth as being 1.8 percent annually.

12 U.S. Energy Information Administration, Annual Energy Outlook 2012, p. 148

13 National Academy of Sciences, Real Prospects for Energy Efficiency in the United States (Washington: The National Academies Press, 2010), p. 233.

14 Ibid., p. 217.

15 McKinsey and Company, "The Untapped Energy Efficiency of the U.S. Industrial Sector: Details of Research, 2008" (2008).

16 Diana Farrell, Jaana Remes, Florian Bressand, Mark Laabs, and Anjan Sundaram, "The Case for Investing in Energy Productivity" (New York: McKinsey Global Institute, 2008), available at http://www.mckinsey.com/ insights/mgi/research/natural resources/the case for investing_in_energy_productivity.

17 These figures and studies are summarized in National Academy of Sciences, Real Prospects for Energy Efficiency in the United States, pp. 204-209.

18 Sean Milmo, "Innovative packaging aims to cut supply chain footprint," ICIS Chemical Business, November 11 2010 .

19 Li Shen, Juliane Haufe, and Martin K Patel, "Product Overview and Market Projection of Emerging Bio-based Plastics: PRO-BIP 2009" (The Netherlands: Utrecht University, Copernicus Institute for Sustainable Development and Innovation, 2009).

20 See Table 6.7 (p. 64) in the Assumptions to the Annual Energy Outlook 2012 for details. The estimates of capita costs vary based on the scale of the CHP system. The high-end estimate $(\$ 1,719$ per $\mathrm{KWh})$ is only for smallscale (3000kw or less) gas turbines. Therefore, we base our calculations on the capital costs of CHP systems other than such very small-scale operations. Table 6.7 gives estimates for 2010 and 2035 . The range of capital cost estimates for gas turbines for 2010 is approximate y $\$ 900$ to $\$ 1,200$ per KWh of installed capacity while the range for 2035 is roughly $\$ 800$ to $\$ 1,000$ per kw. Therefore, we take $\$ 1,100$ as a reasonable conservative estimate of the average capital cost of installed CHP capacity over the period 2010 to 2030 .

21 The per-Q-BTU investment figure implicit in the IWG report is $\$ 12.1$ billion in 1995 dollars. We adjust this to account for inflation using the GDP deflator and express the investment per Q-BTU saved in 2010-the year used as the current baseline in the U.S. Energy Information Administration, Annual Energy Outlook 2012 (U.S. Department of Energy, 2012), available at http://www.eia.gov/forecasts/aeo/pdf/0383(2012).pdf. 
22 A 2010 McKinsey brief also includes cost estimates for the various approaches. See Jon Creyts, Hannah Choi Granade, and Kenneth J. Ostrowski, "U.S. energy savings: opportunities and challenges" (New York: McKinsey, 2010), available at http://hmfportal.squarespace.com/ storage/research-and-learning-documents/Jan $\% 20$ $2010 \% 20$ McKinsey\%20report\%20on\%20energy\%20 savings\%20opportunities.pdf. The authors estimate that 1.2 Q-BTUs can be saved through CHP and an additional 2.45 Q-BTUs saved in energy-intensive industrial processes. They present cost estimates of $\$ 28$ billion for CHP and $\$ 85$ billion for all other industrial EE. Thus $\$ 113$ billion saves 3.65 Q-BTUs in the industrial sector over the next 10 -year period, or $\$ 31$ billion per $\mathrm{Q}-\mathrm{BTU}$ saved. The estimates presented in the text require $\$ 208$ billion to save 7.7 Q-BTUs-putting aside the issue of electricity related losses-or $\$ 28$ billion in investment per Q-BTU saved. Therefore, the two sets of estimates are reasonably close.

23 U.S. Energy Information Administration, Annual Energy Outlook 2012.

24 Ibid., p. 84.

25 Ibid., p. 84

26 For the White House announcement, as well as all details presented in this paragraph, see The White House, "President Obama Announces Historic 54.5 mpg Fuel Efficiency Standards," Press release, July 29, 2011, available at http://www.whitehouse.gov/the-pressoffice/2011/07/29/president-obama-announces-historic-545-mpg-fuel-efficiency-standard.

27 Julia Pyper, “Transportation: U.S. Lags in a Race for Global Fuel Efficiency," E\&E Publishing, September 28, 2012, available at http://www.eenews.net/special reports/The_Race/stories/1059970588.

28 An extensive 2011 analysis by the National Highway Traffic Safety Administration and Environmental Protection Agency estimated that the average additional vehicle costs for reaching the 54.5 fuel efficiency standard would be $\$ 1,900$ by 2030 . See U.S Environmental Protection Agency and National Highway Traffic Safety Administration, Greenhouse Ga Emissions Standards and Fuel Efficiency Standards for Medium- and Heavy-Duty Engines and Vehicles. Working draft. (2010), p. 367, available at http://epa.gov/OMS/ climate/regulations/hd-preamble-regs.pdf. However, it is not clear in the study how they derived this average figure. As such, for this discussion, we focus on a higher-end estimate of cost differences at $\$ 2,500$.

29 Executive Office of the President, The President's Climate Action Plan (The White House, 2013), p. 8, available at http://www.whitehouse.gov/sites/default/files/image/ president27sclimateactionplan.pdf. President Obama reaffirmed his commitment to more stringent standards for HDVs' in a February 18, 2014, speech. The White House, "Remarks by the President on Fuel Efficiency Standards of Medium and Heavy-Duty Vehicles," Press release, February 18, 2014, available at http://www.whitehouse.gov/the-press-office/2014/02/18/remarks-president-fuel-efficiencystandards-medium-and-heavy-duty-vehicl.

30 Cambridge Systematics, Inc., "National Rail Freight Infrastructure Capacity and Investment Study" (2007), available at http://www.aar.org/ /media/aar/Files/ natl_freight_capacity_study.ashx.

31 ICF Consulting, "Assessing the Effects of Freight Movement on Air Quality at the National and Regional Level, Final Report" (2005), available at http://www. fhwa.dot.gov/environment/air_quality/publications/ effects_of_freight_movement/chapter00.cfm.

32 Another factor is simply inflation, with the overall price level having risen by about 5 percent since the McKinsey report was published in 2008.

33 This paragraph is paraphrased from Sheetal Gavankar and Roland Geyer, "The Rebound Effect: State of the Debate and Implications for Energy Efficiency Research" (Santa Barbara, CA: Bren School of Environmental Science and Management, 2010), available at http://iee. ucsb.edu/files/pdf/Rebound\%20Report\%20for\%20 IEE-UCSB.pdf.

34 For a less formal but still quite useful recent discussion of the topic, see Steven Nadel, "The Rebound Effect: Large or Small?" (Washington: American Council for an Energy Efficient Economy, 2012), available at http:// www.aceee.org/files/pdf/white-paper/rebound-largeand-small.pdf. For a brief updated assessment of what they term "a vast academic literature" on this issue, see Kenneth Gillingham, Matthew J. Kotchen, David S. Rapson, and Gernot Wagner, "The Rebound Effect is Overplayed," Nature 493 (2013): 473-474. The main conclusion reached by Gillingham is fully consistent with the more lengthy survey studies.

35 The precise definition of the rebound effect is the elasticity of demand for energy services with respect to energy efficiency.

36 Manuel Frondel, Nolan Ritter, and Colin Vance, "Heterogeneity in the Rebound Effect: Further Evidence on Germany," Energy Economics 34 (2012): 461-467 finds that the rebound effect for automobile travel in Germany is higher, averaging between 57 percent and 62 percent. But they also acknowledge that their results show considerable heterogeneity in the extent of the rebound effect among German automobile drivers and their results are "substantially larger than those obtained from other studies (p. 461)-meaning that their results are outliers relative to the overall body of evidence provided in the contemporary professional literature. 
Chapter 3

Prospects for clean renewable energy 


\section{Introduction}

In order for the United States to meet its $\mathrm{CO}_{2}$ emission targets for 2030 and subsequently for 2050, it will be necessary to create an expanding and successful renewable energy sector. Even if the United States were able to lower its overall energy consumption to around 70 Q-BTUs by 2030-2035, in order to meet the 20-year emissions reduction target of no more than $3,200 \mathrm{mmt}$ in $\mathrm{CO}_{2}$ emissions, it would still be necessary for between roughly 20 percent and 25 percent of this overall energy level to be supplied by clean renewable sources. This translates to between about 15 to 20 Q-BTUs of energy consumed in the United States supplied by renewable sources whose net impact on carbon emissions is zero or close to zero.

In considering the prospects for clean renewable energy supplies to meet that target by 2030-2035, the first point to emphasize is that renewable energy sourcesincluding biofuels and biomass, hydro, wind, geothermal, and solar power-vary widely in terms of their basic feedstocks, the means by which they generate energy, and their environmental impacts.

Corn ethanol, for example, is currently the most heavily consumed biofuel in the United States. Depending on the refining methods used, the emissions produced by corn ethanol can be comparable to burning petroleum. This is also true for biomass energy when - as is mostly the case - the energy sources and production practices are not carefully managed to minimize carbon emissions. Biomass and biofuels can also be a carbon-neutral source of energy if the raw materials are wastes and nonfood crops and if these raw materials are refined through the use of renewable sources of process energy. But these techniques for producing bioenergy are utilized only minimally at present in the United States.

The other renewable sources - hydro, wind, solar, and geothermal power-produce virtually no emissions. Yet at present, among these, only hydro is producing energy on a significant scale in the United States. For a host of reasons, however, it is also neither likely nor desirable that large-scale hydro projects will expand 
significantly beyond their current capacity. One factor here is that the most favorable sites in the United States for constructing large-scale dams are already built out and operating at capacity. Beyond this existing capacity, there are likely to be serious environmental issues connected with additional large-scale dam construction in terms of disrupting existing communities and ecosystems. Prospects are more favorable for expanding electricity-generating capacity from small-scale hydro sites, which, as we discuss below, are in abundance throughout the country. This would be in addition to expanding the capacity from the other emissions-free renewable energy sources.

Working from the available evidence, it is realistic to expect that these clean renewable sources within the United States combined could generate around 15 Q-BTUs or more of energy within 20 years. Indeed, one could make the case that this is a highly conservative estimate of what is realistic over the next two decades. We consider the range of realistic prospects in what follows, within the context of the current level of operations of the various renewable energy sources and the projections for expansion, as estimated by the EIA and other sources. 


\section{U.S. renewable energy generation}

In 2010 renewable energy generated about 7.9 Q-BTUs of energy in the United States, or about 8 percent of total energy consumed. As we see in Table 3.1, the biggest source of renewable energy is biomass and biofuels in a range of forms. In all its forms, bioenergy sources combined to provide 4.25 Q-BTUs in 2010, or 54 percent of total renewable energy supplied. Of course, this total can be broken down into highly distinct energy sources. The largest single supply comes from biomass for industry, which accounted for 1.3 Q-BTUs in total in 2010. The other large sources of bioenergy are biofuels for heat and co-products, ethanol blending, and wood biofuels. But as mentioned above and discussed in more depth below, the environmental impact of biomass and biofuels varies widely. Some of these energy sources offer little to no improvement in terms of $\mathrm{CO}_{2}$ emissions, relative to conventional fossil fuels. 
TABLE 3.1

U.S. renewable energy consumption by categories in 2010

In Q-BTUs

\begin{tabular}{|c|c|c|}
\hline & Q-BTUs & Percent of total \\
\hline Renewable energy (all sources) & 7.93 & 100.0 \\
\hline Biomass and biofuels (all sources) & 4.25 & 53.6 \\
\hline Biomass (industry) & 1.31 & 16.5 \\
\hline Biomass (electricity) & 0.19 & 2.4 \\
\hline Biofuels (heat and co-products) & 0.84 & 10.6 \\
\hline Ethanol (blending) & 1.10 & 13.9 \\
\hline Ethanol (E85) & 0.00 & 0.0 \\
\hline Biodiesel used in distillate blending & 0.03 & 0.4 \\
\hline Biofuels (wood) & 0.42 & 5.3 \\
\hline Biomass (commercial) & 0.11 & 1.4 \\
\hline Liquids from biomass & 0.00 & 0.0 \\
\hline Municipal waste (industry and electricity) & 0.25 & 3.2 \\
\hline Hydroelectric (all sources) & 2.51 & 31.7 \\
\hline Hydroelectric (electricity) & 2.49 & 31.4 \\
\hline Hydro (industry) & 0.02 & 0.03 \\
\hline Wind & 0.92 & 11.6 \\
\hline Geothermal & 0.16 & 2.0 \\
\hline Solar (all sources) & 0.06 & 0.8 \\
\hline Solar (thermal electric marketed) & 0.01 & 0.1 \\
\hline Solar (nonmarketed) & 0.05 & 0.6 \\
\hline Solar (photovoltaic marketed) & 0.00 & 0.0 \\
\hline Solar (photovoltaic nonmarketed) & 0.01 & 0.1 \\
\hline
\end{tabular}

Source: Energy Information Administration, Annual Energy Outlook 2012 (U.S. Department of Energy, 2012), table A17.

Hydropower for electricity is the largest single source of renewable energy as of 2010. Hydroelectricity produced 2.49 Q-BTUs in 2010, which amounted to slightly less than one-third of all renewable energy that year. In addition, hydroelectricity for industry produced a modest additional amount. 
Bioenergy sources and hydroelectricity combined accounted for 85 percent of all renewable energy in 2010. Put another way, wind, geothermal, and solar power in total accounted for only 15 percent of total renewable energy. Given that renewable energy overall contributed 8 percent to total energy supply in 2010, this means that wind, geothermal, and solar power accounted for just more than 1 percent of all U.S. energy supply in 2010. Of these three sources, wind is the largest contributor, having supplied 0.92 Q-BTUs in 2010. Geothermal produced about 0.16 Q-BTUs, roughly at the level of biomass electricity. The contribution of solar power in 2010 was negligible: From all solar sources, including both thermal and photovoltaic power generation and both marketed and nonmarketed distribution, total supply was $0.06 \mathrm{Q}-\mathrm{BTUs}$.

In its Reference case forecasts, the EIA estimates that the production of renewable energy will expand substantially over the next 20 to 25 years. We present the detailed figures for those Reference case projections in Table 3.2, with the forecast for 2030, and Table 3.3, with the 2035 forecast, as published in the EIA's 2012 edition of its "Annual Energy Outlook." As seen in Table 3.2, the EIA projects that total renewable supply will be at 13.25 Q-BTUs in 2030, which is a 67 percent increase from the 2010 level. Within that overall growth trajectory, the EIA estimates that biomass and biofuels will expand significantly more rapidly than the renewable sector overall, at around 86 percent. This means that bioenergy will supply almost 60 percent of total renewable energy in 2030. 
TABLE 3.2

EIA Reference case projection of 2030 U.S. renewable energy consumption In Q-BTUs

\begin{tabular}{|c|c|c|c|}
\hline & \multicolumn{2}{|c|}{2030 projections } & \multirow{2}{*}{$\begin{array}{l}\text { Projected change } \\
\text { from } 2010 \text { through } \\
2030 \text { (percent) }\end{array}$} \\
\hline & Q-BTUs & $\begin{array}{l}\text { Percent } \\
\text { of total }\end{array}$ & \\
\hline Renewable energy (all sources) & 13.25 & 100 & +67.1 \\
\hline Biomass and biofuels (all sources) & 7.90 & 59.6 & 85.9 \\
\hline Biomass (industry) & 1.68 & 12.7 & 28.2 \\
\hline Biomass (electricity) & 0.64 & 4.8 & 236.8 \\
\hline Biofuels (heat and co-products) & 1.92 & 14.5 & 128.6 \\
\hline Ethanol (blending) & 1.35 & 10.2 & 22.7 \\
\hline Biodiesel used in distillate blending & 0.25 & 1.9 & 733.3 \\
\hline Ethanol (E85) & 0.47 & 3.5 & N/A \\
\hline Biofuels (wood) & 0.43 & 3.2 & 2.4 \\
\hline Biomass (commercial) & 0.11 & 0.8 & 0.0 \\
\hline Liquids from biomass & 0.78 & 5.9 & N/A \\
\hline Municipal waste (industry and electricity) & 0.27 & 2.0 & 8.0 \\
\hline Hydroelectric (all sources) & 3.02 & 22.8 & 20.3 \\
\hline Hydroelectric (electricity) & 3.00 & 22.6 & 20.5 \\
\hline Hydro (industry) & 0.02 & 0.2 & 0.0 \\
\hline Wind & 1.67 & 12.6 & 81.5 \\
\hline Geothermal & 0.41 & 3.1 & 156.3 \\
\hline Solar (all sources) & 0.22 & 1.7 & 266.7 \\
\hline Solar (thermal electric marketed) & 0.03 & 0.2 & 200 \\
\hline Solar (nonmarketed) & 0.13 & 1.0 & 160 \\
\hline Solar (photovoltaic marketed) & 0.06 & 0.5 & N/A \\
\hline Solar (photovoltaic nonmarketed) & 0.07 & 0.5 & 600 \\
\hline
\end{tabular}

Source: Energy Information Administration, Annual Energy Outlook 2012 (U.S. Department of Energy, 2012), table A17.

The EIA estimates that hydroelectric power will grow by a relatively modest 23 percent between 2010 and 2030, supplying 3.02 Q-BTUs of energy in total by 2030. The relative contribution of hydroelectric power to the renewable energy total would thus fall to 20 percent. However, the EIA predicts that hydroelectric will remain the largest single source of renewable energy in 2030. Virtually all of this hydro energy is expected to come from large-scale projects. 
The EIA estimates that the supply of wind, geothermal, and solar power will all increase dramatically between 2010 and 2030—wind by 81 percent, geothermal by 156 percent, and solar from all sources by about 267 percent. Of course, all of these gains are in relation to a very small baseline level in 2010. Solar, for example, is projected to grow from 0.06 to 0.22 Q-BTUs. In other words, even by 2030 the EIA Reference case forecasts that solar will provide only about 1.7 percent of total U.S. renewable energy supply. The EIA estimates the contribution of wind power to be much more substantial, rising to 1.67 Q-BTUs by 2030 . Wind would thus represent about 13 percent of total renewable energy supply by 2030 .

Because the EIA is projecting that renewable energy supply will experience an expansion through 2030, it is useful to consider the extent to which it sees this trend continuing through 2035 as well. As we see with the EIA's Reference case forecasts for 2035, the EIA does indeed estimate that strong growth of renewables will continue through 2035. (see Table 3.3) The EIA forecasts that the supply of renewable energy will grow by nearly 15 percent over the five-year period from 2030 to 2035 alone. For the overall 2010 to 2035 period, the EIA estimates renewable supply expanding by 92 percent. It sees the areas for the most rapid relative increases being biodiesel fuel, solar, biofuels for heat and coproducts, and geothermal. 
TABLE 3.3

EIA Reference case projection of 2035 U.S. renewable energy consumption

In Q-BTUs

\begin{tabular}{|c|c|c|c|c|}
\hline & \multicolumn{2}{|c|}{2035 projections } & \multicolumn{2}{|c|}{ Projected rate of change } \\
\hline & Q-BTUs & $\begin{array}{l}\text { Percent } \\
\text { of total }\end{array}$ & $\begin{array}{c}\text { Percent change } \\
\text { from } 2010 \\
\text { through } 2035\end{array}$ & $\begin{array}{c}\text { Percent change } \\
\text { from } 2030 \\
\text { through } 2035\end{array}$ \\
\hline Renewable energy (all sources) & 15.2 & 100 & 91.7 & 14.7 \\
\hline Biomass and biofuels (all sources) & 9.41 & 61.9 & 121.4 & 19.1 \\
\hline Biomass (industry) & 1.76 & 11.6 & 34.4 & 4.8 \\
\hline Biomass (electricity) & 0.56 & 3.7 & 194.7 & -12.5 \\
\hline Biofuels (heat and co-products) & 2.57 & 16.9 & 206 & 33.9 \\
\hline Ethanol (blending) & 1.34 & 8.8 & 21.8 & -0.7 \\
\hline Biodiesel used in distillate blending & 0.26 & 1.7 & 766.7 & 4.0 \\
\hline Ethanol (E85) & 0.80 & 5.3 & $\mathrm{~N} / \mathrm{A}$ & 70.2 \\
\hline Biofuels (wood) & 0.43 & 2.8 & 2.4 & 0.0 \\
\hline Biomass (commercial) & 0.11 & 0.7 & 0.0 & 0.0 \\
\hline Liquids from biomass & 1.31 & 8.6 & N/A & 67.9 \\
\hline Municipal waste (industry and electricity) & 0.27 & 1.8 & 8.0 & 0.0 \\
\hline Hydroelectric (all sources) & 3.05 & 20.1 & 21.5 & 1.0 \\
\hline Hydroelectric (electricity) & 3.03 & 19.9 & 21.7 & 1.0 \\
\hline Hydro (industry) & 0.02 & 0.2 & 0.0 & 0.0 \\
\hline Wind & 1.87 & 12.3 & 103.3 & 12 \\
\hline Geothermal & 0.48 & 3.2 & 200 & 17.1 \\
\hline Solar (all sources) & 0.36 & 2.4 & 500 & 63.6 \\
\hline Solar (thermal electric marketed) & 0.03 & 0.2 & 200 & 0.0 \\
\hline Solar (nonmarketed) & 0.13 & 0.9 & 160 & 0.0 \\
\hline Solar (photovoltaic marketed) & 0.20 & 1.3 & $\mathrm{~N} / \mathrm{A}$ & 233.3 \\
\hline Solar (photovoltaic nonmarketed) & 0.07 & 0.5 & 600 & 0.0 \\
\hline
\end{tabular}


In terms of percentages, the EIA projects that by 2035, biofuels and biomass will constitute nearly 62 percent of all renewable energy, roughly the same as its 2030 projection. Hydroelectric will account for 20 percent, with wind at 12.3 percent, geothermal at 3.2 percent, and all sources of solar at 2.4 percent. In short, even as of 2035, the EIA estimates that solar will be a small source of overall renewable energy supply, which of course means a still smaller source of overall energy supply. This is in contrast with wind power, which the EIA projects as becoming a significant source of renewable power by 2035 . 


\section{EIA's low-cost renewable energy forecast}

In addition to its Reference case estimates, the EIA also generates alternative sets of forecasts. In these alternative scenarios, the assumptions as to the rate of improvement in technologies, relative prices, and the policy environment are made to vary significantly relative to the EIA's Reference case. For the purposes of this current section on renewable energy, we are particularly interested in the EIA's Low-Cost Renewable Technology case.

In the Low-Cost Renewable Technology case, the EIA focuses on technological improvements for wind, biomass, geothermal, and solar technologies. It assumes no technological improvements for either hydroelectric or landfill-based renewable technologies.

In the 2012 edition of its "Annual Energy Outlook," the EIA provides projections of its Low-Cost Renewable Technology case for the years 2015, 2025, and 2035. Our own focus in this study has been mainly organized around 2030 as the target year for reducing $\mathrm{CO}_{2}$ emissions. But because the EIA does not include a Low-Cost Renewable Technology case for 2030, we will instead work with the findings that it presents for 2035 .

Of course, making assumptions as to the impact of technological change on costs and production levels for renewable energy inevitably entails guesswork, even when researchers, such as those at the EIA, operate with carefully developed modeling methods. This becomes clear from examining the assumptions guiding the EIA's Low-Cost Renewable Technology case. Thus, in its 2010 "Annual Energy Outlook," the EIA assumes that renewable energy technologies in the specified areas will be able to reduce the overall costs of energy produced by 25 percent. ${ }^{1}$ But in the 2011 and 2012 editions of the "Annual Energy Outlook," the EIA assumes that the costs of wind, solar, geothermal, and biomass technologies will fall by 40 percent relative to the Reference case. ${ }^{2}$ Despite this large difference in the 2011 and 2012 EIA projections relative to 2010, in both the 2010 and the 2011/2012 pricing scenarios, the EIA still assumes that the renewable electricity supply will increase by between 30 percent and 36 percent in relation to its 2035 Reference case. 
Alternatively, it would be reasonable to expect that if the costs of renewable energy electricity generation could fall by 40 percent rather than 25 percent, we would also see a significantly larger increase in the supply of renewable energy. Yet this is not the place to examine in depth the underlying mechanisms from which the EIA generated these results for 2035. For our purposes, we will simply work with its overarching conclusion-that cost-saving technological improvements in the renewable sector, in the range of between 25 percent and 40 percent in cost savings, are capable of increasing overall renewable electricity supply by up to 36 percent.

Moreover, because the EIA is projecting that roughly 90 percent of all renewable power will be delivered in the form of electricity in 2035, we can roughly extrapolate that the gains in renewable electricity supply from technological gains will apply to the entire renewable sector, including the remaining 10 percent of the sector that supplies energy through direct end-use energy, such as combined heat and power plants. ${ }^{3}$ Given the EIA's Reference case projection that overall renewable energy supply will be 15.2 Q-BTUs in 2035, it is reasonable to expect that if costs fall as the EIA describes in its Low-Cost Renewable Technology case, then overall renewable energy supply in 2035 could rise by about 36 percent, to around 21 Q-BTUs. 


\section{Alternative projections for U.S. renewable energy production}

The EIA estimates for renewable energy in the range of 13 Q-BTUs for the 2030 Reference case, 15 Q-BTUs in the 2035 Reference case, and 21 Q-BTUs in 2035 under the Low-Cost Renewable Technology case are fairly consistent with other studies on this issue.

Three other studies that have projected renewable energy supply and costs into the future are those of the National Academy of Sciences (2009a), Google (2008), and the American Council on Renewable Energy (2007). The main estimates for these three other studies are shown in Table 3.4.

TABLE 3.4

Alternative estimates for renewable energy generation

\begin{tabular}{|c|c|c|c|}
\hline & $\begin{array}{l}\text { Sectors included in } \\
\text { estimate }\end{array}$ & Scenario & $\begin{array}{c}\text { Total Q-BTUs } \\
\text { of renewable energy }\end{array}$ \\
\hline $\begin{array}{l}\text { U.S. Energy Information } \\
\text { Administration (2012a) }\end{array}$ & $\begin{array}{l}\text { Electricity; transporta- } \\
\text { tion; buildings; industrial } \\
\text { (includes heating and cool- } \\
\text { ing and industrial processes) }\end{array}$ & 2035 Reference case & $\begin{array}{l}15.20 \text { (all renewable uses); } \\
6.22 \text { (electricity only) }\end{array}$ \\
\hline $\begin{array}{l}\text { National Academy } \\
\text { of Sciences (2009a) }\end{array}$ & Electricity only & $\begin{array}{l}20 \text { percent non-hydro } \\
\text { renewable electricity by } \\
2035 \text { plus current levels } \\
\text { of hydropower }\end{array}$ & 6.66 (electricity only) \\
\hline Google (2008) & Electricity only & $\begin{array}{l}\text { In combination with efficiency } \\
\text { gains, replaces all coal and oil } \\
\text { and half of natural gas in } \\
\text { electricity by } 2030\end{array}$ & 12.23 \\
\hline $\begin{array}{l}\text { American Council On } \\
\text { Renewable Energy (2007) }\end{array}$ & Electricity only & $\begin{array}{l}25 \text { percent renewable } \\
\text { energy by } 2025\end{array}$ & 14.75 \\
\hline
\end{tabular}


At the low end, the National Academy estimate is 6.66 Q-BTUs of renewable electricity by 2035, which is very close to the EIA's 2035 Reference case of 6.2 Q-BTUs for electricity generation only-in the EIA case, the remaining 8.98 Q-BTUs of the 15.2 Q-BTU total is for nonelectricity uses. The estimates of Google and ACORE are also for electricity only. As shown in Table 3.4, these are both roughly double EIA's electricity-only estimate for 2035. That is, Google's figure is 12.23 Q-BTUs of renewable electricity by 2030, while ACORE projects that 14.75 Q-BTUs of renewable electricity will be attainable by 2025 . Overall, we can see from Table 3.4 that the EIA's Reference case presents a mid-range figure among these alternative estimates.

It will also be useful to consider other perspectives as well, including those that are not presented in the form of full quantitative forecasts of future renewable energy consumption. On the one hand, there is a growing optimism among a wide range of investors and analysts within the renewable energy industry over the fact that costs are coming down and, as a result, production is expanding at a rapidly accelerating rate. For example, the "2012 Clean Energy Trends" report from Clean Edge reads as follows:

Solar photovoltaics ... increased from $\$ 71.2$ billion in 2010 to a record $\$ 91.6$ billion in 2011. We project the market to continue to expand to $\$ 130.5$ billion by 2021. These market numbers, while impressive, do not fully capture the extent of actual industry expansion. While market revenues were up 29 percent, installations climbed more than 69 percent from $15.6 \mathrm{GW}$ in 2010 to more than $26 \mathrm{GW}$ worldwide last year. This reflects a more than 40 percent decline in crystalline module prices between 2010 and 2011. Between now and 2021 we project that installed costs for $P V$ will continue to decline, falling to nearly onethird of their current levels. ${ }^{4}$

Similarly, a 2013 article from Renew Economy titled "Unsubsidized Solar Revolution Starting, UBS Reports," argues that:

The revolution in energy markets caused by the growing impact of rooftop solar $P V$ is about to take a dramatic leap in scale. According to analysts from the global investment banking giant UBS, the arrival of socket parity - where the cost of installing solar is cheaper than grid-sourced supplies-is about to cause a boom in unsubsidized solar installation in Europe, and the energy market may never be quite the same again. ${ }^{5}$ 
These figures and observations do indeed provide grounds for greater optimism than are conveyed by the EIA's estimates. Yet it is difficult to extrapolate a longterm trend from these recent patterns because the baseline levels of costs, especially for solar, are relatively high and the scale of production has been so modest. Bringing renewables up to scale faces significant challenges. These less favorable considerations are emphasized by, among others, Professor Kerry Emanuel, a leading climate scientist at MIT. Emanuel writes as follows:

There are three issues with solar and wind that make them either impracticable or somewhat less attractive than alternatives. The first is simply cost ... Onshore wind is in the ballpark of other energy costs, but offshore is expensive, as is solar. The second issue is reliability. Both solar and wind are intermittent sources that must be supplemented with other sources, absent efficient storage. Finally, in the case of wind, there is not enough of it. The rate at which the earth system naturally dissipates wind energy is only a factor of ten larger than global electrical power consumption, and accounting for efficiency of wind to power conversion, were the world to try to produce most of its energy from wind there would be serious consequences for climate. And this would not allow any growth in energy consumption. ${ }^{6}$

Due to these considerations, Emanuel concludes that wind and solar power have "limited potential and high costs," and that these "prevent them from meeting more than a small part of our energy needs."

Given these sharply divergent perspectives from a range of serious analysts and industry observers, we conclude that a prudent approach to move forward with our own analysis is to continue to focus our analysis around the mid-range perspectives advanced by the EIA. 


\section{Advancing clean renewables}

Assuming that the EIA's projections of renewable energy supply and prices as of 2030 and 2035 are broadly reliable, we can then conclude that generating between 15 and 20 Q-BTUs of affordable renewable energy is a realistic prospect. This is especially the case within the framework of the EIA's Low-Cost Renewable Technology case. In that scenario, total renewable costs will fall for most technologies by 40 percent relative to the EIA's 2035 Reference case, and supply will increase overall by 36 percent, to about 21 Q-BTUs.

However, we need to consider this finding further with respect to the most basic purpose of reducing $\mathrm{CO}_{2}$ emissions to no more than $3,200 \mathrm{mmt}$ by 2030 . As we saw with the 2035 Reference case and Low-Cost Renewable Technology case, roughly two-thirds of the projected renewable energy supplied by 2035 will come from biofuels and biomass. Some of these energy sources provide only modest, if any, gains in reducing $\mathrm{CO}_{2}$ emissions relative to burning fossil fuels. It therefore becomes crucial to consider the extent to which the expansion of renewables overall can be based specifically on clean renewable sources. This entails examining the prospects for expanding the supply of: the cleanest biofuels and biomass sources; small-scale hydro projects; and wind, solar, and geothermal power, as the EIA has proposed under its Low-Cost Renewable Technology case.

\section{Clean bioenergy}

The term "biomass," as described by the Environmental Protection Agency, is defined as:

... many different fuel types from such sources as trees, construction, wood, and agricultural wastes; fuel crops; sewage sludge; and manure. Agricultural wastes include materials such as corn husks, rice hulls, peanut shells, grass clippings, and leaves. ${ }^{8}$ 
Biomass can be converted into energy in solid, liquid, or gas form. A biomass energy source converted into liquid form is a biofuel.

Based on the feedstock used and the refining technology, biomass and biofuel energy sources vary greatly in their emission levels. We see this in Table 3.5 with respect to biofuels. The table reports the level of greenhouse gas emissions for five types of ethanol, as well as one biodiesel energy source, relative to emissions from gasoline or diesel fuel used in $2005 .^{9}$

TABLE 3.5

Greenhouse gas emissions reductions for alternative biofuels and biomass energy sources

Percentage change in emissions levels of biofuels versus gasoline or diesel fuel over 30-year cycle

\footnotetext{
Lifecycle analysis of greenhouse gas emissions from renewable fuels

Corn ethanol (refined through coal-fired processing) $\quad+34 \%$

Corn ethanol (refined through biomass-fired processing with $\quad-26 \%$ combined heat and power)

Sugarcane ethanol

$-26 \%$

Waste-grease biodiesel

$-80 \%$

Corn stover ethanol

$-116 \%$

Switchgrass ethanol

$-124 \%$

Source: U.S. Environmental Protection Agency, 2009, May. "EPA Lifecycle Analysis of Greenhouse Gas Emissions from Renewable Fuels," Office of Transportation and Air Quality. EPA-420-F-09-024. Retrieved from: http://nepis.epa.gov/Exe/ZyPURL.cgi?Dockey=P100B3F8.txt

Starting with corn ethanol refined through coal firing, we see that over a 30 -year cycle, the overall level of greenhouse gas emissions - incorporating all stages in production from growing crops, refining, and burning the fuel to generate energy-actually is 34 percent higher relative to burning gasoline. But corn ethanol can also produce lower emission levels than gasoline if it is refined through a biomass-fired refining process. Even in this case, however, the emissions reductions compared with gasoline are relatively modest, at about 26 percent over a 30 -year cycle. The emissions reductions are also about 26 percent lower than gasoline when burning sugarcane-based ethanol.
} 
As is clear from Table 3.5, the way to achieve major emissions reductions is by burning waste-grease biodiesel fuel, corn stover, or switchgrass-based ethanol. With either waste grease or corn stover, there are no production costs, including energy consumption, required to supply the bioenergy raw material. With switchgrass as the raw material, the production costs-including energy consumptionare minimal. Even when including the refining and energy-generating processes, the EPA study finds that, netting out everything, these fuel sources achieve reduced emission levels.

More generally, according to the Union of Concerned Scientists (2010), bioenergy sources can be considered part of the terrestrial carbon cycle-the balanced cycling of carbon from the atmosphere into plants and then into soils and the atmosphere during plant decay. When bioenergy is developed properly, emissions of biomass carbon are taken up or recycled by subsequent plant growth within a relatively short time, resulting in low net carbon emissions. As such, the Union of Concerned Scientists includes the following as clean—or what it terms "beneficial"-biomass resources:

1. Energy crops that do not compete with food crops for land

2. Portions of crop residues such as wheat straw or corn stover

3. Sustainably harvested wood and forest residues

4. Clean municipal and industrial wastes

The Union of Concerned Scientists contrasts these with "harmful biomass resources and practices," which include clearing forests, savannas, or grasslands to grow energy crops and displacing food production for bioenergy production that ultimately leads to the clearing of carbon-rich ecosystems elsewhere to grow food. It writes that "harmful biomass adds net carbon to the atmosphere by either directly or indirectly decreasing the overall amount of carbon stored in plants and soils." 
At present, as mentioned above, the proportion of bioenergy generated through clean processes in the United States is negligible. But the potential is high for a major expansion in these energy sources. A 2009 study by the National Academy of Sciences estimated that by 2020,550 tons of biomass could be sustainably harvested to produce cellulosic and other advanced biofuels, or bioenergy exclusive of that derived from corn ethanol or other heavy carbon-emitting sources. This study further estimates that this supply of biomass could produce 45 billion gallons of ethanol, which translates into 6.4 Q-BTUs of energy from "clean" biofuels. ${ }^{10}$

This NAS study emphasizes that its estimate of 550 tons/6.4 Q-BTUs of biomass and biofuels supply could also vary up or down, depending on circumstances. It writes:

The panel presented a scenario in which 550 million dry tons of cellulosic feedstock can be harvested or produced sustainably in 2020. Its estimates are not predictions of what would be available for fuel production in 2020. The actual supplies of biomass could exceed the panel's estimates if existing croplands are used more efficiently or if genetic improvement of dedicated fuel crops exceeds the panel's estimate. In contrast, the panel's estimates could be lower if producers decide not to harvest agricultural residues or not to grow dedicated fuel crops on their Conservation Reservation Program land.

Given that as of 2008, the National Academy of Sciences study concluded that the United States could produce approximately 6.4 Q-BTUs of clean biomass and biofuels by 2020, it is reasonable — conservative even - for us to assume that we could reach that 6.4 Q-BTUs goal at least by 2030 through an appropriate set of supportive policies.

\section{Bioenergy and food prices}

One major concern raised about a rapid expansion of biofuels production is that it will raise food prices, which could then produce an adverse impact on low-income and poor families, both in the United States and globally.

As we have discussed, the manufacturing of biofuels uses agricultural products as basic inputs, and large increases in the production of biofuels will increase the demand for agricultural output. The potential problem is that this rapid growth in demand will translate into higher prices for food. ${ }^{11}$ The possibility that biofuels would raise food prices became a growing concern with the increase in global 
agricultural prices, which began around 2004. The most intense period of the global Great Recession, from the second half of 2008 through 2009, interrupted the upward trend in food prices. But by 2011 the prices of many food commodities had rebounded to around their pre-crisis peaks. ${ }^{12}$

This was also a period in which production of biofuels surged. World biofuel production grew five-fold between 2001 and 2011, with the most rapid increases occurring in 2007 and 2008 - the peak of the food-price rise. ${ }^{13}$ The fact that the growth in biofuels production corresponded with the increase in agricultural commodity prices raised questions of whether biofuels were responsible for the high food prices. However, the precise nature of the link between biofuel production and food prices remains unsettled. Many factors contributed to the increase in food prices over this period, and the growing supply of biofuels may not have been the most important. ${ }^{14}$ Other considerations include the large-scale entry of financial investors into commodity futures markets and shocks to agricultural production from droughts and other extreme weather. ${ }^{15}$

During the period in which food prices soared, other commodity prices experienced similar increases, including those having little connection to biofuels, such as metals. This suggests that a common factor that operates across diverse markets was behind the price increases - for example, speculative investment in a range of commodity futures. ${ }^{16}$ Biofuels production does not fit this description. A study of commodity price increases over this period by World Bank researchers concludes that the expansion of biofuels played a modest role in raising food prices, but other factors were more significant. ${ }^{17}$ This same report notes that biofuels account for only about 1.5 percent of the agricultural area under grains/oilseeds cultivation. Other studies find little evidence of a connection between biofuel production and the increases in food prices over this period. ${ }^{18}$ To the extent that there is an emerging consensus among researchers on this question, it appears to be that the expansion of biofuels had some impact on food prices, but that other factors exerted greater influence in explaining the kind of price increases experienced from 2004 to 2008.

It is also important to recognize that until this point in time, the growth of biofuels production has largely been a response to high prices of gasoline, not to issues of sustainability and climate change. ${ }^{19}$ Increased biofuels production reduced the cost of gasoline. ${ }^{20}$ Ironically, the growth in biofuels likely reinforced the use of fossil fuels by keeping gasoline prices low and thereby reducing incentives to develop cleaner alternatives. 
New biofuel technologies have the potential to both reduce the threat of climate change and address concerns over food security. As we have discussed, cellulosic biofuels produced from corn stover, switchgrass, or waste grease are not direct substitutes for food commodities and would help improve food security. ${ }^{21}$ What is needed is a new approach to biofuels policy-one that jointly emphasizes environmental sustainability and food security. This more comprehensive approach would include land-use policy, support for developing new technologies, research to raise agricultural yields, and strategies for confronting the primary threats to food security. ${ }^{22}$

Food price increases have been associated with extreme weather events and climate change, and this has the potential to emerge as a significant contributor to food insecurity and rising food prices in the future. ${ }^{23}$ Strategies that aim to stabilize food prices and improve food security must therefore focus on reducing greenhouse gas emissions and directly addressing climate change. Switching to clean biofuels technologies is a central part of an overall strategy to reduce emissions and, because of this, a well-designed biofuels policy will enhance-not undermine-food security over the long run.

\section{Prospects for expanding hydro-power supply}

As we have noted above, hydroelectric power is the largest single source of renewable energy within the U.S. economy, providing 2.51 Q-BTUs of energy in 2010. The EIA Reference case projects hydro supply will rise by about 22 percent by 2035, to 3.05 Q-BTUs. This power is generated almost entirely by large-scale hydroelectric dams, with electricity-generating capacity at 100,000 megawatts or more. There is virtually no potential for expanding large-scale hydro capacity beyond this EIA Reference case projection because, as noted above, the most favorable sites in the United States for constructing large-scale dams are already built out and operating at capacity. There are likely to be serious environmental issues connected with additional largescale dam construction in terms of disrupting existing communities and ecosystems.

Under the EIA's Low-Cost Renewable Technology case for 2035, the EIA does not forecast any significant declines in costs or increases in the supply of hydro power relative to its Reference case. This is in contrast with its projections for all other renewable energy sources, where the EIA estimates costs falling by 40 percent virtually across the board and energy supply expanding by about 36 percent overall relative to its 2035 Reference case. 
Despite this, it is still realistic to anticipate that hydro-power capacity could expand significantly if the United States were to begin developing the country's abundant small-scale hydro-power sites. Small-scale hydro projects are defined as having a generating capacity of 30 megawatts or less per site. Crucially, these sites operate without requiring the construction of a dam or reservoir. As described in a 2006 study by the Idaho National Laboratory for the U.S. Department of Energy, small-scale hydro projects operate as follows:

The development model included a penstock ${ }^{24}$ running parallel to the stream, culminating in a powerhouse whose tailwater returned the working flow to the stream. ... The working flow was restricted to half the stream flow rate at the site or sufficient to produce $30 \mathrm{MW}$, whichever was less. Penstock lengths were limited by the lengths of penstocks of a majority of existing low power or small hydroelectric plants in the region. ${ }^{25}$

Kosnik summarizes this case for such small-scale hydro operations more broadly, as follows:

Such small generation facilities have very few of the negative riverine impacts to which larger, more conventional hydropower plants have been prone to. As the main criticism of conventional hydropower development has been the local impact on fishery resources and riverine ecosystems, small scale hydropower presents an alternative, win-win situation: no carbon emissions and a negligible carbon footprint. ${ }^{26}$

The Idaho National Lab study estimated that there are more than 130,000 sites within the United States that could feasibly be used as sites for small-scale hydro plants, with a collective capacity of nearly 100,000 megawatts. This study concluded, however, that after taking account of a range of environmental, technological, and cost concerns, only about 5,400 of these sites could be realistically developed as small hydro plants, generating about 18,000 megawatts of electricitygenerating capacity. But even expanding small-scale hydro to this extent would represent a 50 percent increase in total hydropower generating capacity within the United States.

The 2010 study by Kosnik estimates that the realistic potential for small-scale hydro is still less, after carefully factoring in the costs of constructing these smallscale plants. Kosnik concludes as follows: 
Small scale hydropower is subject to nonlinear economies of scale so that tiny ("mini" or "micro") hydropower projects should probably remain undeveloped, given current technologies... While the average construction costs of small scale hydropower are relatively high, there remains hundreds of sites on the low end of the cost side ... that are cost effective to construct right now.

Kosnik thus reduces the estimate of overall realistic generating capacity for the near-term to about 13,000 megawatts - that is, about 30 percent lower than the Idaho National Lab estimate of 18,000 megawatts. If Kosnik's lower estimate is roughly accurate, that suggests that the total hydro capacity-including both large- and small-scale projects - would still have the potential to expand by about 36 percent, which is the same range of capacity expansion that the EIA is projecting for overall renewable resources under its 2035 Low-Cost Renewable Technology case. This would further imply that overall hydro supply within the United States could increase to around 4.15 Q-BTUs, or about 36 percent more than EIA's 2035 Reference case of 3.05 Q-BTUs.

\section{Wind, solar, and geothermal energy}

We have seen above that under the EIA's Low-Cost Renewable Technology case for 2035, the EIA is projecting significant increases in the supply of wind and especially solar photovoltaic power relative to its 2035 Reference case. We can use the EIA's estimates of the supply increases for these renewable sources to calculate the projected level of energy supplied by 2035 for these two renewable sources. (see Table 3.6)

TABLE 3.6

2035 projections for wind, solar, and geothermal energy supply on EIA Low-Cost Renewable Technology case

\begin{tabular}{|c|c|c|c|}
\hline & $\begin{array}{l}\text { 1. EIA } 2035 \\
\text { Reference case } \\
\text { Q-BTUs }\end{array}$ & $\begin{array}{l}\text { 2. } 2035 \text { electricity supply } \\
\text { increase under EIA Low } \\
\text { Renewable Technology } \\
\text { Cost case (percent) }\end{array}$ & $\begin{array}{c}\text { 3. } 2035 \text { Q-BTUs under EIA } \\
\text { Low Renewable Technology } \\
\text { Cost case } \\
\text { (column } 1 \times(1+\text { column } 2 / 100\end{array}$ \\
\hline Wind & 1.87 & +62.9 & 3.05 \\
\hline Geothermal & 0.48 & +9.3 & 0.52 \\
\hline $\begin{array}{l}\text { Solar } \\
\text { photovoltaic }\end{array}$ & 0.27 & +316.2 & 1.12 \\
\hline Solar thermal & 0.16 & 0 & 0.16 \\
\hline Total & 2.78 & $\mathrm{~N} / \mathrm{A}$ & 4.85 \\
\hline
\end{tabular}

Source: Energy Information Administration, Annual Energy Outlook 2012 (U.S. Department of Energy, 2012), tables A17 and D8. 
As the table shows, under the EIA Low-Cost Renewable Technology for 2035, wind power supply would increase to 3.05 Q-BTUs, a 62.9 percent increase. The largest percentage increase is solar photovoltaic supply, which the EIA projects as rising by 316 percent under its Low-Cost Renewable Technology case. An increase of this magnitude would bring solar photovoltaic supply to 1.12 Q-BTUs by 2035 .

As shown in Table 3.6, the total 2035 energy supplied from wind, solar, and geothermal power under the EIA's Low-Cost Renewable Technology case is 4.85 Q-BTUs. This is a 74 percent increase over the EIA's 2035 Reference case of 2.78 Q-BTUs. This increased supply of wind, solar, and geothermal power will make an important contribution toward the United States reaching the target of a total of about 15 Q-BTUs of clean renewable energy supply by 2030 to 2035.

\section{Clean renewable energy supply projections}

In reviewing the projections for 2030 to 2035 for clean biofuels and biomass, small-scale hydro, and wind, solar, and geothermal power under the EIA's Low-Cost Renewable Technology case, we can conclude that with an ambitious approach to deployment focused on reducing the costs of clean renewable energy, it is reasonable to anticipate that the total supply of clean renewables could realistically reach roughly 15 Q-BTUs by between 2030 and 2035. The main findings of this foregoing discussion are summarized in Table 3.7. As this table shows, the overall clean renewable supply that results from the projections we summarized above is 15.4 Q-BTUs. Moreover, within a framework of policy initiatives focused on promoting clean renewables, this estimated level of supply can be considered fairly conservative.

TABLE 3.7

Summary of clean renewable supply potential from 2030 through 2035

\begin{tabular}{lc}
\hline Renewable energy source & Q-BTUs \\
\hline Clean biofuels and biomass & 6.4 \\
Total hydro, including small-scale projects & 4.1 \\
Total wind & 3.1 \\
Solar photovoltaic & 1.1 \\
Solar thermal & 0.2 \\
Geothermal & 0.5 \\
Total & 15.4
\end{tabular}

Source: Figures derived from discussions in text. 
In the area of biomass and biofuels supply, for example, our estimate of 6.4 Q-BTUs supplied by 2030 is based on the National Academy of Sciences projection of what is possible as of 2020, not 2030. With respect to small-scale hydro projects, we worked from conservative assumptions from the Idaho National Lab study and the 2010 Kosnik research paper as to the prospects for building out small-scale hydro over the next 20 years. As is made clear in both the Idaho lab and Kosnik studies, small-scale hydro projects could expand beyond what we have projected if construction costs from such projects could be reduced.

While our estimates for wind, solar, and geothermal are all derived from the EIA's relatively optimistic scenario - the Low-Cost Renewable Technology case-the cost reductions and supply increases in this optimistic projection are not outside of recent actual experience, especially with regard to wind power. Between 2008 and 2010 alone, the actual supply of wind power expanded by 67 percent, from 0.55 to $0.92 \mathrm{Q}-\mathrm{BTU}$. With respect to solar, as we have seen, some industry analysts emphasize that the pattern of rapidly falling costs and increasing supply is likely to accelerate significantly in the near future. Thus, operating within an encouraging policy environment and with economies of scale and scope being attained, there is a good likelihood that technologies could improve more rapidly than the EIA is projecting. This would then create the conditions for the supply of wind, solar, and geothermal power to increase beyond the EIA's relatively optimistic scenario.

Overall, it is reasonable-if still ambitious - to allow that the United States could reach our figure of about 15 Q-BTUs of clean renewable energy production by 2030 , as opposed to 2035 . To understand these prospects more fully, we now consider the issue of costs for renewable energy in some detail. 


\section{Costs of expanding clean renewable energy capacity}

Our basic resource for examining the costs of expanding the supply of clean renewable energy production capacity is the research generated by the EIA titled "Levelized Cost of New Generation Resources in the Annual Energy Outlook," as developed for the 2012 "Annual Energy Outlook." ${ }^{27}$ As explained by the EIA:

Levelized cost is often cited as a convenient summary measure of the overall competiveness of different generating technologies. It represents the per-kilowatt hour cost (in real dollars) of building and operating a generating plant over an assumed financial life and duty cycle. Key inputs to calculating levelized costs include overnight capital costs, fuel costs, fixed and variable operations and maintenance (O\& $M$ ) costs, financing costs, and an assumed utilization rate for each plant type. The importance of the factors varies among the technologies. For technologies such as solar and wind generation that have no fuel costs and relatively small $O \mathrm{H} M$ costs, the levelized cost changes in rough proportion to the estimated overnight capital cost of generation capacity. For technologies with significant fuel cost, both fuel cost and overnight cost estimates significantly affect the levelized cost.

Importantly, the EIA notes in this summary document that its calculations do not attempt to incorporate the impact of costs of any existing or future policy interventions. As such, when policies are established to lower costs, the impact of such interventions should be measured relative to the EIA figures established independent of any new policy interventions.

In Table 3.8, we present the EIA figures of average levelized costs for all renewable energy sources, expressed in billions of dollars per Q-BTU of energy. The figures are estimates for technologies that will be brought into operation in $2017 .{ }^{28} \mathrm{In}$ Table 3.9, we then present the EIA's range of estimates around the average figures shown in Table 3.8. It is important to consider the range of costs with renewable energy sources, since these costs can vary widely depending on where the electricity is being generated. As the EIA writes in its 2012 report, “There is significant 
local variation in costs based on local labor markets and the cost and availability of fuel or energy resources such as windy sites."

Table 3.8 presents average figures from least to most expensive, as of 2017.

Following the EIA's own presentation, we break out overall costs into their component parts, including levelized capital costs, fixed operations and maintenance, or O\&M, costs, variable O\&M costs, including fuel, and transmission investment costs. We also show the EIA's estimate for the average capacity utilization rate for each renewable technology. We report all these figures in terms of both dollars per megawatt hour and billions of dollars per Q-BTU. ${ }^{29}$

TABLE 3.8

\section{Estimated average levelized costs of electricity from renewable energy sources}

Plants entering service in 2017 (in 2010 dollars)

\begin{tabular}{|c|c|c|c|c|c|c|}
\hline \multicolumn{7}{|c|}{ A. In dollars per megawatt hour } \\
\hline & $\begin{array}{l}\text { Levelized } \\
\text { capital } \\
\text { costs }\end{array}$ & $\begin{array}{c}\text { Fixed } \\
\text { operations } \\
\text { and mainte- } \\
\text { nance }\end{array}$ & $\begin{array}{l}\text { Variable op- } \\
\text { erations and } \\
\text { maintenance, } \\
\text { including fuel }\end{array}$ & $\begin{array}{c}\text { Transmission } \\
\text { investment }\end{array}$ & $\begin{array}{l}\text { Capacity } \\
\text { factor } \\
\text { (percent) }\end{array}$ & $\begin{array}{c}\text { Total system } \\
\text { levelized } \\
\text { costs }\end{array}$ \\
\hline Hydro & $\$ 76.9$ & $\$ 4.0$ & $\$ 6.0$ & $\$ 2.1$ & 53 & $\$ 88.9$ \\
\hline Wind & $\$ 82.5$ & $\$ 9.8$ & 0 & $\$ 3.8$ & 33 & $\$ 96.0$ \\
\hline Geothermal & $\$ 75.1$ & $\$ 11.9$ & $\$ 9.6$ & $\$ 1.5$ & 91 & $\$ 98.2$ \\
\hline Biomass & $\$ 56.0$ & $\$ 13.8$ & $\$ 44.3$ & $\$ 1.3$ & 83 & $\$ 115.9$ \\
\hline $\begin{array}{l}\text { Solar } \\
\text { photovoltaic }\end{array}$ & $\$ 140.7$ & $\$ 7.7$ & 0 & $\$ 4.3$ & 25 & $\$ 152.7$ \\
\hline Solar thermal & $\$ 195.6$ & $\$ 40.1$ & 0 & $\$ 6.3$ & 20 & $\$ 242.0$ \\
\hline \multicolumn{7}{|c|}{ B. In billions of dollars per Q-BTUs } \\
\hline & $\begin{array}{l}\text { Levelized } \\
\text { capital } \\
\text { costs }\end{array}$ & $\begin{array}{c}\text { Fixed } \\
\text { operations } \\
\text { and mainte- } \\
\text { nance }\end{array}$ & $\begin{array}{l}\text { Variable op- } \\
\text { erations and } \\
\text { maintenance, } \\
\text { including fuel }\end{array}$ & $\begin{array}{c}\text { Transmission } \\
\text { investment }\end{array}$ & $\begin{array}{l}\text { Capacity } \\
\text { factor } \\
\text { (percent) }\end{array}$ & $\begin{array}{c}\text { Total system } \\
\text { levelized } \\
\text { costs }\end{array}$ \\
\hline Hydro & $\$ 22.5$ & $\$ 1.3$ & $\$ 1.8$ & $\$ 0.6$ & 53 & $\$ 26.1$ \\
\hline Wind & $\$ 24.2$ & $\$ 3.1$ & 0 & $\$ 1.1$ & 33 & $\$ 28.1$ \\
\hline Geothermal & $\$ 22.0$ & $\$ 2.5$ & $\$ 2.8$ & $\$ 0.4$ & 91 & $\$ 27.7$ \\
\hline Biomass & $\$ 16.4$ & $\$ 4.0$ & $\$ 13.0$ & $\$ 0.4$ & 83 & $\$ 33.8$ \\
\hline $\begin{array}{l}\text { Solar } \\
\text { photovoltaic }\end{array}$ & $\$ 41.2$ & $\$ 2.3$ & 0 & $\$ 1.3$ & 25 & $\$ 44.6$ \\
\hline Solar thermal & $\$ 57.3$ & $\$ 11.7$ & 0 & $\$ 1.8$ & 20 & $\$ 70.9$ \\
\hline
\end{tabular}

Source: U.S. Energy Information Administration. 2012b, August. "Assumptions to the Annual Energy Outlook 2012." U.S. Department of Energy. Retrieved from: http://www.eia.gov/forecasts/aeo/assumptions/pdf/0554(2012).pdf. 
As we see, the EIA projects that hydro power will be the least expensive source of renewable energy in 2017 , at $\$ 88.9$ per megawatt hour on average (or $\$ 26.1$ billion per Q-BTU). However, wind and geothermal are close to hydro in average costs, at $\$ 96$ and $\$ 98.2$ dollars per megawatt hour, respectively. This is significant because, unlike hydro, wind and geothermal are only now starting to emerge as significant suppliers of energy.

Biomass is the next-lowest-cost renewable source, at an average cost of $\$ 115.9$ dollars per megawatt hour ( $\$ 33.8$ billion per Q-BTU). The EIA does not distinguish here between clean and dirty biomass sources, but we are only interested in the clean biomass sources for the present discussion. The cost differences between the clean and dirty production techniques should not be large once the scale for clean biomass production starts to expand significantly. In large measure, this is because biomass is unique among renewable sources in that variable costs-in the form of agricultural feedstocks_-account for a major share of overall costs. (see Table 3.8) As such, alone among the renewable energy sources, biomass costs will fluctuate significantly along with the price of oil and agricultural commodities on global markets.

Finally, we see that solar photovoltaics and solar thermal both have much higher average cost figures - at $\$ 152.7$ and $\$ 242$ per megawatt hour, respectively ( $\$ 44.6$ billion and $\$ 70.9$ billion per Q-BTU). As such, within this EIA technological and cost framework, for 2017 at least, these energy sources are not likely to emerge as major new suppliers.

This conclusion is consistent with the energy supply figures we have reviewed above, showing especially that solar energy sources are projected to remain as a modest source of new energy supply over the next 20 years. Of course, we have also cited evidence above emphasizing that average solar costs have fallen sharply in recent years, with projections that this will continue to fall. This could well be the trajectory for the solar industry moving forward. But for the solar industry to grow to become a major source of energy supply over the next 20 years, costs must fall well below those reported in Table 3.8.

One factor that could contribute toward lowering costs of wind and especially solar power is the expansion of small-scale distributed-power systems, as opposed to relying on utility-scale solar or wind-generating transmission through the power grid. This is precisely the prospect being highlighted in the article referenced above on the unsubsidized solar revolution. This article described the development of what it termed "socket parity," in which the cost of generating 
electricity through solar panels is becoming cheaper than electricity produced by utilities and transmitted through the grid. The well-known renewable industry observer Amory Lovins recently emphasized a similar point, writing that:

Momentum is shifting not just from fossil-fueled power plants to renewables but also from centralized to distributed generators. The game changer here is that the means of producing electricity have shifted from slow, gigantic projects-akin to building a cathedral — to scalable, mass-produced, manufactured products. ${ }^{30}$

Within the context of the EIA's levelized cost analysis, however, the cost reductions available through distributed power seem real but relatively modest. The EIA is clear that its estimates apply to utility-scale uses of solar technology, not to distributed power systems. One can obtain a sense of the cost benefits available from distributed power by subtracting the "transmission investment" cost from the total system levelized costs within the EIA's calculations. As we see in Table 3.8, transmission costs are $\$ 4.30$ and $\$ 6.30$, respectively, for solar PV and solar thermal technologies per megawatt hour. These figures represent between 2.5 percent and 3 percent of total levelized costs, as estimated by the EIA. If these figures are accurate, then it would be difficult to see how moving from utility-scale to distributed energy systems will have a major direct impact on costs. At the same time, as Lovins writes, increasing the scale of distributed energy supply could also accelerate the process of scaling up the industry, since the industry's growth would not be inhibited by the need to wait on constructing, as Lovins put it, the cathedral equivalent of new major utility plants.

\section{Range of levelized costs for renewables}

Table 3.9 presents the EIA's estimates of the range of levelized costs in 2017 for the various renewable energy sources. The range in costs is especially high for hydro, solar PV, and solar thermal energy, while the ranges are more narrow for wind, geothermal, and biomass and biofuels. 
Range for total system levelized costs for electricity from renewable energy sources

Plants entering service in 2017 (in 2010 dollars)

\begin{tabular}{lccccc}
\hline & $\begin{array}{c}\text { Minimum } \\
\text { (dollars per } \\
\text { megawatt } \\
\text { hour) }\end{array}$ & $\begin{array}{c}\text { Average } \\
\text { (dollars per } \\
\text { megawatt } \\
\text { hour) }\end{array}$ & $\begin{array}{c}\text { Maximum } \\
\text { (dollars per } \\
\text { megawatt } \\
\text { hour) }\end{array}$ & $\begin{array}{c}\text { Difference between } \\
\text { minimum and maxi- } \\
\text { mum costs (dollars } \\
\text { per megawatt hour) }\end{array}$ & $\begin{array}{c}\text { Minimum-maximum } \\
\text { cost difference as } \\
\text { percentage of } \\
\text { average costs }\end{array}$ \\
\hline Hydro & 57.8 & 88.9 & 146.7 & 88.9 & 100 \\
Wind & 77.0 & 96.0 & 112.2 & 35.2 & 36.7 \\
Geothermal & 84.0 & 98.2 & 112.0 & 28.0 & 28.5 \\
Biomass and biofuels & 97.8 & 115.4 & 136.7 & 38.9 & 33.7 \\
Solar photovoltaic & 119.0 & 152.7 & 238.8 & 119.8 & 78.4
\end{tabular}

Source: U.S. Energy Information Administration. 2012b, August. “Assumptions to the Annual Energy Outlook 2012." U.S. Department of Energy. Retrieved from: http://www.eia.gov/forecasts/aeo/assumptions/pdf/0554(2012).pdf.

With hydro, the minimum cost figure is extremely low, at $\$ 57.80$, but the maximum figure goes up to $\$ 146.70$. (see Table 3.9) This means that hydro is both the lowest-cost renewable energy source and also the one with the widest range of costs. This wide range of hydro costs reflects differences in the strength of currents in rivers and streams, which can result in part from variations in environmental patterns, including rain and snowfall levels and the incidence of droughts. The costs for solar vary widely by region, in addition to being high on average. The cost variation between the minimum and maximum ranges by between 80 percent and 87 percent for PV and thermal technologies, which primarily reflects differences in the intensity of sunlight in various regions of the country.

The overall point that emerges from these figures is that the opportunities for expanding electricity generation from renewable sources vary significantly by region. This is especially true for solar, since levelized costs for generating electricity are both relatively high and range widely. Still, if we allow that costs will fall across the board within the solar sector, as the EIA itself projects in its Low-Cost Renewable Technology case and as many industry analysts emphasize still more strongly, renewable electricity should become increasingly competitive even in the higher-cost regions of the country. We will be able to understand these prospects more clearly through comparing the levelized cost figures for renewables with those of conventional energy sources. This is the issue to which we now turn. 
In Table 3.10, we compare the average total levelized costs, as operations coming online in 2017, of hydro, on-shore wind, and biomass - the three most costeffective renewable energy sources - with the EIA's estimates for the costs of three major nonrenewable energies: coal, natural gas, and nuclear power. In the cases of coal and natural gas, we present the EIA's figures both for conventionally generated supplies, as well as the costs of utilizing carbon capture and sequestration, or CCS, technologies in both cases. Table 3.11 then examines the range of levelized cost estimates for these conventional sources of electricity.

TABLE 3.10

\section{Average levelized costs of renewables versus fossil fuels and nuclear}

Plants entering service in 2017 (in 2010 dollars)

\begin{tabular}{|c|c|c|c|c|c|}
\hline & \multicolumn{2}{|c|}{$\begin{array}{l}\text { Average total system } \\
\text { levelized costs }\end{array}$} & \multirow{2}{*}{$\begin{array}{l}\text { Average costs } \\
\text { relative to hydro } \\
\text { percentages }\end{array}$} & \multirow{2}{*}{$\begin{array}{l}\text { Average costs } \\
\text { relative to wind } \\
\text { percentages }\end{array}$} & \multirow{2}{*}{$\begin{array}{c}\text { Average costs rel- } \\
\text { ative to biomass } \\
\text { percentages }\end{array}$} \\
\hline & $\begin{array}{l}\text { In dollars } \\
\text { per mega- } \\
\text { watt hour }\end{array}$ & $\begin{array}{c}\text { In billions of } \\
\text { dollars per } \\
\text { Q-BTUs }\end{array}$ & & & \\
\hline Conventional coal & $\$ 97.7$ & $\$ 28.6$ & +9.9 & +1.8 & -15.7 \\
\hline $\begin{array}{l}\text { Advanced coal with } \\
\text { carbon capture and } \\
\text { sequestration }\end{array}$ & $\$ 138.8$ & $\$ 40.7$ & +56.1 & +44.6 & +19.8 \\
\hline $\begin{array}{l}\text { Natural gas (conventional } \\
\text { combined cycle) }\end{array}$ & $\$ 66.1$ & $\$ 19.4$ & -25.6 & -45.2 & -43.0 \\
\hline $\begin{array}{l}\text { Natural gas (advanced } \\
\text { combined cycle with } \\
\text { carbon capture and } \\
\text { sequestration) }\end{array}$ & $\$ 90.1$ & $\$ 26.4$ & +1.3 & -6.2 & -22.3 \\
\hline Advanced nuclear & $\$ 111.4$ & $\$ 32.6$ & +25.3 & +15.8 & -4.1 \\
\hline
\end{tabular}

SSource: U.S. Energy Information Administration. 2012b, August. "Assumptions to the Annual Energy Outlook 2012." U.S. Department of Energy. Retrieved from: http://www.eia.gov/forecasts/aeo/assumptions/pdf/0554(2012).pdf.

Before reviewing the figures themselves, we need to recognize that the EIA's estimates on levelized costs with CCS technology are more speculative than with the other technologies, given that at present CCS technology is not operating anywhere in the world at a commercial scale. We discuss these and related issues concerning CCS technology in Chapter 4. 
Nevertheless, it is important to include the EIA's cost estimates for CCS in this current discussion. One reason is that the EIA's figures are meant to apply to 2017, not to present-day electricity-generating operations. These figures are the EIA's best estimate of where costs will be in 2017 using CCS technologies. The significance of these figures is amplified further because President Obama's 2013 Climate Action Plan relies heavily on the assumption that CCS technology will be fully integrated into the operations of coal-fired utility plants over the next decade.

The basic result shown in Table 3.10 is that the EIA estimates that in terms of average costs, hydro, wind, and biomass are all competitive with four of the five nonrenewable energy sources shown - conventional coal, coal with CCS, natural gas with CCS, and nuclear. That is, according to these figures, conventionally produced natural gas is the only nonrenewable energy source included that is consistently less expensive to produce than renewables -25 percent lower than hydro, 31 percent less than wind, and 43 percent less than biomass. The low cost figures for conventional natural gas result from an assumption of growing reliance on hydraulic fracturing technology for extracting natural gas from shale rock deposits. We consider in Chapter 4 the environmental issues around hydraulic fracturing technology.

As of 2010, conventional coal was the most significant source of electricity, generating about 48 percent of total U.S. supply. Nuclear power generated another 21 percent of total supply. In combination, then, conventional coal and nuclear power were responsible for generating nearly 70 percent of all U.S. electricity in 2010 . It is therefore notable that the EIA is projecting that in terms of average costs, hydro, wind, and biomass will all be fully competitive with coal plants operating in 2017. In addition, the EIA is projecting that the average costs for nuclear energy will be significantly higher than for hydro and on-shore wind- -26 percent and 16 percent more expensive, respectively - than the average costs of hydro and on-shore wind installations operating in 2017. The EIA projects that the average costs for nuclear power will be only 4 percent less expensive than the average for bioenergy.

In Table 3.11, we show the EIA's estimated range for total levelized electricitygenerating costs for the five conventional energy sources. As we see here, the cost range for these conventional sources is substantially more narrow than for renewables. The most wide-ranging source is natural gas with CCS, where the cost difference is 32.5 percent relative to the average costs. With advanced nuclear energy, the range is only 10.5 percent of the average cost estimate. 


\section{Range for total system levelized costs for conventional electricity sources}

Plants entering service in 2017 (in 2010 dollars)

\begin{tabular}{|c|c|c|c|c|c|}
\hline & $\begin{array}{l}\text { Minimum } \\
\text { (dollars per } \\
\text { megawatt } \\
\text { hour) }\end{array}$ & $\begin{array}{c}\text { Average } \\
\text { (dollars per } \\
\text { megawatt } \\
\text { hour) }\end{array}$ & $\begin{array}{l}\text { Maximum } \\
\text { (dollars per } \\
\text { megawatt } \\
\text { hour) }\end{array}$ & $\begin{array}{l}\text { Difference be- } \\
\text { tween minimum } \\
\text { and maximum } \\
\text { costs (dollars } \\
\text { per megawatt } \\
\text { hour) }\end{array}$ & $\begin{array}{l}\text { Minimum- } \\
\text { maximum cost } \\
\text { difference as } \\
\text { percentage of } \\
\text { average costs }\end{array}$ \\
\hline Conventional coal & 90.5 & 97.7 & 114.4 & 23.9 & 24.4 \\
\hline $\begin{array}{l}\text { Advanced coal with } \\
\text { carbon capture and } \\
\text { sequestration }\end{array}$ & 127.7 & 138.8 & 158.2 & 30.5 & 22.0 \\
\hline $\begin{array}{l}\text { Natural gas (conventional } \\
\text { combined cycle) }\end{array}$ & 59.5 & 66.1 & 81.0 & 21.5 & 32.5 \\
\hline $\begin{array}{l}\text { Natural gas (advanced } \\
\text { combined cycle with } \\
\text { carbon capture and } \\
\text { sequestration) }\end{array}$ & 80.1 & 90.1 & 108.5 & 28.4 & 31.5 \\
\hline Advanced nuclear & 107.1 & 111.4 & 118.7 & 11.6 & 10.4 \\
\hline
\end{tabular}

These figures suggest two main conclusions. The first is that conventional energy sources do still provide less variability, and thus less uncertainty, in terms of levelized costs. But considered from another angle, these figures do also show the growing promise of renewables as a competitive source of electricity. For example, the EIA's minimum cost estimate for solar PV, at $\$ 119$ per megawatt hour, is effectively equal to the maximum cost estimate for nuclear, at $\$ 118.70$ per megawatt hour, and even within range of the minimum estimate of nuclear, at $\$ 107.10$. As another example, the minimum figure for wind, at $\$ 77$ per megawatt hour, is nearly 15 percent below the minimum estimate for conventional coal.

Here again, we can see the emerging prospects for renewable energy even within the EIA's Reference case cost scenarios. Of course, these prospects become even stronger under the EIA's Low-Cost Renewable Technology scenario, in which the average renewable costs will fall by as much as 40 percent relative to the Reference case. As we have also discussed, some industry analysts project renewable costs as falling still further. 
In Table 3.12, we calculate the costs of generating 15.4 Q-BTUs of clean renewable energy based on the EIA's Reference case figures for costs. In Table 3.13, we perform the same overall cost estimates using the EIA's Low-Cost Renewable Technology case, in which the costs for producing bioenergy, wind, solar, and geothermal all fall by 40 percent relative to the Reference case, while the costs for hydro remain fixed.

Of course, the EIA assumes that renewable energy supply will increase by 36 percent in the Low-Cost Renewable Technology case relative to the Reference case. But for the sake of simplicity in this discussion, we hold the renewable energy supply constant at 15.4 Q-BTUs in both the Reference case and the Low-Cost Renewable Technology case.

TABLE 3.12

Total levelized costs for clean renewables in 2030 based on EIA Reference case cost figures

$\$ 488.1$ billion for 15.4 Q-BTUs $=\$ 31.7$ billion per Q-BTU

\begin{tabular}{|c|c|c|c|c|}
\hline & \multicolumn{2}{|c|}{ Total system levelized costs } & \multirow[b]{2}{*}{$\begin{array}{l}\text { 3. Estimated } \\
\text { Q-BTUs for } 2030\end{array}$} & \multirow[b]{2}{*}{$\begin{array}{l}\text { 4. Total costs of supply } \\
\text { under Reference case } \\
\text { (column } 2 \text { x column } 3 \text {, in } \\
\text { billions of dollars) }\end{array}$} \\
\hline & $\begin{array}{c}\text { 1. In dollars } \\
\text { per megawatt } \\
\text { hour }\end{array}$ & $\begin{array}{l}\text { 2. In billions } \\
\text { of dollars per } \\
\text { Q-BTUs }\end{array}$ & & \\
\hline Biomass and biofuels & $\$ 115.9$ & $\$ 33.8$ & 6.4 & $\$ 216.3$ \\
\hline Hydro & $\$ 88.9$ & $\$ 26.1$ & 4.1 & $\$ 107.0$ \\
\hline Wind & $\$ 96.0$ & $\$ 28.1$ & 3.1 & $\$ 87.1$ \\
\hline Solar photovoltaic & $\$ 152.7$ & $\$ 44.6$ & 1.1 & $\$ 49.1$ \\
\hline Solar thermal & $\$ 242.0$ & $\$ 70.9$ & 0.2 & $\$ 14.2$ \\
\hline Geothermal & $\$ 98.2$ & $\$ 28.8$ & 0.5 & $\$ 14.4$ \\
\hline Total & -- & --- & 15.4 & $\$ 488.1$ \\
\hline
\end{tabular}

Sources: U.S. Energy Information Administration. 2012a, June. Annual Energy Outlook 2012. Department of Energy. table A17; U.S. Energy Information Administration. 2012b, August. "Assumptions to the Annual Energy Outlook 2012." U.S. Department of Energy.

Note: The total electricity expenditure figure includes purchases of electricity for both intermediate use in production and as part of final consumption within the U.S. economy. See footnote 5 in this chapter for details.

Starting with the Reference case figures in Table 3.12, we see, for example, that total levelized costs for biomass and biofuels, expressed in terms of billions of dollars per Q-BTU of energy, will be at $\$ 33.8$ billion per Q-BTU. Given that we are estimating that 6.4 Q-BTUs of clean biomass and biofuels can be generated by 2030 , that sets the total costs at $\$ 216.3$ billion. We then perform this same 
calculation for hydro, wind, solar, and geothermal sources. As we see from the last row of Table 3.12, these total costs add up to $\$ 488$ billion to generate the total of 15.4 Q-BTUs annually with the fuel mix presented in the table. This amounts to $\$ 31.7$ billion per Q-BTU. ${ }^{31}$

In Table 3.13, we perform the same set of calculations but work instead from the EIA's Low-Cost Renewable Technology case. In this case, as we see, the total costs to generate 15.4 Q-BTUs of clean renewable energy falls to $\$ 336.1$ billion, or $\$ 21.8$ billion per Q-BTU.

TABLE 3.13

Total levelized costs for renewables in 2030 based on EIA Low-Cost Renewable Technology case

\$336.1 billion for 15.4 Q-BTUs = \$21.8 billion per Q-BTU

\begin{tabular}{|c|c|c|c|c|}
\hline & \multicolumn{2}{|c|}{ Total system levelized costs } & \multirow[b]{2}{*}{$\begin{array}{l}\text { 3. Estimated } \\
\text { Q-BTUs for } 2030\end{array}$} & \multirow[b]{2}{*}{$\begin{array}{l}\text { 4. Total costs of supply } \\
\text { under Low-Cost case } \\
\text { (column } 2 \times \text { column } 3 \text {, in } \\
\text { billions of dollars) }\end{array}$} \\
\hline & $\begin{array}{c}\text { 1. In dollars } \\
\text { per megawatt } \\
\text { hour }\end{array}$ & $\begin{array}{l}\text { 2. In billions } \\
\text { of dollars per } \\
\text { Q-BTUs }\end{array}$ & & \\
\hline Biomass and biofuels & $\$ 69.2$ & $\$ 20.3$ & 6.4 & $\$ 129.9$ \\
\hline Hydro & $\$ 88.9$ & $\$ 26.1$ & 4.1 & $\$ 107.0$ \\
\hline Wind & $\$ 57.6$ & $\$ 16.9$ & 3.1 & $\$ 52.4$ \\
\hline Solar photovoltaic & $\$ 91.6$ & $\$ 26.9$ & 1.1 & $\$ 29.6$ \\
\hline Solar thermal & $\$ 145.2$ & $\$ 42.5$ & 0.2 & $\$ 8.5$ \\
\hline Geothermal & $\$ 58.9$ & $\$ 17.3$ & 0.5 & $\$ 8.7$ \\
\hline Total & -- & -- & 15.4 & $\$ 336.1$ \\
\hline
\end{tabular}

Sources: U.S. Energy Information Administration. 2012a, June. Annual Energy Outlook 2012. Department of Energy. table A17; U.S. Energy Information Administration. 2012b, August. "Assumptions to the Annual Energy Outlook 2012." U.S. Department of Energy.

Note 1:Total renewable-supply figures are based on EIA estimate for 2035 electricity under Low Renewable Technology Cost case, which estimates renewable electricity supply increasing by 36 percent relative to its 2035 Reference case (Table D8). Following the EIA, we assume that the hydro supply remains fixed in this case relative to 2035 Reference case. We then assume all other renewable sources increase supply by 45 percent relative to the 2035 Reference case. This generates an overall expansion of renewable supply by 36 percent relative to the 2035 Reference case.

Note 2: The total electricity expenditure figure includes purchases of electricity for both intermediate use in production and as part of final consumption within the U.S. economy. See footnote 5 in this chapter for details. 


\section{Weighted costs for nonrenewables}

To examine comparative costs of renewables and nonrenewables further, we show in Table 3.14 the costs of delivering 15.4 Q-BTUs of energy from coal, natural gas, and nuclear power. Specifically, for the purpose of this exercise, we assume that with both coal and natural gas, half of total supply is generated through conventional technologies, while the other half utilizes CCS technologies. As we see with this case, the costs of producing 15.4 Q-BTUs through this combination of sources at Reference case costs will be $\$ 32.6$ billion per Q-BTU, totaling $\$ 502$ billion.

TABLE 3.14

Total levelized costs for producing 15.4 Q-BTUs of electricity powered by a combination of coal, natural gas, and nuclear energy (2010 prices)

- Proportions of coal, natural gas, and nuclear based on EIA 2035 Reference cases

- Assumes coal and natural gas supplied 50 percent each through conventional and CCS technologies

$\$ 502$ billion for 15.4 Q-BTUs $=\$ 32.6$ billion per Q-BTU

\begin{tabular}{|c|c|c|c|}
\hline & \multicolumn{2}{|c|}{ Total system levelized costs } & \multirow{2}{*}{$\begin{array}{l}\text { Proportions of coal, } \\
\text { natural gas, and nuclear } \\
\text { electricity supplied under } \\
\text { EIA } 2035 \text { Reference case } \\
\text { (percent) }\end{array}$} \\
\hline & $\begin{array}{l}\text { 1. In dollars } \\
\text { per megawatt } \\
\text { hour }\end{array}$ & $\begin{array}{l}\text { 2. In billions } \\
\text { of dollars per } \\
\text { Q-BTUs }\end{array}$ & \\
\hline Conventional coal & $\$ 97.7$ & $\$ 28.6$ & 24.0 \\
\hline $\begin{array}{l}\text { Advanced coal with carbon } \\
\text { capture and sequestration }\end{array}$ & $\$ 138.8$ & $\$ 40.7$ & 24.0 \\
\hline Conventional natural gas & $\$ 66.1$ & $\$ 19.4$ & 13.5 \\
\hline $\begin{array}{l}\text { Natural gas with carbon cap- } \\
\text { ture and sequestration }\end{array}$ & $\$ 127.9$ & $\$ 37.5$ & 13.5 \\
\hline Nuclear power & $\$ 111.4$ & $\$ 32.6$ & 25.0 \\
\hline
\end{tabular}

Sources: U.S. Energy Information Administration. 2012a, June. Annual Energy Outlook 2012. Department of Energy. table A17; U.S. Energy Information Administration. 2012b, August. "Assumptions to the Annual Energy Outlook 2012." U.S. Department of Energy.

We bring together these alternative weighted cost figures in Table 3.15. As is clear from this table, the combination of renewable sources developed through the EIA's Reference and Low-Cost Renewable Technology cases are clearly cost competitive with the combination of nonrenewable sources where supplies are weighted based on the EIA's 2030 Reference case production levels for coal, natural gas, and nuclear power respectively. That is, with the Reference case renewable combination, producing 15.4 Q-BTUs is 2.8 percent less expensive than the nonrenewable combination of coal, natural gas, and nuclear. With the low-cost renewable combination, the overall costs are 33 percent lower than the nonrenewable combination. 

electricity through Alternative Renewable and Nonrenewable cases

\begin{tabular}{l|cc|c}
\hline & \multicolumn{2}{|c|}{ Total system levelized costs } & $\begin{array}{c}\text { Costs of weighted renew- } \\
\text { able electricity sources } \\
\text { relative to weighted coal, } \\
\text { natural gas, and nuclear } \\
\text { (percent) }\end{array}$ \\
\hline $\begin{array}{l}\text { 1. In dollars } \\
\text { per megawatt } \\
\text { hour }\end{array}$ & $\begin{array}{c}\text { 2. In billions } \\
\text { of dollars per } \\
\text { Q-BTUs }\end{array}$ & N/A \\
\hline $\begin{array}{l}\text { Nonrenewable case: } \\
\begin{array}{l}2035 \text { Weighted Reference case for } \\
\text { coal, natural gas, and nuclear }\end{array}\end{array}$ & $\$ 9.56$ & $\$ 32.6$ & -2.8 \\
$\begin{array}{l}\text { Renewable case 1: } \\
2035 \text { Weighted Reference case }\end{array}$ & $\$ 9.29$ & $\$ 31.7$ & -33.1 \\
$\begin{array}{l}\text { Renewable case 2: } \\
2035 \text { Weighted Low Technology } \\
\text { Cost case }\end{array}$ & $\$ 6.39$ & $\$ 21.8$ & \\
\hline
\end{tabular}

Sources: U.S. Energy Information Administration. 2012a, June. Annual Energy Outlook 2012. Department of Energy. table A17; U.S. Energy Information Administration. 2012b, August. "Assumptions to the Annual Energy Outlook 2012." U.S. Department of Energy.

It is true that these alternative scenarios do not present apples-to-apples cases of renewable versus nonrenewable sources. For one thing, we are including more expensive CCS technologies for coal and natural gas along with the conventional technologies in both cases, with the CCS supply being equal to the less expensive conventional supply. In addition, we are comparing Reference case costs for nonrenewables with the Low-Cost Renewable Technology case. We do not present the EIA's estimates of low-cost cases for nonrenewables. Finally, we are working with average cost figures for the purposes of this exercise. But in reality, it is important to keep in mind that the range of costs is significantly more narrow with nonrenewables.

However, the point of these data exercises is to explore the cost feasibility of expanding renewable energy resources. What we see from these exercises is that working within the EIA's projections, renewable energy can become cost competitive with nonrenewables at the level of roughly 15 Q-BTUs of supply as of 2030-2035. Moreover, this would be especially true to the extent that policies are adopted to encourage the acceleration of technological progress for renewables. Note again that the EIA's estimates do not incorporate any effects of policies that could both subsidize renewable energy or raise the costs of nonrenewables through, for example, an explicit carbon tax or carbon cap. However, it is true that the effect of a carbon cap or tax on costs would likely be similar to introducing the added costs of producing electricity from nonrenewables through CCS technology, which we have included in our calculations. We return to these alternative considerations and policy options in Chapter 4 on nonrenewables and Chapter 8 on policy proposals. 


\section{Renewable energy capital expenditures}

The cost figures we have presented thus far show total annual levelized costs for generating electricity with renewable energy, as well as nonrenewable sources. As Table 3.8 shows, the largest component of annual levelized costs is capital expenditures. As appropriate for estimating total annual costs for electricity generation, these levelized capital cost figures include annual financing costs, as well as the direct costs of creating the stock of physical equipment that is needed for expanding renewable capacity.

But in addition to showing these annual levelized capital cost figures, it will also be useful to separate out the direct costs of creating new capital equipment in the renewable sector from the annual compounding financing charges. In Table 3.16, we thus present these in terms of the present value of the new capital equipment investments. Once we have generated these present value figures, we can then also estimate the total amount of capital expenditures (in present values) necessary to expand clean renewables to 15.4 Q-BTUs by 2030.

TABLE 3.16

Renewable energy capital expenditures for electricity generation: Annual levelized costs and present values

\begin{tabular}{|c|c|c|c|c|c|c|}
\hline & \multicolumn{2}{|c|}{$\begin{array}{c}\text { Reference case: } \\
\text { Costs per megawatt hour }\end{array}$} & \multicolumn{2}{|c|}{$\begin{array}{c}\text { Reference case: } \\
\text { Costs per Q-BTU } \\
\$ 1 \text { per } M W h=(\$ 1 \text { billion/3.42) } \\
\text { Q-BTUs }\end{array}$} & \multicolumn{2}{|c|}{$\begin{array}{l}\text { Low Renewable Technology Cost } \\
\text { case: Costs per Q-BTU } \\
\text { Assumes } 40 \text { percent cost reduction } \\
\text { except for hydro }\end{array}$} \\
\hline & $\begin{array}{l}\text { 1. Levelized } \\
\text { annual } \\
\text { capital costs }\end{array}$ & $\begin{array}{l}\text { 2. Present } \\
\text { value of total } \\
\text { capital costs }\end{array}$ & $\begin{array}{l}\text { 3. Present } \\
\text { value of total } \\
\text { capital costs } \\
\text { per Q-BTU } \\
\text { (in billions) }\end{array}$ & $\begin{array}{l}\text { 4. Average } \\
\text { costs over 20- } \\
\text { year cycle } \\
\text { (in billions) }\end{array}$ & $\begin{array}{l}\text { 5. Present } \\
\text { value of total } \\
\text { capital costs } \\
\text { per Q-BTU } \\
\text { (in billions) }\end{array}$ & $\begin{array}{l}\text { 6. Average } \\
\text { costs over 20- } \\
\text { year cycle } \\
\text { (in billions) }\end{array}$ \\
\hline Clean bioenergy & $\begin{array}{c}\$ 56 \\
\text { per } M W h\end{array}$ & $\$ 709$ & $\$ 207$ & $\$ 10.4$ & $\$ 124$ & $\$ 6.2$ \\
\hline Hydro & $\begin{array}{c}\$ 76.90 \\
\text { per MWh }\end{array}$ & $\$ 974$ & $\$ 284$ & $\$ 14.2$ & \multicolumn{2}{|c|}{ Same as Reference case } \\
\hline Wind & $\begin{array}{c}\$ 82.50 \\
\text { per MWh }\end{array}$ & $\$ 1,045$ & $\$ 306$ & $\$ 15.3$ & $\$ 183$ & $\$ 9.1$ \\
\hline Solar photovoltaic & $\begin{array}{c}\$ 140.70 \\
\text { per MWh }\end{array}$ & $\$ 1,782$ & $\$ 521$ & $\$ 26.1$ & $\$ 312$ & $\$ 15.6$ \\
\hline Solar thermal & $\begin{array}{l}\$ 195.60 \\
\text { per MWh }\end{array}$ & $\$ 2,477$ & $\$ 724$ & $\$ 36.2$ & $\$ 435$ & $\$ 21.7$ \\
\hline Geothermal & $\begin{array}{c}\$ 75.10 \\
\text { per MWh }\end{array}$ & $\$ 974$ & $\$ 285$ & $\$ 14.2$ & $\$ 167$ & $\$ 8.3$ \\
\hline
\end{tabular}

Source: U.S. Energy Information Adminstration. 2012b, August. "Assumptions to the Annual Energy Outlook 2012." U.S. Department of Energy. Notes: Following EIA, present value calculation assumes 6.8 percent discount rate over 30-year cost-recovery period. 
The EIA presents figures on annual levelized capital costs for its Reference case. The EIA's figures are calculated based on a 30-year cost-recovery period using a real after-tax weighted average cost of capital of 6.8 percent. From these assumptions, we are able to convert the reported Reference case levelized costs per megawatt hour into present values of lump-sum capital expenditures, using the EIA's 6.8 percent figure as the discount rate for financing these capital expenditures.

Column 1 of Table 3.16 shows the levelized annual capital cost figures for the EIA's Reference case, expressed as dollars per megawatt hour of electricity generated, as taken directly from the EIA's 2012 study. In column 2, we show these same capital investment figures, as converted into present values. In column 3, still working with the EIA's Reference case, we then convert the units of the present value figures from megawatt hours into a lump sum of billions of dollars per Q-BTU of new investment. Column 4 presents these same Reference case figures as an average annual level of investment per year over 20 years. Column 5 then presents current-value capital-expenditure figures in terms of the EIA's LowCost Renewable Technology case. Column 6 shows these Low-Cost Renewable Technology figures as spread out over a 20 -year investment period. We assume here that the 40 percent reduction in costs that the EIA applies to total levelized costs for clean bioenergy, wind, solar, and geothermal energy is also the appropriate figure for cost reduction for capital costs alone..$^{32}$ As noted above, the EIA's Low-Cost Renewable Technology case assumes that the levelized costs for hydro power do not decline at all relative to its Reference case.

These figures show that, in the EIA's Reference case, the present value of capital expenditures ranges between $\$ 207$ billion per Q-BTU for bioenergy to $\$ 724$ billion for solar thermal. Spanning a 20 -year investment period, this amounts to between $\$ 10.4$ billion and $\$ 36.2$ billion annually. Moving to the Low-Cost Renewable Technology case, the range is between $\$ 124$ billion and $\$ 435$ billion per Q-BTU, which amounts to between $\$ 6.2$ billion and $\$ 21.7$ billion per year for 20 years. 
In Table 3.17, we present estimates as to the level of capital expenditures needed to expand renewable capacity to levels we presented in Table 3.7-that is, to get clean renewable production to 15.4 Q-BTUs by 2030. We see in Table 3.17 that the total amount of investment necessary is $\$ 2.1$ trillion, or roughly $\$ 107$ billion per year over 20 years. The major investment areas are clean bioenergy, at around $\$ 40$ billion per year, as well as hydro, wind, and solar PV, all with the range of $\$ 17$ billion to $\$ 23$ billion per year.

TABLE 3.17

Capital expenditures for estimated clean renewable capacity expansion from 2010 through 2030

\begin{tabular}{|c|c|c|c|c|c|}
\hline & $\begin{array}{l}\text { 1. } 2010 \\
\text { actual } \\
\text { supply } \\
\text { (Q-BTUs) }\end{array}$ & $\begin{array}{l}\text { 2. } 2030 \\
\text { PERI/CAP } \\
\text { case } \\
\text { potential } \\
\text { supply }\end{array}$ & $\begin{array}{l}\text { 3. Capacity } \\
\text { expansion } \\
\text { (= column } 2 \text { - } \\
\text { column 1), in } \\
\text { Q-BTUs }\end{array}$ & $\begin{array}{l}\text { 4. Capital expenditures } \\
\text { to expand capacity } \\
\text { (in billions) } \\
\text { Present values under } \\
\text { Low Renewable } \\
\text { Technology Cost case }\end{array}$ & $\begin{array}{l}\text { 5. Average capi- } \\
\text { tal expenditures } \\
\text { per year over } \\
\text { 20-year cycle } \\
\text { (= column 4/20) } \\
\text { (in billions) }\end{array}$ \\
\hline Clean bioenergy & $\sim 0$ & 6.4 & 6.4 & $\$ 796$ & $\$ 39.8$ \\
\hline Hydro & 2.5 & 4.1 & 1.6 & $\$ 454$ & $\$ 22.7$ \\
\hline Wind & 0.9 & 3.1 & 2.2 & $\$ 403$ & $\$ 20.1$ \\
\hline Solar photovoltaic & $\sim 0$ & 1.1 & 1.1 & $\$ 343$ & $\$ 17.2$ \\
\hline Solar thermal & $\sim 0$ & 0.2 & 0.2 & $\$ 87$ & $\$ 4.3$ \\
\hline Geothermal & 0.2 & 0.5 & 0.3 & $\$ 50$ & $\$ 2.5$ \\
\hline Total & 3.6 & 15.4 & 11.8 & $\begin{array}{c}\$ 2.1 \\
\text { trillion }\end{array}$ & $\$ 106.6$ \\
\hline
\end{tabular}

Source: Tables 3.1, 3.7, and 3.16. 


\section{Conclusion}

With these figures, we can now provide an overall estimate of the capital expenditures necessary for advancing the clean energy agenda we have described, including both efficiency and renewable investments - an agenda that is realistically capable of bringing overall consumption down to 70 Q-BTUs with about 15 Q-BTUs coming from clean renewables. We pull these combined figures together in Chapter 5. In Chapter 6, we then use our overall investment cost estimates as one important basis for estimating the employment effects of building a clean energy U.S. economy.

Considering this chapter by itself, our focus has been on the project of greatly expanding the supply of energy in the United States coming from clean renewable sources, including solar, wind, geothermal, small-scale hydropower, and low- to zero-emissions bioenergy. As of 2010, as we have shown, the United States was producing about 3.5 Q-BTUs of energy from these clean renewable sources. We argue that this figure needs to increase roughly four-fold, to about 15 Q-BTUs by 2030-2035, if the United States is going to achieve its intermediate emissions target.

As of 2010 wind, solar, and geothermal energy accounted for only slightly more than 1 percent of all U.S. energy supply. We have therefore considered in this chapter what would be needed to make wind, solar, and geothermal, along with clean bioenergy and hydro, a major source of U.S. energy supply. Working with projections on electricity capital costs for renewables from the EIA, we estimate that the total direct capital expenditures (not including financing costs) needed to expand clean renewable capacity to around 15 Q-BTUs will be around $\$ 2.1$ trillion, or roughly $\$ 107$ billion per year for 20 years. The major investment areas would be clean bioenergy, at around $\$ 40$ billion per year, as well as hydro, wind, and solar PV, all within the range of $\$ 17$ - $\$ 23$ billion per year. 
Still working with the EIA's cost estimates, we show that the costs for producing electricity from most clean renewable sources — including wind, hydro, geothermal, and clean bioenergy - will be at rough cost parity with most nonnonrenewable sources by 2017. According to the EIA, solar costs are still not likely to be at cost parity with nonrenewables by 2017 under average conditions, but solar costs are coming down the most rapidly of all sources. Moreover, through technical innovations and expanded market opportunities over the next one to two decades, solar promises to become the cleanest, safest, and most abundant renewable energy source. Overall, then, our conclusion from examining the evidence in Chapter 3 is that a large-scale expansion of clean renewable energy is both critical for the success of achieving the 20-year emissions targets and is feasible in terms of the investment commitment that will be required. 
1 U.S. Energy Information Administration, Assumptions to Annual Energy Outlook 2010: Renewable Fuels Module (U.S. Department of Energy, 2010), p. 57, available at http://www.eia.gov/oiaf/aeo/assumption/pdf/ renewable.pdf.

2 U.S. Energy Information Administration, Assumptions to the Annual Energy Outlook 2011 (U.S. Department of Energy, 2011), p. 175, available at http://www.eia.gov/ forecasts/archive/aeo11/assumptions/pdf/0554(2011) pdf; U.S. Energy Information Administration,

Assumptions to the Annual Energy Outlook 2012 (U.S. Department of Energy, 2012), p. 171.

3 In its 2012 Annual Energy Outlook (Table D8), the EIA estimates that end-use renewable energy would increase by 33 percent relative to the 2035 Reference case. In addition to combined heat and power systems, these end uses include small on-site generating systems in the residential, commercial, and industrial sectors used primarily for own-use generation, but which may also sell some power to the grid. The category excludes off-grid photovoltaics and other generators not connected to the distribution or transmission systems.

4 Ron Pernick, Clint Wilder, and Trevor Winnie, “Clean Energy Trends 2012" (San Francisco: The Clean-Tech Market Authority, 2012), p. xxi, available at http://www. cleanedge.com/sites/default/files/CETrends2012_Final Web.pdf?attachment=true.

5 Quoted from Giles Parkinson, "Boom in unsubsidised solar PV flags energy revolution," Renew Economy, January 23, 2013, available at http://reneweconomy. com.au/2013/ubs-boom-in-unsubsidised-solar-pv-flagsenergy-revolution-60218. These observations are clearly consistent with broad recent market developments, as reported, for example, by Bloomberg New Energy Finance and Business Council for Sustainable Energy, "Sustainable Energy in America 2013 Factbook" (2013), available at http://www.bcse.org/factbook/pdfs/BCSE BNEF_Sustainable_Energy_in_America_2013_Factbook pdf. "The levelized costs of electricity for renewable technologies have plummeted. For example, the cost of electricity generated by average solar power plants has fallen from $\$ 0.31$ per kilowatt-hour in 2009 to $\$ 0.14$ per kilowatt-hour in 2012, according to our global benchmarking analysis based on already financed projects from around the world. These figures exclude the effect of tax credits and other incentives, which would bring those costs down even lower. Over the same period, the cost of power from a typical large wind farm has fallen from $\$ 0.09$ in 2009 to $\$ 0.08$ per kilowatt-hour," p. 3. The price declines for solar and accompanying recent growth surge in the industry, in particular, prompted Jon Wellinghoff, the current chair of the Federal Energy Regulatory Commission, or FERC, to assert that "Solar is growing so fast it is going to overtake everything ... At its present growth rate, solar will overtake wind in about 10 years. It is going to be the dominant player. Everybody's roof is out there." Herman K. Trabish, "FERC Chair Jon Wellinghoff: Solar'Is Going to Overtake Everything,"' Greentech Media, August 21, 2013, available at http://www.greentechmedia.com/articles/read/ ferc-chair-wellinghoff-sees-a-solar-future-and-a-utilityof-the-future?utm source $=$ Daily\&utm medium=Headline\&utm_campaign=GTMDaily.

6 Private correspondence by email with Professor Kerry Emanuel of the Massachusetts Institute of Technology, Cambridge, MA, March 27, 2013.
7 In terms of policy approaches, Emanuel further argues that "by focusing on solar and wind power sources ... the environmental movement is engaged in unproductive theatre that detracts from serious debate about energy." Kerry Emanuel, What We Know About Climate Change, Second Edition (Cambridge, MA: MIT Press, 2012), p. 89.

8 U.S. Environmental Protection Agency, “Non-Hydroelectric Renewable Energy Sources" (2013), available at http://www.epa.gov/cleanenergy/energy-and-you/ affect/non-hydro.html.

9 Table 1 from the EPA study that provides these figures. U.S. Office of Transportation and Air Quality, EPA Lifecycle Analysis of Greenhouse Gas Emissions from Renewable Fuels (U.S. Environmental Protection Agency, 2009), available at http://nepis.epa.gov/Exe/ZyPDF.cgi/ P100B3F8.PDF?Dockey=P100B3F8.PDF, includes a fulle listing than those shown in Table 3.5. The study also includes emission figures over a 100-year cycle, as well as the 30-year cycle shown in the table.

10 National Academy of Sciences, Liquid Transportation Fuels from Coal and Biomass: Technological Status, Costs, and Environmental Impacts (Washington: The National Academies Press, 2009).

11 Steven Sexton, Deepak Rajagopal, David Zimmerman, and Gal Hochman,"Food Versus Fuel: How Biofuels Make Food More Costly and Gasoline Cheaper," Agricultural and Resource Economics Update 12 (1) (2008), available at http://www.ncsu.edu/cenrep/ research/documents/food_v_fuel.pdf.

12 Phillip C. Abbott, Christopher Hurt, and Wallace E. Tyner, "What's Driving Food Prices in 2011?" (Oak Brook IL: Farm Foundation, 2011), available at http://www. farmfoundation.org/news/articlefiles/1742-FoodPrices web.pdf.

13 Committee on World Food Security, High Level Panel of Experts on Food Security and Nutrition, "Biofuels and Food Security" (2013)

14 Sexton, Rajagopal, Zimmerman, and Hochman, "Food Versus Fuel."

15 John Baffes and Tassos Haniotis, "Placing the 2006/8 Commodity Price Boom Into Perspective." Policy Research Working Paper 5371 (The World Bank, 2010).

16 Christopher L. Gilbert, "How to Understand High Food Prices," Journal of Agricultural Economics 61 (2) (2010): 398-425.

17 Baffes and Haniotis, "Placing the 2006/8 Commodity Price Boom Into Perspective."

18 Gilbert, “How to Understand High Food Prices.”

19 Committee on World Food Security, "Biofuels and Food Security."

20 Sexton, Rajagopal, Zimmerman, and Hochman, “Food Versus Fuel."

21 Ibid

22 As with solar energy, major technical breakthroughs in generating clean bioenergy appear to be advancing at a significant pace. One case in point is with waste-toenergy gasifier systems. The New York Times recently 
described such a system as follows "... a waste gasifier that's about the size of a shower stall, essentially a modified blast furnace. A chemical reaction inside the gasifier heats any kind of trash ... to extreme temperatures without combustion. The output ... can be burned to generate electricity or made into ethano of diesel fuel .... Ethanol produced from trash-or agricultural waste-would allay concerns" over pushing up food prices. This New York Times article notes that the United States has begun to purchase gas from this system from a company named Sierra Energy. Paul Tullus, "Trash into Gas, Efficiently? An Army Test May Tell," The New York Times August 17, 2013, available at http://www.nytimes.com/2013/08/18/business/ trash-into-gas-efficiently-an-army-test-may-tell. html?pagewanted=all.

23 Oxfam, “Extreme Weather, Extreme Prices: The costs of feeding a warming world" (2012); Commission on Sustainable Agriculture and Climate Change, "Achieving Food Security in the Face of Climate Change" (2012).

24 Two definitions of the term "penstock" are: a sluice or gate used to control a flow of water; and a pipe or conduit used to carry water to a water wheel or turbine.

25 Douglas G. Hall, Kelly S. Reeves, Julie Brizzee, Randy D. Lee, Gregory R. Carroll, and Garold L. Sommers, "Feasibility Assessment of the Water Energy Resources of the United States for New Low Power and Small Hydro Classes of Hydroelectric Plants" (Idaho Falls: Idaho National Laboratory, 2006), p. v, available at http://www1.eere.energy.gov/water/pdfs/doewater-11263.pdf

26 Lea Kosnik, "The Potential for Small Scale Hydropower Development in the U.S.," Energy Policy 38 (10) (2010): 5512-5519, p. 5512.

27 The EIA produces its analysis of levelized costs for new electricity generation resources on an annual basis, to accompany the publication of its "Annual Energy Outlook." A summary of this work and the basic findings are presented here http://www.eia.gov/ forecasts/aeo/electricity_generation.cfm.
28 The EIA reports these earliest figures as of 2017 because as it notes, "the long lead times needed for some technologies means that they could not be brought on line prior to 2017 unless they were already under construction." U.S. Energy Information Administration, Assumptions to the Annual Energy Outlook 2012 (U.S. Department of Energy, 2012), p. 4, available at http:// www.eia.gov/forecasts/aeo/assumptions/ pdf/0554(2012).pdf.

29 We use here the standard conversion factor, 1 kilowatt hour of electricity $=3,412$ BTUs of approximate heat content. U.S. Energy Information Administration, Annual Energy Outlook 2012 (U.S. Department of Energy 2012), p. 239, available at http://www.eia.gov/forecasts/ aeo/pdf/0383(2012).pdf.

30 Amory B. Lovins, "Amory Angle: Three Major Energy Trends to Watch," Rocky Mountain Institute Solution Journal 6 (1) 2013, available at http://www.rmi.org/ summer_2013_esj_amorys_angle_three_major_energy trends_main.

31 Note that with this overall expenditure figure and that with the low-cost case, we are including the cost of electricity consumed both as an intermediate input in production within the U.S. economy, as well as electricity consumed as part of final consumption. As such, the figures for electricity consumption will not correspond to the figures in the U.S. National Income and Product Accounts, which only report figures for final consumption. The consumption of electricity as an intermediate input would be incorporated into the U.S. input/output tables, which does include intermediate inputs.

32 This is a safe assumption given that capital costs are dominant with wind, solar, and geothermal power Variable costs are nearly as large with biomass. But as a first approximation, it would still be reasonable to assume that capital costs would fall here as well by 40 percent. 
Chapter 4

\section{Oil, coal, natural gas, and nuclear power}




\section{Introduction}

Following our discussions in Chapters 2 and 3 on energy efficiency and renewables, we assume that by 2030-2035 the United States will need to supply approximately 55 Q-BTUs of energy through nonrenewable sources or high-emissions renewables. This level of nonrenewable energy consumption will be supplemented by at least 15 Q-BTUs of clean renewable energy. We also assume that overall U.S. energy consumption as of 2030-2035 will be approximately 70 Q-BTUs.

In this chapter, we consider alternative possibilities for meeting this 55-Q-BTU level of energy demand in the United States through consuming oil, coal, natural gas, nuclear power, and high-emissions renewables. Within this framework, our focus will be on how to meet this level of demand in ways that can still maintain overall $\mathrm{CO}_{2}$ emission levels at no more than $3,200 \mathrm{mmt}^{1}$

We will proceed by first examining the demand for liquid fuels. We established in Chapter 2 that overall energy demand in the transportation sector will be about 20 Q-BTUs by 2030. We then determined in Chapter 3 that a realistic figure for the production of clean biofuels in the Unites States as of 2030 is 6.4 Q-BTUs. For the purposes of simplicity and to err, if anything, on the conservative side, we round that figure down to 6 Q-BTUs of clean biofuels in the foregoing discussion. These figures establish clear parameters in determining the overall demand for oil or high-emissions ethanol. ${ }^{2}$

The other possible source of energy supply for transportation would be electricity to power electric vehicles. Even in this case, however, electric cars could be powered by coal or natural gas as the electricity source, in which case the impact on emission reduction would be minimal. As such, for the purposes of this discussion and again to err, if anything, on the conservative side, we assume that 19 of the total of 20 Q-BTUs of energy required for the transportation sector will need to be supplied by liquid fuels - either petroleum products or clean biofuels - with the remaining 1 Q-BTU coming from electricity-based sources. 
Once we establish the demand for oil, we then need to consider the most appropriate combinations of coal, natural gas, and nuclear power for meeting overall U.S. energy needs, as well as reaching the $2030 \mathrm{CO}_{2}$ emissions reduction target of no more than 3,200 mmt. For this discussion, we consider two sets of topics in this chapter: alternative forecasts of U.S. electricity demand and environmental and safety concerns with certain technologies.

\section{Alternative forecasts of U.S. electricity demand by 2030 to 2035}

We consider here four alternative forecasts for U.S. electricity-generating capacity and consumption as of 2030 to 2035 . These include three alternative scenarios developed by the EIA - its Reference cases, its case based on enforcing significant emissions controls over the next 20 years, and its case assuming that the federal government sets a price on carbon emissions. The fourth scenario is from Deutsche Bank Climate Change Advisors (2011), which assumes strong emissions regulations are maintained, but no price on carbon emissions is implemented. Examining these four cases enables us to consider the types of policy interventions that will be most effective for meeting the $\mathrm{CO}_{2}$ emissions reduction targets, as well as producing adequate electricity to meet U.S. demand.

In addition, examining the alternative electricity supply projections will provide a basis for addressing the fact that there will almost certainly be excess capacity for nonrenewable electricity sources as of 2030-2035. A major task in managing a clean energy transition will be to anticipate such issues of excess capacity and to develop policies of handling them fairly and effectively.

\section{Environmental and safety concerns with specific technologies}

We consider three specific technologies. We begin with the issue of public safety with nuclear power, a longstanding question that has become an increasingly pressing concern worldwide following the 2011 earthquake and tsunami and subsequent nuclear meltdown at the Fukishima Daiichi power plant in Japan. We then consider hydraulic fracturing technology_or "fracking" - especially with regard to the use of this technology to extract natural gas from shale rock deposits. Finally, we consider carbon capture and sequestration technology that aims to reduce the emission levels generated by burning coal and natural gas relative to the conventional technologies used today. 
Following these discussions, we then turn in Chapter 5 to addressing in detail the question of $\mathrm{CO}_{2}$ emission levels from alternative combinations of nonrenewable energy sources. Specifically, we consider alternative paths of generating 55 Q-BTUs of energy from various combinations of oil, coal, natural gas, and nuclear power, and calculate the $\mathrm{CO}_{2}$ emissions levels that would result from each of the scenarios we consider. 


\section{Overall demand for oil}

Under the EIA 2030 Reference case, total U.S. oil consumption is projected to be 37 Q-BTUs. Of that total, the breakdown by usage is as follows:

- Transportation: 27 Q-BTUS

- Industry: 8.1 Q-BTUs

- Buildings: 1.5 Q-BTUs

- Electricity: 0.3 Q-BTUs

Of this total, we have established two means through which we estimate that the consumption of oil in transportation can fall relative to these 2030 Reference case figures. First, we achieve an 8 Q-BTU reduction in demand through energy efficiency investments primarily in automobiles (light-duty vehicles), but also with heavy-duty vehicles and other modes of transportation. We then reduce demand for oil by producing about $6 \mathrm{Q}-\mathrm{BTU}$ s of clean biofuels. This means that total demand for oil in the transportation sector falls from 27 to 13 Q-BTUs. These calculations and related figures are shown in Table 4.1.

TABLE 4.1

Estimated U.S. overall oil demand in 2030

In Q-BTUs

\begin{tabular}{lccc}
\hline $\begin{array}{l}\text { Oil-consuming } \\
\text { sectors }\end{array}$ & $\begin{array}{c}\text { EIA 2030 } \\
\text { Reference case }\end{array}$ & $\begin{array}{c}\text { PERI/CAP 2030 } \\
\text { scenario }\end{array}$ & Details \\
\hline $\begin{array}{l}\text { Transportation } \\
27.0\end{array}$ & 13.0 & $\begin{array}{r}\text { Reductions due to higher fuel-economy standard (eight Q-BTUs) } \\
\text { and clean biofuels (six Q-BTUs) }\end{array}$ \\
$\begin{array}{l}\text { Industrial } \\
\text { Buildings }\end{array}$ & 1.5 & 0.1 & $\begin{array}{c}\text { Includes refining consumption (1.9); liquid petroleum gas } \\
\text { feedstocks (1.8); petroleum feedstocks (1.3); distillate fuel oil (1.2); } \\
\text { asphalt and road oil (0.9); and other lesser uses (1.0) }\end{array}$ \\
$\begin{array}{l}\text { Electricity } \\
\text { Total }\end{array}$ & 0.3 & 0 & Assume natural gas or other substitutes
\end{tabular}

Sources: U.S. Energy Information Administration, Annual Energy Outlook 2012 (U.S. Department of Energy, 2012). PERI/CAP 2030 case derived in text. 
Beyond this, we assume that the 8.1 Q-BTUs of demand for industry remains as is. We also assume that the 1.8 Q-BTUs in oil consumption for buildings and electricity would be replaced by natural gas. But this is not a significant consideration either way. Considering all of these factors, we arrive at a figure for total oil consumption of 21.1 Q-BTUs. 


\section{Domestic production and imports}

The EIA's 2030 Reference case estimates that total U.S. oil demand in 2030 will be met by this combination of sources: ${ }^{3}$

- Domestic production (plus exports): 18.4 Q-BTUs

- Imports: 20.1 Q-BTUs

Given that we are estimating total demand for oil at 21.1 Q-BTUs, it is clear that the United States could virtually eliminate its oil imports under the scenario we have developed. As we discuss in Chapter 7, this would have a major positive benefit on the U.S. trade deficit. It could also have important geopolitical benefits by reducing the U.S. dependence on oil from politically unstable regions.

It is possible that eliminating oil imports would entail significant costs. These could include the costs of delivering oil to various areas of the United States through domestic sources only, when delivery might be less expensive through established supply lines that include imports. There could also be geopolitical concerns in terms of U.S. relations with its trading partners. Nevertheless, insofar as minimizing oil imports is a policy priority, this becomes an achievable goal through the energy efficiency measures and the expansion of clean biofuel production that we have described above.

For the United States to consume 21.1 Q-BTUs of oil as opposed to 37 Q-BTUs will, of course, also result in a major reduction in overall $\mathrm{CO}_{2}$ emissions. Burning oil for energy purposes generates $66.3 \mathrm{mmt}$ of $\mathrm{CO}_{2}$ emissions per Q-BTU of consumption. It is also important to note that the level of emissions generated by industrial uses is much lower per barrel of oil consumed - only about 5 percentthan for transportation uses per barrel of oil consumed. We will examine these and related calculations in detail in Chapter 5 . 


\section{Alternative forecasts of U.S. electricity demand}

The four alternatives for the electricity-generating sector include the following: the EIA Reference cases, the EIA case based on enforcing emissions controls, the EIA case on incorporating a price on carbon, and the Deutsche Bank Climate Change Advisors' scenario.

\section{EIA Reference cases for 2030 and 2035}

The EIA Reference cases are derived from the projections of the National Energy Modeling System, or NEMS. These estimates build from assumptions about the U.S. economic environment, international energy markets, currently known levels of resource availability, production and investment costs, consumption behavior, technological choice criteria, characteristics of energy technologies, and broad demographics such as population growth.

The Reference cases are "business as usual" scenarios, in that they assume the given policy environment will remain in place. These cases do not attempt to analyze the effects of the implementation of new policies in the future. Technologies do change under the Reference case scenarios, but these changes occur only when the costs of adopting new technologies are competitive with existing technologies within the existing policy environment. Similarly, capacity is assumed to retire when older plants are no longer competitive with new or existing plants under current policies. 


\section{ElA emissions regulations scenario}

According to the EIA, under this scenario:

Power plants are required to install flue-gas desulfurization (FGD) scrubbers and selective catalytic reduction (SCR) in order to continue operating after 2020 , based on the assumption that stringent controls will be required by the EPA for compliance with clean air rules. The combined cost of the two retrofits could range from $\$ 500$ to $\$ 1000$ per kilowatt of capacity, depending on plant size and characteristics."

These regulatory measures would alter the capital costs associated with new investments in electricity power plants since they would require older plants to incur additional costs by retrofitting their facilities. The biggest impact would be on coal-fired plants.

The scenario assumes a 20-year period over which the costs of any capital investments associated with retrofitting are recovered. The EIA also considers a "Retrofit-5-year" scenario, which we will not examine here. But it is notable that the 20-year scenario assumes that more retrofits will take place relative to the fiveyear scenario because the economics of retrofit projects improve with the longer capital-recovery period.

\section{Carbon-Price scenario}

This scenario assumes that a price on carbon emissions is established through public policy. The EIA model assumes that this price begins at $\$ 25$ per ton of $\mathrm{CO}_{2}$ emissions in 2013, then rises to $\$ 77$ per ton in 2035 (in 2009 dollars). This EIA scenario does not consider in its analysis many of the provisions that are commonly attached to carbon cap-and-trade legislation, including carbon offsets, specific allocations of carbon-emission allowances, or a secondary market for trading carbon-emission permits. It therefore represents an attempt to analyze the introduction of a carbon price, separate from these other considerations. 
As with the alternative EIA estimates, the Deutsche Bank scenario estimates electricity demand for 2030, and the energy sources that will be used to meet that demand. The Deutsche Bank approach, however, is distinct from all the EIA models because it does not assume the establishment of a price on carbon, nor does it make strong assumptions about any new environmental regulations around issues other than controlling carbon emissions.

At the same time, Deutsche Bank assumes that the existing EPA regulations on air pollution - as opposed to carbon emissions - will be strongly enforced, and that the impact of those policies will be significant in the electricity market. In particular, the Deutsche Bank model assumes that strong enforcement of existing pollution regulations will significantly reduce the commercial viability of a large segment of coal-fired electricity. For example, the Deutsche Bank study makes the following observation regarding the regulation that requires scrubbers to control emissions of mercury from coal-fired utility plants, known as the Utility Maximum Achievable Control Technology, or MACT:

We gained a first look at how pending EPA regulation is affecting (and will continue to affect) producer behavior and the wholesale market in the May 2011 ... auction, which ties to the compliance period for Utility Maximum Achievable Control Technology (MACT) regulation. The sharp 16 percent yearover-year reduction of coal generator capacity bidding into the auction reflects expectations of higher fixed costs for EPA compliance. ${ }^{5}$

Deutsche Bank also assumes that most of the reduction in coal-fired electricity will be matched with a sharp increase in electricity generated by natural gas. It assumes that natural gas supplies from shale gas will become increasingly "cheap and abundant." Crucially, the Deutsche Bank study also assumes that the environmental challenges of extracting natural gas through hydraulic fracturing technology will be resolved successfully, and as such, "sustainably managed extraction of shale gas supplies are a core part of the energy future that we envision.” 


\section{Prefatory note on statistical references}

Unlike elsewhere in this study, the figures we report from the EIA's 2030 and 2035 scenarios come from the 2011 "Annual Energy Outlook," not from the 2012 edition. We have done this for two reasons. First, relative to the 2012 edition, in the 2011 report the EIA provides a more sharply defined set of alternative policy settings through 2030 and 2035, including both the 20-Year Retrofit scenario and the Carbon-Price scenario on which we draw extensively here. In addition, the Deutsche Bank study is a 2011 publication, so its statistical time series matches up more closely with the EIA's 2011 edition. Since we are therefore working from 2011 publications here both with the EIA figures and those from Deutsche Bank, the year 2009 is the starting point for the time period we are examining, rather than 2010, which is the starting year for the data discussed in other chapters.

In Tables 4.2 through 4.8, we first present the alternative scenarios for electrical generating capacity through 2030 and 2035 in gigawatts, or GWe. Under the alternative assumptions, we then also show levels of electricity consumption in billions of kilowatt hours, or BkWh, and total energy consumed to generate electricity, expressed in Q-BTUs. The difference between electricity generated and total energy consumed to produce that electricity are referred to as electricitygenerated losses. We show the relevant figures separately, for coal, natural gas, and nuclear power. We then bring together the three sets of consumption figures and present total consumption data from all three conventional sources.

\section{Coal}

Under both the EIA Reference cases for 2030 and 2035, coal-fired capacity rises modestly from about 313 to 318 gigawatts. (see Table 4.2) This is a growth rate of less than 2 percent for the full 22-year (2009 to 2030) or 27-year (2009 to 2035) periods. 
Coal-fired electricity capacity: Alternative projections

\begin{tabular}{|c|c|c|c|c|c|c|}
\hline & $\begin{array}{c}2009 \\
\text { actual }\end{array}$ & $\begin{array}{c}\text { EIA Reference } \\
2030 \text { case }\end{array}$ & $\begin{array}{c}\text { EIA Reference } \\
2035 \text { case }\end{array}$ & $\begin{array}{c}2035 \text { ElA } \\
\text { Retrofit-20 } \\
\text { scenario }\end{array}$ & $\begin{array}{c}2035 \text { ElA: } \\
\text { Carbon-Price } \\
\text { scenario }\end{array}$ & $\begin{array}{c}\text { Deutsche } \\
\text { Bank }\end{array}$ \\
\hline $\begin{array}{l}\text { Capacity (in giga- } \\
\text { watts) }\end{array}$ & $\begin{array}{l}312.9 \\
\text { GWe }\end{array}$ & $\begin{array}{l}317.6 \\
\text { GWe }\end{array}$ & $\begin{array}{l}317.9 \\
\text { GWe }\end{array}$ & $\begin{array}{l}307.8 \\
\text { GWe }\end{array}$ & $\begin{array}{l}191.2 \\
\text { GWe }\end{array}$ & $\begin{array}{l}185.6 \\
\text { GWe }\end{array}$ \\
\hline $\begin{array}{l}\text { Percentage change } \\
\text { in capacity from } \\
2009\end{array}$ & -- & $+1.5 \%$ & $+1.6 \%$ & $-1.6 \%$ & $-38.9 \%$ & $-40.7 \%$ \\
\hline $\begin{array}{l}\text { Retirements (in } \\
\text { gigawatts) }\end{array}$ & $\mathrm{N} / \mathrm{A}$ & $\begin{array}{c}8.8 \\
\text { GWe }\end{array}$ & $\begin{array}{c}8.8 \\
\text { GWe }\end{array}$ & $\begin{array}{l}19.3 \\
\text { GWe }\end{array}$ & $\begin{array}{l}135.2 \\
\text { GWe }\end{array}$ & $\begin{array}{l}151.7 \\
\text { GWe }\end{array}$ \\
\hline $\begin{array}{l}\text { Retirements as } \\
\text { percentage of } 2009 \\
\text { capacity }\end{array}$ & $\mathrm{N} / \mathrm{A}$ & $2.8 \%$ & $2.8 \%$ & $6.2 \%$ & $43.2 \%$ & $48.5 \%$ \\
\hline
\end{tabular}

TheEIA also projects that generating significant changes in the policyenvironmentestablishing either new retrofitting requirements or setting a price on carbon-will produce a steady fall in coal-generating capacity through 2035. Under Retrofit-20, coal capacity will fall modestly, to about 308 gigawatts. But with the establishment of a carbon price, the EIA projects that the decline in coal capacity will be sharp, to 191 gigawatts by 2035. Under this Carbon-Price scenario, the decline in coal-fired capacity from 2009 to 2035 is nearly 40 percent.

Finally, with the Deutsche Bank scenario, where existing regulations on mercury and other emissions are strongly enforced, the projection is that coal-fired capacity will fall to 186 gigawatts by 2030 . This is a 41 percent decline in capacity between 2009 and 2030.

These projections with respect to coal-fired electricity-generating capacity can also be seen through estimates on capacity retirements. That is, under the EIA's 2030 and 2035 Reference scenarios, the retirements are quite modest-less than 10 gigawatts under the Reference cases, which is equal to less than 3 percent of the capacity level for 2009. Under the 20-year Retrofit scenario, the EIA does anticipate a somewhat increased rate of retirements by 2035, equal to 6.2 percent of 2009 capacity. However, the EIA projects that imposing a carbon price will generate a major increase in the retirement of coal-fired capacity, amounting to 135 gigawatts, or 43 percent of the 2009 capacity level. 
Under the Deutsche Bank scenario whereby existing EPA pollution requirements are strongly enforced, the result that Deutsche Bank projects is a major increase in retirements as of 2030 - to 152 gigawatts, or nearly 50 percent of the 2009 capacity level.

These effects on coal-generating capacity are then also reflected in estimates of energy consumption for coal, which we report in Table 4.3, both with electricity generation itself (in billions of kilowatt hours) and total energy consumption to generate electricity (in Q-BTUs). Focusing for now on the electricity generation figures in kilowatt hours, according to the EIA Reference cases, the demand for coal-fired electricity rises to between 2,138 BkWh and 2,218 BkWh by 2030 and 2035 , respectively - by between about 20 percent and 25 percent. The EIA estimates that something close to this level of coal-fired electricity generation continues under its 20-Year Retrofit scenario. With the EIA's Carbon-Price scenario, however, coal-fired electricity generation falls to $699 \mathrm{BkWh}$, a nearly 30 percent decline relative to 2009. Note also that in this case, the rate of coal-plant capacity utilization falls sharply, to about 37 percent, in contrast with the 20-Year Retrofit scenario of 67.1 percent.

\section{TABLE 4.3}

\section{Coal-fired electricity consumption: Alternative projections}

Electricity generation in billions of kilowatt hours

Total energy consumption to produce electricity in Q-BTUs

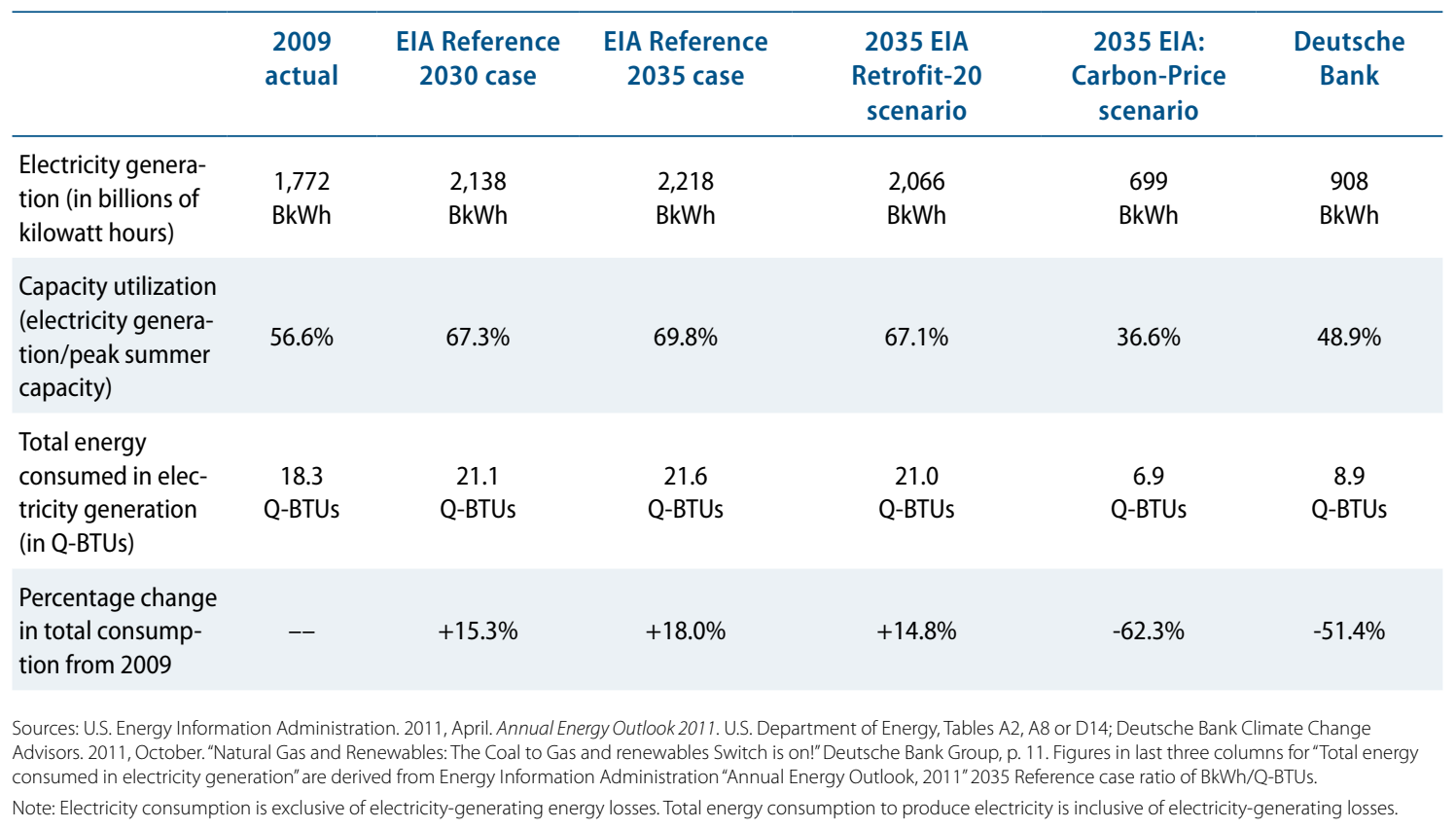


According to the Deutsche Bank's scenario, the drop in coal generation is significantly sharper still when assuming that existing environmental regulations are enforced through 2030. Deutsche Bank estimates that demand for coal-fired electricity falls to $908 \mathrm{BkWh}$, a 50 percent decline relative to 2009 levels.

\section{Natural gas}

In Table 4.4, the EIA Reference cases show natural gas generating capacity growing by about 10 percent, to 494 gigawatts in 2030, and by 18 percent, to 530 gigawatts in 2035 . The accelerated rate of capacity expansion between 2030 and 2035 reflects the idea that coal capacity would remain flat between 2030 and 2035, and that natural gas would be the primary alternative fuel source compensating for the decline of coal. This point becomes stronger still under the EIA's 20-Year Retrofit scenario. With the EIA's Carbon-Price scenario, though, the EIA projects a significantly slower growth of natural-gas-fired capacity, to 497 gigawatts. This is the same level the EIA expects for natural gas under the 2030 Reference case, prior to the large build-out the EIA is otherwise expecting between 2030 and 2035.

TABLE 4.4

Natural gas-fired electricity capacity: Alternative projections

\begin{tabular}{|c|c|c|c|c|c|c|}
\hline & $\begin{array}{l}2009 \\
\text { actual }\end{array}$ & $\begin{array}{l}\text { EIA Reference } \\
2030 \text { case }\end{array}$ & $\begin{array}{l}\text { EIA Reference } \\
2035 \text { case }\end{array}$ & $\begin{array}{l}2035 \text { EIA } \\
\text { Retrofit-20 } \\
\text { scenario }\end{array}$ & $\begin{array}{l}2035 \text { EIA: } \\
\text { Carbon-Price } \\
\text { scenario }\end{array}$ & $\begin{array}{c}\text { Deutsche } \\
\text { Bank }\end{array}$ \\
\hline $\begin{array}{l}\text { Capacity (in giga- } \\
\text { watts) }\end{array}$ & $\begin{array}{l}449.1 \\
\text { GWe }\end{array}$ & $\begin{array}{l}493.8 \\
\text { GWe }\end{array}$ & $\begin{array}{l}530.0 \\
\text { GWe }\end{array}$ & $\begin{array}{l}537.2 \\
\text { GWe }\end{array}$ & $\begin{array}{l}496.9 \\
\text { GWe }\end{array}$ & $\begin{array}{l}535.4 \\
\text { GWe }\end{array}$ \\
\hline $\begin{array}{l}\text { Percentage change } \\
\text { in capacity from } \\
2009\end{array}$ & -- & $+10.0 \%$ & $+18.0 \%$ & $+19.6 \%$ & $+10.6 \%$ & $+19.2 \%$ \\
\hline $\begin{array}{l}\text { Retirements (in } \\
\text { gigawatts) }\end{array}$ & N/A & $\begin{array}{l}28.8 \\
\text { GWe }\end{array}$ & $\begin{array}{l}29.9 \\
\text { GWe }\end{array}$ & $\begin{array}{l}26.0 \\
\text { GWe }\end{array}$ & $\begin{array}{l}37.2 \\
\text { GWe }\end{array}$ & N/A \\
\hline $\begin{array}{l}\text { Retirements as } \\
\text { percentage of } 2009 \\
\text { capacity }\end{array}$ & $\mathrm{N} / \mathrm{A}$ & $6.4 \%$ & $6.7 \%$ & $5.8 \%$ & $8.3 \%$ & N/A \\
\hline
\end{tabular}

Sources: U.S. Energy Information Administration. 2011, April. Annual Energy Outlook 2011. U.S. Department of Energy, Tables A8 or D14; Deutsche Bank Climate Change Advisors. 2011, October. "Natural Gas and Renewables: The Coal to Gas and renewables Switch is on!" Deutsche Bank Group.

Note: Capacity figures are net summer capacity in all cases.

The Deutsche Bank scenario is similar to the EIA 20-Year Retrofit case in that it estimates that natural gas capacity will increase by nearly 20 percent between 2009 and 2030 to compensate for the decline of coal capacity. 
Based on these figures showing expanding natural gas electricity-generating capacity through 2030 and 2035, it is interesting that the EIA projects natural gas retirements as being greater than those for coal in all scenarios other than the Carbon-Price case. This reflects the fact that there is currently a relatively large stock of aging natural gas capacity. ${ }^{6}$ The Deutsche Bank study does not project retirement rates for natural gas.

Turning now to Table 4.5, we see that in all of the EIA scenarios, natural-gas-fired electricity generation is rising, but the rate of increase accelerates as we move between 2030 and 2035, and as the 20-Year Retrofit case or Carbon-Price regulations are established. Thus, under the EIA 2030 Reference case, natural-gas-fired electricity generation rises from $931 \mathrm{BkWh}$ to $1,152 \mathrm{BkWh}$, resulting in a 5.6 percent increase in total energy consumed in Q-BTUs. But the EIA assumes that even with the Reference case for 2035, natural gas-fired electricity will expand further, to $1,288 \mathrm{BkWh}$ - a rise of 14 percent relative to 2009 in Q-BTUs. The EIA's estimates of total energy consumed for natural-gas-fired electricity generation then rises to between 24 percent and 30 percent under the 20-Year Retrofit and Carbon-Price scenarios. Clearly we see here that to a significant degree, the EIA is projecting that natural-gas-fired electricity is supplanting coal through 2035, regardless of the particulars of the future policy environment.

TABLE 4.5

Natural gas-fired electricity consumption: Alternative projections

Electricity generation in billions of kilowatt hours

Total energy consumption to produce electricity in quadrillions of BTUs

\begin{tabular}{|c|c|c|c|c|c|c|}
\hline & $\begin{array}{c}2009 \\
\text { actual }\end{array}$ & $\begin{array}{c}\text { EIA Reference } \\
2030 \text { case }\end{array}$ & $\begin{array}{c}\text { EIA Reference } \\
2035 \text { case }\end{array}$ & $\begin{array}{l}2035 \text { ElA } \\
\text { Retrofit-20 } \\
\text { scenario }\end{array}$ & $\begin{array}{c}2035 \text { ElA: } \\
\text { Carbon-Price } \\
\text { scenario }\end{array}$ & $\begin{array}{c}\text { Deutsche } \\
\text { Bank }\end{array}$ \\
\hline $\begin{array}{l}\text { Electricity genera- } \\
\text { tion (in billions of } \\
\text { kilowatt hours) }\end{array}$ & $\begin{array}{c}931 \\
\text { BkWh }\end{array}$ & $\begin{array}{l}1,152 \\
\text { BkWh }\end{array}$ & $\begin{array}{l}1,288 \\
\text { BkWh }\end{array}$ & $\begin{array}{l}1,063 \\
\text { BkWh }\end{array}$ & $\begin{array}{l}1,345 \\
\text { BkWh }\end{array}$ & $\begin{array}{l}1,642 \\
\text { BkWh }\end{array}$ \\
\hline $\begin{array}{l}\text { Capacity utilization } \\
\text { (electricity genera- } \\
\text { tion/net summer } \\
\text { capacity) }\end{array}$ & $20.7 \%$ & $23.59 \%$ & $24.3 \%$ & $19.8 \%$ & $27.1 \%$ & $30.7 \%$ \\
\hline $\begin{array}{l}\text { Total energy } \\
\text { consumed in elec- } \\
\text { tricity generation } \\
\text { (in Q-BTUs) }\end{array}$ & $\begin{array}{c}7.1 \\
\text { Q-BTUs }\end{array}$ & $\begin{array}{c}7.5 \\
\text { Q-BTUs }\end{array}$ & $\begin{array}{c}8.1 \\
\text { Q-BTUs }\end{array}$ & $\begin{array}{c}8.8 \\
\text { Q-BTUs }\end{array}$ & $\begin{array}{c}9.2 \\
\text { Q-BTUs }\end{array}$ & $\begin{array}{c}11.3 \\
\text { Q-BTUs }\end{array}$ \\
\hline $\begin{array}{l}\text { Percentage change } \\
\text { in total consump- } \\
\text { tion from } 2009\end{array}$ & -- & $+5.6 \%$ & $+14.1 \%$ & $+23.9 \%$ & $29.6 \%$ & $+59.2 \%$ \\
\hline
\end{tabular}


Deutsche Bank projects a still greater displacement of coal with natural gas-fired electricity through 2030. As Table 4.4 shows, the Deutsche Bank scenario for 2030 estimates natural-gas-fired electricity at 1,642 BkWh, a 59 percent rise in total energy consumed relative to 2009. In addition, Deutsche Bank assumes a significant rise in the capacity-utilization rate for natural-gas electricity plants-to 31 percent by 2030, relative to the actual 21 percent utilization rate for 2009 .

\section{Nuclear power}

Table 4.6 shows that nuclear-powered electrical-generating capacity totaled 101 gigawatts in 2009. In Table 4.7, we see that electricity generated by nuclear power totaled nearly $800 \mathrm{BkWh}$. Under the EIA references cases and the 20-Year Retrofit scenario, both capacity and generation will grow through 2030 and 2035 but at a relatively modest rate, in the range of 8 percent to 11 percent over the full 22 - or 27-year period.

TABLE 4.6

Nuclear-powered electricity capacity: Alternative projections

\begin{tabular}{|c|c|c|c|c|c|c|}
\hline & $\begin{array}{c}2009 \\
\text { actual }\end{array}$ & $\begin{array}{l}\text { EIA Reference } \\
2030 \text { case }\end{array}$ & $\begin{array}{c}\text { EIA Reference } \\
2035 \text { case }\end{array}$ & $\begin{array}{c}2035 \text { ElA } \\
\text { Retrofit-20 } \\
\text { scenario }\end{array}$ & $\begin{array}{l}2035 \text { EIA: } \\
\text { Carbon-Price } \\
\text { scenario }\end{array}$ & $\begin{array}{l}\text { Deutsche } \\
\text { Bank }\end{array}$ \\
\hline $\begin{array}{l}\text { Capacity (in giga- } \\
\text { watts) }\end{array}$ & $\begin{array}{c}101 \\
\text { GWe }\end{array}$ & $\begin{array}{l}110.5 \\
\text { GWe }\end{array}$ & $\begin{array}{l}110.5 \\
\text { GWe }\end{array}$ & $\begin{array}{l}110.5 \\
\text { GWe }\end{array}$ & $\begin{array}{l}133.6 \\
\text { GWe }\end{array}$ & $\mathrm{N} / \mathrm{A}$ \\
\hline $\begin{array}{l}\text { Percentage change } \\
\text { in capacity from } \\
2009\end{array}$ & -- & $+9.4 \%$ & $+9.4 \%$ & $+9.4 \%$ & $+32.3 \%$ & $\mathrm{~N} / \mathrm{A}$ \\
\hline $\begin{array}{l}\text { Retirements (in } \\
\text { gigawatts) }\end{array}$ & $\mathrm{N} / \mathrm{A}$ & $\begin{array}{c}0.6 \\
\text { GWe }\end{array}$ & $\begin{array}{c}0.6 \\
\text { GWe }\end{array}$ & $\begin{array}{c}0.6 \\
\text { GWe }\end{array}$ & $\begin{array}{c}0.7 \\
\text { GWe }\end{array}$ & $\mathrm{N} / \mathrm{A}$ \\
\hline $\begin{array}{l}\text { Retirements as } \\
\text { percentage of } 2009 \\
\text { capacity }\end{array}$ & $\mathrm{N} / \mathrm{A}$ & $0.6 \%$ & $0.6 \%$ & $0.6 \%$ & $0.7 \%$ & $\mathrm{~N} / \mathrm{A}$ \\
\hline
\end{tabular}


TABLE 4.7

Nuclear-powered electricity consumption: Alternative projections

Electricity generated in billions of kilowatt hours

Total energy consumption to produce electricity in Q-BTUs

\begin{tabular}{|c|c|c|c|c|c|c|}
\hline & $\begin{array}{c}2009 \\
\text { actual }\end{array}$ & $\begin{array}{l}\text { EIA Reference } \\
2030 \text { case } \\
\text { (Table A8) }\end{array}$ & $\begin{array}{c}\text { EIA Reference } \\
2035 \text { case }\end{array}$ & $\begin{array}{c}2035 \text { ElA } \\
\text { Retrofit-20 } \\
\text { scenario } \\
\text { (Table D14) }\end{array}$ & $\begin{array}{c}2035 \text { EIA } \\
\text { Carbon-Price } \\
\text { scenario } \\
\text { (Table D14) }\end{array}$ & $\begin{array}{c}\text { Deutsche } \\
\text { Bank }\end{array}$ \\
\hline $\begin{array}{l}\text { Electricity genera- } \\
\text { tion (in billions of } \\
\text { kilowatt hours) }\end{array}$ & $\begin{array}{c}799 \\
\text { BkWh }\end{array}$ & $\begin{array}{c}877 \\
\text { BkWh }\end{array}$ & $\begin{array}{c}874 \\
\text { BkWh }\end{array}$ & $\begin{array}{c}874 \\
\text { BkWh }\end{array}$ & $\begin{array}{l}1,052 \\
\text { BkWh }\end{array}$ & $\begin{array}{c}735 \\
\text { BkWh }\end{array}$ \\
\hline $\begin{array}{l}\text { Capacity utilization } \\
\text { (electricity genera- } \\
\text { tion/net summer } \\
\text { capacity) }\end{array}$ & $79.1 \%$ & $79.4 \%$ & $79.1 \%$ & $79.1 \%$ & $78.7 \%$ & N/A \\
\hline $\begin{array}{l}\text { Total energy } \\
\text { consumed in elec- } \\
\text { tricity generation } \\
\text { (in Q-BTUs) }\end{array}$ & $\begin{array}{c}8.3 \\
\text { Q-BTUs }\end{array}$ & $\begin{array}{c}9.2 \\
\text { Q-BTUs }\end{array}$ & $\begin{array}{c}9.1 \\
\text { Q-BTUs }\end{array}$ & $\begin{array}{c}9.0 \\
\text { Q-BTUs }\end{array}$ & $\begin{array}{c}10.9 \\
\text { Q-BTUs }\end{array}$ & $\begin{array}{c}8.0 \\
\text { Q-BTUs }\end{array}$ \\
\hline $\begin{array}{l}\text { Percentage change } \\
\text { in total consump- } \\
\text { tion from } 2009\end{array}$ & -- & $+10.8 \%$ & $+9.6 \%$ & $+8.4 \%$ & $+31.3 \%$ & $-3.6 \%$ \\
\hline
\end{tabular}

Sources: Figures are directly from U.S. Energy Information Administration. 2011, April. Annual Energy Outlook 2011. U.S. Department of Energy, Tables A2, A8 or D14. Figures in last three columns for "Total energy consumed in electricity generation" are derived from equal weighting of AEO 2009 actual and 2035 Reference case ratio of BkWh/Q-BTUs. Note: Electricity consumption is exclusive of electricity-generating energy losses. Total energy consumption to produce electricity is inclusive of electricity-generating losses.

With its Carbon-Price scenario, the EIA forecasts an accelerated rate of growth for both nuclear capacity and electricity consumption, increasing to more than 30 percent between 2009 and 2035. Once a carbon price is established, the EIA anticipates that a significant rise in the use of nuclear power will compensate for the decline in the use of fossil-fuel-generated electricity.

The Deutsche Bank study provides a strongly contrasting view. Rather than expecting demand for nuclear power to increase, it sees a sharp long-term decline for the industry. According to this scenario, nuclear power in 2030 will provide $735 \mathrm{BkWh}$ of electricity, about 8 percent less than in 2009. The main driver here, according to Deutsche Bank, will be growing safety concerns about nuclear power, resulting primarily from the Fukushima disaster in Japan. The authors of this study write: 
Nuclear energy maintains share through 2020 because of the expected success of the Department of Energy's loan program and regulatory support in the US Southeast, where regulators see nuclear power as an important contributor to the state and local economies and hedge to the coal-dominated supply mix. But nuclear energy loses modest share between 2020 and 2030 due to more stringent regulatory requirements, high capital costs and accelerated retirements due to EPA regulation of cooling water intake structures. This also reflects an expected change in attitudes and cost following the Fukushima disaster, which has put nuclear energy under considerably more pressure and tougher regulatory scrutiny given the tail risk. 


\section{Overall assessment of conventional fuels for electricity sector}

In Table 4.8, we summarize the level of overall energy supplied for electricity by coal, natural gas, and nuclear power in 2030 and 2035, according to the various EIA scenarios and the Deutsche Bank scenario. The figures reported here provide valuable background for assessing alternative approaches to managing excess capacity with these conventional energy sources that will result after significant gains in energy efficiency are established throughout the U.S. economy. Table 4.8 shows these summary electricity-consumption figures, both in terms of electricity consumed in billions of kilowatt hours and as total energy consumed to produce electricity, measured in Q-BTUs. Because we will now focus on overall energy supply and demand in a unified way, it will be most convenient to consider the figures expressed through the uniform metric of Q-BTUs.

We began this chapter with the assumption that for meeting both electricity and nonelectricity energy needs, the United States would require about 34 Q-BTUs of supply coming from coal, natural gas, and nuclear power as of 2030 -2035. As Table 4.8 shows, the actual level of energy used in 2009 to supply electricity alone was itself about 34 Q-BTUs. In addition to the figures shown in Table 4.8, natural gas supplied another 16 Q-BTUs of energy for a range of applications within buildings and industry in 2009, while coal provided another 1.4 Q-BTUs for mostly industrial uses in the same year. Nuclear power is used exclusively for electricity.

Focusing just on electricity generation, as Table 4.8 shows, both the EIA and Deutsche Bank each provide a scenario in which electricity produced by these sources would end up falling significantly relative to the 2009 level—to between 27 and 28 Q-BTUs. The EIA reaches this target by 2035, while Deutsche Bank's projection is for 2030 . 
TABLE 4.8

Electricity generation from all nonrenewable energy sources: Alternative projections

Electricity consumed from nonrenewable sources in billions of kilowatt hours

\begin{tabular}{|c|c|c|c|c|c|c|}
\hline & $\begin{array}{l}2009 \\
\text { actual }\end{array}$ & $\begin{array}{l}\text { EIA Reference } \\
2030 \text { case }\end{array}$ & $\begin{array}{l}\text { EIA Reference } \\
2035 \text { case }\end{array}$ & $\begin{array}{c}2035 \text { ElA } \\
\text { Retrofit-20 } \\
\text { scenario }\end{array}$ & $\begin{array}{c}2035 \text { ElA: } \\
\text { Carbon-Price } \\
\text { scenario }\end{array}$ & $\begin{array}{l}\text { Deutsche } \\
\text { Bank }\end{array}$ \\
\hline Coal & $1,772 \mathrm{BkWh}$ & 2,138 BkWh & 2,218 BkWh & 2,066 BkWh & $699 \mathrm{BkWh}$ & $908 \mathrm{BkWh}$ \\
\hline Natural gas & $931 \mathrm{BkWh}$ & 1,152 BkWh & 1,288 BkWh & 1,063 BkWh & 1,345 BkWh & 1,642 BkWh \\
\hline Nuclear & 799 BkWh & 877 BkWh & $874 \mathrm{BkWh}$ & $874 \mathrm{BkWh}$ & $1,052 \mathrm{BkWh}$ & 735 BkWh \\
\hline Total & 3,502 BkWh & 4,167 BkWh & 4,380 BkWh & 4,003 BkWh & 3,096 BkWh & 3,285 BkWh \\
\hline
\end{tabular}

Total nonrenewable energy consumed to produce electricity in Q-BTUs

\begin{tabular}{lcccccc}
\hline 2009 actual & $\begin{array}{c}\text { EIA Reference } \\
2030 \text { case } \\
\text { (Table A8) }\end{array}$ & $\begin{array}{c}\text { EIA Reference } \\
2035 \text { case }\end{array}$ & $\begin{array}{c}2035 \text { EIA } \\
\text { retrofit-20 } \\
\text { scenario } \\
\text { (Table D14) }\end{array}$ & $\begin{array}{c}2035 \text { EIA: } \\
\text { Carbon-Price } \\
\text { scenario } \\
\text { (Table D14) }\end{array}$ & $\begin{array}{c}\text { Deutsche } \\
\text { Bank } \\
(p .11)\end{array}$ \\
\hline Coal & 18.3 Q-BTUs & 21.1 Q-BTUs & 21.6 Q-BTUs & 21.0 Q-BTUs & 6.9 Q-BTUs & 8.9 Q-BTUs \\
Natural gas & 7.1 Q-BTUs & 7.5 Q-BTUs & 8.1 Q-BTUs & 8.8 Q-BTUs & 9.2 Q-BTUs & 11.3 Q-BTUs \\
Nuclear & 8.3 Q-BTUs & 9.2 Q-BTUs & 9.1 Q-BTUs & 9.0 Q-BTUs & 10.9 Q-BTUs & 8.0 Q-BTUs \\
Total & $\mathbf{3 3 . 7}$ Q-BTUs & $\mathbf{3 7 . 8}$ Q-BTUs & $\mathbf{3 8 . 8}$ Q-BTUs & $\mathbf{3 8 . 8}$ Q-BTUs & $\mathbf{2 7 . 0}$ Q-BTUs & $\mathbf{2 8 . 2}$ Q-BTUs
\end{tabular}

Source: See Tables 4.2, 4.4, and 4.6.

These two scenarios for which we would be consuming between 27 and 28 Q-BTUs total for electricity powered by coal, natural gas, and nuclear power are themselves distinct. Under the EIA's model, pushing total electricity consumption from nonrenewable sources to 27 Q-BTUs will occur if a price on carbon is established. With the carbon price, the EIA assumes that coal-fired electricity will fall by 62 percent as of 2035, to 6.9 Q-BTUs. Natural-gas-fired electricity, by contrast, will increase by 30 percent, to 9.2 Q-BTUs, and nuclear-generated electricity also rises by around 30 percent, to 10.9 Q-BTUs.

The Deutsche Bank scenario, as we have discussed, does not rely on setting a price on carbon or any other significant new environmental regulations, but rather only assumes that the EPA strongly enforces existing pollution regulations-which would be extended to regulate carbon pollution. The Deutsche Bank scenario, then, allows that these regulations by themselves will be effective enough to produce a decline by half in coal consumption for electricity by 2030. The Deutsche Bank 
study then also assumes that there will be no growth in nuclear power, but rather a modest decline of about 4 percent, due to rising safety concerns. In the Deutsche Bank scenario, the consumption of natural gas for electricity rises sharply, to 11.3 Q-BTUs-a nearly 60 percent increase.

Overall, then, either with the EIA or Deutsche Bank, we see two plausible scenarios based on distinct policy frameworks through which electricity supplied by coal, natural gas, and nuclear power fall below its 2009 level as of 2030-2035. In both scenarios, the coal industry faces a major contraction relative to 2009. By contrast, the projections for natural gas and nuclear power vary accordingly between the alternative scenarios. 


\section{Environmental and safety concerns}

\section{Nuclear power}

As we have seen, by 2010 nuclear power provided about 8.4 Q-BTUs of energy within the U.S. economy, which represented about 8.6 percent of overall U.S. energy supply. Worldwide, nuclear power contributes about 5.1 percent of overall energy supply. ${ }^{7}$ In terms of the United States achieving its 20 -year $\mathrm{CO}_{2}$ emissions reduction target of 3,200 $\mathrm{mmt}$ - the main focus of this study-nuclear power provides the obvious important benefit that it does not generate emissions or air pollution of any kind while operating. As we will see, this becomes a key issue when we estimate alternative paths for reaching the 2030 emissions target.

At the same time, as the EIA recognizes:

The processes for mining and refining uranium ore and making reactor fuel require large amounts of energy. Nuclear power plants have large amounts of metal and concrete, which also require large amounts of energy to manufacture. If fossil fuels are used to make the electricity and manufacture the power plant materials, then the emissions from burning those fuels could be associated with the electricity that nuclear power plants generate. ${ }^{8}$

It is difficult to reach firm conclusions as to the extensiveness of these secondary GHG emissions effects from producing nuclear energy. In their survey of the relevant literature, Beerten and co-authors conclude that none of the relevant studies on this question "takes into account the different mining techniques in a proper manner." They also conclude that insufficient evidence is available as to the "energy and GHG emissions involved with the waste processing, storage and disposal on the one hand and the decommissioning of the plant on the other hand." 
However, even if we assume a best-case scenario in terms of full-cycle emissions from generating nuclear energy, we still of course need to recognize the longstanding environmental and public safety issues associated with nuclear energy. These concerns include:

- Radioactive wastes: These wastes include uranium mill tailings, spent reactor fuel, and others, which, according to the EIA's 2012 report, "can remain radioactive and dangerous to human health for thousands of years."

\section{- Storage of spent reactor fuel and power-plant decommissioning: Spent} reactor fuel assemblies are highly radioactive and must be stored in specially designed pools or specially designed storage containers. When a nuclear power plant stops operating, the decommissioning process involves safely removing the plant from service and reducing radioactivity to a level that permits other uses of the property.

- Political security: Nuclear energy can obviously be used to produce deadly weapons, as well as electricity. Thus, the proliferation of nuclear-energy production capacity creates dangers if this capacity is acquired by organizations-governments or otherwise - that would use that energy as instruments of war or terror.

- Nuclear reactor meltdowns: An uncontrolled nuclear reaction at a nuclear plant can result in widespread contamination of air and water, with radioactivity for hundreds of miles around a reactor.

Even while recognizing these problems with nuclear energy, it is still the case, as noted above, that nuclear power supplies more than 8 percent of all U.S. energy and about 5 percent of global energy supply. For decades, a widely-held view throughout the world was that these risks associated with nuclear power were small and acceptable, when balanced against the benefits. As we quoted from the Deutsche Bank Climate Change Advisors study earlier, however, this view has been upended in the aftermath of the March 2011 nuclear meltdown at the Fukushima Daiichi power plant in Japan, which resulted from the massive 9.0 Tohuku earthquake and tsunami. 
The full effects of the Fukushima meltdown cannot possibly be known for some time. But an initial recent research paper by Ten Hoeve and Jacobson ${ }^{10}$ on the overall health effects of Fukushima finds that they are likely to be very large. Ten Hoeve and Jacobson conclude that the health effects from inhalation, external exposure, and ingestion of radionuclides will range between 15 and 1,100 cancerrelated deaths and between 24 and 1,800 morbidities, with most of the impact within Japan itself. Their estimates do not include the effects on the roughly 20,000 workers at the plant in the months following the accident. They also do not include the nearly 600 deaths that had been certified as "disaster related," through fatigue or aggravation of chronic illnesses due to the disaster. ${ }^{11}$

In its 2011 "International Energy Outlook," the EIA acknowledges that Fukushima has substantially intensified concerns worldwide about the viability of expanding — or even maintaining—nuclear energy as a major power source. ${ }^{12}$ The EIA writes:
Although the long-term implications of the disaster at Japan's Fukushima
Daiichi nuclear power plant for world nuclear power development are unknown,
Germany, Switzerland, and Italy have already announced plans to phase out or cancel all of the existing or future reactors. Thus plans, and new policies that other countries may adopt in response to the disaster ... indicated that some reduction in the projection for nuclear power should be expected.

Overall, then, it is clear that these safety considerations with nuclear energy must be accorded significant weight alongside the benefit that nuclear-powered electricity generation itself produces no greenhouse gas emissions.

\section{Hydraulic fracturing}

We saw in Chapter 3 that the EIA's forecast of total levelized costs for generating electricity from natural-gas-powered processes will be substantially lower than those from any other conventional or renewable energy source. We summarize the figures presented in Chapter 3 in Table 4.9 below. 
TABLE 4.9

Total levelized costs for electricity generation from alternative energy sources

ElA projections for 2017

\begin{tabular}{lcc}
\hline & $\begin{array}{c}\text { Total } 2017 \\
\text { estimated costs } \\
\text { per megawatt hour }\end{array}$ & $\begin{array}{c}\text { Total 2017 estimated costs } \\
\text { relative to natural gas } \\
\text { (percent) }\end{array}$ \\
\hline Conventional natural gas (no CCS) & $\$ 66.1$ & -- \\
Hydro & $\$ 88.9$ & +34.5 \\
Wind & $\$ 96.0$ & +45.2 \\
Conventional coal (no CCS) & $\$ 97.7$ & +47.8 \\
Nuclear & $\$ 111.4$ & +68.5 \\
Biomass & $\$ 115.4$ & +74.6 \\
Solar photovoltaic & $\$ 152.7$ & +131.0
\end{tabular}

Source: U.S. Energy Information Administration. 2012, July. "Levelized Cost of New Generation Resources in the Annual Energy Outlook $2012 . "$ U.S. Department of Energy.

As we see, the EIA projects that by 2017 the total costs of electricity generation from natural gas without CCS technology will be $\$ 66.1$ per megawatt hour. The cost of hydropower, the next-lowest cost source for electricity generation, is 34 percent higher, at $\$ 88.9$ per megawatt hour. Coal, wind, biomass, nuclear, or solar photovoltaic costs are then between 45 percent and 131 percent higher than natural-gas-fired electricity costs, according to the EIA's projections.

The factor that is producing such low-cost electricity projections from natural gas is the EIA's assumption of a rapidly expanding use of hydraulic fracturing technology to extract natural gas from shale rock. But the issue with fracking technology is that some - though not all—credible research finds that fracking consistently produces serious environmental costs, along with an inexpensive energy supply. In particular, fracking has been demonstrated to contaminate drinking water with methane gas in aquifers overlying the major shale formations of northeastern Pennsylvania and upstate New York. Yet other recent research has found that methane emissions can be significantly reduced when producers take active measures to control methane emissions. 
It will be useful here to review these alternative perspectives. To begin with, we draw from an important 2011 overview paper by Jackson et al. of Duke University. Jackson et al. begin by describing the basics of fracking technology and explain why this technology is capable of extracting natural gas at significantly lower costs than conventional extraction methods:

The extraction of natural gas from shale formations is one of the fastest growing trends in American on-shore domestic oil and gas production. ... Large-scale production of shale gas has become economically viable in the last decade attributable to advances in horizontal drilling and hydraulic fracturing (also called "hydrofracturing" or "fracking"). Such advances have significantly improved the production of natural gas in numerous basins across the United States, including the Barnett, Haynesville, Fayetteville, Woodford, Utica, and Marcellus shale formations. In 2010, shale gas production doubled to 137.8 billion cubic meters, and the EIA projects that by 2035 shale gas production will increase to 340 billion cubic meters per year, amounting to $47 \%$ of the projected gas production in the United States.

Hydraulic fracturing typically involves millions of gallons of fluid that are pumped into an oil or gas well at high pressure to create fractures in the rock formation that allow oil or gas to flow from the fractures to the wellbore. Fracturing fluid is roughly 99\% water but also contains numerous chemical additives as well as propping agents, such as sands, that are used to keep fractures open once they are produced under pressure. The chemicals added to fracturing fluid include friction reducers, surfactants, gelling agents, scale inhibitors, acids, corrosion inhibitors, antibacterial agents, and clay stabilizers. The Interstate Oil and Gas Compact Commission (IOGCC) estimates that hydraulic fracturing is used to stimulate production in $90 \%$ of domestic oil and gas wells, though shale and other unconventional gas recovery utilizes high-volume hydraulic fracturing to a much greater extent than conventional gas development does. Horizontal wells, which may extend two miles from the well pad, are estimated to be 2-3 times more productive than conventional vertical wells, and see an even greater increase in production from hydraulic fracturing. The alternative to hydraulic fracturing is to drill more wells in an area, a solution that is often economically or geographically prohibitive. ${ }^{13}$ 
One perspective of the environmental impact of fracking is represented by the Deutsche Bank Climate Change Advisors in its 2011 study, which considers the issue in some detail. It concludes that the environmental and safety issues with shale extraction are manageable. It writes:

We see no technical reasons that will impede shale gas from being extracted safely and responsibly with minimal environmental footprint. Diffusing industry best practices with respect to well-casing, disclosure of chemicals used in fracking fluid, and wastewater disposal will be critical to ensuring that shale gas production proceeds in a safe and environmentally-friendly way.

This position expressed by Deutsche Bank is consistent with the findings reached in a major 2013 research study directed by David T. Allen of the University of Texas, Austin, which was funded by the natural gas industry. Allen et al. found that methane emissions could be cut by as much as 98 percent-from 81 to 1.7 megatons per well-when controls were utilized to capture these emissions.

The 2011 study by Jackson et al. presents a sharply different view, especially around the issue of groundwater contamination. It concludes:

A recent study by Osborn and colleagues in the Proceedings of the National Academy of Sciences, USA provides to our knowledge the first systematic evidence of methane contamination of private drinking-water in areas where shale gas extraction is occurring. The research was performed at sites above the Marcellus and Utica formations in Pennsylvania and New York. Based on groundwater analyses of 60 private water wells in the region, methane concentrations were found to be 17-times higher on average in areas with active drilling and extraction than in non-active areas, with some drinking-water wells having concentrations of methane well above the "immediate action" hazard level. ${ }^{14}$

In a more recent 2013 study, "Increased Stray Gas Abundance in a Subset of Drinking Water Wells Near Marcellus Shale Gas Extraction,” Jackson et al. reached basically the same conclusion as their 2011 paper regarding the impact of fracking technology on drinking water. In their 2013 paper, for example, they conclude that "Methane was detected in 82 percent of drinking water samples, with average concentrations six times higher for homes less than one kilometer from natural gas wells," and that "Ethane was 23 times higher in homes less than one kilometer from gas wells.” 
Certainly, neither the University of Texas nor the Duke University studies can be considered to have produced definitive findings. Yet taken together, they bring greater clarity regarding a key question at hand: whether adequate controls can be put in place for greatly reducing the methane emissions that are occurring in the absence of such controls. Establishing such controls would no doubt be costly, and the industry would likely prefer to avoid paying these costs. ${ }^{15}$ From this perspective, the safety concerns regarding fracking are comparable to those connected with nuclear energy.

As a result of the negative findings regarding contamination of drinking water, in May 2012, Vermont became the first state in the United States to pass legislation banning fracking. As of this writing, New York state also operates with a moratorium on fracking. Other states and municipalities have either imposed temporary moratoria or are in the process of debating such measures. In Europe, as of October 2013, countries that have banned fracking include France and Bulgaria, which have the largest deposits of exploitable shale rock resources in on the Continent. The Czech Republic, Northern Ireland, and the regions of Cantabria in Spain, and Friebourg in Switzerland have also established bans, while Romania, Germany and Luxembourg have declared moratoria. ${ }^{16}$ 


\section{Carbon capture and sequestration}

Carbon capture and sequestration, or CCS, is a broad term that encompasses a number of specific technologies that are capable of capturing $\mathrm{CO}_{2}$ from point sources such as power plants and other industrial facilities. Through CCS technologies, the captured $\mathrm{CO}_{2}$ is then transported, usually through pipelines, in some form to locations where it is then stored indefinitely in subsurface geological formations.

One specific approach entails converting the captured $\mathrm{CO}_{2}$ into liquid form, then moving the liquid $\mathrm{CO}_{2}$ through pipelines to oil reservoirs. If the oil has already been extracted from such reservoirs, then the dormant reservoir can serve as a permanent $\mathrm{CO}_{2}$ storage facility. But if the reservoir does still contain oil, then the $\mathrm{CO}_{2}$ injections can be used to push the remaining oil out of the repository more efficiently. In 2009 Science reported on five CCS projects of this type that were in operation around the world and another seven that were in the process of being planned. Two of the operating projects were in the North Sea, and the other three were in Sastatchewan, Canada; Kaniow, Poland; and Salah, Algeria. ${ }^{17}$

The broad case on behalf of CCS is straightforward: The development of effective CCS technologies will allow for the world's enormous fossil fuel energy resources to continue to be exploited without these energy sources releasing such high levels of $\mathrm{CO}_{2}$ into the atmosphere. As former U.S. Energy Secretary Steven Chu wrote in 2009:

The world has abundant fossil fuel reserves, particularly coal. The United States possesses one-quarter of the known coal supply, and the United States, Russia, China and India account for two-thirds of the reserves. Coal accounts for 25 percent of the world's energy supply and 40 percent of the carbon emissions. It is highly unlikely that any of these countries will turn their back on coal any time soon, and for this reason, the capture and storage of $\mathrm{CO}_{2}$ emissions from fossil fuel power plants must be aggressively pursued. ${ }^{18}$ 
At the same time, as surveyed forcefully by Romm (2008), there are four major problems associated with CCS technologies, which combined render the approach unsuitable to serve as a major clean-energy strategy either in the relatively short run or the longer term. These four problems entail issues of costs, timing, scale, and permanence and transparency. It is worth quoting at length from Romm's excellent overview:

1. Cost: Coal plants with CCS are very expensive today. The total extra cost for this process, including geological storage in sealed underground sites, is currently quite high, $\$ 30$ to $\$ 80$ a ton of carbon dioxide, according to the Department of Energy's Office of Fossil Energy. ${ }^{19}$ And that is on top of the cost of new coal plants, which have become very expensive. In the future, it seems rather unlikely that CCS would be a low-cost solution. The modeling work done for the California Public Utility Commission (CPUC) on how to comply with the AB32 law (California's Global Warming Solutions Act), puts the cost of coal gasification with carbon capture and storage at a staggering 16.9 cents per kWh. Energy efficiency along with lots of low-carbon generation sources beat that easily now or will very soon.

2. Timing: The world does not even have a single large-scale $(300+\mathrm{MW})$ coal plant with CCS anywhere in the world. ... In the past year, most governments and most U.S. utilities have scaled back, delayed, or cancel their planned CCS projects (see below). As Howard Herzog of MIT's Laboratory for Energy and the Environment said in February 2008 "How can we expect to build hundreds of these plants when we're having so much trouble building the first one?”20

3. Scale: We need to put in place a dozen or so clean energy "stabilization wedges" by mid-century to avoid catastrophic climate outcomes. ... For CCS to be even one of those would require a flow of $\mathrm{CO}_{2}$ into the ground equal to the current flow of oil out of the ground. That would require, by itself, re-creating the equivalent of the planet's entire oil delivery infrastructure, no mean feat.

4. Permanence and transparency: If Putin's Russia said it was sequestering 100 million tons of $\mathrm{CO}_{2}$ in the ground permanently, and wanted other countries to pay it billions of dollars to do so, would anyone trust them? No. The potential for fraud and bribery are simply too enormous. But would anyone trust China? Would anyone trust a U.S. utility, for that matter? We need to set up some sort of international regime for certifying, monitoring, verifying, and inspecting 
geologic repositories of carbon-like the U.N. weapons inspections systems. The problem is, this country hasn't been able to certify a single storage facility for a high-level radioactive waste after two decades of trying and nobody knows how to monitor and verify underground $\mathrm{CO}_{2}$ storage. It could take a decade just to set up this system.

In addition to the issues highlighted by Romm's survey, there are also broader environmental issues at stake. The possibility of leaks from the underground $\mathrm{CO}_{2}$ repositories is one such danger. Any such leakage could produce contamination of ground water-and thereby, drinking water. Leaks could also mean new releases of the very $\mathrm{CO}_{2}$ emissions that the technology is designed to mitigate. Still another issue is the environmental damage from continuing to extract coal through mountaintop removal and strip mining.

From this review of the evidence, Romm thus concludes that "we should continue to pursue CCS research, development, and demonstration ... but efficiency, wind, solar PV and baseload solar are where we should be placing the big deployment dollars right now."

Beyond these environmental issues and safety concerns associated with nuclear power, hydraulic fracturing, and carbon capture and sequestration is the most basic environmental issue on which we are focusing in this study: controlling $\mathrm{CO}_{2}$ emissions and climate change. We now turn to these questions in Chapter 5. 
1 Here again we refer to the energy-based emissions target of 3,200 $\mathrm{mmt} \mathrm{CO}$ rather than the target emissions level of $4,200 \mathrm{mmt} \mathrm{CO2e}$ from both energy and nonenergy sources.

2 Throughout the rest of this study, unless otherwise specified, we will include high-emissions ethanol energy sources as being included in the total supply figures for oil.

3 The total of domestic production plus imports do not add up to the total of 37.0 Q-BTUs of supply, to match the 37.0 Q-BTUs of demand, since domestic production includes corn ethanol and other high-emissions renewables.

4 Quoted text is from U.S. Energy Information Administration, Annual Energy Outlook 2011 (U.S. Department of Energy, 2011), p. 49, available at http://www.eia.gov/ forecasts/archive/aeo11/pdf/0383(2011).pdf. FGD is a set of technologies used to remove sulfur dioxide, or $\mathrm{SO}_{2}$, from exhaust fuel gases of fossil-fuel power plants and from the emissions of other sulfur oxide emitting processes. Selective catalytic reduction is a process of converting, with the aid of a catalyst, nitrogen oxides, or NOx, into pure nitrogen and water vapor. These systems have been shown to reduce emissions of NOx by 75 percent to 90 percent when used with large utility boilers.

5 Deutsche Bank, "Natural Gas and Renewables: The Coal to Gas and renewables Switch is on!" (2011), p. 22, available at http://www.cleanlineenergy.com/sites/cleanline/ media/resources/Natural-Gas-and-Renewables.PDF.

6 In general, oil and gas steam-electric generators are older, less-efficient plants. According to the 2010 EIA Annual Electric Generator Report, the average oil/gas steamelectric plant was built in 1967, with the oldest operating unit built in 1924. Combined cycle and combined heat and power systems are much more efficient than oil and gas electric generation technologies and account for most new natural gas capacity; some gas combustion turbines are also used as peaking plants. Many oil and gas steam-electric generators are being retired in favor of these types of plants. Some are being retrofitted to incorporate these new technologies, as evidenced by U.S. Energy Information Administration, "Most Generator Retirements Over the Past Decade Were Older Natural Gas-Fired units," Today in Energy, December 13, 2011. Because oil and gas steam-electric generators are becoming relatively expensive to operate compared to other plant types, they tend to also have low utilization rates. In some areas, due to the new construction of more efficient natural gas generators, there is some surplus capacity, in which case it becomes less expensive to retire the oil and gas steam-electric generators rather than run them intermittently.

7 Nuclear power accounted for 5.1 percent of total World Primary Energy Supply in 2011, according to the International Energy Agency's "2013 Key World Energy Statistics."

8 U.S. Energy Information Administration. Assumptions to the Annual Energy Outlook 2011 (U.S. Department of Energy, 2011), available at http://www.eia.gov/forecasts/ archive/aeo11/assumptions/pdf/0554(2011).pdf.

9 Jef Beerten, Erik Laes, Gaston Meskens, and William D'haeseleer, "Greenhouse Gas Emissions in the Nuclear Life Cycle: A Balanced Appraisal," Energy Policy 37 (12) (2009): 5056-5068, p. 5067.

10 John E. Ten Hoeve and Mark Z. Jacobson, “Worldwide health effects of the Fukushima Daiichi nuclear accident," Energy \& Environmental Science 9 (5) (2012): 8743-8757, available at http://web.stanford.edu/ group/efmh/jacobson/TenHoeveEES12.pdf.
11 For a broader set of political and economic considerations of the Fukishima disaster, see Miranda A. Schreurs and Fumikazu Yoshida. Fukushima: A Political Economic Analysis of a Nuclear Disaster (Sapporo: Hokkaido University Press, 2012). As of August 2013, the Fukushima crisis escalated seriously as Japan's Nuclear Regulatory Authority, NRA, stating, as reported by Reuters, "that it feared more storage tanks were leaking contaminated water." According to Reuters, "Water in the latest leak is so contaminated that a person standing close to it for an hour would receive five times the annual recommended limit for nuclear workers." Kiyoshi Takenaka and James Topham “Japan's nuclear crisis deepens, China expresses 'shock,' Reuters. August 21, 2013, available at http:// www.reuters.com/article/2013/08/21/us-japanfukushima-severity-idUSBRE97K02B20130821.

12 U.S. Energy Information Agency, International Energy Outlook 2011 (U.S. Department of Energy, 2011), available at http://www.eia.gov/forecasts/archive/ ieo11/pdf/0484\%282011\%29.pdf.

13 Robert B. Jackson, Brooks Rainey Pearson, Stephen G. Osborn, Nathaniel R. Warner, and Avner Vengosh, "Research and Policy Recommendations for Hydraulic Fracturing and Shale-Gas Extraction" (Durham, NC: Center on Global Change, 2011), pp. 1-2, available at http://www.nicholas.duke.edu/cgc/ HydraulicFracturingWhitepaper2011.pdf.

14 Ibid., pp. 3-4.

15 Thus, Professor Robert Howarth of Cornell University commented that he was skeptical that the findings by Allen and others could be considered representative of the typical level of controls at well sites, since he says that natural gas companies "do better when they know they are being carefully watched." See David T. Allen, Vincent M. Torres, James Thomas, David W. Sullivan, Matthew Harrison, Al Hendler, Scott C. Herndon, Charles E. Kolb, Matthew P. Frasier, A. Daniel Hill, Brian K. Lamb, Jennifer Miskimins, Robert F. Sawyer, and John H. Seinfeld, "Measurements of Methane Emissions at Natural Gas Production Sites in the United States," Proceedings of the National Academy of Sciences 110 (44) (2013); Wendy Koch, "Study: Natural Gas Industry Can Cut Fracking," USA Today, September 17, 2013, available at http://www.usatoday.com/story/news/nation/2013/ 09/16/natural-gas-industry-fracking-methanegreenhouse-gas-emissions/2811193/.

16 This listing of countries comes from Petro Global News, " 9 countries or regions that ban fracking," October 14 2013, available at http://petroglobalnews.com/2013/10/ 9-countries-or-regions-that-ban-fracking/.

17 "Carbon Sequestration," Science 325 (5948) (2009): 1644-1645, pp. 1644-1645, available at http://www. sciencemag.org/content/325/5948/1644.

18 Steven Chu, "Editorial: Carbon Capture and Sequestration," Science 325 (5948) (2009): 1599.

19 Sean Plasynski, "Carbon Sequestration R\&D Overview” (Washington: National Energy Technology Laboratory, Office of Fossil Energy, 2007), available at http://www. netl.doe.gov/File\%20Library/Research/Coal/ carbon-storage/Carbon-Sequestration-R-D-Overview.pdf.

20 Quoted in David Biello, '“Clean' Coal Power Plant Canceled - Hydrogen Economy, Too," Scientific American, February 6, 2008, pp. 1644-1645, available at http:// sams.scientificamerican.com/article/clean-coal-powerplant-canceled-hydrogen-economy-too/. 
Chapter 5

\section{Carbon dioxide emissions levels under alternative scenarios}




\section{Introduction}

Our purpose in this chapter is to evaluate the prospects for the United States achieving the $\mathrm{CO}_{2}$ emissions target of no more than 3,200 mmt within the next 20 years. As of 2010, total $\mathrm{CO}_{2}$ emissions generated within the U.S. economy were at around 5,600 $\mathrm{mmt}$. Hitting the target of 3,200 $\mathrm{mmt}$ within 20 years would therefore entail a roughly 40 percent absolute decline in U.S. $\mathrm{CO}_{2}$ emissions. As we have discussed, to achieve this level of emissions reductions, especially while U.S. economic growth is proceeding at a healthy rate over the next 20 years, will obviously entail a successful implementation of a highly ambitious clean energy project.

The approach that we have developed in previous chapters for reaching this emissions-reduction goal include, most importantly, bringing overall U.S. energy consumption as of 2030 to about 70 Q-BTUs and utilizing no less than 15 Q-BTUs of clean renewable energy sources to meet that overall level of 70 Q-BTUs of energy demand. We also showed in Chapter 4 that the demand for oil as a liquid fuel in transportation would need to fall by more than half from the level of 27 Q-BTUs estimated by the EIA in its 2030 Reference case.

We estimate that the consumption of oil in the transportation sector could fall to about 13 Q-BTUs through a combination of implementing the 54.5 miles per gallon fuel-efficiency standard for automobiles by 2025 and substituting about 6 Q-BTUs of clean biofuels for oil to be used in transportation. About 8 Q-BTUs of oil would still also be needed for a range of industrial purposes. Within this basic framework, we then examined in Chapter 4 a range of considerations for relying on coal, natural gas, and nuclear power to provide the remaining roughly 34 Q-BTUs of energy supply in 2030 — mostly for generating electricity — within the context of 70 Q-BTUs as the overall level of U.S. energy consumption. 
In this chapter, we examine the $\mathrm{CO}_{2}$ emissions levels that will result from alternative overall energy scenarios to see how these scenarios compare in meeting the goal of stabilizing the global climate. In pursuing this question, we first need to examine the evidence on the extent of emissions that are generated by the consumption of oil, coal, and natural gas, as well as high-emission renewables such as corn ethanol. We will rely on the EIA's figures in generating our estimates of emission levels.

We then consider three alternative energy scenarios for 2030. The first is the EIA's 2030 reference case. We also specify what we call the PERI/CAP case for 2030. This builds from the conclusions we have developed in Chapters 2 through 4 on prospects for energy efficiency and renewables, as well as the demand for liquid fuels. As a third scenario, we introduce a 2030 case that aims to take full account of the most recent major initiatives by the Obama administration, including the establishment of the $54.5 \mathrm{mpg}$ auto-efficiency standard for 2025 and the main proposals from the president's Climate Change Action Plan introduced in June $2013,{ }^{1}$ especially noting the commitment to aggressively reduce utility-sector power-plant emissions under existing clean air legislation. This scenario models efforts to advance clean energy, while remaining within the current policy and political context. That is, this scenario assumes that existing policies are advanced aggressively but does not include the efforts to expand capital investments in renewable energy and energy efficiency at the scales we have described in Chapters 2 and 3. We develop this scenario in detail in what follows and will refer to it as the "Aggressive Reference case." As we will see, the PERI/CAP scenario is the only one of the three scenarios through which there is any realistic prospect for achieving the 20-year $\mathrm{CO}_{2}$ emissions reduction target of 3,200 mmt.

We conclude this chapter by considering some additional alternative scenarios. In these cases, we test the sensitivity of our assumptions by examining the impact on emissions of varying the amounts of energy supply from coal, natural gas, and nuclear power, respectively. 


\section{Emissions levels from alternative energy sources}

To estimate the effect on emissions of any given level of energy consumption in the United States supplied from oil, coal, natural gas, and high-emissions renewable sources, we need to begin with the basic data on emissions that result from these alternative nonrenewable sources. As we discussed in Chapter 4, generating electricity from operating nuclear power plants does not produce $\mathrm{CO}_{2}$ emissions. ${ }^{2}$

Table 5.1 reproduces figures reported by the EIA as to the $\mathrm{CO}_{2}$ emissions levels from oil, coal, natural gas, and bioenergy sources, with specific figures referring to the use of these energy sources for alternative purposes.

TABLE 5.1

$\mathrm{CO}_{2}$ emissions levels from alternative fossil fuel energy sources

\begin{tabular}{lc}
\hline Fuel type & $\begin{array}{c}\text { Emissions levels (millions of metric tons of } \\
\mathrm{CO}_{2} \text { equivalent per Q-BTU) }\end{array}$ \\
\hline Petroleum & 71.26 \\
Gasoline (net of ethanol) & \\
Liquefied petroleum gas & 62.97 \\
$\quad$ Used as fuel & 12.25 \\
Used as feedstock & 70.88 \\
Jet fuel & 73.15 \\
Distillate fuel (net of biodiesel) & 78.80 \\
Residual fuel & 0 \\
Asphalt and road oil & 37.11 \\
Lubricants & 25.09 \\
Petrochemical feedstocks & 72.31 \\
Kerosene & 92.05 \\
Petroleum coke & 64.20 \\
Petroleum still gas & 74.54 \\
Other industrial &
\end{tabular}




\begin{tabular}{|c|c|}
\hline \multicolumn{2}{|l|}{ Coal } \\
\hline Residential and commercial & 95.35 \\
\hline Metallurgical & 93.71 \\
\hline Coke & 114.14 \\
\hline Industrial other & 93.98 \\
\hline Electrical utility & 95.52 \\
\hline \multicolumn{2}{|l|}{ Natural gas } \\
\hline Used as fuel & 53.06 \\
\hline Used as feedstock & 27.96 \\
\hline \multicolumn{2}{|l|}{ High-emissions bioenergy } \\
\hline Biomass & 88.45 \\
\hline Biogenic waste & 90.65 \\
\hline Biofuels heats and co-products & 88.45 \\
\hline Ethanol & 65.88 \\
\hline Biodiesel & 73.88 \\
\hline Liquids from biomass & 73.15 \\
\hline \multicolumn{2}{|c|}{$\begin{array}{l}\text { Source: Energy Information Administration, "Assumptions to the Annual Energy Outlook 2012" (U.S. Department of } \\
\text { Energy, 2012), p. } 13 .\end{array}$} \\
\hline \multicolumn{2}{|c|}{$\begin{array}{l}\text { Note: As indicated in the table itself, most of emissions derived in the table result from combusting alternative fossil } \\
\text { fuel energy sources. As such, the emissions are predominantly CO2, as opposed to the other, less prevalent sources of } \\
\text { greenhouse gas emissions. }\end{array}$} \\
\hline
\end{tabular}

The figures in Table 5.1 are shown in terms of millions of metric tons of $\mathrm{CO}_{2}$ equivalent per Q-BTU of energy. The basic results are as follows:

- Petroleum: Emissions levels vary according to how petroleum is being utilized. This includes the extent to which the oil is being combusted with the various usages. When petroleum is used for gasoline, it emits $71.3 \mathrm{mmt}$ of $\mathrm{CO}_{2}$ per Q-BTU of energy. By contrast, as a petrochemical feedstock, the emissions level is $25.1 \mathrm{mmt}$ of $\mathrm{CO}_{2}$ per Q-BTU of energy. There are no emissions when gasoline is used for producing asphalt and road oil, since these processes entail no petroleum combustion.

- Coal: The range of emissions levels is more narrow with coal, between 94 and 95 $\mathrm{mmt}$ of $\mathrm{CO}_{2}$ per Q-BTU, for all purposes other than combusting coke, in which case the emissions are higher, at $114.1 \mathrm{~mm}$ tof $\mathrm{CO}_{2}$ per Q-BTU. 
- Natural gas: Emissions are at $53 \mathrm{mmt}$ of $\mathrm{CO}_{2}$ per Q-BTU when natural gas is used as a fuel, or about 45 percent lower than those for coal-based energy. Emissions from natural gas are then cut roughly in half when used as a feedstock, to $28 \mathrm{mmt}$ of $\mathrm{CO}_{2}$ per Q-BTU.

- High-emissions bioenergy: The level of emissions varies according to the specific uses being put to bioenergy sources. Thus, biomass and biogenetic waste are roughly equivalent to coal in their level of emissions per Q-BTU of energy, while traditional ethanol and biodiesel are comparable to gasoline.

\section{Weighted averages for emissions levels}

In addition to providing the emissions figures for specific energy sources presented in Table 5.1, the EIA does also present overall emissions figures for oil, coal, and natural gas, both in terms of actual emissions for 2010 and forecasted figures in their 2030 reference case and alternative cases. These figures enable us to generate weighted averages of emissions levels that will be useful for maintaining clarity in our discussion. We show these figures for 2010 in Table 5.2 below.

TABLE 5.2

Weighted averages of U.S. emissions levels for oil, coal, and natural gas

Actual figures for 2010

\begin{tabular}{lccc}
\hline & $\begin{array}{c}\text { Energy consumption } \\
\text { (in Q-BTUs) }\end{array}$ & $\begin{array}{c}\mathrm{CO}_{2} \text { emissions (in millions } \\
\text { of metric tons, or mmt) }\end{array}$ & $\begin{array}{c}\mathrm{CO}_{2} \text { emissions per Q-BTU } \\
\text { (= column 2/column 1) }\end{array}$ \\
\hline Petroleum and other liquid fuels & 37.2 & 2,349 & $63 \mathrm{mmt}$ \\
Coal & 20.8 & 1,990 & $96 \mathrm{mmt}$ \\
Natural gas & 24.7 & 1,283 & $52 \mathrm{mmt}$
\end{tabular}

Source: Energy Information Administration, Annual Energy Outlook 2012 (U.S. Department of Energy, 2012), table D5, p. 203.

Note: According to the Energy Information Administration, the "petroleum and other liquid fuels" category includes "petroleum-derived fuels and non-petroleum derived fuels, such as ethanol and biodiesel, and coal-based synthetic liquids. Petroleum coke, which is a solid, is included. Also included are natural gas plant liquids and crude oil consumed as a fuel" and liquid hydrogen.

As we see, these weighted average figures are $63 \mathrm{mmt}$ per Q-BTU of energy derived from petroleum or other liquid fuels; $96 \mathrm{mmt}$ per Q-BTU of coal-derived energy; and 52 Q-BTUs for natural-gas derived energy. We note that the figure for petroleum and other liquid fuels is inclusive of ethanol and other biofuel sources. ${ }^{3}$ 


\section{Alternative 2030 scenarios for U.S. energy consumption and emissions}

We consider now three alternative scenarios for total U.S. energy consumption in 2030, along with the actual consumption figures for 2010. The three 2030 alternative scenarios are the EIA's Reference case, the PERI/CAP case as derived from our discussions in Chapters 2 to 4, and what we are calling the Aggressive Reference case.

The EIA's Reference case is developed fully in various editions of their "Annual Energy Outlook" and accompanying publications. We have discussed in detail the main features of the EIA's reference case in Chapters 2 through 4 . It will be useful here, though, to summarize the main features of the PERI/CAP case that we have developed in Chapters 2 to 4 . We also need to describe the Aggressive Reference case. As mentioned above, we constructed the Aggressive Reference case to take full account of the recent major climate change/clean energy initiatives advanced by the Obama administration that will not have been fully incorporated into the EIA's reference case with either the 2012 or 2013 editions of the "Annual Energy Outlook."

We also note that this is not the place in this study in which we examine policy options in depth. We present our full policy discussion in Chapter 8, after having reviewed all the key issues regarding energy consumption and emission levels, as well as both employment and macroeconomic impacts of clean energy investments. 
The 2030 PERI/CAP case includes three main components:

1. A robust commitment to investment in energy efficiency, spanning across the building, industrial, and transportation sectors. As we developed in Chapter 2, these investments are designed to bring overall U.S. energy consumption down from its 2010 level of roughly 100 Q-BTUs to 70 Q-BTUs by 2030.

2. A commitment to standards, incentives, and public investment in renewable energy sufficient to generate roughly 15.4 Q-BTUs of clean renewable energy by 2030 , as captured in Chapter 3.

3. An ongoing reliance on petroleum as a liquid fuel at roughly $13 \mathrm{Q}-\mathrm{BTU}$ s for transportation and 8.1 Q-BTUs for industrial purposes, totaling 21.1 Q-BTUs.

With the overall level of consumption at 70 Q-BTUs, clean renewables at 15.4 Q-BTUs, and petroleum at 21.1 Q-BTUs, that leaves about 34 Q-BTUs that will need to be supplied by some combination of natural gas, coal, and nuclear power. We examine alternative options here.

In addition to looking at energy production levels in Chapters 2 and 3, we also developed estimates of the overall levels of new investments in energy efficiency necessary to bring total U.S. energy consumption down to about 70 Q-BTUs, as well as the investments needed to expand clean renewable investments to 15.4 Q-BTUs. We summarize these overall investment requirements in Table 5.3. As the table shows, the annual level of total new investments will need to be about $\$ 195$ billion over 20 years, including about $\$ 88$ billion for energy efficiency and $\$ 107$ billion for renewables. Table 5.3 also shows details as to how these investments break out by specific sectors. The $\$ 195$ billion annual investment level is equal to about 1.2 percent of U.S. GDP in 2012. 
TABLE 5.3

Summary of investment requirements under 2030 PERI/CAP scenario

\begin{tabular}{|c|c|c|}
\hline & $\begin{array}{l}\text { Total investment } \\
\text { requirements }\end{array}$ & $\begin{array}{c}\text { Average annual investments } \\
\text { over } 20 \text { years }\end{array}$ \\
\hline \multicolumn{3}{|l|}{ Energy-efficiency investments } \\
\hline Buildings & $\$ 450$ billion & $\$ 22.5$ billion \\
\hline Industry & $\$ 301$ billion & $\$ 15.1$ billion \\
\hline Transportation & $\$ 1$ trillion & $\$ 50$ billion \\
\hline Total efficiency investments & $\$ 1.75$ trillion & $\$ 87.5$ billion \\
\hline \multicolumn{3}{|l|}{ Clean renewables investments } \\
\hline Clean bioenergy & $\$ 796$ billion & $\$ 39.8$ billion \\
\hline Hydro & $\$ 454$ billion & $\$ 22.7$ billion \\
\hline Wind & $\$ 403$ billion & $\$ 20.1$ billion \\
\hline Solar photovoltaic & $\$ 343$ billion & $\$ 17.2$ billion \\
\hline Solar thermal & $\$ 87$ billion & $\$ 4.3$ billion \\
\hline Geothermal & $\$ 50$ billion & $\$ 2.5$ billion \\
\hline Total renewables investments & $\$ 2.1$ trillion & $\$ 106.6$ billion \\
\hline Total all clean energy investments & $\$ 3.9$ trillion & \$195.0 billion \\
\hline
\end{tabular}

Source: See tables 2.16 and 3.17 .

For purposes of our general discussions on overall clean energy investment costs - as opposed to showing our exact derivation of these costs - we will round our overall $\$ 195$ billion per year cost estimate to $\$ 200$ billion. By rounding our $\$ 195$ billion cost estimate upward, we aim to convey first that the $\$ 195$ billion cost figure is itself, in any case, an approximation — by all means not a precise estimate-of what we regard as the necessary level of investments in efficiency and clean renewables to bring annual $\mathrm{CO}_{2}$ emissions in the United States down to around 3,200 mmt within 20 years.

In addition, through rounding upward we are explicitly acknowledging considerations on clean energy investments in addition to the factors on which we have concentrated in Chapters 3 and 4. The first additional factor is rebound effects. As we discussed in detail in Chapter 2, we expect rebound effects will be modest. But let's allow that rebound effects did mean that energy consumption rises by 10 percent relative to what would occur without the gains in energy efficiency. This 10 percent increase in energy consumption would then mean that investments in efficiency would also have to rise by 10 percent relative to our $\$ 87.5$ billion annual 
investment figure in order for total U.S. energy consumption to still fall to 70 Q-BTUs within 20 years. Such a 10 percent addition increase in costs would amount to about $\$ 9$ billion per year over our $\$ 87.5$ billion annual investment level-i.e., total efficiency investment would have to rise to about $\$ 96$ billion, and total clean energy investments would then amount to about $\$ 204$ billion rather than $\$ 195$ billion. However, while incorporating rebound effects into consideration would raise the costs of energy efficiency investments, on the other hand, our cost calculations on efficiency investments also did not take account of the possibility that innovations in energy efficiency technologies would lower investment costs per Q-BTU of efficiency savings. It is a near certainty that over a 20 -year period of intense investments in energy efficiency, the costs of achieving efficiency gains will fall with time, perhaps by significant amounts.

Ending up with an approximate overall clean energy investment cost figure of $\$ 200$ billion per year takes adequate account of our three additional considerations: 1) All of our investment cost figures are approximations only, not precise estimates; 2) modest rebound effects would entail higher levels of efficiency investments than would be necessary otherwise; and 3) technical innovations in efficiency technologies will tend to counteract the higher cost requirements resulting from rebound effects.

We discuss later in this chapter the impact of this level of investments on $\mathrm{CO}_{2}$ emissions. In Chapters 6 and 7, we then consider the effects on employment opportunities and overall macroeconomic performance.

\section{Defining the 2030 Aggressive Reference case}

Our approach in developing the Aggressive Reference case has been to deliberately construct a highly ambitious interpretation of what is possible within existing legislation and aggressive utilization of executive authorities, with further support from regional regulations and financing sources. This approach builds on the "down payment” laid out in President Barack Obama's June 2013 Climate Action Plan and his follow-up details announced in June 2014 on implementing the Climate Action Plan. It focuses on robust enforcement of utility regulation under existing clean air laws backed by full implementation of executive commitments such as the increased fuel-economy standards, renewable energy procurement efforts, and major public-private partnerships to promote energy efficiency in commercial buildings. 
We adopted this approach of optimistically interpreting the impact of incremental efforts that operate within current federal political constraints, absent major new legislative commitments, while also recognizing that the EIA's own 2030 reference case itself provides a highly optimistic scenario for 2030, especially with respect to energy efficiency. This is because, as discussed in Chapter 2, under the EIA Reference case, overall energy consumption increases between 2010 and 2030 from 98.2 to only 104.3 BTUs. That is, the EIA is estimating in its Reference case that overall U.S. energy consumption increases by only 6 percent over 20 years. This is while the EIA also projects that U.S. GDP will grow by an average of 2.5 percent per year through 2030. This amounts to a 64 percent expansion of the U.S. economy, fueled with essentially no increase in overall energy consumption.

Beyond these ambitious energy efficiency goals that are incorporated into the EIA's reference case, further major advances being introduced through the Obama administration's recent policy initiatives include the following:

- Efficiency: The increase in auto fuel-efficiency standards to 54.5 miles per gallon as of 2025

- Renewables: The U.S. military's project to meet 25 percent of its own overall energy consumption needs by clean renewable sources as of 2025

- Main features of the president's Climate Action Plan: The single most significant feature of President Obama's June 2013 plan was the proposal to establish stringent standards for coal emissions generated by U.S. power plants. The Action Plan did not provide specifics for this agenda, but rather stated that:

President Obama is issuing a Presidential Memorandum directing the Environmental Protection Agency to work expeditiously to complete carbon pollution standards for both new and existing power plants. This work will build on the successful first-term effort to develop greenhouse gas and fuel economy standards for cars and trucks.

Obama announced the details of this plan in June $2014 .{ }^{4}$ As of this writing, the administration's success implementing this plan remains to be seen. 
Other major elements of the Action Plan include the goals of doubling renewable electricity generation by 2020 and establishing fuel-efficiency standards for trucks, buses, and other heavy-duty vehicles that would parallel the 2025 standards for automobiles. The Action Plan also includes a range of more modest proposals for promoting energy efficiency and the use of renewable energy.

With respect to both energy efficiency and renewable energy investments, however, without significant new measures to ensure a level playing field for clean energy within existing markets, incremental efforts to promote deployment will unfold against a backdrop that heavily favors rapid expansion of low-cost naturalgas resources.

To provide quantitative specificity to these combined recent efforts to ambitiously employ existing executive authorities by the administration in defining our Aggressive Reference case, we have incorporated the following changes in assumptions relative to the EIA's reference case.

\section{The EIA's Extended Policies case as a baseline}

In addition to its Reference case estimates, the EIA develops alternative scenarios and projections for energy production and consumption based on alternative assumptions. In Chapter 3, for example, we drew extensively on the EIA's Low-cost Renewable Technology case. For our purpose of defining an Aggressive Reference case for 2030, the EIA's extended policies case is an appropriate baseline. Under the Extended Policies case, the EIA assumes that all existing clean energy policies that were due to sunset prior to 2030 would remain in force. These include existing investment and production tax credits for renewable energy projects, as well as updates in federal equipment efficiency and building codes. In Appendix 3, we present a full description of the EIA's Extended Policies case, including the figures for energy consumption from all sources in this case alongside the figures from the Reference case, the Aggressive Reference case, and the PERI/CAP case that we present in the main text of this chapter.

\section{Enhanced automobile and heavy-duty vehicle efficiency standards}

The extended policies case does incorporate the effects of the $54.5 \mathrm{mpg}$ fuel-efficiency standard for automobiles that will be introduced in 2025. However, the EIA's estimate of the effects of this standard is much smaller than what we have derived out of our discussions in Chapter 3. In addition, as mentioned above, the president's Climate Action Plan does also propose establishing higher efficiency standards for heavy-duty vehicles. Thus, for our Aggressive Reference case, we include our own 
estimate that fuel-efficiency standards throughout the transportation sector will be able to lower overall U.S. transportation energy consumption by 8 Q-BTUs relative to the EIA's reference case.

\section{Natural gas for coal fuel switching}

The most ambitious and heavily emphasized feature of the president's Climate Action Plan, both in its initial June 2013 presentation and the June 2014 follow-up announcement, is its proposal for stringent federal carbon pollution standards for electricity power plants. The main impact of any such initiative will be for natural gas to substitute for coal as a source of electrical power. To give a highly optimistic assessment of the impact of these forthcoming but still unspecified federal carbon pollution standards for utilities, we assume in our Aggressive Reference case that the impact on U.S. coal consumption would be equal to that estimated in the Deutsche Bank study that we discussed in Chapter 4. That is, we allow in the Aggressive Reference case that the new federal standards will result in U.S. coal consumption in 2030 falling from the EIA reference case of 20.6 Q-BTUs to 9 Q-BTUs-a 56 percent decline.

We also assume that this 11.6 Q-BTU reduction in coal-fired electricity will largely be replaced by an expansion in natural-gas consumption. U.S. natural-gas consumption will therefore rise in 2030 from the Reference case level of 26.7 Q-BTUs to 36.1 Q-BTUs in the Aggressive Reference case. ${ }^{5}$ This 41 percent expansion as of 2030 in natural-gas consumption as a substitute for coal is in keeping with the president's Climate Action Plan, which states that the plan "reflects and reinforces the ongoing trend towards cleaner technologies, with natural gas increasing its share of electricity generation in recent years."

\section{More ambitious expansion of clean renewables}

Under the EIA's Extended Policies case, clean renewables rise from their actual 2010 level of 3.5 Q-BTUs to 6 Q-BTUs - an increase of 67 percent. But the president's Climate Action Plan proposes a more ambitious goal for clean renewables-a doubling of renewable electricity generation by 2020 relative to 2012 . To again give a highly optimistic assessment of the president's plan out to 2030, we assume in our Aggressive Reference case that its impact by 2030 will be to triple clean renewables consumption to 10.5 Q-BTUs relative to 2010. We also assume that a large share of this expansion comes from the use of clean bioenergy, following from our discussion in Chapter 3 as to the highly favorable prospects for this sector. 
Table 5.4 summarizes these four features of our 2030 Aggressive Reference case relative to the EIA's reference case.

TABLE 5.4

Features of Aggressive Reference case for U.S. energy consumption in 2030

\begin{tabular}{l|c}
\hline $\begin{array}{l}\text { Components of Aggressive } \\
\text { Reference case }\end{array}$ & $\begin{array}{c}\text { Reason for adjustment with } \\
\text { Aggressive Reference case }\end{array}$ \\
\hline $\begin{array}{l}\text { 1. ElA's Extended Policies case rather than } \\
\text { Reference case as baseline }\end{array}$ & $\begin{array}{r}\text { Assume existing clean energy policies will not } \\
\text { expire or be otherwise weakened }\end{array}$ \\
$\begin{array}{l}\text { 2. Transportation energy consumption falls } \\
\text { by eight Q-BTUs relative to Reference case }\end{array}$ & $\begin{array}{r}\text { Incorporate full impact of enhanced } \\
\text { fuel-efficiency standards in transportation }\end{array}$ \\
$\begin{array}{l}\text { 3. Coal consumption falls from 20.6 Q-BTUs } \\
\text { to 9 Q-BTUs }\end{array}$ & $\begin{array}{r}\text { President's Action Plan focused on carbon emissions from } \\
\text { power plants and coal to natural gas fuel switching }\end{array}$ \\
$\begin{array}{l}\text { 4. Clean renewables consumption } \\
\text { triples relative to } 2010 \text { actual level }\end{array}$ & $\begin{array}{r}\text { Full range of new policies supportive of this goal, including } \\
\text { those in president's Action Plan and by U.S. military }\end{array}$
\end{tabular}

Source: See discussion in text. 


\section{Consumption levels from alternative scenarios}

Table 5.5 presents the figures on energy consumption levels in our three alternative 2030 scenarios - the EIA's reference case, the Aggressive Reference case, and the PERI/CAP case-along with the actual 2010 consumption figures. For ease of reference, these data are also presented in Figure 5.1.

\section{TABLE 5.5}

Alternative U.S. energy consumption scenarios for 2030

Energy consumption expressed in Q-BTUs

\begin{tabular}{|c|c|c|c|c|}
\hline $\begin{array}{l}\text { Energy source or efficiency gain } \\
\text { (efficiency measured relative to } \\
2030 \text { Reference case) }\end{array}$ & 2010 actual & $\begin{array}{c}2030 \text { EIA } \\
\text { Reference case }\end{array}$ & $\begin{array}{l}2030 \text { Aggressive } \\
\text { Reference case }\end{array}$ & $\begin{array}{c}2030 \text { PERI/ } \\
\text { CAP case }\end{array}$ \\
\hline Total energy consumption & 98.2 & 104.3 & 94.1 & 70.0 \\
\hline All efficiency & -- & -- & 10.2 & 34.3 \\
\hline Transportation efficiency & -- & -- & 8 & 8 \\
\hline Industrial efficiency & -- & -- & 1.0 & 10.4 \\
\hline Building efficiency & -- & -- & 1.2 & 15.9 \\
\hline Petroleum and other liquid fuels & 37.2 & 37.0 & 26.8 & 21.1 \\
\hline Coal & 20.8 & 20.6 & 9.0 & 9.0 \\
\hline Natural gas & 24.7 & 26.7 & 36.1 & 16.5 \\
\hline Nuclear & 8.4 & 9.6 & 9.3 & 8.0 \\
\hline High-emissions biomass ${ }^{1}$ & 3.6 & 5.1 & 2.4 & $0^{2}$ \\
\hline Clean renewables & 3.5 & 5.3 & 10.5 & 15.4 \\
\hline Clean bioenergy & 0 & 0 & 4.0 & 6.4 \\
\hline Hydro & 2.5 & 3.0 & 3.0 & 4.1 \\
\hline Wind & 0.9 & 1.7 & 2.0 & 3.1 \\
\hline Solar & 0.1 & 0.2 & 1.0 & 1.3 \\
\hline Geothermal & 0 & 0.4 & 0.5 & 0.5 \\
\hline
\end{tabular}

1 High-emissions biofuels are included in "petroleum and other liquid fuels."

2 High-emissions biomass, as well as biofuels, are distributed among "petroleum and other liquid fuels" and coal in this case.

Sources: 2010 Actual and 2030 EIA Reference case from EIA's Annual Energy Outlook 2012. 2030 Aggressive Reference case and 2030 PERI/CAP derived in text. Note that the figures in this table differ slightly from those in Chapter 4, which were based on the 2011 version of the EIA's Annual Energy Outlook. 


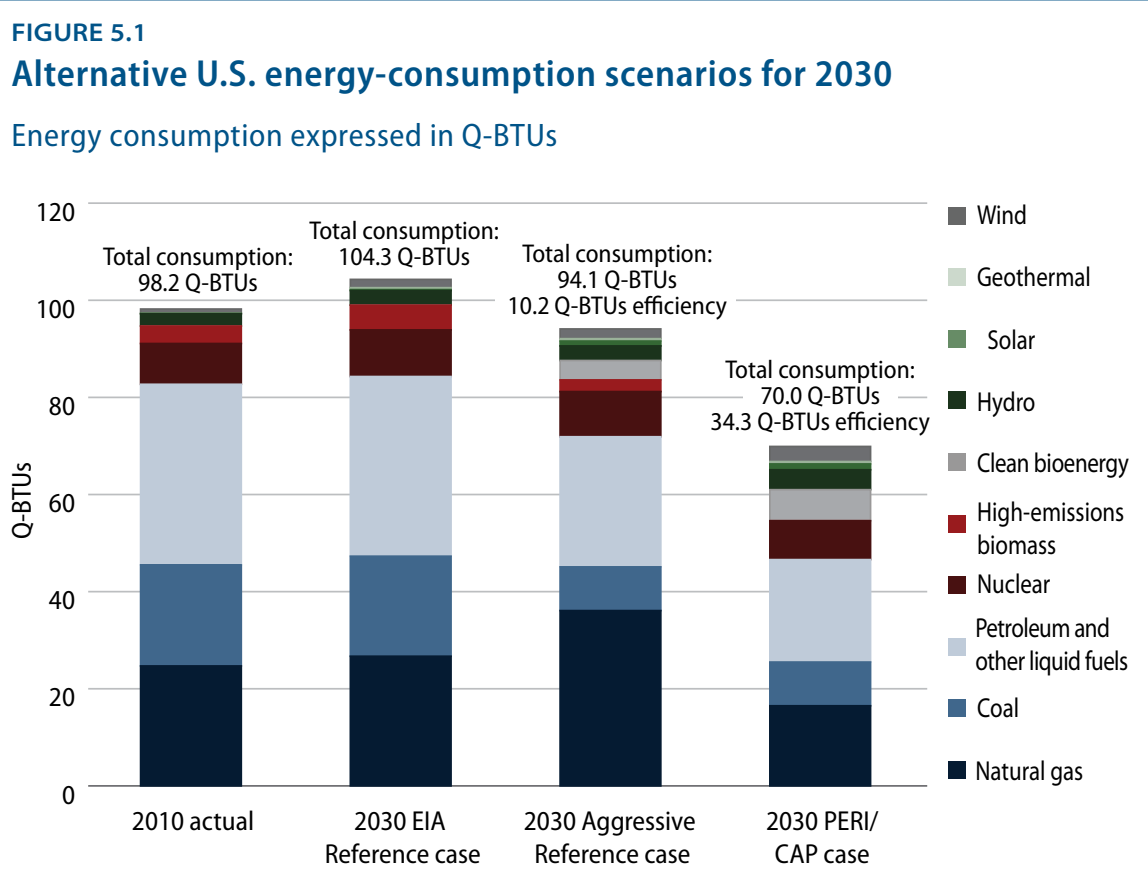

Source: See Table 5.5 .

The main features of the alternative scenarios described above are presented here for the categories of energy efficiency, petroleum, coal, natural gas, nuclear power, and clean renewables:

\section{Energy efficiency}

Under the EIA's Reference case, overall energy consumption rises from 98.2

Q-BTUs in 2010 to 104.3 Q-BTUs in 2030. But overall consumption falls in 2030 in our two alternative 2030 scenarios, to 94.1 Q-BTUs in the Aggressive Reference case and to 70 Q-BTUs in the PERI/CAP case.

\section{Petroleum}

Relative to the 2030 Reference case, this falls sharply in both the Aggressive Reference and PERI/CAP cases, from 37 Q-BTUs in the reference case to 26.8 and 21.1 Q-BTUs, respectively, in the Aggressive Reference and PERI/CAP cases. These lower figures reflect both the impact of the $54.5 \mathrm{mpg}$ fuel-efficiency standard that begins in 2025 for automobiles plus the expansion in the use of clean biofuels as substitutes for petroleum. 
Coal

Under the EIA's Reference case, coal consumption in 2030 is at 20.6 Q-BTUs. This figure falls to 9 Q-BTUs in both the Aggressive Reference and PERI/CAP cases. This lower figure for coal comes out of the Deutsche Bank study discussed in Chapter 4. It follows from the idea that the strict enforcement of existing regulations on carbon emissions from utilities will lead to a sharp contraction in coal production and consumption.

\section{Natural gas}

Relative to the EIA's Reference case, natural-gas consumption rises sharply under the Aggressive Reference case, from 26.7 to 36.1 Q-BTUs. In this scenario, the contraction in coal consumption is roughly matched by an increase in natural gas. By contrast, under the PERI/CAP case, natural gas declines to 16.5 Q-BTUs. The big difference here derives from the fact that under the PERI/CAP case, overall energy consumption is much lower, at 70 Q-BTUs, so there is no need to expand natural-gas consumption even while coal consumption is cut sharply. The substitution of renewables for declining coal generation, rather than increased naturalgas utilization is a defining feature of the PERI/CAP case, resulting in the attainment of carbon pollution goals. But this will require specific policy support.

\section{Nuclear power}

Relative to the EIA's Reference case of 9.6 Q-BTUs in 2030, the Aggressive Reference case is modestly lower at 9.3 Q-BTUs. This figure comes directly from the EIA's extended policies case. With the PERI/CAP case, nuclear is set at 8 Q-BTUs. This is derived directly from the Deutsche Bank scenario, which assumes a modest contraction of nuclear relative to the actual 2010 figure, due to increasing concerns over nuclear safety.

\section{Clean renewables}

Clean renewables expand rapidly under both the Aggressive Reference and PERI/ CAP cases. From the EIA reference case of 5.3 Q-BTUs in 2030, this figure rises to 10.5 Q-BTUS under the Aggressive Reference case and to 15.4 Q.BTUs in the PERI/CAP case. The figure from the Aggressive Reference case is derived from the president's Climate Action Plan calling for a doubling of clean renewables in 2020 relative to 2012 . We interpreted this optimistically as a tripling of clean renewables by 2030 relative to the actual 2010 figure. In the PERI/CAP case, clean renewables were at 15.4 Q-BTUs-a number that we reached in our detailed discussion in Chapter 3 built on a bottom-up analysis of the prospects for each of the clean renewable energy sources. 


\section{Carbon dioxide emission levels from alternative scenarios}

We show overall $\mathrm{CO}_{2}$ emissions levels generated by the alternative scenarios in Table 5.6 and Figure 5.2. Relative to the actual 2010 emissions level of 5,634 mmt, we see that emissions rise modestly through the EIA's 2030 reference case, to $5,733 \mathrm{mmt}$. We then see that emissions will fall sharply under both the Aggressive Reference case and the PERI/CAP case.

TABLE 5.6

$\mathrm{CO}_{2}$ emissions generated by alternative U.S. energy scenarios

Emissions are in millions of metric tons carbon dioxide, or $\mathrm{mmt}$

\begin{tabular}{lccccc}
\hline & $\begin{array}{c}\text { Weighted average } \\
\text { emissions levels } \\
\text { (mmt per Q-BTU) }\end{array}$ & $\begin{array}{c}2010 \text { actual } \\
\text { (in mmt) }\end{array}$ & $\begin{array}{c}\text { 2030 EIA } \\
\text { Reference case } \\
\text { (in mmt) }\end{array}$ & $\begin{array}{c}\text { 2030 Aggressive } \\
\text { Reference case } \\
\text { (in mmt) }\end{array}$ & $\begin{array}{c}\text { 2030 PERI/CAP } \\
\text { case (in mmt) }\end{array}$ \\
\hline $\begin{array}{l}\text { Petroleum and other } \\
\text { liquid fuels }\end{array}$ & 63 & 2,349 & 2,331 & 1,688 & 1,329 \\
$\begin{array}{l}\text { Coal and high-emis- } \\
\text { sions biomass }\end{array}$ & 96 & 2,002 & 2,014 & 876 \\
$\begin{array}{l}\text { Natural gas } \\
\text { Total }\end{array}$ & 52 & 1,283 & 1,388 & 1,877 & 864 \\
\end{tabular}

Sources: Energy Information Administration, Annual Energy Outlook 2012 (U.S. Department of Energy, 2012), tables A1 and D5.

Notes: The 2010 emissions figures are taken directly from Table 2030 D5. Reference case emissions figures are derived from reference case consumption figures in Table A1 of 2012 EIA Annual Energy Outlook and weighted average emissions figures. Aggressive Reference case and PERI/CAP cases are derived from consumption figures in the text and weighted-average emission figures. High-emissions biofuels are included in "petroleum and other liquid fuels" total. High-emissions biomass and other components of the

"other" category in Table D5 are included in coal. 


\section{FIGURE 5.2 \\ $\mathrm{CO}_{2}$ emissions generated by alternative U.S. energy scenarios}

Emissions are in millions of metric tons, or $\mathrm{mmt}$

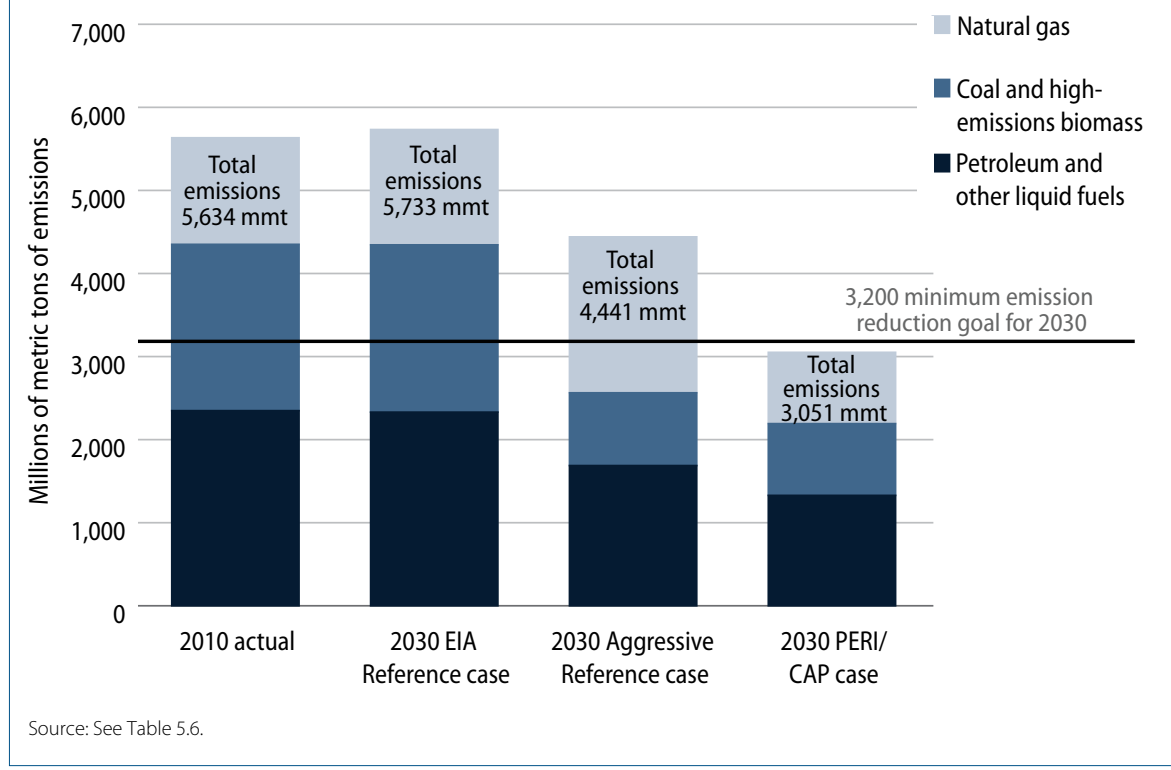

Under the Aggressive Reference case, emissions are at 4,441 mmt, a 23 percent decline relative to the EIA Reference case. Nevertheless, we observe here a key finding from our overall analysis in this chapter. That is, even while incorporating highly optimistic assessments of an aggressive use of executive authorities, and building on the president's policy initiatives-including the $54.5 \mathrm{mpg}$ vehicle fuel-efficiency standard for 2025, the commitment by the U.S. Defense Department to increase its consumption of clean renewables to 25 percent of total consumption by 2025 , and a sharp contraction in coal consumption resulting from the president's Climate Action Plan - the resulting overall emissions level is still about 1,200 mmt, or about 38 percent, above the target level of 3,200 $\mathrm{mmt}$ of $\mathrm{CO}_{2}$ by 2030 .

By contrast, under the PERI/CAP case, emissions do fall below 3,200 $\mathrm{mmt}$ of $\mathrm{CO}_{2}$ by 2030 - to $3,051 \mathrm{mmt}$. It is therefore clear that among the alternative 2030 scenarios we have examined here, something akin to the PERI/CAP case-which involves significantly more ambitious commitments, specifically to zero-carbon energy alternatives as developed in Chapters 2 and 3-offers the only realistic prospect for approaching, much less meeting, the $2030 \mathrm{CO}_{2}$ emissions reduction standard necessary for controlling climate change. Further, it must be noted that these emissions levels themselves are not based on a stringent reading of the climate science, but rather are extrapolated from climate commitments that more correctly define a minimum threshold for carbon emissions reductions. 


\section{Further alternatives with coal, natural gas, and nuclear power}

In addition to the three 2030 scenarios we have presented thus far, it will be illuminating to consider some variations on these cases. One principal aim in considering additional side cases is to explore the prevailing notion of natural gas functioning as a bridge fuel to a low-carbon economy. In our principal side case, we examine an extremely aggressive coal-to-natural-gas fuel-switching agenda operating in parallel with the Aggressive Reference case, with its accelerated renewables and efficiency assumptions to test the effectiveness over the intermediate term of a natural gas "bridge fuel" scenario.

In addition, we consider the effects on emission levels of reducing nuclear energy further, in light of the major safety concerns associated with nuclear power, and similarly test the impact of natural-gas substitution under this sensitivity analysis. We present three side cases that address these issues.

Table 5.7 presents the first side case. In this scenario, we work off of the Aggressive Reference case. Within the Aggressive Reference case, we then consider what the effects will be on overall emissions if we were to eliminate coal production and consumption entirely by 2030, with natural gas substituting fully for coal. All other energy consumption levels within this side case are identical to the 2030 Aggressive Reference case. This is presented as a sensitivity analysis of a dramatic implementation, where natural gas serves as a complete alternative to coal in the fuel mix, to see whether a natural-gas bridge is capable of meeting our climate stabilization goal. 


\begin{tabular}{lcc}
\hline & $\begin{array}{c}\text { Energy-consumption level } \\
\text { (in Q-BTUs) }\end{array}$ & $\begin{array}{c}\text { Emissions (in millions of metric } \\
\text { tons carbon dioxide equivalent) }\end{array}$ \\
\hline $\begin{array}{l}\text { Petroleum and other high- } \\
\text { emissions liquid fuels }\end{array}$ & 26.8 & 1,688 \\
$\begin{array}{l}\text { Coal and high-emissions } \\
\text { biomass }\end{array}$ & 0 & 0 \\
Natural gas & 45.1 & 2,345 \\
Nuclear & 9.3 & 0 \\
High-emissions biomass & 2.4 & 230 \\
Clean renewables & 10.5 & 0 \\
Total & 94.1 & 4,263
\end{tabular}

Source: Hypothetical scenario is developed in text.

Note: Emissions from high-emissions biomass is included with coal.

As we see in Table 5.7, natural-gas consumption in 2030 now rises to 45.1 Q-BTUsa level that is 69 percent higher than the EIA 2030 reference case of 26.7 Q-BTUs. Meanwhile, coal falls to zero consumption by 2030 . We do not consider this to be a realistic scenario. But working within the framework of the Aggressive Reference case, it does establish the outer boundaries of the gains in emissions reductions that can be achieved through switching from coal to natural gas in an ambitious clean energy scenario.

As the table shows, even working within the framework of the Aggressive Reference case, overall $\mathrm{CO}_{2}$ emissions are still at 4,263 $\mathrm{mmt}$,_-fully 33 percent above the emissions reduction goal of $3,200 \mathrm{mmt}$ in 2030 . What this result makes clear is that even by relying on natural gas as a substitute for coal, there is no path through which we can achieve the level of emissions reductions necessary for controlling climate change. In fact, the PERI/CAP case shows that absolute natural-gas consumption levels are likely to decline in the intermediate term under a climate stabilization pathway.

Table 5.8 presents figures for the second side case. This case operates within the context of the PERI/CAP case. Here, we make only one adjustment to the PERI/ CAP case, which is to reduce nuclear-energy consumption from 8 to 5 Q-BTUs and to increase natural-gas consumption by the same 3 Q-BTUs. As we see in Table 5.8, $\mathrm{CO}_{2}$ emissions rise in this case to $3,207 \mathrm{mmt}$. This is exactly on the 
threshold of the minimally acceptable level of 3,200 mmt of emissions for 2030 . Within this scenario, it would therefore be possible to begin reducing dependence on nuclear power should that be adopted as a public policy goal, and natural gas could play a role in this transition if nested within the broader context of a priority focus on a highly efficient and renewable-based energy system - that is, with overall consumption at 70 Q-BTUs and clean renewables expanding strongly to 15.4 Q-BTUs by 2030.

TABLE 5.8

2030 side case 2: Natural gas partially replaces nuclear power under PERI/CAP case

Nuclear power at five Q-BTUs

\begin{tabular}{lcc}
\hline & $\begin{array}{c}\text { Energy-consumption level } \\
\text { (in Q-BTUs) }\end{array}$ & $\begin{array}{c}\text { Emissions (in millions of metric } \\
\text { tons carbon dioxide equivalent) }\end{array}$ \\
\hline $\begin{array}{l}\text { Petroleum and other high- } \\
\text { emissions liquid fuels }\end{array}$ & 21.1 & 1,329 \\
$\begin{array}{l}\text { Coal and high-emissions } \\
\text { biomass }\end{array}$ & 9.0 & 864 \\
Natural gas & 19.5 & 1,014 \\
Nuclear & 5 & 0 \\
High-emissions biomass & 0 & 0 \\
Clean renewables & 15.4 & 0 \\
Total & 70 & 3,207
\end{tabular}

Source: Hypothetical scenario is developed in text.

Note: Emissions from high-emissions biomass is included with coal.

In Table 5.9, we explore this logic still further, by considering in the third side case the prospects for bringing nuclear-energy consumption down to zero by 2030 . Natural gas is substituted for the loss of 8 Q-BTUs of energy. As we see in this case, overall emissions reach $3,467 \mathrm{mmt}$, a figure above the minimum threshold of 3,200 $\mathrm{mmt}$. In the European and Japanese policy debates regarding the complete elimination of nuclear, this idea has recently gained new currency. What therefore becomes clear from the third side case is that if the goal is to eliminate nuclear power and still achieve the 2030 emissions reduction target of no more than 3,200 mmt of $\mathrm{CO}_{2}$ emissions, it will also be necessary to go beyond what we have developed in Chapters 2 and 3 of this study with respect to advancing both energy efficiency and renewables. That is, we will need to push overall consumption below 70 Q-BTUs, expand clean renewables beyond 15.4 Q-BTUs, or some combination of the two. 
TABLE 5.9

2030 side case 3: Natural gas fully replaces nuclear power under PERI/ CAP case

Nuclear power at zero Q-BTUs

\begin{tabular}{lcc}
\hline & $\begin{array}{c}\text { Energy-consumption level } \\
\text { (in Q-BTUs) }\end{array}$ & $\begin{array}{c}\text { Emissions (in millions of metric } \\
\text { tons carbon dioxide equivalent) }\end{array}$ \\
\hline $\begin{array}{l}\text { Petroleum and other high- } \\
\text { emissions liquid fuels }\end{array}$ & 21.1 & 1,329 \\
$\begin{array}{l}\text { Coal and high-emissions } \\
\text { biomass }\end{array}$ & 9.0 & 864 \\
Natural gas & 24.5 & 1,274 \\
Nuclear & 0 & 0 \\
High-emissions biomass & 0 & 0 \\
Clean renewables & 15.4 & 0 \\
Total & 70 & 3,467
\end{tabular}

Source: Hypothetical scenario is developed in text.

Note: Emissions from high-emissions biomass is included with coal.

Natural gas can certainly play a role in transition, but only to the extent that truly zero-carbon alternatives are prioritized as a leading source of electricity generation. In our analysis, we see the PERI/CAP case relying first on efficiency and then on renewables, while also preserving moderate reliance on existing nuclear-power facilities. This pathway presents the most plausible and achievable scenario toward controlling climate change within the next two decades. Of course, should the expansion of clean renewables exceed the ambitious but achievable estimates that we propose, they will certainly help to further reduce emissions to levels below the 3,200 mmt target, should that prove necessary. A more ambitious expansion of clean renewables could also allow for greater or lesser consumption levels for natural gas or nuclear power, as public policy mandates evolve. 
1 Executive Office of the President, The President's Climate Action Plan (The White House, 2013), available at http://www.whitehouse.gov/sites/default/files/image/ president27sclimateactionplan.pdf.

2 For the purposes of this discussion, we are also not taking account of the emissions generated through mining and refining uranium needed in generating nuclear energy and in the process of constructing nuclear power plants. We reviewed the evidence on these factors in Chapter 4.

3 The "petroleum and other liquid fuels" category does not include emissions from biomass sources. In the 2012 Annual Energy Outlook, Table D-5, these emissions are included, at least in part, in the "other" category. We incorporate these emission figures into our coal category. We also note that these weighted averages of emissions per Q-BTU of energy, as derived from the 2010 actual levels of energy consumption, are nearly identical to the estimated figures the EIA projects in their scenarios for 2030 and beyond. It will therefore be reliable to use these 2010 figures in our calculations of emissions generated through the alternative 2030 scenarios.
4 For a summary of the main elements of the plan, see Juliet Eilperin and Steven Mufson, "Everything you need to know about the EPA's proposed rule on coal plants," The Washington Post, June 2, 2014, available at http://www.washingtonpost.com/national/healthscience/epa-will-propose-a-rule-to-cut-emissions-fromexisting-coal-plants-by-up-to-30-percent/2014/06/02/ f37f0a10-e81d-11e3-afc6-a1dd9407abcf_story.html.

5 The differences between the EIA's Reference and Extended Policies cases for coal and natural gas consumption are minor, with coal at 19.6 and natural gas at 25.5 Q-BTUs under the extended policies case for 2030 . 


\section{Chapter 6 \\ Employment effects of the clean energy investment framework}




\section{Introduction}

In this chapter, we evaluate the employment effects of undertaking the investments in energy efficiency and clean renewable energy that would enable the United States to reach its 20-year $\mathrm{CO}_{2}$ emissions target of 3,200 mmt. As we have seen, we estimate that investments in energy efficiency in the building, industrial, and transportation sectors will need to reach approximately $\$ 1.75$ trillion over 20 years or about $\$ 88$ billion per year for 20 years — to bring down annual U.S. energy consumption to about 70 Q-BTUs, as opposed to the EIA's 2030 Reference case of 104 Q-BTUs. We have also estimated that the capital investments needed to expand clean renewables to where they can supply roughly 15 Q-BTUs of power by 2030 to 2035 would be about $\$ 2.1$ trillion, or about $\$ 107$ billion per year. ${ }^{1}$ In total, new clean energy capital expenditures in both efficiency and renewable investments would amount to about $\$ 195$ billion per year.

As discussed in Chapter 5, we do also round up the total clean energy investment cost figure to $\$ 200$ billion per year in our general discussion on these investment levels. Through this rounding exercise, we are, again, 1) emphasizing that our cost figures are all approximations, and are not meant by any means to be taken as precise estimates; 2 ) recognizing that rebound effects through energy efficiency investments might entail a modestly greater level of efficiency investments to bring total U.S. energy consumption down to 70 Q-BTUs within 20 years than our estimate of $\$ 88$ billion annually; and 3) recognizing that concurrent with any possible rebound effects will be innovations in energy efficiency technologies that will encourage falling costs of these investments.

Beyond these questions around capital expenditures on energy efficiency and clean renewables, we also need to factor into our overall employment calculation figures that there would be an expanded level of spending on operations and maintenance for these clean energy activities. Our aim in this chapter is therefore to estimate the job-generating potential from the overall increase in spending on energy efficiency and clean renewables. 
At the same time, to measure the net employment effects of clean energy investments, we also need to estimate the reductions in employment in the nonrenewable sectors-oil, natural gas, coal, and nuclear power-through contracting the production of nonrenewable energy significantly over the next 20 years. As we have seen in a scenario of operating the U.S. economy at 70 Q-BTUs of overall energy consumption, we roughly estimate that nonrenewable energy needs will be about 55 Q-BTUs. This entails a contraction in nonrenewables consumption by about 39 percent as of 2030-2035, relative to the EIA's Reference case. Reducing the consumption of nonrenewables by such a substantial amount will, of course, entail a comparable contraction of job opportunities for U.S. workers in these sectors of the economy. We provide some rough estimates of the magnitude of this contraction in this chapter.

As we will show, the overall effects of both expanding investments in energy efficiency and clean renewables while contracting production in the nonrenewable sectors will be a significant increase in job creation in the United States economy over the next 20 years. The basic reason for this outcome is straightforward: Investments in expanding the clean renewable sectors require more employment per unit of activity - these sectors are more "labor intensive" — and require a higher proportion of spending within the domestic U.S. economy-renewables have a higher level of "domestic content"-than spending within the existing nonrenewable energy sectors. For the most part, operations and maintenance of the clean renewables sectors generates roughly the same level of employment as nonrenewables. But there is one important exception-the clean biofuels sector-that requires significantly higher levels of employment than either nonrenewables or other renewable sectors.

Overall, the net effect of expanding clean energy investments while allowing the nonrenewable sectors to contract will be to expand overall demand for workers within the U.S. economy by approximately 2.7 million jobs overall. We explain why we believe this to be, if anything, a low-end estimate of the net gain in employment opportunities that will result through a clean energy transformation in the United States. We then turn in this chapter to providing a statistical sketch of the categories of job opportunities generated by an expansion of investments in the clean energy sector. As we show, these job opportunities range across the full spectrum of the U.S. labor market. As such, investing in expanding the clean energy sector will create substantially more "good jobs," as well as additional mid-range and low-paying or entry-level jobs, relative to maintaining the nonrenewable sector at roughly its current level. 
Before presenting the empirical findings of this chapter in detail, we begin by setting out some basic points on methodology and definitions. This discussion is necessary for establishing clarity in the analysis of the empirical findings. We also examine these methodological and definitional issues in much greater detail in Appendix 4. 


\section{Methodological and definitional issues in generating job estimates}

\section{Building from U.S. industrial surveys and the input-output model}

Our employment estimates are figures generated directly from data from the U.S. Commerce Department's surveys of businesses within the United States and organized systematically within their input-output model. The "inputs" within this model are all the employees, materials, land, energy, and other products that are utilized in economic activities by U.S. enterprises - public and private- to create goods and services. The "outputs" are the goods and services themselves that result from these activities, which are then made available to households, private businesses, and governments as consumers. Within the given structure of the current U.S. economy, these figures within the input-output model provide the most accurate evidence available as to what happens within private and public enterprises when they produce the economies' goods and services. In particular, these data enable researchers to observe how many workers were hired to produce a given set of products or services and what kinds of materials were purchased in the process. Our methodology is to work within this detailed survey evidence and the input-output model.

Here is one specific example of how our methodology works (see Appendix 4 for details): If we invest an additional $\$ 1$ million on energy efficiency retrofits of an existing building, how will the business undertaking this retrofit project utilize that funding to actually complete the project? How much of the $\$ 1$ million will they spend on hiring workers? How much will they spend on nonlabor inputs, including materials, energy costs, and renting office space? How much will be left for business profits? Moreover, when businesses spend money on nonlabor inputs, what are the employment effects of giving orders to suppliers, such as lumber and glass producers or trucking companies?

We ask this same set of questions for investment projects in renewable energy, as well as spending on operations within the nonrenewable energy sectors. For example, to produce $\$ 1$ million worth of petroleum that can be sold to consumers at gas 
stations as a refined product, how many workers will need to be employed, and how much money will need to be spent on nonlabor inputs? Through this approach, we have been able to make observations as to the potential job effects of alternative energy investment and spending strategies at a level of detail that is not available through any alternative approach.

There are certainly limitations with our use of the input-output model. Perhaps the most significant is that, within its standard framework, the input-output model is not designed to take account of the effects on job creation of technical change and labor productivity growth over time. In fact, production technologies do certainly shift over time, so that a different mixture of inputs may be used to produce a given output. New technologies emerge while others become obsolete. Certain inputs may become scarcer, and, as result, firms may substitute other goods and services. The production process could simply become more efficient, so that fewer inputs are needed to produce a given amount of output. Energy efficiency investments do themselves produce a change in production processesi.e., a reduction in the use of energy inputs to generate a given level of output. In short, we recognize that the input-output relationships in any given economyincluding its employment effects of clean energy investments-are likely to look different 20 years from now compared to the results we will generate through utilizing the current-period input-output tables.

This raises the question of how we might take into account these kinds of changes in production technologies. Specifically, how would the employment estimates be affected if we were to take into account productivity changes over time? We review this question in detail in Appendix 4. We reach two main conclusions from these discussions. The first is that the changes in the labor requirements for clean energy investment activities are likely to be relatively modest over our relevant time period. We reach this conclusion by examining the changes in the input-output relationships for the United States between 1995 to 2007. In addition, we conclude that if anything, the positive employment creation effects from clean energy investments are most likely to increase with time. This is because the average rate of GDP growth will typically exceed the average rate of labor productivity growth. This means that economic growth - and specifically the expansion of the clean energy sectors tied to the economy's growth rate-will require more employment over time.

Beyond this discussion on the effects of technical change and labor productivity, we consider in Appendix 4 the limitations of the input-output model approach in the context of alternative approaches that, for our purposes, have more serious 
limitations. These alternative approaches include computable general equilibrium models, as well as recent efforts by the U.S. Bureau of Labor Statistics to measure the number of "green jobs" in the U.S. economy through direct survey methods. In short, as we discuss in detail in Appendix 4, we hold that for our particular purposes of estimating employment effects of alternative energy spending activities within the U.S. economy, the input-output approach is the most reliable methodology available.

\section{Direct, indirect, and induced job creation}

Spending money in any area of the U.S. economy will create jobs since people are needed to produce any good or service that the economy supplies. This is true regardless of whether the spending is done by private businesses, households, or a government entity. At the same time, for a given amount of spending within the economy-for example, $\$ 1$ million - there are differences in the relative levels of job creation through spending that $\$ 1$ million in different ways. Again, this is true regardless of whether the spending is done by households, private businesses, or the government.

There are three sources of job creation associated with any expansion of spending: direct, indirect, and induced effects. For purposes of illustration, consider these categories in terms of investments in home retrofitting or building wind turbines:

1. Direct effects: the jobs created, for example, by retrofitting homes to make them more energy efficient or by building wind turbines

2. Indirect effects: the jobs associated with industries that supply intermediate goods for building retrofits or wind turbines, such as lumber, steel, and transportation

3. Induced effects: the expansion of employment that results when people who are paid in the construction or steel industries spend the money they have earned on other products in the economy

Within the framework of these three categories of job creation, how is it that spending a given amount of money in one set of activities in the economy could generate more employment than other activities? As a matter of simple arithmetic, there are only three possibilities. We can illustrate these three possibilities by comparing investment projects in clean energy versus nonrenewable sectors. 


\section{Labor intensity}

When proportionally more money of a given overall amount of funds is spent on hiring people - as opposed to spending on machinery, buildings, energy, land, and other inputs - then spending this given amount of overall funds will create more jobs. As we will see, relative to spending within the nonrenewable energy sectors, investments in clean energy-including the direct spending on specific projects plus the indirect spending on purchasing supplies_-devote significantly more of their overall budgets on hiring people and relatively less on acquiring machines, supplies, land (either on- or offshore), and energy itself.

\section{Domestic content}

Given that we are considering job creation within the U.S. economy, when a higher proportion of a given amount of funds is spent within the United States as opposed to spending on imports or activities in other countries, the given amount of money will, again, create more jobs. The clean energy investment program that we have described relies significantly more on economic activities taking place within the United States and less on imports than spending within the nonrenewable energy sectors.

\section{Compensation per worker}

If there is $\$ 1$ million total to spend in a given year, and one employee earns $\$ 1$ million per year at a given business enterprise, then that obviously means that only one job is created through spending the $\$ 1$ million. However, if, at another enterprise, the average pay is $\$ 50,000$ per year, then the same $\$ 1$ million will generate 20 jobs at $\$ 50,000$ per employee. In fact, the average pay for all of the industries associated with clean energy_including direct, indirect, and induced effects-is about 20 percent lower than the average pay in the nonrenewable sectors, and as such, more jobs will be created through spending a given amount of money in clean energy than in nonrenewables. At the same time, as we discuss below, because clean energy investments produce significantly more jobs with a given dollar of expenditure, this also means that clean energy investments produce more jobs at all pay levels - higher-paying as well as lower-paying jobs-than the nonrenewable energy sectors. 
Any type of spending activity creates employment over a given amount of time. To understand the impact of a given spending activity on jobs, one must therefore incorporate a time dimension into the measurement of employment creation. For example, a program that creates 100 jobs that last for one year only needs to be distinguished from a another program that creates 100 jobs that continue for 10 years each. It is important to keep this time dimension in mind in any assessment of the impact on job creation of any clean energy investment activity.

There are two straightforward ways in which one can express such distinctions. One is through measuring "job years." This measures cumulative job creation over the total number of years that jobs have been created. An activity that generates 100 jobs for 1 year would therefore create 100 job years. By contrast, the activity that produces 100 jobs for 10 years each would generate 1,000 job years.

The other way to report the same figures would be in terms of jobs per year. Through this measure, we are able to provide detail on the year-to-year breakdown of the overall level of job creation. With the 10-year program we are using in our example, we could express its effects as creating 100 jobs per year for 10 years. The advantage of this approach becomes clear when there are differences in the extent of job creation on a year-to-year basis. Thus, with our case of the 10 -year project, it would be important to observe, for example, if on a year-to-year basis, 50 jobs per year were created in years one through four, 200 jobs per year were generated in years five and six, and 100 jobs per year were generated in years seven through 10 .

One specific area where it is important to proceed clearly on this issue is in the consideration of construction-industry job creation through clean energy investments. Construction-sector jobs created by clean energy investments are frequently regarded as being short term, while manufacturing jobs are seen as inherently longer term. However, especially in evaluating the impact of alternative areas of spending within a broad clean energy investment agenda, the distinctions are not so straightforward. Of course, any single construction project is limited by the amount of time required to complete that project, while manufacturing activity in a single plant can continue indefinitely as long as the manufacturer is able to sell the goods produced at a profit. But if we consider any large-scale clean energy construction project, total job creation over time can vary widely depending precisely on the annual level of expenditure that is laid out to complete the project. 
Consider an example of a project to retrofit the entire publicly owned building stock within the United States, in which we assume the entire budget devoted to labor in the project is $\$ 50$ billion, and each worker on the project receives, on average, total compensation of $\$ 50,000$ per year. This means that the project will generate a total of 1 million job years, no matter how these job years are divided up over time. If the annual budget for the project is $\$ 5$ billion, that means the project will generate 100,000 jobs over 10 years, making it a long-term source of job creation. However, if the annual budget could rise to $\$ 25$ billion, that means the project would generate 500,000 jobs over two years. In this case, the project is no longer a source of long-term job creation. It is rather an intense new source of employment, but only over a two-year time horizon.

In addition to this issue of being clear on how to count job years, there is also the more familiar question in the time dimension of employment as to whether the jobs are full- time or part time. As purely a matter of measurement, one can of course convert part-time jobs into full-time equivalents. But in terms of assessing the welfare effects of clean energy investments and policy initiatives, one would want to distinguish the creation of full-time jobs from part-time jobs, especially since full-time jobs are generally more stable and of higher quality.

\section{Measuring job creation through new clean energy investment activity only}

Our approach to measuring the employment impacts of investments in energy efficiency and clean renewables is to focus only on the expansion of activities that would not take place otherwise. Thus, we include in our estimates the job-generating effects of all building retrofit projects and the installation of new equipment and other high-efficiency operating systems, such as combined heat and power systems. We also include in our estimates all new investments required to expand the clean renewable sector and to operate this expanded sector over time.

By contrast, we do not include in our job-creation measures the investments necessary to build highly fuel-efficient automobiles - those that can operate at the 2025 fuel efficiency standard of 54.5 miles per gallon - even though, as we have seen, such investments will be critical for enabling the United States to achieve its 2030 emissions target. We are not including these investments in our employment-creation figures because the production of more fuel-efficient cars will, for the most part, substitute for existing auto-production operations. While some 
economists have documented increased capital investment and labor content per car generated by the purchase of more fuel-efficient parts such as advanced fuel injectors and variable speed drives, ${ }^{2}$ we have not tried to capture this distinction in our current analysis.

As such, we do not claim in these job estimates any large-scale expansion in employment by producing roughly the same number of automobiles in the United States as would otherwise have been the case, with the only difference being that the cars will now be built to achieve the higher fuel-efficiency standard. In similar fashion, we assume that there will be no net employment gains for increasing the level of energy efficiency of computers, light bulbs, and appliances produced in the United States. We again assume that the overall level of production of these products will remain roughly comparable to what would have been the case otherwise-again, with the only difference being that more efficient products are substituting for less efficient ones. ${ }^{3}$

It is reasonable to argue that producing more efficient automobiles, appliances, and other products will help preserve jobs in the United States that could otherwise be lost if foreign producers delivered more efficient versions of these products, while U.S. producers continued producing less efficient versions. Within our framework of analysis, however, we have no clear metric for estimating jobs preserved as opposed to jobs newly created through new investment projects. By not attempting to include any measure of jobs preserved through investments in more energy efficient products, we are therefore providing a more conservative estimate of the job expansion generated through our clean energy investment scenario. 


\section{Job-creation estimates through clean energy investments}

\section{Energy efficiency investments}

Table 6.1 shows the basic job estimates per $\$ 1$ million of expenditures in energy efficiency. We have divided this into building and industry investments. The activities for each type of investment are distinct, as we show in Appendix 4. Nevertheless, despite the distinct activities involved for achieving efficiencies in buildings and industry, the level of job creation is basically identical for both sets of activities - about 14.6 jobs per $\$ 1$ million in capital investment spending, divided between 6.3 direct, 4.1 indirect, and 4.2 induced jobs.

\section{TABLE 6.1}

Employment creation through energy-efficiency capital expenditures in buildings and industry

Employment creation per $\$ 1$ million in capital expenditures

\begin{tabular}{lcccc}
\hline & $\begin{array}{c}\text { Direct jobs } \\
\text { per \$1 million }\end{array}$ & $\begin{array}{c}\text { Indirect jobs } \\
\text { per \$1 million }\end{array}$ & $\begin{array}{c}\text { Induced jobs } \\
\text { per \$1 million }\end{array}$ & $\begin{array}{c}\text { Total jobs } \\
\text { per \$1 million }\end{array}$ \\
\hline $\begin{array}{l}\text { Buildings efficiency } \\
\text { investments }\end{array}$ & 6.3 & 4.1 & 4.2 & 14.6 \\
$\begin{array}{l}\text { Industrial efficiency } \\
\text { investments }\end{array}$ & 6.3 & 4.1 & 4.2 & 14.6
\end{tabular}

Source: See Appendix 4

In Table 6.2, we estimate the employment effects of the energy efficiency expenditure levels on buildings and industry that we reported in our Chapter 2 summary table, Table 2.16. The figures we present in Table 6.2 are for investments in building retrofits and industrial efficiencies only. As discussed above, we are not including the investments to build a new fleet of energy efficient automobiles to meet the 2025 fuel-efficiency standard of $54.5 \mathrm{mpg}$ as a source of net new job creation. 
TABLE 6.2

Job creation through buildings and industry efficiency investments

For reaching 70 Q-BTU U.S. energy-consumption level over 20 years

\begin{tabular}{lccc}
\hline & Buildings & Industry & $\begin{array}{c}\text { Total for buildings } \\
\text { and industry }\end{array}$ \\
\hline $\begin{array}{l}\text { 1. Energy savings relative to EIA } \\
2030 \text { Reference case (in Q-BTUs) }\end{array}$ & 16.0 Q-BTUs & 10.4 Q-BTUs & 26.4 Q-BTUs \\
$\begin{array}{l}\text { 2. Capital expenditures needed } \\
\text { over } 20 \text { years for energy savings }\end{array}$ & $\$ 450$ billion & $\$ 301$ billion & $\$ 751$ billion \\
$\begin{array}{l}\text { 3. Job creation per } \$ 1 \text { million in } \\
\text { capital expenditures }\end{array}$ & 14.6 & 14.6 & N/A \\
$\begin{array}{l}\text { 4. Total job creation through } \\
\text { efficiency investments (total job } \\
\text { years }=\text { row } 2 \times 3)\end{array}$ & 6.6 million & 4.4 million & 11.0 million \\
$\begin{array}{l}\text { 5. Annual capital expenditures } \\
\text { over } 20 \text { years }(=\text { row } 2 / 20)\end{array}$ & $\$ 22.5$ billion & $\$ 15.1$ billion & $\$ 37.6$ billion \\
$\begin{array}{l}\text { 6. Annual job creation over } 20 \\
\text { years }(=\text { row } 4 / 20)\end{array}$ & 328,500 & 220,500 & 549,000 \\
Sources: Investment figures documented in Table 2.16. Total jobs/million documented in Table 6.1. &
\end{tabular}

We see in Table 6.2 that the total new investments in buildings and industry needed to achieve 26.4 Q-BTUs of energy savings relative to the EIA's 2030 reference case scenarios for these sectors will be $\$ 751$ billion, or about $\$ 38$ billion per year for 20 years. Working from our estimates of jobs created per $\$ 1$ million in spending in Table 6.1, this will produce about 11 million job years over the period in which these investments take place. If we assume that these investments occur on a steady basis for 20 years, the $\$ 38$ billion per year in new investments would produce about 549,000 new jobs per year. Obviously, if this rate of new investment were accelerated, the annual rate of new job creation would also increase by a commensurate amount.

Note that we do not report on any expansion in operations and maintenance due to these investments. There is not likely to be any significant increase in operations and maintenance due to these investments in efficiency. In fact, depending on the specific situation, there may be some increase in operations, while there may be a reduction in other cases. For example, if buildings are operating more efficiently with better equipment, the operations and maintenance costs should decrease. However, in industry, if a high proportion of savings are resulting through the installation of CHP systems, then operations and maintenance costs should increase to maintain this new equipment. Still, the net change in operations and maintenance employment from these activities should be small, moving either in a positive or negative direction. 


\section{Renewable energy investments}

Building out the renewable energy sector will entail both capital expenditures and ongoing maintenance and operations. Jobs will be generated through both the capital expenditures, as well as the operations and maintenance activities. We separate those two out in this discussion.

Jobs per $\$ 1$ million in expenditures

\section{Capital expenditures}

Table 6.3 reports on our calculations for job creation for seven specific renewable energy investment areas. As we see, the range of job creation for these investment areas is narrow, with six of the specific investments generating between 12.7 and 13.4 jobs per $\$ 1$ million in spending. Geothermal energy investments are the least labor intensive, at 10.3 jobs per $\$ 1$ million.

TABLE 6.3

Job creation through renewable energy capital investments

Employment creation per \$1 million in investment

\begin{tabular}{lcccc}
\hline & $\begin{array}{c}\text { Direct jobs } \\
\text { per } \mathbf{1} \text { million }\end{array}$ & $\begin{array}{c}\text { Indirect jobs } \\
\text { per \$1 million }\end{array}$ & $\begin{array}{c}\text { Induced jobs } \\
\text { per \$1 million }\end{array}$ & $\begin{array}{c}\text { Total jobs } \\
\text { per \$1 million }\end{array}$ \\
\hline Bioenergy & 5.4 & 3.8 & 3.7 & 12.9 \\
Hydro & 5.2 & 4.2 & 3.8 & 13.2 \\
Wind onshore & 4.7 & 4.4 & 3.6 & 12.7 \\
Solar photovoltaic & 5.5 & 4.1 & 3.8 & 13.4 \\
Solar thermal & 5.0 & 4.3 & 3.7 & 13.0 \\
Geothermal & 3.0 & 4.4 & 3.0 & 10.3
\end{tabular}

Source: See Appendix 4 


\section{Operations and maintenance}

Table 6.4 reports on employment needs for operations and maintenance of renewable energy projects. As we see, with the exception of bioenergy, the employment needs for all O\&M activities in renewable energy are basically identical, at 5.5 jobs per $\$ 1$ million in spending. That of bioenergy is nearly four times larger, at 19.7 jobs per $\$ 1$ million. This result is not surprising, since operating and maintaining the bioenergy sector requires either producing raw agricultural materials or gathering waste materials, transporting the materials, in some cases refining the materials, and then burning them. No such operations are required with hydro, wind, solar, or geothermal power.

The much larger employment requirements for operating and maintaining bioenergy projects is especially pertinent for our purposes, given that, as we have discussed earlier, bioenergy constitutes the largest proportion of renewable energy delivered in the United States. This would remain true even if we were to reduce the proportion of corn ethanol in the overall mix of bioenergy and expand that of corn stover and switchgrass-based ethanol, as well as diesel fuels from waste grease.

TABLE 6.4

Job creation through renewable energy operations and maintenance expenditures

Job creation per \$1 million in spending

\begin{tabular}{lcccc}
\hline & $\begin{array}{c}\text { Direct jobs } \\
\text { per \$1 million }\end{array}$ & $\begin{array}{c}\text { Indirect jobs } \\
\text { per \$1 million }\end{array}$ & $\begin{array}{c}\text { Induced jobs } \\
\text { per \$1 million }\end{array}$ & $\begin{array}{c}\text { Total jobs } \\
\text { per \$1 million }\end{array}$ \\
\hline Bioenergy & 8.9 & 5.2 & 5.6 & 19.7 \\
Hydro & 1.5 & 2.4 & 1.6 & 5.5 \\
Wind & 1.5 & 2.4 & 1.6 & 5.5 \\
Solar photovoltaic & 1.5 & 2.4 & 1.6 & 5.5 \\
Solar thermal & 1.5 & 2.4 & 1.6 & 5.5 \\
Geothermal & 1.5 & 2.4 & 1.6 & 5.5
\end{tabular}

Source: See Appendix 4. 
Table 6.5 works from the material we presented in Chapter 3, summarized in Table 3.17, on the capital investment requirements for the U.S. renewable sector to generate 15.4 Q-BTUs of renewable energy by 2030 and 2035-an expansion of 11.8 Q-BTUs relative to the actual supply in 2010. Increasing U.S. clean energy supply relative to the 2010 level includes an expansion, in terms of Q-BTUs, of approximately 6.4 of clean bioenergy, 1.6 of hydro, 2.2 of wind, 1.3 of solar, and 0.3 of geothermal. We explain in Chapter 3 how we derive these figures.

In Table 6.5, we also show the EIA's level of capital expenditures per Q-BTU necessary to achieve this $11.8 \mathrm{Q}-\mathrm{BTU}$ expansion, which is capable of bringing total clean energy supply to 15.4 Q-BTUs as of 2030. Total capital expenditures come to nearly $\$ 2.1$ trillion over 20 years, or about $\$ 107$ billion per year. Based on these figures, we are then able to generate an estimate of total employment creation from these new capital investments in renewable energy projects. As we see in Table 6.5, that figure is 27.6 million job years. Assuming those capital expenditures are spread evenly over 20 years, this would mean a total of about 1.4 million jobs per year for the 20-year investment period.

TABLE 6.5

Job creation through capital expenditures to produce a net expansion of 11.8 Q-BTUs of clean renewable energy

Investment levels are under Low Renewable Technology Cost case

\begin{tabular}{|c|c|c|c|c|c|c|c|}
\hline & $\begin{array}{l}\text { 1. Q-BTU } \\
\text { capacity } \\
\text { expansion }\end{array}$ & $\begin{array}{l}\text { 2. Capital } \\
\text { expenditures } \\
\text { per Q-BTU } \\
\text { expansion } \\
\text { (in billions of } \\
2010 \text { dollars) }\end{array}$ & $\begin{array}{l}\text { 3. Total } \\
\text { capital costs } \\
\text { (in billions of } \\
2010 \text { dollars; } \\
=\text { column } 1 \mathrm{x} \\
\text { column } 2 \text { ) }\end{array}$ & $\begin{array}{l}\text { 4. Job } \\
\text { creation } \\
\text { per } \$ 1 \\
\text { million in } \\
\text { investment }\end{array}$ & $\begin{array}{c}\text { 5. Total jobs } \\
\text { created through } \\
\text { investments (in job } \\
\text { years; = column } 3 \mathrm{x} \\
\text { column 4); Figures } \\
\text { are in millions }\end{array}$ & $\begin{array}{l}\text { 6. Annual } \\
\text { capital costs } \\
\text { over } 20 \text { years } \\
\text { (in billions of } \\
2010 \text { dollars; }= \\
\text { column } 3 / 20 \text { ) }\end{array}$ & $\begin{array}{l}\text { 7. Annual } \\
\text { job creation } \\
\text { over } 20 \text {-year } \\
\text { investments } \\
\text { (= column } \\
5 / 20)\end{array}$ \\
\hline $\begin{array}{l}\text { Clean } \\
\text { bioenergy }\end{array}$ & 6.4 & $\$ 124.4$ & $\$ 796$ & 12.9 & 10.3 & $\$ 39.8$ & 515,000 \\
\hline Hydro & 1.6 & $\$ 284.0$ & $\$ 454$ & 13.2 & 6.0 & $\$ 22.7$ & 300,000 \\
\hline Wind & 2.2 & $\$ 183.4$ & $\$ 403$ & 12.7 & 5.1 & $\$ 20.1$ & 255,000 \\
\hline $\begin{array}{l}\text { Solar } \\
\text { photovoltaic }\end{array}$ & 1.1 & $\$ 311.7$ & $\$ 343$ & 13.4 & 4.6 & $\$ 17.2$ & 230,000 \\
\hline Solar thermal & 0.2 & $\$ 434.6$ & $\$ 87$ & 13.0 & 1.1 & $\$ 4.3$ & 55,000 \\
\hline Geothermal & 0.3 & $\$ 166.9$ & $\$ 50$ & 10.3 & 0.5 & $\$ 2.5$ & 26,000 \\
\hline Total & 11.8 & -- & $\$ 2.1$ trillion & -- & 27.6 million & \$106.6 billion & 1.38 million \\
\hline
\end{tabular}

Sources: Table 3.17 for capital expenditures per Q-BTU; Table 6.3 for employment multipliers. 


\section{Job creation through operations and maintenance of renewable energy projects}

Table 6.6 reports on employment creation through operations and maintenance of generating a total of 15.4 Q-BTUs of renewable energy. This 15.4 figure of total clean renewables includes both the existing production level of 3.6 Q-BTUs of clean renewables and our estimate that 11.8 Q-BTUs of new production would result through capital investments through 2030 and 2035.

As Table 6.6 shows, there is a large overall expansion of employment through these operation and maintenance activities - roughly 2.3 million jobs per year. At the same time, virtually all of this job creation-2.1 million of the 2.3 millioncomes out of the clean bioenergy sector. Other than this activity from the bioenergy sector, operations and maintenance from operating a clean renewable sector at around 15.4 Q-BTUs would generate about 164,000 jobs per year. This is not insignificant but is, of course, quite modest in comparison to the jobs generated through operating the clean bioenergy sector.

TABLE 6.6

Job creation through operations and maintenance of 15.4 Q-BTUs of clean renewable energy by 2030 to 2035

\begin{tabular}{lccccc}
\hline & $\begin{array}{c}\text { 1. Energy } \\
\text { generation } \\
\text { (in Q-BTUs) }\end{array}$ & $\begin{array}{c}\text { 2. Operations and } \\
\text { maintenance cost per } \\
\text { Q-BTU, including fixed } \\
\text { and variable (in billions } \\
\text { of } 2010 \text { dollars) }\end{array}$ & $\begin{array}{c}\text { 3. Annual operations } \\
\text { and maintenance } \\
\text { costs }(=\text { column } 1 \times x \\
\text { column } 2 \text { in billions } \\
\text { of 2010 dollars) }\end{array}$ & $\begin{array}{c}\text { 4. Total job } \\
\text { creation per } \$ 1 \\
\text { million in } \\
\text { expenditures }\end{array}$ & $\begin{array}{c}\text { 5. Annual } \\
\text { employment } \\
(=\text { column } 3 \times \\
\text { column } 4)\end{array}$ \\
\hline Clean bioenergy & 6.4 & $\$ 17.0$ billion & $\$ 108.8$ billion & 19.7 & $2,143,400$ \\
Hydro & 4.1 & $\$ 3.1$ billion & $\$ 12.7$ billion & 5.5 & 69,900 \\
Wind & 3.1 & $\$ 3.1$ billion & $\$ 9.6$ billion & 5.5 & 52,800 \\
Solar photovoltaic & 1.1 & $\$ 2.3$ billion & $\$ 2.5$ billion & 5.5 & 13,800 \\
Solar thermal & 0.2 & $\$ 11.7$ billion & $\$ 2.3$ billion & 5.5 & 12,600 \\
Geothermal & 0.5 & $\$ 5.3$ billion & $\$ 2.6$ billion & 5.5 & 14,300
\end{tabular}

Sources: Table 3.7 for column 1; U.S. Energy Information Administration. 2012, June. Annual Energy Outlook 2012. Department of Energy. for column 2; Table 6.4 for column 4. 
As Table 6.7 shows, the overall increase in total job years through investments in energy efficiency and renewable energy, as well as operations and maintenance for the renewable energy sector, will be 85 million new job years. On an annual basis over 20 years, this amounts to about 4.2 million new jobs per year. Roughly half of these jobs would be generated through the operations and maintenance of an expanded clean bioenergy sector.

Of course, if the project of building a clean energy economy were able to proceed more rapidly than over the 20-year time frame we have stipulated, the annual rate of new employment creation would also rise correspondingly. For example, if the two projects of bringing annual overall U.S. energy consumption down to 70 Q-BTUs and producing roughly 15 Q-BTUs of clean renewables were to occur over a 15 -year time span rather than 20 years, this would mean that the annual expansion of employment for these projects would rise to about 5.7 million new jobs per year.

TABLE 6.7

Summary of job creation for achieving a 70 Q-BTU economy with 15.4 Q-BTUs of clean renewable energy by 2030 to 2035

\begin{tabular}{|c|c|c|c|}
\hline & $\begin{array}{l}\text { 1. Total } \\
\text { expenditures }\end{array}$ & $\begin{array}{l}\text { 2. Total job years } \\
\text { (in millions) }\end{array}$ & $\begin{array}{l}\text { 3. Jobs per year over } 20 \\
\text { years (= [column } 2] / 20)\end{array}$ \\
\hline $\begin{array}{l}\text { Energy efficiency (annual capital } \\
\text { expenditures over } 20 \text { years) }\end{array}$ & $\$ 37.6$ billion & 11.0 & 549,000 \\
\hline $\begin{array}{l}\text { Renewable energy (annual capital } \\
\text { expenditures over } 20 \text { years) }\end{array}$ & $\$ 106.6$ billion & 27.6 & $1,380,000$ \\
\hline $\begin{array}{l}\text { Biofuels (annual operations and } \\
\text { maintenance expenditures) }\end{array}$ & $\$ 108.8$ billion & 42.9 & $2,143,400$ \\
\hline $\begin{array}{l}\text { Other renewable energy genera- } \\
\text { tion (operations and maintenance } \\
\text { expenditures) }\end{array}$ & \$29.7 billion & 3.3 & 163,400 \\
\hline Total & $\begin{array}{l}\$ 282.7 \text { billion for new } \\
\text { investments plus operations } \\
\text { and maintenance }\end{array}$ & 85.0 & 4.2 million \\
\hline
\end{tabular}

Sources: Tables 6.2, 6.5, and 6.6. 


\section{Employment effects for nonrenewable energy sectors}

Table 6.8 shows job-creation figures for the nonrenewable energy sectors, including both capital expenditure and operations and maintenance figures for oil, coal, natural gas, and nuclear power.

TABLE 6.8

Job creation within nonrenewable energy sectors: New capital expenditures and operations and maintenance for coal, natural gas, nuclear power, and oil

\begin{tabular}{|c|c|c|c|c|}
\hline & $\begin{array}{c}\text { Direct jobs } \\
\text { per } \$ 1 \text { million }\end{array}$ & $\begin{array}{l}\text { Indirect jobs } \\
\text { per } \$ 1 \text { million }\end{array}$ & $\begin{array}{l}\text { Induced jobs } \\
\text { per } \$ 1 \text { million }\end{array}$ & $\begin{array}{c}\text { Total jobs } \\
\text { per } \$ 1 \text { million }\end{array}$ \\
\hline \multicolumn{5}{|c|}{ Employment through capital investments } \\
\hline Oil and natural gas & 3.2 & 4.3 & 3.0 & 10.5 \\
\hline Coal & 3.2 & 4.4 & 3.0 & 10.6 \\
\hline Nuclear & 3.8 & 4.1 & 3.2 & 11.1 \\
\hline Nuclear decommissioning & 7.3 & 3.9 & 4.5 & 15.7 \\
\hline \multicolumn{5}{|c|}{ Employment through operations and maintenance } \\
\hline Oil & 0.8 & 3.0 & 1.5 & 5.3 \\
\hline Coal & 1.5 & 2.4 & 1.7 & 5.5 \\
\hline Natural gas & 1.5 & 2.4 & 1.57 & 5.5 \\
\hline Nuclear & 1.5 & 2.4 & 1.57 & 5.5 \\
\hline
\end{tabular}

Source: See Appendix 4

A few key results emerge from this table.

With the exception of the case of nuclear decommissioning, the level of job creation generated by capital expenditures in the nonrenewable sectors-at between 10 and 11 jobs per $\$ 1$ million in spending - are about one-third lower than those we saw in Table 6.1 for energy efficiency investments in buildings and industry. These job-creation figures for nonrenewable capital expenditures are also about 15 percent below most of those for renewable energy capital expenditures. 
Additionally, job creation through operations and maintenance in the nonrenewable sectors is basically identical to those in most renewable sectors, at about 5.5 jobs per $\$ 1$ million in expenditures. However, there is one major exception, which, as we have seen, is the operations and maintenance activities in bioenergy, where job creation is nearly 20 jobs per $\$ 1$ million in expenditures. Of course, this one exception is significant in our overall framework, since the expansion of clean bioenergy is a major component of the overall expansion of the clean energy sectors. As such, operations and maintenance for nonrenewables will therefore generate less employment than spending the same amount of money for operations and maintenance in renewables, including the expansion of the clean biomass/biofuels sector.

Lastly, the most important disparity in the job-creation figures is between capital expenditures in efficiency and renewables versus operations and maintenance in the nonrenewable sectors. This is because the project of significantly expanding clean energy activities in the United States entails mounting large-scale capital investments in efficiency and renewables, while also undertaking reductions in the operations and maintenance of the nonrenewable sectors. Thus, under the scenarios we have developed to meet the $2030 \mathrm{CO}_{2}$ energy-based target of 3,200 $\mathrm{mmt}$ of emissions, the nonrenewable sectors cannot experience significant expansions in capital expenditures. Virtually all of the overall expenditures in these sectors will therefore be concentrated in operations and maintenance. 


\section{Comparing employment effects of clean and nonrenewable energy spending}

To illustrate the effects of these differences in overall employment creation between the clean energy and nonrenewable energy sectors, we consider two simple scenarios, based on the figures we have presented thus far in this chapter. We show these two scenarios in Table 6.9.

TABLE 6.9

Net change in employment through transferring funds from nonrenewable to clean energy sector spending

Scenario 1: $\$ 144$ billion in clean energy capital expenditures is matched by equal reduction in nonrenewable operations and maintenance

1. Jobs created through $\$ 37.6$ billion annual capital expenditures on buildings and industrial energy efficiency

2. Jobs created through $\$ 106.6$ billion annual capital expenditures on renewables

3. Total jobs created through annual efficiency and renewables capital expenditures

4. Jobs per \$1 million through non-renewables operations and maintenance

5. Jobs created through $\$ 144$ billion annual expenditures on nonrenewables operations and maintenance

6. Difference in job creation between efficiency/renewables capital expenditures and nonrenewables operations and maintenance (= row 3 - row 5 )

549,000 jobs

1.38 million jobs

1.92 million

5.5 jobs per \$1 million

792,000 jobs

1.1 million jobs

Scenario 2: \$138 billion expansion in clean renewables operations and maintenance is matched by equal reduction in nonrenewables operations and maintenance

1. Jobs created through $\$ 138$ billion expansion in clean renewables operations and maintenance

2.3 million jobs

2. Jobs created through $\$ 138$ billion annual expenditures on nonrenewables operations and maintenance

3. Difference in job creation between renewables and nonrenewables operations/maintenance (= row 1 - row 2 )

759,000 jobs

1.5 million jobs

Source: Figures taken from Tables 6.7 and 6.8. 
In the first scenario, we begin with our basic findings regarding investment levels in buildings and industrial efficiency, as well as in clean renewable energy sources. That is:

- Buildings and industrial efficiency investments: $\$ 37.6$ billion annually toward bringing U.S. overall energy consumption to 70 Q-BTUs by 2030. As discussed above, we do not include our estimate of $\$ 41$ billion annually in transportation efficiency investments as a net new source of job creation.

- Clean renewable investments: Overall annual investments of about $\$ 106.6$ billion to produce about 15 Q-BTUs of energy as of 2030.

We then assume that this total of about $\$ 144$ billion in annual clean energy investments will be exactly matched by an equal dollar reduction in nonrenewable operations and maintenance expenditures. As we see in the upper panel of Table 6.9, the net effect of this scenario would be an increase of about 1.1 million jobs per year.

In the second scenario, shown in the lower panel of Table 6.9, we work with our estimate that total annual spending on operations and maintenance to produce about 15 Q-BTUs of clean renewables will be $\$ 138$ billion, with the bulk of these funds going to clean biofuels O\&M. We then assume that this spending total is, again, matched by an equal decline in spending on O\&M in the nonrenewable sectors. As we see with this scenario, due to the heavy labor requirements for bioenergy operations and maintenance activities, the net impact in this case is an expansion in employment of more than 1.5 million jobs per year.

The overall impact of these two scenarios is therefore to increase U.S. employment by 2.7 million jobs per year. That is, if the United States were to undertake new clean energy investments annually at the rate we have described in Chapters 2 and 3 , and if we assumed that every dollar spent on both these new investments and on operations and maintenance within the expanded clean energy sector was matched by an equal dollar reduction in O\&M spending within the nonrenewable sectors, the net result would be to increase employment opportunities in the United States by about 2.7 million jobs per year.

Is it plausible that fully $\$ 283$ billion in annual spending on buildings and industrial efficiency investments, new clean renewable investments, and clean renewables O\&M would be matched dollar-for-dollar in reductions in annual spending on nonrenewables? We can obtain some useful perspectives on this by considering 
the current magnitude of economic activity in the U.S nonrenewable energy sectors. In the U.S. national income accounts and input-output accounts, total gross output in oil, coal, and natural gas consists of the following activities:

- Extraction of oil, coal, and natural gas and support services

- Purchases of supplies ("inputs") for these extraction activities

- Production of petroleum and coal products, such as petrochemicals

- Purchases of supplies for petroleum and coal products

The total value of these four activities in 2011 was $\$ 1.3$ trillion. ${ }^{4}$ As such, transferring about $\$ 280$ billion annually out of the fossil fuel sector to spending on renewable energy and building and industrial efficiency would entail a decline of about 22 percent in activity in the fossil fuel sector relative to its activity level in 2011. This 22-percent figure is lower than the level of contraction for consumption in oil, coal, and natural gas that we described in Chapter 5 under the PERI/CAP 2030 scenario. As such, it is indeed reasonable to expect that $\$ 280$ billion in new investments in building and industrial efficiency, as well as new investments and O\&M spending in renewable energy, could come about through transferring funds away from fossil fuels.

To provide some perspective on how significant a net expansion of roughly 2.7 million jobs in the U.S. energy sector by 2030 would be, in July 2013 the total U.S. labor market included 156 million people, with approximately 144 million employed and 12 million officially unemployed. Given the official projections of U.S. population growth (which the Census Bureau estimates will average about 0.73 percent per year through $2030^{5}$ ), this would mean a labor force of about 177 million people in 2030. A net increase of 2.7 million jobs would therefore amount to about 1.5 percent of this 2030 labor force.

As an absolute number, this would not represent a large expansion in overall employment opportunities in the U.S. economy. However, another way of measuring this is that these 2.7 million jobs would be roughly equal to a 1.5 percentage point reduction in the unemployment rate within the 2030 U.S. economy. It would represent the difference between a 6 percent and 4.5 percent unemployment rate, all else equal. Seen in this way, the net increase of 2.7 million jobs does represent a significant level of expanded opportunities for those who would be seeking employment in the 2030 U.S. labor market. 


\section{Other considerations in measuring net employment effects}

In addition to the factors we have addressed in some detail above, three additional factors suggest that our estimates of the employment effects of the clean energy investment program we have developed are probably conservative, perhaps by a significant amount. On the other hand, a net increase of 2.7 million jobs, and possibly more, could also create stresses in U.S. labor markets. The first type of stress would be macroeconomic - i.e., the general inflationary pressures that are typically associated with tight labor markets. The second would be potential shortages of workers with the specific skills necessary to perform effectively in the new employment areas opened up by large-scale clean energy investments. We now consider these issues in turn.

\section{Potential sources of additional job creation}

One factor, as we have discussed above, is that we do not include in our estimates any accounting for jobs preserved through investments in efficiency and renewables. The example on which we focused earlier was investments in the auto industry to bring automobiles up to the 54.5-mpg fuel-efficiency standards mandated by 2025 . If U.S. automakers do not make the necessary adjustments to meet or exceed this standard, they will see their market share fall relative to imports, which would then mean job losses for U.S. autoworkers.

A second related factor is that we do not include any figures for public transportation investments in our overall energy efficiency investment project. We explain in Chapter 2 why we chose not to incorporate public transportation into the overall portfolio of efficiency investments. But as a subsidiary point, we do in Appendix 1 examine the benefits of pursuing a major expansion of public investment, with new capital expenditures at around $\$ 6.5$ billion per year. Among these benefits, we show in Appendix 1 that investments at this level could generate around 157,000 jobs per year. 
A third factor could emerge through the impact of generating energy savings and redirecting those savings into spending in other sectors within the U.S. economy. The situation is comparable to what we have seen with funds transferred out from the nonrenewable energy sectors and into energy efficiency and renewable activities. That is, if the funds saved through efficiency investments are then transferred into all other sectors of the U.S. economy, and if those other sectors on average generate more jobs per $\$ 1$ million in spending than nonrenewable energy, then this transfer of funds will be a net source of job creation. We have seen earlier in this chapter that most capital expenditures in nonrenewables generate between about 10 and 11 jobs per $\$ 1$ million, while operations and maintenance in these sectors produce about 5.5 jobs per $\$ 1$ million in spending. In contrast with these figures, overall spending within the U.S. economy generates an average of about 15 jobs per $\$ 1$ million in spending. As such, on average, any reduction in spending on nonrenewables, which then converts into increased spending on everything else produced within the U.S. economy, will yield a net increase in job creation.

It is difficult to gauge how large such an effect would be, given that we are considering a set of adjustments that would operate at a fully integrated level throughout the entire economy, as opposed to being confined, at least within the initial round of increased spending, within economy's energy sectors. As one indicator of the magnitude of this economywide effect, Laitner et al. have estimated that this effect would produce a net expansion of U.S. employment of between 1.2 million and 1.8 million jobs per year by $2050 .{ }^{6}$ Considering this result, it would be reasonable to assume that by 2030, this effect could account for a net increase of job opportunities at the level of hundreds of thousands. This expansion in overall employment levels would of course be an increment beyond the job increases on which we have focused in this chapter.

\section{Potential sources of labor market stress}

\section{Impacts of a tighter labor market}

Economists have long recognized that tight labor markets create the potential to generating rising inflationary pressures. This is because, all else equal, when labor markets are sufficiently tight, workers' power to bargain up wages should increase. Rising wages could then cause business profits to fall, which could in turn discourage businesses from investing. Alternatively, rather than having their profits squeezed as unemployment falls, businesses could pass on higher labor costs to customers through price increases, causing a wage-price spiral, i.e., accelerating inflation. 
Increasing the demand for workers in the United States through a clean energy investment program could possibly be a source of such inflationary pressures. Overall though, this is not likely to be a significant problem.

To begin with, the relationship between changes, respectively, in the U.S. unemployment and inflation rates have been highly unstable, especially since the 1970s. Indeed, considering the 60-year period between 1950 and 2009, there is no statistically robust relationship at all —either positive or negative-between the inflation and unemployment rates. This long-term instability has been recently affirmed by, among others, a 2011 study by Federal Reserve economists Dotsey, Fujita, and Stark. Concentrating on the 20-year period from 1990 to 2009, they find that variation in the unemployment rate has no more predictive power in estimating inflation than simply looking at past movements in the inflation rate itself. ${ }^{7}$

The reason for the long-term instability in the unemployment/inflation relationship is that other factors in the economy also exert a major influence on determining inflation rates. For example, in the 1970s, the overwhelming factor causing rising inflation was not low unemployment, but the two oil price shocks-the threefold jump in 1973-74 and a similar spike in 1979. In the 1990s, inflationary pressures remained weak despite relatively low unemployment for much of the decade. This was due primarily to workers losing bargaining power, even at low unemployment rates, due to rising global competition and related factors. ${ }^{8}$

Of course, over the 20-year period on which we are focusing with our clean energy investment project, we cannot know in advance what other factors might emerge to influence U.S. labor markets and inflationary pressures. However, we can anticipate three factors that will add flexibility to U.S. labor markets as the clean energy investment program proceeds. The first, as we have examined at length, is that clean energy sectors of the economy will be rising concurrently with contractions in the fossil fuel sectors. This will expand the supply of workers seeking new employment opportunities. In addition, through changes in immigration rates, U.S. labor markets have the capacity to expand and contract, depending on the economy's overall level of labor demand. One obvious area within the clean energy program where changes in immigration rates should matter significantly is agriculture. As we have seen, the single biggest new area for job creation through the clean energy investment program is bioenergy. In turn, the largest area for new employment in bioenergy will be agriculture. In a tight U.S. labor market, the need for more workers in agriculture should be readily accommodated through increasing immigration rates. 
The U.S. labor market also becomes more flexible through changes in the labor force participation rate-i.e., the percentage of working-age people who either have a job or would like a job. As of May, 2014, the participation rate was 62.6 percent. But its peak before the 2007-09 financial crisis was 66.4 percent. In today's economy, the difference between 66.4 and 62.6 percent of people participating in the paid labor market is about 7 million people. This additional number of available workers is, of course, on top of the nearly 20 million people who, as of mid-2014, are either unemployed, underemployed, or discouraged from seeking work. ${ }^{9}$

Considering all of these factors, it appears likely that the U.S. economy will be able to accommodate the demands for about 2.6 million net new jobs per year without creating major strains in the overall labor market, and, correspondingly, accelerating inflation. However, it could still be possible that the clean energy investment program could lead to significant specific bottlenecks in the labor market tied to shortages of workers qualified to perform new tasks and responsibilities tied specifically to new areas of clean energy investments. Yet here as well, the evidence suggests that any such effects are likely to be modest. We reach this conclusion on the basis of our detailed analysis of the occupational categories that will be created by the clean energy investment program. It is within the context of analyzing these detailed employment creation categories that we can also understand the issue of where, and to what extent, skills upgrading and retraining are necessary to sustain healthy growth in clean energy job creation. We therefore now turn to that analysis. 


\section{Categories of jobs created by clean energy investments}

What are the types of jobs that would be created by the clean energy investment agenda, and how do they compare with the jobs that are likely to be lost when production declines in the nonrenewable sectors? We have examined this question in detail in previous research work, including a 2009 study, "Green Prosperity," as well as in numerous reports for the U.S. Department of Energy. ${ }^{10}$ It will be useful here to present some of the main findings of that earlier research.

In "Green Prosperity" specifically, we focused on comparing jobs that would be generated through a combined clean energy investment program, with spending within the fossil fuel sector at its current overall spending proportions. The combined clean energy program included the following investment areas: building retrofits (40 percent of total spending), smart grid (10 percent), public transportation and freight rail (20 percent), and all renewable areas ( 30 percent total).

In Figure 6.1, we present the main overall finding of this exercise. As the figure shows, we found that spending \$1 million on the combined clean energy investment program would generate 16.7 jobs while spending the same $\$ 1$ million on maintaining the existing fossil fuel sector generates 5.3 jobs. That is, investing in this combined set of clean energy investments produces roughly three times more jobs per dollar of expenditure than spending on fossil fuel energy.

Beyond this overall finding, we also presented in "Green Prosperity" more detailed descriptions as to a representative sample of jobs that are likely to expand significantly through this clean-energy investment agenda. In Table 6.10, we present a listing of those representative jobs. We organized these jobs according to the range of education credential levels required for each of them. As such, we have sorted the full set of representative occupations according
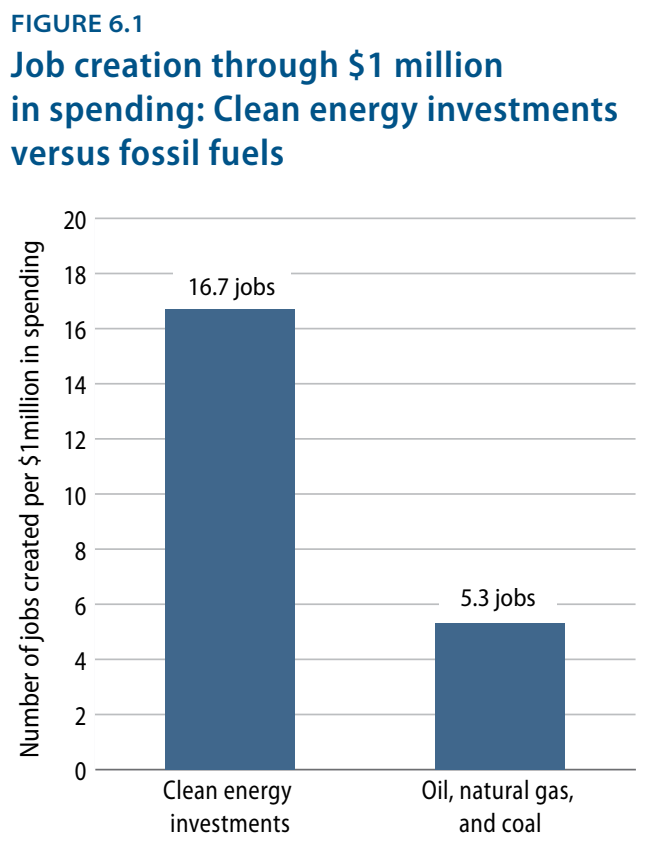

Source: See Appendix 4 and Robert Pollin, James Heintz, and Heidi Garrett-Peltier. 2009, "The Economic Benefits of Investing in Clean Energy." Washington: Center for American Progress, June. http://www.peri.umass.edu/fileadmin/pdf/other_ publication_types/green_economics/economic_benefits/economic_benefits.PDF

Note: Employment estimates include direct, indirect, and induced jobs. See Appendix 4 for details of calculations. 
to three education credential categories - college-degree jobs, requiring at least a bachelors degree; some-college jobs, requiring some college but not a completed bachelors degree; and high school or less jobs, requiring a high school degree or less.

TABLE 6.10

Occupations with large growth potential through green investments

College degree jobs

Operations managers

Human resource managers

Sales managers

Lawyers

Accountants

Architects

Civil engineers

Electrical engineers

Mechanical engineers

Computer programmers

Some college jobs

Construction managers

Farmers and ranchers

First-line supervisors of office workers

First-line supervisors of production workers

Engineering technicians

Computer support specialists

Accounting clerks

Payroll clerks

Secretaries

Paralegals

High school or less jobs

Agricultural workers

Janitors

Machinery assemblers

Grounds maintenance workers

Material movers

Cashiers

Customer service representatives 
High school or less jobs

Retail salespersons

Shipping clerks

Stock clerks

Carpenters

Construction laborers

Electricians

Insulation workers

Roofers

Machinists

Sheet metal workers

Bus drivers

Industrial truck drivers

Truck and bus dispatchers

Source: U.S. Census Bureau, 2008 January-December Current Population Survey (U.S. Department of Commerce, 2008).

Note: These occupations are selected from the top 100 occupations with the largest growth potential within each educational category.

It is clear in examining Table 6.10 that some of the jobs associated with the clean energy investment agenda are in specialized areas, such as installing solar panels and researching new building material technologies. Moreover, many of these jobs fall within the college-degree job category. But others are available to people with fewer education credentials. More generally, the majority of the jobs are in the same areas of employment that people already work in today throughout the United States and in all three of our education credential categories. Constructing wind farms, for example, creates jobs for sheet metal workers, machinists, and truck drivers, among many others. Some of these workers have received some college education, while others' occupations require less formal education requirements. Increasing the energy efficiency of buildings through retrofitting requires roofers, insulators, and architects—again, jobs that entail different levels of formal education requirements. Expanding mass transit systems employs civil engineers, electricians, and dispatchers. In addition, all of these clean energy investment strategies engage the normal range of service and support activitiesincluding accountants, lawyers, office clerks, human resource managers, cashiers, and retail sales people. Here again, these are occupations that span the range of formal education requirements. 
In Table 6.11, we compare the percentage and total numbers of jobs created by both clean energy investments and the fossil fuel industry, according to our three education credential categories. To begin with, we can see in this table that job creation is substantially higher with clean energy investments than with fossil fuels across all three credential categories.

TABLE 6.11

Breakdown of job creation by formal educational credential levels Job creation per \$1 million in spending

\begin{tabular}{|c|c|c|c|}
\hline & $\begin{array}{l}\text { 1. Clean energy } \\
\text { investments }\end{array}$ & 2. Fossil fuels & $\begin{array}{l}\text { 3. Difference in job } \\
\text { creation (= column } 1 \text { - } \\
\text { column } 2)\end{array}$ \\
\hline Total job creation & 16.7 jobs & 5.3 jobs & 11.4 jobs \\
\hline $\begin{array}{l}\text { College-degree jobs } \\
\text { - Bachelor's degree or above } \\
\text { - } \$ 24.50 \text { average hourly wage }\end{array}$ & $\begin{array}{l}3.9 \text { jobs } \\
\text { (23.3\% of clean } \\
\text { energy jobs) }\end{array}$ & $\begin{array}{l}1.5 \text { jobs } \\
\text { (28.3\% of fossil } \\
\text { fuel jobs) }\end{array}$ & 2.4 jobs \\
\hline $\begin{array}{l}\text { Some-college jobs } \\
\text { - Some college but no bachelor's degree } \\
\text { - } \$ 14.60 \text { average hourly wage }\end{array}$ & $\begin{array}{l}4.8 \text { jobs } \\
\text { (28.7\% of clean } \\
\text { energy jobs) }\end{array}$ & $\begin{array}{l}1.6 \text { jobs } \\
\text { (30.2\% of fossil } \\
\text { fuel jobs) }\end{array}$ & 3.2 jobs \\
\hline $\begin{array}{l}\text { High school or less jobs } \\
\text { - High school degree or less } \\
\text { - } \$ 12.00 \text { average hourly wage }\end{array}$ & $\begin{array}{l}8.0 \text { jobs } \\
\text { (47.9\% of clean } \\
\text { energy jobs }\end{array}$ & $\begin{array}{l}2.2 \text { jobs } \\
\text { (41.5\% of fossil } \\
\text { fuel jobs) }\end{array}$ & 5.8 jobs \\
\hline
\end{tabular}

Compared to investments in fossil fuel energy, clean energy investments create 2.5 times more college-degree jobs; 3 times more some-college jobs; and 3.5 times more high school or less jobs. This is true even while the proportions of jobs created in the different categories differ. For example, about 23 percent of the total clean energy investment jobs are college-degree jobs, while with fossil fuel spending, 28 percent of the jobs generally require a college degree. Likewise, the proportion of some-college jobs in fossil fuels is 30.2 percent, higher than with clean energy investments. The most substantial difference is with high school or less jobs.

While it is therefore true that the clean energy agenda will create significantly larger numbers of higher-credentialed and well-paying jobs, it is also true that the clean energy agenda creates far more lower-credentialed and low-paying jobs. However, it is not correct to assume that all, or even most, of these low-credentialed jobs created through clean energy investments need to be considered bad jobs, 
offering only low pay and no opportunities for advancement. As we discuss in detail in "Green Prosperity," about 5 of the roughly 17 jobs in total generated by $\$ 1$ million in spending through the clean energy investment agenda fall into the category of requiring high school degrees or less, but still offer decent earnings potential. These are clean energy jobs within the construction and manufacturing industries, where training opportunities and career ladders can play a crucial role in raising pay levels. But that still leaves about three jobs per $\$ 1$ million in clean energy spending for people with high school degrees or less that do not generally, at present, offer decent training opportunities or job ladders. As we have listed in Table 6.10, these are mostly jobs in agricultural or services such as cleaning, retail, and food preparation.

It is certainly preferable that an abundance of such jobs be available to people with low credentials than not be available at all. At the same time, these jobs need to be supported by policies to ensure that they will offer at least minimally decent pay and working conditions. As we see, on its own, the clean energy investment agenda will generate an expansion of employment opportunities in these job categories. But it cannot in itself improve conditions for such jobs. However, two complementary sets of policies can serve this purpose: minimum-wage laws that require a "living wage" standard throughout the country as the legal pay-level minimum; and a more favorable environment for union organizing among low-wage workers that would, in turn, improve the bargaining power for workers hired into low-paying occupations. This is not the place to examine these issues in depth. But we, among many other analysts, have done so elsewhere. ${ }^{11}$ 


\section{Job creation through bioenergy operations and maintenance}

Beyond these general patterns on the composition of new jobs created through clean energy investments, it is important to also profile in detail the jobs generated through operations and maintenance activities in the bioenergy sector. As we have seen above, the extent of job creation through O\&M in this sector, at 19.7 jobs per $\$ 1$ million in spending, is nearly four times greater than that generated by any other renewable or nonrenewable energy sector. Moreover, as we have also seen, bioenergy O\&M accounts for roughly half of the total number of new jobs that would be generated by the clean energy investment program that we have developed in this study.

In Table 6.12, we provide the breakdown of jobs created through biofuels/biomass O\&M, according to our education credential categories, just as we did in Table 6.11 above for the clean energy and fossil fuel sectors overall. As Table 6.12 shows, job creation in this sector is weighted heavily toward high school or less jobs. The jobs in this credential category account for 57.4 percent of all jobs created through this activity. This figure is nearly 10 percentage points higher than the 47.9 percent figure we saw in Table 6.11 for clean energy investments overall. The percentage gap is still greater relative to the 41.5 percent of high school or less jobs that result through spending on fossil fuels. Correspondingly, the proportion of collegedegree and some-college jobs generated by biofuels/biomass O\&M are low, at 19.2 percent and 23.4 percent, respectively. 
Bioenergy operations and maintenance: Job creation breakdown by formal educational credential levels

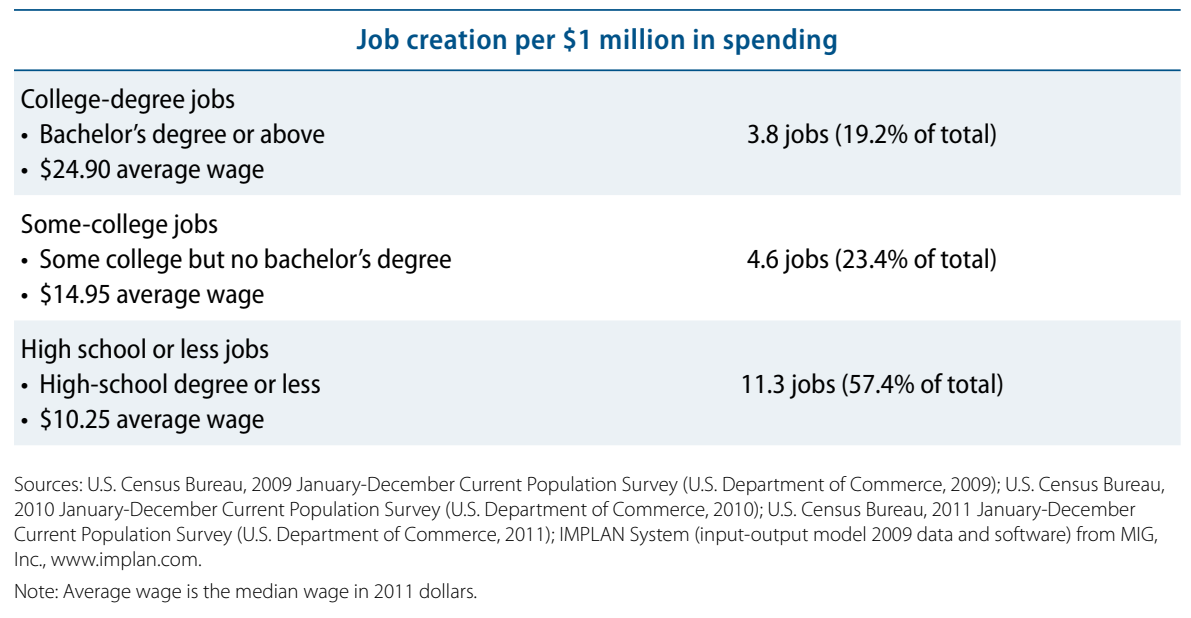

That said, what Table 6.12 also shows is that the total number of college-degree or some-college jobs generated by bioenergy $\mathrm{O} \& \mathrm{M}$ are both still significantly higher than the figures for fossil fuels and are roughly comparable to those for the combined clean energy investment program. That is, bioenergy O\&M generates 3.8 college-degree jobs per $\$ 1$ million in expenditures, as opposed to 1.5 collegedegree jobs with fossil fuels. Bioenergy O\&M also generates 4.6 some-college jobs per $\$ 1$ million in expenditures, compared to 1.6 some-college jobs created through spending $\$ 1$ million in the fossil fuel sectors.

In Table 6.13, we present some details on a representative sample of jobs that will expand disproportionately through new investments in bioenergy O\&M. Not surprisingly, jobs in agricultural-related activities are more heavily represented than with the combined clean energy investment project. There are also fewer jobs in areas such as research and engineering. However, the service-oriented areas of employment-including financial managers, accountants, operations managers, and attorneys-look comparable to those for the overall clean energy project. 
TABLE 6.13

Bioenergy operations and maintenance: Occupations with large growth potential

College degree jobs

Farmers

Farm managers

Real estate brokers

Accountants

Chief executives

Property managers

Sales representatives, wholesale

Operations managers

Financial managers

Lawyers

Some college jobs

Secretaries

Accounting clerks

Customer service representatives

First-line managers of office workers

Bill collectors

Office clerks

Receptionists

First-line managers of non-retail sales workers

Machinery mechanics

First-line supervisors of operating workers

High school or less jobs

Agricultural workers

Driver/sales workers

Grounds maintenance workers

Agricultural product graders

Material movers

Hand packers

Janitors

First-line supervisors of farm workers

Tractor operators

Heavy vehicle mechanics

Sources: U.S. Census Bureau, 2008 January-December Current Population Survey (U.S. Department of Commerce, 2008); U.S. Census Bureau, 2009 January-December Current Population Survey (U.S. Department of Commerce, 2009): U.S. Census Bureau, 2010 January-December Current Population Survey (U.S. Department of Commerce, 2010); U.S. Census Bureau, 2011 January-December Current Population Survey (U.S. Department of Commerce, 2011); IMPLAN System (input-output model 2009 data and software) from MIG, Inc., www.implan.com.

Note: These occupations are selected from the top 100 occupations with the largest growth potential within each educational category. 


\section{Skill requirements and training for clean energy jobs}

It is clear that some of the newly created jobs generated by clean energy investments will entail new activities and skills. For example, installing solar panels on roofs and wiring these panels so they supply electricity are distinct tasks relative to the jobs that are traditionally performed by either roofers or electricians. Similarly, refining agricultural wastes into biofuels is different than refining corn into ethanol or, for that matter, refining petroleum into gasoline. As such, there already have been demands for the provision of new types of training and skill acquisition.

At the same time, the body of research on this question that has emerged to date, both in the United States and among OECD economies more generally, mainly concludes that most clean energy occupations will require updating skills as opposed to training workers for entirely new occupations. The most extensive such study, Skills for Green Jobs: A Global View (Strietska-Ilina et al. 2011) concludes as follows ${ }^{12}$ :

The number of existing occupations that will change and update their skills content by far exceeds the number of new occupations that will emerge and will affect more jobs than the latter. This finding corresponds to the results of other studies. The greening of established occupations implies incremental changes in qualifications. New skills are needed because specific competencies are currently lacking, some existing skills relating to job tasks that become obsolete cease to be used, some tasks require global or interdisciplinary approaches, and sustainable development constraints are increasingly taken into account. This may lead to the diversification of existing occupations (for example, in management, with increased environmental management responsibilities) or to increased specialization of occupations. 


\section{Conclusion}

Overall, then, the figures on job creation through operations and maintenance of biofuels and biomass activities support our general findings in this chapter on job creation through the clean energy investment agenda. That is, investments in clean energy will produce a substantial expansion in job opportunities at all levels of the U.S. labor market. Within the PERI-CAP scenario for bringing overall energy consumption down to 70 Q-BTUs, expanding clean renewable supply to about 15 Q-BTUs, and achieving the 20-year $\mathrm{CO}_{2}$ emissions reduction level of 3,200 $\mathrm{mmt}$, we estimate that overall annual employment expansion will be about 4.2 million jobs. This includes jobs created both by new investments, as well as expanded levels of operations and maintenance in the clean energy sectors. We also find that total net employment-after taking account of job losses in the nonrenewable sectors tied to retrenchment in these sectors-is still at 2.7 million jobs.

What would be the likely impact on the U.S. labor market in 20 years through expanding overall employment by about 2.7 million jobs? One gauge of this impact that we have discussed is that, all else equal, it would bring a reduction in unemployment by about 1.5 percentage points. Thus, if the economy were otherwise at a 6.5 percent unemployment rate, operating under a clean energy framework as we have described would instead mean that the unemployment rate would be about 5 percent. We also provide a profile of the types of jobs that will be created under the clean energy agenda. As we show, building and operating the clean energy economy in the United States will produce large increases in job opportunities at all levels of credentials and pay. In short, the clean energy investment agenda creates more jobs, better jobs, and a broad distribution of opportunity across all wages and skill levels. 
1 The cost of expanding renewable energy supply from the 2010 actual level of 3.6 Q-BTUs to the 2030 PERI/ CAP case potential supply of 15.4 Q-BTUs is $\$ 106.6$ billion per year for 20 years, as shown in Table 3.17.

2 Alan Baum and Daniel Luria, “Driving Growth: How Clean Cars and Climate Policy Can Create Jobs" (Washington and Detroit: National Resources Defense Council, Center for American Progress, and United Automobile Workers, 2010), available at http://www. nrdc.org/energy/drivinggrowth.asp.

3 We also note that the employment creation estimates we report here do not include any investments to expand public transportation offerings. In Appendix 1, we do incorporate estimates of increasing public transportation along the lines we discuss briefly in Chapter 2.

4 The figures all come from the U.S. Bureau of Economic Analysis, "Industry Data," available at http://www.bea.gov/ iTable/iTable.cfm?ReqlD $=51$ \&step $=1$ \#reqid $=51$ \&step $=5$ $1 \&$ isuri $=1 \& 5114=a \& 5102=15$ (last accessed August 2014), as well as Marcel P. Timmer, ed., "The World Input-Output Database (WIOD): Contents, Sources and Methods." Working Paper 10 (European Commission, Research Directorate General, 2012), available at http:// www.wiod.org/publications/papers/wiod10.pdf. We are choosing to not include in these figures the activity in the U.S. electrical utility sector. This figure totaled $\$ 376$ billion in 2011, including both the utility sector's output, as well as their supply purchases. As such, the $\$ 1.3$ trillion figure we are using in the text for the overall size of the nonrenewable energy sector is a conservative estimate.

5 Bureau of the Census, Table 1. Projections of the Population and Components of Change for the United States: 2015 to 2060 (U.S. Department of Commerce, 2012), available at http://www.census.gov/population/ projections/data/national/2012/summarytables.html.

6 John A. “Skip" Laitner, Steven Nadel, R. Neal Elliot, Harvey Sachs, and A. Siddiq Khan, "The Long-term Energy Efficiency Potential: What the Evidence Suggests" (Washington: American Council for an Energy-Efficient Economy, 2012), available at http:// www.cleanenergyfinancecenter.org/wp-content/ uploads/ACEEE-Long-Term-EE-potential-Jan-2012.pdf.

7 James H. Stock and Mark W. Watson reach similar conclusions to Dotsey and others in their survey of the relevant literature since 1993 . See James H. Stock and Mark W. Watson, "Phillips Curve Inflation Forecasts." Working Paper 14322 (National Bureau of Economic Research, 2008), available at http://www.nber.org/ papers/w14322.pdf.

8 Robert J. Gordon has been a major contributor developing what he terms the "Time-Varying NAIRU," which incorporates the influences of supply shocks and inertia, along with the extent of labor market tightness, in explaining inflationary patterns. For example, Gordon observes "The two especially large changes in the NAIRU .... are the increase between the early and late 1960s and the decrease in the 1990s. The late 1960s were a time of labor militancy, relatively strong unions, a relatively high minimum wage, and a marked increase in labor's share in national income. The 1990s have been a time of labor peace, relatively weak unions, a relatively low minimum wage, and a slight decline in labor's income share." Robert J. Gordon, "The Time-Varying NAIRU and its Implications for Economic Policy," Journal of Economic Perspectives 11(1) (1997): 30 . The collection edited by Krueger and Solow (2002) presents a range of perspectives both on the effects of tight U.S. labor markets-including views on the time-varying NAIRU- as well as research on how to effectively with tight labor markets. For more information, see Alan B. Krueger and Robert M. Solow, eds., The Roaring Nineties: Can Full Employment be Sustained? (New York: Russell Sage Foundation, 2001). It is also worth mentioning that inflation is by no means necessarily an obstacle to economic growth but rather can be a byproduct of a rapidly growing economy. For more information on the relationship between inflation and growth, see Michae Bruno, "Does Inflation Really Lower Growth?" Finance and Development 32 (3) (1996): 35-38; Robert Pollin and Andong Zhu "Inflation and Economic Growth: A CrossCountry Nonlinear Analysis" Journal of Post Keynesian Economics 28 (4) (2006): 593-614.

9 The figures in this paragraph are from the U.S. Bureau of Labor Statistics, "The Employment Situation - May 2014" Press release, June 6, 2014, available at: http://www.bls. gov/news.release/archives/empsit_06062014.pdf. The broad measure of unemployment being cited is what the BLS terms U-6, which is inclusive of the unemployed, underemployed, and discouraged workers.

10 Robert Pollin, Jeannette Wicks-Lim, and Heidi GarrettPeltier, "Green Prosperity: How Clean Energy Policies Can Fight Poverty and Raise Living Standards in the United States" (Amherst, MA and Washington: Political Economy Research Institute, National Resources Defense Council, and Green for All, 2009), available at http:// www.peri.umass.edu/fileadmin/pdf/other_publication types/green economics/green_prosperity/ Green_Prosperity.pdf. The reports written by PERI for the U.S. Department of Energy are unpublished works.

11 See for example Robert Pollin, Heidi Garrett-Peltier, James Heintz, and Helen Scharber, "Green Recovery: A Program to Create Good Jobs and Start Building a Low-Carbon Economy" (Amherst, MA: Political Economy Research Institute, 2008), available at http://www.peri.umass. edu/fileadmin/pdf/other_publication_types/green_ economics/peri_report.pdf.; Jeannette Wicks-Lim and Robert Pollin, "Making Work Pay: Combining the Benefits of the Earned Income Tax Credit and Minimum Wage" (Amherst, MA: Political Economy Research Institute, 2012), available at http://www.peri.umass.edu/fileadmin/ pdf/published_study/PERI_WorkPay.pdf.

12 Other recent studies that reach similar conclusions include Carol Zabin and Megan Emiko Scott, "Proposition 39: Jobs and Training for California's Workers" (Berkeley CA: Donald Vial Center on Employment in the Green Economy, 2013), available at http://www.irle.berkeley. edu/vial/publications/prop39_jobs_training.pdf; Organisation for Economic Co-operation and Development, "The Jobs Potential of a Shift Towards a Low-Carbon Economy: Final Report for the European Commission, DG Employment" (2012), available at http://www.oecd.org/els/emp/50503551.pdf; Erich C. Dierdorff and others have developed a detailed breakdown of the occupations and skill requirements associated with "green economic activities" in the United States. The authors' definition of "green economic activities" is broader than our own focus on jobs generated through new investments in energy efficiency and clean renewable energy. Nevertheless, their conclusion is similar to that of the ILO authors in that they focus on the need for incremental adjustments and flexibility in training and skill acquisition tied to the expansion of green economic activities. For more information, see Erich C. Dierdorff, Jennifer J. Norton, Christina M. Gregory, David Rivkin, and Phil Lewis, "Greening the World of Work: Revisiting Occupational Consequences" (The National Center for O*NET Development, 2011), available at http://www. onetcenter.org/dl_files/Green2.pdf. 
Chapter 7

\section{Macroeconomic issues with clean energy investments}




\section{Introduction}

In this chapter, we consider the major macroeconomic effects, in addition to employment, that would result from a clean energy investment agenda such as the one described in chapters 2 through 6 . To set an overall context for this topic, we begin by reviewing the literature on the effects of such an energy transition, as seen through the lens of a series of forecasts on the projected impact of cap-and-trade legislation on U.S. GDP growth. Although our focus in this study is not on cap-and-trade legislation per se, the findings of these forecasting exercises are nevertheless informative for understanding the broader set of macroeconomic impacts. In particular, it is extremely important to note that despite opponents' public rhetoric about climate policies in the United States, none of the macroeconomic models reviewed forecast that cap-and-trade regulations would create significant negative effects on GDP growth. Indeed, in all the model forecasts, without exception, any possible negative effects of climate regulation on GDP growth are virtually indiscernible.

The information from this review underscores that a broad clean energy investment agenda as laid out in this study-driven by investment incentives for energy efficiency and renewable energy, as well as regulations on fossil fuel consumptioncan in fact deliver net gains in GDP growth along with numerous other economic benefits. This chapter then briefly considers the impact of such a program in terms of overall U.S. investment, productivity, energy prices, and the U.S. trade balance, respectively. We also consider how mitigating climate change may itself impact U.S. macroeconomic activity.

Early evidence is now becoming available on the first major effort to utilize clean energy investments to stimulate employment and economic growth in the U.S. economy_the 2009 American Recovery and Reinvestment Act, or ARRA. ARRA included about $\$ 90$ billion in funding of various sorts to advance a clean energy agenda in the United States. ${ }^{1}$ This was a major feature of the overall two-year $\$ 800$ billion ARRA program to counteract the 2008-2009 financial crisis and subsequent Great Recession. It is therefore important in this section to consider how well the clean energy components of ARRA succeeded in their overall purpose. 
Within this context, we also wish to give special consideration to the one project within the clean energy/ARRA program that has received the most attention by far: the 2011 bankruptcy of the northern California solar energy firm, Solyndra. Solyndra had received $\$ 535$ million in federal loan guarantees through ARRA prior to declaring bankruptcy. ${ }^{2}$ We will review the Solyndra experience as a means of drawing broader lessons on the viability of a government-supported clean energy investment agenda. 


\section{Environmental regulations and GDP growth}

Environmental regulations aimed directly at reducing fossil fuel consumption operate through both raising fossil fuel prices and limiting supply. There are two major policy approaches here. One is a carbon tax, which directly raises the price of polluting and indirectly limits supply through the impact of higher prices. The other is a carbon cap, which explicitly mandates reductions in fossil fuel production by specified amounts. The explicit limit on supply would then likely raise prices. Cap-and-trade legislation is one variant of a carbon cap, but the "trade" feature of such a measure - the capacity to buy or sell rights to produce the limited amount of overall fossil fuel supply-is a secondary effect, which, at least in principle, will not alter the impact of the cap itself.

What is likely to be the impact of any such measures on economic activity in general? Of course, coming up with reliable forecasts of such measures is notoriously unreliable, especially if one is considering the effects over an extended period of time. Nevertheless, it is useful to study the forecasting exercises that have been undertaken — specifically with respect to cap-and-trade legislation — to obtain a sense of the range of effects that researchers anticipate.

With this limited ambition in mind-as opposed to presuming one can accurately forecast the future growth rate of the economy over the next generation-let us now consider the various forecasts that were generated to estimate the effects on long-term GDP growth of the most recent piece of cap-and-trade legislation that was considered in Congress. This was the American Clean Energy and Security Act, or ACESA, otherwise known as the Waxman-Markey bill, named for its two sponsors in the House of Representatives. Waxman-Markey did pass in the House of Representatives in May 2009 but failed to pass in the Senate. ${ }^{3}$ 
In Table 7.1, we show the results of alternative forecasts generated by the Energy Information Administration, along with the Environmental Protection Agency and the American Council on Capital Formation/National Association of Manufacturers. The ACCF/NAM is a business lobbying group that was strongly opposed to Waxman-Markey. We present in Table 7.1 only the worst-case scenario generated by the ACCF/NAM model, their "high-cost case."

\section{TABLE 7.1}

\section{Comparison of alternative U.S. GDP growth forecasts under baseline and with cap-and-trade legislation}

Figures are average annual growth-rate forecasts for specified time periods

\begin{tabular}{|c|c|c|c|}
\hline & $\begin{array}{l}\text { 1. Baseline } \\
\text { GDP forecast }\end{array}$ & $\begin{array}{c}\text { 2. GDP forecast } \\
\text { under Waxman- } \\
\text { Markey cap and trade }\end{array}$ & $\begin{array}{l}\text { 3. Difference between } \\
\text { baseline and cap-and- } \\
\text { trade growth forecasts } \\
\text { (column } 1 \text { - column } 2 \text { ) }\end{array}$ \\
\hline $\begin{array}{l}\text { Energy Information } \\
\text { Administration (basic } \\
\text { scenario } 2010 \text { to 2030) }\end{array}$ & 2.71 & 2.67 & 0.04 \\
\hline $\begin{array}{l}\text { Energy Information } \\
\text { Administration (high-cost } \\
\text { scenario } 2010 \text { to 2030) }\end{array}$ & 2.71 & 2.66 & 0.05 \\
\hline $\begin{array}{l}\text { Environmental Protection } \\
\text { Agency-1 (ADAGE model; } \\
2015 \text { to 2050) }\end{array}$ & 2.41 & 2.36 & 0.05 \\
\hline $\begin{array}{l}\text { Environmental Protection } \\
\text { Agency-2 (IGEM model; } \\
2015 \text { to 2050) }\end{array}$ & 2.38 & 2.32 & 0.06 \\
\hline $\begin{array}{l}\text { ACCF/NAM "high-cost case" } \\
\text { (2007 to 2030) }\end{array}$ & 2.31 & 2.21 & 0.10 \\
\hline
\end{tabular}

Sources: Energy Information Administration, “Model Documentation Report: Macroeconomic Activity Module (MAM) of the National Energy Modeling System” (U.S. Department of Energy, 2009); U.S. Environmental Protection Agency, "EPA Lifecycle Analysis of Greenhouse Gas Emissions from Renewable Fuels" (2009); American Council for Capital Formation and the National Association of Manufacturers, "Analysis of the Waxman-Markey Bill" (2009).

The results of these modeling exercises can be readily summarized. With the two sets of models produced by the EIA and EPA, the effects of Waxman-Markey would be virtually indiscernible statistically. That is, the difference between their baseline GDP forecast and GDP if cap-and-trade legislation were in effect is in the range of one-twentieth of 1 percentage point of GDP growth. For example, in the first case shown in Table 7.1, the EIA Reference case, the difference is between a 2.71 percent and a 2.67 percent average annual growth rate between 2010 and 2030 . 
What is equally, if not more, remarkable with these models is that the worst-case scenario from ACCF/NAM - the analysis from strong opponents of cap-andtrade legislation - reaches basically the same conclusion as the EIA and EPA models. Under their worst-case scenario, cap-and-trade legislation would reduce average GDP growth by only one-tenth of 1 percentage point.

This basic finding is even more notable given that all of these models leave out significant considerations that would tend to encourage the long-term growth rate to rise. These basic considerations include: the positive effects of higher employment; the benefits of a higher level of domestic content and thus a reduced trade deficit; and the economic benefits of reducing greenhouse gas emissions. We examine these additional factors in the discussion below. 


\section{Clean energy spending and overall U.S. investment}

We have argued in this report that the level of clean energy investments needed to reach the 2030 emission targets is about $\$ 200$ billion per year (as shown in Table 5.3). This breaks down to about $\$ 88$ billion for energy efficiency investments and $\$ 107$ for renewable energy investments, and a rough adjustment upward to account for additional investment spending needed to cover possible modest rebound effects. ${ }^{5}$

In absolute dollars, $\$ 200$ billion is a very large sum of money. But relative to overall activity and investment within the U.S. economy, it is an amount that can be readily absorbed within the operations of the economy without requiring substantial shifts in spending patterns. We can see this from the figures in Table 7.2, which shows the $\$ 200$ billion annual clean energy investment level relative to U.S. GDP and to total U.S. investment in 2012. As we see in the table, the $\$ 200$ billion in investments is equal to about 1.2 percent of U.S. GDP and 6.5 percent of total U.S. investment for 2012. We should note that the overall investment figure includes both public and private investment, and among areas of public investment, federal, state, and local investments are included, and federal investment includes military, as well as nonmilitary, investments. Of course, investments in clean energy will need to be made both by the public and private sectors, and at all levels within the public sector. It is therefore entirely appropriate to compare the $\$ 200$ billion overall level of clean energy investments with this combined figure for investments of all types at all levels of the economy.

TABLE 7.2

Projected clean energy investments as share of U.S. economy

Assume $\$ 200$ billion per year in clean energy investments

\begin{tabular}{lcc}
\hline & $\begin{array}{c}\text { U.S. macroeconomic } \\
\text { indicator }\end{array}$ & $\begin{array}{c}\text { Clean energy investments } \\
\text { relative to macroeconomic } \\
\text { indicator }\end{array}$ \\
\hline $\begin{array}{l}\text { U.S. GDP, } 2012 \\
\text { Total investment in U.S. economy, } \\
2012\end{array}$ & $\$ 16.2$ trillion & $1.2 \%$ \\
\hline 3.1 trillion & $6.5 \%$
\end{tabular}

Sources: Bureau of Economic Analysis, National Income and Product Accounts Tables (U.S. Department of Commerce), tables 1.1.5 and 5.1. 
If an amount in the range of 6.5 percent of new investment in the United States were to flow into clean energy sectors, it does not mean that funds to support other areas of investment would face more difficulties getting supported. There are two basic reasons why this would not be the case. The first is that the rise in clean energy investments will be matched to a significant degree by declining levels of investment in the conventional energy areas. Estimates of current investment levels in the oil and natural gas sectors range between $\$ 150$ billion (the most recent 2011 figures from U.S. National Income and Product Accounts) to $\$ 348$ billion (from the Oil and Gas Industry Journal). ${ }^{6}$ These figures indicate that there is considerable room for the financing of clean energy investments to grow as a substitute for expanding the fossil fuel sector. Moreover, according to the PERI/CAP scenario we have developed in Chapter 5 to meet the 20-year emissions reduction target, none of the nonrenewable energy sectors will experience growth in overall consumption relative to 2010 levels.

In addition, even if investments in nonrenewable energy sectors were not declining, expanding clean energy investments by about $\$ 200$ billion still would not place excessive demands on U.S. productive capacity to raise the overall investment share in the economy. In 2012 total investment spending equaled roughly 19 percent of U.S. GDP, but in 2007, just prior to the Great Recession, total investment spending represented 22.3 percent of GDP. ${ }^{7}$ The investment-to-GDP ratio for 2007, moreover, was basically equal to the average ratio over the 43-year period from 1970 through 2012. It is therefore clear that the U.S. economy has the resources to raise its investment share of GDP at least back to the 22-percent range that had been the average from 1970 through 2012 . As we have seen, the $\$ 200$ billion level of clean energy investments would represent only about 1.2 percentage points to overall GDP. In today's economy, then, adding $\$ 200$ billion to overall investment would raise the economy's investment share up to 20.3 percent of GDP, still comfortably below the 22-percent average figure for 1970 through 2012.

Related to this, there is no evidence to suggest that increasing the investment share of GDP by about 1 percentage point would consistently exert upward pressure on long-term interest rates on loans that would be available to private investors. In fact, interest rates for private borrowers in the United States are determined by a much broader set of influences than small increases in the economy's investment/GDP ratio. The more significant determinants of long-term interest rates include conditions in U.S. financial markets and the monetary policy stance of the Federal Reserve at any given time. ${ }^{8}$ 


\section{Productivity growth}

\section{Energy productivity}

A crucial first step in assessing the impact of the clean energy investment agenda on aggregate productivity requires that we be clear as to what we mean when we refer to "productivity." The measure of productivity on which we have focused in this report is energy intensity - that is, how much energy is required to produce a given amount of GDP. As we saw in Chapter 2 (especially Figure 2.1 and the accompanying discussion), the U.S. energy intensity ratio has improved dramatically since 1970s, having cut in half the amount of energy used to produce each unit of GDP, falling from 15.9 thousands of BTUs per dollar of GDP in 1970 to 7.4 thousands of BTUs per dollar in 2010.

The clean energy investment agenda we are proposing will entail still further major improvements in energy intensity over the next 20 years. To estimate these gains, we will work wth the EIA's Reference case forecast for U.S. GDP through 2030 of 2.5 percent per year. Under this growth trajectory, the level of GDP would be $\$ 24.1$ billion in 2030 , as opposed to the 2010 figure of $\$ 14.7$ billion.

Let us then also assume that by 2030, the overall level of energy consumption will be approximately 70 Q-BTUs in total. In that case, energy intensity in the United States will fall to 2.9 thousands of BTUs per dollar of GDP. This is a 61 percent reduction in U.S. energy intensity relative to 2010, or an average rate of declining intensity of 4.6 percent per year.

\section{Labor productivity}

By a standard definition, labor productivity simply measures total output per worker. By this standard definition, if we increase labor intensity through clean energy investments - if we generate about 17 jobs per $\$ 1$ million through clean energy investments versus about five jobs per $\$ 1$ million through fossil fuel 
spending - then we reduce labor productivity in the energy sector through shifting spending toward clean energy. In short, the project of building a clean energy economy entails concurrently raising energy productivity while lowering labor productivity, as conventionally measured.

However, the idea of inverse patterns for energy and labor productivity does not adequately capture the full story on the movement of labor productivity because it neglects two crucial and widely understood additional considerations. First, by raising overall employment, clean energy investments provide new opportunities for previously unemployed workers. This raises the productivity level of millions of workers from zero to a positive number. Any economywide measure of labor productivity has to take account of this effect. Similarly, clean energy investments create new opportunities for underemployed workers, thereby raising their productivity from a lower to a higher level.

Second, given the global climate crisis, we need to begin incorporating environmental effects in the measurement of output and productivity. That is, spending on fossil fuels creates the output "good" of energy to power machines, but it also creates the output "bad" of pollution and $\mathrm{CO}_{2}$ emissions. This point has long been recognised in discussions of the environmental costs of economic growth and is included in virtually every introductory economics textbook. Thus, with every unit of energy generated by clean energy investments as opposed to fossil fuels, the net increase in output is greater to the extent that we are not producing the "bad" of pollution and greenhouse gas emissions.

Clean energy investments will therefore substantially raise economywide labor productivity—defined appropriately—through two channels:

- By expanding total employment per dollar of expenditure in the economy, it provides millions of people with new opportunities to become productive workers.

- By generating energy from clean sources, it increases the level of "goods" we produce and correspondingly reduces our production of "bads," or harmful external costs to the economy.

Overall, then, the productivity effects - energy productivity, as well as labor productivity, when defined properly_on a macro scale of clean energy investments are all strongly favorable. 


\section{Energy prices}

Under the agenda we have developed above, the demand for nonrenewable energy sources will fall substantially. As we have seen, overall energy consumption will fall by nearly 30 percent from its 2010 level of about 98 Q-BTUs to about 70 Q-BTUs. Within that broad framework, the demand for oil, at around 21 Q-BTUs, will be more than 40 percent below its 2010 level of about 36 Q-BTUs. ${ }^{9}$ Further, according to the scenario we have developed, the demand for natural gas and nuclear power will be, at most, flat relative to their 2010 levels by 2030 and 2035 . Coal consumption will have fallen by more than half.

Of course, these changes in consumption patterns will not occur as a one-time event but rather will adjust incrementally over a roughly 20 -year period. Still, the long-run demand trajectory is downward. As such, based on supply and demand forces alone, there is no reason to expect that nonrenewable energy prices will rise through this transition to a clean energy economy. Rather, based on supply and demand dynamics alone, we will expect that the more basic problem will be adjusting to excess capacity of nonrenewable energy as demand and prices fall.

With respect to renewable energy prices, the agenda we have presented entails expanding investment levels significantly at the point where these energy sources can be produced at costs that are competitive with nonrenewables. As we have seen above, according to the EIA, generating electricity from wind, bioenergy, and geothermal sources will be produced at competitive costs under average cost conditions by 2017. The EIA estimates that generating electricity from solar power will not be as close to reaching competitiveness under average conditions by 2017, even while solar has experienced sharp cost declines in recent years. Still, under the low-cost renewable technology scenario, the EIA does anticipate continued significant cost reductions in solar over the next 20 years. Overall, within the renewable energy investment agenda we have set out, there is no reason to expect that expanding the supply of clean renewables to approximately 15 Q-BTUs will entail increases in energy prices. 
In assessing the future movements of energy prices, however, it is important to recognize that underlying forces-including market supply and demand, investment levels to expand capacity or to advance technical innovations, and costs of production-are not the only determinants of market prices. Two other major factors include the large-scale speculative activity on the energy commodities futures markets and policy interventions aimed explicitly at raising fossil fuel prices such as a carbon cap or carbon tax. We consider these in turn.

\section{Commodities futures market speculation}

Increasingly since the early 2000s, oil prices in particular have been heavily influenced by the exponential growth in speculative market trading around oil prices through the oil commodities futures market. This type of speculative activity influences the prices today—called spot prices—of both crude oil and gasoline at the pump because it affects expectations of future price changes. That is, traders in the market for current supplies - called the spot marketlook to the speculative futures market to determine where to set the price today. As an example, between October 2010 and May 2011, the average gasoline price at the pump in the United States rose by $\$ 1.03$ per gallon, from $\$ 2.93$ to $\$ 3.96$, a 35 percent rise. ${ }^{10}$ Pollin and Heintz estimated that speculative market forces were responsible for 83 cents of that increase, while all supply and demand factors combined explained only the remaining 20 cents of the full increase. ${ }^{11}$

Commodities futures market speculation also influences other energy prices, though not as much as the oil market to date. In any case, whatever the influences of commodities futures markets on energy spot prices, all such factors will exert their effects independently of the clean energy investment agenda per se. Speculation on energy commodities futures markets can be constrained, but this needs to be accomplished through financial market regulations focused on the commodities markets. ${ }^{12}$

\section{Policy interventions}

The aim of a carbon cap or tax is to discourage fossil fuel consumption by raising the costs of purchasing fossil fuel energy. With a carbon cap-such as a cap-andtrade measure-the direct policy lever is to explicitly limit carbon emissions, but the impact of any such limit will also be to raise fossil fuel prices. With either a 
carbon cap or tax as an active policy, conventional energy prices would certainly rise, but as with the case of the energy futures market, the price increase would not be driven by the clean energy investment agenda. Rather, in this case prices would be rising through the policy intervention itself, so that as a result of such an intervention, the market prices of fossil fuels will reflect the environmental costs of emitting greenhouse gases into the atmosphere.

Still, on this issue, it is again worth noting that with the aforementioned energy forecasting models of the effects of cap-and-trade legislation on economic growth, the conclusion incorporated into all of these models is that large increases in fossil fuel prices will not have a significant impact on GDP growth. Overall, we can reach the following conclusions regarding the relationship between energy prices and the clean energy investment agenda we have proposed:

- Considered on its own, independent of any pressures from speculative commodities futures markets, there is no reason to expect that the clean energy investment agenda we have developed here should lead to higher energy prices. The much more likely scenario is that this investment agenda will promote lower energy prices due to the decline in energy demand tied to energy efficiency investments.

- It will almost certainly be important that public policy interventions set fossil fuel prices higher than where they would fall due to supply and demand factors only. Such higher prices would reflect the environmental costs of burning fossil fuels.

- The forecasting models that have analyzed the macro effects of significantly higher fossil fuel energy prices do not find that such price increases lead to significant negative effects on GDP growth. 


\section{U.S. trade balance ${ }^{13}$}

The United States has run trade deficits-purchases of imports in excess of sales of exports - for 37 years straight. The trade deficit equaled 4.6 percent of U.S. GDP in 2011, which is significantly down from the pre-recession level of 6 percent in 2007.

U.S. imports of foreign oil are the largest single factor contributing to the trade deficit. In 2011 U.S. purchases of imported oil amounted to around $\$ 460$ billion, which equaled about 21 percent of all U.S. imports that year and fully 82 percent of the total 2011 trade deficit. The clean energy investment agenda we have developed here would certainly bring major reductions in U.S. oil imports. As we have discussed, we would anticipate that total U.S. oil consumption will be around 21 Q-BTUs. The EIA forecasts that domestic U.S. oil production will be around 13 Q-BTUs in 2030 and 2035. That would mean the United States would need to import only about 8 Q-BTUs of oil by 2030, which is about half the EIA's projected figure for 2030 in its Reference case.

The capacity to conduct U.S. macroeconomic policy would benefit significantly from such a large reduction in the country's trade deficit. The trade deficit has been financed by foreigners accumulating portfolios of dollar assets, which pay for the imports we purchase in excess of our exports. Foreign holdings of U.S. Treasury bonds alone now stand at roughly $\$ 5$ trillion, and as a result, U.S. policymakersespecially in the area of monetary policy—need to remain highly responsive to the needs of U.S. creditors. For example, to promote U.S. exports, policymakers may wish to lower the value of the dollar relative to the Euro, the Chinese yuan, and the Japanese yen. But to push aggressively in this direction would entail reducing the dollar-based wealth of foreign creditors, which in turn would provoke a reaction from these creditors. This constraint on U.S. monetary policy would be greatly diminished to the extent that the U.S. trade deficit could be reduced if we cut oil imports significantly. 
Of course, for the United States or any other country to purchase imports of oil or other products is not necessarily harmful. Even running a persistent trade deficit can have benefits to the U.S. economy, in that we receive access to products that are cheaper or of higher quality than would be possible by relying entirely on domestic producers. But the persistent U.S. trade deficit does exert long-term corrosive effects on the country's financial balances, as foreign holdings of dollar assets continue to expand. Closing the U.S. trade deficit would therefore be an additional benefit of the clean energy investment agenda through its ability to dramatically reduce U.S. oil imports. 


\section{Benefits of lower carbon emissions}

Within the framework of GDP accounting, it is difficult to quantify the economic benefits of protecting ourselves against the impacts of climate change, even while we know that such benefits are potentially enormous. We can start with the basic point that most climate scientists hold: Global climate change is contributing throughout the world to extreme weather patterns, a rising sea level, and significant shifts in many ecosystems. These patterns will intensify as long as we fail to limit carbon emissions.

Disruptions of normal economic activities will increase as a result of the rising frequency of extreme weather patterns, which in turn will reduce economic well-being. Some of these negative economic impacts—such as a rising sea level and destroying natural habitats for species-are not well captured through traditional GDP statistics. But other negative impacts will register in the GDP accounts. A 2012 study by CERES on the impact of climate change on the U.S. insurance industry, for example, finds that "rising losses related to extreme weather events are significantly impacting the insurance industry and will increasingly challenge the sector's risk models and underwriting capabilities." ${ }^{14}$ This study estimates that extreme weather events cost U.S. property and casualty insurers more than $\$ 32$ billion in losses in 2011. These losses experienced by the insurance industry result from, among other events, the hurricanes, wild fires, and droughts that have become increasingly frequent. ${ }^{15}$

Of course, the most important consideration here is to recognize the overall welfare costs and especially the real dangers of an irreversible environmental crisis that could result from allowing carbon emissions to continue unchecked. These considerations transcend the issue of whether such costs and risks are captured within our conventional GDP statistics. Still, considering models that attempt only to forecast future GDP and leave broader welfare considerations outside the model, the benefits of controlling carbon emissions will be measureable and significant. Neglecting all such benefits means that future GDP forecasts - the baseline forecasts, as well as those that allow for a carbon-cap mandate-are likely to be understated. 


\section{The effects of the American Recovery and Reinvestment Act}

The Obama administration's February 2009 economic stimulus program-the American Recovery and Reinvestment Act-represented a dramatic step forward on the issue of jobs and the environment. ARRA included between $\$ 90$ billion and $\$ 100$ billion in clean energy funding as part of the overall $\$ 840$ billion two-year measure. ARRA also embraced the concept that clean energy or "green" investments could serve as a significant new engine of job opportunities throughout the economy. This idea directly contradicted the long-dominant view that the goals of environmental sustainability and job creation were inevitably and painfully at odds.

Since roughly the 2010 midterm national elections, the level of mainstream political support for the green investment agenda within ARRA eroded substantially, while the traditional position - that economic policies can protect the environment or expand job opportunities but cannot do both at once-regained traction. According to the revived traditional view, the green features of ARRA did not succeed either in rapidly generating new jobs or significantly increasing green investments. The question that has been posed repeatedly since ARRA's passage is: Where is the evidence that the green jobs that were promised were actually created?

In addition, government support for renewable energy investment projects is widely seen as unworkable and wasteful. The most widely cited piece of evidence here has been the bankruptcy in September 2011 of Solyndra, the northern Californiabased manufacturer of solar panels. Solyndra had received \$535 million in federal loan guarantees though ARRA only two years prior to declaring bankruptcy.

In assessing the broader macroeconomic impacts of the green investment agenda we are proposing here, it is of course important to evaluate the performance of ARRA's green features, as the first large-scale green investment program in the United States. 
There are various ways through which one can measure the size of the green economy components of ARRA. For example, do we include clean energy projects only or also include nonenergy-related green activities? Do we focus only on projects managed through the Department of Energy, or do we consider all projects managed by all agencies? Do we include public transportation, water management, and related public investment projects as components of the green economy agenda? The overall size of the ARRA green programs will depend on how one answers these and related questions.

One standard reference point for grounding such discussions is the January 2010 report by the President's Council of Economic Advisors, or CEA, on the clean energy components of ARRA. ${ }^{16}$ Table 7.3 below shows figures from this report. As the table shows, the CEA's figure for overall allocation is $\$ 90.2$ billion, with the various subcategories - including renewable energy generation, energy efficiency, public transportation, grid modernization, and advanced vehicles-also presented. ${ }^{17}$

TABLE 7.3

Expenditure allocation for all ARRA clean energy appropriations from U.S. Council of Economic Advisers, January 2010

\begin{tabular}{lc}
\hline Category & Amount appropriated \\
\hline Renewable generation & $\$ 26.6$ billion \\
Energy efficiency & $\$ 19.9$ billion \\
Traditional transit and high-speed rail & $\$ 18.1$ billion \\
Grid modernization & $\$ 10.5$ billion \\
Advanced vehicles and fuels technologies & $\$ 6.1$ billion \\
Green innovation and job training & $\$ 3.5$ billion \\
Carbon capture and sequestration & $\$ 3.4$ billion \\
Clean energy equipment manufacturing & $\$ 1.6$ billion \\
Other & $\$ 408$ million \\
Total & $\$ 90.2$ billion \\
Source: Council of Economic Advisers, "The Economic Impact of the American Recovery and Reinvestment Act of 2009: Second Quarterly \\
Report" (2010).
\end{tabular}


However, the CEA reports in this same January 2010 document that total funding “appropriations" for the clean energy components of ARRA was $\$ 60.7$ billion across 45 different spending categories, while $\$ 29.5$ billion was allocated through 11 tax incentive programs. ${ }^{18}$ A careful analysis by Carley and Hyman (2013) finds that funding through contracts, grants, and loans, as reported by recipients of these funding allocations, was a still lower figure, $\$ 43.8$ billion.

But even if one accepts the $\$ 90$ billion CEA figure as authoritatively presenting the overall allocation figure, we are still left with the problem of sorting out how much of the allocated funds were actually spent. The lack of certainty here is due to differences in reporting requirements by activity and project, as well as, again, different ways to categorize many activities. Yet to assess the impact of ARRA on both job creation and the environment, we must know how much money was spent, not merely how much was allocated.

In fact, there is considerable evidence showing that significant problems emerged in moving the allocated ARRA funds into the economy's spending stream. To begin with, the CEA's own report on spending activity through the end of 2009that is, over nearly the first full year of what was designed as primarily a two-year program - found that that only $\$ 5.1$ billion had been delivered as outlays. This was only 5.7 percent of the $\$ 90.2$ billion total allocation. To date, the CEA has not provided a more current set of figures on clean energy ARRA outlays.

More recently, the Carley and Hyman study examined this question as well. ${ }^{19}$ According to their accounting, as of the first quarter of 2013 - nearly three full years after ARRA had begun - only $\$ 27.7$ billion, or about 30 percent of the $\$ 90$ billion allocated, had been spent by fund recipients. Carley and Hyman cite several factors as contributing to the delays in moving allocated funds into the economy. As they write:

The Recovery Act required actors within several layers of the government-as well as outside of the government - to coordinate on projects of varying sizes and time frames. Miscommunication and administrative challenges may have been inevitable, but there are other instances that were unique to the ARRA, because of how it was implemented and the sheer magnitude of the effort. For example, reporting requirements were a challenge to communicate to recipients from the federal level, and staffing shortages at all levels of government hindered implementation. Laws and regulations varied by locality, as did local-and state-level experience with the implementation of energy-related projects. The speed of implementation of an ARRA project rested with its implementation by each participant, thereby confounding efforts to expedite these projects at the other levels. ${ }^{20}$ 
Over time, it will be crucial to consider more fully the problems of implementation with the clean energy elements of ARRA. Addressing these questions carefully will enable us to evaluate the capacity of a clean energy investment agenda to serve effectively as a short-term stimulus program. Nevertheless, our primary focus in this present study is not the viability of a short-run stimulus program, but rather whether over a longer term, the types of investments undertaken under ARRA auspices are capable of producing significant gains in employment opportunities along with large-scale reductions in greenhouse gas emissions. By these standards, we do see strong evidence that the clean energy components of ARRA have been successful.

To begin with, we know that ARRA spending did launch hundreds of effective programs throughout the country. These include projects to increase energy efficiency, restructure the transportation system, greatly expand renewable energy production, build out the smart grid electrical transmission system, and finance longterm research and development on renewable energy. Some examples, as described in a January 2012 report by the Department of Energy, include the following:

- Energy Efficiency-Home Weatherization: The Recovery Act's weatherization program has helped more than 650,000 low-income families nationwide through December 2011 ... Families saved an average of $\$ 437$ per year on their energy bills as a result of the weatherization program.

- Modernizing the Grid-Smart Grid: Recovery Act seed money for smart grid projects in 49 states and two territories is helping build a more stable, secure nationwide electrical grid. From an initial federal investment of over $\$ 4$ billion, smart grid award recipients are providing an additional $\$ 5.6$ billion in private sector cost-share for a total investment of nearly $\$ 10$ billion. This investment ... will help improve the efficiency and reliability of the electrical system by providing operators with better information and control over the flow of electricity, [and] support the broader integration of renewable energy sources onto the grid.

- Transportation-Electric Drive Vehicles: 70 private companies and researchers in over 30 states have received grants to help build the American advanced battery and electric vehicle manufacturing industry ... Thirty new advanced battery and electric vehicle component plants are opening across the country as a result of these investments. ${ }^{21}$ 
We again encounter major difficulties in attempting to accurately measure the overall level of job creation through the clean energy programs within ARRA, even when working with the reported job-creation figures from ARRA recipients themselves. The federal government itself has reported ARRA-generated job-creation figures on a quarter-by-quarter basis only. Indeed the government makes a point of not attempting to generate total job-creation numbers from these quarter-by-quarter recipient-reported figures. The official ARRA website, Recovery.gov, explains as follows the reasons that it does not report overall job-creation figures:

Recipients only report job numbers by quarter. To total the quarters would be misleading and inaccurate because some of the jobs span quarters, so they would be counted more than once. And, some recipients only report the job in the first quarter but mistakenly believe that they don't have to report the same job in subsequent quarters. ${ }^{22}$

We provide in Table 7.4 below the annual averages of the quarterly recipientreported figures from the DOE's ARRA programs. Note that these reported figures are for direct jobs only_-for people hired directly by recipients of DOE-directed ARRA funds. These figures do not include indirect or induced job creation. We will provide rough estimates of these additional job-creation categories below.

TABLE 7.4

Estimates of direct job creation through ARRA clean energy projects within the U.S. Department of Energy

Figures based on funding-recipient reports to DOE: Annual averages of quarterly data

\begin{tabular}{lccc}
\hline & 2009 & 2010 & 2011 \\
\hline $\begin{array}{l}\text { Number of projects } \\
\text { reporting }\end{array}$ & 3,110 & 4,554 & 3,917 \\
$\begin{array}{l}\text { Reported number of direct } \\
\text { jobs created }\end{array}$ & 16,179 & 30,193 & 39,797 \\
$\begin{array}{l}\text { Total expenditures } \\
\text { Direct job creation per }\end{array}$ & $\$ 1.97$ billion & $\$ 3.88$ billion & $\$ 11.63$ billion \\
$\begin{array}{l}\text { 1 million in expenditure } \\
\text { M. }\end{array}$ & 8.2 & 7.8 & 3.4 \\
\hline
\end{tabular}

Source: Internal U.S. Department of Energy documents provided to authors. Available by request to authors. 
From these recipient-reported figures, we see that the direct job creation was at 8.2 jobs per $\$ 1$ million in $2009,7.8$ jobs per $\$ 1$ million in 2010 , and 3.4 jobs per $\$ 1$ million in 2011. These reported figures for 2009 and 2010 are broadly in line with estimates of direct job creation we have estimated previously based on data from the U.S. input/output model. For example, Pollin, Heintz, and GarrettPeltier estimated that direct job creation per $\$ 1$ million in spending on a range of clean energy investments was as follows: 7 for building retrofits, 11 for public transportation, 4.3 for smart grid, 4.6 for wind energy, 5.4 for solar, and 7.4 for biomass. ${ }^{23}$ By contrast, the 3.4 direct jobs per $\$ 1$ million figure for 2011 is lower than any of the clean energy investment areas we had studied in our 2009 research.

It is not entirely clear why there should be a major drop-off in the reported jobs figures per \$1 million in spending in 2011 relative to the initial two years of the DOE-based ARRA programs. But the most likely explanation is from the Recovery.gov observation cited above, that "Some recipients only report the job in the first quarter but mistakenly believe that they don't have to report the same job in subsequent quarters." To the extent that this has occurred, it would follow that reported job figures should fall off in 2011 relative to prior years. This is because the recipients would have reported the creation of new jobs tied to ARRA initially when they received their ARRA funds but may not have continued to report these jobs again in subsequent quarters - even though the fund recipients would have been still spending down their previously received ARRA funds. The result of such reporting errors would be to bias downward the reported figures for job creation as we move outward in time. The 2011 figures would therefore be lower than those for previous years.

Another possible explanation for the decrease in job creation in 2011 is that projects that were earmarked to receive ARRA support actually undertook their new hiring before they received their ARRA funding in hand. To the extent this occurred, the ratio of job creation to ARRA expenditures would be biased upward in 2009 and 2010 since the new hiring would have been undertaken before the ARRA funds would have been spent. Moreover, once we move into 2011, after the funds had been received and spent, the ratio of job creation to ARRA expenditures would shift to being biased downward.

While recognizing these problems on the reliability of recipient reports on job creation, we can still extract useful information from these available data. This becomes more clear when we use the reported figures on direct job creation as a basis for estimating total job creation, including indirect and induced jobs, along 
with direct jobs. We show these estimates in Table 7.5. For this exercise, we generated estimates for indirect and induced jobs derived from our previous research based on the U.S. input/output model. Specifically, we estimated figures for total indirect job creation as a proportion of direct jobs, with our estimate being that the multiplier for indirect job creation is 70 percent as large as direct job creation (a multiplier of 0.7 , as shown in row 2 of Table 7.5). We then estimate induced job creation as a proportion of direct and indirect jobs, with our estimate that the induced job multiplier is 40 percent as large as total direct and indirect job creation combined (a multiplier of 0.4 , as shown in row 3 ).

TABLE 7.5

\section{Estimate of total job creation on DOE-funded ARRA projects}

Figures based on recipient-reported direct job figures

\begin{tabular}{lccc}
\hline & 2009 & 2010 & 2011 \\
\hline $\begin{array}{l}\text { 1. Direct jobs per \$1 million } \\
\text { (from Table 6.4) }\end{array}$ & 8.2 & 7.8 & 3.4 \\
$\begin{array}{l}\text { 2. Indirect jobs per \$1 million } \\
\text { (from PERI l/O model; indirect jobs }\end{array}$ & 5.7 & 5.5 & 2.4 \\
7 direct jobs) & & & \\
$\begin{array}{l}\text { 3. Induced jobs per \$1 million } \\
\text { (from PERI l/O model; induced jobs }\end{array}$ & 5.6 & 5.3 & 2.3 \\
$\begin{array}{l}\text { 0.4 direct and indirect jobs) } \\
\begin{array}{l}\text { 4. Total jobs per \$1 million } \\
\text { (= rows 1+2+3) }\end{array}\end{array}$ & 19.5 & 18.6 & \\
$\begin{array}{l}\text { 5. Total expenditures } \\
\text { (from Table 6.4) }\end{array}$ & $\$ 1.97$ billion & $\$ 3.88$ billion & $\$ 11.63$ billion \\
$\begin{array}{l}\text { 6. Total job creation } \\
\text { (= row 4 x row 5) }\end{array}$ & 38,400 & 72,200 & 94,200 \\
\hline
\end{tabular}

Sources: Noted in column 1 above.

Working with these assumptions for indirect and induced job creation, we then derive figures for total job creation. As row 4 of Table 7.5 shows, these estimates are 19.5 total jobs per $\$ 1$ million of expenditure in $2009,18.6$ total jobs per $\$ 1$ million in 2010, and 8.1 total jobs per \$1 million in 2010. The 2009 and 2010 figures for overall job creation are very close to the figures we have derived from using the U.S. input/output model, of 16.7 jobs per $\$ 1$ million in spending on a range of clean energy investments, with these investments weighted at 70 percent energy efficiency investments and 30 percent renewable energy investments. ${ }^{24}$ The 2011 overall job-creation estimate of 8.1 jobs per $\$ 1$ million in spending is, of course, well below the 16.7 jobs per $\$ 1$ million figure we have derived from 
input/output data alone. But again, that large disparity is likely related to problems discussed above in how recipients of ARRA funds reported their job-creation activities to the Department of Energy.

Considering the results for total job creation from 2009 to 2011, it is notable that the average estimated figure for total job creation over the three years is 15.4 jobs per $\$ 1$ million in ARRA spending-( 19.5 jobs +18.6 jobs +8.1 jobs $) / 3$. Here again, this average figure of 15.4 jobs per $\$ 1$ million is close to the 16.7 figure that we derived strictly through the U.S. input/output data.

These results suggest that the funds that were spent on the DOE-directed ARRA projects did indeed create jobs basically at the rate we had anticipated-within the range of 16.7 total jobs per $\$ 1$ million in spending. As such, it is reasonable to conclude that the clean energy components of ARRA were successful at creating jobs when these programs first succeeded at moving funds into the economy. The biggest obstacle with ARRA was getting the funds into the economy on a large enough scale at a fast enough rate.

Put another way, the absolute level of job creation through clean energy ARRA projects was indeed modest. But this was because of the bureaucratic challenges in getting funds out effectively, not because jobs were being created below the anticipated rate when funds were spent. This point becomes clear when we consider the figures in rows 5 and 6 of Table 7.5. Again, Row 5 shows the annual figures on total DOE-based ARRA expenditures by years. Working from these figures and our estimates of jobs per $\$ 1$ million spent in row 4 , we then derive estimated figures for total jobs created in 2009 to 2011 . As we see, these figures range between 38,400 and 94,200 total jobs. Given that the total number of officially unemployed people in the United States ranged between 13.7 million and 14.8 million from 2009 to 2011, it is clear that the magnitude of the effect of DOE-based ARRA projects on reducing unemployment was modest.

It is of great importance that the bureaucratic difficulties that were encountered in implementing the clean energy components of ARRA over the short run be understood, especially so that they can be handled more effectively with any future such initiatives. But in considering clean energy investments over a longerterm horizon, these bureaucratic problems should not continue to remain as significant constraints. Indeed, one major defining difference between short- and longer-run horizons with such large-scale economywide projects is precisely that over the longer term, the opportunities exist to learn from and overcome the bureaucratic problems that are encountered in the short term. 


\section{Solyndra and loan guarantees for clean energy investments}

Probably the most widely publicized project among all clean energy components of ARRA was the $\$ 535$ million in federal loan guarantees awarded in 2009 to Solyndra, the northern California-based manufacturer of solar panels. Solyndra declared bankruptcy in September 2011, which meant that the federal government was obligated to pay Solyndra's creditors the full \$535 million in guaranteed loans.

Solyndra had obtained the loan guarantee through a clean energy component of ARRA, Section 1705. The total costs Solyndra had incurred to expand its operations was $\$ 723$ million. The federal loan guarantee therefore amounted to 74 percent of these total costs. At this point, the government owns the assets of borrowers that default under this program and can either manage the assets itself or sell them. The total value of the assets owned by Solyndra at the time of its bankruptcy filing was $\$ 859$ million. As such, if the federal government were able to sell these assets at, for example, fifty cents on the dollar, it would recover $\$ 430$ million. The remaining roughly $\$ 100$ million of the government's guarantee would have to come out of the government's reserve fund established through the 1705 program within ARRA. ${ }^{25}$

Solyndra's bankruptcy triggered a heavy wave of criticism, mainly by leading Republican figures, that the clean energy components of ARRA had been a failure, wasting tens of billions of taxpayer dollars on ineffective "green jobs" programs. ${ }^{26}$ However, it is not reasonable to offer sweeping generalizations about the entire clean energy project within ARRA — or even more broadly about governmentsubsidized clean energy investments-from the one case of Solyndra. Here is not the place for a full-scale post-mortem on the details of the Solyndra case. But we will address two concerns that emerge from the Solyndra experience that are important for evaluating the overall merits of a government-led clean energy project. These points address first, the use of loan guarantees as a policy tool for subsidizing clean energy investments; and second, the provision of subsidies of any kind to advance the development of the renewable energy sector in the United States. 
The way all government loan-guarantee programs operate is that they create contingent liabilities for the government. The government's funding liability is contingent on the number of cases in which borrowers default on loans that have been guaranteed, as well as the percentage of the total loan amounts that the government had guaranteed. The initial budget provided in Section 1705 of ARRA for clean energy loan guarantees was $\$ 6$ billion. ${ }^{27}$ This $\$ 6$ billion was the reserve fund available to cover government obligations when the guaranteed loans went into default. However, that figure was scaled back to $\$ 2.5$ billion, with the remaining funds being reallocated to the "Cash for Clunkers" program and the Education Jobs Fund. ${ }^{28}$

In setting up this loan-guarantee program, the operating assumption was that the maximum amount of guarantee would be 80 percent of any approved project. Solyndra was somewhat below that, with a 74 percent guarantee. Moreover, the government assumed that in the event of default, it could recover 55 percent of the value of its liabilities through selling the assets of the failed company. Finally, the government assumed that the default rate on the Section 1705 guaranteed loans would be 11.5 percent of the value of all loans. Based on these assumptions, the total amount of loans that the government could underwrite and still be fully covered with their $\$ 2.5$ billion in reserve funds would be about $\$ 30$ billion. ${ }^{29}$

Of course, the whole idea behind any such loan-guarantee arrangement is to encourage private-sector bankers and financiers to extend credit for clean energy projects that would otherwise be perceived as too risky for private investors to finance at affordable rates. If we were to assume that these loans were without risk, then there would have been no purpose to providing the loan guarantees to begin with. As such, the Solyndra default should not be seen as reflecting a failure of the loan-guarantee program. Indeed, the only way to evaluate the relative success of the loan-guarantee program overall is to consider the Solyndra experience alongside the complete portfolio of other renewable energy projects that ARRA subsidized through its Section 1705 of the loan-guarantee program.

The evidence here is summarized in Table 7.6. As the table shows, under Section 1705 , the federal government provided guarantees for a total of about $\$ 14$ billion in new loans for 24 clean energy projects. Of these, there has been one other default in addition to Solyndra to date, which was the $\$ 400$ million guarantee to Abound Solar in December 2010. However, Abound had only borrowed \$68 million of the $\$ 400$ million the government had guaranteed. ${ }^{30}$ 
Overall, then, the government's guarantees for Solyndra—which had drawn $\$ 528$ million of the $\$ 535$ million guarantee-and Abound amounts to $\$ 596$ million. This is equal to 4.3 percent of the approximately $\$ 14$ billion in outstanding guarantees. Some significant share of those funds will also be recovered by the federal government when selling the assets of these firms. If we assume that the government's recovery rate is 50 percent of the value of the defaulted companies' total assets, that means that the government will have spent $\$ 298$ million to support $\$ 14$ billion in clean energy investments. The leverage rate for this loan-guarantee program therefore amounts to nearly $\$ 50$ in private clean energy investments for every $\$ 1$ of federal government spending.

TABLE 7.6

ARRA clean energy 1705 loan guarantee program: Recipients of guarantees from 2009 through 2013

\begin{tabular}{|c|c|c|c|}
\hline Program & Technology & Location & Guarantee amount \\
\hline 1366 Technologies, Inc. & Solar manufacturing & Lexington, MA & $\$ 150$ million \\
\hline $\begin{array}{l}\text { Abengoa Bioenergy Biomass } \\
\text { of Kansas LLC }\end{array}$ & Biofuel & Hugoton, KS & $\$ 132.4$ million \\
\hline $\begin{array}{l}\text { Abengoa Solar, Inc. } \\
\text { (Mojave Solar) }\end{array}$ & Solar generation & San Bernardino County, CA & $\$ 1.2$ billion \\
\hline Abengoa Solar, Inc. (Solana) & Solar generation & Gila Bend, AZ & $\$ 1.446$ billion \\
\hline Abound Solar & Solar manufacturing & Longmont, $\mathrm{CO}$ and Tipton, IN & $\$ 400$ million \\
\hline Caithness Shepherds Flat & Wind generation & Gilliam, Morrow Counties, OR & $\$ 1.3$ billion \\
\hline Cogentrix of Alamosa, LLC & Solar generation & Alamosa, CO & $\$ 90$ million \\
\hline $\begin{array}{l}\text { Exelon } \\
\text { (Antelope Valley Solar Ranch) }\end{array}$ & Solar generation & Lancaster, CA & \$646 million \\
\hline Granite Reliable & Wind generation & Coos County, NH & \$168.9 million \\
\hline $\begin{array}{l}\text { Kahuku Wind Power } \\
\text { (First Wind) }\end{array}$ & Wind generation & Kahuku, Oahu, HI & \$117 million \\
\hline $\begin{array}{l}\text { LS Power Associates (ON Line - } \\
\text { formerly known as SWIP-S) }\end{array}$ & Transmission & Eastern Nevada, NV & $\$ 343$ million \\
\hline $\begin{array}{l}\text { Mesquite Solar 1, LLC } \\
\text { (Sempra Mesquite) }\end{array}$ & Solar generation & Maricopa County, AZ & \$337 million \\
\hline $\begin{array}{l}\text { Nevada Geothermal Power Com- } \\
\text { pany, Inc. (Blue Mountain) }\end{array}$ & Geothermal & Humbolt County, NV & $\begin{array}{l}\text { Partial guarantee } \\
\text { of } \$ 98.5 \text { million }\end{array}$ \\
\hline $\begin{array}{l}\text { NextEra Energy Resources, LLC } \\
\text { (Desert Sunlight) }\end{array}$ & Solar generation & Riverside County, CA & $\begin{array}{l}\text { Partial guarantee } \\
\text { of } \$ 1.46 \text { billion }\end{array}$ \\
\hline $\begin{array}{l}\text { NextEra Energy Resources, LLC } \\
\text { (Genesis Solar) }\end{array}$ & Solar generation & Riverside County, CA & $\begin{array}{l}\text { Partial guarantee } \\
\text { of } \$ 852 \text { million }\end{array}$ \\
\hline NRG Energy, Inc. (BrightSource) & Solar generation & Baker, CA & $\begin{array}{l}\text { Partial guarantee } \\
\text { of } \$ 1.6 \text { billion }\end{array}$ \\
\hline
\end{tabular}




\begin{tabular}{|c|c|c|c|}
\hline Program & Technology & Location & Guarantee amount \\
\hline $\begin{array}{l}\text { NRG Solar (California Valley Solar } \\
\text { Ranch) }\end{array}$ & Solar generation & San Luis Obispo, CA & $\$ 1.237$ billion \\
\hline NRG Solar, LLC (Agua Caliente) & Solar generation & Yuma County, AZ & \$967 million \\
\hline Ormat Nevada, Inc. & Geothermal & $\begin{array}{l}\text { Jersey Valley, McGinness Hills, } \\
\text { and Tuscarora, NV }\end{array}$ & \$350 million \\
\hline Record Hill Wind & Wind generation & Roxbury, ME & \$102 million \\
\hline $\begin{array}{l}\text { SolarReserve, LLC } \\
\text { (Crescent Dunes) }\end{array}$ & Solar generation & Nye County, NV & \$737 million \\
\hline Solyndra Inc. & Solar manufacturing & Fremont, CA & $\$ 535$ million \\
\hline $\begin{array}{l}\text { Stephentown Spindle } \\
\text { (Beacon Power) }\end{array}$ & Energy storage & Stephentown, NY & $\$ 43$ million \\
\hline US Geothermal, Inc. & Geothermal & Malheur County, OR & $\$ 97$ million \\
\hline
\end{tabular}

Source: U.S. Department of Energy, “Loan Program Office Projects," available at http://energy.gov/lpo/projects (last accessed January 2014).

Among the projects that are operating successfully to date, the Department of Energy includes one of the world's largest wind farms, the first two all-electric vehicle manufacturing facilities in the United States (Ford \& Nissan), one of the country's first commercial-scale cellulosic ethanol plants, the largest utility-scale solar PV generation facility to date, and the largest concentrated solar power plants in the world. ${ }^{31}$ Placed within this broader context, the Solyndra experience can be seen as one instance of default within a broader portfolio of loans that, to date, are succeeding at underwriting the development of an expanded U.S. renewable energy sector.

\section{Broader question of renewable energy subsidies}

Whether or not the loan-guarantee program is working effectively, after taking account of both the Solyndra loan, the other failure with Abound, and the 22 projects that are operating successfully, there is still the broader question as to whether the federal government should provide private renewable energy firms in the United States subsidies of any kind.

To address this issue, we start with the basic point that we have stressed throughout: Clean, renewable energy sources need to soon become abundant and cheap if the United States is going to achieve its targeted reductions in $\mathrm{CO}_{2}$ emissions over the next 20 years and beyond and, most critically, if we are to stabilize the climate and avoid the prospect of severe ecological disruptions. As we have reviewed in 
Chapter 3, renewable energy is steadily becoming cost competitive with nonrenewable sources. As we saw, the EIA estimates in its Reference case that under average conditions, clean bioenergy, wind, geothermal, and hydro power will all be cost competitive with most nonrenewable sources by 2017. The EIA expects that solar will still be more expensive by 2017 , but we have also reviewed the evidence that solar costs have been coming down rapidly in recent years.

The case for subsidizing clean, renewable energy is straightforward: to support an acceleration in the trend that is already happening, in which clean renewables become fully cost competitive with nonrenewables under a broad range of conditions. This kind of accelerated development of the clean renewable sector is, as we have seen, critical for meeting the country's $\mathrm{CO}_{2}$ emission reduction targets - and thereby controlling climate change.

The benefits of providing subsidies for clean renewables can be understood more clearly through considering parallels with the research and development programs that have been financed and directed by the U.S. Defense Department for generations. The Defense Department's programs have been the basis for some major-and even epoch-defining — technological breakthroughs, including jet aviation, the computer, and the internet. Moreover, Pentagon-supported research and development was further enhanced by the Defense Department's procurement policies, which created and sustained huge guaranteed markets for the products emerging from its $\mathrm{R} \& \mathrm{D}$ programs. The establishment of these guaranteed markets in turn led to reduced financing costs for investors, which then allowed for accelerated growth in the commercialization of new technologies. This is how new technologies became available to consumers at dramatically reduced prices and is also what enabled emerging technologies such as the internet to incubate slowly over time. The incubation period for the internet was about 35 years. ${ }^{32}$

Based on the evidence we have reviewed in Chapter 3, the time period necessary for creating a fully cost-effective clean renewable industry in the United States will certainly be less than 35 years. But for the present, it is still critical that the development of this sector be given levels of public support comparable to what was provided in creating a fully cost-effective internet. How exactly to deliver that public support most effectively is what we turn to in our concluding chapter. 
1 U.S. Council of Economic Advisers, The Economic Impact of the American Recovery and Reinvestment Act of 2009, Supplement to the Third Quarterly Report: The ARRA and the Clean Energy Transformation (The White House, 2010), available at http://www.whitehouse.gov/administration/ eop/cea/factsheets-reports/economic-impact-arra-3rdquarterly-report/supplement_greenjobs.

2 Information on recipients of loan guarantees through the U.S. Department of Energy's Loan Programs Office, including Solyndra, can be found at U.S. Department of Energy, "Projects," available at http://energy.gov/lpo/ projects (last accessed August 2014).

3 American Clean Energy and Security Act of 2009, H.R. 2454, 111 th Cong. 2 d. sess., available at https://www. govtrack.us/congress/bills/111/hr2454.

4 American Council for Capital Formation and the National Association of Manufacturers, "Analysis of the Waxman-Markey Bill" (2009), available at http://accf. org/wp-content/uploads/2009/10/accf-nam_study.pdf.

5 We emphasize again that we are using the rounded figure $\$ 200$ billion to be clear that we do not claim to have produced a precise estimate of the necessary investments in new energy efficiency and clean renewable energy capacity. The $\$ 200$ billion figure is rather meant to convey a midpoint for the cost estimates we generated via our detailed analyses presented in Chapters 2 and 3 for both energy efficiency and clean renewable investments. It would be impossible to estimate in advance these investment cost figures with greater precision. Among other factors that will influence the costs per Q-BTU for expanding clean renewable capacity and raising energy efficiency standards will be the rate at which technology improves, along with, as noted in the text, the extent to which improvements in efficiency are counteracted through rebound effects. As we discuss in Chapter 2, we expect rebound effects to be generally modest.

6 The 2011 figure is from the U.S. Bureau of Economic Analysis, "National Income and Product Accounts Tables," (U.S. Department of Commerce, 2002), Table 3.7ES, available at http://www.bea.gov/National/nipaweb/ nipawebLegacy/FAweb/AIIFATables.asp\#S3. The 2013 figure is from Conglin Xu, "Capital Spending in US, Canada to Rise Led by Pipeline Investment Boom," Oil and Gas Journal, March 4, 2013, available at http:// www.ogj.com/articles/print/volume-111/issue-3/ s-p-capital-spending-outlook/capital-spending-in-uscanada-to-rise.html. Note that these investment figures are only a subset of the total output figures for the fossil fuel sector that we presented in Chapter 6 .

7 All U.S. aggregate investment and GDP figures are from the U.S. Bureau of Economic Analysis, "National Income and Product Accounts," available at http://www.bea.gov/ national/index.htm\#gdp (last accessed August 2014).

8 The relationship between saving, investment, and interest rates in the U.S. economy is covered in depth in Robert Pollin, "Financial Intermediation and the Variability of the Saving Constraint." In Robert Pollin, ed., The Macroeconomics of Saving, Finance and Investment (Ann Arbor, MI: University of Michigan Press, 1996), p. 309-366. For a more recent discussion, see specifically Chapter 10, "Sources of Funds for Business Investment" in Robert Pollin and James Heintz, "Study of U.S. Financial System." Working Paper 10 (Financialisation, Economy, Society and Sustainable Development, 2013), available at http://fessud.eu/wp-content/uploads/2012/08/ USA-Financial-Systems-Studies10.pdf.
9 According to the U.S. Energy Information Administration consumption of liquid fuels and other petroleum products was 37.25 Q-BTUs in 2010. Of this, approximately 1.1 Q-BTUs is ethanol (see Tables A2 and A17). For more information, see U.S. Energy Information Administration, "Annual Energy Outlook 2012: With Projections to 2035" (2012), available at http://www.eia.gov/forecasts/aeo/ pdf/0383(2012).pdf.

10 Quoted from Robert Pollin and James Heintz, "How Wall Street Speculation is Driving Up Gasoline Prices Today" (Amherst, MA: Political Economy Research Institute, 2011), available at http://www.peri.umass.edu/fileadmin/pdf/ research_brief/PERI_AFR_Research_Brief_June20.pdf.

11 lbid.

12 The Dodd-Frank financial regulatory system that became law in 2010 does include extensive provisions for controlling excessive speculation on commodities futures markets. However, as of this writing, it remains an open question as to whether these regulations will be enforced in an effective way. For more information, see Gerald Epstein and Robert Pollin, "Regulating Wall Street: Exploring the Political Economy of the Possible" (Amherst MA: Political Economy Research Institute, 2011), available at http://www.peri.umass.edu/fileadmin/pdf/ working_papers/working_papers_251-300/WP256.pdf.

13 All data presented in this section on the U.S. internationa accounts can be found in U.S. Government Printing Office, Economic Report of the President (2013), Tables B103-B105, available at http://www.whitehouse.gov/ sites/default/files/docs/erp2013/full_2013_economic report_of_the_president.pdf.

14 Cynthia McHale and Sharlene Leurig, "Stormy Future fo U.S. Property/Casualty Insurers: The Growing Costs and Risks of Extreme Weather Events" (Boston: Ceres, 2012) p. 6, available at http://www.ceres.org/resources/reports/ stormy-futures/view.

15 McHale and Leurig, "Stormy Future for U.S. Property/ Casualty Insurers"; IPCC (2012) considers this issue in depth from a more global perspective. IPCC estimates that the overall global losses from weather- and climate- related disasters were about $\$ 90$ billion in 2010 the most recent year for which data are available. The IPCC found that insurance covered less than one-third of these total 2010 losses. Frank Ackerman and Elizabeth A. Stanton address the costs of hurricanes and droughts in particular within the United States in Frank Ackerman and Elizabeth A. Stanton, "The Cost of Climate Change: What We'll Pay if Global Warming Continues Unchecked" (New York: Natural Resources Defense Council, 2008), available at http://www.nrdc.org/globalwarming/ cost/cost.pdf.

16 U.S. Council of Economic Advisors, The Economic Impact of the American Recovery and Reinvestment Act of 2010: Second Quarterly Report (The White House, 2010), available at http://www.whitehouse.gov/sites/default/ files/microsites/100113-economic-impact-arra-secondquarterly-report.pdf.

17 A 2011 joint study by the Blue/Green Alliance and Economic Policy Institute set this figure at $\$ 93$ billion. For more information, see Jason Walsh, Josh Bivens, and Ethan Pollack "Rebuilding Green: The American Recovery and Reinvestment Act and the Green Economy" (Washington: BlueGreen Alliance and Economic Policy Institute, 2011), available at http://www.bluegreenalliance.org/news/publications/document/BGA-EPIReport-vFINAL-MEDIA.pdf). However, our own previous 
research set the figure at closer to $\$ 100$ billion, as found in Robert Pollin, James Heintz, and Heidi Garrett-Peltier, "The Economic Benefits of Investing in Clean Energy" (Amherst, MA: Center for American Progress and Political Economy Research Institute, 2009), available at http:// www.peri.umass.edu/fileadmin/pdf/other_publication types/green_economics/economic_benefits/ economic_benefits.PDF.

18 United States Council of Economic Advisors, The Economic Impact of the American Recovery and Reinvestment Act of 2010, Page 35

19 Sanya Carley and Martin Robert Hyman, "The 'Grand Experiment': An Early Review of Energy-Related Recovery Act Efforts." Working Paper (Indiana University, Bloomington, School of Public and Environmental Affairs, 2013), available at http://papers.ssrn.com/sol3/papers. cfm?abstract_id=2316827.

20 Ibid., p. 15. We are grateful to Sanya Carley and Martin Hyman for carefully working through the details of their analysis and calculations with us in private correspondence.

21 U.S. Department of Energy, Success of the Recovery Act (2012), p. 1-2, available at http://energy.gov/sites/prod/ files/RecoveryActSuccess_Jan2012final.pdf; Studies by Joseph E. Aldy, "A Preliminary Assessment of the American Recovery and Reinvestment Act's Clean Energy Package," Review of Environmental Economics and Policy 7 (1) (2013): 136-155; For reports on additional case studies in a range of project areas within the clean energy ARRA programs, see Jason Walsh, Josh Bivens, and Ethan Pollack, "Rebuilding Green: The American Recovery and Reinvestment Act and the Green Economy" (Washington: BlueGreen Alliance and Economic Policy Institute, 2011), available at http://www.bluegreenalliance.org/news/ publications/document/BGA-EPI-Report-vFINAL-MEDIA. pdf; Michael Grunwald provides a good, journalistic account of the positive benefits generated by the clean energy components of the ARRA in Michael Grunwald, The New XXNEW (twice?)XX Deal: The Hidden Story of Change in the Obama Era (New York: Simon \& Schuster, 2012), p. 359-79.

22 The American Recovery and Reinvestment Act, "FAQS," available at http://www.recovery.gov/arra/FAQ/ Pages/ForCitizens.aspx\#totalnumber (last accessed August 2014).

23 Robert Pollin, James Heintz, and Heidi Garrett-Peltier, "The Economic Benefits of Investing in Clean Energy" (Amherst, MA: Center for American Progress and Political Economy Research Institute, 2009), available at http:// www.peri.umass.edu/fileadmin/pdf/other_publication types/green_economics/economic_benefits/ economic_benefits.PDF.

24 The exact weights we used with the input/output model in generating the 16.7 jobs per $\$ 1$ million in spending figure are 40 percent retrofits; 20 percent mass transit/freight rail; and 10 percent each for smart grid, wind power, solar power, and bioenergy.

25 For further details, see Mark Muro and Jonathan Rothwell, “Why the U.S. Should Not Abandon Its Clean Energy Lending Programs" The Brookings Institution, September 27, 2011, available at http://www. brookings.edu/blogs/the-avenue/posts/2011/09/27solyndra-muro-rothwell.
26 Republicans in the U.S. House of Representatives led a Congressional hearing on the Solyndra case on September 14, 2011. Documents on that hearing can be found at U.S. House of Representatives Energy and Commerce Committee, "Hearings and Votes," available at http://energycommerce.house.gov/hearings/ hearingdetail.aspx?NewsID=8897 (last accessed July 2014).

27 ARRA Title 17, "Innovative Technology Loan Guarantee Program," appropriates $\$ 6$ billion to pay for loan guarantees for Section 1705 projects. For more information, see The American Recovery and Reinvestment Act of 2009, Public Law 111-5, 111 th Cong. 1st sess. (February 17, 2009), p. 26, available at http://www.gpo. gov/fdsys/pkg/BILLS-111hr1enr/pdf/BILLS-111hr1enr.pdf.

28 Memorandum from the U.S. House of Representatives Committee on Energy and Commerce Democratic Staff to the Democratic Members of the U.S. House of Representatives Subcommittee on Oversight and Investigation regarding "Hearing on 'Budget and Spending Concerns at DOE,"' April 17, 2012, p. 2 available at http://democrats.energycommerce.house. gov/sites/default/files/documents/SupplementalMemo-DOE-Budget-and-Spending-2012-4-18.pdf.

29 With a reserve fund of $\$ 2.5$ billion, a default rate of 11.5 percent, and an 80 percent guarantee, the total amount of lending that could be underwritten is $\$ 27.2$ billion, or ( $\$ 2.5$ billion/.115)/.8). But since the 80 percent guarantee was a maximum rate, the actual amount that the government could underwrite with a $\$ 2.5$ billion reserve fund will be somewhat higher than $\$ 27.2$ billion.

30 Loan guarantees, which, as of January 2014, were discontinued for various reasons include the two 1705 projects discussed here, as well as two ATVM projects. For more information on these four projects, see U.S. Department of Energy, "Projects," available at http:// energy.gov/lpo/projects (last accessed August 2014).

31 These projects are described in detail at U.S. Department of Energy, "Awards and Accomplishments," available at http://energy.gov/lpo/about-us/awards-accomplishments (last accessed August 2014); Joseph E. Aldy offers a much more critical assessment of the 1705 program, writing that it "has not had a meaningful impact on the U.S. power sector. A pipeline of quality renewable power projects did not materialize and the program has focused its efforts on a small number of large wind and solar projects (p. 14). However, Aldy is clear that his assessment is based only on evidence through 2010, when only eight projects had been financed through the 1705 program. Aldy also does not make clear what would constitute a "meaningful impact on the U.S. power sector." By some measures, \$14 billion in new investments in what is still an infant industry in the United States could fairly be considered a "meaningful impact." For more information on Aldy's argument, see Joseph E. Aldy, "A Preliminary Assessment of the American Recovery and Reinvestment Act's Clean Energy Package," Review of Environmental Economics and Policy 7 (1) (2013): 136-155.

32 These issues are discussed in depth in Robert Pollin, "Public Policy, Community Ownership and Clean Energy," Cambridge Journal of Regions, Economy and Society 5 (3) (2012): 339-359. 
Chapter 8

Advancing a workable clean energy policy agenda 


\section{Introduction}

This chapter develops a set of policy proposals that combined can enable the United States to achieve the 20-year $\mathrm{CO}_{2}$ emissions-reduction target that has been the focus of this study. Achieving this emission-reduction goal would demonstrate global leadership and drive the technological, market, and policy innovations that are necessary to meet this challenge.

The high stakes at play in considering this chapter's policy agenda become clear within the context of the central conclusions of the previous seven chapters of this study: The project of undertaking an economywide clean energy transformation in the United States must be brought to full scale without delay in order to meet the IPCC's emissions-reduction targets. Specifically, as we have documented in the previous chapters, this means that over the next 20 years, the combination of public and private investments in energy efficiency in the United States needs to reach roughly $\$ 90$ billion per year in order to bring down total U.S. energy consumption to roughly 70 Q-BTUs - a 35-percent decline in overall consumption relative to the EIA's 2030 Reference case. The U.S. clean energy project also needs to include roughly $\$ 110$ billion per year in combined public and private investments in order to increase energy production from clean renewable sources nearly four-fold relative to the 2010 level-expanding clean renewable energy production to roughly 15 Q-BTUs per year within 20 years.

In combination, then, we estimate that overall U.S. clean energy investmentsinvestments in energy efficiency and clean renewable energy sources-will need to total around $\$ 200$ billion per year for 20 years to achieve the IPCC's 2030 emissions-reduction target. This amounts to about 1.2 percent of current U.S. GDP. ${ }^{1}$

Finally, the U.S. clean energy project also requires that, by 2030 to 2035, the decline in fossil fuel consumption relative to 2010 levels will involve roughly a 60-percent cut for coal, a 40-percent cut for oil, including from both domestic sources and imports, and a 30-percent cut for natural gas. ${ }^{2}$ 
Expanding public and private investments in energy efficiency and clean renewables at this scale - to a total of roughly $\$ 200$ billion per year, or about 1.2 percent of current U.S. GDP - offers the only realistic path through which the United States can achieve the 20-year emissions-reduction targets of cutting total greenhouse gas emissions from U.S. sources down to no more than 4,200 $\mathrm{mmt}$ and total $\mathrm{CO}_{2}$ emissions from energy-based sources to no more than 3,200 $\mathrm{mmt}$ (with $\mathrm{CO}_{2}$ emissions from energy-based sources accounting for about 76 percent of all GHG emissions). Greatly expanding the level of energy efficiency and the production of clean renewables will also create a realistic prospect for the United States to cut fossil fuel consumption dramatically without having to sacrifice job opportunities and economic growth.

The challenge of meeting these emissions-reduction targets is enormous. As we have discussed, as of 2010 total U.S. greenhouse gas emissions were at about 6,800 $\mathrm{mmt}$ and energy-based $\mathrm{CO}_{2}$ emissions were at 5,600 $\mathrm{mmt}^{3}$ This means that the United States needs to cut emissions - $\mathrm{CO}_{2}$ emissions and overall GHG emissionsby roughly 40 percent over the next 20 years.

There is also the challenge of scaling up U.S. clean energy investments relative to current investment levels. The 2013 edition of the Bloomberg "Sustainable Energy in America Factbook" reports that total U.S. investments in energy efficiency and renewables was about $\$ 60$ billion in 2011 and $\$ 44$ billion in 2012. As we discuss further below, the falloff in investments in 2012 was "largely due to uncertainty over the fate of certain federal incentives that support financing for renewables." ${ }^{\prime 4}$ In any case, the $\$ 200$ billion per year investment program that we have developed in the preceding chapters entails a roughly three- to four-fold expansion relative to the level of investment achieved even under the more favorable policy environment of 2011.

Nevertheless, as will become clearer as we proceed with our policy framework in this chapter, we are confident that the investment program we have developed is achievable. Fundamentally, this is because, as Podesta et al. wrote in 2009, building a clean energy economy in the United States "is a fundamentally affirmative agenda, rather than a restrictive one. Moving beyond pollution from fossil fuels will involve exciting work, new opportunities, new products, innovation and stronger communities."

The purpose of this chapter is to examine a range of policy initiatives that can make this "fundamentally affirmative agenda" achieve success in the United States over the next 20 years. As we will see, all of our proposed policy measures are 
currently in operation within the country at either the federal, state, or municipal level. Our aim here is to show how these measures can be most effectively combined and brought to scale. The policies we discuss in this chapter range widely in their approach. Some entail large-scale public-sector involvement, while others require little to no public funding while still providing effective levers to encourage private clean energy investments. As a general principle, these policy measures need to succeed as public/private partnerships. This principle follows naturally from the wide range of public/private partnerships and alternative ownership forms that already operate within the U.S. energy industry, including both the fossil fuel and renewable sectors. These alternative ownership forms include public enterprises such as public utilities, large-scale and fully private corporations, smaller private enterprises, and private cooperative and community-owned firms. ${ }^{6}$

Even while recognizing this wide range of ownership types in the U.S. energy sector, we are also clear that our policy agenda must ultimately be effective in mobilizing clean energy investments by private business owners. There is no other way in which the United States can realistically achieve its 20 -year $\mathrm{CO}_{2}$ emissionsreduction target. As Podesta et al.correctly note, "Private sector investments will be the main engine driving growth in the clean energy economy. The scale of the energy transformation is simply too large for public sector resources and programs to tackle alone." 


\section{Specifying the policy agenda}

It follows from our discussion thus far that the first set of challenges in designing an effective clean energy policy agenda is to identify public policy interventions that can best encourage private-sector clean energy investments in the United States. The policy agenda needs to be correspondingly focused on removing the obstacles that, to date, have been holding back large-scale private clean energy investments. Hendricks et al. emphasize three basic problems with the existing private-sector clean energy industry, including both the energy efficiency and renewable sectors: unpredictable demand in their respective markets; a lack of certainty in both the tax code and policy incentives; and unavailable long-term, low-cost financing. ${ }^{8}$ Following from these observations, what is therefore necessary is a range of policies that are capable of both stabilizing and expanding market demand for clean energy, reducing uncertainty for private investors, and greatly expanding the supply of affordable financing for clean energy investments.

At the same time, we need to take seriously the fact that cutting back on coal, oil, and natural gas production will create uncertainty and major challenges for workers, communities, and regions where livelihoods depend heavily on the fossil fuel sectors. We therefore need to establish as a policy priority the provision of major transitional support for workers and communities facing retrenchment. This will be true, despite the fact that large-scale investments in energy efficiency and renewable energy will be a major new engine of net job creation, as we established in Chapter 6. Roughly three times more jobs will be created through new investment spending and the expansion of operations and maintenance in energy efficiency and renewable energy than will be lost when spending in the fossil fuel industries is cut by an equivalent amount. 
Overall then, we advance here a policy agenda along four broad categories:

- Market-shaping rules that level the playing field and build demand for new technology

- Direct public spending that invests in infrastructure, procurement, and research and development $(\mathrm{R} \& \mathrm{D})$

- Private investment incentives that manage risk and improve access to capital

- Transitional support for regions, communities, and workers facing cutbacks and job losses through contraction of the fossil fuel industry

In Table 8.1, we list all the specific measures that we discuss under each of these four broad headings - 19 policy initiatives in all. Of course, we do not claim that our list of proposals is comprehensive. But we believe it does cover a representative range of the most significant initiatives that are currently active or have a feasible chance of getting implemented in the foreseeable future. 
TABLE 8.1

A clean energy policy agenda for achieving the U.S. 20-year $\mathrm{CO}_{2}$ emission reduction target

1. Market-shaping rules

Carbon cap or tax

Enforcement of Clean Air Act

Vehicle fuel-efficiency standards

Renewable portfolio and energy-efficiency resource standards

Improving state utility market rules

Electricity grid infrastructure regulations

\section{Direct public spending}

Energy-efficiency public investments

Federal renewable energy procurement projects

Federal R\&D for efficiency and renewables

\section{Private investment incentives}

Production and investment tax credits

Feed-in tariffs

Green banks

Loan guarantees

Property Assessed Clean Energy, or PACE, financing

Master-limited partnerships, or MLPs, and real estate investment trusts, or REITs

\section{Regional equity and worker transition assistance}

Promoting regional equity

Targeted community adjustment assistance

Worker training

Worker adjustment assistance

Our discussion of these 19 specific initiatives considers each of them as distinct areas for action, with their relative strengths and weaknesses being assessed independently. But we also examine how these 19 separate measures can function in conjunction with one another. One consideration here is that each of the four broad policy areas and many of the 19 specific policy measures need to be advanced through coordinated interventions at each of the three levels of U.S. policymaking- 
federal, state, and municipal government. But still further, the effectiveness of each of the specific policy measures will be strengthened substantially to the extent that they operate in conjunction with the other initiatives. Forging strong ties between the specific types of market-shaping rules, direct public spending initiatives, private investment incentives, and community/worker transition assistance programs will be critical for achieving overall success.

This is especially the case since, as mentioned above, the programs vary widely in terms of their impacts on public spending and revenues. In this chapter, we provide rough approximations of the fiscal impacts of these policies, assuming they are designed to operate at a scale capable of supporting the overall $\$ 200$ billion per year clean energy investment project. The program with the greatest fiscal impact would be the carbon tax or cap. If this were designed to operate, for example, at a level outlined in the EIA's 2011 "Annual Energy Outlook," it would generate, on average, over $\$ 200$ billion per year in revenues over the 20 -year investment period. In terms of public expenditures, the production and investment tax credits would provide large-scale financial support for private clean energy investments, probably in the range of $\$ 50$ billion per year if they are going to significantly support a major expansion in clean energy investments. By contrast, the regulatory programs we discuss are capable of achieving major impacts without requiring large-scale public expenditures.

It is beyond the scope of this discussion to establish in specific terms the most effective levels at which to set tax rates, subsidies, or regulatory standards with these programs. Our aim here is rather to provide a broad framework for understanding the scale at which these programs will need to operate and the fiscal impacts of operating at scale. Within that framework, we can then also offer perspectives on how the overall set of policies is strengthened by operating in combination. 


\section{Market-shaping rules}

Well-structured market rules provide a critical framework for encouraging investments in clean renewables and energy efficiency. Having clear and ambitious standards operating within firm deadlines offers stability to companies and their investors, supports long-term predictability in the growth of market demand, and encourages innovation. Effective regulations can also foreclose environmentally unsustainable expansions of the coal, oil, and natural gas sectors.

A wide array of regulatory measures is already in place throughout the United States to reduce $\mathrm{CO}_{2}$ emissions and promote the clean energy industry, and still more well-understood policy approaches are available. We focus here on six major areas: carbon caps or taxes; use of the Clean Air Act to regulate $\mathrm{CO}_{2}$ emissions; vehicle fuel-economy standards; Renewable Portfolio Standards, or RPS, and Energy Efficiency Resource Standards, or EERS; improving state utility-market rules to support investment in energy efficiency and distributed generation; and electrical-grid infrastructure regulations.

\section{Carbon cap or carbon tax}

The best-known regulatory approaches for reducing $\mathrm{CO}_{2}$ and other $\mathrm{GHG}$ emissions are to establish a firm limit on emissions - a carbon cap—or to set a price on emissions that reflects the environmental costs that they generate-a carbon tax. As with all policy interventions, both approaches have strengths and weaknesses, and there is a longstanding debate as to their relative merits. We do not aim here to adjudicate this debate but simply to present some key considerations. ${ }^{9}$

In principle, a carbon cap sets a firm limit on the allowable level of carbon dioxide emissions produced economywide in one year. A carbon cap is working effectively when it establishes certainty as to the minimum rate at which emissions will decline as a result of the cap. Operating with a carbon cap will also raise the price of fossil fuels by limiting the allowable consumption levels. But how much fossil fuel energy 
prices will rise is unknown, since it will depend on the impact of the carbon cap on the broader set of supply and demand conditions in the energy market.

With a carbon tax, by contrast, there is greater certainty as to how much fossil fuel prices will rise due to the policy intervention, since the price increase will be tied to the tax rate itself. However, there is no certainty as to the extent to which the fossil fuel price increase will lead to a fall in fossil fuel energy demand, and thereby $\mathrm{CO}_{2}$ emission reductions.

Given that the fundamental aim of all such policy interventions is to reduce emissions, this suggests that, in principle at least, a carbon cap is a more effective policy tool because it is focused more precisely on emissions control. The carbon tax is a blunter instrument but possesses the virtue of greater simplicity. All else equal, a carbon tax will raise fossil fuel energy prices at least by the extent of the tax.

Two design principles are critical as starting points, whether operating with a carbon cap or carbon tax. The first is that the cap or tax rate must be set high enough so that the policy is capable of achieving its intended effect of promoting a major shift away from fossil fuel consumption in favor of investments in efficiency and renewables. The second is that allowing exemptions to the law or opportunities to purchase offsets as an alternative to meeting the standards must be carefully limited. With offsets, businesses with emissions levels above the designated cap can purchase emissions allowances from other firms with emissions below the cap. This kind of emissions allowance trading system does build greater flexibility into the carbon cap system, making it easier for firms to comply with the law. As such, allowing for an emission allowance trading system is probably a political necessity for a carbon cap to become law anywhere in the United States. But it is important to recognize that including an emission allowance trading system also increases the complexity of the carbon cap regulation, which in turn creates opportunities for businesses to circumvent the basic intentions of the law.

We note that the EIA's Carbon-Price case from the 2011 Annual Energy Outlook, reviewed in Chapter 4, operates with simple premises. That is, a carbon price is set at $\$ 25$ per ton of $\mathrm{CO}_{2}$ equivalent in 2013 , and rises to $\$ 75$ per ton in 2035 . The simplicity of this framework maintains the policy's focus on the issue of the carbon price itself, and in particular whether this is the appropriate price for achieving the intended policy goals. This approach also has the virtue of being phased in over time rather than implemented all at once, which would be disruptive throughout the economy. Everything else about any such emissions-reduction policy-such 
as whether and how much to allow offsets and tradable permits-need to be treated as secondary matters that cannot undermine the effective implementation of the regulations.

We estimate that a carbon price policy at this EIA level would generate $\$ 140$ billion in revenue in the first year of the program, with $\mathrm{CO}_{2}$ emissions at about 5,600 $\mathrm{mmt}$ and the carbon price starting at $\$ 25$ per metric ton (we present our full calculations in Appendix 5). By Year 20, assuming $\mathrm{CO}_{2}$ emissions do fall to around 3,000 mmt as in the PERI/CAP scenario presented in Chapter 5 and the carbon price has risen to $\$ 75$ per metric ton, the program would generate $\$ 225$ billion. On average over the full 20-year time frame, the program would generate average annual revenues of $\$ 203$ billion. We provide details on our derivation of these estimates in Appendix 5.

This raises the question as to how these revenues could be most effectively allocated and the related issue of the distributional impact of this policy. The most critical consideration here is that all else equal, increasing the price of fossil fuels through a carbon cap or tax would affect lower-income households more than affluent households. This is because purchasing gasoline, home-heating fuels, and electricity consumes a higher share of the consumption basket for lower-income households. An effective solution to this problem is a so-called cap-and-dividend policy, for example, as proposed in 2009 by U.S. Sens. Maria Cantwell (D-WA) and Susan Collins (R-ME).$^{10}$ This approach to a carbon cap would limit emissions, auction off emission permits to $\mathrm{CO}_{2}$-emitting enterprises, and return most of the revenues from the auction to all U.S. households as equal amounts of money for all people. The net effect is that lower-income households would receive more money as dividends from the regulation than they would pay out in higher energy prices. At the same time, because the revenues from this policy would be so substantial, even if 75 percent of the revenue were returned directly to the American people, there would still be an average of about $\$ 50$ billion per year leftover that could be channeled into clean energy investments. ${ }^{11}$ We consider this point further below.

We recognize that, as of this writing, the establishment of a carbon cap or tax in any form is not politically realistic at the federal level. Indeed, President Barack Obama made no reference to either a carbon cap or tax in his June 2013 Climate Action Plan. ${ }^{12}$ This reflects the defeat in 2010 of the Waxman-Markey cap-andtrade bill, which failed in the U.S. Senate after having passed with bipartisan support in the then-Democratic-controlled House of Representatives in 2009. 
At the same time, California has implemented the country's first statewide cap-and-trade law, which went into effect in January 2013..$^{13}$ This measure establishes a carbon-emissions cap, which falls by 3 percent per year beginning in 2013. This emissions limit applies only to entities within the state that release more than 25,000 metric tons of carbon or its equivalent in other greenhouse gases, including methane and nitrous oxide. Put another way, the law exempts smaller businesses from compliance. It also includes features that provide flexibility in compliance for the entities that are covered, allowing them to bank and trade their emission allowances. It will take some time to be able to assess how much these opportunities for circumventing compliance with the law will ultimately affect the effectiveness of the cap as a means of enforcing emission reductions. ${ }^{14}$

\section{Enforcement of the Clean Air Act}

The centerpiece of President Obama's June 2013 Climate Action Plan is its proposal to "complete carbon pollution standards for both new and existing power plants." ${ }^{15}$ The Environmental Protection Agency issued a draft version of new standards for new power plants in September 2013 and a final version in June 2014. ${ }^{16}$

We anticipate that the new EPA regulations will be strong and effectively enforced. As such, we presented two scenarios in our discussion in Chapter 4 on energy consumption and emission levels for coal-the EIA Retrofit-20 case and the Deutsche Bank scenario-both of which assume strong enforcement of the Clean Air Act moving forward, particularly for coal-fired electricity generation. As we discussed, it is expected that strict enforcement of the Clean Air Act will significantly reduce the commercial viability of a large segment of the coal utility sector. In particular, under the Deutsche Bank scenario, coal-fired utility capacity falls to $186 \mathrm{GW}$ by 2030, a 41 percent decline in capacity relative to 2009 . This level of regulatory enforcement will be a necessary baseline condition to even allow for the possibility of achieving the 2030 emissions-reduction targets.

Moreover, such strong enforcement of the Clean Air Act is already built into the Aggressive Reference case that we developed in Chapter 5. It is also a central component of the emissions reductions achieved in the PERI/CAP climate stabilization scenario summarized in Chapter 5. It is critically important to note that while such enforcement would create a strong market signal to investors that the national fuel mix needs to shift, it will likely generate major political resistance from a number of industries and regions of the country. These rulemaking 
proceedings have already garnered significant efforts to weaken standards and slow enforcement. While this is to be expected, it is also imperative to recognize that it will be virtually impossible to meet climate stabilization goals by 2030 - 2035 if these rules are not aggressively enforced and absolute coal consumption be allowed to decline significantly.

In terms of public-sector fiscal impact, the only direct effects here will be on administrative and enforcement costs. We assume that relative to 2013, the EPA's budget will need to rise by 50 percent for environmental regulations and by 300 percent for its climate change programs. This entails a $\$ 415$ million annual increase in enforcement costs and a $\$ 480$ million increase in climate change program costs. We note here that these administrative and enforcement cost increases will not only cover the increased regulations of the Clean Air Act, but also serve as our approximation of the increased costs for all the regulatory programs we discuss in this chapter at the state and local levels, as well as the federal level. We provide details on these cost assumptions in Appendix 5.

\section{Vehicle fuel-efficiency standards}

A major regulation in place for reducing $\mathrm{CO}_{2}$ emissions is the establishment of a light-duty-vehicle automobile fuel-efficiency standard, which is set to rise to 54.5 miles per gallon by 2025. More specifically, as we discussed in Chapter 2, enforcing that standard is, by far, the most important measure in place that will contribute to bringing down energy consumption in the transportation sector by nearly 30 percent relative to the EIA 2030 Reference case.

As we noted in Chapter 2, the Obama administration did also establish in 2011 fuel economy standards for heavy-duty vehicles — trucks, buses, and combination tractors. These standards aim to reduce emissions from HDVs by between 9 percent and 23 percent as of 2017 relative to 2010 levels. In his June 2013 Climate Action Plan, President Obama proposed raising the standards for HDVs further. ${ }^{17}$ This could enable the United States to reduce emissions to 30 percent below the 2030 Reference case or perhaps still further. 


\section{Renewable portfolio and energy efficiency resource standards}

Two other closely related regulatory mechanisms that can drive significant industry investment in clean energy projects are Renewable Portfolio Standards, or RPS, and Energy Efficiency Resource Standards, or EERS. RPS measuressometimes called Renewable Electricity Standards, or RES—require minimum yearly standards for renewable energy generation by the utility sector to meet customer demands. According to Bloomberg's 2013 Sustainable Energy Factbook, as of 2012, Renewable Portfolio Standards were operating successfully in 29 states. The report states that these standards have been "critical to the expanding investments and capacity in the renewable sector." ${ }^{18}$

RPS implementation by states has had a substantial impact on their respective energy mixes. For example, utilities in California are required to have 20 percent of their retail sales derived from renewable energy sources by the end of $2013 .{ }^{19}$ The figure then rises to 25 percent by the end of 2016 and 33 percent by 2020, then holding at that level on a sustained basis. New York mandates a 29 percent standard for utilities by 2015, Colorado has required its utilities to sell 30 percent renewable energy by 2020, and Rhode Island has legislated a 16 percent RPS by 2019 . Around the country RPS laws are generating significant reductions in fossil fuel use. Richard Caperton has also shown that RPS policies have had no discernable impact on energy prices, contrary to the claims of critics. ${ }^{20}$

Energy Efficiency Resource Standards are the equivalent of RPS measures for energy efficiency. Under an EERS, "utilities are required to implement energy efficiency measures, typically among their consumers, equivalent to a target value for Kwh." ${ }^{21}$ For example, California's EERS requires a 10-percent reduction in forecasted electricity consumption over 10 years. The New York law mandates a 15-percent reduction relative to projected use as of 2014. ${ }^{22}$ Bloomberg reports that EERS regulations have been one of two major drivers for U.S. utilities to increase energy efficiency expenditures from \$1.9 billion in 2006 to $\$ 7$ billion in 2011. The other additional policy measure has been decoupling policies, which we describe below. 
Decisions concerning the distribution of electricity in the United States occur primarily at the state level. As such, establishing state regulatory frameworks that promote investment in advanced energy efficiency as part of utility planning is critical for transforming the nation's energy infrastructure. State regulatory policies are equally important for promoting investments in smaller-scale on-site renewable energy sources - including solar, wind, geothermal, or combined heat/ power systems - for individual homes or businesses and other small-scale enterprises such as college campus microgrids.

These small-scale renewable energy systems, called distributed energy systems, do not operate in conventional relationships with utilities. Among other factors, they are frequently in a position to sell the surplus energy they produce to utilities, as well as to buy electricity from utilities when their locally generated power supplies are insufficient to meet their demand. These unconventional relationships with the utilities need to be nurtured to encourage the establishment and maintenance of distributed energy systems. We discuss here several policies that can effectively promote efficiency investments by utilities while concurrently supporting the development of distributed renewable energy systems.

\section{Decoupling}

One widely recognized tool for driving investment in energy efficiency is "decoupling". This refers to policies that restructure utility rates so that the determination of the appropriate rates is not dependent solely on the amount of electricity that a utility sells to its customers. Rather, decoupling policies provide for a rate adjustment that compensates utilities for the reduction in electricity demand resulting from their efficiency investments by allowing them to raise their rates per kilowatt hour to recoup the costs of their energy efficiency investments. A common approach is to establish a revenue-per-customer formula, as opposed to a revenue system based on electricity consumption..$^{23}$

The Bloomberg Factbook reports that utility investments in energy efficiency accounted for fully 44 percent of all energy efficiency investments in 2010, a year that also featured considerable efficiency investment spending from the ARRA. ${ }^{24}$ Bloomberg asserts that the advances in utility-based efficiency investments stem in large part from the complementary nature of decoupling policies and EERS. Implementing EERS laws force utilities to make serious commitments to efficiency investments, while decoupling and related policies remove the economic disincentive for utilities to make such investments. At present, 21 of the 29 states 
with EERS requirements for electricity also have some kind of decoupling program for electric utilities.

Though decoupling policies will in general weaken the disincentives that utilities face to invest in energy efficiency measures, the specifics of the policy design are crucial for the implementation to succeed. Thus, as noted in an analysis by the American Council for an Energy Efficient Economy, decoupling does not create a positive financial incentive to save energy through investing in energy efficiency that is comparable to the financial incentives that exist for utilities to invest in capital assets such as new power plants and facilities. ${ }^{25}$ Consequently, given that our policy aim is to establish energy efficiency as a comparable demand-side control alternative to supply-side investments in electricity-generating equipment, it is therefore also necessary to establish a performance-reward mechanism that allows utilities to earn a positive return on their energy efficiency investments.

In addition, from a broader social perspective, it would be preferable to create efficiency incentives that directly benefit consumers and businesses, not primarily utilities, as is the case with decoupling. Still, a 2009 study by the National Renewable Energy Lab reports that retail electricity price adjustments-positive or negative-experienced by consumers as a result of decoupling tend to be small. The NREL study finds that, on average, price adjustments are less than 1 percent up or down. ${ }^{26}$ To the extent that this can remain the case, decoupling policies should be able to serve effectively as a complement to EERS interventions to promote efficiency investments by utilities.

\section{Utilities and distributed energy}

Smaller-scale distributed energy systems will play an important role in advancing viable clean energy systems throughout the country. It is certainly the case that these systems will be moving into the markets currently dominated by traditional utilities, just as mobile phone systems cut into the markets of traditional phone companies. State utility regulators therefore need to establish a level playing field for distributed energy suppliers, rather than allowing utilities to create obstacles for the distributed suppliers.

One of the central types of policies needed to support distributed energy are fair net-metering rules. Under net metering, distributed energy suppliers receive credit for the surplus energy they produce and have available to sell back to utilities. Distributed energy suppliers need to receive fair-price compensation for the energy they are able to sell back to utilities. Similarly, the grid interconnections for distributed energy suppliers need to be inexpensive and simple. If the process 
is lengthy, difficult, or expensive, this will dissuade people from investing in distributed energy. The Federal Energy Regulatory Commission, or FERC, has the capacity to play a critical role here in establishing simple and effective rules to support the development of distributed energy. ${ }^{27}$

\section{Government policy's role in electricity grid infrastructure investments}

The U.S. electrical grid system is mainly owned and maintained by large private utilities that are publicly regulated. ${ }^{28}$ These utilities serve about 86 percent of the country's electricity customers, with publicly owned municipal utilities accounting for the remaining 14 percent. ${ }^{29}$ Correspondingly, unlike many other forms of infrastructure, the U.S. electrical grid is largely funded not by direct public investment, but rather through fees paid by utility customers in their energy bills.

These organizational features of the U.S. grid system do not adequately convey the central role of both government regulatory policies and public investment in supporting investments in upgrading the grid. Because the privately owned utilities are heavily regulated, investments in the grid result from this regulatory decision making process, even while the funds for investment come from private funding. The public role in planning, siting, and determining investment levels for electricity grid infrastructure is far-reaching and complex. ${ }^{30}$ Given this complexity, the federal government, as an overarching regulator, will need to work closely in partnership with states, cities, and private developers to build strong regional markets operating on decentralized, networked grid systems. ${ }^{31}$

This is especially important because upgrading the electrical grid will be necessary to successfully advance the overall clean energy investment agenda. Hendricks et al. highlight four key areas in which major new investments are necessary: ${ }^{32}$

- Building transmission lines that can connect remote areas with strong wind and solar energy potential to urban centers

- Upgrading distribution networks to operate as a smart grid powered by information technology and automated energy management

- Placement of a charging infrastructure for electric vehicles to integrate transportation effectively into our existing electricity grid

- Secure and reliable transmission systems 
Although the 2007 Energy Independence and Security Act authorized a Smart Grid Investment Grant Program, which was then amended and funded by the ARRA in 2009, the scale of new investments needed to upgrade the grid greatly exceeded the ARRA level of funding. About $\$ 4.5$ billion in ARRA funds went to support this grid program, which covered slightly less than 40 percent of the $\$ 11$ billion in total new grid investments resulting from the ARRA program. As of 2009 the Edison Electric Institute - the leading U.S. utility association-had itself projected that investments in transmission infrastructure to meet rising demand for electricity would be around $\$ 12$ billion per year through $2030 . .^{33}$ This is without fully factoring in the costs of upgrading the grid to efficiently accommodate renewables and a decentralized network, as well as to protect the grid from increasing incidents of extreme weather ${ }^{34}$ In order to prepare the nation for a clean energy economy, transmission infrastructure will require significantly more investment, which will be ultimately paid for by a mix of public funds, private investors, and ratepayers.

Unlike other areas of infrastructure investment, the most difficult challenge is less how to pay for these improvements, but rather how to align industry, consumers, public agencies, and regulators around a shared strategy for navigating this transition. The federal executive branch alone is uniquely positioned to provide leadership and a shared vision for mobilizing the nation to rewire the grid so that it becomes far cleaner, more efficient, and ultimately cheaper to operate. The White House therefore needs to take an active role in coordinating with utilities, governors, state regulators, and tribal governments to refocus on grid modernization for renewable energy as a major national undertaking, similar to how President Franklin Roosevelt led the massive project of building an electrical grid system that could serve rural America during the New Deal era. 


\section{Direct public spending}

While regulations and market rules are often the primary focus of public debates over climate and energy policy, the government's direct investments in clean energy play a similarly critical role in lowering costs, promoting private investment, and speeding the growth of markets. There is ample precedent for catalytic public investment in transformative infrastructure-from the Hoover Dam and the Interstate highway system to the basic research supported by the Defense Department to create the Internet. Public investment takes many forms, including federal funding for research and development, or R\&D, procurement policy, and matching grants for infrastructure projects. Each of these tools can send a strong signal to private investors and emerging industries.

We consider here three areas of public investment in clean energy: energy efficiency retrofits for public buildings; renewable energy procurement; and federal research and development investments. In all three of these public investment areas, the executive branch of the federal government can play a major leadership role in moving the clean energy investment project forward immediately.

\section{Public investments in energy efficiency}

There are at present major opportunities for large-scale public investment projects that could effectively advance energy efficiency throughout the U.S. economy. The most straightforward opportunity would be for government entities at all levels to retrofit their own buildings to significantly increase their energy efficiency. The argument on behalf of this particular public investment program is overwhelming, given, as seen in Chapter 2, that buildings both consume and waste more energy than any other sector of the U.S. economy; that the technologies for achieving efficiency gains of 30 percent or more in buildings are available and demonstrated to be cost effective, typically achieving full returns in roughly three years; and that the federal government owns and manages more buildings than any other landlord 
in the country. Indeed, as of 2012 the federal government owned 365,041 buildings with more than 2.75 billion square feet and annual operating costs totaling more than $\$ 15$ billion, and leased approximately 500,000 additional buildings. ${ }^{35}$

At the federal level in particular, such an energy efficiency investment project was mandated in 2007 by the Energy Independence and Security Act, or EISA, which was signed into law by then-President George W. Bush. Specifically, Section 431 requires each agency to apply conservation measures so that energy consumption is reduced by 30 percent per square foot from 2003 levels by $2015 .{ }^{36}$ According to section 432, agencies must "identify all 'covered' facilities that constitute at least 75 percent of the agency's facility energy use." ${ }^{37}$ The efficiency measures must be "life cycle cost-effective," which means that the estimated savings must exceed the estimated costs over the lifespan of the measure. ${ }^{38}$ The law specifies that in order to fund the implementation of these efficiency measures, federal agencies can use appropriated federal funds, private financing otherwise authorized under federal law (including energy-savings performance contracts or utility energy-service contracts), or a combination of appropriated funds and private financing. ${ }^{39}$

EISA received its first significant funding support from the ARRA. ${ }^{40}$ According to communications with a program analyst of the Department of Energy's Federal Energy Management Program, ${ }^{41}$ approximately $\$ 10$ billion in efficiency improvements have been implemented in the past four years (much of that from Recovery Act funding) and there is an additional potential of $\$ 10$ billion of investment in cost-effective energy-saving measures that could be set in motion. ${ }^{42}$ Government agencies estimate that as of July 2014, the implemented retrofits that have been reported are saving roughly 0.2 Q-BTUs in energy consumption per year, as well as $\$ 840$ million per year in total energy costs. ${ }^{43}$ This represents a cost savings of 5 percent of annual operating costs of federally owned buildings. The reported reduction in energy use of 0.2 Q-BTUs amounts to about 1.2 percent ${ }^{44}$ of the total savings necessary to reduce overall building energy consumption for both publicly and privately owned buildings by about 16 Q-BTUs - that is, the target buildingefficiency gain we describe in Chapter $2 .^{45}$

A major benefit of fully implementing this federal energy efficiency public investment project would be to serve as an incentive for state and local governments, as well as private building owners, to invest in efficiency retrofits. The federal government's investments in this project could create wide recognition as to the available opportunities for cost savings and environmental benefits. 
In terms of estimating the fiscal impact of combined federal, state, and local government public buildings retrofit programs, we assume that the federal EISA program will be fully funded and completed over the next five years. We then assume that all buildings owned by state and local governments establish the same standard as the federal EISA program for their own buildings. (We show the details of the fiscal impacts of these measures in Appendix 5.) Over the 20-year investment cycle, the federal EISA program should result in a net savings to the government of $\$ 1.3$ billion per year, while comparable programs at the state and local levels would generate average net savings of $\$ 8.5$ billion per year. Overall then, a combined federal, state, and local efficiency program at the current EISA standard would generate fiscal savings of $\$ 9.8$ billion per year.

\section{Federal renewable energy procurement projects}

The U.S. military has recently begun a major effort to advance its own use of renewable energy. In April 2012 the Obama administration announced that the military will seek to deploy 3 gigawatts of renewable energy by 2025, including solar, wind, biomass, and geothermal. President Obama affirmed this commitment in his June 2013 Action Plan.

This initiative is designed to operate without requiring additional costs to taxpayers. Accordingly, we have assumed this program will have no net fiscal impact on any government budgets. This is because the Defense Department plans to leverage private-sector financing to establish renewable microgrids, with private firms selling renewable power to the military. As reported by Forbes magazine:

The military wants to attract developers and private investments for building solar, wind, and other renewable electricity power projects on its land. It plans to lease the land to developers and buy some or all of the power from each project for its own use, and any unused power will be sold to local utilities. ${ }^{46}$

More generally, the military has set a goal of meeting 25 percent of its total energy needs with renewable energy by 2025 , including both liquid fuels and electricity generation. ${ }^{47}$ Given that the Defense Department consumes about 80 percent of the federal government's total energy use, this initiative will greatly expand the overall renewable energy market. Energy Digital reports that this initiative will provide $\$ 7$ billion in procurement contracts making it "the largest series of renewable energy contracts in history." ${ }^{48}$ Moreover, the program will serve as a testing opportunity for new and advanced technologies that could be more widely commercialized. 
The article quotes a Defense Department spokesperson as saying "Just like GPS systems and the internet came out of the DOD first, the more involved we are with these projects, the more prices will come down and we'll start to see more renewables across the board."

Following up on this program for the military, President Obama also mandated in December 2013 that the federal government increase its reliance on renewable energy sources to provide 20 percent of its overall electricity supply by $2020{ }^{49}$

\section{Federal R\&D for efficiency and renewables}

Federal research and development efforts are another form of direct public investment that has long been critical to advancements in the U.S. energy industry. These government investments are catalytic in supporting the establishment of transformative technologies. Under most circumstances, private businesses acting on their own are not able to afford the investments in early-phase basic research or the long lead times before new technologies can generate commercially viable products and profits. The Congressional Research Service offered this overview: ${ }^{50}$

Energy-related R\&D-on coal-based synthetic petroleum and on atomic power-played an important role in the successful outcome of World War II. In the post-war era, the federal government conducted R\&D on fossil fuel and nuclear energy sources to support peacetime economic growth. The energy crises of the 1970s spurred the government to broaden the focus to include renewable energy and energy efficiency.

Despite this broad-based approach to energy R\&D funding, it is nevertheless the case that the levels of R\&D support for energy efficiency and renewable energy have been modest in comparison with the support given for fossil fuels and nuclear power. Between 1978 and 2012, funding for efficiency and renewables R\&D totaled $\$ 39.6$ billion, while support for fossil fuels and nuclear power was twice as high, at $\$ 79.1$ billion, according to the Congressional Research Service study. This is despite the fact that fossil fuel and nuclear technologies had been receiving major R\&D support since the 1940s.

In its 2013 budget request, the Obama administration prioritized funding energy efficiency and renewables over fossil fuels and nuclear energy R\&D. The efficiency and renewables $R \& D$ request was for $\$ 2.1$ billion, in comparison with $\$ 1.3$ billion 
for fossil fuels and nuclear power. Still, President Obama's request for energy efficiency and renewable R\&D amounted to only 1.5 percent of the overall 2013 budgetary request of $\$ 140.8$ billion for all types of $\mathrm{R} \& \mathrm{D}$ across all agencies. By contrast, the 2013 Defense Department R\&D funding request was $\$ 71.2$ billion34 times greater than that for energy efficiency and renewables. Moreover, after the House and Senate both included cuts in their proposed renewables/efficiency $\mathrm{R} \& \mathrm{D}$ budgets, the federal renewables and efficiency $\mathrm{R} \& \mathrm{D}$ operating plan for fiscal year 2013 ended up at $\$ 1.6$ billion. This was 25 percent below President Obama's requested budget and a 4.9 percent absolute reduction in clean energy $R \& D$ spending relative to $2012 . .^{51}$

The systematic problem of underfunding clean energy $R \& D$ is most pressing in the case of renewable electricity. We saw in Chapter 3 that under average conditions, electricity generation from wind, geothermal, hydro, and clean biofuels will be at approximate cost parity with conventional energy by 2017, according to the EIA. The EIA expects solar to still be more expensive at that point, even though solar has also achieved major cost reductions over the past decade and will continue to do so. Nevertheless, technological gains in areas such as storage and transmission systems can significantly reduce the costs of renewable-generated electric power. Coupled with other factors, such technical advances should be able to reduce cost differences among regions that vary in terms of their natural endowments of wind, sun, and strong-running water. R\&D investments can therefore have quite significant benefits in speeding the rate of market adoption of renewables.

Energy efficiency can also benefit heavily from R\&D funding. As we described in Chapter 2, it is already the case that new investments yield rapid and reliable returns in the three areas of buildings, industry, and transportation while relying on existing technologies. Yet advanced R\&D can deliver major additional gains in areas such as electric vehicles, combined heat and power technology, improved industrial processes, automated controls, and advanced lighting, smart windows, roofing, and insulation materials for buildings.

As we have seen in previous chapters of this study, ultimately achieving the 2030 GHG emissions-reduction targets can be accomplished only through innovations and major gains in energy efficiency and the use of clean renewable energy sources. For this reason, federal R\&D funding in support of energy efficiency and renewables needs to be elevated to become a first-order national priority. What we have seen instead-just as with the 2013 federal R\&D budget relative to 2012 — is that the level of support is getting smaller precisely when it needs to be growing substantially. 
It is beyond the scope of this study to establish systematically what would constitute a sufficient level of public $R \& D$ spending to provide the technological foundation for delivering low-cost clean renewable energy and energy efficiency systems over the next 20 years. But for purposes of providing some framework on fiscal impacts, we assume that the total amount of clean energy R\&D should equal the amount now spent on fossil fuels and nuclear power, in addition to the current budget for renewables and efficiency. That would mean a total annual clean energy R\&D budget of about $\$ 3.5$ billion per year. We include the impact of this level of funding increase in our overall fiscal analysis presented in Appendix 5. 


\section{Private-investment incentives}

Public policies can create strong incentives for private businesses to undertake large-scale expansions in energy efficiency and renewable energy investments. Moreover, if well designed, these government incentive programs can operate effectively without having to depend on large amounts of public spending. This is the most important lesson that emerges from examining a range of incentive programs that are already operating in various forms and at various government levels throughout the United States.

We focus our discussion in this section on six policy areas: the Production Tax Credit and Investment Tax Credit; feed-in tariffs; green banks; loan guarantees; property-assessed clean energy, or PACE, financing; and policy-driven investment vehicles, including master-limited partnerships, or MLPs, and real estate investment trusts, or REITs. We explore the ways in which, over the next 20 years, these and related incentive programs can most effectively expand their scope on behalf of advancing the large-scale growth in private clean energy investments.

\section{Production Tax Credit and Investment Tax Credit}

The federal Production Tax Credit and Investment Tax Credit-PTC and ITC, respectively-are the most significant incentive programs now operating to support the growth of the U.S. clean energy industry. Both are managed by the federal government.

As of the end of 2013, the PTC provided a tax credit of 2.3 cents per kilowatt hour of energy generated for producers of wind, solar, geothermal, and some forms of biomass energy. To date, the PTC has been used primarily for wind projects. The ITC has allowed investors in such renewable energy projects to take a tax credit equal to 30 percent of the cost of constructing their project for solar and wind projects, and 10 percent for geothermal. To date, the ITC has been used most frequently to support solar energy projects. ${ }^{52}$ 
The 2013 edition of the Bloomberg Sustainable Energy Factbook writes that "these tax credits are truly the lifeblood of the renewables industry as they allow renewable energy technologies to be more cost competitive with other sources of generation." 53 Bloomberg also emphasizes that any potential expiration of these credits inevitably unsettles the industry:

For instance, when the PTC was due to expire at the end of 2012, wind developers rushed to get their projects generating by midnight on 31 December to ensure that they received the benefit of the credit. On 1 January 2013 Congress extended the credit an additional year and changed the qualifications so that projects merely need to be under construction by 31 December 2013 to receive the benefit of the PTC. This critical adjustment means the benefit of this latest 'one-year' extension will be felt well into 2014 and potentially into 2015.

As of July 2014, projects that had not begun construction by the end of $2013 \mathrm{did}$ not qualify for the PTC, though the credit will continue to apply to projects in which at least 5 percent of total costs had been incurred by the end of 2013. ${ }^{54}$ The 30 percent ITC remains available to projects in the United States through the end of 2016 for solar, fuel cells, and small wind projects. The credit is at 10 percent through 2016 for geothermal systems, micro wind turbines, and combined heat and power systems. After 2016 the credits for solar are scheduled to fall to 10 percent and to expire for all other renewable energy sources. ${ }^{55}$ In our view, it is critical that these investment incentives be extended and, indeed, expanded. In our discussion below on fiscal effects, we offer thoughts on a structure for expanding the scope of both the PTC and ITC

Despite the importance of these policies, they do also present significant problems that need to be carefully addressed. The first, as is clear from the above discussion, is the uncertainty that surrounds their availability. In order to incentivize private businesses to commit to long-term clean energy investments, it is critical that they know that these major subsidies are going to remain available to them in the future.

In addition, these policies are only useful to companies that need to pay meaningful amounts of taxes on income generated annually. This problem is highlighted in the 2013 Bloomberg Sustainable Energy Factbook, which notes that renewable energy project developers frequently do not have heavy tax obligations and therefore cannot benefit from the PTC and ITC subsidies. As such, as Bloomberg notes, "the sector has traditionally relied on investment from outside 'tax equity' investors (primarily banks) to provide capital in return for receiving the pass-through 
benefit of the tax credits." Such arrangements therefore become highly sensitive to macroeconomic fluctuations. Bloomberg continues that, "The financial crisis of 2008 squeezed availability of tax equity: a potentially calamitous situation for the industry was averted by the [U.S. Treasury Department's] 'cash grant' program established under the ARRA. ${ }^{56}$

Another challenge presented by the PTC and ITC is that while they create more favorable financial opportunities for private investors to supply renewable energy, they do not help build the market for renewable energy on the demand side. Creating a stable market is critical for reducing uncertainly among investors in the clean energy industry. A Renewable Portfolio Standard, as described earlier in this chapter, is one important mechanism for creating predictable market demand. Another important way to do this is through an alternative subsidy policy called feed-in tariffs, which we discuss next.

For purposes of our fiscal impact analysis, we assume that both the PTC and ITC will be renewed and are allowed to operate over our full 20-year investment period at generous levels. Specifically, we assume that the PTC is set at 2 cents per kWh and that it applies to all new renewable projects starting in year 1 of our investment cycle. We then also assume that the ITC is set at 30 percent and that it applies to all energy efficiency investments. Again, it is beyond the scope of this study to determine whether these are the levels that would be appropriate for achieving our overall goal of $\$ 200$ billion per year in combined private and public clean energy investments, but setting these investment-incentive programs at relatively generous levels does allow us to observe what a high-end set of incentives would cost. Defined according to these specifications, as we detail in Appendix 5, the PTC would provide an average of $\$ 26.8$ billion annually in tax benefits for clean renewable energy projects, and the ITC would provide $\$ 27$ billion in annual energy efficiency investment incentives. Assuming that clean energy investment incentives could be established, it would then also be preferable that the programs be redesigned as cash grants, as under ARRA, rather than as tax credits.

\section{Feed-in tariffs}

Renewable energy feed-in tariffs, or FITs, are contracts that require utility companies to purchase electricity from private renewable energy generators at prices that are fixed by long-term contracts. The long-term prices are set to reflect either the levelized costs of producing renewable energy from various sources, the broader 
value of renewables to society, or some combination of the two. In practice, prices that are set based on cost of production are generally higher than when there is a cost benchmark for setting a fair social-value-based price. In either case, however, private producers of renewable energy are guaranteed a market for the electricity they produce through the FIT. This encourages more private investment in renewables by creating certainty. In terms of expanding the market for the renewable energy industry, the effect of feed-in tariffs is therefore equivalent to the Defense Department's provision of long-term procurement contracts for private renewable energy providers.

Feed-in tariff policies were first implemented in the United States in the 1970s, and a number of state and local FIT programs are currently operational in the United States today. ${ }^{57}$ However, the impact of FITs in the renewable energy market has been much more significant outside of the United States. Most significantly, FIT policies have played a critical role in expanding the market for renewable energy in Germany, Spain, and Canada. Although questions have recently been raised about the costs of FIT programs, they continue to be broadly supported. ${ }^{58}$

The contrast between the European and U.S. experiences is due in large part to the fact that the guaranteed prices for renewable energy have been higher in Europe, where the prices have been set to reflect the levelized costs of production plus a profit for the provider, while this has not been standard practice in the United States. This point was underscored in a 2009 report by the Department of Energy's National Renewable Energy Lab. ${ }^{59}$ This report concluded that:

Most successful European FIT policies, which resulted in quick and substantial renewable energy capacity expansion (often at both distributed and utility-scale levels), have FIT payments structured to cover the renewable energy product cost, plus an estimated profit. Many U.S. states currently use value-based cost methodologies to support renewable projects. However, value-based FIT policies, whether tied to avoided costs or to external social and environmental costs, have so far been unsuccessful at driving rapid growth in renewable energy.

As of January 2014, five states-California, Hawaii, Maine, Vermont, and Washington-have mandatory FIT programs in operation..$^{60}$ Under the California program, for example, operators of small-scale renewable energy systems (i.e., up to 3 megawatts) can enter into 10-, 15- or 20-year standard contracts with their utilities. The price for the renewable electricity is based on a formula that is derived from market conditions. When the program began in late 2013, the starting price 
was 8.9 cents per kilowatt hour. ${ }^{61}$ However, this price is 70 percent below the EIA's estimate of levelized costs for solar PV-15.2 cents per kilowatt hour as of 2017, as we discussed in Chapter 4. By contrast, a voluntary FIT program established in March 2013 by Dominion Virginia Power offers 15 cents per kilowatt hour for five years for all PV-generated electricity provided to the grid. ${ }^{62}$ This price is clearly tied to the actual costs of producing solar electricity and therefore resembles the approach to FIT policies that the National Renewable Energy Lab described as the successful European approach.

As with other regulatory policies discussed here, the feed-in tariff will have no public-sector fiscal impact other than the administrative and enforcement costs that we have incorporated into our overall cost estimates.

\section{Green banks}

One important means of achieving adequate funding levels for project finance in energy efficiency and renewable energy investments is the establishment of dedicated clean energy financial institutions. A proposal for a national green bank was a central feature of recent climate legislation in both the U.S. House and Senate. ${ }^{63}$ Despite partisan divisions over climate policy more broadly, the green bank proposal received strong support from both Democrats and Republicans, as well as the endorsement of constituencies as diverse as the U.S. Chamber of Commerce and the AFL-CIO. ${ }^{64}$ President Obama has also proposed the establishment of an independent federal infrastructure bank, which could easily incorporate the core functions of a green bank as part of its overall mission.

Other countries have already established clean energy finance entities. One leading example here is Sustainable Development Technology Canada, or SDTC. SDTC is a not-for-profit financial institution that was created with funding from the Canadian government and primarily finances the development and demonstration of renewable energy projects - two traditionally under-supported phases of technological innovation. Similar institutions are also operating in the United Kingdom, Germany, and China. ${ }^{65}$

A detailed framework for advancing this idea was developed by the Coalition for Green Capital and the Center for American Progress under the name Energy Independence Trust, or EIT. ${ }^{66}$ An EIT would function as a federally chartered, independent nonprofit entity that would not be an agency of the federal government. 
It would be authorized to borrow from the Treasury Department and to request additional borrowing as needed. Its specific purpose would be to provide low-cost loans, loan guarantees, and other forms of financing either directly to projects or through state green banks. These funds would help advance the large-scale deployment of creditworthy clean energy projects, including clean energy manufacturing, energy efficiency investments in buildings, and the development of new transmission and distribution grid infrastructure investments.

A variation on the EIT proposal was developed at the state level by Connecticut in 2011 as the Clean Energy Finance and Investment Authority, or CEFIA, which was a quasi-public corporation with its own budget outside of the state. It also consolidated several existing programs that were operating in a disconnected way from each other and from the Connecticut Department of Energy and Environmental Protection and related agencies. Moreover, this statewide green bank approach is focused on making loans as opposed to outright grants. This enables green investments to limit costs to taxpayers while more effectively connecting private investors who are looking for projects with clear balance sheets and profit-and-loss statements with such projects.

As one of its first projects, CEFIA created a new solar financing facility in July 2013CT Solar Lease II - in an effort to substantially expand solar capacity in Connecticut. Under the arrangement, the state invests $\$ 9.5$ million in solar deployment and private investments contribute $\$ 50$ million. CT Solar funds will be available to both residential and commercial customers. The arrangements will include elimination of upfront solar PV leasing costs, so that customers' energy bill savings will outweigh lease payments. The program also aims to increase competition, allowing customers to choose from a wider range of installers than just those that manage to raise capital and tax equity. The system is designed to enable CEFIA to recover most, if not all, of the state subsidies paid out to support solar leases. ${ }^{67}$

Still further variations on this basic approach can be developed at the state or federal levels, depending on specific conditions. Efforts along these lines are currently underway in New York state, where $\$ 1$ billion is being dedicated to capitalize a new state green bank, as well as in states and territories such as California, Hawaii, and Puerto Rico. ${ }^{68}$

To estimate the fiscal impact of green banks, we consider the operations of both federal and state-level banks as one integrated program. We assume that the initial overall capitalization of these banks will be $\$ 4$ billion, with those funds being fully 
lent out as 10-year loans carrying a 4-percent interest rate. In Appendix 5, we show our detailed calculations as to how the cash flows from such a program would proceed over our full 20-year investment program. We find that the average cost of this integrated program would be about $\$ 1.1$ billion per year.

\section{Loan guarantees}

Federal loan guarantees help support the financing of clean energy projects by reducing the risks borne by early investors. Emerging companies frequently struggle to raise the necessary capital to bring new clean energy technologies to commercial scale due to the large amount of financing required and because such technologies have not yet been proven at commercial scale. Through loan guarantees, the federal government backs loans issued by private lenders, promising to repay the outstanding balance in the event of default or bankruptcy.

As we have discussed in Chapter 6, the Department of Energy Loan Guarantee Program (1705) helped underwrite about $\$ 14$ billion in new clean energy investments as part of the American Recovery and Reinvestment Act. Even after taking full account of the large-scale failure of the Northern California solar company Solyndra, the default rate and corresponding government financial obligations stemming from this program were modest. As we show in Chapter 6, the government's obligations resulting from defaults have amounted to $\$ 596$ million, or 4.3 percent of the $\$ 14$ billion in outstanding guarantees. Some significant share of this $\$ 596$ million - perhaps as much as 50 percent of the total obligation-will be recovered by the federal government when it sells the assets of the firms that defaulted, including Solyndra and one other firm, Abound Solar. This means that the program will have experienced losses in the range of $\$ 300$ million, or about 2.1 percent of the $\$ 14$ billion in new loans that the government guaranteed. This experience shows that clean energy loan guarantee programs can be a cost-effective policy for leveraging relatively small amounts of taxpayer funds into very large net investments in energy efficiency and renewables. ${ }^{69}$

Despite this, financial support via the Department of Energy's 1705 program is no longer available. ${ }^{70}$ Moreover, Congress has not proposed extending this program for efficiency and renewable investments, while authorization has been preserved for "advanced fossil energy projects," such as carbon capture and sequestration. Following from our discussion in Chapter 6, we clearly conclude that Department of Energy loan guarantees should be continued for energy efficiency and renewable energy projects rather than being reserved for new fossil fuel-based projects. 
The federal government also operates many other programs that offer both direct government loans and publicly backed loan guarantees, which could be used effectively to prioritize clean energy investments. These other programs include the Rural Utilities Service-Electric Loan Program, the Rural Development Loan Assistance programs, the Rural Development Biorefinery Assistance Program, and the Transportation Infrastructure Finance and Innovation Act Program. These established financing programs provide direct and/or guaranteed loans to various entities -including businesses, individuals, communities, and local and state governments - for investments in energy efficiency, biofuel production, and surface transportation projects with environmental benefits.

One program with strong prospects for expansion into the areas of clean energy loan guarantees is the Energy Efficiency and Conservation Loan Program of the U.S. Department of Agriculture's Rural Utilities Service. This program was initially established under the New Deal to support rural electrification, ${ }^{71}$ but over time it has proven to be an excellent investment for U.S. taxpayers, with negligible default rates, positive returns to the U.S. Treasury, and strong economic outcomes.

At present, the USDA's Rural Utility Service has the same financing authorities put in place when President Franklin D. Roosevelt established the Treasury Rate Loan Program under the Rural Electrification Act of $1936 .{ }^{72}$ This program allows the USDA to make direct loans and loan guarantees for rural infrastructure. In the 2008 federal Farm Bill, Congress approved an amendment that simply inserted the words "efficiency and" into the list of eligible purposes to which USDA's lending authority can be applied. On December 5, 2013, the Obama administration finalized a rulemaking to implement the legislation, establishing a new Energy Efficiency and Conservation Loan Program. Conservation under the new rule can include measures that reduce electric load served by the grid, opening the provision beyond typical energy efficiency measures to encompass a broad range of eligible technologies. These include rooftop solar, smart microgrid investments, and combined heat and power generation.

The initial implementation of this Energy Efficiency and Conservation Program, as outlined in the president's Climate Action Plan and described in the final rule, ${ }^{73}$ caps loans at \$250 million through FY 2014. However, this low figure is deceptive because after the first fiscal year, the statute allows the program to operate on an equal basis within the larger Treasury Rate Loan Program, which currently stands at $\$ 6.5$ billion annually. ${ }^{74}$ In fact, in recent years at least $\$ 3$ billion in this loan authority has remained unused at the end of each year. In short, this program 
offers an existing annual stream of $\$ 3$ billion in underutilized debt capacity available for clean energy projects in rural America. Further, the Energy Efficiency and Conservation Program does not need appropriations because it only makes secured loans to utilities. Therefore, rapidly scaling up the use of this new program provides a pathway to achieving strong financial support for a major program of investment in rooftop solar and home retrofits across rural America, without having to face opposition around broader issues with the federal budget.

To assess the fiscal impact of these federal loan guarantee programs, considered as one integrated whole for our purposes, we assume a large-scale generous federal initiative modeled on the 1705 program within ARRA. We assume that 10 percent of the full $\$ 200$ billion in annual clean energy investments will receive these federal loan guarantees as part of their overall financing package with a private lender. We then assume that the terms of these guarantees are structured along the lines of the 1705 program, and that the default rate on these loans is somewhat higher than has been experienced with the 1705 program.

Based on these assumptions, as we detail in Appendix 5, we estimate that the average annual costs of the program would be $\$ 590$ million per year. Given that these costs would support $\$ 20$ billion in annual loans provided by private financial institutions, the program would therefore cost the federal government 2.9 cents for every dollar of private loans extended.

\section{Property Assessed Clean Energy financing}

Property Assessed Clean Energy, or PACE, financing applies a long-established method of infrastructure finance, the special assessment district, which uses local taxing authorities to collect payments on the debt that finances publicly beneficial infrastructure investments. Under typical PACE financing arrangements, property owners borrow from a local government or bank to finance clean energy investments. The amount borrowed is then repaid via a special assessment on property taxes or another locally collected tax or bill. The security of the tax collection mechanism reduces the risk to the private lender or bond investor, and the note on the property offers collateral to secure the loan.

PACE financing harnesses public tax collection authorities to establish a strong form of repayment security and offer long-term fixed-rate loans to finance clean energy projects and building retrofits. PACE does not need to rely on a general obligation from local governments or any form of public subsidy and can be 
administered purely through the private sector. The security created by incorporating repayment into the tax bill makes clean energy projects more affordable for borrowers and more attractive for participating financial institutions.

Under PACE financing, when a property owner participating in the program sells the property, the repayment obligation legally transfers with the property. This feature creates an important incentive for building owners who might otherwise be disinclined to tie up their personal credit. Because, formally speaking, PACE financing is a tax bill, it can be accounted for as an operating expense and not a form of traditional debt. PACE financing also offers an important tool for overcoming the so-called split incentive with energy efficiency investments-when building owners are reluctant to take on capital expenses that will reduce utility bills for their tenants but that do not provide landlords with direct financial benefits-because tax bills can generally be passed through in commercial lease arrangements. By allowing the costs of raising the efficiency standards of buildings to be transferred, PACE financing allows the owner and tenant to remain closely aligned in lowering energy costs in the building. These features of PACE financing mean that the risks of lending for energy efficiency projects are reduced and the costs of borrowing can correspondingly decline. Further, PACE potentially offers a deduction of the repayment obligation from federal taxable income, as part of the local property tax deduction. ${ }^{75}$

A variation on PACE is on-bill financing. With on-bill financing, a loan that pays for an energy efficiency investment is repaid through a utility bill and secured by a strong contract with the utility. Additional collateral must be obtained by the lender since nonpayment can lead to borrowers having their electricity delivery suspended.

From 2008 to 2010 new state laws authorizing PACE financing spread rapidly throughout the country. At present, 29 states and the District of Columbia have authorized local governments or state entities to create PACE financing programs. ${ }^{76}$ These programs are presently operating successfully in at least 11 states, including California, Connecticut, Florida, Georgia, Maine, Michigan, Minnesota, Missouri, Ohio, New York, and Wisconsin, along with Washington, D.C. Programs are also under development in Arkansas, Maryland, New Jersey, Oregon, Texas, Virginia, and elsewhere around the country. The most extensive program is in California, where, as of 2012, nonresidential property owners in 126 cities and 14 counties were able to finance renewable energy and energy efficiency projects with PACE financing. ${ }^{77}$ Meanwhile, Connecticut's green bank has demonstrated over the past year that well-functioning PACE programs can grow rapidly to build market share and consumer awareness. 
Currently, the majority of programs operating have focused on the use of PACE financing in commercial and multifamily real estate. The Federal Housing Finance Agency, which oversees single-family residential mortgage markets, has expressed reservations about PACE financing, unless the holders of the original mortgage loan agree to the arrangement. ${ }^{78}$ Because of the FHFA's position on single-family PACE loans, the vast majority of PACE lending to date has concentrated on developing commercial PACE programs that fall outside of FHFA's domain. The PACE financing market for single-family housing could grow rapidly if the FHFA's concerns are resolved in the near-future. In any case, the expansion of PACE financing in the commercial real estate market itself represents a significant new financing tool to support energy efficiency investments.

As with other regulatory policies discussed here, the PACE and on-bill financing programs will have no public-sector fiscal impact other than the administrative and enforcement costs that we have incorporated into our overall cost estimates.

\section{Master Limited Partnerships and Real Estate Investment Trusts}

Another way to leverage additional capital to finance energy efficiency and renewable energy investments is through repurposing existing financing tools that are routinely utilized in both corporate and project finance within the federal tax code. Two financing structures with proven track records are Master Limited Partnerships, or MLPs, and Real Estate Investment Trusts, or REITs. Both MLPs and REITs are corporate tax structures designed to encourage investments in large-scale projects by limiting the resulting tax burden of such investments. MLPs and REITs are familiar investment products with large and established investor pools that have a long history of financing conventional energy and real estate investments. These tools can provide access to new groups of investors and substantial new sources of capital at an efficient cost to finance renewable and efficiency energy projects. ${ }^{79}$

Congress created MLPs in the 1980s to help companies attract investments in large-scale real estate and fossil fuel energy projects such as pipelines and transmission lines. Since the 1980s, more than $\$ 350$ billion has been raised for investments via MLP financing, making this a huge potential funding pool that could be tapped for clean energy projects. ${ }^{80}$ MLPs are attractive to investors because they are taxed as personal income only, rather than being additionally subject to corporate income taxes. Further, MLPs can raise funds through public exchanges and their shares are traded like stocks, which allows for added flexibility in attracting investment funds. 
Within the energy sector, MLP eligibility is currently limited to fossil fuel projects, and specifically excludes renewable energy and energy efficiency investments from eligibility. However, in 2012 Sen. Chris Coons (D-DE) introduced the MLP Parity Act with bipartisan support in both the Senate and House, which would extend MLP financing eligibility to clean energy projects. ${ }^{81}$ As such, the Coons bill would open low-cost investment capital to clean energy projects by conferring benefits already enjoyed by the oil and gas industries to investors in renewable energy and energy efficiency projects.

Similar to MLPs, REITs are tax structures created by Congress in 1960 to drive investment into new properties such as housing, factories, and hotels. ${ }^{82}$ REIT designation allows a company to deduct the cost of shareholder dividends from its corporate tax liability as long as the dividends account for at least 90 percent of the company's taxable income. REITs draw long-term investments from a wide pool of investors as publicly traded stocks and have leveraged a market of more than $\$ 440$ billion in property investments.

REIT status is determined by the IRS on a case-by-case basis. The IRS however, could issue a permanent ruling that defines renewable energy and energy efficiency assets as property within REITs. Congress could also establish an expanded definition that includes renewable energy and efficiency projects for REITs, similar to the goal of the MLP Parity Act.

In the meantime, clean energy companies can apply for REIT status, as Hannon Armstrong Sustainable Infrastructure Capital Inc. did in April 2013. ${ }^{83}$ Launching as a clean energy REIT, Hannon Armstrong raised an IPO of \$167 million, following a private ruling by the IRS to specify what renewable assets would qualify as REIT property. It is notable that this new clean energy REIT is seeking to purchase PACE-financed retrofit projects as an asset to hold within its portfolio. The Hannon Armstrong case illustrates how these various project-financing strategies can work in parallel to make more projects financially viable, which in turn will promote private investments in energy efficiency and renewable energy.

To provide a rough estimate of the fiscal impact of MLP and REIT programs focused on promoting clean energy investments, we again make generous assumptions as to the scope of the program. That is, as we document in Appendix 5, we assume that $\$ 10$ billion per year in private-sector clean energy investments receive the tax benefits of either an MLP or REIT. Over our full 20-year investment cycle, these tax benefits therefore cover $\$ 200$ billion in accumulated assets. We assume that 
the rate of return on these assets is 10 percent and that the tax benefit of either the MLP or REIT is equal to 35 percent of the return on these assets. Based on these assumptions, we calculate that these programs would entail an average of $\$ 3.7$

billion per year in annual government expenditures (i.e., tax revenue reductions or tax expenditures). 


\section{Complementarities between policy initiatives}

There are many ways in which these policies, operating in combination, complement each other to create a significantly more effective overall policy framework. For instance, as described above, energy efficiency resource standards that work in conjunction with utility price decoupling is an important example of how policies can operate more effectively when they work in conjunction with one another. Another example is the positive spillover effect that federal investments in building energy efficiency can have in improving construction practices and market transparency. Expanding access to low-cost, long-term financing opportunities through PACE financing, loan guarantees, and green banks can further bolster market conditions for private-sector energy efficiency retrofits. Clean energy REITs can then hold the PACE assets that have been financed as investments in their portfolios. All of these positive incentives for energy efficiency investments would of course be further reinforced by an effective carbon cap or tax and through the introduction of new materials and building technologies as a result of increased $\mathrm{R} \& \mathrm{D}$ investment.

In encouraging renewable energy investments, the federal government's procurement initiatives - starting with the Department of Defense establishing a 25-percent target by 2025 for renewable energy to supply the department's electricity needs - will have widespread impacts. These programs will promote economies of scale for the industry and provide a strong undergirding of technology, skills, and supply chains. The effect of this policy will be further magnified when operating in conjunction with comparably sized Renewable Portfolio Standards in a large number of states. These initiatives could then be strengthened further with the establishment of feed-in tariffs that provide guaranteed markets and price certainty for renewable energy projects. In addition, the combination of PACE financing, loan guarantees, and green banks would similarly drive innovation through affordable financing and establishing a supportive market environment for renewable investments. Finally, with renewables especially, it is critical that the industry be able to benefit from a major government-funded R\&D initiative. ${ }^{84}$ 
Overall, these wide-ranging clean energy policies are capable of operating effectively as complements to one another. That is, when combined, they can accomplish substantially more than they would operating as stand-alone measures. As a full, unified policy package, they are capable of delivering an investment climate that addresses key concerns for advancing private-sector investments in clean energy: strong and predictable market demand; long-term certainty with respect to incentives, taxes, and regulations; and affordable long-term financing.

However, there are major challenges facing this set of clean energy policies in order for them to operate with sufficient coordinated impact to achieve the 20-year emissions-reduction target. One factor is that various individual initiatives are not being implemented explicitly as components within a clear and integrated policy agenda. The Bloomberg 2013 Factbook highlights this problem, writing:

The U.S. generally lacks an over-arching policy framework for furthering the deployment of sustainable energy technologies. It has set no formal national goals for expanding sustainable generating capacity or for cutting harmful greenhouse gas emissions from the energy sector, for instance-though the Environmental Protection Agency is in the midst of establishing emission-related regulations for the sector. Still a patchwork offederal laws and regulations and critical state-level policies has lent important and substantial support to the sector. Much to the frustration of the sustainable energy sector, however, many of these policies, such as key federal incentives for renewables, lack permanence — creating unnecessary uncertainty in the marketplace. ${ }^{85}$

Furthermore, even if the various relevant government entities greatly improved their coordination around clean energy policies, this alone would not be sufficient to achieve the 20-year $\mathrm{CO}_{2}$ emissions target. We still need to assess two central aspects to these policies: the amount of financial resources being committed in the various policy areas to support clean-energy investments and the strength of the regulations in limiting emissions from fossil fuels.

Again, the budgetary figures we have provided here are rough estimates of how large-scale programs might be financed at effective levels of support. The actual operational levels of these programs are at present distinct from these estimates. To date, some policy initiatives are already making significant impacts or will do so in the near future. These include the Defense Department's renewable energy procurement program; the 2025 automobile fuel-efficiency standard; and the state-level renewable energy and energy efficiency portfolio standards. However, 
in other areas, policies may be well-designed and coherent but do not yet operate with sufficient resources to create a significant impact. These include the federal government's energy efficiency program, investments to upgrade the electrical grid, and R\&D for both efficiency and renewables. In addition, all of the financing programs - PACE, loan guarantees, state-level green banks, and variations thereofare still operating at a small scale. Feed-in tariffs also need to be implemented much more widely throughout the country with prices for renewable electricity that are high enough for suppliers to earn a profit. Similarly, there are, as yet, no federal Renewable Portfolio or Energy Efficiency Resource Standards, nor is there a federal carbon cap or tax.

The Obama administration has made EPA's serious enforcement of the Clean Air Act as applied to carbon pollution the major initiative of its 2013 Climate Action Plan. It is critical that the administration continue to follow through with this commitment as it has done thus far in announcing specific features of the plan in June 2014. Doing so will result in a substantial contraction of the U.S. coal industry, but as we have seen, even if coal-fired electricity generation is reduced in the United States by 50 percent to 60 percent - as we have projected with our PERI-CAP scenario in Chapter 5-it will still be necessary to achieve major advances in energy efficiency and renewable energy in order to reach the 20-year $\mathrm{CO}_{2}$ emissions-reduction target. Specifically, overall U.S. energy consumption needs to fall to around 70 Q-BTUs by 2030 from its current level of about 100 Q-BTUs, and clean renewable energy needs to supply 15 Q-BTUs or more of that total 70 Q-BTU of national consumption. Further, the 20 -year $\mathrm{CO}_{2}$ emissionsreduction target will not be achieved if the primary outcome of the Obama administrations' tight enforcement of the Clean Air Act is simply substituting natural gas for coal in electricity generation.

Moving forward, a major leadership opportunity exists for the president in tackling climate change. The executive branch should therefore first and foremost prioritize mobilizing the full set of incentives available across federal agencies to the task of reducing $\mathrm{CO}_{2}$ emissions to around 3,200 $\mathrm{mmt}$ within 20 years. This project would also need to be joined with comparable efforts to reduce other greenhouse gas emissions by similar amounts. 


\section{Regional equity and worker transition assistance}

The clean energy investment project is an economywide endeavor. At the same time, any given investment projects will be tied to specific locations. Some localities and regions will gain because they are the beneficiaries of new clean energy investment projects. Other localities and regions will lose to the extent they are currently heavily dependent on the fossil fuel industry.

This raises some critical questions for successfully advancing the clean energy policy agenda. How can the clean energy project be advanced in ways that are equitable across regions and do not waste money through inter-regional competition for funds? And how can communities and workers with close ties to the fossil fuel industry be provided with sufficient assistance to prosper in the face of this transition?

\section{Promoting regional equity}

It is clear that some regions and states will have built-in advantages tied to climate, topography, or geography, including areas that are more sunny or windy or are capable of producing agricultural products as feedstocks for the next generation of clean biofuels. But obvious political problems will arise if U.S. policymakers privilege certain regions with disproportionate shares of public support based on these advantages, while other regions end up providing taxpayer funds for such projects without receiving a reasonable share of immediate benefits.

Beyond such purely political considerations, it is also true that on analytic grounds alone, it would be difficult to establish clear criteria for providing disproportionate benefits to any given region or state based purely on climate or geography. For example, Arizona is very sunny, but is that area or natural resource more deserving of investment support than parts of Minnesota or Wyoming that are very windy? It is even more important to consider this same problem from the opposite vantage point - that is, from the view of regions that are currently heavily invested in various sectors of the fossil fuel industry. These regions will inevitably experience 
disproportionate negative impacts through policies targeted at boosting the clean energy economy and achieving major cuts in fossil fuel emissions. The heavily fossil-fuel dependent regions include oil-producing states such as Texas, Louisiana, and Oklahoma, and coal-producing areas such as the Appalachian region, Wyoming, and Montana. Again, purely political concerns aside, we must determine the proper approach to establishing policies for compensating these regions for the economic losses they will experience.

In fact, there are straightforward and well-established approaches to resolving such issues. We can start with the fact that crucial elements of the clean energy agenda will require large-scale investments in all regions. The most obvious example of this is the project to retrofit the country's entire existing building stock to increase its energy efficiency — starting, as described above, with the federal government's approximately 850,000 buildings that it owns or leases in productive use. Similarly, federal, state, and local governments will need to undertake the task of expanding public transportation systems and upgrading electrical grid transmission lines in all parts of the country, regardless of any particular geographic or climatic advantages or disadvantages.

As such, the most straightforward approach for allocating public investment funds and subsidies tied to the clean energy agenda will be a simple formula through which all regions benefit equivalently. For example, in previous work, we proposed a formula for allocating funds that distributes clean energy investment support equally based on a state's share of total national GDP and its share of the total U.S. population. ${ }^{86}$ Distributing funds on the basis of each state's share of total GDP means assigning proportions of total spending based on existing patterns of financial investments and levels of development. This provides an accurate measure of how clean energy investments would flow if they followed current levels of economic development across states. But it would, of course, also mean that states that already have higher levels of income and production would benefit disproportionately from the clean energy investments. Distributing the funds based on each state's population provides an egalitarian counterbalance, with each person in the country effectively receiving an equal dollar claim on an overall pool of public support and investment funds.

Within this framework, the simplest approach to addressing the disproportionately negative impacts on fossil fuel dependent regions is to provide that states with larger-than-average fossil fuel industries will be given compensation that will focus on adjustment and relocation issues, and equally on advancing the elements of a 
clean energy agenda that are most appropriate for that region. For example, Texas and Montana could receive additional support on behalf of building a wind energy industry in those areas, while the Appalachian region could receive extra support for upgrading the energy efficiency of their building stock and electrical grid transmission system.

In fact, distributing public investment and other forms of support equitably on a regional basis is an approach with which U.S. policymakers have long been familiar. Spending by the Pentagon is already distributed on a basis of reasonable parity across all states ${ }^{87}$ Whether or not these funds are being allocated in the most efficient possible way by other criteria, the Pentagon's concern with regional parity in their funding allocations demonstrates that, for other areas of public policy where equitable distribution is a major issue, workable approaches have already been implemented.

\section{Targeted community-adjustment assistance}

In addition to this general framework, there are also specific federal policy precedents that can serve as useful models in providing effective transition-adjustment assistance to affected communities and workers.

One such example is the Worker and Community Transition program that operated through the Department of Energy from 1994 to 2004 and whose mission was "to minimize the social and economic impacts of changes in the Department's activities." ${ }^{88}$ This program was targeted at 13 communities that had been heavily dependent on the nuclear industry but subsequently faced retrenchment due to nuclear decommissioning. The Worker and Community Transition program provided grants to communities, as well as other forms of assistance, in order to diversify the economic base of these 13 affected communities and to maintain jobs or create new employment opportunities elsewhere in the affected communities.

The program targeted sites where job losses exceeded 100 workers in a single year. It encouraged voluntary separations, assisted workers in securing new employment, and provided basic benefits for a reasonable transition period. The program also provided local impact assistance and worked with local economic development planners to identify public and private funding and assist in creating new economic activities and replacement employment. ${ }^{89}$ Annual appropriations for the program totaled around $\$ 200$ million in its initial years but became much smaller-in the range of $\$ 20$ million -in the final years of operation..$^{90}$ 
Lynch and Kirshenberg, writing in the Bulletin of the Energy Communities Alliance, provide a generally favorable assessment of the program. ${ }^{91}$ They conclude as follows:

Surprisingly, the 13 communities, as a general rule have performed a remarkable role in attracting new replacement jobs and in cushioning the impact of the cutbacks at the Energy-weapons complex across the country ... The community and worker adjustments to the $1992-2000$ DOE site cutbacks have been strong and responsive, especially when compared with any other industrial adjustment programs during the same decade.

But they did also note that, "The most serious problem facing the energy-impacted communities ... was the lack of a basic regional economic development and industrial diversification capacity for most of the regions affected by the DOE cutbacks beginning in the mid-1990s." ${ }^{12}$ This issue is precisely the problem that coal mining and other fossil-fuel-producing regions will face. To address this problem directly, community assistance initiatives could encourage the formation of new clean energy businesses in the affected area. One example of a successful diversification program coming out of the Worker and Community Transition Program is the repurposing of a nuclear test site in Nevada to what is now a solar-proving ground. More than 25 miles of the former nuclear site will now be used to demonstrate concentrated solar power technologies and help bring them to commercialization. ${ }^{93}$

In terms of estimating the fiscal impact of these program areas, we assume that the budgetary level will be at the high end of where the program had been in its initial years of operation-i.e., at $\$ 200$ million per year of federal support. This assumption is integrated into our overall fiscal impact assessment in Appendix 5.

\section{Worker training}

As we have discussed in Chapter 6, there is clearly a need for expanding training programs to provide workers with adequate opportunities to acquire new skills to perform effectively in many clean energy investment sectors. This is especially important for generating new opportunities for women and minorities-groups that have long been badly underrepresented in the areas of manufacturing and construction that will grow substantially from clean energy investments. At the same time, as we have also discussed in Chapter 6, clean energy investments mainly generate direct jobs in the same areas of employment-manufacturing, 
construction, and agriculture - in which people already work. This then raises the question: how much needs to be spent by all levels of government to ensure sufficient opportunities for workers to perform well in these clean energy areas?

Section 1002 of the 2007 Energy Independence and Security Act established a federal Energy Efficiency and Renewable Energy Training program. ${ }^{94}$ This program supports national training grants that are geographically distributed, state training grants, demonstration grants that are prioritized for low-income populationscalled the Pathways Out of Poverty demonstration program - and research on training needs and labor markets. The specific types of training programs included in this measure are occupational skills training, safety and health training, basic skills and job readiness training, college training programs, internship programs, apprenticeship programs, and skill upgrading and retraining. The funding allocated for this program is $\$ 125$ million per year, including at least 60 percent for the various training programs themselves, 20 percent for the Pathways Out of Poverty measures, and no more than 20 percent for labor-market research.

Assessments of this program to date have been mixed. A 2012 report from the U.S. Department of Labor found that the program had been only partially successful in placing workers into jobs in clean energy sectors. ${ }^{95}$ A 2013 study by an outside consulting group, IMPAC International, reported that, according to the majority of program administrators, funding to support the programs was not available for a sufficiently long time. ${ }^{96}$

It is clear that worker-training programs do need to continue and operate at a high-quality level to both support the clean energy investment agenda and to expand opportunities for workers to move into these new employment areas. Given that we are proposing that annual clean energy investments expand roughly four-fold relative to current levels_-from around $\$ 50$ billion to $\$ 200$ billion per year-it would suggest, at least as an initial reference point, that worker-training programs increase equivalently relative to the ARRA level of funding. This would imply an annual budget for worker training in the range of $\$ 500$ million per year. In practice, there is likely to be overlap between worker training programs and the separate programs tied to both community and worker adjustment. Nevertheless, for the purpose of not underestimating costs of important programs aimed at assisting workers and communities, we assume that the budget for clean energy worker training programs should be treated as distinct from and in addition to those for both community and worker adjustment. 
Helping communities rebuild and diversify their economies is a process that takes years. Meanwhile, displaced workers need financial support in the short term to replace their lost income. They are also likely to need further assistance with retraining and finding new employment.

How many workers are likely to require this type of assistance as part of a clean energy transition? We need to focus only on workers directly employed in the fossil fuel industry, as opposed to also considering those included under the indirect or induced employment categories, as described in Chapter 6. The levels of indirect and induced employment will, on balance, expand with the overall gains in employment we presented in Chapter 6.

Within the domestic U.S. economy as of June 2014, there are about 212,000 domestic workers employed in oil and gas extraction and 79,000 in coal mining. ${ }^{97}$ The levels of employment in support activities are roughly equal to those engaged in mining and extraction itself. This means a total level of direct employment in fossil fuels of about 580,000 people..$^{98}$ As a rough calculation based on scenarios we presented in Chapter 4, let us assume that U.S. oil and gas production falls by 20 percent between now and 2030 and that coal production falls by 50 percent over this period. That means an overall contraction of about 100,000 direct jobs in the fossil fuel sector as of 2030 relative to 2013. If these losses were to occur on a steady basis between now and 2030, that would mean a contraction of about 10,000 jobs per year in oil and gas extraction and coal mining.

To determine the level of support these displaced workers will require, we can first look to the federal Trade Adjustment Assistance, or TAA. The TAA began in 1962 as a program to provide retraining and financial assistance to workers affected by increased trade liberalization. ${ }^{99}$ In its current form, it provides assistance to workers in the areas of wage subsidies, health insurance, counseling and retraining, relocation, and job search costs. As of fiscal year 2013, annual spending on TAA totaled \$784 million. ${ }^{100}$ The Obama administration projects that figure to increase to approximately $\$ 1$ billion per year over the next decade, but the administration's 2015 TAA budget proposal was — at $\$ 751$ million - lower than spending in 2013, including about $\$ 400$ million in benefits and $\$ 300$ million for training and related activities. ${ }^{101}$ 
Considering these various initiatives, total TAA spending has amounted to about to about $\$ 10,000$ per displaced worker per year over a two-year period. If we applied this level of support to displaced workers in the fossil fuel sector, this would mean roughly $\$ 200$ million per year in funding to support U.S. workers displaced by the clean energy transition. However, this level of funding has long been recognized as insufficient for meeting the needs of displaced workers in other sectors of the economy. It is therefore necessary to consider providing more adequate levels of support. One approach is Gene Sperling's 2006 proposal for wage insurance that would be available prior to a worker facing a layoff. Sperling also proposes a system of "one-stop shopping" to make sure that workers have ready access to all the forms of support they require. ${ }^{102}$

A more expansive approach was first proposed by the late U.S. labor and environmental leader Tony Mazzocchi, who developed the idea of a "Superfund for workers" who lose their jobs as a result of necessary environmental transitions. As Mazzocchi wrote as early as 1993 :

Paying people to make the transition from one kind of economy - from one kind of job - to another is not welfare. Those who work with toxic materials on a daily basis ... in order to provide the world with the energy and the materials it needs deserve a helping hand to make a new start in life.... There is a Superfund for dirt. There ought to be one for workers." ${ }^{103}$

To meet the Superfund standard outlined by Mazzocchi, by way of illustration, let's assume that the cost per worker needs to be four times higher than the current level of TAA assistance- $\$ 40,000$ per year over two years. That means the program would cost roughly $\$ 800$ million per year. This is the figure we have incorporated into our overall fiscal impact calculations presented fully in Appendix 5. Even at this level of funding, this Superfund proposal would still only represent about 0.02 percent of the current federal budget.

Such details aside, the critical point is that the overall level of financial assistance needed to provide a solid basis of supportive services for displaced workers now employed in the fossil fuel industry is going to be relatively modest within the context of the epoch-defining project of building a clean energy U.S. economy. At the same time, providing high-quality adjustment assistance to today's fossil fuel industry workers will represent a major contribution toward creating a viable overall policy agenda for successfully building a clean energy economy in the United States. 
We also need to recognize that the impact on workers and communities from retrenchments in the fossil fuel sectors will not just depend on the level of support provided through public programs such as a Superfund - no matter how generous the provisions of any such fund. The broader set of economic opportunities available to workers will also be critical. The fact that the clean energy investment project will generate a net increase of about 2.7 million jobs means that there will be new opportunities for displaced fossil fuel workers within the energy industry itself. As we showed in Chapter 6, this expansion in new job opportunities in the energy industry will be at all levels of the industry. There will be more jobs for operations managers, mechanical engineers, construction managers, farmers and ranchers, roofers, electricians, and sheet metal workers, among other occupations.

But further than this, the single best form of protection for displaced workers is an economy that operates at full employment. A full-employment economy is simply one in which there is an abundance of decent jobs available for all people seeking work. In a full-employment economy, the challenges faced by displaced workersregardless of the reasons for their having become displaced-are greatly diminished because they should be able to find another decent job without excessive difficulties. It also follows that in a full-employment economy, the costs to taxpayers of providing reasonable levels of financial support for displaced workers would be greatly diminished. Overall then, in the realm of overarching social, economic, and environmental policy priorities, a commitment to full employment should be understood as being completely consistent with and supportive of the project of building a clean energy economy. ${ }^{104}$

This raises a further broader point: We can advance a viable agenda for building a green economy while equally addressing the altogether legitimate concerns of workers and communities that will be hurt by this agenda. There is no reason, in other words, for the fight to control climate change to continue becoming derailed over false tradeoffs between the environment and the well-being of workers. 


\section{Overall fiscal impact of clean energy policies}

From the discussions in this chapter thus far and the underlying detailed calculations we present in Appendix 5, we can now provide a summary assessment of the fiscal impacts of the clean energy programs we have examined here. Before doing so, we should again emphasize that we are not necessarily advocating on behalf of the specific tax rates or expenditure levels that we present here for any of the programs we present. Significantly more detailed research is necessary to establish what the most effective specific features would be with each of our expenditure or revenue-generating programs. The purpose of the fiscal-impact estimates in this chapter is rather to provide a broad framework for assessing the scale at which these programs will need to operate and the fiscal impacts of operating the programs at the appropriate scale.

In Table 8.2, we present the summary budget figures at annual average levels over the 20-year investment period. The year-by-year estimates range widely around these averages for some of the programs, depending on the specific ways they are structured to be implemented. Appendix 5 shows the detailed year-by-year figures for all programs. 
TABLE 8.2

Summary of average annual sources of revenues/net savings and expenditures from clean energy policies

Revenues and net savings

\begin{tabular}{|c|c|}
\hline Program & $\begin{array}{l}\text { Revenues or net savings } \\
\text { (in billions) }\end{array}$ \\
\hline Carbon tax or cap & $\$ 203.0$ \\
\hline $\begin{array}{l}\text { Federal and state/local public building energy- } \\
\text { efficiency investments }\end{array}$ & $\$ 9.8$ \\
\hline Total revenue or net saving & $\$ 212.8$ \\
\hline \multicolumn{2}{|l|}{ Expenditures } \\
\hline Program & $\begin{array}{l}\text { Expenditures } \\
\text { (in billions) }\end{array}$ \\
\hline \multicolumn{2}{|l|}{ Market-shaping rules } \\
\hline $\begin{array}{l}\text { Administration/enforcement costs for new clean } \\
\text { energy regulations }\end{array}$ & $\$ 0.9$ \\
\hline \multicolumn{2}{|l|}{ Direct public spending } \\
\hline Federal $R \& D$ for efficiency and renewables & $\$ 3.5$ \\
\hline \multicolumn{2}{|l|}{ Private investment incentives } \\
\hline Production tax credits & $\$ 26.8$ \\
\hline Investment tax credits & $\$ 27.0$ \\
\hline Green banks & $\$ 1.1$ \\
\hline Loan guarantees & $\$ 0.6$ \\
\hline MLPs and REITS & $\$ 3.7$ \\
\hline \multicolumn{2}{|l|}{ Regional equity and worker transition assistance } \\
\hline Worker training & $\$ 0.5$ \\
\hline Community adjustment assistance & $\$ 0.2$ \\
\hline Worker adjustment assistance & $\$ 0.8$ \\
\hline Total expenditures & $\$ 65.1$ \\
\hline
\end{tabular}

Net fiscal impact

\begin{tabular}{lc}
\hline Revenues and net savings & $\$ 212.8$ billion \\
Expenditures & $\$ 65.1$ billion \\
Net fiscal impact (surplus/deficit) & $\$ 147.7$ billion \\
& in average annual surplus
\end{tabular}

Sources: See text of Chapter 8 and Appendix 5. 
As we see in Table 8.2, total average annual revenues and net savings amount to $\$ 212.8$ billion, while average annual expenditures are at $\$ 65.1$ billion. The net fiscal impact of all programs combined would therefore amount to an average annual surplus of $\$ 147.7$ billion.

Of all of the programs, the primary source of revenues or net savings, of course, is the carbon tax or cap, either of which would generate $\$ 203$ billion in average annual revenues. The primary source of expenditures would be the production and investment tax credits, which would amount to $\$ 54$ billion in combined federal expenditures. The overall fiscal posture of a clean energy policy agenda would therefore change dramatically if either of these two programs were not implemented or if their design varied significantly relative to the specific features we have assigned to them here.

Working with these figures does provide some useful perspectives. As one major overarching point, as noted above, even if we were to assume that 75 percent of the revenues from a carbon cap or tax were returned directly to taxpayers-as proposed in the Cantwell/Collins cap-and-dividend initiative - this would still leave roughly $\$ 50$ billion per year to channel into clean energy investments. In addition, the combined annual net savings to the federal, state, and local governments of roughly $\$ 10$ billion from making investments in energy efficiency building retrofits could also be channeled into other areas of clean energy investments.

Thus, these two sources of revenues or net savings from clean energy policies could provide about $\$ 60$ billion annually in funding for clean energy spending policies. This figure is roughly equal to our estimate that, on average, about $\$ 65$ billion per year would be needed to support clean energy expenditure policies. In short, the clean energy policies that we have discussed here combined would operate at a rough fiscal balance-again, after assuming that 75 percent of the funds generated by a carbon tax or cap would be distributed directly to U.S. taxpayers.

If we assume that a federal carbon tax or cap is not enacted, but that all the other programs are implemented as we have specified them, this would then imply an average annual level of net federal expenditures at $\$ 55$ billion. Under this scenario, the net level of government spending would amount to about 25 percent of the overall $\$ 200$ billion annual clean energy investment program, including both public and private funds for this level of investments. In this situation, the main source of spending would, again, be the federal tax credits for clean energy investments. As noted earlier, these funds could be distributed more effectively as 
direct cash grants to investors, as was done through the ARRA. But regardless of the program design specifics, this $\$ 50$ billion in funds would count as contributing 25 percent of the total amount required to reach the $\$ 200$ billion annual level of overall clean energy investments. This is because these funds would constitute a direct transfer from the government to clean energy investors. 


\section{Conclusion}

The purpose of this study has been to present a realistic path for meeting the massive environmental challenge posed by global climate change. We also explore the ways in which advancing a large-scale clean energy investment project in the United States can promote job opportunities and economic growth throughout the economy.

The overarching conclusions that emerge from this study are straightforward. That is, there is a clear path for the United States to achieve a 20 -year $\mathrm{CO}_{2}$ emissions target from energy-based sources of 3,200 $\mathrm{mmt}$. We have concluded that a viable path does exist for achieving this target, even while recognizing that hitting this goal would represent a nearly 40-percent decline in U.S. $\mathrm{CO}_{2}$ emissions relative to the 2010 level of 5,600 $\mathrm{mmt}$. We show that the large-scale investments necessary to build a clean energy economy over the next 20 years will also promote expanded job opportunities throughout the U.S. labor market. Further, pursuing these clean energy investments will not act as an obstacle to moving the U.S. economy back onto a healthy growth trajectory. Rather, undertaking these investments themselves and the benefits that will result from them will improve prospects for long-term GDP growth. Some regions and communities that depend heavily on nonrenewable energy as their main source of economic vitality will certainly be hurt by the transition to a clean energy economy. This is why effective policies for regional adjustment must not be treated as an afterthought. They are rather one crucial component of the transformational project before us: to achieve success over the next 20 years in creating a clean energy economy in the United States. 
1 According to the U.S. Bureau of Economic Analysis, Table 1.1.5, "Gross Domestic Product," GDP in the United States was approximately $\$ 17$ trillion in the first half of 2014. Thus, $\$ 200$ billion represents 1.2 percent of this amount. For more information, see U.S. Bureau of Economic Analysis, "Survey of Current Business" (U.S. Department of Labor, July 2014), available at http:// www.bea.gov/national/pdf/dpga.pdf.

2 Another area of major policy concern with respect to climate change-both in the United States and even more seriously in developing countries-is implementing adaptation measures that can effectively protect people, communities, and the physical infrastructure against the effects of climate change. As we have discussed in Chapter 7, these impacts of climate change are already occurring with increasing frequency and force, including droughts, floods, and other severe weather events. But as we stated at the outset of Chapter 1, our focus in this study, and this chapter specifically, is on policies capable of controlling climate change, rather than adapting to its effects.

3 U.S. Environmental Protection Agency, Inventory of U.S Greenhouse Gas Emissions and Sinks: 1990-2012 (2014), available at http://www.epa.gov/climatechange/ Downloads/ghgemissions/US-GHG-Inventory2014-Main-Text.pdf.

4 Bloomberg New Energy Finance and Business Council for Sustainable Energy, "Sustainable Energy in America 2013 Factbook" (2013), p. 2, available at http://www. bcse.org/factbook/pdfs/2014\%20Sustainable $\% 20$ Energy\%20in\%20America\%20Factbook.pdf.

5 John D. Podesta, Kate Gordon, Bracken Hendricks, and Benjamin Goldstein, "The Clean-Energy Investment Agenda: A Comprehensive Approach to Building the Low-Carbon Economy" (Washington: Center for American Progress, 2009), p. 1, available at http://www. americanprogress.org/wp-content/uploads/ issues/2009/09/pdf/clean_energy_investment.pdf.

6 For an examination of alternative ownership forms within the energy sector, both in the United States and Europe, see Robert Pollin, "Public Policy, Community Ownership and Clean Energy," Cambridge Journal of Regions, Economy and Society 5 (3) (2012): 339-359. As one important example of a nontraditional ownership form operating at a large scale, Bolinger (2001, 2005), reports that, as of 2000 , roughly 80 percent of all wind power capacity in four northern European countries-Germany, Denmark, Sweden, and the United Kingdom - could be considered "community-owned." For more information, see Mark Bolinger, "Community Wind Power Ownership Schemes in Europe and their Relevance to the United States" (Berkeley, CA: Lawrence Berkeley National Laboratory, 2001), available at http://emp.lbl.gov/publications/ community-wind-power-ownership-schemes-europeand-their-relevance-united-states; see also Mark Bolinger, "Making European-style Community Wind Power Development Work in the US" Renewable \& Sustainable Energy Reviews 9 (6) (2005): 556-575. Moreover, because these four countries accounted for roughly half of the world's installed wind power capacity at that time, this means that community-owned projects accounted for roughly 40 percent of global wind power supply at the end of 2000. A valuable small-scale case study is Freimant, a rural community of 4,200 residents in Germany's Black Forest region. As of 2008, Freimant had achieved 100 percent electric power supply through community-owned renewable sources. For more information, see Liwen Li, Janine Birmele, Harald Schaich, and Werner Konold, "Transitioning to CommunityOwned Renewable Energy: Lessons from Germany" Procedia Environmental Sciences 17 (2013): 719-728.
7 Podesta, Gordon, Hendricks, and Goldstein, "The Clean-Energy Investment Agenda," p. 3.

8 Bracken Hendricks, Lisbeth Kaufman, Ken Berlin, Monty Humble, Reed Hundt, Alex Kragie, and Gerry Waldron, "Cutting the Cost of Clean Energy 1.0: Toward a Clean Energy Deployment Plan for Jobs, Security, and BroadBased Economic Growth in 2011" (Washington: Center for American Progress, 2010), p. 2, available at http:// www.americanprogress.org/issues/green/report/2010/ 11/16/8655/cutting-the-cost-of-clean-energy-1-0/.

9 For a textbook treatment of these issues, see Eban Goodstein, Economics and the Environment (Hoboken, NJ:Wiley, 2010).

10 Carbon Limits and Energy for America's Renewal, or CLEAR, Act, Senate Bill 2877, 111th Cong., 1st. sess.

11 For a careful analysis of the net distributional impact of the Cantwell-Collins bill, see James K. Boyce and Matthew E. Riddle, "CLEAR Economics: State-Level Impacts of the Carbon Limits and Energy for America's Renewal Act on Family Incomes and Jobs" (Amherst, MA: Political Economy Research Institute, 2011), available at http:// www.peri.umass.edu/236/hash/863fdbde6e/ publication/403/.

12 U.S. Executive Office of the President, The President's Climate Action Plan (The White House, 2013), available at http://www.whitehouse.gov/sites/default/files/ image/president27sclimateactionplan.pdf.

13 The California Air Resources Board provides a summary of the measure here at California Air Resources Board "Cap-and-Trade Program," available at http://www.arb. ca.gov/cc/capandtrade/capandtrade.htm (last accessed July 2014).

14 The Environmental Defense Fund has provided highly favorable, if still early, assessment of the first year of operations for California's Cap-and-Trade Program, concluding that the policy is effectively forcing significant reductions in emissions without showing any signs of inhibiting the state's broader economic recovery. See Katherine Hsia-Kiung, Emily Reyna, and Timothy O'Connor, "California Carbon Market Watch: A Comprehensive Analysis of the Golden State's Cap and Trade Program/Year One: 2012-2013" (Washington: Environmental Defense Fund, 2014), available at http:// www.edf.org/sites/default/files/CA_Carbon_Market Watch-Year_One_WebVersion.pdf.

15 U.S. Executive Office of the President, The President's Climate Action Plan, p. 6.

16 The new regulations are described at the EPA website, see U.S. Environmental Protection Agency, "Carbon Pollution Standards," available at http://www2.epa.gov/ carbon-pollution-standards (last accessed July 2014).

17 President Obama affirmed that commitment and outlined the specific steps toward operationalizing it in a February 17, 2014, speech. As reported in The New York Times, "The new regulations, to be drafted by the Environmental Protection Agency and the Transportation Department by March 2015 and completed a year later so they are in place before Mr. Obama leaves office, are the latest in a series of actions intended to cut back on greenhouse gases without the sort of comprehensive legislation the president failed to push through Congress in his first term." See Peter Baker and Coral Davenport, "Obama Orders New Efficiency for Big Trucks," The New York Times, February 18, 2014, available at http://www. nytimes.com/2014/02/19/us/politics/obama-torequest-new-rules-for-cutting-truck-pollution.html?_r=0. 
18 Full documentation on state-level RPS and EERS policies are provided at the DSIRE website, Database for State Initiatives for Renewables and Efficiency, "Resources," available at http://www.dsireusa.org/ (last accessed August 2014).

19 All RPS statistics in this paragraph are from Ibid.

20 Richard W. Caperton, "Renewable Energy Standards Deliver Affordable, Clean Power: Right-Wing Attacks on These Standards Are Misguided" (Washington: Center for American Progress, 2012), available at http://www. americanprogress.org/issues/green/report/2012/04/11/ $11397 /$ renewable-energy-standards-deliver-affordableclean-power/.

21 Bloomberg New Energy Finance and Business Council for Sustainable Energy, "Sustainable Energy in America 2013 Factbook," p. 59.

22 Figures are from Database for State Initiatives for Renewables and Efficiency, "Resources."

23 Details on alternative approaches to decoupling are described in Karlynn Cory, Toby Couture, and Claire Kreycik, "Feed-in Tariff Policy: Design, Implementation, and RPS Policy Interactions" (Golden, CO: National Renewable Energy Laboratory, 2009), available at http://www.nrel.gov/docs/fy09osti/45549.pdf. As compliments to decoupling policies, Hendricks and others identify unbundled rate structures, improved utility cost tests in ratemaking proceedings, and stronger penalties for noncompliance with efficiency standards, as effective measures to promote efficiency investments by utilities. For more information, see Hendricks, Kaufman, Berlin, Humble, Hundt, Kragie, and Waldron, "Cutting the Cost of Clean Energy 1.0."

24 Bloomberg New Energy Finance and Business Council for Sustainability, "Sustainable Energy in America 2013 Factbook," p. 68. ARRA efficiency spending accounted for another 22 percent of the 2010 total, according to this source.

25 Martin Kushler, Dan York, and Patti Witte, "Aligning Utility Interests with Energy Efficiency Objectives: A Review of Recent Efforts at Decoupling and Performance Incentives," (Washington, D.C.: American Council for an Energy Efficient Economy, 2006).

26 Cory, Couture, and Kreycik, "Feed-in Tariff Policy."

27 These issues are discussed at length with respect to the market for solar photovoltaic energy in J.P. Ross and Bracken Hendricks, "Developing State Solar Photovoltaic Markets: Riding the Wave to Clean Energy Independence" (Washington: Center for American Progress, 2008), available at http://votesolar.org/linked-docs/CAP_solar_ report.pdf. The potential opportunities for distributed solar energy and the challenge it poses for traditional utilities and regulators was discussed by the outgoing Chair of FERC Jon Wellinghoff as he left office in August 2013. An August 21, 2013, article in Greentech Media based on an interview with Wellinghoff begins "If anyone doubts that federal energy regulators are aware of the rapidly changing electricity landscape, they should talk to Jon Wellingtoff."The article quotes Wellinghoff as saying, "Rate structures need to be formulated in ways that fully recognize the costs and benefits of distributed resources. In many utility retail rates, a disproportionate amount of the fixed costs are recovered through a variable rate. This is problematic when a lot of people go to distributed generation." For more information, see Herman K. Trabish, "FERC Chair Jon Wellinghoff: Solar 'Is Going to Overtake Everything," Greentech Media, August 21, 2013, available at http:// www.greentechmedia.com/articles/read/ferc-chairwellinghoff-sees-a-solar-future-and-a-utility-of-thefuture?utm_source=Daily\&utm_medium=Headline\&utm _campaign=GTMDaily.
28 The utilities own power generation and maintain the transmission system. Also, the delivery of power is generally considered part of the overall process of generation and transmission. At the same time, again, there is a strong government presence in the operation of the grid through the regulation of the utilities.

29 American Public Power Association, "2014-15 Annual Directory \& Statistical Report" (2014), available at http://www.publicpower.org/files/PDFs/ USElectricUtilitylndustryStatistics.pdf.

30 Thus, in some parts of the country, electricity transmission and wholesale marketing is in fact provided directly by public agencies called Power Marketing Authorities. These are federal government agencies within the U.S. Department of Energy. In other parts of the country, the federal role in shaping investment decisions is more indirect, the result of Federal Energy Regulatory Commission oversight, and guided by Department of Energy planning processes and technical assistance.

31 For reports on the difficulties being encountered in trying to upgrade the grid, in particular to accommodate electricity generated by wind power in the eastern twothirds of the United States, see Matthew L. Wald, "Ideas to Bolster Power Grid Run Up Against System's Many Owners," The New York Times, July 13, 2013, available at http://www.nytimes.com/2013/07/13/us/ideas-tobolster-power-grid-run-up-against-the-systems-manyowners.html. The problem identified in the article is that different segments of the power grid are operated by an excessively large number of separate owners.

32 Hendricks, Kaufman, Berlin, Humble, Hundt, Kraigie, and Waldron, "Cutting the Cost of Clean Energy 1.0."

33 As discussed in James Heintz, Robert Pollin, and Heidi Garrett-Peltier, “How Infrastructure Spending Supports the U.S. Economy: Employment, Productivity, and Growth" (Amherst, MA: Political Economy Research Institute, 2009), p. 19, available at http://www.peri. umass.edu/fileadmin/pdf/other_publication_types/ green_economics/PERI_Infrastructure_Investments.

34 See lbid. for a discussion of these investment needs in the broader context of upgrading the U.S. infrastructure

35 U.S. General Services Administration, "FY 2012 Federal Real Property Report" (2012), available at http://www. gsa.gov/portal/mediald/179655/fileName/FY_2012 FRPP_intro_508.action; See also Director of Physical Infrastructure Issues David Wise, "Federal Real Property: Overreliance on Leasing Contributed to High-Risk Designation,"Testimony before the Subcommittee on Federal Financial Management, Government Information, Federal Services, and International Security, U.S. Senate Committee on Homeland Security and Government Affairs, August 4, 2011, available at http://www.gao.gov/ assets/130/126817.pdf.

36 Energy Independence and Security Act of 2007, Public Law 140, 110th Cong., 1st sess. (December 19, 2007) available at http://www.gpo.gov/fdsys/pkg/ PLAW-110publ140/html/PLAW-110publ140.htm

37 U.S. Department of Energy, "Energy Independence and Security Act of 2007: Major Provisions of Interest to Federal Energy Managers," available at http://www1. eere.energy.gov/femp/news/news detail.html?news id $=11683$ (accessed August 2014).

38 Energy Independence and Security Act of 2007, Public Law 140.

39 Ibid., section 432 (10) (B)

40 In addition to funding support from the American Recovery and Reinvestment Act of 2009, or ARRA, the Obama administration also strengthened the Energy 
Independence and Security Act of 2007, or EISA standards through Executive Order 13514, which mandated that all new construction and 15 percent of existing federal buildings meet Energy Star's "Guiding Principles for Federal Leadership in High Performance and Sustainable Buildings."

41 Chris Temper, Program Analyst of the Federal Energy Management Program, email correspondence with author, July 10, 2014

42 The Compliance Tracking System of the DOE shows just more than $\$ 3$ billion in implemented measures; however, according to our communications with the DOE, there is some lag in reporting implementation of evaluated measures, and there is also underreporting of implementation by agencies. See U.S. Department of Energy, "FEMP EISA 432 Compliance Tracking System," available at http://ctsedwweb.ee.doe.gov/CTSDataAnalysis/Default. aspx?ReturnUrl=\%2fCTSDataAnalysis\%2fReports\% 2fPublicAgencyReport_ProjectsByFiscalYear.aspx (last accessed July 2014).

43 Figures on number of projects and energy savings are from the EISA 432 Compliance Tracking System, "Projects by Fiscal Year," which is updated daily at Ibid. For the figures on dollar savings, see "Comprehensive Evaluation Findings" in the EISA 432 Compliance Tracking System, available at http://ctsedwweb.ee.doe. gov/CTSDataAnalysis/Reports/PublicAgencyReport ComprehensiveEvaluationFindings.aspx (last accessed July 2014).

44 Note that 0.2 Q-BTUs of energy savings have been reported, but reported values are about one-third of actual values, according to communications with $\mathrm{DOE}$ staff. Thus, the true measure may be closer to 0.6 quads, or 3.9 percent, of our recommended building energy savings by 2030 .

45 The cost per Q-BTU of the federal building efficiency estimates falls within the range of building energy efficiency investments we have detailed in Chapter 2. The FEMP EISA 432 Compliance Tracking System shows that, out of all evaluated projects, energy savings cost $\$ 22.92$ per Q-BTU - amounting to a $\$ 10.246$ billion cost of implementation for 0.447 Q-BTUs saved annually. Of the reported projects that have been initiated thus far the costs are $\$ 15.75$ per Q-BTU without financing costs, or \$23.07 per Q-BTU when we include finance costs.

46 Ucilla Wang, “U.S. Military's Big Plan for Renewable Energy Projects," Forbes, August 6, 2012, available at http://www.forbes.com/sites/uciliawang/2012/08/ 06/u-s-military-opens-up-16m-acres-for-renewableenergy-projects/.

47 National Defense Authorization Act for Fiscal Year 2010, Public Law 111-84, 111th Cong., 1st sess. (October 28 2009), available at http://www.gpo.gov/fdsys/pkg/ PLAW-111 publ84/pdf/PLAW-111 publ84.pdf.

48 Green Tech, “Top 10: Exciting New Developments in Energy," Energy Digital, December 17, 2012, available at http://www.energydigital.com/greentech/2073/ TOP-10:-Exciting-New-Developments-in-Energy.

49 Matthew Daly, "Obama to Feds: Boost Renewable Power 20 Percent," AP, December 5, 2013, available at http://bigstory.ap.org/article/obama-feds-boostrenewable-power-20-percent.

50 Fred Sissine, "Renewable Energy R\&D Funding History: A Comparison with Funding for Nuclear Energy, Fossil Energy, and Energy Efficiency R\&D" (Washington: Congressional Research Service, 2012), available at http://fas.org/sgp/crs/misc/RS22858.pdf.

51 In lbid. p. 2, Sissine notes that some funding for renewable energy $R \& D$ has been provided by the
Department of Defense, but this funding has been "on a much smaller scale" than the figures we are reporting that have come through the Department of Energy. The figures on the fiscal year 2013 "operating plan" - as well as the spending proposals passed in both the House and Senate, $\$ 1.3$ billion in the House and $\$ 1.7$ billion in the Senate-are reported in its December 5, 2013, report on federal R\&D funding for fiscal year 2013 by the Congressional Research Service. See John F. Sargent, "Federal Research and Development Funding: FY2013" (Washington: Congressional Research Service, 2013), pp. 29-30, available at http://www.fas.org/sgp/ $\mathrm{crs} / \mathrm{misc} / \mathrm{R} 42410 . \mathrm{pdf}$.

52 Bloomberg New Energy Finance and Business Council for Sustainable Energy, "Sustainable Energy in America 2013 Factbook," p. 21

53 Ibid., p. 22.

54 President Obama proposed a permanent extension of the PTC in his FY 2014 budget, but this provision did not pass Congress.

55 For details, see Database of State Incentives fo Renewables and Efficiency, "Home," available at http:// www.dsireusa.org/ (last accessed August 2014). For more information on the Production Tax Credit, see, Database of State Incentives for Renewables and Efficiency, "Renewable Electricity Production Tax Credit (PTC)," available at http://www.dsireusa.org/incentives/ incentive.cfm? Incentive_Code $=$ US13F\&re $=1$ \&ee $=1$ (las accessed August 2014); for more information on the Investment Tax Credit, see Database of State Incentives for Renewables and Efficiency, "Business Energy Investment Tax Credit (ITC)," available at http://dsireusa. org/incentives/incentive.cfm?Incentive_Code= US02F\&re=1\&ee=1 (last accessed July 2014).

56 Bloomberg New Energy Finance and Business Council for Sustainable Energy, "Sustainable Energy in America 2013 Factbook," p. 22

57 For a useful background survey of feed-in tariff policies in the United States at different levels of government in recent years, see Richard W. Caperton, Bracken Hendricks, John Lauer, and Courtney Hight, "CLEAN Contracts: Making Clean Local Energy Accessible Now" (Washington: Center for American Progress, 2011), available at http:// www.americanprogress.org/wp-content/uploads/ issues/2011/01/pdf/clean_contracts.pdf. As Caperton and others point out, another term for these policies in the U.S. context is "Clean Local Energy Accessible Now" or CLEAN contracts.

58 For example, the 2012 OECD economic report on Germany provides a favorable overall assessment of the impact of Germany's feed-in tariff policies while also suggesting the need for further policy innovations over time. The report found that these tariffs are generally well designed; they are transparent and predictable, thus fostering long-term investment, and are decreasing over time, thus encouraging innovation. Tariffs also vary across technologies; while this is potentially supporting non-mature but promising power sources more than others, it increases $\mathrm{CO}_{2}$-abatement costs for certain technologies to excessive levels. Given the relatively high costs of feed-in tariffs, efficiency improving adjustments to the system should be considered. It is thus welcome that the government revised the photovoltaic tariffs; it should continue to monitor the generosity of the feed-in tariffs and adjust them tightly in line with market developments. See Organisation for Economic Co-operation and Development "OECD Economic Surveys: Germany" (2012), available at http://www. keepeek.com/Digital-Asset-Management/oecd/ economics/oecd-economic-surveys-germany-2012 eco_surveys-deu-2012-en\#page1 
59 Cory, Couture, and Kreycik, "Feed-in Tariff Policy."

60 U.S. Energy Information Administration, “Feed-in Tariff A Policy Tool Encouraging Deployment of Renewable Electricity Technologies," May 30, 2013, available at http://www.eia.gov/todayinenergy/detail.cfm?id=11471.

61 The starting price is posted at the DSIRE website, Database of State Incentives for Renewables and Efficiency, "CALIFORNIA Incentives/Policies for Renewables and Efficiency," available at http://www. dsireusa.org/incentives/incentive.cfm? Incentive Code $=$ CA167F\&re $=0 \&$ \&ee $=0$ (last accessed July 2014). The California FIT's system of adjustment around this starting price was explained to us in detailed personal communication with Adam Schultz of the California Public Utilities Commission Renewable Energy Policy \& Procurement program, on July 9, 2013. We are grateful to Mr. Schultz's careful explanation of the California FIT program.

62 See U.S. Energy Information Administration, "Feed-in Tariff."

63 A "green bank" was part of the American Clean Energy and Security Act, passed by the House in 2009, and was re-introduced as the central feature of the Green Bank Security Act of 2014. For a summary, see Office of Congressman Chris Van Hollen, "FACT SHEET:The Green Bank Act of 2014," April 30, 2014, available at http:// vanhollen.house.gov/sites/vanhollen.house.gov/files/ 04-30-14_CVH_Green\%20Bank\%20Fact\%20Sheet.pdf.

64 Darren Samuelsohn and Darren Goode, "Cuts force Congress to get creative on energy," Politico, June 19, 2011, available at http://www.politico.com/news/ stories/0611/57322.html.

65 Caperton and Hendricks discuss in detail how launching a Green Bank financing facility in the United States can provide a proven, broadly popular approach to expanding clean energy financing opportunities. See Richard W. Caperton and Bracken Hendricks, "A Green Bank is the Right Tool for Jobs" (Washington: Center for American Progress, 2011), available at http://www. americanprogress.org/wp-content/uploads/issues/ 2011/09/pdf/green_bank.pdf.

66 Hendricks, Kaufman, Berlin, Humble, Hundt, Kragie, and Waldron, "Cutting the Cost of Clean Energy 1.0."

67 Conway Irwin, “Connecticut's Green Bank: A Model for Public-Private Renewables Partnerships?", Breaking Energy, July 2, 2013, available at http://breakingenergy. com/2013/07/02/connecticuts-green-bank-a-modelfor-public-private-renewables-partnerships/.

68 Further variations on the state-based framework are explored usefully in Ken Berlin, Reed Hundt, Mark Muro, and Devashree Saha,"State Clean Energy Finance Banks: New Investment Facilities for Clean Energy Deployment" (Washington: The Brookings Institution, 2012), available at http://www.brookings.edu/research/ papers/2012/09/12-state-energy-investment-muro.

69 Caperton makes similar arguments in his congressional testimony addressing the implications of the Solyndra case. For more information, see Richard W. Caperton, "Testimony on 'American Energy Initiative"' (Washington: Center for American Progress, 2012), available at http:// www.americanprogressaction.org/wp-content/uploads/ issues/2012/07/pdf/caperton_american_energy1.pdf.

70 Bloomberg New Energy Finance and Business Council for Sustainable Energy, "Sustainable Energy in America 2013 Factbook," p. 22
71 U.S. Department of Agriculture, A Brief History of the Rural Electric and Telephone Programs (1982), available at http://www.rurdev.usda.gov/rd/70th/rea-history.pdf.

72 Ibid.

73 U.S. Executive Office of the President, The President's Climate Action Plan.

74 Program level in 2015 budget, United States Department of Agriculture, "FY 2015 Budget Summary and Annual Performance Plan" (Washington, D.C.: USDA, 2014), available at http://www.obpa.usda.gov/ budsum/FY15budsum.pdf

75 This and other features of PACE financing are summarized at Database of State Incentives for Renewables and Efficiency, "Pace Financing," available at http://www. dsireusa.org/solar/solarpolicyguide/?id=26 (last accessed August 2014)

76 Database of State Incentives for Renewables and Efficiency, "Pace Financing Policies Map," http://dsireusa. org/documents/summarymaps/PACE_Financing_Map. pdf (last accessed August 2014).

77 Justin Gerdes, "California Launches Nation's Largest Clean Energy PACE Program," Forbes, September 28 2012, available at http://www.forbes.com/sites/ justingerdes/2012/09/28/california-launches-nationslargest-clean-energy-pace-program/.

78 Center for Sustainable Energy, “Frequently Asked Questions on PACE," available at http://energycenter.org/ policy/property-assessed-clean-energy-pace (last accessed August 2014).

79 For a useful overview of these financing options for clean energy projects, see Felix Mormann and Dan Reicher, "How to Make Renewable Energy Competitive," The New York Times, June 1, 2012, available at http:// www.nytimes.com/2012/06/02/opinion/how-to-makerenewable-energy-competitive.html?gwh=305717709 CA7D5518F275D47773C1D3F\&gwt=pay\&assetType $=0$ pinion; The Pew Charitable Trusts, “Expanding Investment Opportunities for Clean Energy: Master Limited Partnerships and Real Estate Investment Trusts" (2013), available by request from www.PewTrusts.org. For a brief and useful description of MLP financing, see Richard W. Caperton, "Master of My Domain: What the Heck are Master Limited Partnerships And How Could They Boost Clean Energy?" ClimateProgress, June 8 2012, available at http://thinkprogress.org/climate/ 2012/06/08/496621/master-of-my-domain-what-theheck-are-master-limited-partnerships-and-can-theyboost-clean-energy/.

80 The Pew Charitable Trusts, “Expanding Investment Opportunities for Clean Energy."

81 Office of Sen. Christopher Coons, "Bipartisan support for Master Limited Partnerships Parity Act grows," Press release, November 12, 2013, available at http://www. coons.senate.gov/newsroom/releases/release/ bipartisan-support-for-master-limited-partnershipsparity-act-grows.

82 The Pew Charitable Trusts, “Expanding Investment Opportunities for Clean Energy."

83 Jesse Morris, “How Real Estate Investment Trusts Can Change the Clean Energy Industry," Rocky Mountain Institute Blog, June 5, 2013, available at http://blog.rmi. org/blog_06_05_2013_how_real_estate_investment_ trusts_can_change_the_clean_energy_industry. 
84 Building from the seminal work of Ruttan (2006), Pollin (2012) describes complementarities with Pentagonbased industrial policies in critical areas such as jet aviation and the Internet and the lessons that can be extracted from those previous experiences in supporting the rapid expansion of a viable renewable energy sector. Pollin summarizes the findings from Ruttan as follows: “The key idea in Ruttan's work ... is how military-based R\&D and procurement operated in combination to create conditions for major technologies to develop. That is, R\&D alone would not have brought new technologies to the point of commercial success. It was also necessary that, over the course of decades, the military provided a guaranteed market for new technologies. This enabled the technologies to incubate over time without having to prematurely face the test of the private market," (2012, p. 9). For more information, see Vernon W. Ruttan, Is War Necessary for Economic Growth? Military Procurement and Technology Development (New York: Oxford University Press, 2006); and Pollin, "Public Policy, Community Ownership and Clean Energy.."

85 Bloomberg New Energy Finance and Business Council for Sustainable Energy, "Sustainable Energy in America 2013 Factbook," p. 10

86 Robert Pollin, James Heintz, and Heidi Garrett-Peltier, "The Economic Benefits of Investing in Clean Energy: How the economic stimulus program and new legislation can boost U.S. economic growth and employment" (Washington: Center for American Progress, 2009), available at http://www.peri.umass.edu/fileadmin/pdf/ other_publication types/green economics/ economic benefits/economic benefits.PDF.

87 Bureau of the Census, Federal Aid to States for Fiscal Year 2010 (U.S. Department of Commerce, 2011), Figure 2 available at http://www.census.gov/prod/2011pubs/ fas-10.pdf

88 U.S. Department of Energy, Performance and Accountability Report: Fiscal Year 2002 (2003), available at http://www.paducaheic.com/media/39813/ lb09900-0167-grc01.pdf.

89 Ibid.

90 John Lynch and Seth Kirshenberg, "Economic Transition By The Energy-Impacted Communities" (Washington: U.S. Department of Energy, 2000), available at http:// www.energyca.org/PDF/EDArticle.PDF; U.S. Department of Energy, Performance and Accountability Report: Fiscal Year 2002.

91 Lynch and Kirshenberg, "Economic Transition By The Energy-Impacted Communities."

92 Ibid.

93 U.S. Department of Energy, “U.S. Departments of Energy and Interior Announce Site for Solar Energy Demonstration Projects in the Nevada Desert," Press release, July 8,2010 , available at http://energy.gov/ articles/us-departments-energy-and-interior-announcesite-solar-energy-demonstration-projects-nevada.

94 Energy Independence and Security Act of 2007, Public Law 140.
95 The DOL study found, in particular, that "the impact of the Recovery Act Green Jobs training program has been limited in terms of reported employment outcomes... entered employment and retention results are far lower than planned." For more information, see U.S. Department of Labor, Recovery Act: Green Jobs Program Reports Limited Success in Meeting Employment and Retention Goals as of June 30, 2012 (2012), p. 29, available at http://www.oig.dol.gov/public/reports/oa/2013/18-13001-03-390.pdf.

96 See also the reports by the Congressional Research Service and the U.S. Government Accountability Office (2013), which were also mixed in their assessments. See David H. Bradley, "The Workforce Investment Act and the One-Stop Delivery System" (Washington: Congressional Research Service, 2013), available at http://fas.org/sgp/crs/misc/R41135.pdf; and U.S. Government Accountability Office, "Employment and Training: Labor's Green Jobs Efforts Highlight Challenges of Targeted Training Programs for Emerging Industries," GAO-13-555, Report to Congressional Requestors, June 2013, available at http://www.gao.gov/assets/660/ 655331.pdf.

97 U.S. Bureau of Labor Statistics, Employment, Hours, and Earnings from the Current Employment Statistics survey (U.S. Department of Commerce, 2014).

98 These figures come from the establishment data from U.S. Bureau of Labor Statistics, "Table B-1. Employees on nonfarm payrolls by industry sector and selected industry detail" (U.S. Department of Commerce, 2014), available at http://www.bls.gov/news.release/empsit. t17.htm. Note that these are the preliminary, non-seasonally adjusted estimates from the BLS as of June 2014.

99 J.F. Hornbeck, "Trade Adjustment Assistance (TAA) and Its Role in U.S. Trade Policy" (Washington: Congressional Research Service, 2013), available at http://fas.org/sgp/ $\mathrm{crs} / \mathrm{misc} /$ R41922.pdf.

100 U.S. Congressional Budget Office, “Unemployment Compensation and Trade Adjustment Assistance for Workers" (2012), available at http://www.cbo.gov/ sites/default/files/cbofiles/attachments/43100 UnemploymentCompensation.pdf.

101 Ibid. U.S. Executive Office of the President, The Budget for Fiscal Year 2015 (2014), available at http://www. whitehouse.gov/sites/default/files/omb/budget/ fy2015/assets/lab.pdf.

102 Sperling's proposal builds from the research found in Lori Kletzer and Robert Litan, "A Prescription to Relieve Worker Anxiety" (Washington: The Brookings Institution, 2001), available at http://www.brookings.edu/ /media/ research/files/papers/2001/3/labor\%20kletzer/pb73.pdf.

103 Tony Mazzocchi, "A Superfund for Workers," Earth Island Journal 9 (1) (1993): 40.

104 These and related issues around a full employment program for the United States are examined in Robert Pollin, Back to Full Employment (Cambridge, MA: MIT Press, 2012). 
Appendices 


\section{Appendix 1: Public transportation and energy efficiency}

This appendix details the overall costs and benefits of expanding public transportation usage in the United States by a substantial amount. Among other topics, we show here how we derive the estimate that a level of investment between $\$ 130$ billion and $\$ 210$ billion over 20 years - or between $\$ 6.5$ billion and $\$ 10.5$ billion per year-could expand the ridership of the public bus transportation system by as much as 85 percent.

\section{Strategies for increasing public transportation use}

As we see in Table A1.1, as of 2011, rail transportation was 25 percent more efficient than cars, at 2,513 BTUs per passenger mile versus 3,364 BTUs for cars. As such, increases in rail transport could have an immediate environmental benefit. However, with buses the level of energy consumption is 4,240 BTUs per passenger, or about 26 percent less efficient than cars. As is clear from Table A1.1, the problem here is that the average load factor for buses is 8.9 passengers per vehicle. This contrasts with the load factor for transit rail, which averages 27 passengers per vehicle. That is, the load factor for buses is about one-third that for rail.

TABLE A1.1

U.S. energy consumption in 2011 through alternative transportation modes

\begin{tabular}{lcccc}
\hline & $\begin{array}{c}\text { Load factor } \\
\text { (persons/vehicle) }\end{array}$ & $\begin{array}{c}\text { BTU per } \\
\text { vehicle mile }\end{array}$ & $\begin{array}{c}\text { BTU per } \\
\text { passenger mile }\end{array}$ & $\begin{array}{c}\text { Energy use } \\
\text { in trillion BTU }\end{array}$ \\
\hline Cars & 1.6 & 5,214 & 3,364 & 8,831 \\
Rail & 27.1 & 68,217 & $\begin{array}{c}2,513 \\
(25 \% \text { more efficient than } \\
\text { cars })\end{array}$ & 91.9 \\
Buses (transit) & 8.9 & $\begin{array}{c}4,240 \\
\text { (26\% less efficient } \\
\text { than cars) }\end{array}$ & 95.3 \\
& & & 37,718 &
\end{tabular}

Source: Stacy C. Davis, Susan W. Diegel, and Robert G. Boundy, Transportation Energy Data Book: Edition 32 (Knoxville, TN: Oak Ridge National Laboratory, 2013), table 2.12, available at http://cta.ornl.gov/data/tedb32/Edition32_Chapter02.pdf. 
If buses could improve their load factor by about 70 percent to 15 passengers per vehicle, the energy intensity of buses would be roughly equal to that for rail, at about 2,500 BTUs per passenger mile. This would then also mean that the energy intensity for buses would be about 25 percent below that for cars. Further, any shift in ridership in favor of bus transit relative to cars would also generate additional energy efficiency savings through the reduction in road congestion.

\section{Increasing load factor in buses}

At present, the level of U.S. public-transportation usage is very low. On average, U.S. households spend roughly 95 percent of their total transportation budget on private cars as opposed to public transportation. These figures even apply, on average, to people whose family income places them within the lowest 20 percent income bracket - that is, among families for whom transportation spending represents a significant 16 percent share of their total household expenditures. ${ }^{1}$

There are two main factors influencing the lack of ridership on buses-inconvenience, most importantly, but also price. This conclusion emerges, for example, out of a 2001 survey by Giuliano, $\mathrm{Hu}$ and $\mathrm{Lee}^{2}$ that focused on the transportation needs of low-income people in particular. Not surprisingly, the survey found that public transportation is consistently much less convenient than driving-access is bad, off-peak-hours service is limited, and transferring is difficult. Together, this makes public transportation especially impractical for low-income people, who, as part of their regular routine, often need to commute between multiple jobs, as well as transport children to child care and school. Among those who were using public transportation, a significant share did also say that it is expensive. Such survey evidence suggests that ridership could be expected to rise substantially if both the convenience and price issues could be addressed with reasonable success.

These conclusions are also supported through a careful econometric study of the experiences in Houston and San Diego, where transit ridership grew dramatically throughout the 1980s. According to the authors of the study, Kain and Liu, ${ }^{3}$ Houston's METRO increased its annual passenger boardings by 85 percent, while San Diego's MTS increased its ridership by 49 percent. Kain and Liu emphasized that the central finding of their research was that "the large increases in transit use achieved by Houston and San Diego transit providers were caused principally by large service increases and fare reductions." They also found that the same experience characterized increased boardings in a number of other urban areas, including Portland, Los Angeles, and Atlanta. In all cases, they note that the service improvements and fare reductions were made possible by large subsidies from federal and state governments. ${ }^{4}$ 
Kain and Liu test the reliability of their models using various elasticities both for bus and rail miles, as well as fares - that is, for every percentage point improvement in convenience or reduction in fare, how much did bus ridership increase? Their statistical models had strong predictive power when they worked with these elasticities:

- Bus ridership increases by 7 percent for every 10 percent expansion in bus service.

- Bus ridership increases by 3 percent for every 10 percent reduction in fares.

We can work with these figures to generate rough estimates of the costs needed to increase the average ridership in buses by 70 percent-the amount needed for bus transportation to become equal to rail transportation in terms of BTU levels per passenger mile of travel.

\section{Doubling bus line availability}

According to the Kain and Liu elasticity analysis, doubling the availability of bus lines would itself increase ridership by 70 percent. What would be involved in doubling the level of bus service throughout the United States today? As of 2011, there were 69,700 transit buses operating throughout the United States. ${ }^{5}$ To double service would therefore first entail getting a total of about 140,000 transit buses into operation.

As of 2010, the average cost of manufacturing a bus in the United States was about $\$ 425,000$. The level of investment needed to double the total number of buses in service would then be $\$ 29.7$ billion, which we can round to $\$ 30$ billion. Of course, these expenditures would be in excess of those needed to replace the existing fleet when older buses become inoperable. But these replacement expenses would be included in the depreciation allowance budgets of the relevant transit authorities. Focusing only on the net increase in investments in buses, a program to double the level of service over 20 years would require about $\$ 1.5$ billion per year in additional investments.

In addition to the investments needed to manufacture new buses, we would also have to take account of the additional costs of operating the 70,000 new buses. To estimate these operating costs, let us assume that the total compensation, including wages and benefits, for one full-time, 52-weeks-per-year driver is $\$ 60,000$. Then, we assume fuel, maintenance, administration, and overhead is another $\$ 100,000$ per year per bus. That means a total of $\$ 160,000$ per year to operate one bus for a full 
year. For 70,000 buses, that comes to about $\$ 11$ billion per year. Of course, those costs would be stretched out as the new buses came on line. The average cost over the 20 years for an incremental rollout would be about $\$ 5$ billion per year.

Overall, then, including both new capital investments and operating costs, the costs of doubling the availability of bus service in the United States within 20 years would be about $\$ 6.5$ billion per year over the 20-year period, or about $\$ 130$ billion cumulatively. With this level of investment, and working from the elasticity estimate of Kain and Liu - that a 10 percent improvement in service would yield a 7 percent increase in ridership - we can conclude that a doubling of service, or a 100 percent increase, would itself be sufficient to increase ridership by 70 percent. That is, a doubling of the availability of bus service would itself increase average ridership from 9 to 15 passengers per bus. This would raise the energy efficiency per passenger mile traveled to the point where it equals that of rail transit and is 25 percent greater than that of private cars.

\section{Reducing fares}

In addition to investing in dramatically increasing the convenience of bus service, let us further consider the impact on both costs and ridership of lowering bus fares. In 2010 there were 5.2 billion "unlinked transit passenger trips" by bus. ${ }^{6}$ The average (median) bus fare in 2010 was about $\$ 1.50$. That means that the total gross revenue from fares was $\$ 7.8$ billion, which we can round to $\$ 8$ billion.

Now let us assume that, in the interests of continuing to increase bus ridership to raise energy efficiency standards, bus fares were cut by 50 percent, to an average of 75 cents per fare. According to the Kain and Liu elasticity estimate in this casethat a 10 percent reduction in fares would generate a 3 percent increase in ridership - the 50 percent cut in fares would produce another 15 percent increase in ridership. The average ridership would now be about 17.25 people per bus. In terms of energy efficiency, this level of average ridership would push BTU per passenger mile 35 percent below that for automobiles and even 13 percent lower than for commuter trains.

In terms of costs, the 50 percent fare cut would mean $\$ 4$ billion per year in lost revenue. Over 20 years, that would amount to a total of $\$ 80$ billion. At the same time, it is important to note that one could obtain a comparable impact on ridership through increasing the price of automobile travel through higher gasoline prices, rather than only cutting the fares on buses. Moreover, when bus ridership rises through increases in gasoline prices, the out-of-pocket costs for either consumers 
or governments - as the source of financing for public-transit agencies-will be small. Consumers would of course have to pay higher gasoline prices at the pump. But they would also have the option to use a cheap and convenient public transportation system. The costs to government agencies would actually fall, even if they had also cut fares, because they will make back their revenue through an increased volume of bus riders.

If we consider maximum figures for doubling bus service and lowering costs directly through cutting bus fares in half, this adds to a total of about $\$ 210$ billion through 2030 , or about $\$ 10$ billion per year. However, if the relative price of public transit were to fall through an increase in gasoline prices, the total costs of achieving this expansion in public transit would fall significantly, perhaps to as low as $\$ 130$ billion, or $\$ 6.5$ billion per year. In terms of energy efficiency and environmental impacts, the result of this level of investment would be to increase bus ridership by about 85 percent. This, in turn, would lower consumption per passenger mile traveled by 37 percent.

\section{Total costs}

The total costs of increasing average bus ridership from 9 to 17.25 passengersan increase of over 90 percent $^{7}$ — would be about $\$ 210$ billion total, or about $\$ 10$ billion per year. Again, though, if the relative price of public transit were to fall through an increase in fossil fuel prices, the total costs of achieving this expansion in public transit would fall to $\$ 130$ billion, or $\$ 6.5$ billion per year through 2030 .

\section{Additional benefits}

There are other important benefits that would accrue through expanding public transportation ridership within the range that we are discussing, by about 90 percent.

\section{Reducing living expenses for low-income households}

At least for urban centers throughout the United States, it is reasonable to assume that doubling the provision of bus service coupled with a major reduction in fares could lead to an increase in public-transportation use to the point where it meets between 25 percent and 50 percent of all transportation needs for lower-income households. This range is currently equal to the proportion of workers who use public transportation to commute to work in cities that already have well-functioning public transit systems, including New York City; Washington, DC; Boston; San Francisco; and Chicago. 
If low-income households did use public transportation to this extent, the impact on their living standard would be significant. In particular, low-income households that would be in a position to replace one car with public transit would see their annual transportation expenditures fall by roughly $\$ 2,000$. This would represent a reduction in their total living expenses of about 10 percent-they would have $\$ 2,000$ more to spend on meeting their basic needs, covering their debts, or enjoying some modest discretionary spending. ${ }^{8}$

\section{Supporting U.S. manufacturing}

A program to double the number of buses operating in the United States-to expand the total supply of operating buses from its current level of about 70,000 to 140,000 — could produce a significant boost to U.S. manufacturing, especially, of course, for those firms that are already producing passenger buses. If we assume, for example, that all the new buses would be produced by the current U.S. manufacturers, this program would represent an increase in annual sales of nearly 40 percent. It would also increase the level of manufacturing employment by about 7,500 jobs per year and overall employment by about 20,000 jobs per year. These sales and employment benefits would also increase proportionally if the program to expand bus service proceeded more rapidly than over a 20 -year roll-out period. ${ }^{9}$

\section{Employment effects of expanding public transportation}

In Tables A1.2 and A1.3, we present calculations through which we estimate the employment effects of doubling public-bus transportation in the United States over a 20-year period. Table A1.2 shows employment creation in bus transportation per \$1 million in expenditures, both for capital expenditures to increase the number of buses in operation, as well as the employment generated by operations and maintenance of this expanded level of bus service. Table A1.3 then shows the results of $\$ 6.5$ billion per year in additional expenditures on both new capital equipment and on operations and maintenance in bus service. This is the amount we have calculated would be required to expand bus service in the United States over a 20-year period. As we see from Table A1.3, this level of expenditure would generate about 157,000 jobs per year. 
TABLE A1.2

Employment creation through investments in public transportation

Job Creation per $\$ 1$ million in expenditures

\begin{tabular}{lcccc}
\hline & $\begin{array}{c}\text { Direct Jobs } \\
\text { per \$1 million }\end{array}$ & $\begin{array}{c}\text { Indirect Jobs } \\
\text { per \$1 million }\end{array}$ & $\begin{array}{c}\text { Induced Jobs } \\
\text { per \$1 million }\end{array}$ & $\begin{array}{c}\text { Total Jobs } \\
\text { per \$1 million }\end{array}$ \\
\hline $\begin{array}{l}\text { Capital expenditures in } \\
\text { public transportation }\end{array}$ & 4.9 & 4.2 & 3.6 & 12.7 \\
$\begin{array}{l}\text { Operations and } \\
\text { maintenance in public } \\
\text { transportation }\end{array}$ & 17.2 & 2.5 & 7.9 & 27.6 \\
$\begin{array}{l}\text { Source: See Appendix } 3 . \\
\text { S. }\end{array}$ & & & & \\
\end{tabular}

TABLE A1.3

Employment creation through doubling public bus transportation availability in 20 years

\begin{tabular}{lccc}
\hline & $\begin{array}{c}\text { Capital } \\
\text { expenditures }\end{array}$ & $\begin{array}{c}\text { Operations and } \\
\text { maintenance }\end{array}$ & Totals \\
\hline $\begin{array}{l}\text { Total jobs per } \$ 1 \text { million } \\
\text { in expenditure }\end{array}$ & 12.7 & 27.6 & 40.3 \\
$\begin{array}{l}\text { Expenditures } \\
\text { over 20 years }\end{array}$ & $\$ 30$ billion & $\$ 100$ billion & $\$ 130$ billion \\
$\begin{array}{l}\text { Employment over 20 } \\
\text { years (total job years } \\
\text { rows } 1 \times 2)\end{array}$ & 381,000 & 2.8 million & 3.2 million \\
$\begin{array}{l}\text { Average expenditures } \\
\text { per year (= row 2/20) }\end{array}$ & $\$ 1.5$ billion & & \\
$\begin{array}{l}\text { Jobs per year over 20 } \\
\text { years }(=\text { row 3/20) }\end{array}$ & 19,000 & $\$ 5$ billion & 157,000 \\
\hline
\end{tabular}

Source: See Appendix 3.

\section{Expanding public freight and rail systems}

By 2035 demand for freight rail transportation is expected to double..$^{10}$ Maintaining adequate infrastructure is essential if freight rail is to continue to provide a more environmentally benign alternative to long-distance trucking. Intercity passenger rail-mostly trains operated by Amtrak — currently links more than 500 cities nationwide and provides a viable alternative to air and road transport. ${ }^{11}$ Insufficient capital investment in freight and intercity rail would compromise the future contributions of railroads to the U.S. economy. In turn, these investment gaps would slow down the transition to a clean-energy economy. 
Unlike road transportation, rail infrastructure is largely financed by private companies. Since railroads were deregulated in the late 1970s, securing the funds for ongoing capital improvements has been a challenge. It is unclear to what extent railroad companies will be able to finance future fixed capital requirements from ongoing revenues. ${ }^{12}$ If railroads cannot finance sufficient capital improvements, the growth in demand for rail services would shift onto the road system. This will in turn bring increased congestion and road-maintenance costs, as well as increasing greenhouse gas emissions.

A 2007 study by the Association of American Railroads projects that infrastructure investment in the range of $\$ 150$ billion over the next 30 years will be needed to be able to meet the projected level of demand. ${ }^{13}$ This translates into a capital investment need of about $\$ 5$ billion per year. ${ }^{14}$

In addition to the infrastructure investment expenditures over the next 30 years, we would also have to take account of the need for operating expenses. But we will need to incorporate this factor in the broader framework of how we handle ongoing operating costs of all new investment projects, against the initial capital investment expenditures. 


\section{Appendix 2: Auto fuel-economy standards and energy consumption}

The figure we need to estimate in this appendix is the likely average fuel-efficiency level for the entire U.S. auto fleet by 2030 . We derive that estimated figure as follows:

1. Following the 2011 agreement between the Obama administration and the major automakers in the United States, the fuel-economy standard for new cars in the United States will be $54.5 \mathrm{mpg}$ by 2025 . This is a near doubling of the standard for 2010 of $29.2 \mathrm{mpg}$.

2. For our purposes, however, the key figure is not what the fuel-economy level will be for new cars only, but rather for the entire fleet of LDVs operating in the United States. To estimate that key figure, we must first estimate the age distribution of LDVs in operation in the United States. A 2006 study by the National Automobile Dealers Association, or NADA, estimated the age range for all vehicles as of 2001. We see this in Table A2.1 below.

3. This age distribution will have varied between 2001 and the present, given that the average age of LDVs in operation increased from 8.9 years to 10.8 years from 2001 to 2011 . However, a significant factor in this increasing average age was that consumers reduced their new auto purchases during the Great Recession and subsequent weak economic recovery. Especially given that LDVs will have been making major gains in fuel efficiency between now and 2030, it is reasonable to assume that by 2030 the age distribution of vehicles will revert back to approximately the 2001 pattern, as reported by NADA.

4. Based on the NADA age distribution figures of the U.S. auto fleet, we can estimate the average level of fuel economy for the entire 2030 fleet following the calculations shown in Table A2.2. We begin in this table by showing in column 1 the distribution of the full fleet of LDVs in the U.S. average age range for LDVs as of 2001 from the NADA report. That then enables us to establish a midpoint value for these age ranges in column 2 . We assume the midpoint figure for cars older than 10 years to be 15 years. This is the age figure that would enable the overall average age of the fleet to be the actual 2001 figure of 8.9 years.
TABLE A2.1

Age range for entire U.S. auto fleet in 2001

\begin{tabular}{lc}
\hline $\begin{array}{l}\text { Age range } \\
\text { (years) }\end{array}$ & Percent of fleet \\
\hline $0-2$ & 13.5 \\
$3-6$ & 25.8 \\
$7-10$ & 22.3 \\
$10+$ & 38.3
\end{tabular}

Source: National Automobile Dealers Association, "NADA Data"(2002), p. 16. 
TABLE A2.2

Calculations for estimating the average fuel economy level for U.S. light-duty vehicles as of 2030

\begin{tabular}{lcccc}
\hline $\begin{array}{l}\text { 1. Age range } \\
\text { for light-duty } \\
\text { vehicles, or } \\
\text { LDVs (years) }\end{array}$ & $\begin{array}{c}\text { 2. Midpoint } \\
\text { for age } \\
\text { range (years) }\end{array}$ & $\begin{array}{c}\text { 3. Percent of total } \\
\text { fleet in age range }\end{array}$ & $\begin{array}{c}\text { 4. Fuel economy } \\
\text { level for age } \\
\text { range (mpg) }\end{array}$ & $\begin{array}{c}\text { 5. Calculation for } \\
\text { weighted average of } \\
\text { overall fuel economy } \\
\text { level (= column } 3 \times \\
\text { column }\end{array}$ \\
\hline $0-2$ & 1 & 13.5 & 54.5 & 7.4 \\
$3-6$ & 4.5 & 25.8 & 54.5 & 14.1 \\
$7-10$ & 8.5 & 22.3 & 35.9 & 8.0 \\
$10+$ & 15 & 38.3 & 33.8 & 12.9 \\
& & & & 42.4 mpg $=$ Summation \\
& & & & $\begin{array}{c}\text { of weighted average } \\
\text { figures in column } 5\end{array}$
\end{tabular}

Source: Figures derived as discussed in text, based on Table A2.1 data.

5. From these midpoint figures in column 2, we can establish the fuel-economy standard for cars in that range, working backward from 2030. Thus, for cars that are both 1.5 years or 4.5 years old in 2030, the applicable fuel-economy standard is the 2025 standard of $54.5 \mathrm{mpg}$. For cars that are 8.5 years old, the applicable standard is the 2020 figure of $35.9 \mathrm{mpg}$. For cars that are 15 years old, the applicable standard is that for 2016 of $33.8 \mathrm{mpg}$.

6. Based on these figures, we can derive a weighted average for fuel economy for the overall fleet in 2030. We show those calculations in column 5. The result, as we see at the bottom of column 5 , is that the weighted average fuel-economy level for the entire fleet in 2030 would be $42.4 \mathrm{mpg}$.

7. This average fuel-economy standard of $42.4 \mathrm{mpg}$ is 78 percent of the mandated standard for new cars in 2030 of $54.5 \mathrm{mpg}$. It is significant to observe that we obtain virtually the same percentage in the ratio of actual fuel-economy level to mandated level with the figures for 2010 . Thus, the actual average fuel-economy level for the U.S. fleet in 2010 was $23.3 \mathrm{mpg}$, while the mandated level for new cars was $29.2 \mathrm{mpg} .{ }^{15}$ In this case, then, the actual level was 80 percent of the mandated level.

8. Based on these calculations, we can also estimate the relationship between the overall level of fuel economy for 2030 under the EIA Reference case. The EIA reports that under its 2030 Reference case, the mandated fuel-economy standard 
for new cars will be $35.9 \mathrm{mpg}$. If we allow that the actual fuel-economy level for the full fleet will be approximately 80 percent of this figure, that implies that the actual average fuel-economy level for LDVs in the 2030 Reference case would be $28.7 \mathrm{mpg}$.

9. As such, raising the mandated fuel-economy standard for 2030 from $35.9 \mathrm{mpg}$ to $54.5 \mathrm{mpg}$ will imply that the average fuel-economy level for all LDV's in 2030 will rise from $28.7 \mathrm{mpg}$ to $42.4 \mathrm{mpg}$. This is a 32 percent reduction in fuel consumption in 2030 relative to the EIA Reference case.

10.Under the EIA 2030 Reference case, the level of energy consumption with LDVs is estimated at 15.1 Q-BTUs. If we assume that the full LDV fleet is able to reduce fuel consumption by 32 percent relative to the EIA Reference case-an improvement from $28.7 \mathrm{mpg}$ to $42.4 \mathrm{mpg}$ - that then implies that energy consumption from LDV use will also fall by 32 percent, to about 10 Q-BTUs.

The overall conclusion is that the rise in the mandated fuel-efficiency standard for new cars to $54.5 \mathrm{mpg}$ by 2025 implies that there will be a savings of approximately 5 Q-BTUs in energy consumption in the operations of LDVs by 2030. 


\section{Appendix 3: Explanation of the ElA's Extended Policies case}

As discussed in the main text of Chapter 5, we developed the Aggressive Reference case using the EIA's Extended Policies side-case as our baseline. In this appendix, we provide a detailed description of the Extended Policies case beyond the brief discussion provided in the main text of Chapter 5.

The clearest way to understand the Extended Policies case is in comparison with the Reference case. The following passage, paraphrased from the EIA's 2012 Annual Energy Outlook, ${ }^{16}$ is useful here:

The ... Reference Case is best described as a "current laws and regulations" case, because it generally assumes that existing laws and regulations will remain unchanged throughout the projection period, unless the legislation establishing them sets a sunset date or specifies how they will change. The Reference Case often serves as a starting point for the analysis of proposed legislative or regulatory change. But we also need to consider additional scenarios. These include the following situations:

- Laws or regulations that have a history of being extended beyond their legislated sunset dates. Examples include the various tax credits for renewable fuels and technologies, which have been extended with or without modifications several times since their initial implementation.

- Laws or regulations that call for the periodic updating of initial specifications. Examples include appliance efficiency standards issued by the U.S. Department of Energy (DOE), and CAFE and greenhouse gas (GHG) emissions standards for vehicles issued by the National Highway Traffic Safety Administration (NHTSA) and the U.S. Environmental Protection Agency (EPA).

- Laws or regulations that allow or require the appropriate regulatory agency to issue new or revised regulations under certain conditions. Examples include the numerous provisions of the Clean Air Act that require the EPA to issue or revise regulations if it finds that an environmental quality target is not being met. 
The EIA developed both the Extended Policies case and the related No Sunset case to provide some insight into the sensitivity of results to scenarios in which existing policies do not sunset. These two cases incorporate all the assumptions from the 2030 Reference case, except as identified below. Changes from the Reference case assumptions in these cases include the following.

No Sunset case $^{17}$

- Extension through 2035 of the Production Tax Credit, or PTC, for cellulosic biofuels of up to $\$ 1.01$ per gallon (set to expire at the end of 2012)

- Indefinite extension of tax credits for renewable energy sources in the utility, industrial, and buildings sectors or for energy-efficient equipment in the buildings sector, including: the PTC of 2.2 cents per kilowatt-hour, or the 30-percent investment tax credit, or ITC, available for wind, geothermal, biomass, hydroelectric, and landfill gas resources, currently set to expire at the end of 2012 for wind and 2013 for the other eligible resources

- Indefinite 30-percent extension for a 30-percent ITC for solar power investment that is scheduled to revert to a 10-percent credit in 2016

- Indefinite extension of: the buildings sector's tax credits for the purchase of energy-efficient equipment, including photovoltaics, or PV, in new houses, scheduled to end in 2011 or 2016 as prescribed by current law; the business ITCs for commercial-sector generation technologies and geothermal heat pumps, scheduled to expire in 2016; and the business ITC for solar systems, to remain at 30 percent instead of reverting to 10 percent

- Extension through 2035 of the industrial sector's ITC for combined heat and power, or CHP, that ends in 2016 in the AEO2012 Reference case

\section{Extended Policies case ${ }^{18}$}

The Extended Policies Case includes additional updates in federal equipment efficiency standards that were not considered in the Reference case or No Sunset case. Residential end-use technologies subject to updated standards are not eligible for tax credits in addition to the standards. Also, the PTC for cellulosic 
biofuels beyond 2012 is not included because the renewable fuel standard, or RFS, program that is already included in the 2030 Reference case tends to be the binding driver of cellulosic biofuels use.

Other than these exceptions, the Extended Policies case adopts the same assumptions as the No Sunset case, plus the following:

- Federal equipment efficiency standards are updated at periodic intervals, consistent with the provisions in the existing law, with the levels based on ENERGY STAR specifications, or Federal Energy Management Program, or FEMP, purchasing guidelines for federal agencies. Standards are also introduced for products that are not currently subject to federal efficiency standards.

- Updated federal residential and commercial building energy codes reach 30-percent improvement in 2020 relative to the 2006 International Energy Conservation Code in the residential sector and the American Society of Heating, Refrigerating and Air-Conditioning Engineers Building Energy Code 90.1-2004 in the commercial sector. Two subsequent rounds in 2023 and 2026 each add an assumed 5 percent incremental improvement to building energy codes.

- The equipment standards and building codes assumed for the Extended Policies case are meant to illustrate the potential effects of these policies on energy consumption for buildings. No cost-benefit analysis or evaluation of impacts on consumer welfare was completed in developing the assumptions. Likewise, no technical feasibility analysis was conducted, although standards were not allowed to exceed "maximum technologically feasible" levels described in DOE's technical support documents.

\section{Impact of Extended Policies case on energy consumption}

The changes made to Reference case assumptions in the No Sunset and Extended Policies cases generally lead to lower estimates for overall energy consumption, increased use of renewable fuels, particularly for electricity generation, and reduced energy-related emissions of $\mathrm{CO}_{2}$. Because the Extended Policies case includes most of the assumptions in the No Sunset case but adds others, the effects of the Extended Policies case tend to be greater than those in the No Sunset case.

The results of the Reference, No Sunset, and Extended Policies cases are presented in Table D5 of the EIA's 2012 Annual Energy Outlook. We see there that overall energy consumption is about 6 Q-BTUs lower in the Extended Policies case than 
in the Reference case. The results are shown for years 2025 and 2035. In the earlier year, the Extended Policies case results in 99.11 Q-BTUs as compared to 101.99 in the Reference case. By 2035 the Extended Policies case results in consumption of 100.79 Q-BTUs, as compared to 106.93 in the Reference case. If we assume that the 2030 level of energy consumption is the midpoint between 2025 and 2035, then the Extended Policies case would yield 100.0 Q-BTUs in 2030.

$\mathrm{CO}_{2}$ emissions, also listed in Table D5, would drop by about $460 \mathrm{mmt}$ from the 2035 Reference case to the 2035 Extended Policies case-from 5,756 mmt to 5,295 mmt. Again, using 2030 as a midpoint value, the Reference case estimates emissions of 5,655 mmt in 2030, while the Extended Policies case yields emissions of 5,331 $\mathrm{mmt}$ by 2030 , or a difference of just higher than $300 \mathrm{mmt}$ between these cases.

We can see from these figures that even if we were to reduce consumption under this case by the additional level of savings that we calculate as possible with the $54.5 \mathrm{mpg}$ fuel-economy level - to a total of about 94 Q-BTUs - we still would not be close to reducing energy-based $\mathrm{CO}_{2}$ emissions to about 3,000 $\mathrm{mmt}$.

In Tables A3.1 and A3.2, respectively, we show the figures for energy consumption levels and emissions for the Extended Policies case alongside the figures we present in Tables 5.55 and 5.66 in the main text. From these tables, we can see clearly the differences between the Extended Policies case relative to both the EIA's Reference case and the Aggressive Reference case that we have developed. 
TABLE A3.1

Alternative U.S. energy consumption scenarios for 2030 including EIA's extended policies case Energy consumption expressed in Q-BTUs

\begin{tabular}{|c|c|c|c|c|c|}
\hline $\begin{array}{l}\text { Energy source or efficiency gain } \\
\text { (efficiency measured relative to } \\
2030 \text { Reference case) }\end{array}$ & $\begin{array}{c}2010 \\
\text { actual }\end{array}$ & $\begin{array}{c}2030 \text { EIA } \\
\text { Reference case }\end{array}$ & $\begin{array}{c}2030 \text { ElA } \\
\text { Extended } \\
\text { Policies case }\end{array}$ & $\begin{array}{c}2030 \\
\text { Aggressive } \\
\text { Reference case } \\
\text { defined in } \\
\text { Chapter } 5\end{array}$ & $\begin{array}{c}2030 \text { PERI/ } \\
\text { CAP case }\end{array}$ \\
\hline Total energy consumption & 98.2 & 104.3 & 100.0 & 94.1 & 70.0 \\
\hline All efficiency & -- & -- & 4.3 & 10.2 & 34.3 \\
\hline Transportation efficiency & -- & -- & 2.1 & 8 & 8 \\
\hline Industrial efficiency & -- & -- & 1.0 & 1.0 & 10.4 \\
\hline Building efficiency & -- & -- & 1.2 & 1.2 & 15.9 \\
\hline Petroleum and other liquid fuels & 37.2 & 37.0 & 34.5 & 26.8 & 21.1 \\
\hline Coal & 20.8 & 20.6 & 19.6 & 9.0 & 9.0 \\
\hline Natural gas & 24.7 & 26.7 & 25.5 & 36.1 & 16.5 \\
\hline Nuclear & 8.4 & 9.6 & 9.3 & 9.3 & 8.0 \\
\hline High-emissions biomass ${ }^{1}$ & 3.6 & 5.1 & 5.1 & 2.4 & $0^{2}$ \\
\hline Clean renewables & 3.5 & 5.3 & 6.0 & 10.5 & 15.4 \\
\hline Clean bioenergy & 0 & 0 & 0 & 4.0 & 6.4 \\
\hline Hydro & 2.5 & 3.0 & 3.0 & 3.0 & 4.1 \\
\hline Wind & 0.9 & 1.7 & 2.0 & 2.0 & 3.1 \\
\hline Solar & 0.1 & 0.2 & 0.6 & 1.0 & 1.3 \\
\hline Geothermal & 0 & 0.4 & 0.4 & 0.5 & 0.5 \\
\hline
\end{tabular}

1 High-emissions biofuels are included in "petroleum and other liquid fuels."

2 High-emissions biomass, as well as biofuels, are distributed among "petroleum and other liquid fuels" and coal in this case.

Sources: 2010 Actual and 2030 EIA Reference case from EIA's Annual Energy Outlook 2012. 2030 Aggressive Reference case and 2030 PERI/CAP derived in text. Note that the figures in this table differ slightly from those in Chapter 4, which were based on the 2011 version of the EIA's Annual Energy Outlook. 
TABLE A3.2

$\mathrm{CO}_{2}$ emissions generated by alternative U.S. energy scenarios

Emissions are in millions of metric tons, or mmt

\begin{tabular}{lcccccc}
\hline & $\begin{array}{c}\text { Weighted average } \\
\text { emissions levels } \\
\text { (mmt per Q-BTU) }\end{array}$ & $\begin{array}{c}2010 \\
\text { actual } \\
(\mathrm{mmt})\end{array}$ & $\begin{array}{c}2030 \mathrm{EIA} \\
\text { Reference case } \\
(\mathrm{mmt})\end{array}$ & $\begin{array}{c}2030 \text { EIA } \\
\text { Extended } \\
\text { Policies case } \\
(\mathrm{mmt})\end{array}$ & $\begin{array}{c}2030 \\
\begin{array}{c}\text { Aggressive } \\
\text { Reference case } \\
\text { (mmt) }\end{array}\end{array}$ & $\begin{array}{c}2030 \text { PERI/ } \\
\text { CAP case } \\
\text { (mmt) }\end{array}$ \\
\hline $\begin{array}{l}\text { Petroleum and } \\
\text { other liquid fuels }\end{array}$ & 63 & 2,349 & 2,331 & 2,173 & 1,688 & 1,329 \\
$\begin{array}{l}\text { Coal and high- } \\
\text { emissions biomass }\end{array}$ & 96 & 2,002 & 2,014 & 1,893 & 876 & 864 \\
$\begin{array}{l}\text { Natural gas } \\
\text { Totals }\end{array}$ & 52 & 1,283 & 1,388 & 1,326 & 1,877 & 858
\end{tabular}

Sources: Energy Information Administration, Annual Energy Outlook 2012, (U.S. Department of Energy, 2012). Tables A1 and D5.

Notes: 2010 emissions figures taken directly from table D5. Reference case emissions figures derived from Reference case consumption figures in table A1 of ElA's "Annual

Energy Outlook 2012" and weighted average emissions figures. Aggressive Reference case and PERI/CAP cases derived from consumption figures in text and weighted average

emission figures. High-emissions biofuels are included in "petroleum and other liquid fuels" total. High-emissions biomass and other components of the "other" category in table D5 are included with coal emissions. 


\section{Appendix 4: Methodology for estimating the employment effects of alternative energy industry expenditures}

Use of the input-output model for estimating employment effects

\section{General methodological issues}

The employment multipliers for each of the energy categories studied in this report were constructed through an input-output, or I-O, model. Input-output models estimate the economywide and sectoral impact on the output, employment, and value added of changes in the final demand for the goods and services produced by a particular sector or combination of sectors.

I-O models are derived from detailed information on the supply and demand relationships between various industrial sectors and distinct categories of final demand. The data underlying the I-O models show how much output is produced by each sector, the amount of the production used by each of the sectors, and the amount of final demand for each sector's production. To give a concrete example, the I-O table will detail the production of the agricultural sector and indicate how other sectors of the economy use this output - for example, how much is used as inputs to food processing, how much is used by the agricultural sector itself, and how much consumers purchase directly. An increase in purchases of agricultural output will cause purchases of intermediate inputs to rise-fertilizers, for instance. Higher demand for fertilizers will subsequently increase demand for the inputs used by the fertilizer industry, and so forth. The I-O model captures these relationships and uses them to track how an initial increase in demand travels throughout the productive structure of the economy.

I-O models also disaggregate the sources of final demand in the economy. Typical final demand categories include household consumption, capital formation, government expenditures, inventories, and exports. Information on imports is also included, often implicitly, in the I-O model. This allows documentation of "leakages"- or when rises in demand are met by higher imports rather than by increased domestic production. 
One challenge with using an I-O model or Social Accounting Matrix, or SAM, to evaluate expenditures on clean energy investments is that these activities are not grouped together into distinct industrial sectors - there are, for example, no sectors for solar power or building retrofits. Since the I-O family of models is structured using the sector as the basic building block, this poses a significant challenge. There are two ways around this constraint: using the existing sectors in the I-O model to construct a synthetic sector, which reflects the composition of activities associated with the activity in question; or conducting an enterprise survey in order to modify an existing I-O model to introduce an entirely new sector. In this study, we pursue the first approach. Below, we document in detail our method for establishing relative weights for the various energy sectors.

Spending on clean energy, as with every other activity in the economy, creates jobs through three channels: direct, indirect, and induced effects. Input-output models are extremely useful in documenting the indirect and induced employment that a current level of productive activity supports. For example, these three effects on investments in home retrofitting and building wind turbines can be described in this way:

- Direct effects: the jobs created by retrofitting homes to make them more energy efficient or by building wind turbines

- Indirect effects: the jobs associated with the industries that supply intermediate goods for the building retrofits or wind turbines, such as lumber, steel, and transportation

- Induced effects: the expansion of employment that results when people who are paid in the construction or steel industries spend the money they have earned from producing these immediate and intermediate goods on other products in the economy

\section{Methodological concerns with the I-O model}

Basic I-O models include a number of simplifying assumptions. This enables the models to be relatively transparent and tractable. But these simplifying assumptions also create limitations on the reliability of I-O models.

\section{Linear model}

A basic input-output model is a linear model with no supply-side constraints imposed. That is, a basic input-output model assumes that a given amount of 
spending will have a proportionate effect on employment, no matter how much the level of spending changes, either up or down. For example, the impact of spending $\$ 1$ billion on an energy-efficiency project will be exactly 1,000 times greater than spending only $\$ 1$ million on the exact same project. This will be approximately accurate in many situations but may not be in other situations. In using the I-O model for our estimation, we are assuming that it is reasonable to work with the assumption of linearity for our purposes.

\section{Absence of supply constraints}

The most significant consequence of the linearity assumption is that the I-O model takes no account of potential supply constraints in moving from a $\$ 1$ million project to a $\$ 1$ billion project. Under some circumstances, this could be a serious deficiency in the model. However, with the current U.S. and global economies still operating with widespread slack due to the weak recovery from the 2007 to 2009 Great Recession, it is reasonable to assume that supply constraints are less binding than demand constraints. In the longer-term, these same conditions may not hold true, and the models will need to be adjusted to reflect this reality.

\section{Relative prices fixed}

Another result of the assumption of linearity is that a basic I-O model assumes that prices remain fixed, regardless of changes in demand. A more fully specified model would take account of such factors-for example, if a recession leads to reduced demand for solar panels, then the prices of the panels will fall, perhaps mitigating the decline in demand.

\section{Fixed industrial structures}

Basic input-output models also assume that productive relationships remain stable over the period of analysis. But it is certainly the case that industrial structures evolve over time. This issue would seem especially relevant in considering employment conditions within the clean energy economy, since economies will certainly undergo significant structural changes in the course of a clean energy transformation. How does structural change affect the reliability of employment forecasts?

In fact, the use of workers in clean energy industries and services will not change at an equivalently rapid pace over time, even though clean energy technologies will be advancing substantially. Consider this example: a high proportion of energy efficiency investments - such as in building retrofits, public transportation, and smart grid electrical transmission systems - will heavily rely on the construction industry. Some aspects of the work involved in retrofitting a home, for example, 
will change as retrofitting methods develop. But other aspects can be expected to remain stable because the technologies are relatively mature and are not expected to change quickly. Depending on the activity in question, the overall level of demand for workers to conduct retrofits may remain fairly stable, at least in the short to medium term.

A similar situation is likely to hold with the production of renewable energy in the short-run, regardless of whether the solar panels, wind turbines, or biomass fuel-refining plants are more or less efficient because of technologies that convert their raw materials into useful energy. That is, the need to employ workers to manufacture, transport, and install these newly developed renewable energy products is likely to remain fairly stable as a proportion of overall activity in the industry in the short to medium term. Therefore, the use of an I-O model or SAM may be appropriate for research scenarios in which technology and productive relationships can be assumed to be fairly stable.

\section{Treatment of time dimension}

The I-O model generates estimates as though everything is happening at one fixed point in time. A more realistic picture of the economy would of course have to recognize that the effects of public- and private-sector spending will take place in sequences over time, and that these timing effects are important. Adding a time dimension would make the model dynamic. If these considerations are of concern, a dynamic I-O model could be used that allows for changes over time.

\section{Overall assessment of $\mathrm{I}-\mathrm{O}$ models}

Recognizing all of the above simplifying assumptions of the I-O model, we nevertheless conclude that it is the most effective available tool for estimating the employment effects of a large-scale clean energy investment project in the United States.

The model is most reliable when we can reasonably assume that supply-side constraints are relatively insignificant. That is, the clean energy industry is able to expand without assuming that this expansion will be strongly impacted by supply shortages, which in turn could cause major changes in relative prices.

At the same time, we recognize that the clean energy program we have developed in this study entails substantial long-term structural changes in the U.S. economy, in which resources will shift out of the fossil fuel sectors and into the clean energy 
sectors. In principle, this structural shift could cause prices to rise and subsequent supply constraints in the growing clean energy sectors and those areas of the economy that are closely linked to these sectors. Any combination of rising prices and supply constraints could, in turn, reduce the expansion of output and employment relative to the levels we have estimated through our I-O analysis.

However, for several reasons that we discuss at various points in this study, we do not think these will be significant problems over the 20 -year period of our clean energy investment program, either in terms of material shortages or human resources. First, as we discuss in Chapter 7, the expansion of the clean energy sector will occur in conjunction with retrenchments in the nonrenewable energy sectors, which will free up material resources for investment throughout the economy. As we also discuss in Chapter 7, the macro level—the current ratio of investment to GDP - of roughly 19 percent is well below the historic average of about 22 percent. Thus, there is presently considerable room for an expansion in clean energy investment activity overall within the range we are discussing in this study, about 1.2 percent of current GDP. Perhaps this historically low investmentto-GDP ratio is more of a short-term phenomenon. Still, considered over a 20-year period, it is important to recognize that the currently low investment-to-GDP ratio operates in conjunction with the fact that investments in the oil, coal, and natural gas industries will experience large-scale contractions as one major feature of the clean energy investment program.

With respect to human resources, as we discuss in Chapter 6, we do not expect there to be problems with attracting an adequate supply of workers with the requisite skills to operate effectively within the clean energy economy. This has been the experience to date in both the United States and elsewhere, according to the research on this question that we cite in Chapter 6. Moreover, any problems with shortages of skilled workers for the clean energy sector can be relaxed through maintaining worker-training programs, as we discuss in Chapter 8. At the macroeconomic level, there is no evidence that increasing net employment in the U.S. economy by around 3 million jobs over the course of 20 years will produce shortages within an overall labor market that will be growing to more than 180 million people within the next 20 years. Any such pressures that might occur within the short term would diminish over time as the labor market expands.

Finally, with respect to both material and human resources, it is important to keep in mind that the clean energy investment program will be advancing within the framework of an economy in which both output and labor productivity are growing 
over time. We consider the impact of these factors in more detail below, but the general rise in labor productivity will enable the clean energy sectors to grow without creating increasing constraints on the resources available to accommodate that sector's growth.

While recognizing these various considerations, we are not suggesting that the clean energy investment agenda that we have developed will not create any supply constraints or corresponding price increases at any time. Perhaps the most likely area for supply constraints will be in agriculture, resulting from the major expansion in clean bioenergy that we describe in Chapter 3. Such an increase in bioenergy production could cause an increase in agriculture prices, but given the various other factors that influence variation in global agricultural prices-the most important being speculation on the commodities futures markets - the impact of the growth in bioenergy production is likely to be modest. Moreover, as we discuss in Chapter 7, to the extent that any such constraints within agriculture are labor related, these constraints could be readily relaxed by allowing increases in immigration, and thereby an expanded supply of agricultural workers.

\section{I-O vs. Computable General Equilibrium models}

The strengths of the relatively simple and transparent I-O structure can be seen more clearly by comparing this approach with a more complex approach, represented by Computable General Equilibrium, or CGE, models. In fact, CGE models are simply I-O models with price dynamics, supply-side constraints, and assumptions about technological change incorporated into the basic I-O structure. As such, CGE models typically place a much stronger emphasis on the role that prices play in influencing behavior and determining economic outcomes.

The core of a CGE model is typically an I-O model, showing the various relationships between industrial sectors and final demand. The I-O framework is typically supplemented by a variety of elasticities, which describe how demand reacts to changes in prices. CGE models also incorporate some kind of equilibrium condition such as market clearing (prices adjust so that supply must equal demand) or full employment. This allows for a unique solution to the system of equations to exist.

CGE models are costly to develop. Moreover, given the high fixed cost of creating the models, CGE models are often proprietary. This means that access to the model is restricted to the organization or researchers who developed the model. This can raise concerns regarding transparency and independent verification of the accuracy of the model's assumptions. The complex and proprietary nature of most CGE 
models makes it difficult to perform a careful analysis of the assumptions used in different applications and to determine if the assumptions are reasonable for answering a specific research question. This is because detailed descriptions of the models (including the equations which constitute the model) are often not available. The individual assumptions are often difficult, if not impossible, to identify from the general description and the implications of specific assumptions are hard to trace. The reliability of such models therefore depends first and foremost on an assessment of the model's assumptions - that is, are the assumptions realistic? Are they helping us to understand important issues about the likely growth trajectory of the green economy? To give one important case in point, CGE models may assume the economy operates at full employment at all times. Working with this assumption, it is inevitably difficult to trace out any possible impacts of clean energy investments as a net source of new job creation.

Given these challenges of working with a CGE model, for our purposes of estimating employment effects of clean energy investments, we have again concluded that the I-O model is our preferred methodology.

\section{Estimating direct and indirect employment impacts with the I-O model}

For each technology, the general approach in our study was to identify a source document or set of source documents that contained detailed cost information for the equipment and installation costs of the technology, as well as for operations and maintenance. Next, we mapped the cost structure into the industrial categories within the IMPLAN input-output model. These categories include industries such as industrial machinery, turbines, boilers, ducts, construction of industrial facilities, and so on.

The IMPLAN I-O model allows us to observe relationships between different industries in the production of goods and services. We can also observe relationships between consumers of goods and services, including households and governments, and the various producing industries. For our purposes specifically, the I-O modeling approach enables us to estimate the effects on employment resulting from an increase in final demand for the products of a given industry. For example, we can estimate the number of jobs directly created in the construction industry for each $\$ 1$ million of spending on building weatherization. We can also estimate the jobs that are indirectly created in other industries through the $\$ 1$ million in spending on building weatherization -industries such as insulation, windows, and hardware. Overall, the I-O model allows us to estimate the economywide employment results from a given level of spending in any one industry or combination of industries. 
For this report, we used the IMPLAN 3.0 software with IMPLAN 2009 data compiled by the Minnesota IMPLAN Group, Inc. This data provides 440 industrylevel details and is based on the Bureau of Economic Analysis input-output tables, which are compiled from millions of surveys of businesses nationwide, as well as administrative records. Below, following our discussion of induced effects, we present the industry composition for each energy category in this report.

\section{Induced employment estimates}

Induced effects refer to the additional employment, output, and value added that is produced when the additional employment income generated by an initial demand stimulus - as captured by the direct and indirect effects - is spent elsewhere in the economy. The magnitude of the induced effects depends on how the additional employment income translates into household expenditures and the size of the multiplier effects associated with the increase in household spending.

Induced effects are often estimated by endogenizing the household sector in the input-output model. The assumption is that increases in employee compensation (or value added) finance greater household spending, as reflected in the vector of household consumption in overall final demand. The endogenous household model often yields very large induced effects, in part because the propensity to consume out of the employee compensation implicit in the endogenous household I-O model is large.

Instead of relying on the consumption function that is implicit in the I-O accounts, we estimate the relationship between real gross employee compensation and real personal consumption expenditures econometrically using a dynamic empirical model. This gives us a more accurate sense of how household consumption responds to changes in employee compensation. We then integrate this estimated relationship into our basic input-output model to calculate induced effects.

The first step of the process is to estimate the relationship between personal consumption expenditures and employee compensation. To do this, we begin with the following dynamic empirical model:

$$
C_{t}=\alpha+\beta_{1} C_{t-1}+\beta_{2} C_{t-2}+\beta_{3} C_{t-3}+\gamma E_{t}+\mu_{t}
$$

In the above equation, $\mathrm{Ct}$ represents real personal consumption expenditures in time period ' $t$,' Et represents real employee compensation, and $\mu \mathrm{t}$ is a stochastic error term. We are interested in how changes in employee compensation affect 
changes in personal consumption expenditures. Therefore, we estimate the model in first differences. First differencing also ensures that the variables are stationary (based on augmented Dickey-Fuller unit root tests). The GDP-deflator for personal consumption expenditures is used to transform nominal values into real variables. The time series is quarterly and extends from 1950 to 2007 . All data come from the Bureau of Economic Analysis at the U.S. Department of Commerce.

The estimated model is (rounding off the coefficients):

$$
\begin{aligned}
C_{t}= & 7.83+0.10 C_{t-1}+0.20 C_{t-2}+0.21 C_{t-3}+0.30 E_{t} \\
& (3.2)(1.7) \quad(3.5) \quad(3.6)
\end{aligned}
$$

T-values are reported in parentheses. From this model, we can calculate the impact of a change in employee compensation on personal consumption expenditures, taking into account the dynamic feedback effects captured by the lag endogenous variables:

$$
\frac{\gamma}{1-\left(\beta_{1}+\beta_{2}+\beta_{3}\right)}=\frac{0.2952}{1-0.5186}=0.6132
$$

This implies that a $\$ 1$ million increase in gross employee compensation will be associated with a $\$ 613,200$ increase in household consumption. Next, we need to estimate the feedback effects - the impacts of the increase in household consumption on employee compensation. Additional household consumption expenditures will increase the vector of final demand in the input-output model and, through direct and indirect employment effects, will raise employee compensation. Using our input-output model and restricting the estimates to direct and indirect effects only, we find that a $\$ 1$ increase in household final demand is associated with an increase in employee compensation of $\$ 0.416 .^{19}$

We can now estimate the number of jobs that would be created for each additional $\$ 1$ million in employee compensation generated by the direct and indirect effects of any particular final demand stimulus. First, we calculate the total impact on household consumption of a $\$ 1$ increase in employee compensation. This would be given by the following expression:

Total impact on $\mathrm{HH}$ consumption $=x+x^{2} y+x^{3} y^{2}+x^{4} y^{3}+\ldots \ldots$ 
In which $\mathrm{x}$ is the estimated propensity to consume out of additional employee compensation (0.6132, according to our estimates described above) and $y$ is the additional employee compensation generated by a $\$ 1$ increase in final household demand ( 0.416 , from the basic input-output model). We can factor out a single $\mathrm{x}$, giving us:

$$
\text { Total impact on } \mathrm{HH} \text { consumption }=\mathrm{x}\left[1+\mathrm{xy}+(\mathrm{xy})^{2}+(\mathrm{xy})^{3}+\ldots \ldots .\right]
$$

The expression in the brackets is an infinite series. Since $x y<1$, we know that the series converges to:

Total impact on $\mathrm{HH}$ consumption $=\mathrm{x} /(1-\mathrm{xy})$.

Using our estimates, the total impact on household consumption expenditures of a $\$ 1$ increase in employee compensation is $+\$ 0.8232$.

Finally, we use these estimates to calculate a general induced employment multiplier. From the basic input-output model, we estimate that a $\$ 1$ million change in final household consumption would create 10.6 additional jobs. However, we are interested in the number of jobs that would be generated by an additional $\$ 1$ million in employee compensation. We know that $\$ 1$ in employee compensation will generate $\$ 0.8232$ in induced household consumption. Therefore, $\$ 1$ million in additional employee compensation generates $\$ 823,200$ in new household expenditures and approximately 8.7 additional jobs $(10.6 * 0.8232)$ — when all dynamic multiplier effects are taken into account.

We can apply this general analysis of induced effects to any specific stimulus-all we need to know is the direct and indirect effects of the stimulus in terms of employee compensation. For each $\$ 1$ million in additional employee compensation generated, we know that 8.7 additional jobs would be generated through induced effects. For example, an additional $\$ 10$ million spent on building weatherization generates $\$ 6.49$ million in additional employee compensation through the direct and indirect effects. These direct and indirect effects would generate about 125 new jobs. These numbers come directly from the basic input-output model. The induced job creation — taking into account all multiplier effects—-would amount to approximately 56 additional jobs $(6.49 * 8.7)$ for a total employment impact of 181 jobs. In this case, we see that the induced jobs represent 44.8 percent of the combined direct and indirect employment. 
Using this modeling approach to estimate induced employment effects across multiple industries, we have found that, on average, induced effects represent approximately 40 percent of the combined direct and indirect effects. This level of induced effects is supported by other estimates reported in the literature. A 2002 article by economists at the International Monetary Fund surveyed the professional literature estimating the size of the induced effects in the United States, among other economies, in a range of circumstances and time periods. ${ }^{20}$ The authors report wide variations in these estimates. This includes some estimates of a negative induced effect to a doubling of the initial expansion.

The economy at present is operating with high unemployment, with plenty of slack resources to be utilized. Given this, one might expect that the induced effect would be closer to the higher end estimates of the IMF study - that the total number of jobs would be double the level of direct and indirect job creation. Nevertheless, to be cautious, it is appropriate to underestimate rather than overestimate the induced employment effects, even if conditions are favorable for a relatively large induced effect. We therefore assume that the induced employment effects of this program will add 40 percent to the overall level of job creation generated by the direct and indirect effects nationwide. This is in line with the lower-end estimate of such effects for the U.S. economy reported in the IMF survey study.

\section{Composition of energy industries}

In Table A4.1, we present the details as to how we specified each of energy industries within the U.S. input-output model for the purposes of our employment estimates in Chapter 6. In the discussion that follows, we discuss the most significant issues regarding our specifications. 
TABLE A4.1

\section{Composition of energy industries using input-output model}

\begin{tabular}{|c|c|c|}
\hline \multicolumn{2}{|r|}{ Industry composition } & Source \\
\hline \multicolumn{3}{|c|}{ Energy efficiency } \\
\hline \multirow[t]{2}{*}{ Buildings } & $\begin{array}{l}50 \% \text { residential efficiency, of which } 30 \% \text { is construction; } 10.5 \% \\
\text { lighting; } 42 \% \text { HVAC equipment; } 17.5 \% \text { materials for envelope } \\
\text { improvements, including windows, roofing, and insulation }\end{array}$ & $\begin{array}{l}\text { Brown et al., "U.S. Building Sector Energy } \\
\text { Efficiency Potential,” (Berkeley: Ernest } \\
\text { Orlando Berkeley National Laboratory, } \\
\text { 2008) and National Academy of Sciences, } \\
\text { Real Prospects for Energy Efficiency in the } \\
\text { United States, (Washington: The National } \\
\text { Academies Press, 2010), used to construct } \\
\text { figures 2.2-2.4 in current study }\end{array}$ \\
\hline & $\begin{array}{l}50 \% \text { commercial efficiency, of which } 30 \% \text { is construction; } 18 \% \\
\text { lighting; } 14 \% \text { HVAC equipment; } 8 \% \text { water heating; } 6 \% \text { motors } \\
\text { and drives; } 2 \% \text { office equipment; } 18 \% \text { environmental controls; } \\
4 \% \text { envelope materials, including windows, insulation, roofing, } \\
\text { paint, and coating materials }\end{array}$ & $\begin{array}{l}\text { Heidi Garrett-Peltier, "Employment } \\
\text { Estimates for Energy Efficiency Retrofits of } \\
\text { Commercial Buildings: Tables and Meth- } \\
\text { odology," (Amherst, MA: Political Economy } \\
\text { Research Institute, 2011). }\end{array}$ \\
\hline Industry & $\begin{array}{l}10 \% \text { each for air purification and ventilation, heating equipment, } \\
\mathrm{A} / \mathrm{C} \text {, industrial machinery, turbines and generators; } 30 \% \text { environ- } \\
\text { ment and tech services; } 20 \% \text { construction }\end{array}$ & $\begin{array}{l}\text { PERI analysis of U.S. Department of Energy } \\
48 \mathrm{C} \text { clean energy tax rebate stimulus } \\
\text { program, "Industry" category }\end{array}$ \\
\hline
\end{tabular}

Renewable energy

\section{Capital investment}

Hydro (large scale)

Wind onshore

Hydro (small scale)

(1)

Geothermal

Biofuels

(2)

Solar PV
$30 \%$ construction; $20 \%$ turbines and generators; $18 \%$ cement manufacturing; $3 \%$ each for power distribution equip, motors and generators, switchgears, and relays and industrial controls; $10 \%$ each for architecture and engineering, environmental and tech services

$50 \%$ infrastructure construction; $10 \%$ concrete pipes; $10 \%$ engineering and design; $15 \%$ turbines; $5 \%$ mechanical power transmission; $5 \%$ motors and generators; $5 \%$ energy wires and cables

$37 \%$ machinery; $12 \%$ fabricated metal; $12 \%$ plastic products; $3 \%$ power transmission; $3 \%$ electronic connectors; $7 \%$ R\&D; $26 \%$ construction

$20 \%$ each for drilling wells, ventilation equipment manufacturing, heating equipment manufacturing, $A / C$ equipment manufacturing, and pumping equipment manufacturing

$30 \%$ construction; $7 \%$ boiler and heat exchanger; $15 \%$ fluid power process machinery; $39 \%$ industrial process machinery; $9 \%$ pipe and pipe fittings

$30 \%$ construction; $17.5 \%$ each for hardware, power transmission equipment, electronic components, and scientific and technical services
2010 PERI analysis of " 40 applied technologies" for the U.S. Department of Energy

Category developed for this analysis using primarily: International Renewable Energy Agency, "Hydropower," Renewable Energy Technologies: Cost Analysis Series. Vol. 1, Issue 3/5. (Abu Dhabi: IRENA, 2012).

PERI standard composition (e.g., Pollin, Heintz, and Garrett-Peltier, "The Economic Benefits of Investing in Clean Energy," (Amherst, MA: Political Economy Research Institute, 2009)

2010 PERI analysis of " 40 applied technologies" for the U.S. Department of Energy

Construction of ethanol plant, from Heidi Garrett-Peltier, "The Employment Impacts of a Low-Carbon Fuel Standard for Minnesota," (Amherst, MA: Political Economy Research Institute, 2012).

PERI standard composition (e.g., Pollin and others, "The Economic Benefits of Investing in Clean Energy." 
Wind offshore

Grid upgrades

to support

expanded RE
$25 \%$ construction; $27 \%$ machinery; $10 \%$ each for environmenta and tech services, plastic products, and fabricated metal products; $0.67 \%$ each for power transformer and distribution equipment, motor and generator, and switchgear manufacturing; $0.4 \%$ each for electron tube, semiconductor, electronic capacitor, electronic connector, and other electronic components; $8 \%$ cement manufacturing; $6 \%$ transport by water

$30 \%$ construction; $15 \%$ water tank; $13.5 \%$ heat exchanger; $13.5 \%$ electronic controller; $11 \%$ piping; $11 \%$ hardware; $6 \%$ flat glass

$33 \%$ construction; $9.53 \%$ each for transformers, motors and generators, switchgears, relays and industrial controls, storage batteries, energy wire and cable, and wiring devices
2010 PERI analysis of " 40 applied technologies" for the U.S. Department of Energy

Category developed for this analysis using various source documents

Slight variation on 2010 PERI analysis of "40 applied technologies" for the U.S. Department of Energy (combines previous categories)

\section{Operations and maintenance}

Hydro (large
scale)
Hydro (small
scale)

Wind onshore

.

Wind offshore

Solar thermal
$100 \%$ power generation

$10 \%$ environmental and technical services; $10 \%$ industrial machinery repair; $80 \%$ electric power generation, transmission, and distribution

$25 \%$ remote monitoring; $25 \%$ repair and maintenance construction; $25 \%$ commercial and industrial machinery repair; $25 \%$ utilities

$50 \%$ maintenance and repair construction; $20 \%$ mechanical engineers; $20 \%$ environmental and technical consulting; $10 \%$ utilities

$58 \%$ grain farming; $7 \%$ refining; $14 \%$ natural gas; $3 \%$ water systems; $5 \%$ power generation; $2 \%$ machinery repair; $4 \%$ business support services; $2 \%$ transport by rail; $5 \%$ transport by truck

$25 \%$ remote monitoring; $25 \%$ maintenance and repair construction; $25 \%$ electronic precision equipment repair and maintenance; $25 \%$ utilities

$20 \%$ remote monitoring; $20 \%$ repair and maintenance construction; $20 \%$ commercial and industrial machinery repair; $20 \%$ water transportation; $20 \%$ utilities

$25 \%$ remote monitoring; $25 \%$ maintenance and repair construction; $25 \%$ commercial and industrial repair and maintenance; $25 \%$ utilities
Standard I-O category

Category developed for this analysis using primarily: International Renewable Energy Agency, "Hydropower," Renewable Energy Technologies: Cost Analysis Series. Vol. 1, Issue 3/5. (Abu Dhabi: IRENA, 2012).

PERI composition using the U.S. Department of Labor's O*NET-SOC crosswalk for wind production managers and wind technicians, plus power plant operations

PERI composition using the U.S. Department of Labor's O*NET-SOC crosswalk for primary occupations listed under geothermal

Garrett-Peltier, "The Employment Impacts of a Low-Carbon Fuel Standard for Minnesota."

Category developed for this analysis using primarily Energy Market Authority, "Handbook for Solar Photovoltaic (PV) Systems," (Singapore: EMA, 2011) and BLS "Careers in Solar"

Composition is same as wind onshore, plus water transportation

PERI composition using the U.S. Department of Labor's O*NET-SOC crosswalk for solar technicians, plus BLS "Careers in Solar" 


\begin{tabular}{|c|c|c|}
\hline Coal & $\begin{array}{l}14.1 \% \text { coal mining; } 3.1 \% \text { support activities for mining; } 82.8 \% \\
\text { power generation }\end{array}$ & \multirow{4}{*}{$\begin{array}{l}\text { Composition based on current output lev- } \\
\text { els of extraction, production, distribution, } \\
\text { and power generation of each energy type } \\
\text { within IMPLAN U.S. } 2009 \text { data set }\end{array}$} \\
\hline Natural gas & $\begin{array}{l}25.9 \% \text { natural gas extraction; } 9.1 \% \text { drilling oil and gas wells; } \\
5.5 \% \text { support activities for extraction; } 12.9 \% \text { power generation; } \\
43.4 \% \text { natural gas distribution; } 3.2 \% \text { pipeline transport }\end{array}$ & \\
\hline Nuclear & $12.9 \%$ uranium mining; $87.1 \%$ power generation & \\
\hline Oil & $\begin{array}{l}12.4 \% \text { oil extraction; } 4.3 \% \text { drilling oil and gas wells; } 2.6 \% \text { sup- } \\
\text { port activities for extraction; } 79.2 \% \text { oil refining; } 1.5 \% \text { pipeline } \\
\text { transport }\end{array}$ & \\
\hline \multicolumn{3}{|l|}{ Other } \\
\hline $\begin{array}{l}\text { New oil and } \\
\text { natural gas } \\
\text { capacity }\end{array}$ & $\begin{array}{l}18 \% \text { material handling equipment; } 46 \% \text { turbine and generating } \\
\text { equipment; } 15 \% \text { ventilation equipment; } 14 \% \text { industrial process } \\
\text { instruments; } 7 \% \text { construction }\end{array}$ & $\begin{array}{l}2010 \text { PERI analysis of " } 40 \text { applied technolo- } \\
\text { gies" for the U.S. Department of Energy }\end{array}$ \\
\hline $\begin{array}{l}\text { New advanced } \\
\text { coal capacity }\end{array}$ & $\begin{array}{l}30 \% \text { industrial machinery; } 30 \% \text { boiler and heat exchanger } \\
\text { equipment; } 5 \% \text { air purification and ventilation; } 15 \% \text { turbines } \\
\text { and generators; } 10 \% \text { industrial process instruments; } 10 \% \\
\text { construction }\end{array}$ & $\begin{array}{l}2010 \text { PERI analysis of " } 40 \text { applied technolo- } \\
\text { gies" for the U.S. Department of Energy }\end{array}$ \\
\hline $\begin{array}{l}\text { New nuclear } \\
\text { (Gen II) }\end{array}$ & $\begin{array}{l}\text { 8.6\% each for boiler and heat exchange equipment, valves } \\
\text { and fittings, refrigeration equipment, turbines and generators, } \\
\text { environmental controls, measuring and controlling devices, and } \\
\text { inorganic chemical manufacturing; } 40 \% \text { construction }\end{array}$ & $\begin{array}{l}2010 \text { PERI analysis of " } 40 \text { applied technolo- } \\
\text { gies" for the U.S. Department of Energy }\end{array}$ \\
\hline $\begin{array}{l}\text { Nuclear decom- } \\
\text { missioning }\end{array}$ & $\begin{array}{l}80 \% \text { heavy civil construction; } 10 \% \text { environmental services; } 10 \% \\
\text { scientific, technical, and miscellaneous services }\end{array}$ & $\begin{array}{l}2009 \text { PERI analysis of the U.S. Department } \\
\text { of Energy's ARRA programs for internal } \\
\text { DOE use }\end{array}$ \\
\hline \multicolumn{3}{|c|}{ Public transportation } \\
\hline $\begin{array}{l}\text { Public transpor- } \\
\text { tation: Capital }\end{array}$ & $\begin{array}{l}50 \% \text { infrastructure construction; } 25 \% \text { bus manufacturing; } 25 \% \\
\text { railroad rolling stock manufacturing }\end{array}$ & PERI composition for this analysis \\
\hline $\begin{array}{l}\text { Public transpor- } \\
\text { tation: Opera- } \\
\text { tions }\end{array}$ & $100 \%$ transit and ground passenger transportation & Standard I-O category \\
\hline
\end{tabular}




\section{Modeling energy efficiency}

In this report, two categories of energy efficiency are considered: buildings and industry.

\section{Buildings}

The category of buildings includes both residential and commercial buildings. Energy efficiency upgrades in commercial buildings include the manufacturing and installation of lighting, HVAC equipment, building envelope materials and improvements, environmental controls, water heating, office equipment, and motors and drives. These categories were developed in coordination with the U.S. Green Building Council and are based on installations in Energy Savings Companies, or ESCO, projects. ${ }^{21}$

Residential-building energy efficiency materials and installations include lighting, HVAC, and building envelope improvements. These are the three categories with the highest potential for energy savings in residential buildings. Within the residentialbuildings category, the weights for lighting, HVAC, and envelope improvements were developed based on the potential savings shown by Brown et al. and the National Academy of Sciences. ${ }^{22}$

\section{Industry}

The industry category contains a variety of industry-specific equipment and process changes in energy-intensive industries such as paper, cement, and iron and steel, among others. Efficiency upgrades in the industry category also include increased use of combined heat and power, or CHP, systems. The employment estimates used for this category are based on work PERI conducted for the U.S. Department of Energy in late 2009 and early $2010 .{ }^{23}$ We use the definition developed with the Department of Energy for industry, which includes HVAC equipment, turbines and generators, industrial machinery, environmental and technical services, and installation.

\section{Modeling renewable energy}

The expansion of renewable energy generation will entail two types of employment creation: in the manufacturing and installation of the renewable energy technologies and in the maintenance and operations of those technologies. In some cases, this will be for utility workers operating utility-scale wind or solar power, and in other cases it will be for electricians and other repair workers to maintain rooftop PV systems or smaller-scale wind turbine installations. The O\&M category also includes farmers, truckers, and biorefinery workers to produce biofuels. We present the capital-related employment and the O\&M employment separately. 
Capital cost estimates for renewable energy are derived from the EIA's assumptions to the "Annual Energy Outlook" in 2011, in which levelized costs for new energy generation resources are presented in a table that breaks out capital investment costs, O\&M costs, and transmission investment costs. ${ }^{24}$ In the LowCost Renewable case of the "Annual Energy Outlook," the cost per Q-BTU for renewable energy is lower, and the number of Q-BTUs produced is higher. According to the assumptions to the "Annual Energy Outlook" in 2011, the capital costs for renewable energy are 40 percent lower in the Low-Cost Renewable case than in the Reference case.

The O\&M employment is similar for all categories except for biofuels and biomass. The biofuels and biomass estimate includes employment in agriculture, trucking and rail transport, and biorefining. For all other renewable energy categories, we use the input-output industry of power generation as a proxy. In previous work with MJ Bradley and CERES, we developed O\&M estimates for renewable energy using this same method and verified our estimates with a number of electricity industry CEOs, who confirmed their validity. ${ }^{25}$

\section{Modeling fossil fuels}

Capital investments in nonrenewable power plants include building new natural gas power plants and oil refineries, and could include advanced coal power plants. In this study, we also examine the costs and impacts of decommissioning nuclear power plants. The industry composition for the fossil fuel capacity additions and nuclear decommissioning was previously developed by PERI in consultation with the U.S. Department of Energy.

To model the capital requirements for these types of projects, we used a series of documents titled "Cost and Performance Comparison of Fossil Fuel Energy Power Plants," which were compiled by the U.S. Department of Energy and the National Energy Technology Laboratory. These documents list the various equipment and construction costs of a new fossil fuel power plant. We converted the dollar values into percentages of the total cost of building the plant-so, for example, in the case of a new pulverized coal power plant, the cost shares were as follows: 30 percent boiler, 15 percent flue gas clean-up, 15 percent coal-handling machinery, 15 percent turbine generator, 10 percent building construction, 9 percent instrumentation, 5 percent ducts, and 1 percent water cooling. We then mapped these components into IMPLAN categories and estimated the employment effects per $\$ 1$ million in spending according to this cost structure. 
The industry composition of operations and maintenance in the fossil fuel and nuclear power industries was based on the 2009 composition of output levels of extraction, production, distribution, and power generation of each energy type within the IMPLAN data set used for the analysis within this report.

\section{Why we do not attempt to measure green jobs}

In recent years, there have been several efforts undertaken at various official statistical agencies and independent research institutions to define and measure "green jobs." Beginning in 2010 the U.S. Bureau of Labor Statistics began one of the most ambitious such undertakings. The BLS is taking a two-track approach to defining and measuring the number of green jobs within the U.S. economy. These are the output approach, which identifies establishments that produce green goods and services and counts the associated jobs, as well as the process approach, which identifies establishments that use environmentally friendly production processes and practices, and counts the associated jobs.

The BLS has already generated useful information through this effort, and further valuable material is no doubt forthcoming. This is also true of similar efforts elsewhere in the world. At the same time, such initiatives face serious methodological difficulties. These include the following:

\section{- Identifying green activities vs. employment within these activities: We} could, for example, unequivocally define the manufacturing of solar panels as a "green activity." However, are all the jobs tied to that manufacturing activity green jobs? For example, does an accountant employed by that firm hold a green job? Would the accountant still hold a green job if she worked for an independent accounting firm, and the solar manufacturing firm subcontracted out its accounting work?

- Divided work week: Does a truck driver have a green job if, for example, he works 10 hours a week delivering solar panels and 30 hours a week delivering pipes for an oil refinery?

- Indirect and induced jobs: If an academic conducts research on the green economy with, say, 60 percent of his or her time, we would likely consider that person as having a green job. But what about the businesses that supply the university with paper, pencils, and computers? They would not normally be considered part of the 
green jobs category. On the other hand, in measuring the induced and indirect effects of green investment activities, these categories of employment would get counted as among those influenced by green investment activities.

- Dividing economy into green vs. nongreen sectors: The project of building a clean energy economy will necessarily engage all sectors of the economy. In our view, it is therefore more appropriate to conceptualize this transformation as such — that is, as engaging all sectors of the economy at least to some degree, just as, to some degree, all sectors of the economy are presently connected to the nonrenewable energy sectors. The divisions between green- and nongreen jobs is thus not only difficult to establish within a static framework at present; it will also become increasingly difficult to sustain any given definition over time, as clean energy technologies emerge and become more integrated into the overall functioning of the economy.

For these reasons, our approach relies on identifying specific types of capital investments and operational spending — on energy efficiency, clean renewables, and maintaining production within the nonrenewable energy sectors - within the U.S. input-output model. Within that simple framework, we then remain focused on the conventional measures of job creation-direct, indirect, and induced jobs. We find this approach more straightforward and therefore more reliable than working within any given definition of "green jobs," for the purposes of this project.

\section{Methodology for estimating job categories and characteristics}

As noted in the main text of Chapter 6, most of the material in the section of the chapter describing job categories and characteristics was first presented in a 2009 publication by Pollin, Heintz, and Garrett-Peltier. ${ }^{26}$ We describe the methodology in full for generating these estimates on job categories and characteristics in the Technical Appendix of the 2009 study.

The one extension in the current study beyond that presented in Pollin et al.s 2009 study are the data we provide here on job creation through spending on biofuels and biomass operations and maintenance. The methodology we use for these estimates is identical to that in the 2009 study. Nevertheless, for completeness, we describe that methodology here, specifically as it applies to the biofuels and biomass sector. 
Our basic strategy for identifying the types of jobs that would result through spending on biofuels and biomass O\&M involves two steps. The first step is to calculate each of the 440 industry shares of total employment created through a specific investment program. We calculated the percentage of new employment generated in each of these 440 sectors with our input-output model. These industry shares take into account the direct, indirect, and induced effects, as discussed earlier. The second step is to combine this information on the industry composition of the new employment created through spending in any given industry with data on workers currently employed in those industries. We use the characteristics of these workers to create a profile of the types of jobs that will be added with a specific spending program, including the types of occupations, the credential requirements, and wages.

The worker data we used is from the 2008 to 2011 data files of the Current Population Survey, or CPS. The CPS is a monthly household survey conducted for the Bureau of Labor Statistics by the U.S. Census Bureau. The basic monthly survey collects information from about 50,000 households every month on a wide range of topics, including current employment status, wages, and work schedules. Specifically, we used the industry shares to weight the worker data in the CPS so that the industry composition of the workers in the CPS sample matches the industry composition of the new jobs that will be added by spending on biofuels and biomass O\&M. We do this by using the industry shares to adjust the CPS-provided sampling weights, which weight the survey sample so that it is representative at the national and state levels. We use the industry shares to adjust these sampling weights so that the sample of workers in the CPS is representative of the industrial mix of jobs that IMPLAN estimates will be produced by a particular investment. We merge the industry share data from our IMPLAN input-output model to the CPS worker data using the most detailed industry variable provided in the CPS. ${ }^{27}$

Some of the IMPLAN industries had to be aggregated to match the industry variable in the CPS, which has 273 categories, and vice versa. So, for example, at the 440-sector level, there are seven construction sectors, while the CPS has only one construction industry. In the end, 181 industry sectors are common to both sets of data.

We adjusted the CPS-provided sampling weights by multiplying each individual worker's sampling weight with the following formula:

$$
S \times \frac{\text { IMPLAN's estimate of the share of new jobs in worker i's industry } j}{\Sigma \text { CPS sampling weights of all workers in industry } j}
$$


where $S$ is a scalar equal to the number of jobs produced overall the level of investment being considered. For example, say a national investment of $\$ 1$ billion would generate 20,000 jobs, then $S$ is equal to 20,000 . We use these adjusted sampling weights to estimate the proportion of workers in jobs associated with an investment program that has a high school degree and no college experience, some college but no bachelor's degree, and a bachelor's degree or more. We then assume that the same proportion of jobs produced by an investment program requires each level of education credentials.

Incorporating effects of technical change and labor productivity in employment estimates

As emphasized in the Chapter 6 text, the most significant limitation of standard I-O models is that they are fixed coefficient models. As such, they are not designed to take account of the effects on job creation of technical change and labor productivity growth over time. For our purposes, this raises the question of how our employment estimates might be affected if we were take account of technical change and labor productivity growth over time.

We consider here two sets of evidence to address this question: output multipliers over time for alternative U.S. energy sectors, based on figures from annual I-O tables; and data on U.S. labor productivity growth trends relative to aggregate output growth trends. We also consider here a broader set of relevant analytic and empirical issues on the relationship between output, labor productivity and employmentboth with respect to the U.S. economy specifically, as well as more generally.

\section{Evidence from output multipliers}

The World Input-Output Database, or WIOD, a project of the European Commission, produces annual I-O tables on a country-by-country basis. To date, they have produced tables for 40 countries from 1995 to 2011, including the United States. These I-O tables enable us to generate output multipliers-the amount of output across all sectors of the economy that is generated by a given dollar amount of spending - as they apply within each of the relevant U.S. energy sectors. But they do not contain sufficient information through which we can produce employment-to-output ratios-i.e., the amount of employment associated with a given level of output. ${ }^{28}$ 
The WIOD annual I-O tables are more aggregated than the ones we used to produce the employment estimates presented in Chapter 6. The sectors in the WIOD are standardized across countries. There are 34 industrial sectors in the I-O tables for the United States.

Output multipliers are calculated from the Leontief inverse from the U.S. I-O data. The Leontief inverse matrix is given by $\mathrm{L}=(\mathrm{I}-\mathrm{A})^{-1}$ in which $\mathrm{L}$ is the Leontief inverse matrix, I is the identify matrix, and $\mathrm{A}$ is the matrix of input-output coefficients derived from the WIOD tables. The energy sectors analyzed in this report are synthetic sectors in that they represent weighted averages of the sectors that actually appear in the I-O tables. The weights for determining the output multipliers of these sectors correspond to the weights used in the employment estimates as discussed earlier in this appendix. Since the WIOD tables are more aggregated than the I-O tables used in the primary analytics of this report, the weights had to be adjusted to match the 34 sectors of the WIOD tables.

We are able to generate comparative energy-sector output multipliers for 1995the first year of the available WIOD tables_-and 2007. We are using the 2007 I-O tables as the end point in our time series rather than 2011, the last year of available data, because we want to avoid having the patterns we observe be influenced by the impact of the 2008-2009 global financial crisis and Great Recession. Our focus here is longer-term developments in the U.S. economy's productive structures, not on cyclical effects.

We present the results of this exercise in Table A4.2, which, for both 1995 and 2007, shows the output multipliers for the following energy sectors: bioenergy, hydro, wind, solar, geothermal, building retrofits, grid upgrades, industrial efficiency, oil and gas, and coal. From these 1995 and 2007 figures, we then show the average annual percentage change in the output multipliers for each of these energy sectors. As we can see, the change in the sectoral output multipliers between 1995 and 2007 are modest across the board. The full range of estimates for the clean energy sectors falls between -0.1 and -0.9 percent per year, and the median estimate for these sectors is -0.4 percent per year.

The modestly negative trends for the output multipliers reflect some combination of three possible factors: a decline in domestic inputs relative to foreign inputs (imports) in contributing to total U.S. output; productivity improvements in the sectors providing inputs; or price reductions independent of productivity improvements for the goods and services used as inputs. But, assuming these 
figures are accurate, we can conclude that production relationships between the various U.S. energy sectors did not change significantly over the 12-year period between 1995 and 2007.

TABLE A4.2

Change in U.S. output multipliers for alternative energy sectors, 1995-2007

\begin{tabular}{|c|c|c|c|}
\hline & $\begin{array}{l}1995 \text { output } \\
\text { multiplier }\end{array}$ & $\begin{array}{l}2007 \text { output } \\
\text { multiplier }\end{array}$ & $\begin{array}{c}\text { Average annual } \\
\text { percent change in output } \\
\text { multipliers }\end{array}$ \\
\hline \multicolumn{4}{|l|}{ Renewables } \\
\hline Bioenergy & 1.95 & 1.85 & $-0.4 \%$ \\
\hline Hydro & 1.80 & 1.77 & $-0.1 \%$ \\
\hline Wind & 1.90 & 1.83 & $-0.1 \%$ \\
\hline Solar & 1.88 & 1.72 & $-0.7 \%$ \\
\hline Geothermal & 1.76 & 1.70 & $-0.3 \%$ \\
\hline \multicolumn{4}{|l|}{ Energy efficiency } \\
\hline Building retrofits & 1.90 & 1.77 & $-0.6 \%$ \\
\hline Grid upgrades & 1.97 & 1.76 & $-0.9 \%$ \\
\hline Industrial efficiency & 1.85 & 1.78 & $-0.4 \%$ \\
\hline \multicolumn{4}{|l|}{ Fossil fuels } \\
\hline Oil and gas & 1.59 & 1.59 & 0 \\
\hline Coal & 1.76 & 1.66 & $-0.5 \%$ \\
\hline $\begin{array}{l}\text { Range of estimates for } \\
\text { clean energy sectors }\end{array}$ & $1.76-1.97$ & $1.70-1.85$ & $-0.1--0.9 \%$ \\
\hline $\begin{array}{l}\text { Median estimates for } \\
\text { clean energy sectors }\end{array}$ & 1.89 & 1.77 & $-0.4 \%$ \\
\hline
\end{tabular}

\section{Evidence on labor productivity, output, and employment}

What is likely to be the combined effects of U.S. GDP and labor productivity growth over our 20-year clean energy investment period? This will depend on the relative rates of output and labor productivity growth. Before considering the relevant data trends for the U.S. economy, it will be useful to consider three broad sets of 
possibilities: that both GDP and productivity grow, alternatively, at low, medium and high rates. As we present in Table A4.3, these three sets of possibilities produce nine alternative possibilities for employment growth, based on the alternative trajectories for both GDP and labor productivity growth.

TABLE A4.3

Possible impacts on employment from varying rates of GDP growth and labor productivity growth

\begin{tabular}{l|l|c|c|c}
\hline \multirow{2}{*}{} & \multicolumn{4}{|c}{ Rate of labor productivity growth } \\
\cline { 2 - 5 } & Low & No employment impact & Medium & High \\
\hline \multirow{3}{*}{$\begin{array}{l}\text { Rate } \\
\text { of GDP } \\
\text { growth }\end{array}$} & Medium & $\begin{array}{c}\text { Small employment } \\
\text { increase }\end{array}$ & $\begin{array}{c}\text { No employment impact } \\
\text { decline }\end{array}$ & $\begin{array}{c}\text { Sarge employment } \\
\text { decline }\end{array}$ \\
\cline { 2 - 5 } & High & $\begin{array}{c}\text { Large employment } \\
\text { increase }\end{array}$ & $\begin{array}{c}\text { Small employment } \\
\text { increase }\end{array}$ & No employment impact \\
\end{tabular}

Source: Based on author analysis

As Table A4.3 shows, if output and labor productivity are both growing at the same rate - that is, if both are growing at low, medium, or high rates - there will be no change in employment over the 20-year investment period relative to the effects that we estimate for year one. Each additional unit of GDP will have been produced as a result of an exactly equal increase in productivity. However, as Table A 4.3 also shows, in all cases in which output growth exceeds labor productivity growth, the net effect will be that employment will expand over time relative to the effects that we estimate in year one of our clean energy investment cycle. As we show in Table A4.3, the only way in which employment from clean energy investments will decline significantly over the 20 -year investment period is when labor productivity growth exceeds output growth by a significant amount.

In Table A4.4, we show figures on U.S. GDP and labor productivity growth over three different time periods: 1995 to 2007, corresponding with the time period of the annual I-O data series; 1994 to 2013, as the most recent full 20-year period; and 1954 to 2103 , the full 60 -year period over which we have adequate data coverage. As we see, in all three time periods U.S. GDP growth has exceeded productivity growth. Over the 12-year period from 1995 to 2007, annual GDP growth was, on average, 0.6 percent faster than productivity growth. Over the full 60 -year period, average GDP growth exceeded labor productivity growth by a 
somewhat greater 0.8 percent average annual figure. The difference between GDP and labor productivity growth narrows to 0.2 percent between 1994 and 2013, since this period incorporates the sharp decline in GDP growth associated with the 2007-2009 financial crisis and Great Recession and the subsequent weak recovery from the recession. But even when taking account of the recession and weak recovery, it is still the case that GDP is growing faster, on average, than labor productivity. This result supports the conclusion that our estimates of employment gains from clean energy investments over time will tend to increase as output increases faster than labor productivity growth.

TABLE A4.4

U.S. average annual GDP growth and labor productivity growth over various time periods

\begin{tabular}{lccc}
\hline & $\begin{array}{c}1 . \\
\text { Average annual } \\
\text { GDP growth }\end{array}$ & $\begin{array}{c}2 . \\
\text { Average annual } \\
\text { labor productivity } \\
\text { growth }\end{array}$ & $\begin{array}{c}3 . \\
\text { GDP growth - } \\
\text { labor productivity growth } \\
\text { (= columns 1-2) }\end{array}$ \\
\hline $\begin{array}{l}\text { 1995-2007 } \\
\text { (to match time period } \\
\text { for annual l-0 tables) }\end{array}$ & $3.2 \%$ & $2.6 \%$ & $+0.6 \%$ \\
$1994-2013$ & $2.4 \%$ & $2.2 \%$ & $+0.2 \%$ \\
$1954-2013$ & $3.1 \%$ & $2.3 \%$ & $+0.8 \%$
\end{tabular}

Source: U.S. Bureau of Economic Analysis, "National Income and Product Accounts Tables," available at: http://www.bea.gov/iTable/index nipa.cfm; U.S. Bureau of Labor Statistics, "Major Sector Productivity and Cost Tables," available at: http://data.bls.gov/cgi-bin/surveymost?pr.

\section{Broader Evidence on the relationship between output and productivity growth}

The literature on the relationship between labor productivity and output growth shows that these two growth rates do generally move together, with output growth typically increasing at a faster rate than productivity growth. One critical factor here is that, as an arithmetic identity, output can increase through both a rise in the number of people working and the number of hours people are employed at jobs, as well as by raising worker-productivity levels during their time on the job. As such, when demand for a product increases, this will lead to increases in the production of that product, and subsequently, more people employed for more hours to produce the product. An expansion in the demand for clean energy will therefore produce an expansion in output and employment in these sectors that should exceed increases in labor productivity generated within these sectors. 
The relationship between output and labor productivity growth is broadly analyzed in the literature within the framework of the Kaldor-Verdoorn effect. Overall, the empirical results from this literature are robust in finding that increases in labor productivity growth are between 30 percent and 60 percent as large as any given increase in output growth. This would mean, for example, if U.S. output grows by 3 percent over a given period of time, productivity should then typically increase over this same period by between 1 percent and 2 percent. $^{29}$

If we operate broadly within the analytic framework of the Kaldor-Verdoorn law, which is generally supported by the U.S. output and labor productivity growth figures we have reviewed here, it is reasonable for us to conclude that the levels of employment that we have estimated in terms of the I-O relationships in our 2009 data will be typically increasing over the 20 -year investment period.

\section{Conclusion on effects of technical change and labor productivity}

As we state in Chapter 6, we reach two main conclusions from the evidence reviewed here. The first is that the changes in the labor requirements for clean energy investment activities are likely to be relatively modest over our relevant time period. We reach this conclusion by examining the changes in the input-output relationships for the United States between 1995 and 2007. In addition, we conclude that, if anything, the positive employment creation effects from clean energy investments are most likely to increase with time. This is because the average rate of GDP growth will typically exceed the average rate of labor-productivity growth. This means that economic growth - and specifically the expansion of the clean energy sectors tied to the economy's growth rate-will require more employment over time. 


\section{Appendix 5: Estimating fiscal impacts of clean energy public policy programs}

This appendix provides estimates of the fiscal impact of the series of clean energy policies we presented in Chapter 8, which are meant to be representative of the measures that are already in place within the United States at either the federal, state, or local level. This is not meant to be a complete list of all policies that are either in operation today within the United States or that could potentially emerge as new initiatives.

As we state in Chapter 8, we are not necessarily advocating on behalf of the specific tax rates or expenditure levels that we present here. Significantly more detailed research is necessary to establish the most effective specific features for each of our expenditures or revenue-generating programs. We assigned specific features for each program based on how these programs are presently operating or how the analysts we cite in Chapter 8 have proposed they operate. In terms of the various spending programs, we then scaled the levels of expenditure to correspond with the expanded clean energy investment program and simplified the features of the program in order to keep our calculations and presentation as straightforward and accessible as possible.

We present the assumptions underlying each of the programs in the order that we presented them in Chapter 8, including Table 8.1. Based on the assumptions we have made, we then present our estimates for both revenue generation/net savings and expenditures. We present full calculations in Tables A5.1 and A5.2 for the green banks and loan-guarantee programs since the full set of assumptions and cash-flow estimates generated by these assumptions are more complex than with the other programs. We show detailed annual estimates for all programs in Table A5.3. These figures provide the underlying data for the summary figures that we presented in in Chapter 8. We have reproduced those summary figures here in Table A5.4. 
Market-shaping rules

\section{Carbon cap or tax}

We work here with the features of the GHG Price Economywide case presented in the 2011 AEO. In this case:

an economy-wide carbon allowance price is examined. The price begins at $\$ 25$ per metric ton $\mathrm{CO}_{2}$ in 2013 and rises to $\$ 75$ per metric ton $\mathrm{CO}_{2}$ in 2035 (2009 dollars). This trajectory is consistent with the cost containment provisions in both the Kerry-Lieberman and Waxman-Markey GHG legislation. No assumptions are made for offsets, bonus allowances for CCS or specific allocation of allowances in these cases. ${ }^{30}$

In our scenario, the $\mathrm{CO}_{2}$ price begins at $\$ 25$ per metric ton in the first year and rises steadily for 20 years until it reaches $\$ 7520$ years later. Our estimates for revenues are then based on the assumptions of the PERI/CAP case summarized in Chapter 5, in which overall $\mathrm{CO}_{2}$ emissions fall over 20 years from the 2010 approximate level of 5,600 $\mathrm{mmt}$ to approximately 3,000 after 20 years.

\section{Administrative and enforcement costs for new clean energy regulations}

These estimates are based on the Environmental Protection Agency's 2013 Budget in Brief..$^{31}$ The costs of enforcing environmental regulations were $\$ 830$ million in 2013. The costs of EPA's climate change programs were $\$ 240$ million. The climate change programs include fuel-efficiency standards, clean-automobile technologies, and gathering and reporting data on greenhouse gas emissions. We assume a 50 percent increase in the costs of enforcing environmental regulations, bringing the total to $\$ 1.7$ billion, and a tripling of the cost of EPA's climate change programs, bringing that figure to $\$ 720$ million. The total thus comes up to $\$ 2.4$ billion annually, but the net increase over current costs is approximately $\$ 900$ million. That includes a $\$ 415$ million increase in enforcement costs and $\$ 480$ million in climate change program costs.

\section{Direct public spending}

\section{Public-buildings energy efficiency investments}

The information used to estimate the cost of retrofitting federal, state, and local buildings is taken from the Bureau of Economic Analysis and the compliance tracking system for Section 432 of the Energy Independence and Security Act, or 
EISA. ${ }^{32}$ The federal government has budgeted $\$ 20$ billion in total to comply with the terms of EISA that are presented in Chapter 8 , of which $\$ 10$ billion has already been appropriated. We assume the remaining $\$ 10$ billion will be allocated over the next five years.

According to BEA data, the value of state and local government building assets was 7.7 times the value of federal building assets in 2012. Using the ratio of state and local building stock to federal building stock, the total cost to state and local governments to reach a similar standard as that set in EISA would be approximately $\$ 155$ billion. We assume those investments will be spread evenly over the full 20-year program.

We then assume that the average annual level of savings from all such public-building retrofit investments will equal 20 percent of total investment. The evidence we have presented in Chapter 2 suggests that, on average, annual returns from such investments are, in fact, closer to 30 percent. However, for our purposes here, we want to be careful to not overstate the benefits of these building efficiency investments. Rather, if anything, we want to err on the side of understating them. As such, we deliberately chose to work with relatively conservative assumptions on the returns.

\section{Federal research and development for efficiency and renewables}

The analysis of federal research and development spending from Sissine on energy efficiency and renewable energy technologies estimates that cumulative spending over the decade from 2003 to 2012 was $\$ 13.4$ billion (in real 2011 dollars), or $\$ 1.34$ billion a year. ${ }^{33}$ In comparison, over the same decade the Energy Department spent $\$ 20.4$ billion, or \$2.0 billion annually, on fossil fuel and nuclear R\&D. Over the 65-year period from 1948 to 2012, the Energy Department spent an average of $\$ 2$ billion per year on fossil fuel and nuclear R\&D.

It is beyond the scope of this study to establish systematically what would constitute a sufficient level of $R \& D$ spending to provide the technological foundation for delivering low-cost clean renewable energy and energy efficiency systems over the next 20 years. As one reference point, though, we can assume that the total amount of clean energy $R \& D$ should equal the amount now spent on fossil fuels and nuclear power, in addition to the current budget for renewables and energy efficiency. That would mean a total annual clean energy R\&D budget of about $\$ 3.5$ billion per year. 


\section{Production tax credits}

At the time of writing, federal production tax credits of 2.3 cents per kilowatt hour are available for wind, geothermal, and biomass energy production. Credits equal to 1.1 cents per kilowatt hour are given for other renewable forms of electricity production from sources such as small hydro, tidal energy, or landfill gas. Production tax credits typically last for 10 years. For the purposes of these estimates, we assume a credit of 2 cents per kilowatt hour on all clean renewable production, with the subsidy expiring after 10 years.

In Chapter 3, we estimated that clean renewable energy production in the United States will need to reach 15.4 Q-BTUs within 20 years relative to its current level of about 3.6 Q-BTUs - an increase of 11.8 Q-BTUs. We assume clean renewable production increases at a steady rate throughout this 20 -year investment period. Based on these assumptions as to the annual growth in clean renewable energy production over the 20-year investment cycle, we are then able to estimate the level of federal support that would result through a 2 cent per kilowatt hour production tax credit that applied to all U.S. clean renewable production.

\section{Investment tax credits}

The current Business Energy Investment Tax Credit provides a tax credit of 10 percent to 30 percent of capital costs, depending on the technology in question, for renewable energy and energy efficiency investments. Federal tax credits also exist for energy efficiency improvements to commercial spaces. There are also residential tax credits for energy efficiency improvements and renewable energy investments, but many of these have a maximum tax credit $-\$ 500$, for example.

For the purposes of these estimates, we assume an average federal investment tax credit equal to 30 percent that would apply to all $\$ 90$ billion in annual energy efficiency investments. We assume that the investment tax credit does not apply to renewable investments, since these are all eligible to receive the production tax credit described above.

\section{Green banks}

For the purposes of this discussion, we consider the operations of federal and state-level green banks as one integrated program. To generate cost estimates, we make the following assumptions regarding the activities of public green banks: 
- Total initial capitalization is $\$ 4$ billion in the first year, and is fully loaned out in the first year.

- The maturity on the loans is 10 years, and the interest rate is 4 percent.

- Lending increases by $\$ 4$ billion annually every year thereafter for the 20 -year period. As such, the additional $\$ 4$ billion in loans through year 10 are provided by increasing capitalization. Beginning in year 11 , the additional $\$ 4$ billion in loans are covered through the $\$ 4$ billion repayment of principal of the loans extended in the first 10 years.

- Annual interest payments of 1 percentage point are used to fund the operations of the banks. The other 3 percent constitute net returns to the green banks.

In Table A5.1, we see the annual overall cash flow for green banks generated by these assumptions. As we see, the average combined costs over 20 years to both the federal and state governments that establish green banks under these terms is about $\$ 1.1$ billion. But overall costs flip from positive to negative-from net expenditures to net savings-beginning in year 11 . We also do not include in our calculations the fact that the capitalization costs from the green banks can be recovered if the banks were to end their operations. 
TABLE A5.1

Federal and state green bank programs: Estimating annual program costs over 20 years

Assumptions of program:

- Initial capitalization is $\$ 4$ billion

- All loans carry 10-year maturity

- Interest rate on loans is 4 percent

- 1 percent of interest returns covers administrative costs

- Lending increases by \$4 billion/year for 20-year period

\begin{tabular}{|c|c|c|c|c|c|}
\hline $\begin{array}{l}\text { Year of } \\
\text { program }\end{array}$ & $\begin{array}{c}\text { Annual } \\
\text { capitalization } \\
\text { (in billions) }\end{array}$ & $\begin{array}{l}\text { Cumulative } \\
\text { capitalization } \\
\text { (in billions) }\end{array}$ & $\begin{array}{c}\text { Loan } \\
\text { portfolio } \\
\text { (in billions) }\end{array}$ & $\begin{array}{l}\text { Interest returns at } 3 \\
\text { percent net return } \\
\text { (in billions) }\end{array}$ & $\begin{array}{l}\text { Net costs to } \\
\text { government } \\
\text { (in billions) }\end{array}$ \\
\hline 1 & $\$ 4.0$ & $\$ 4.0$ & $\$ 4.0$ & $\$ 0.12$ & $\$ 3.88$ \\
\hline 2 & $\$ 4.0$ & $\$ 8.0$ & $\$ 8.0$ & $\$ 0.24$ & $\$ 3.76$ \\
\hline 3 & $\$ 4.0$ & $\$ 12.0$ & $\$ 12.0$ & $\$ 0.36$ & $\$ 3.64$ \\
\hline 4 & $\$ 4.0$ & $\$ 16.0$ & $\$ 16.0$ & $\$ 0.48$ & $\$ 3.52$ \\
\hline 5 & $\$ 4.0$ & $\$ 20.0$ & $\$ 20.0$ & $\$ 0.60$ & $\$ 3.40$ \\
\hline 6 & $\$ 4.0$ & $\$ 24.0$ & $\$ 24.0$ & $\$ 0.72$ & $\$ 3.28$ \\
\hline 7 & $\$ 4.0$ & $\$ 28.0$ & $\$ 28.0$ & $\$ 0.84$ & $\$ 3.16$ \\
\hline 8 & $\$ 4.0$ & $\$ 32.0$ & $\$ 32.0$ & $\$ 0.96$ & $\$ 3.04$ \\
\hline 9 & $\$ 4.0$ & $\$ 36.0$ & $\$ 36.0$ & $\$ 1.08$ & $\$ 2.92$ \\
\hline 10 & $\$ 4.0$ & $\$ 40.0$ & $\$ 40.0$ & $\$ 1.20$ & $\$ 2.80$ \\
\hline 11 & 0 & $\$ 40.0$ & $\$ 40.0$ & $\$ 1.20$ & $-\$ 1.20$ \\
\hline 12 & 0 & $\$ 40.0$ & $\$ 40.0$ & $\$ 1.20$ & $-\$ 1.20$ \\
\hline 13 & 0 & $\$ 40.0$ & $\$ 40.0$ & $\$ 1.20$ & $-\$ 1.20$ \\
\hline 14 & 0 & $\$ 40.0$ & $\$ 40.0$ & $\$ 1.20$ & $-\$ 1.20$ \\
\hline 15 & 0 & $\$ 40.0$ & $\$ 40.0$ & $\$ 1.20$ & $-\$ 1.20$ \\
\hline 16 & 0 & $\$ 40.0$ & $\$ 40.0$ & $\$ 1.20$ & $-\$ 1.20$ \\
\hline 17 & 0 & $\$ 40.0$ & $\$ 40.0$ & $\$ 1.20$ & $-\$ 1.20$ \\
\hline 18 & 0 & $\$ 40.0$ & $\$ 40.0$ & $\$ 1.20$ & $-\$ 1.20$ \\
\hline 19 & 0 & $\$ 40.0$ & $\$ 40.0$ & $\$ 1.20$ & $-\$ 1.20$ \\
\hline 20 & 0 & $\$ 40.0$ & $\$ 40.0$ & $\$ 1.20$ & $-\$ 1.20$ \\
\hline Total & - & $\$ 40$ billion & - & $\begin{array}{c}\$ 18.6 \text { billion }= \\
\$ 0.93 \text { billion/year } \\
\text { average }\end{array}$ & $\begin{array}{c}\$ 21.4 \text { billion }= \\
\$ 1.07 \text { billion/year } \\
\text { average }\end{array}$ \\
\hline
\end{tabular}

Source: See text of Chapter 8 and Appendix 5 


\section{Loan guarantees}

To provide a high-end estimate of the costs of a major federal loan guarantee program for clean energy investments, we work with the following set of assumptions:

- 10 percent of the $\$ 200$ billion in annual investments in renewable energy and energy efficiency are eligible for government loan guarantees, which amounts to $\$ 20$ billion in new guaranteed loans. This annual figure is greater than the $\$ 14$ billion in total guaranteed loans that were provided over two years through the Section 1705 program within the ARRA, which we discussed in Chapter 7.

- All loans carry a maturity of 10 years.

- Following the 1705 program, the guarantee rate on the loans is 80 percent.

- Total defaults in the 1705 program to date have amounted to 4.3 percent of the $\$ 14$ billion in guaranteed loans outstanding. This is over the roughly five-year period since the first loan guarantees were awarded in the second half of 2009. For our estimates, we therefore assume an annual default rate of 1 percent of the total value of loans outstanding. That is, we round the 4.3 percent of defaults in the 1705 program up to 5 percent. The 5 percent default rate is then over 5 years, which averages to 1 percent per year.

- The asset-recovery rate on defaulted loans is 50 percent.

Working with these assumptions, in Table A5.2, we show the government costs of such a portfolio of guaranteed loans. As we can see, year two is the first year in which the government incurs costs due to defaults, derived from the $\$ 20$ billion in loan guarantees in year one. The cost for those $\$ 20$ billion in loans is $\$ 80$ million, derived as follows:

$$
\begin{gathered}
(\$ 20 \text { billion in guaranteed loans }) \times(80 \% \text { guarantee }) \times \\
(1 \% \text { default rate }) \times(50 \% \text { asset recovery rate })=\$ 80 \text { million }
\end{gathered}
$$


TABLE A5.2

Federal loan guarantee program for clean energy investments:

Estimating annual costs for 20 -year program

Assumptions of program:

- 10 percent of annual investments receive loan guarantees

- All loans carry 10-year maturity

- 80 percent guarantee rate on loans

- 5 percent default rate on loans

- 50 percent asset recovery rate on defaulted loans

\begin{tabular}{|c|c|c|c|}
\hline $\begin{array}{l}\text { Year of } \\
\text { program }\end{array}$ & $\begin{array}{l}\text { Annual increase } \\
\text { in guaranteed loans } \\
\text { (in billions) }\end{array}$ & $\begin{array}{l}\text { Total outstanding } \\
\text { guaranteed loans } \\
\text { (in billions) }\end{array}$ & $\begin{array}{l}\text { Government obligations } \\
\text { on defaulted loans } \\
\text { (in billions) }\end{array}$ \\
\hline 1 & $\$ 20$ & $\$ 20$ & 0 \\
\hline 2 & $\$ 20$ & $\$ 40$ & $\$ 0.08$ \\
\hline 3 & $\$ 20$ & $\$ 60$ & $\$ 0.16$ \\
\hline 4 & $\$ 20$ & $\$ 80$ & $\$ 0.24$ \\
\hline 5 & $\$ 20$ & $\$ 100$ & $\$ 0.32$ \\
\hline 6 & $\$ 20$ & $\$ 120$ & $\$ 0.40$ \\
\hline 7 & $\$ 20$ & $\$ 140$ & $\$ 0.48$ \\
\hline 8 & $\$ 20$ & $\$ 160$ & $\$ 0.56$ \\
\hline 9 & $\$ 20$ & $\$ 180$ & $\$ 0.64$ \\
\hline 10 & $\$ 20$ & $\$ 200$ & $\$ 0.72$ \\
\hline 11 & $\$ 20$ & $\$ 200$ & $\$ 0.80$ \\
\hline 12 & $\$ 20$ & $\$ 200$ & $\$ 0.80$ \\
\hline 13 & $\$ 20$ & $\$ 200$ & $\$ 0.80$ \\
\hline 14 & $\$ 20$ & $\$ 200$ & $\$ 0.80$ \\
\hline 15 & $\$ 20$ & $\$ 200$ & $\$ 0.80$ \\
\hline 16 & $\$ 20$ & $\$ 200$ & $\$ 0.80$ \\
\hline 17 & $\$ 20$ & $\$ 200$ & $\$ 0.80$ \\
\hline 18 & $\$ 20$ & $\$ 200$ & $\$ 0.80$ \\
\hline 19 & $\$ 20$ & $\$ 200$ & $\$ 0.80$ \\
\hline 20 & $\$ 20$ & $\$ 200$ & $\$ 0.80$ \\
\hline Total & - & - & $\begin{array}{c}\$ 11.6 \text { billion }= \\
\$ 580 \text { million/year }\end{array}$ \\
\hline
\end{tabular}

Source: See text of Chapter 8 and Appendix 5 
As we see in Table A5.2, the total portfolio of loan guarantees grows by $\$ 20$ billion per year for the first 10 years of the program. In year 11, the extension of new loans at $\$ 20$ billion per year is matched by the loans either being paid back in full—in the case of the 95 percent of loans that are performing — or taken off the books due to default, as with the remaining 5 percent of loans.

The government's overall portfolio of guaranteed loans outstanding therefore totals $\$ 200$ billion in year 10 . The annual costs of the guarantee program to the government correspondingly levels off at $\$ 4$ billion per year in year 11 . Within this framework, we can see that the total costs over 20 years of the program are $\$ 11.6$ billion, which averages to $\$ 580$ million per year.

\section{Master limited partnerships and real estate investment trusts}

As we discuss in Chapter 8, master limited partnerships, or MLPs, and real estate investment trusts, or REITs are corporate tax structures designed to encourage investments in large-scale projects by limiting the resultant tax burden of such investments. For the purposes of our fiscal impact analysis, we assume that $\$ 10$ billion per year in new private-sector clean energy investments will receive the tax benefits of either an MLP or REIT. Over 20 years, this tax benefit therefore covers $\$ 200$ billion in accumulated assets. We assume the rate of return on these assets is 10 percent, and that the tax benefit of either MLP or REIT status is 35 percent of the return on assets.

\section{Regional equity and worker-transition assistance}

Worker training

Following the discussion in Chapter 8, we assume the costs of this program will be $\$ 500$ million per year.

\section{Targeted community adjustment assistance}

Following the discussion in Chapter 8, we assume the costs of this program will be $\$ 200$ million per year.

\section{Worker adjustment assistance}

Following the discussion in Chapter 8, we assume the costs of this program will be $\$ 800$ million per year. 
TABLE A5.3

Estimated 20-year public budgetary impacts through policies supporting $\$ 200$ billion annual U.S. clean energy investment program

A. Market-shaping rules

\begin{tabular}{|c|c|c|c|c|}
\hline \multirow{2}{*}{$\begin{array}{l}\text { Year of } \\
\text { program }\end{array}$} & \multicolumn{3}{|c|}{$\mathrm{CO}_{2}$ emissions tax or cap } & \multirow{2}{*}{$\begin{array}{l}\text { Administration/enforce- } \\
\text { ment costs for new clean } \\
\text { energy regulations } \\
\text { (expenditures in billions) }\end{array}$} \\
\hline & $\begin{array}{l}\mathrm{CO}_{2} \text { emissions } \\
\text { level (mmt) }\end{array}$ & $\begin{array}{c}\mathrm{CO}_{2} \text { price } \\
\text { (dollars/mmt of } \\
\text { emissions) }\end{array}$ & $\begin{array}{l}\text { Revenues } \\
\text { (in billions) }\end{array}$ & \\
\hline 1 & 5,600 & $\$ 25.00$ & $\$ 140.0$ & $\$ 0.90$ \\
\hline 2 & 5,463 & $\$ 27.63$ & $\$ 151.0$ & $\$ 0.90$ \\
\hline 3 & 5,326 & $\$ 30.26$ & $\$ 161.2$ & $\$ 0.90$ \\
\hline 4 & 5,189 & $\$ 32.89$ & $\$ 170.7$ & $\$ 0.90$ \\
\hline 5 & 5,053 & $\$ 35.53$ & $\$ 179.5$ & $\$ 0.90$ \\
\hline 6 & 4,916 & $\$ 38.16$ & $\$ 187.6$ & $\$ 0.90$ \\
\hline 7 & 4,779 & $\$ 40.79$ & $\$ 194.9$ & $\$ 0.90$ \\
\hline 8 & 4,642 & $\$ 43.42$ & $\$ 201.6$ & $\$ 0.90$ \\
\hline 9 & 4,505 & $\$ 46.05$ & $\$ 207.5$ & $\$ 0.90$ \\
\hline 10 & 4,368 & $\$ 48.68$ & $\$ 212.7$ & $\$ 0.90$ \\
\hline 11 & 4,232 & $\$ 51.32$ & $\$ 217.1$ & $\$ 0.90$ \\
\hline 12 & 4,095 & $\$ 53.95$ & $\$ 220.9$ & $\$ 0.90$ \\
\hline 13 & 3,958 & $\$ 56.58$ & $\$ 223.9$ & $\$ 0.90$ \\
\hline 14 & 3,821 & $\$ 59.21$ & $\$ 226.2$ & $\$ 0.90$ \\
\hline 15 & 3,684 & $\$ 61.84$ & $\$ 227.8$ & $\$ 0.90$ \\
\hline 16 & 3,547 & $\$ 64.47$ & $\$ 228.7$ & $\$ 0.90$ \\
\hline 17 & 3,411 & $\$ 67.11$ & $\$ 228.9$ & $\$ 0.90$ \\
\hline 18 & 3,274 & $\$ 69.74$ & $\$ 228.3$ & $\$ 0.90$ \\
\hline 19 & 3,137 & $\$ 72.37$ & $\$ 227.0$ & $\$ 0.90$ \\
\hline 20 & 3,000 & $\$ 75.00$ & $\$ 225.0$ & $\$ 0.90$ \\
\hline $\begin{array}{l}\text { Averages } \\
\text { per year }\end{array}$ & $4,300 \mathrm{mmt}$ & $\$ 50.00$ per $\mathrm{mmt}$ & $\$ 203.0$ billion & $\$ 0.9$ billion \\
\hline
\end{tabular}

Source: See text of Chapter 8 and Appendix 5 
TABLE A5.3 (continued)

Estimated 20-year public budgetary impacts through policies supporting $\$ 200$ billion annual U.S. clean energy investment program

B. Direct public spending

\begin{tabular}{|c|c|c|c|c|}
\hline \multirow{2}{*}{$\begin{array}{l}\text { Year of } \\
\text { program }\end{array}$} & \multicolumn{2}{|c|}{ Public buildings energy-efficiency investments } & \multirow{2}{*}{$\begin{array}{l}\text { Federal } \\
\text { renewable } \\
\text { energy } \\
\text { procurement } \\
\text { programs }\end{array}$} & \multirow{2}{*}{$\begin{array}{l}\text { Federal R\&D } \\
\text { for efficiency } \\
\text { and renewables } \\
\text { (expenditures } \\
\text { inbillions) }\end{array}$} \\
\hline & $\begin{array}{l}\text { Federal government } \\
\text { buildings (expendi- } \\
\text { tures inbillions) }\end{array}$ & $\begin{array}{c}\text { State and local govern- } \\
\text { ment buildings (expen- } \\
\text { ditures inbillions) }\end{array}$ & & \\
\hline 1 & $\$ 1.60$ & $\$ 6.2$ & 0 & $\$ 3.50$ \\
\hline 2 & $\$ 1.20$ & $\$ 4.7$ & 0 & $\$ 3.50$ \\
\hline 3 & $\$ 0.80$ & $\$ 3.1$ & 0 & $\$ 3.50$ \\
\hline 4 & $\$ 0.40$ & $\$ 1.6$ & 0 & $\$ 3.50$ \\
\hline 5 & $\$ 0.00$ & $\$ 0.0$ & 0 & $\$ 3.50$ \\
\hline 6 & $-\$ 2.00$ & $-\$ 1.6$ & 0 & $\$ 3.50$ \\
\hline 7 & $-\$ 2.00$ & $-\$ 3.1$ & 0 & $\$ 3.50$ \\
\hline 8 & $-\$ 2.00$ & $-\$ 4.7$ & 0 & $\$ 3.50$ \\
\hline 9 & $-\$ 2.00$ & $-\$ 6.2$ & 0 & $\$ 3.50$ \\
\hline 10 & $-\$ 2.00$ & $-\$ 7.8$ & 0 & $\$ 3.50$ \\
\hline 11 & $-\$ 2.00$ & $-\$ 9.3$ & 0 & $\$ 3.50$ \\
\hline 12 & $-\$ 2.00$ & $-\$ 10.9$ & 0 & $\$ 3.50$ \\
\hline 13 & $-\$ 2.00$ & $-\$ 12.4$ & 0 & $\$ 3.50$ \\
\hline 14 & $-\$ 2.00$ & $-\$ 14.0$ & 0 & $\$ 3.50$ \\
\hline 15 & $-\$ 2.00$ & $-\$ 15.5$ & 0 & $\$ 3.50$ \\
\hline 16 & $-\$ 2.00$ & $-\$ 17.1$ & 0 & $\$ 3.50$ \\
\hline 17 & $-\$ 2.00$ & $-\$ 18.6$ & 0 & $\$ 3.50$ \\
\hline 18 & $-\$ 2.00$ & $-\$ 20.2$ & 0 & $\$ 3.50$ \\
\hline 19 & $-\$ 2.00$ & $-\$ 21.7$ & 0 & $\$ 3.50$ \\
\hline 20 & $-\$ 2.00$ & $-\$ 23.3$ & 0 & $\$ 3.50$ \\
\hline $\begin{array}{l}\text { Averages } \\
\text { per year }\end{array}$ & $\begin{array}{c}\$ 1.3 \text { billion } \\
\text { in net savings }\end{array}$ & $\begin{array}{c}\$ 8.5 \text { billion } \\
\text { in net savings }\end{array}$ & $\begin{array}{l}\text { No direct costs } \\
\text { or savings }\end{array}$ & $\begin{array}{l}\$ 3.5 \text { billion in } \\
\text { expenditures }\end{array}$ \\
\hline
\end{tabular}

Source: See text of Chapter 8 and Appendix 5 
TABLE A5.3 (continued)

Estimated 20 -year public budgetary impacts through policies supporting $\$ 200$ billion annual U.S. clean energy investment program

\section{Private investment incentives}

\begin{tabular}{|c|c|c|c|c|c|c|c|}
\hline $\begin{array}{l}\text { Year of } \\
\text { program }\end{array}$ & $\begin{array}{l}\text { Production } \\
\text { tax credits } \\
\text { (in billions) }\end{array}$ & $\begin{array}{l}\text { Investment } \\
\text { tax credits } \\
\text { (in billions) }\end{array}$ & $\begin{array}{l}\text { Feed-in } \\
\text { tariffs }\end{array}$ & $\begin{array}{l}\text { Green banks (in } \\
\text { billions) }\end{array}$ & $\begin{array}{l}\text { Loan } \\
\text { guarantees } \\
\text { (in billions) }\end{array}$ & $\begin{array}{c}\text { PACE } \\
\text { financing }\end{array}$ & $\begin{array}{l}\text { MLPs and REITs } \\
\text { (in billions) }\end{array}$ \\
\hline 1 & $\$ 3.46$ & $\$ 27.00$ & 0 & $\$ 3.88$ & $\$ 0.00$ & 0 & $\$ 0.35$ \\
\hline 2 & $\$ 6.92$ & $\$ 27.00$ & 0 & $\$ 3.76$ & $\$ 0.08$ & 0 & $\$ 0.70$ \\
\hline 3 & $\$ 10.37$ & $\$ 27.00$ & 0 & $\$ 3.64$ & $\$ 0.16$ & 0 & $\$ 1.05$ \\
\hline 4 & $\$ 13.83$ & $\$ 27.00$ & 0 & $\$ 3.52$ & $\$ 0.24$ & 0 & $\$ 1.40$ \\
\hline 5 & $\$ 17.29$ & $\$ 27.00$ & 0 & $\$ 3.40$ & $\$ 0.32$ & 0 & $\$ 1.75$ \\
\hline 6 & $\$ 20.75$ & $\$ 27.00$ & 0 & $\$ 3.28$ & $\$ 0.40$ & 0 & $\$ 2.10$ \\
\hline 7 & $\$ 24.21$ & $\$ 27.00$ & 0 & $\$ 3.16$ & $\$ 0.48$ & 0 & $\$ 2.45$ \\
\hline 8 & $\$ 27.67$ & $\$ 27.00$ & 0 & $\$ 3.04$ & $\$ 0.56$ & 0 & $\$ 2.80$ \\
\hline 9 & $\$ 31.12$ & $\$ 27.00$ & 0 & $\$ 2.92$ & $\$ 0.64$ & 0 & $\$ 3.15$ \\
\hline 10 & $\$ 34.58$ & $\$ 27.00$ & 0 & $\$ 2.80$ & $\$ 0.72$ & 0 & $\$ 3.50$ \\
\hline 11 & $\$ 34.58$ & $\$ 27.00$ & 0 & $-\$ 1.20$ & $\$ 0.80$ & 0 & $\$ 3.85$ \\
\hline 12 & $\$ 34.58$ & $\$ 27.00$ & 0 & $-\$ 1.20$ & $\$ 0.80$ & 0 & $\$ 4.20$ \\
\hline 13 & $\$ 34.58$ & $\$ 27.00$ & 0 & $-\$ 1.20$ & $\$ 0.80$ & 0 & $\$ 4.55$ \\
\hline 14 & $\$ 34.58$ & $\$ 27.00$ & 0 & $-\$ 1.20$ & $\$ 0.80$ & 0 & $\$ 4.90$ \\
\hline 15 & $\$ 34.58$ & $\$ 27.00$ & 0 & $-\$ 1.20$ & $\$ 0.80$ & 0 & $\$ 5.25$ \\
\hline 16 & $\$ 34.58$ & $\$ 27.00$ & 0 & $-\$ 1.20$ & $\$ 0.80$ & 0 & $\$ 5.60$ \\
\hline 17 & $\$ 34.58$ & $\$ 27.00$ & 0 & $-\$ 1.20$ & $\$ 0.80$ & 0 & $\$ 5.95$ \\
\hline 18 & $\$ 34.58$ & $\$ 27.00$ & 0 & $-\$ 1.20$ & $\$ 0.80$ & 0 & $\$ 6.30$ \\
\hline 19 & $\$ 34.58$ & $\$ 27.00$ & 0 & $-\$ 1.20$ & $\$ 0.80$ & 0 & $\$ 6.65$ \\
\hline 20 & $\$ 34.58$ & $\$ 27.00$ & 0 & $-\$ 1.20$ & $\$ 0.80$ & 0 & $\$ 7.00$ \\
\hline $\begin{array}{l}\text { Averages } \\
\text { per year }\end{array}$ & $\$ 26.8$ billion & $\$ 27$ billion & No direct costs & $\$ 1.1$ billion & $\$ 0.6$ billion & No direct costs & $\$ 3.7$ billion \\
\hline
\end{tabular}

Source: See text of Chapter 8 and Appendix 5 
TABLE A5.3 (continued)

Estimated 20-year public budgetary impacts through policies supporting $\$ 200$ billion annual U.S. clean energy investment program

D. Regional equity and worker transition assistance

\begin{tabular}{|c|c|c|c|c|}
\hline $\begin{array}{l}\text { Year of } \\
\text { program }\end{array}$ & $\begin{array}{l}\text { Promoting } \\
\text { regional equity }\end{array}$ & $\begin{array}{l}\text { Worker training } \\
\text { (in billions) }\end{array}$ & $\begin{array}{c}\text { Targeted community } \\
\text { adjustment assistance (in } \\
\text { billions) }\end{array}$ & $\begin{array}{l}\text { Worker adjustment } \\
\text { assistance } \\
\text { (in billions) }\end{array}$ \\
\hline 1 & 0 & $\$ 0.5$ & $\$ 0.2$ & $\$ 0.8$ \\
\hline 2 & 0 & $\$ 0.5$ & $\$ 0.2$ & $\$ 0.8$ \\
\hline 3 & 0 & $\$ 0.5$ & $\$ 0.2$ & $\$ 0.8$ \\
\hline 4 & 0 & $\$ 0.5$ & $\$ 0.2$ & $\$ 0.8$ \\
\hline 5 & 0 & $\$ 0.5$ & $\$ 0.2$ & $\$ 0.8$ \\
\hline 6 & 0 & $\$ 0.5$ & $\$ 0.2$ & $\$ 0.8$ \\
\hline 7 & 0 & $\$ 0.5$ & $\$ 0.2$ & $\$ 0.8$ \\
\hline 8 & 0 & $\$ 0.5$ & $\$ 0.2$ & $\$ 0.8$ \\
\hline 9 & 0 & $\$ 0.5$ & $\$ 0.2$ & $\$ 0.8$ \\
\hline 10 & 0 & $\$ 0.5$ & $\$ 0.2$ & $\$ 0.8$ \\
\hline 11 & 0 & $\$ 0.5$ & $\$ 0.2$ & $\$ 0.8$ \\
\hline 12 & 0 & $\$ 0.5$ & $\$ 0.2$ & $\$ 0.8$ \\
\hline 13 & 0 & $\$ 0.5$ & $\$ 0.2$ & $\$ 0.8$ \\
\hline 14 & 0 & $\$ 0.5$ & $\$ 0.2$ & $\$ 0.8$ \\
\hline 15 & 0 & $\$ 0.5$ & $\$ 0.2$ & $\$ 0.8$ \\
\hline 16 & 0 & $\$ 0.5$ & $\$ 0.2$ & $\$ 0.8$ \\
\hline 17 & 0 & $\$ 0.5$ & $\$ 0.2$ & $\$ 0.8$ \\
\hline 18 & 0 & $\$ 0.5$ & $\$ 0.2$ & $\$ 0.8$ \\
\hline 19 & 0 & $\$ 0.5$ & $\$ 0.2$ & $\$ 0.8$ \\
\hline 20 & 0 & $\$ 0.5$ & $\$ 0.2$ & $\$ 0.8$ \\
\hline $\begin{array}{l}\text { Averages } \\
\text { per year }\end{array}$ & No direct costs & $\$ 0.5$ billion & $\$ 0.2$ billion & $\$ 0.8$ billion \\
\hline
\end{tabular}


TABLE A5.4

Summary of Average Annual Sources of Revenues/Net

Savings and Expenditures from Clean Energy Policies

Revenues and net savings

\begin{tabular}{|c|c|}
\hline Program & $\begin{array}{l}\text { Revenues or net savings } \\
\quad \text { (in billions) }\end{array}$ \\
\hline Carbon tax or cap & $\$ 203.0$ \\
\hline $\begin{array}{l}\text { Federal and state/local public building energy- } \\
\text { efficiency investments }\end{array}$ & $\$ 9.8$ \\
\hline Total revenue or net saving & $\$ 212.8$ \\
\hline \multicolumn{2}{|l|}{ Expenditures } \\
\hline Program & $\begin{array}{l}\text { Expenditures } \\
\text { (in billions) }\end{array}$ \\
\hline \multicolumn{2}{|l|}{ Market-shaping rules } \\
\hline $\begin{array}{l}\text { Administration/enforcement costs for new clean } \\
\text { energy regulations }\end{array}$ & $\$ 0.9$ \\
\hline \multicolumn{2}{|l|}{ Direct public spending } \\
\hline Federal R\&D for efficiency and renewables & $\$ 3.5$ \\
\hline \multicolumn{2}{|l|}{ Private investment incentives } \\
\hline Production tax credits & $\$ 26.8$ \\
\hline Investment tax credits & $\$ 27.0$ \\
\hline Green banks & $\$ 1.1$ \\
\hline Loan guarantees & $\$ 0.6$ \\
\hline MLPS and REITS & $\$ 3.7$ \\
\hline \multicolumn{2}{|l|}{ Regional equity and worker transition assistance } \\
\hline Worker training & $\$ 0.5$ \\
\hline Community adjustment assistance & $\$ 0.2$ \\
\hline Worker adjustment assistance & $\$ 0.8$ \\
\hline Total expenditures & $\$ 65.1$ \\
\hline
\end{tabular}

Net fiscal impact

\begin{tabular}{lc}
\hline Revenues and net savings & $\$ 212.8$ billion \\
Expenditures & $\$ 65.1$ billion \\
Net fiscal impact (surplus/deficit) & $\$ 147.7$ billion \\
& in average annual surplus
\end{tabular}


1 Robert Pollin, Jeannette Wicks-Lim, and Heidi GarrettPeltier, "Green Prosperity: How Clean-Energy Policies Can Fight Poverty and Raise Living Standards in the United States" (Amherst, MA: Political Economy Research Institute, 2009), available at http://www.peri.umass. edu/fileadmin/pdf/other_publication_types/green economics/green_prosperity/Green_Prosperity.pdf.

2 Genevieve Giuliano, Hsi-Hwa Hu, and Kyoung Lee, "The Role of Public Transit in the Mobility of Low Income Households" (Los Angeles, CA: School of Policy, Planning, and Development, University of Southern California 2001), available at http://www.metrans.org/sites/ default/files/research-project/99-11_Final_0_0.pdf.

3 John F. Kain and Zvi Liu, "Secrets of success: assessing the large increases in transit ridership achieved by Houston and San Diego transit providers," Transportation Research Part A: Policy and Practice 33 (7) (1999): 601-624.

4 Ibid., p. 623.

5 Stacy C. Davis, Susan W. Diegel, and Robert G. Boundy, "Transportation Energy Data Book: Edition 33" (Oak Ridge, TN: Oak Ridge National Laboratory, 2014), Table 5.18, available at http://cta.ornl.gov/data/tedb33/ Edition33_Chapter05.pdf.

6 American Public Transportation Associate, "Public Transportation Ridership Report: Fourth Quarter 2010" (2011), available at http://www.apta.com/resources/ statistics/Documents/Ridership/2010_q4_ridership_ summary.pdf.

7 Total increase in bus ridership of approximately 90 percent results from the increase due to expanded service from 9 to 15 passengers per bus plus the further increase from reduced fares from 15 to 17.25 passengers per bus. Total average ridership would then have grown from 9 to 17.25 passengers per bus, a 91.7 percent increase.

8 This issue is examined at length in Pollin, Wicks-Lim and Garrett-Peltier, "Green Prosperity."

9 Examined in depth in Robert Pollin and Dean Baker "Reindustrializing America: A Proposal for Reviving U.S. Manufacturing and Creating Millions of Good Jobs," New Labor Forum 19 (2) (2010): 17-34.

10 Cambridge Systematics Inc., "National Rail Freight Infrastructure Capacity and Investment Study" (2007), available at http://www.camsys.com/pubs/AAR Nat_\%20Rail_Cap_Study.pdf.

11 See discussion on this and background references in Pollin and Baker, "Reindustrializing America."

12 American Society of Civil Engineers, "Report Cards for America's Infrastructure: Rail" (2005), available at https://apps.asce.org/reportcard/2005/index2005.cfm.

13 Cambridge Systematics Inc, “National Rail Freight Infrastructure Capacity and Investment Study."
14 The American Society of Civil Engineers estimates that investment needs of freight rail and intercity systems would total $\$ 12$ billion to 13 billion a year over the next 20 years in American Society of Civil Engineers, "Report Cards for America's Infrastructure: Rail." However, this estimate includes investments that would have taken place anyway, given historical trends. Therefore, we use the $\$ 5$ billion figure as the best available rough estimate of the need for additional rail infrastructure in the future.

15 Figures on actual fuel economy levels come from U.S. Energy Information Administration, March 2013 Monthly Energy Review (U.S. Department of Energy, 2013), p. 17, available at http://www.eia.gov/ totalenergy/data/monthly/archive/00351303.pdf.

16 U.S. Energy Information Administration, Annual Energy Outlook 2012 (U.S. Department of Energy, 2012), pp. 18-20, available at http://www.eia.gov/forecasts/aeo/ pdf/0383(2012).pdf.

17 Ibid., p. 19

18 Ibid., p. 19

19 We use the IMPLAN calibrated model and restrict our focus to households with annual incomes between $\$ 10,000$ and $\$ 100,000$, under the assumption that the vast majority of the jobs created would affect households with incomes in this range.

20 Richard Hemming, Michael Kell, and Selma Mahfouz, "The Effectiveness of Fiscal Policy in Stimulating Economic Activity: A Review of the Literature" (Washington: International Monetary Fund, 2002), available at http://www.imf.org/external/pubs/cat/ longres.cfm?sk=16198.0.

21 Heidi Garrett-Peltier, “Employment Estimates for Energy Efficiency Retrofits of Commercial Buildings: Tables and Methodology" (Amherst, MA: Political Economy Research Institute, 2011), available at http://www.peri. umass.edu/fileadmin/pdf/research_brief/PERI_USGBC_Research_Brief.pdf.

22 Rich Brown, Sam Borgeson, Jon Koomey, and Peter Biermayer, "U.S. Building Sector Energy Efficiency Potential" (Berkeley, CA: Lawrence Berkeley National Laboratory, 2008), available at http://escholarship.org/ uc/item/8vs9k2q8; National Academy of Sciences, America's Energy Future: Technology and Transformation (Washington: The National Academies Press, 2009).

23 PERI's consulting work for the U.S. Department of Energy consists of a series of unpublished internal studies. Details on these studies can be made available through requests to the authors.

24 U.S. Energy Information Administration, Levelized Cost and Levelized Avoided Cost of New Generation Resources in the Annual Energy Outlook 2014 (U.S. Department of Energy, 2014), available at www.eia.gov/forecasts/aeo/ electricity_generation.cfm. 
25 See Heintz, Garrett-Peltier, and Zipperer, "New Jobs - Cleaner Air: Employment Effects Under Planned Changes to the EPA's Air Pollution Rules."

26 Robert Pollin, James Heintz, and Heidi Garrett-Peltier, "The Economic Benefits of Investing in Clean Energy" (Washington: Center for American Progress, 2009), available at http://www.peri.umass.edu/fileadmin/pdf/ other_publication types/green_economics/ economic_benefits/economic_benefits.PDF.

27 This detailed industry variable is labeled "PEIO1ICD" in the CPS data. See Center for Disease Control and Prevention, Current Population Survey (CPS) - 2010 (U.S Department of Health and Human Services, 2011), available at http://wwwn.cdc.gov/wisards/cps/ document/2010\%20CPS\%20Annual\%20Data\%20 Dispatch.pdf.

28 We are using the World Input-Output Database, or WIOD, I-O annual tables here rather than the U.S. Department of Commerce's annual tables because the WIOD tables begin two years before those for produced by the Department of Commerce: in 1995 as the WIOD beginning year versus 1997 for the U.S. Department of Commerce. At the same time, we have compared the energy sector output multipliers from both data sources. We have found that there are no significant differences in the patterns that emerge from the WIOD figures as opposed to those from the U.S. Department of Commerce. The full set of WIOD data can be found at World Input-Output Database, "WIOD," available at http://www.wiod.org/new_site/home.htm (last accessed August 2014). An extensive discussion of the contents, sources, and methods used with WIOD is Marcel Timmer, ed.,"The World Input-Output Database (WIOD): Contents, Sources and Methods" (World Input-Output Database, 2012), available at http://www. wiod.org/publications/papers/wiod10.pdf.

29 S. Storm and C.W.M. Naastepad, Macroeconomics Beyond the NAIRU (Cambridge, MA: Harvard University Press, 2012) reviewed the empirical research on the Kaldor-Verdoorn effect from the original work of Petrus Johannes Verdooorn through studies published in 2010. Observing primarily studies focused on
Organisation for Economic Co-operation and Development, or OECD, economies, including-of course - the United States, they report that the relationship "has been confirmed in the overwhelming majority of these studies, irrespective of the differences in econometric methods and data employed. The effect is found statistically significant for cross-section estimations across countries or regions and for specific industries, but also for time series econometric studies for single countries or regions" $(2012$, p. 82). Recognizing this robust general pattern between aggregate output and productivity growth does not imply that the relationship should hold constantly over all industries and all time periods. For example, with the U.S. manufacturing sector from 1987 to 2011, a sharp disparity emerged between the very rapid rates of productivity growth in the computer and electronics industry and the non-computer manufacturing industries, in which productivity growth was below the economy-wide average. See Martin Neil Baily and Barry P. Bosworth, "U.S. Manufacturing: Understanding Its Past and Its Potential Future," Journal of Economic Perspectives 28 (1) (2014): 3-26.

30 U.S. Energy Information Administration, Annual Energy Outlook 2011 (U.S. Department of Energy, 2011), p. 223 available at http://www.eia.gov/forecasts/archive/ aeo11/pdf/0383\%282011\%29.pdf.

31 U.S. Environmental Protection Agency, Budget in Brief (2013), available at http://yosemite.epa.gov/ sab\%5CSABPRODUCT.NSF/2B686066C751F34A852579 A4007023C2/\$File/FY2013_BIB.pdf.

32 We also benefitted substantially through personal communications with Chris Tremper, program analyst, Federal Energy Management Program, Office of Energy Efficiency and Renewable Energy, U.S. Department of Energy, July 10, 2014.

33 Fred Sissine, "Renewable Energy R\&D Funding History: A Comparison with Funding for Nuclear Energy, Fossil Energy, and Energy Efficiency R\&D" (Washington: Congressional Research Service, 2012), available at https://www.fas.org/sgp/crs/misc/RS22858.pdf. 


\section{References}

Abbott, Phillip C., Christopher Hurt, and Wallace E. Tyner. 2011. "What's Driving Food Prices in 2011?" Oak Brook, IL: Farm Foundation. Available at http:// www.farmfoundation.org/news/articlefiles/1742FoodPrices_web.pdf.

Ackerman, Frank, and Elizabeth A. Stanton. 2008. “The Cost of Climate Change: What We'll Pay if Global Warming Continues Unchecked.” New York: National Resources Defense Council. Available at http://www. nrdc.org/globalwarming/cost/cost.pdf.

Aldy, Joseph E. 2013. "A Preliminary Assessment of the American Recovery and Reinvestment Act's Clean Energy Package." Review of Environmental Economics and Policy 7 (1): 136-155.

Allcott, Hunt, and Michael Greenstone. 2012. "Is There an Energy Efficiency Gap?” Journal of Economic Perspectives $26(1): 3-28$.

Allen, David T., Vincent M. Torres, James Thomas, David W. Sullivan, Matthew Harrison, Al Hendler, Scott C. Herndon, Charles E. Kolb, Matthew P. Frasier, A. Daniel Hill, Brian K. Lamb, Jennifer Miskimins, Robert F. Sawyer, and John H. Seinfeld. 2013. "Measurements of Methane Emissions at Natural Gas Production Sites in the United States." Proceedings of the National Academy of Sciences 110 (44).

American Council for Capital Formation and the National Association of Manufacturers. 2009. "Analysis of the Waxman-Markey Bill.” Available at http://accf.org/ wp-content/uploads/2009/10/accf-nam_study.pdf.

American Council on Renewable Energy. 2007. "The Outlook on Renewable Energy in America." Washington. Available at http://www.acore.org/wp-content/uploads/ 2011/02/OutlookonRenewableEnergy2007.pdf.
American Iron and Steel Institute. 2005. "Saving One Barrel of Oil per Ton: A New Roadmap for Transformation of Steelmaking Process." Washington. Available at http:// www.climatevision.gov/pdfs/Saving_1005.pdf.

American Public Power Association. 2014. 2014-15 Annual Directory \& Statistical Report. Washington. Available at http://www.publicpower.org/files/PDFs/USElectricUtilityIndustryStatistics.pdf..

American Public Transportation Association. 2011. "Public Transportation Ridership Report: Fourth Quarter 2010." Washington. Available at http://www. apta.com/resources/statistics/Documents/Ridership/ 2010_q4_ridership_summary.pdf.

American Society of Civil Engineers. 2005. "Report Cards for America's Infrastructure: Rail.” Washington. Available at https://apps.asce.org/reportcard/2005/ index2005.cfm.

Baffes, John and Tassos Haniotis. 2010. "Placing the 2006/8 Commodity Price Boom Into Perspective.” Policy Research Working Paper 5371. The World Bank.

Baily, Martin Neil, and Barry P. Bosworth. 2014. "U.S. Manufacturing: Understanding Its Past and Its Potential Future." Journal of Economic Perspectives 28 (1): pp. 3-26.

Baker, Peter and Coral Davenport. 2014. "Obama Orders New Efficiency for Big Trucks," The New York Times. February 20. Available at http://www.nytimes.com/ 2014/02/19/us/politics/obama-to-request-new-rulesfor-cutting-truck-pollution.html.

Baum, Alan and Daniel Luria. 2010. "Driving Growth: How Clean Cars and Climate Policy Can Create Jobs.” NDRC, Center for American Progress, and United Automobile Workers. Available at http://www.nrdc.org/energy/ drivinggrowth.asp. 
Beerten, Jef, Erik Laes, Gaston Meskens, and William D'haeseleer. 2009. "Greenhouse Gas Emissions in the Nuclear Life Cycle: A Balanced Appraisal.” Energy Policy 37 (12): 5056-5068.

Berlin, Ken, Reed Hundt, Mark Muro and Devashree Saha. 2012. "State Clean Energy Finance Banks: New Investment Facilities for Clean Energy Deployment." The Brookings Institution. Available at http://www. brookings.edu/research/papers/2012/09/12-stateenergy-investment-muro.

Biello, David. 2008. “'Clean' Coal Power Plant Canceled Hydrogen Economy, Too.” Scientific American. February 6. pp. 1644-1645. Available at http://sams. scientificamerican.com/article/clean-coal-power-plantcanceled-hydrogen-economy-too/.

Bloomberg New Energy Finance and Business Council for Sustainable Energy. 2013. "Sustainable Energy in America 2013 Factbook.” Available at http://www.bcse.org/ factbook/pdfs/BCSE_BNEF_Sustainable_Energy_ in_America_2013_Factbook.pdf.

Bolinger, Mark. 2001. “Community Wind Power Ownership Schemes in Europe and their Relevance to the United States." Berkeley, CA: Lawrence Berkeley National Laboratory. Available at http://eetd.lbl.gov/ $\mathrm{EA} / \mathrm{EMP} /$.

2005. "Making European-style Community Wind Power Development Work in the US." Renewable \& Sustainable Energy Reviews 9 (6): 556-575.

Boyce, James K., and Matthew E. Riddle. 2011. “CLEAR Economics: State-Level Impacts of the Carbon Limits and Energy for America's Renewal Act on Family Incomes and Jobs." Amherst, MA: Political Economy Research Institute. Available at http://www.peri.umass. edu/236/hash/863fdbde6e/publication/403/.

Bradley, David H. 2013. The Workforce Investment Act and the One-Stop Delivery System. Washington: Congressional Research Service.

Brookes, Leo. 1990. "The Greenhouse Effect: The Fallacies in the Energy Efficiency Solution.” Energy Policy 18 (2): 199-201.

Brown, Rich, Sam Borgeson, Jon Koomey, and Peter Biermayer. 2008. "U.S. Building Sector Energy Efficiency Potential.” Berkeley, CA: Lawrence Berkeley National Laboratory. Available at http://escholarship.org/uc/ item/8vs9k2q8.
Bruno, Michael. 1995. "Does Inflation Really Lower Growth?” Finance and Development, September 1995 (32): 35-38.

California Air Resources Board. "Cap-and-Trade Program.” Available at http://www.arb.ca.gov/cc/capandtrade/ capandtrade.htm.

Cambridge Systematics, Inc. 2007. "National Rail Freight Infrastructure Capacity and Investment Study.” Cambridge, MA. Available at http://www.aar.org/ / media/aar/Files/natl_freight_capacity_study.ashx.

Caperton, Richard W. 2012. "Testimony on 'American Energy Initiative.” Washington: Center for American Progress. Available at http://www.americanprogressaction.org/ wp-content/uploads/issues/2012/07/pdf/caperton_ american_energy1.pdf.

Caperton, Richard W. 2012. "What the Heck are Master Limited Partnerships And How Could They Boost Clean Energy?" ThinkProgress. Available at http:// thinkprogress.org/climate/2012/06/08/496621/ master-of-my-domain-what-the-heck-are-master-limitedpartnerships-and-can-they-boost-clean-energy/.

2012. "Renewable Energy Standards Deliver Affordable, Clean Power." Washington: Center for American Progress. Available at http://www. americanprogress.org/issues/green/report/2012/04/ $11 / 11397 /$ renewable-energy-standards-deliveraffordable-clean-power/.

Caperton, Richard W., Bracken Hendricks, John Lauer, and Courtney Hight. 2011. "CLEAN Contracts: Making Clean Local Energy Accessible Now." Washington: Center for American Progress. Available at http://www.americanprogress.org/wp-content/ uploads/issues/2011/01/pdf/clean_contracts.pdf.

Caperton, Richard W., and Bracken Hendricks. 2011. "A Green Bank is the Right Tool for Jobs." Washington: Center for American Progress. Available at http://www. americanprogress.org/wp-content/uploads/issues/2011/ 09/pdf/green_bank.pdf.

Carbon Limits and Energy for America's Renewal, or CLEAR, Act, Senate Bill 2877, 111th Cong., 1st. session.

“Carbon Sequestration.” 2009. Science 325 (5948): 1644-1645. Available at http://www.sciencemag.org/ content/325/5948/1644. 
Carley, Sanya, and Martin Robert Hyman. 2013. “The 'Grand Experiment': An Early Review of Energy-Related Recovery Act Efforts.” Working Paper. Social Science Research Network. Available at http://papers.ssrn.com/ sol3/papers.cfm?abstract_id=2316827.

Center for Sustainable Energy. 2014. "Frequently Asked Questions on PACE.” Property Assessed Clean Energy (PACE) Programs. Available at http://energycenter.org/ policy/property-assessed-clean-energy-pace.

Chu, Steven. 2009. "Editorial: Carbon Capture and Sequestration.” Science 325 (5948): 1599.

Chupka, Marc W., Robert Earle, Peter Fox-Penner, and Ryan Hledik. 2008. "Transforming America's Power Industry: the Investment Challenge 2010-2030.” Washington: The Edison Foundation. Available at http://www.brattle.com/_documents/UploadLibrary/ Upload725.pdf.

Commission on Sustainable Agriculture and Climate Change. 2012. "Achieving Food Security in the Face of Climate Change." Copenhagen, Denmark. Available at http://www.rockefellerfoundation.org/media/ download/fa9d750e-b37a-46ad-9081-d9bda8fedc9b.

Committee on World Food Security. High Level Panel of Experts on Food Security and Nutrition. 2013.

"Biofuels and Food Security." Rome, Italy.

Congressional Budget Office. 2012. "Unemployment Compensation and Trade Adjustment Assistance for Workers." Washington. Available at http://www.cbo. gov/sites/default/files/cbofiles/attachments/43100UnemploymentCompensation.pdf.

Cory, Karlynn, Toby Couture, and Claire Kreycik. 2009. "Feed-in Tariff Policy: Design, Implementation, and RPS Policy Interactions." Golden, CO: National Renewable Energy Laboratory. Available at http:/ / www.nrel.gov/docs/fy09osti/45549.pdf.

Creyts, Jon, Hannah Choi Granade, and Kenneth J. Ostrowski. 2010. "U.S. energy savings: Opportunities and challenges." New York: McKinsey. Available at http://hmfportal.squarespace.com/storage/research-andlearning-documents/Jan\%202010\%20McKinsey\%20 report\%20on\%20energy\%20savings\%20opportunities.pdf.

Davis, Todd, and Monica Hale. 2007. "Public Transportation's Contribution to U.S. Greenhouse Gas Reduction.” McLean, VA: American Public Transportation Association. Available at http://www.apta.com/resources/ reportsandpublications/Documents/climate_change.pdf.
Deutsche Bank Climate Change Advisors. 2011. "Natural Gas and Renewables: The Coal to Gas and renewables Switch is on!” Available at http://www.cleanlineenergy. com/sites/cleanline/media/resources/Natural-Gasand-Renewables.PDF.

Dierdorff, Erich C., Jennifer J. Norton, Christina M. Gregory, David Rivkin, and Phil Lewis. 2011. Greening the World of Work: Revisiting Occupational Consequences. Raleigh, NC: National Center for O*Net Development. Available at http://www.onetcenter.org/dl_files/Green2.pdf.

Doris, Elizabeth, and S. Busche. 2009. "Decoupling Policies: Options to Encourage Energy Efficiency Policies for Utilities." Washington: U.S. National Renewable Energy Laboratory.

Dotsey, Michael, Shigeru Fujita, and Tom Stark. 2011. "Do Phillips Curves Conditionally Help to Forecast Inflation?" Working Paper 11-40. Research Department, Federal Reserve Bank of Philadelphia.

Emanuel, Kerry. 2012. What We Know About Climate Change, Second Edition. Cambridge, MA: MIT Press.

Energy Digital. 2012. “Top 10: Exciting New Developments in Energy." December 17. Available at http://www. energydigital.com/greentech/2073/TOP-10:-ExcitingNew-Developments-in-Energy.

Energy Independence and Security Act of 2007, Public Law 140, 110th Cong., 1st sess. Available at http://www.gpo. gov/fdsys/pkg/PLAW-110publ140/html/PLAW110publ140.htm.

Epstein, Gerald and Robert Pollin. 2011. "Regulating Wall Street: Exploring the Political Economy of the Possible." Amherst, MA: Political Economy Research Institute. Available at http://www.peri.umass.edu/fileadmin/ pdf/working_papers/working_papers_251-300/ WP256.pdf.

Farrell, Diana, Jaana Remes, Florian Bressand, Mark Laabs, and Anjan Sundaram. 2008. "The Case for Investing in Energy Productivity.” New York: McKinsey Global Institute. Available at http://www.mckinsey.com/ insights/mgi/research/natural_resources/the_case_ for_investing_in_energy_productivity.

Frondel, Manuel, Nolan Ritter, and Colin Vance. 2012. "Heterogeneity in the Rebound Effect: Further Evidence on Germany." Energy Economics 34: 461-467. 
Garrett-Peltier, Heidi. 2012. "The Employment Impacts of a Low-Carbon Fuel Standard for Minnesota.” Amherst, MA: Political Economy Research Institute. Available at http://www.peri.umass.edu/fileadmin/pdf/published_ study/MNcleanfuels_PERI_Sept14_2012.pdf.

2011. "Employment Estimates for Energy Efficiency Retrofits of Commercial Buildings: Tables and Methodology." Amherst, MA: Political Economy Research Institute. Available at http://www.peri.umass. edu/fileadmin/pdf/research_brief/PERI_USGBC_ Research_Brief.pdf.

Gavankar, Sheetal, and Roland Geyer. 2010. “The Rebound Effect: State of the Debate and Implications for Energy Efficiency Research.” Santa Barbara, CA: Bren School of Environmental Science and Management. Available at http://iee.ucsb.edu/files/pdf/ Rebound\%20Report\%20for\%20IEE-UCSB.pdf.

Gerdes, Justin. 2012. “California Launches Nation's Largest Clean Energy PACE Program,” Forbes. Available at http://www.forbes.com/sites/justingerdes/2012/09/ 28/california-launches-nations-largest-clean-energypace-program/.

Ghosh, Jayati, James Heintz, and Robert Pollin. 2012. "Speculation on Commodities Futures Markets and Destabilization of Global Food Prices: Exploring the Connections." International Journal of Health Services 42 (3): 465-483.

Gilbert, Christopher L. 2010. "How to Understand High Food Prices.” Journal of Agricultural Economics 61 (2): 398-425.

Gillingham, Kenneth, Matthew J. Kotchen, David S. Rapson, and Gernot Wagner. 2013. "The Rebound Effect is Overplayed.” Nature 493: 473-474.

Giuliano, Genevieve, Hsi-Hwa Hu, and Kyoung Lee. 2001. "The Role of Public Transit in the Mobility of Low Income Households." Los Angeles: School of Policy, Planning, and Development. Available at http://www. metrans.org/research/final/99-11_Final.pdf.

Goodstein, Eban. 2010. Economics and the Environment. Hoboken, NJ: Wiley.

Google. 2008. “Clean Energy 2030: Google's Proposal for Reducing U.S. Dependence on Fossil Fuels.” October 6. Available at http://archive.today/jVNV3.
Gordon, Robert J. 1997. “The Time-Varying NAIRU and its Implications for Economic Policy." Journal of Economic Perspectives. 11 (1): 11-32.

Greening, Lorna A., David L. Greene, and Carmen Difiglio. 2000. "Energy Efficiency and Consumption: The Rebound Effect: A Survey.” Energy Policy 28 (6-7): 389-401.

Grunwald, Michael. 2012. The New New Deal: The Hidden Story of Change in the Obama Era. New York: Simon \& Schuster.

Hall, Carin. 2012. “The U.S. Army's Great Drive for Renewable Power.” Energy Digital. October 11. Available at http://www.energydigital.com/green_technology/ the-us-armys-great-drive-for-renewable-power.

Hall, Douglas G., Kelly S. Reeves, Julie Brizzee, Randy D. Lee, Gregory R. Carroll, and Garold L. Sommers. 2006. "Feasibility Assessment of the Water Energy Resources of the United States for New Low Power and Small Hydro Classes of Hydroelectric Plants." Idaho Falls: Idaho National Laboratory. Available at http://www1. eere.energy.gov/water/pdfs/doewater-11263.pdf.

Hearing before the Committee on Energy and Commerce of the House of Representatives. 2011. Solyndra and the DOE Loan Guarantee Program. 112 Congress. 2 sess. Available at http://archives.republicans.energycommerce. house.gov/hearings/hearingdetail.aspx?NewsID $=8897$.

Heintz, James, Heidi Garrett-Peltier, and Ben Zipperer. 2011. "New Jobs - Cleaner Air: Employment Effects Under Planned Changes to the EPA's Air Pollution Rules." Amherst: MA: Political Economy Research Institute. Available at http://www.peri.umass.edu/ fileadmin/pdf/other_publication_types/green economics/CERES_PERI_Feb11.pdf.

Heintz, James, Robert Pollin, and Heidi Garrett-Peltier. 2009. "How Infrastructure Spending Supports the U.S. Economy: Employment, Productivity, and Growth." Amherst: MA: Political Economy Research Institute. Available at http://www.peri.umass.edu/fileadmin/ pdf/other_publication_types/green_economics/ PERI_Infrastructure_Investments.

Hemming, Richard, Michael Kell, and Selma Mahfouz. 2002. "The Effectiveness of Fiscal Policy in Stimulating Economic Activity: A Review of the Literature." Washington: International Monetary Fund. Available at http://www.imf.org/external/pubs/cat/longres. cfm?sk=16198.0. 
Hendricks, Bracken, Lisbeth Kaufman, Ken Berlin, Monty Humble, Reed Hundt, Alex Kragie, and Gerry Waldron. 2010. "Cutting the Cost of Clean Energy 1.0: Toward a Clean Energy Deployment Plan for Jobs, Security, and Broad-Based Economic Growth in 2011." Washington: Center for American Progress. Available at http://www. americanprogress.org/issues/green/report/2010/11/ 16/8655/cutting-the-cost-of-clean-energy-1-0/.

Hornbeck, J.F. 2013. Trade Adjustment Assistance (TAA) and Its Role in U.S. Trade Policy. CRS Report R41922. Washington: Congressional Research Service.

Horwarth, Robert. 2014. "A Bridge to Nowhere: Methane Emissions and the Greenhouse Gas Footprint of Natural Gas." Energy Science and Engineering. Available at http://onlinelibrary.wiley.com/doi/ $10.1002 /$ ese3.35/pdf.

Hsia-Kung, Katherine, Emily Reyna, and Timothy O'Connor. 2014. California Carbon Market Watch: A Comprehensive Analysis of the Golden State's Cap and Trade Program. Washington: Environmental Defense Fund.

ICF Consulting. 2005. "Assessing the Effects of Freight Movement on Air Quality at the National and Regional Level, Final Report." Available at http://www.fhwa.dot. gov/environment/air_quality/publications/effects_ of_freight_movement/chapter00.cfm.

ICF International. 2014. Economic Analysis of Methane Emission Reduction Opportunities in the U.S. Onshore Oil and Natural Gas Industries. Fairfax, VA. Available at http://www.edf.org/sites/default/files/methane_cost_ curve_report.pdf.

IMPAQ International. 2013. Green Jobs and Healthcare Implementation Study: Final Report Appendices. Available at http://wdr.doleta.gov/research/FullText_Documents/ ETAOP_2013_16_Appendices.pdf.

Intergovernmental Panel on Climate Change. 2012. "Managing the Risks of Extreme Events and Disasters to Advance Climate Change Adaption." New York: Cambridge University Press. Available at http://www. ipcc-wg2.gov/SREX/images/uploads/SREX-All_ FINAL.pdf.

Interlaboratory Working Group. 2000. "Scenarios for a Clean Energy Future.” Oak Ridge National Laboratory, Lawrence Berkeley National Laboratory, and National Renewable Energy Laboratory. Available at http:// www.nrel.gov/docs/fy01 osti/29379.pdf.
International Renewable Energy Agency. 2012.

"Hydropower." Renewable Energy Technologies: Cost Analysis Series 1 (3/5). Available at https://www.irena. org/DocumentDownloads/Publications/RE_ Technologies_Cost_Analysis-HYDROPOWĒR.pdf.

Irwin, Conway. 2013. "Connecticut's Green Bank: A Model for Public-Private Renewables Partnerships?” Breaking Energy. Available at http://breakingenergy. com/2013/07/02/connecticuts-green-bank-a-modelfor-public-private-renewables-partnerships/.

Jackson, Robert B., Brooks Rainey Pearson, Stephen G. Osborn, Nathaniel R. Warner, and Avner Vengosh. 2011. "Research and Policy Recommendations for Hydraulic Fracturing and Shale-Gas Extraction.” Durham, NC: Center on Global Change. Available at http://www. nicholas.duke.edu/cgc/HydraulicFracturingWhite paper2011.pdf.

Jackson, Robert B., Avner Vengosh, Thomas H. Darrah, Nathaniel R. Warner, Adrian Down, Robert J. Poreda, Stephen G. Osborn, Kaiguang Zhao, and Jonathan D. Karr. 2013. "Increased stray gas abundance in a subset of drinking water wells near Marcellus shale gas extraction." Proceedings of the National Academy of Sciences Early Edition. Available at http://www.pnas. org/content/early/2013/06/19/1221635110.full. pdf + html.

Jevons, William Stanley. 1906. The coal question: An inquiry concerning the progress of the nation, and the probable exhaustion of our coal-mines: 3 rd edition, London: Macmillan.

Kain, J. F., and Z. Liu. 1999. "Secrets of Success: Assessing the Large Increases in Transit Ridership Achieved by Houston and San Diego Transit Providers." Transportation Research Part A: Policy and Practice 33 (7): 601-624.

Khazzoom, J. Daniel. 1980. “Economic Implications of Mandated Efficiency Standards for Household Appliances." The Energy Journal 1 (4): 21-40.

Kletzer, Lori, and Robert Litan. 2001. "A Prescription to Relieve Worker Anxiety." The Brookings Institution. Available at http://www.brookings.edu/ /media/ research/files/papers/2001/3/labor\%20kletzer/pb73.pdf.

Koch, Wendy. 2013. "Study: Natural Gas Industry Can Cut Fracking.” USA Today. September 17. Available at http://www.usatoday.com/story/news/nation/2013/ 09/16/natural-gas-industry-fracking-methane-greenhouse-gas-emissions/2811193/. 
Kosnik, Lea. 2010. “The Potential for Small Scale Hydropower Development in the U.S.” Energy Policy 38 (10): 5512-5519.

Krueger, Alan B., and Robert M. Solow, eds. 2001. The Roaring Nineties: Can Full Employment be Sustained? New York: Russell Sage Foundation.

Kushler, Martin, Dan York, and Patti Witte. 2006. Aligning Utility Interests with Energy Efficiency Objectives: A Review of Recent Efforts at Decoupling and Performance Incentives. Washington: American Council for an Energy Efficient Economy.

Lacey, Stephen. 2013. “This 'Monumental Shift' in the US Buildings Sector May Surprise You.” Greentech Media. May 9. Available at https://www.greentechmedia.com/ articles/read/federal-data-shows-sweeping-savings-inenergy-usage-by-us-building-sector.

Laitner, John A. “Skip,” Steven Nadel, R. Neal Elliot, Harvey Sachs and A. Siddiq Khan. 2012. "The Long-term Energy Efficiency Potential: What the Evidence Suggests.” Washington: American Council for an EnergyEfficient Economy.

Li, Liwen, Janine Birmele, Harald Schaich, and Werner Konold. 2013. "Transitioning to Community-Owned Renewable Energy: Lessons from Germany." Procedia Environmental Sciences 17: 719-728.

Lovins, Amory B. 2013. "Amory Angle: Three Major Energy Trends to Watch." Rocky Mountain Institute Solutions Journal 6 (1). Available at http://www.rmi.org/summer_ 2013_esj_amorys_angle_three_major_energy_ trends_main.

Lynch, John, and Seth Kirshenberg. 2000. "Economic Transition by the Energy-Impacted Communities." Sacramento, CA: California Energy Commission. Available at http://www.energyca.org/PDF/ EDArticle.PDF.

Mazzochi, Tony. 1993. "A Superfund for Workers.” Earth Island Journal 9 (1): 40

McHale, Cynthia, and Sharlene Leurig. 2012. "Stormy Future for U.S. Property/Casualty Insurers: The Growing Costs and Risks of Extreme Weather Events." Boston: Ceres. Available at http://www.ceres.org/ resources/reports/stormy-futures/view.

McKinsey and Company. 2007. "The Untapped Energy Efficiency Opportunity in the U.S. Industrial Sector." New York: McKinsey and Company.
2008. "The Untapped Energy Efficiency of the U.S. Industrial Sector: Details of Research, 2008.” New York: McKinsey and Company.

Milmo, Sean. 2010. "Innovative packaging aims to cut supply chain footprint." ICIS Chemical Business. November 11. Available at http://www.icis.com/ Articles/2010/11/15/9409646/innovative-packagingaims-to-cut-supply-chain-footprint.html.

Mormann, Felix, and Dan Reicher. 2012. "How to Make Renewable Energy Competitive." The New York Times. June 1. Available at http://www.nytimes.com/2012/06/ 02/opinion/how-to-make-renewable-energy-competitive. html? pagewanted=2\&_r=0\&pagewanted =print.

Morris, Jesse. 2013. "How Real Estate Investment Trusts Can Change the Clean Energy Industry." Rocky Mountain Institute. Available at http://blog.rmi.org/blog_06_ 05_2013_how_real_estate_investment_trusts_can change_the_clean_energy_industry.

Muro, Mark, and Jonathan Rothwell. 2011. "Why the U.S. Should Not Abandon Its Clean Energy Lending Programs.' The Brookings Institution. September 27. Available at http://www.brookings.edu/blogs/the-avenue/posts/ 2011/09/27-solyndra-muro-rothwell.

Nadel, Steven. 2012. “The Rebound Effect: Large or Small?” Washington: American Council for an Energy Efficient Economy. Available at http://www.aceee.org/files/pdf/ white-paper/rebound-large-and-small.pdf.

National Academy of Sciences. 2010. Real Prospects for Energy Efficiency in the United States. Washington: The National Academies Press.

2009. America's Energy Future: Technology and Transformation. Washington: The National Academies Press.

2009. Liquid Transportation Fuels from Coal and Biomass: Technological Status, Costs, and Environmental Impacts. Washington: The National Academies Press.

National Aeronautics and Space Administration. "Global Land-Ocean Temperature Index in 0.01 degrees Celsius, Base Period: 1951-1980 [data file]." Available at http:// data.giss.nasa.gov/gistemp/tabledata_v3/GLB. Ts+dSST.txt.

National Defense Authorization Act for Fiscal Year 2010, Public Law 111-84, 111th Cong., 1st sess. Available at http://www.gpo.gov/fdsys/pkg/PLAW-111publ84/ pdf/PLAW-111publ84.pdf. 
National Research Council. 2010. Adapting to the Impacts of Climate Change. Washington: The National Academies Press.

New York State Energy Research and Development Authority. 2012. "On-Bill Recovery Financing Program Frequently Asked Questions.” August 20. Available at http://www.nyserda.ny.gov/Governor-Initiatives/ On-Bill-Recovery-Financing-Program/FAQ.aspx.

Office of U.S. Senator Christopher Coons of Delaware. 2013. "Bipartisan Support for Master Limited Partnerships Parity Act Grows." Press release. Available at http:// www.coons.senate.gov/newsroom/releases/release/ bipartisan-support-for-master-limited-partnershipsparity-act-grows.

Organisation for Economic Co-operation and Development. 2012. The jobs potential of a shift towards a low-carbon economy. Available at http://www.oecd. org/els/emp/50503551.pdf.

2012. "OECD Economic Surveys: Germany." Available at http://www.keepeek.com/Digital-AssetManagement/oecd/economics/oecd-economic-surveysgermany-2012 eco surveys-deu-2012-en\#page1.

Oxfam. 2012. "Extreme Weather, Extreme Prices: The costs of feeding a warming world." Available at http:// www.oxfam.org/sites/www.oxfam.org/files/20120905ib-extreme-weather-extreme-prices-en.pdf.

Parkinson, Giles. 2013. "Boom in unsubsidised solar PV flags energy revolution." Renew Economy. January 23. Available at http://reneweconomy.com.au/2013/ubs-boom-inunsubsidised-solar-pv-flags-energy-revolution-60218.

Parry, M.L., O.F. Canziani, J.P. Palutikof, P.J. van der Linden and C.E. Hanson, eds. 2007. Contribution of Working Group II to the Fourth Assessment Report of the Intergovernmental Panel on Climate Change. Cambridge, U.K: Cambridge University Press. Available at http:// www.cambridge.org/features/earth_environmental/ climatechange/wg2.htm.

Pernick, Ron, Clint Wilder, and Trevor Winnie. 2012. "Clean Energy Trends 2012." San Francisco: The Clean-Tech Market Authority. Available at http:// www.cleanedge.com/sites/default/files/CETrends2012_Final_Web.pdf?attachment=true.
The Pew Charitable Trust. 2013. "Expanding Investment Opportunities for Clean Energy: Master Limited Partnerships and Real Estate Investment Trusts." Available by request from www.PewTrusts.org.

Plasynski, Sean. 2007. "Carbon Sequestration R\&D Overview.” National Energy Technology Laboratory, Office of Fossil Energy. Available at http://www.netl. doe.gov/File\%20Library/Research/Coal/carbonstorage/Carbon-Sequestration-R-D-Overview.pdf.

Podesta, John D., Kate Gordon, Bracken Hendricks, and Benjamin Goldstein. 2009. "The Clean-Energy Investment Agenda: A Comprehensive Approach to Building the Low-Carbon Economy." Washington: Center for American Progress. Available at http://www. americanprogress.org/wp-content/uploads/issues/ 2009/09/pdf/clean_energy_investment.pdf.

Pollin, Robert. 2012. "Public Policy, Community Ownership and Clean Energy." Cambridge Journal of Regions, Economy and Society 5 (3): 339-359.

2012. Back to Full Employment. Cambridge, MA: MIT Press.

1996. "Financial Intermediation and the Variability of the Saving Constraint." In Robert Pollin ed. The Macroeconomics of Saving, Finance and Investment. Ann Arbor, MI: University of Michigan Press, pp. 309-366.

Pollin, Robert, Heidi Garrett-Peltier, James Heintz, and Shouvik Chakraborty. Forthcoming. Global Green Growth: Clean Energy Industrial Investments and Expanding Job Opportunities. Vienna, Austria: U.N. Industrial Development Organization.

Pollin, Robert, and James Heintz. 2013. Study of U.S. Financial System. Financialization, Economy. Society and Sustainable Development. Available at http:// fessud.eu/wp-content/uploads/2012/08/USA-FinancialSystems-Studies 10.pdf.

2011."How Wall Street Speculation is Driving Up Gasoline Prices Today.” Amherst MA: Political Economy Research Institute. Available at http://www.peri.umass. edu/fileadmin/pdf/research_brief/PERI_AFR_ Research_Brief_June20.pdf. 
Pollin, Robert, and Dean Baker. 2010. "Reindustrializing America: A Proposal for Reviving U.S. Manufacturing and Creating Millions of Good Jobs." New Labor Forum 19 (2): 17-34. Available at http://www.peri.umass.edu/ fileadmin/pdf/other_publication_types/magazine journal_articles/final_Spring_2010_Pollin.pdf.

Pollin, Robert, James Heintz, and Heidi Garrett-Peltier. 2009. "The Economic Benefits of Investing in Clean Energy." Washington: Center for American Progress. Available at http://www.peri.umass.edu/fileadmin/ pdf/other_publication_types/green_economics/ economic_benefits/economic_benefits.PDF.

Pollin, Robert, Jeannette Wicks-Lim, and Heidi GarrettPeltier. 2009. "Green Prosperity: How Clean-Energy Policies Can Fight Poverty and Raise Living Standards in the United States." Amherst MA: Political Economy Research Institute. Available at http://www.peri.umass. edu/fileadmin/pdf/other_publication_types/green economics/green_prosperity/Green_Prosperity.pdf.

Pollin, Robert, Mark Brenner, Jeannette Wicks-Lim, and Stephanie Luce. 2008. A Measure of Fairness: The Economics of Living Wages and Minimum Wages in the United States. Ithaca, NY: Cornell University Press.

Pollin, Robert, Heidi Garrett-Peltier, James Heintz, and Helen Scharber. 2008. “Green Recovery: A Program to Create Good Jobs and Start Building a Low-Carbon Economy." Amherst, MA: Political Economy Research Institute. Available at http://www.peri.umass.edu/ fileadmin/pdf/other_publication_types/green economics/peri_report.pdf.

Pollin, Robert, and Andong Zhu. 2006. "Inflation and Economic Growth: A Cross-Country Nonlinear Analysis." Journal of Post Keynesian Economics: 593-614.

Pradhananga, Manisha. 2014. Financialization of the Commodities Futures Markets and its Effects on Prices. Amherst, MA: University of Massachusetts-Amherst.

Pyper, Julia. 2012. “Transportation: U.S. Lags in a Race for Global Fuel Efficiency.” E\&E Publishing. September 28. Available at http://www.eenews.net/special_reports/ The_Race/stories/1059970588.

Radler, Marilyn. 2011. "Special Report: Capital Budgets to Rise this Year in North America and Worldwide." Oil \& Gas Journal. Available at http://www.ogj.com/articles/ print/volume-109/issue-10/general-interest/ special-report-capital-budgets-to-rise-this.html.
Recovery Accountability and Transparency Board. "Recovery.gov: Track the Money: FAQs." Available at http://www.recovery.gov/arra/FAQ/Pages/ ForCitizens.aspx.

Romm, Joe. 2008. "Is coal with carbon capture and storage a core climate solution?” Climate Progress. September 29. Available at http://thinkprogress.org/climate/2008/ $09 / 29 / 203149 /$ is-coal-with-carbon-capture-and-storage-a-core-climate-solution/.

Ross, J.P., and Bracken Hendricks. 2008. "Developing State Solar Photovoltaic Markets: Riding the Wave to Clean Energy Independence." Washington: Center for American Progress. Available at http://votesolar.org/linked-docs/ CAP_solar_report.pdf.

Ruttan, Vernon L. 2006. Is War Necessary for Economic Growth? Military Procurement and Technology Development. New York: Oxford University Press.

Sargent, John F. 2013. "Federal Research and Development Funding: FY2013." Washington: Congressional Research Service. Available at http://www.fas.org/sgp/ crs/misc/R42410.pdf.

Schreurs, Miranda A., and Fumikazu Yoshida. 2013. Fukushima: A Political Economic Analysis of a Nuclear Disaster. Sapporo: Hokkaido University Press.

Sexton, Steven, Deepak Rajagopal, David Zimmerman, and Gal Hochman. 2008. "Food Versus Fuel: How Biofuels Make Food More Costly and Gasoline Cheaper." Agricultural and Resource Economics Update 12 (1). Available at http://www.ncsu.edu/cenrep/ research/documents/food_v_fuel.pdf.

Shen, Li, Juliane Haufe, and Martin K. Patel. 2009. "Product Overview and Market Projection of Emerging Bio-based Plastics: PRO-BIP 2009.” The Netherlands: Utrecht University: Copernicus Institute for Sustainable Development and Innovation.

Sissine, Fred. 2012. "Renewable Energy R\&D Funding History: A Comparison with Funding for Nuclear Energy, Fossil Energy, and Energy Efficiency R\&D." Washington: Congressional Research Service. Available at https://www.fas.org/sgp/crs/misc/RS22858.pdf.

Sorrell, Steve, John Dimitropoulos, and Matt Sommerville. 2009. "Empirical estimates of the direct rebound effect: A review." Energy Policy 37 (4): 1356-1371. 
Sorrell, Steve. 2007. "The Rebound Effect: an assessment of the evidence for economy-wide energy savings from improved energy efficiency." London: U.K.: Energy Research Centre. Available at http://www.ukerc.ac.uk/ Downloads/PDF/07/0710ReboundEffect/ 0710ReboundEffectReport.pdf.

Sperling, Gene. 2005. "The Early-Warning Economy: The time to think about helping displaced workers is before they lose their jobs." Washington Monthly. Available at http://www.washingtonmonthly.com/features/2005/ 0512.sperling.html.

Stock, James H., and Mark W. Watson. 2008. "Phillips Curve Inflation Forecasts,” NBER Working Paper 14322. Cambridge, MA: National Bureau of Economic Research.

Storm, S. and C.W.M. Naastepad. 2012. Macroeconomics Beyond the NAIRU. Cambridge, MA: Harvard University Press.

Takenaka, Kiyoshi and James Topham. 2013. “Japan's nuclear crisis deepens, China expresses 'shock,” Reuters. August 21. Available at http://www.reuters. com/article/2013/08/21/us-japan-fukushima-severityidUSBRE97K02B20130821.

Ten Hoeve, John E., and Mark Z. Jacobson. 2012. "Worldwide health effects of the Fukushima Daiichi nuclear accident." Energy \& Environmental Science 9 (5): 8743-8757. Available at http://web.stanford.edu/ group/efmh/jacobson/TenHoeveEES12.pdf.

Timmer, Marcel P. ed. 2012. The World Input-Output Database (WIOD): Contents, Sources and Methods." World Input-Output Database. Available at http:// www.wiod.org/publications/papers/wiod10.pdf.

Tobias, Leanne. 2011. "3 Sure-Fire Green Solutions Obama Should Put in His Jobs Speech.” Greenbiz.com. September 7. Available at http://www.greenbiz.com/ blog/2011/09/07/3-sure-fire-green-solutions-obamashould-put-his-jobs-speech.

Trabish, Herman K. 2013. "FERC Chair Jon Wellinghoff: Solar 'Is Going to Overtake Everything." Greentech Media. August 21. Available at http://www.greentechmedia.com/ articles/read/ferc-chair-wellinghoff-sees-a-solar-futureand-a-utility-of-the-future?utm_source=Daily\&utm medium=Headline\&utm_campaign=GTMDaily.
Tullus, Paul. 2013. "Trash into Gas, Efficiently? An Army Test May Tell.” The New York Times. August 17.

Available at http://www.nytimes.com/2013/08/18/ business/trash-into-gas-efficiently-an-army-test-maytell.html?pagewanted=all.

Union of Concerned Scientists. 2010. "How Biomass Energy Works.” Available at http://www.ucsusa.org/ clean_energy/our-energy-choices/renewable-energy/ how-biomass-energy-works.html.

U.S. Bureau of Economic Analysis. National Income and Product Accounts Tables: Table 3.7ES: Historical-Cost Investment in Private Fixed Assets by Industry. U.S. Department of Commerce. Available at http://www. bea.gov/National/nipaweb/nipawebLegacy/FAweb/ AllFATables.asp\#S3.

. National Income and Product Accounts Tables, Table 1.1.5, Gross Domestic Product." U.S. Department of Commerce. Available at http://www.bea.gov/iTable/ index_nipa.cfm

National Income and Product Accounts Tables, Table 5.1, Saving and Investment by Sector. U.S. Department of Commerce. Available at http://www.bea.gov/iTable/ index_nipa.cfm.

. National Income and Product Accounts Tables, Table 1.1.9, Implicit Price Deflators for Gross Domestic Product. U.S. Department of Commerce. Available at http://www.bea.gov/iTable/index_nipa.cfm.

_- - 2013. Survey of Current Business. U.S. Department of Commerce. Available at http://www.bea.gov/ national/pdf/dpga.pdf.

U.S. Bureau of Labor Statistics. 2012. A-3: Employment status of the civilian noninstitutional population by sex and age, seasonally adjusted. U.S. Department of Labor. Available at http://www.bls.gov/web/empsit/cpseea03.pdf.

"Green Goods and Services Occupations." Available at http://www.bls.gov/ggsocc/.

U.S. Bureau of Land Management. 2004. American Energy for America's Future: The Role of the U.S. Department of the Interior. U.S. Department of the Interior. Available at http://www.blm.gov/pgdata/etc/medialib/blm/wo/ MINERALS_REALTY_AND_RESOURCE_PROTECTION_.Par.61407.File.dat/EnergyBro.pdf. 
U.S. Bureau of the Census. 2011. Federal Aid to States for Fiscal Year 2010. U.S. Department of Commerce. Available at http://www.census.gov/prod/2011pubs/ fas-10.pdf.

2010. Federal Aid to States for fiscal Year 2009. U.S. Department of Commerce. Available at http://www. census.gov/prod/2010pubs/fas-09.pdf.

U.S. Council of Economic Advisors. 2010. The Economic Impact of the American Recovery and Reinvestment Act of 2010: Second Quarterly Report. The White House. Available at http://www.whitehouse.gov/sites/default/ files/microsites/100113-economic-impact-arra-secondquarterly-report.pdf.

2010. The Economic Impact of the American Recovery and Reinvestment Act of 2009, Supplement to the Third Quarterly Report: The ARRA and the Clean Energy Transformation. The White House. Available at http:// www.whitehouse.gov/administration/eop/cea/ factsheets-reports/economic-impact-arra-3rd-quarterlyreport/supplement_greenjobs.

U.S. Department of Agriculture. 2014. FY 2015 Budget Summary and Annual Performance Plan. Available at http://www.obpa.usda.gov/budsum/FY15budsum.pdf

1982. A Brief History of the Rural Electric and Telephone Programs. Available at http://www.rurdev. usda.gov/rd/70th/rea-history.pdf.

U.S. Department of Energy. "Energy Independence and Security Act of 2007: Major Provisions of Interest to Federal Energy Managers." Available at http://www1. eere.energy.gov/femp/news/news_detail.html?news_ id $=11683$.

2012. Successes of the Recovery Act. Available at http://energy.gov/sites/prod/files/RecoveryActSuccess Jan2012final.pdf.

2010. "U.S. Departments of Energy and Interior Announce Site for Solar Energy Demonstration Projects in the Nevada Desert." Press release. Available at http://energy.gov/articles/us-departments-energyand-interior-announce-site-solar-energy-demonstrationprojects-nevada.

___. 2003. "Performance and Accountability Report: Fiscal Year 2002.” Available at http://www.paducaheic. com/media/39813/lb09900-0167-grc01.pdf.
U.S. Department of Energy Loan Programs Office. "Awards and Accomplishments." U.S. Department of Energy. Available at http://energy.gov/lpo/about-us/ awards-accomplishments

"Projects." Available at http://energy.gov/ lpo/projects.

U.S. Department of Labor. 2012. Recovery Act: Green Jobs Program Reports Limited Success in Meeting Employment and Retention Goals as of June 30, 2012.

U.S. Energy Information Administration. 2014. Annual Energy Outlook 2014. U.S. Department of Energy. Available at http://www.eia.gov/forecasts/aeo/ pdf/0383(2014).pdf.

2013. "Feed-in Tariff: A Policy Tool Encouraging Deployment of Renewable Electricity Technologies." May 30. Available at http://www.eia.gov/todayinenergy/ detail.cfm?id=11471.

2012. Annual Energy Outlook 2012. U.S.

Department of Energy. Available at http://www.eia.gov/ forecasts/aeo/pdf/0383(2012).pdf

U.S. Energy Information Administration. 2012. Assumptions to the Annual Energy Outlook 2012. U.S. Department of Energy. Available at http://www.eia.gov/forecasts/aeo/ assumptions/pdf/0554(2012).pdf.

. 2012. "Levelized Cost of New Generation Resources in the Annual Energy Outlook 2012." June 25. Available at http://www.eia.gov/forecasts/archive/aeo12/ electricity_generation.cfm.

2012. "Nuclear Explained: Nuclear Power and the Environment." Energy Explained. June 28. Available at http://www.eia.gov/energyexplained/index. $\mathrm{cfm}$ ?page=nuclear_environment.

2011. Annual Energy Outlook 2011. U.S. Department of Energy. Available at http://www.eia.gov/ forecasts/archive/aeo11/pdf/0383(2011).pdf.

2011. International Energy Outlook 2011. U.S.

Department of Energy. Available at http://www.eia.gov/ forecasts/archive/ieo11/pdf/0484\%282011\%29.pdf.

2011. Assumptions to the Annual Energy Outlook 2011. U.S. Department of Energy. Available at http:// www.eia.gov/forecasts/archive/aeo11/assumptions/ pdf/0554(2011).pdf. 
___ 2011. "Most Generator Retirements Over the Past Decade Were Older Natural Gas-Fired units." Today in Energy. December 13. Available at http://www. eia.gov/todayinenergy/detail.cfm?id=4290.

- 2010. Annual Energy Outlook 2010. U.S.

Department of Energy. Available at http://www.eia. gov/forecasts/archive/aeo10/pdf/0383(2010).pdf.

-__. 2010. Annual Electric Generator Report. GeneratorsY2010 [data file]. U.S. Department of Energy. Available at http://www.eia.gov/electricity/ data/eia860/index.html.

2010. Assumptions to Annual Energy Outlook 2010: Renewable Fuels Module. U.S. Department of Energy. Available at http://www.eia.gov/oiaf/aeo/ assumption/pdf/renewable.pdf.

2009. "Macroeconomic Activity Module." In The National Energy Modeling System: An Overview 2009. Available at http://www.eia.gov/oiaf/aeo/overview/ pdf/0581(2009).pdf.

U.S. Environmental Protection Agency. 2014. "Inventory of U.S. Greenhouse Gas Emissions and Sinks: 1990-2012.”

U.S. Environmental Protection Agency. 2013. Budget in Brief. Available at http://yosemite.epa.gov/sab\% 5CSABPRODUCT.NSF/2B686066C751F34A852579 A4007023C2/\$File/FY2013_BIB.pdf.

___ 2013. "Non-Hydroelectric Renewable Energy Sources." Available at http://www.epa.gov/cleanenergy/ energy-and-you/affect/non-hydro.html.

- - 2013. EPA Fact Sheet: Reducing Carbon Pollution from PowerPlants. Moving Forward On the Climate Action Plan. Available at http://www2.epa.gov/sites/production/ files/2013-09/documents/20130920factsheet.pdf.

-_ - 2013. EPA Fact Sheet: Reducing Carbon Pollution from Power Plants. Details about the Proposal for New Sources. Available at http://www2.epa.gov/sites/ production/files/2013-09/documents/20130920 technicalfactsheet.pdf.

U.S. Environmental Protection Agency and National Highway Traffic Safety Administration. 2010. Greenhouse Gas Emissions Standards and Fuel Efficiency Standards for Medium- and Heavy-Duty Engines and Vehicles. Working draft. Available at http://epa.gov/ OMS/climate/regulations/hd-preamble-regs.pdf.
U.S. Executive Office of the President. 2013. The President's Climate Action Plan. The White House. Available at http://www.whitehouse.gov/sites/default/files/image/ president 27 sclimateactionplan.pdf.

U.S. Federal Energy Management Program. 2010. Energy Independence \& Security Act. U.S. Department of Energy. Available at http://www1.eere.energy.gov/femp/ regulations/eisa.html.

U.S. General Services Administration. 2012. "FY 2012 Federal Real Property Report.” Available at http:// www.gsa.gov/portal/mediaId/179655/fileName/ FY_2012_FRPP_intro_508.action.

U.S. Government Accountability Office. 2013. "Employment and Training: Labor's Green Jobs Efforts Highlight Challenges of Targeted Training Programs for Emerging Industries." Report to Congressional Requesters. GAO-13-555.

2009. “Federal Energy Management: Agencies Are Taking Steps to Meet High-Performance Federal Building Requirements, but Face Challenges." Report to Congressional Committees. GAO-10-22. Available at http://www.gao.gov/assets/300/297920.pdf.

U.S. Internal Revenue Service. 2011. "SOI Tax Stats Individual Income Returns, Estimated Data Line Counts [data file].” Available at http://www.irs.gov/ uac/SOI-Tax-Stats-Individual-Income-Tax-Returns,Estimated-Data-Line-Counts.

. 2012. “Table 12 - Returns of Active Corporations, Other Than Forms 1120-REIT, 1120-RIC, and $1120 \mathrm{~S}$ [data file].” Available at http://www.irs.gov/uac/ SOI-Tax-Stats-Table-12-Returns-of-Active-Corporations,Other-Than-Forms-1120-REIT,-1120-RIC,-and-1120S.

U.S. National Transportation Research Center. 2013. “Transportation Energy Data Book." Table 2.12. Knoxville, TN: Oak Ridge National Laboratory. Available at http://cta.ornl.gov/data/tedb32/ Edition32_Chapter02.pdf.

U.S. Office of Energy Efficiency and Renewable Energy. 2012. Solid-State Lighting Research and Development: Multi-Year Program Plan. U.S. Department of Energy. Available at http://apps1.eere.energy.gov/buildings/ publications/pdfs/ssl/ssl_mypp2012_web.pdf. 
U.S. Office of Management and Budget. 2013. Budget of the United States Government: Department of Labor. The White House. Available at http://www.whitehouse.gov/ sites/default/files/omb/budget/fy2014/assets/lab.pdf.

U.S. Office of the White House Press Secretary. 2014. "Fact Sheet: Climate Action Plan-Strategy to Cut Methane Emissions." Available at http://www.whitehouse.gov/ the-press-office/2014/03/28/fact-sheet-climate-actionplan-strategy-cut-methane-emissions.

U.S. Office of Transportation and Air Quality. 2009. “EPA Lifecycle Analysis of Greenhouse Gas Emissions from Renewable Fuels." U.S. Environmental Protection Agency. Available at http://nepis.epa.gov/Exe/ZyPDF. cgi/P100B3F8.PDF?Dockey=P100B3F8.PDF.

Vance, Bob. 2013. "Coal Train Fact Check.” Washington: League of Women Voters. Available at http://www. lwv-bf.org/Coal_Train_Fact_Check.pdf.

Wald, Matthew. 2013. "Ideas to Bolster Power Grid Run Up Against System's Many Owners.” The New York Times. July 13. Available at http://www.nytimes.com/ 2013/07/13/us/ideas-to-bolster-power-grid-run-upagainst-the-systems-many-owners.html.

Walsh, Jason, Josh Bivens, and Ethan Pollack. 2011. "Rebuilding Green: The American Recovery and Reinvestment Act and the Green Economy." BlueGreen Alliance and Economic Policy Institute. Available at http://www.bluegreenalliance.org/news/publications/ document/BGA-EPI-Report-vFINAL-MEDIA.pdf.
Wang, Ucilla. 2012. "U.S. Military's Big Plan for Renewable Energy Projects." Forbes. August 6. Available at http://www.forbes.com/sites/uciliawang/2012/ 08/06/u-s-military-opens-up-16m-acres-for-renewableenergy-projects/.

Wicks-Lim, Jeannette, and Robert Pollin. 2012. "Making Work Pay: Combining the Benefits of the Earned Income Tax Credit and Minimum Wage." Amherst, MA: Political Economy Research Institute. Available at http://www.peri.umass.edu/fileadmin/pdf/published_ study/PERI_WorkPay.pdf.

Wise, David. Director of Physical Infrastructure Issues. 2011.

"Federal Real Property: Overreliance on Leasing Contributed to High-Risk Designation." Testimony before the Subcommittee on Federal Financial Management, Government Information, Federal Services, and International Security, Committee on Homeland Security and Government Affairs, U.S. Senate. GAO-11-879T. Washington: Government Accountability Office. Available at http://www.gao.gov/assets/130/126817.pdf.

$\mathrm{Xu}$, Conglin. 2013. "Capital Spending in US, Canada to Rise Led by Pipeline Investment Boom.” Oil and Gas Journal. March 4. Available at http://www.ogj.com/ articles/print/volume-111/issue-3/s-p-capital-spendingoutlook/capital-spending-in-us-canada-to-rise.html.

Zabin, Carol, and Megan Emiko Scott. 2013. "Proposition 39: Jobs and Training for California's Workers. Berkeley, CA: Donald Vial Center on Employment in the Green Economy. Available at http://www.irle.berkeley.edu/ vial/publications/prop39_jobs_training.pdf. 


\section{Index}

A

Abound Solar, 261, 262, 297

ACEEE (see American Council for an Energy Efficient Economy)

ACESA (see Waxman-Markey bill)

advancing policy proposals (see clean energy policy agenda)

Aggressive Reference case, 5-6, 26-27, 176, 180, 183-194

carbon emissions estimates, 342

Clean Air Act, inclusion of enforcement of, 278

energy consumption, 341

expansion of clean renewables, 186-187

overall consumption decrease, $186-187,341$

substituting natural gas for coal, 193-196

Allcott and Greenstone study, 60-61

Allen study, 168

alternative scenarios for energy consumption, 26, 180-190

Aggressive Reference case (see Aggressive Reference case)

Extended Policies case (see Extended Policies case)

PERI/CAP case (see PERI/CAP case)

Reference case (see Reference case)

American Clean Energy and Security Act (ACESA) (see Waxman-Markey bill)

American Council for an Energy Efficient Economy, 282

American Council on Capital Formation/National Association of Manufacturers, 240-241

American Council on Renewable Energy, 110-112

American Iron and Steel Institute, 65

American Recovery and Reinvestment Act

Carley and Hyman study, 254

DOE-directed programs, 256-259

EISA funding, 286

job growth, 30-31, 252, 256-259

loan guarantees (see loan guarantees)

overview, 237-238, 252, 297

size of program, 253-255

Solyndra (see Solyndra)

success of, 255

upgrading grid program, 255, 284

weatherization program under, 255

Annual Energy Outlook, 33, 44-45, 103, 108, 123, 152, 180, 337, 358 air transport, 78

combined heat and power systems, cost of investing in, $67-70$

increased fuel efficiency standards, view of, $26,78-79$

Reference case for transportation sector, 71-82

Annual Technology Outlook

Low-Cost Renewable Technology case (see Low-Cost Renewable Technology case)

automobiles

electric cars (see electric vehicles)

fuel efficiency (see fuel efficiency standards)

jobs preserved through clean energy investments, 221
B

backfire effect, 88, 93

Best Available Technology case, 45

bioenergy, 3, 11, 19, 22-23, 99, 101-103, 113-118, 136-139

carbon dioxide emissions levels, 177-179

costs for expanded use of (see costs of expanding clean renewables)

food prices, effect on, 116-118

job growth, 212-215, 223, 230-232

biofuels, 22, 24, 80, 99, 101-107

costs for expanded use of (see costs of expanding clean renewables) defined, 114

energy supply projections, 121-122

ethanol (see ethanol)

food prices, effect on, 116-118

levelized costs, 126-127, 131-132

biomass energy, 99, 101-104, 106, 115-116, 121-122, 125-129

costs for expanded use of (see costs of expanding clean renewables)

defined, 113-114

energy supply projections, 121-122

job growth, 230

Bloomberg Sustainable Energy in America Factbook

challenges to policy agenda, 305

investment data, 269

production and investment tax credits, 292-293

utility investments, data on, 280, 281

bridge fuel scenario, 27, 151, 186, 193-196

British Thermal Units, 15-17

international consumption levels, 39-40

quadrillion BTUs (see Q-BTUs)

Brookes study, 88

building sector

advanced cooling systems, 57

advanced window technologies, 58

Allcott and Greenstone study, 60-61

Best Available Technology case, 45

commercial-building construction, advances in, 58-59

comparing 2010 and 2030 consumption levels, 43-44

cost of conserved energy for electricity use, 59

cost of conserving energy, 53, 55, 56-61

electricity, reliance on, $43-45$

environmental effects of investment, 56

estimates of job growth per million dollars of expenditure, 209

home construction, advances in, 58

home electronics, lower consumption by, 57

investment needed to achieve improvements, 59-61, 84

NAS scenario for consumption decrease, $46-55$

NEMS model, 44-45

projected consumption, 44-45

Reference case projections, $6,46,54-55$

retrofitting buildings, effect of, 202, 204, 207, 225, 257, 287, 299

returns on investment in building efficiency, 59-61, 86

scenarios showing investment levels, 216-217

servers and data centers, lower consumption in, 57

solid state lighting, 56-57

structural changes, efficiencies derived from, 44-45 
technoeconomic efficiency gains, 46-55, 61

technologies promising improved efficiency, 56-61

thermal-shell investments, 46-55

total energy consumption, 61

weatherization programs, problems with, 60-61

Bush, George W., 286

\section{C}

California, 171, 294-295

cap-and-trade legislation, 278

Property Assessed Clean Energy financing, 300

Cantwell, Maria, 277

cap-and-dividend policy, 12, 277, 317

cap-and-trade legislation, 30, 150, 237, 247-248, 277-278

California, enactment in, 278

forecasts on effects of, 239-241

carbon cap or tax, 12, 32-33, 134, 150, 247-248, 275-278, 316-317, 369 cap-and-dividend policy (see cap-and-dividend policy)

carbon capture and sequestration, 128, 133-134, 170-172 cost in expanding clean renewables, as, 128-129

carbon dioxide $\left(\mathrm{CO}_{2}\right)$ emissions (see also greenhouse gas emissions) benefits of lower emissions, 25

cap-and-dividend policy (see cap-and-dividend policy) cap-and-trade legislation (see cap-and-trade legislation) carbon capture and sequestration (see carbon capture and sequestration)

China, 18

emissions from alternative nonrenewable sources, 175-179

levels in alternative scenarios, 175-179, 191-192, 342

overview, 10-14, 18-19, 175-196

petroleum, 175-179

pollution standards for power plants, 184,186

Q-BTU goal, 83-85, 175, 176

reduction targets, 19, 26-27, 31, 34, 99, 175-196, 242-243

weighted averages, 179

carbon price, $150,152-158,161,276-277$

electricity consumption, effect on, 153-156, 158

Carley and Hyman study, 254

CEFIA (see Clean Energy Finance and Investment Authority)

Center for American Progress, 295

CERES study, 251

China, 18, 92

Chu, Steven, 170

Clean Air Act, enforcement of, 6, 24-25, 275, 278-279, 306

Clean Edge report, 111

Clean Energy Finance and Investment Authority, 296

clean energy policy agenda, 10-14, 19-20, 317

budgetary impacts, 377-380

cap-and-dividend policy (see cap-and-dividend policy)

carbon cap or tax (see carbon cap or tax)

carbon capture and sequestration (see carbon capture and sequestration)

challenges to, 304-306

Clean Air Act, enforcement of (see Clean Air Act, enforcement of)

complementarities between policy initiatives, 304-306

decoupling policies, 281-282, 304

direct public investment (see direct public investment)

electricity grid infrastructure investment by government, 253, 255, 283-284

Energy Efficiency Resource Standards, implementation of, 275, 280 energy efficient public investments, 285-287 federal R\&D projects, $288-290,370$

federal renewable energy procurement projects, 287-288

feed-in tariffs (see feed-in tariffs)

fiscal impact of, 315-319, 368-381

green banks, establishment of, 295-297

investment tax credits, 33, 58, 274, 291-293, 371

loan guarantees (see loan guarantees)

macroeconomic issues (see macroeconomic issues)

market-shaping rules, 6, 273-284, 369

Master Limited Partnerships, 301-303, 304

net savings from, 316-318, 381

on-bill financing, 300

overview, 268-274

private investment incentives, 291-303

Property Assessed Clean Energy financing, 299-301

prospects for clean, renewable energy (see clean renewables)

Real Estate Investment Trusts, 301-303, 304

regional equity considerations, 7, 307-309

Renewable Portfolio Standards, implementation of, 280

state utility market rules, improvement of, 281-283

transitional support for workers and communities (see worker and community adjustment assistance)

worker and community transition assistance (see worker and community adjustment assistance)

clean renewables, 99-100

Aggressive Reference case, 186-187

alternative projections, 110-112

consumption by categories, 102

costs of expansion of (see costs of expanding clean renewables)

energy supply projections, 121-122

Extended Policies case, 186-187

generating 15.4 Q-BTUs from, 131-134, 137, 138

job growth from investment in (see job growth)

overall consumption increase in alternative scenarios, 188-190

Reference case, 103-113

U.S. generation of, 101-103

weighted costs for, 133-134

Climate Action Plan, 129, 176, 190, 192

carbon cap or tax, 277

carbon pollution standards, 277, 306

Clean Air Act, enforcement of, 278-279, 306

expansion of clean renewables, 186-187

federal renewable energy procurement projects, 287-288

fuel efficiency standard, 185-186

more stringent standards for heavy-duty vehicles, 77

natural gas as substitute for coal-fired electricity, 186

overview, 183-186, 287

pollution standards for electricity power plants, 186

Climate Change Action Plan (see Climate Action Plan)

Climate Change Advisors, 24, 144, 149, 151, 164, 168, 364

coal

carbon capture and sequestration, coal plants with, 170-172

carbon dioxide emissions levels, 179

carbon pollution standards, 306

Clean Air Act, effect of enforcement of, 278-279

Climate Action Plan, 186

conversion factor in standard energy units, 15-17

Deutsche Bank scenario, 151, 153-157, 160-162, 278

future demand for, 24

levelized costs for electricity from, 128-130

natural gas as substitute for coal-fired electricity, 27, 186, 193-196 overall consumption decrease in alternative scenarios, $27,188-190$

rebound effect of steam engines, 88,92

The Coal Question, 88

Utility Maximum Achievable Control Technology, 151

Coalition for Green Capital, 295-296

Collins, Susan, 277

combined heat and power systems, $62,63-67,357$

cost of investing in, 67-70

commodities futures, speculation in, 247 
community adjustment assistance (see worker and community adjustment assistance)

concentrated solar power technologies, 310

Congressional Research Service, 288

Connecticut

Property Assessed Clean Energy financing, 300

statewide green bank, 296

Conservation Loan Program, 298

consumption relative to GDP (see energy-intensity ratio)

Coons, Christopher, 302

costs of expanding clean renewables, 110-112, 123, 138-139

capital expenditures, 135-137

carbon capture and sequestration, 128-129

cost of 15.4 Q-BTUs of clean renewable energy, 131-134, 137, 138

electricity, 123-130

estimated average levelized costs, $123-126$

fossil fuel and nuclear costs compared, 128-129

lump-sum capital expenditures, 136-137

range of levelized costs, $126-127$

renewables versus conventional sources, levelized costs for, 128-130

Council of Economic Advisors, 253-254

crosscutting investments, $62-64$

\section{D}

decoupling policies, 281-282, 304

Defense Department, 304, 305

$R \& D$ projects, benefits of, 264

renewable energy procurement projects, 287-288

Department of Agriculture, 298

Department of Energy, 66, 256-259

Federal Energy Management Program, 286

Loan Guarantee Program, 297-299

Worker and Community Transition assistance, 309-310

Department of Labor study, 311

Deutsche Bank studies, 151-158, 278

Climate Change Advisors (see Climate Change Advisors)

coal consumption, 24-25, 157, 160-162

electricity generation, $157-162$

fracking, 168

nuclear energy, prospects for, 25

direct public investment, 10-12, 21, 32, 207, 209, 285-290, 369-370

displaced workers (see worker and community adjustment assistance)

DOE (see Department of Energy)

Dotsey, Fujita and Stark study, 223

Duke University study, 167, 169

\section{E}

ECA, 310

Edison Electric Institute, 284

EERS (see Energy Efficiency Resource Standards)

EIA (see Energy Information Administration)

EIT (see Energy Independence Trust) electric cars (see electric vehicles)

electric vehicles

ARRA funding for, 255

cost of more fuel-efficient vehicles, study on, 75-77

hybrid electric cars, 75-76

manufacturing facilities, 263

electricity

alternative forecasts, 144, 149, 152-159

automobiles and other vehicles (see electric vehicles)

carbon price scenarios, 150

clean renewables, cost of production from, 123-130

Climate Action Plan pollution standards for power plants, 184, 186

coal-fired production of 153-155

combined heat and power systems, effect of (see combined heat and power systems)

conventional sources, cost of production from, 129-130

conversion factor in standard energy units, 15-17

Deutsche Bank scenario, 151, 157, 160-162

emissions regulation scenario, 150

excess capacity issues, 144

hydroelectricity, 102-103

Low-Cost Renewable Technology forecast (see Low-Cost Renewable Technology case)

microgrids, 287

natural gas as substitute for coal-fired electricity, 27, 155-157, 186, 193-196

nonrenewable sources of, 157-162

nuclear-powered electricity, 157-162

Reference case estimates for 2030 and 2035, 149

retrofitting scenarios, 150

Rural Utilities Service-Electric Loan Program, 298

Smart Grid, ARRA funding for, 253, 255, 283-284

thermal-shell investments, savings from, 46-55

upgrading grid program, 253, 255, 283-284

utilities (see utilities)

Utility Maximum Achievable Control Technology, 151

Emanuel, Kerry, 112

employment effects (see also job growth)

comparison of clean and nonrenewable energy spending, 218-220 definitions, 202-204

input-output model, 202-203, 343-356

jobs preserved through clean energy investments, 221

labor force participation rate, 223-224

labor market stress, potential sources of, 222-224

methodology, 202-204, 343-367

net gain, 200

nonrenewable energy sectors, 216-220

overview, 3-4, 13, 28-29, 199-201

public transportation, expansion of, 331-332

skill requirements and training for clean energy jobs, 233, 310-312

tighter labor market, 222-224

unemployment/inflation relationship, 223

employment generation (see job growth)

Energy Communities Alliance, 310

Energy Digital, 287

Energy Efficiency and Conservation Loan Program, 298-299

Energy Efficiency and Renewable Energy Training program, 311

Energy Efficiency Resource Standards

decoupling policies, complementary nature of, 281

implementation of, 275,280

energy efficiency standards, 3-4

advances in, 21, 38-42

Energy Efficiency Resource Standards (see Energy Efficiency Resource Standards)

fuel efficiency standards (see fuel efficiency standards)

Energy Independence and Security Act, 284, 286, 311

Energy Independence Trust, 295-296 
Energy Information Administration

Annual Energy Outlook (see Annual Energy Outlook)

carbon price scenario, 276-277

clean energy cost competitiveness, estimates of, 23, 264, 289

costs of expanding clean renewables, estimates of (see costs of expanding clean renewables)

domestic petroleum production forecast, 249

energy price forecast, $246-247$

Extended Policies case (see Extended Policies case)

forecast on effects of Waxman-Markey, 240-241

GDP forecast, 244

NEMS model, 44-45

nuclear power, 163-165

projected renewable energy supply and costs, 110-112

reference case (see Reference case)

research on costs of expanding clean renewables (see costs of expanding clean renewables)

energy-intensity ratio, 38, 244, 327

energy productivity, 244

Energy Savings Performance Contracts, 286

environmental and safety concerns

carbon capture and sequestration, 172

fracking, 144-145, 165-169

nuclear power, 163-165

Environmental Protection Agency, 24, 113-115, 150-151, 184, 186, 278

EPA (see Environmental Protection Agency)

ethanol, 22, 99, 102, 114-116, 143, 179, 212

Extended Policies case, 186

baseline for Aggressive Reference case, 185

energy consumption scenario, 341

expansion of clean renewables, 186-187

explanation of, 337-340

fuel efficiency standard, 185-186

Reference case compared, 337-340

extreme weather events, effect of, 251

\section{$\mathrm{F}$}

Federal Energy Management Program, 286

Federal Energy Regulatory Commission, 283

Federal Highway Administration, 82

federal R\&D projects, 288-290, 304, 370

feed-in tariffs, 293-295

fiscal impact of clean energy policies, 315-319, 368-381

FIT programs (see feed-in tariffs)

food (see biofuels)

Forbes, 287

Ford, 263

fracking, 25

environmental and safety concerns, 144-145, 165-169

natural gas, $165-169$

freight and rail systems, $82,332-333$

fuel efficiency standards

auto-efficiency standard for 2025, 175-176

Climate Action Plan, 185-186

cost of more fuel-efficient vehicles, 75-77

greenhouse gas emissions; table, 75

heavy-duty vehicles, 185-186, 279 increased standards, effect of, 73-75, 334-336

investment needed to achieve energy reductions, estimate of, 85

jobs preserved through higher standards, 221

jobs resulting from fuel-efficient cars, 207-208, 209-210

long-term savings realized by increased standards, 73-75

rebound effect of increased standards, 74

Fukushima, 20, 158-159, 164-165

G

Gavankar and Geyer study, 90

GDP growth, 30, 93, 184, 237, 248, 319, 364-367

benefits of climate change policies, 251

EIA forecast, 244

energy consumption relative to, 38-39

environmental regulations and, 239-241

extreme weather events, effect of, 251

labor productivity growth and, 364-366

Reference case forecast, 244

geothermal energy, 3,11, 19, 23, 99, 102-108 (see also clean renewables) job growth through operations and maintenance expenditures, 212 levelized costs for electricity from (see costs of expanding clean renewables)

Low-Cost Renewable Technology case, estimates under, 120-122

Google, 110-112

green banks, 295-297

cost estimates for, 371-373

greenhouse gas emissions (see also carbon dioxide $\left(\mathrm{CO}_{2}\right)$ emissions) absolute level, focus on, 39

alternative energy sources, emissions from, 114-116

backfire effect, 88

challenge of meeting reduction targets, $12-14,18-19,28,69,73-75$, 268-269

China, 18

Climate Action Plan, 184

EIA projection, $40-42$

industrial sector efficiencies, 69

overview, 2, 4, 10, 13-14, 18-19, 305-396

proposed policy agenda to reduce (see clean energy policy agenda) secondary greenhouse gas emissions from nuclear power, 163 transportation sector, 80

Greening, Greene and Difiglio study, 90, 91

groundwater contamination, 168

$\mathrm{H}$

Hannon Armstrong, 302

heavy-duty vehicles, 71-73, 77-78 proposed fuel efficiency standards, 185-186, 279

Hendricks study, 270

Herzog, Howard, 171

high-temperature separation technologies, 63

hybrid electric cars, $75-76$

hydraulic fracking (see fracking)

hydro power, 22, 23, 99-100

hydroelectricity, 102-103, 118-120

job growth through operations and maintenance expenditures, 212

levelized costs for electricity from (see costs of expanding clean renewables)

prospects for expansion, $118-120$

hydroelectricity, 102-103, 118-120 
Idaho National Lab, 119-120

IMPAC International study, 311

importation of petroleum, 148, 249-250

industrial sector

chemical manufacturing, 66

combined heat and power systems (see combined heat and power systems)

crosscutting investments, 63-64

energy consumption, generally, 62

estimates of job growth per million dollars of expenditure, 209

greenhouse gas emissions target, efficiencies needed to meet, 69

industry-specific investments, 64-66

Interlaboratory Working Group on Energy-Efficient and Clean Energy Technologies- study by, 69

investment needs, estimate of, 67-70, 84

iron and steel, 65

lack of growth in energy consumption, 62

petroleum refining, 66-67

plastics, 66

pulp and paper industry, 64

scenarios showing investment levels, 216-217

input-output model, 202-203, 343-356

Intergovernmental Panel on Climate Change, 2, 5-6, 13-14, 18-19, 268

Interlaboratory Working Group on Energy-Efficient and Clean Energy Technologies, 69

international comparisons, 39-40, 165

combined heat and power systems (see combined heat and powe systems)

feed-in tariffs, 294

green banks, 295

International Energy Outlook, 165

investment

ARRA (see American Recovery and Reinvestment Act)

Bloomberg data, 269

building sector (see building sector)

costs of expanding clean renewables (see costs of expanding clean renewables)

crosscutting investments, 62-64

decreasing levels in nonrenewable energy sector, 243

direct public investment (see direct public investment)

emission targets, $242-243$

fiscal impact, 315-319, 368-381

industrial sector (see industrial sector)

job growth resulting from (see job growth)

low cost investments defined, 46

National Academy of Sciences studies (see National Academy of Sciences)

overview, 268-270

PERI/CAP scenario, 182-183

private investment (see private investment)

public transportation investment, 85

Real Estate Investment Trusts (see Real Estate Investment Trusts)

Smart Grid Investment Grant Program, 253, 255, 283-284

targets (see clean energy policy agenda)

utilities, 280, 281, 283-284

investment targets (see clean energy policy agenda)

investment tax credits, 33, 58, 291-293, 371

IPCC (see Intergovernmental Panel on Climate Change)

ITC (see investment tax credits)

IWG (see Interlaboratory Working Group on Energy-Efficient and Clean Energy Technologies)
Jackson study, 167-168

Jevons, Stanley, 21, 88, 92

job growth, 29-30

ARRA, effect of, 30-31, 252, 256-259

bioenergy sector, 223, 230-232

categories of jobs created by clean energy investment, 225-229, 360-362

compensation per worker, 205

construction sector jobs, 206-207

direct job creation, 204, 344

domestic nature of, 205

economy's ability to absorb additional jobs, 223-224

educational level, by, 225-229, 228

estimates per million dollars of expenditure, 209-212

fall-off in, 257

fuel efficient cars, resulting from, 207-208, 209-210

Green Prosperity study, 225, 229

indirect job creation, 204, 257-258, 344

induced job creation, 204, 205, 257-258, 344

job years, measuring, 206-207

jobs per year, measuring in terms of, 206-207

labor intensity, 205

Laitner study, 222

lower-credentialed and low-paying jobs, 228-229

net expansion, 200, 218-220

nonrenewable energy sectors, $216-220$

nuclear decommissioning, resulting from, 216

operations and maintenance, derived from, 29, 212-214, 216-217, 230-233

potential additional sources of, 221-222

public transportation investment, resulting from, 221

renewable energy capital expenditures, derived from, 211-215

representative sample of jobs expanding disproportionately,

225-229, 231-232

retrofitting buildings, effect of, 202,204,207,225, 257, 287, 299

scenarios showing investment levels, 218-220

skill requirements and training for clean energy jobs, $233,310-312$

spending on clean energy and fossil fuels compared, 225, 228

summary of, 215

time dimension in measuring creation, 206-207

transfer of energy efficiency savings into other sectors, effect of, 222

unemployment/inflation relationship, 223

K

Khazzoom study, 88

Kosnik study, 119-120

$\mathbf{L}$

labor productivity, 203, 244-245, 347-348, 367 GDP growth and, 364-366

Laitner study, 222

light-duty vehicles overview, 71-74

proposed fuel efficiency standards, 279, 335

loan guarantees

cost estimates for, 374-376

default rate, 297-299 passim, 374-376

overview, 260-263, 297-299

Solyndra (see Solyndra)

Treasury Rate Loan Program, 298-299

Lovins, Amory, 126

low-cost investments, 46-55 
Low-Cost Renewable Technology case, 108-109, 113, 118, 120-122, 127, $130-134,136$

costs of expanding clean renewables (see costs of expanding clean renewables)

Lynch and Kirshenberg study, 310

\section{M}

macroeconomic issues, 30-31

ARRA, effect of (see American Recovery and Reinvestment Act) commodities futures, speculation in, 247

decreasing energy consumption, 244, 246

employment effects (see employment effects)

energy productivity, 244

environmental regulation, 239-241

extreme weather events, effect of, 251

fiscal impact of clean energy policies, 315-319, 368-381

GDP growth (see GDP growth)

investment needed to reach 2030 goals, 242-243

job growth (see job growth)

labor productivity (see labor productivity)

overview, 237-238

policy interventions, effect of, 247-248

trade balance, $249-250$

Master Limited Partnerships, 301-304, 376

Mazzocchi, Tony, 313

McKinsey study, 64-65, 86

microgrids, 287

MLPs (see Master Limited Partnerships)

N

National Academy of Sciences

consumption projections, $41-42$

cost of conserved energy, 46-55

cost of conserving energy, 53,55, 56-61

cost of more fuel-efficient vehicles, study on, 75-77

energy-efficient investment opportunities, study on, 56-61

estimate of biomass and biofuel supply, 116

low-cost investments, efficiencies achieved through, 46-55

projected renewable energy supply and costs, $110-112$

public transportation, data on, $80-81$

rail and waterway freight, data on, 82

scenario for energy efficient investments, 41-42

National Energy Modeling System, 44-45, 149

National Renewable Energy Lab

decoupling policies, analysis of, 282

feed-in tariffs, study of, 294

natural gas

alternative projections, 155-157

"bridge fuel" scenario, 27, 151, 186, 193-196

carbon dioxide emissions levels, 177-179

consumption forecast, 25

conversion factor in standard energy units, 15-17

demand for, 151

Deutsche Bank scenario, 160-162

estimates of generating capacity, 193-196

fracking, 165-169

levelized costs for electricity from, 128-130

overall consumption decrease in alternative scenarios, 188-190

primary alternative fuel source for coal, 151

thermal-shell investments, savings from, 46-55

NEMS (see National Energy Modeling System)

Nissan, 263 nonrenewable energy sector, 20, 24, 360

coal (see coal)

commodities futures market, cost effect of, 247

decreasing demand for, 4-5

decreasing investment levels, 243

electricity (see electricity)

employment effects, 216-220

levelized costs, 134

natural gas (see natural gas)

nuclear power (see nuclear power)

oil (see petroleum)

prospects for (see prospects for nonrenewable energy)

weighted costs, 133-134

nuclear power

alternative projections, 157-162, 188-189, 190, 194-195, 34

decommissioning, 309-310, 358

Deutsche Bank study, 25, 157-162, 158-159, 190

electricity generation, 157-162

environmental and safety concerns, 20, 144-145, 163-165

Fukushima, effects of (see Fukushima)

levelized costs for electricity from, 128-130, 166

meltdowns, 20, 164-165

overall consumption decrease in alternative scenarios, 188-190

production of weapons, 164

R\&D, 288-290

radioactive waste, 164

replacement by natural gas, 195-196

secondary greenhouse gas emissions from, 163

share of power sector, 164

storage of used reactor fuel, 164

Ten Hoeve and Jacobson study, 165

0

Obama, Barack, 278, 287, 288, 289

Obama administration

ARRA (see American Recovery and Reinvestment Act)

Clean Air Act, enforcement of (see Clean Air Act, enforcement of)

Climate Change Action Plan (see Climate Action Plan)

Energy Efficiency and Conservation Loan Program, 298-299

federal R\&D projects, $288-289$

federal renewable energy procurement projects, 287-288

fuel efficiency standards, 21, 73, 77-78, 85, 176, 279, 334

green banks, proposed establishment of, 295-297

Trade Adjustment Assistance, funding for, 312

oil (see petroleum)

on-bill financing, 300

P

PACE (see Property Assessed Clean Energy financing)

PERI/CAP case, 2, 5-6, 26-30, 176, 180-183, 234

annual level of employment, effect on, 29

emissions levels, 194, 243, 277, 342

investment requirements, $182-183$

natural gas as replacement fuel, 195-196

overall consumption decrease, 26-28, 188-192, 341

petroleum

conversion factor in standard energy units, 15-17

domestic production, 148, 249

emissions levels, 175-179, 342

future demand for, 24

imports, 148, 249-250

natural gas as replacement fuel, 194

overall consumption decrease in alternative scenarios, $24,188-190$

overall demand for, 146-147

prospects for nonrenewable energy, 148

$\mathrm{R} \& \mathrm{D}, 288$

refining, 66-67

trade deficit, effect of imports on, 249-250 
plastics, 66

Podesta study, 11, 269, 270

policy proposals (see clean energy policy agenda)

Pollin, Heintz and Garrett-Peltier study, 257, 360

Pollin and Heintz study, 247

private investment, 2, 21, 30, 32, 242, 268-269, 272-274

complementarities between policy initiatives, 7, 304-306

cost of incentives, 316, 379, 381

green banks, 295-297, 371-373

loan guarantees (see loan guarantees)

Master Limited Partnerships, 301-303, 304

on-bill financing, 300

overview, 10-12

Property Assessed Clean Energy financing, 299-301

Real Estate Investment Trusts, 301-303, 304

tax credits for, 33, 58, 291-293, 371

production tax credits, 291-293, 338, 371

Property Assessed Clean Energy financing, 296, 299-301

prospects for clean, renewable energy (see clean renewables)

prospects for nonrenewable energy

carbon capture and sequestration (see carbon capture and sequestration)

coal (see coal)

electricity (see electricity)

environmental and safety concerns, 144-145

natural gas (see natural gas)

nuclear power (see nuclear power)

oil consumption, 146-147

overview, 143-144

PTC (see production tax credits)

public transportation

benefits of supporting, 331-332

costs of increasing ridership, 83,86

expansion of, $80,81,85,308$

investment needed to achieve energy reductions, 85

strategies to promote, $81,326-331$

total energy consumption for, 80

table showing, 72

pulp and paper industry, 64

Q

Q-BTUs

consumption figures, 6, 14, 19, 22-28, 40-42, 188-191, 194-196

conversion factors for, $15-17$

cost of 15.4 Q-BTUs of clean renewable energy, 131-134, 137, 138

emissions goals in, 83-85, 175-179

investments to reduce consumption to 70 Q-BTUs, 99-100, 213-215, 268

job growth from operations and maintenance at 15.4 Q-BTU level, 214 nonrenewable energy, 143, 145-148, 154, 156, 160-163

PERI/CAP case, summary of, 181

renewable energy, 99-106, 109-111, 116-118, 120-125

savings through efficiency in building sector, 43-61

savings through efficiency in industry sector, 62-70

savings through efficiency in transportation sector, 71-74, 77-79, 83-86

quadrillion BTUs (see Q-BTUs)

R

R\&D projects, 264, 304, 306, 370

nuclear power, 288-290

petroleum, 288

rail systems, $72,80-82,326,328-329,332-333$

Real Estate Investment Trusts, 301-303, 304, 376

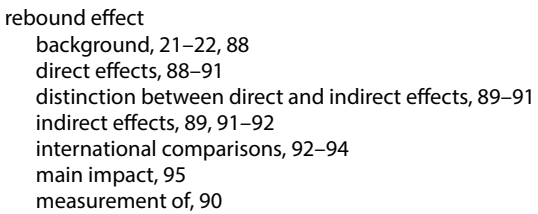

Recovery Act (see American Recovery and Reinvestment Act)

Reference case, 13,176

alternative consumption scenario, 180, 188-190, 34

alternative emissions scenario, 342

building sector, increased consumption by, $6,46,54-55$

clean renewables, estimates as to, 103-113

coal projections, 152-154, 190

costs of expanding clean renewables (see costs of expanding clean renewables)

electricity estimates, 144,149

emissions estimates, 5, 13, 191-192

energy consumption estimates, 24, 26-28, 40-42

Extended Policies case compared, 337-340

GDP forecast, 244

hydro power forecast, 118

industrial sector, energy consumption in, 62, 67-70

investment requirements, $83-86$

job growth, 210

Low-Cost Renewable Technology forecast (see Low-Cost Renewable Technology case)

natural gas, 155-156, 190

nuclear power, 190

oil consumption, 146-147

oil production and imports, 148

projection for energy consumption, 40-42, 146-147

transportation sector, 71-82

REITs (see Real Estate Investment Trusts)

Renew Economy article, 11

Renewable Energy (see clean renewables)

Renewable Portfolio Standards, 275, 280, 304

Retrofit-20 scenario, 153-16

retrofitting scenarios

electricity, 150

job growth (see job growth)

Retrofit-20 scenario, 152-161

Romm study, 171-172

RPS (see Renewable Portfolio Standards)

Rural Utilities Service-Electric Loan Program, 298

$S$

Skills for Green Jobs: A Global View, 233

Smart Grid, 253, 255, 283-284

Smart Grid Investment Grant Program, 284

solar power, 102, 105, 111-112 (see also clean renewables) Abound Solar, 263

clean energy cost competitiveness, estimates of, 23, 126, 137-138,

$$
\text { 291-293 }
$$

concentrated solar power technologies, 310

cost reduction forecasts, 246

costs of expanding (see costs of expanding clean renewables)

CT Solar Lease II, 296

facilities, 263

job growth through operations and maintenance expenditures, 212

Low-Cost Renewable Technology case, estimates under, 120-121

PV, 126, 137-138, 263, 295, 296, 338, 357

Solyndra (see Solyndra)

thermal, 120, 121, 124-127, 131-132, 135-137, 182, 211-214 
Solyndra, 31, 238, 252, 260-263, 297

Sorrell study, 90-92 passim

Sperling, Gene, 313

state laws, 300

mandatory FIT programs, 294-295

Superfund for workers, 313, 314

Sustainable Development Technology Canada, 295

\section{T}

tax credits for production and investment, 33, 58, 274, 291-293, 338, 371

technoeconomic efficiency gains, 46-55, 61

Ten Hoeve and Jacobson study, 165

The Coal Question, 88

thermal-shell investments, 46-55

Trade Adjustment Assistance, 312-313

trade balance, 249-250

training for clean energy jobs, 7, 229, 233, 310-312

cost estimates, 376, 380, 381

Energy Efficiency and Renewable Energy Training program, 311

transportation sector

air transport, 78-79

cost of more fuel-efficient vehicles, 75-77, 85

energy consumption, 72-73

expanded use of clean-burning fuels, 80

fuel efficiency standard (see fuel efficiency standards)

heavy-duty vehicles, 77-78

investment needs, estimate of, 85

job growth from investment in, 221

light-duty vehicles, 73-74

overall costs of lowering consumption, 79

public transportation (see public transportation)

rail and waterway freight, 82

Reference case assumptions regarding, 71-82

savings from more fuel-efficient vehicles, 85

Treasury Rate Loan Program, 298-299

2030 scenarios

Aggressive Reference case (see Aggressive Reference case)

Extended Policies case (see Extended Policies case)

PERI/CAP case (see PERI/CAP case)

Reference case (see Reference case)

\section{U}

Union of Concerned Scientists report, 115

units of measurement, $15-17$

University of Texas study, 168-169

utilities

Bloomberg data on investments, 280, 281

decoupling, 281-282, 304

distributed energy suppliers, effect of, 282-283

electricity grid infrastructure investment by government, 253, 255,

283-284

fair net metering rules, 282

investment data, 280, 281, 283-284

microgrids, 287

Rural Utilities Service-Electric Loan Program, 298

Smart Grid Investment Grant Program, 283-284

state market rules, improvement of, 281-283

Utility Maximum Achievable Control Technology, 151

Utrecht University study, 66

W

Waxman-Markey bill, 239-241, 277

weatherization program, 60-61, 255, 349

wind power, 23, 102, 105 (see also clean renewables)

job growth through operations and maintenance expenditures, 212

Low-Cost Renewable Technology case, estimates under, 120-121

workable clean energy policy (see clean energy policy agenda)

worker and community adjustment assistance, 7, 32, 271-274, 307, 309-314, 376

cost estimates, 376,380

Energy Efficiency and Renewable Energy Training program, 311

training for clean energy jobs (see training for clean energy jobs) 


\section{Acknowledgments}

The PERI-CAP collaboration began in 2008 on the huge, burning question of how to build a clean energy economy in the United States. In September 2008, we published "Green Recovery: A Program to Create Good Jobs and Start Building a Low-Carbon Economy," the first product of this collaboration. We then published "The Economic Benefits of Investing in Clean Energy: How the Economic Stimulus Program and New Legislation Can Boost U.S. Economic Growth and Employment" in June 2009. We assumed that the final installment of the collaboration would require another six months to one year of additional work, instead of the five years that it did take. The challenges of developing a coherent understanding of how to create a clean energy U.S. economy that generates widely shared benefits throughout the economy were obviously more formidable than we had originally anticipated. At this point, we can only hope that readers will be persuaded that our years of labor have been worth the effort.

We have benefitted tremendously from the ideas, suggestions, criticisms, and support from many people along the way, at both PERI and CAP, as well as from many outside commentators. It is a pleasure to recognize these contributions now.

Industry experts who gave us valuable perspectives include Jigar Shah, Adam Browning, Mark Fulton, and members of the Deutsche Bank Climate Change Advisors. Mark Muro of the Brookings Institution, Ron Blackwell of the Labor Network for Sustainability, and David Howell of the New School for Social Research also provided important insights.

This book would not have been possible without the dedicated support of many members of the CAP staff, past and present. Sarah Wartell and Michael Ettlinger were there at the start to help shape the economic modeling and test the policy proposals that have been incorporated in this work along with the two previous PERI-CAP publications. A deep debt of gratitude goes to Adam James, who helped manage the project over years, and who made many important contributions to the analysis. Richard Caperton, Darryl Banks, Carmel Martin, Dan Weiss, Kate Gordon, Pete Ogden, and Greg Dotson each offered constructive observations of various drafts. Ben Bovarnick and Danielle Baussan have been indispensable in delivering a difficult combination of ideas, editorial suggestions, and enthusiasm, as well as managing a complex editorial review process all the way to the finish line. We are also extremely grateful to Danielle for her outstanding work in redrafting the summary of this study. John Podesta was a tireless champion of the importance of this work, and 
his impatience to see it published was appreciated. Neera Tanden offered key insights that helped make the research more relevant to the national debate. Marc Jarsulic and Michael Madowitz of the CAP Economic Policy team helped stress test the modeling assumptions and economic theory. Lauren Vicary, Pete Morelewicz, Ed Paisley, Emilie Openchowski, Anne Paisley, Will Beaudouin, Emily Haynes, Eliot Sasaki, Meghan Miller, Meredith Lukow, Chester Hawkins, and Jason Chow provided the bedrock of a detailed editorial review over multiple revisions.

At PERI, we benefitted greatly from the research contributions and comments at various points of Jenna Allard, Jim Boyce, Ying Chen, Jerry Epstein, Thomas Herndon, Jeannette Wicks-Lim, and Ben Zipperer. Debbie Zeidenberg and Emily Bloch did excellent work helping us see the project through its many labyrinthine stages. PERI brought two outside consultants onto the project: Kim Weinstein did her usual outstanding job laying out the massive number of tables and figures in this study and James Connell produced an excellent index. Nothing worthwhile at PERI, including this study, would ever get accomplished if not for the off-the-charts abilities of our Administrative Director Judy Fogg. 
Robert Pollin is the Project Director of the study and a Distinguished Professor of Economics and Co-Director of the Political Economy Research Institute, or PERI, at the University of Massachusetts Amherst. His books include The Living Wage: Building a Fair Economy, Contours of Descent: U.S. Economic Fractures and the Landscape of Global Austerity, An Employment-Targeted Economic Program for South Africa, A Measure of Fairness: The Economics of Living Wages and Minimum Wages in the United States, Back to Full Employment, and Greening the Global Economy, which is to be published in 2015. He has worked recently as a consultant for the U.S. Department of Energy, the International Labour Organization, the U.N. Industrial Development Organization, and numerous nongovernmental organizations on various aspects of building high-employment green economies. Pollin has also directed projects on employment creation and poverty reduction in sub-Saharan Africa for the U.N. Development Program and has been a member of the U.S. Competitive Policy Council. He is presently a member of the Scientific Advisory Committee of the European Commission project on Financialization, Economy, Society, and Sustainable Development, or FESSUD. He is the founder and president of Pear Energy, an Amherst, Massachusetts-based private company that finances and develops energy efficiency and renewable energy projects throughout the United States. Pollin was selected by Foreign Policy magazine as one of the "Leading Global Thinkers of 2013."

Heidi Garrett-Peltier is an Assistant Research Professor with PERI at the University of Massachusetts Amherst. She received her Ph.D. from the University of Massachusetts Amherst in 2010. Her research focuses on the employment impacts of public and private investments, particularly those that support the transition to a low-carbon economy. She is the author of the 2011 book, Creating a Clean-Energy Economy: How Investments in Renewable Energy and Energy Efficiency Can Create Jobs in a Sustainable Economy. Other recent publications include the reports "Analysis of Job Creation and Energy Cost Savings from Building Energy Rating and Disclosure Policy," "Pedestrian and Bicycle Infrastructure: A National Study of Employment Impacts," “The U.S. Employment Effects of Military and Domestic Spending Priorities," "Green Prosperity: How Clean-Energy Policies Can Fight Poverty and Raise Living Standards in the United States," and "Global Green Growth," which is to be published later in 2014. She has developed a quantitative methodology that has been used extensively by PERI and other researchers in the United States as well as globally to estimate the impacts of spending on various domestic programs, including infrastructure investments, military spending, clean 
energy, education, and health care. She has served as a consultant with the U.S. Department of Energy, the U.N. Industrial Development Organization, and numerous nongovernmental organizations.

James Heintz is the Andrew Glyn Professor of Economics and Associate Director of PERI at the University of Massachusetts Amherst. He has written on a wide range of economic policy issues, including job creation, global labor standards, and the distributive consequences of macroeconomic policies. His books include An Employment-Targeted Economic Program for Kenya, The Field Guide to the U.S. Economy, and Progress of the World's Women: Women, Work and Poverty. Heintz has worked on collaborative projects with numerous U.N. agencies, including the International Labour Organization, the U.N. Research Institute for Social Development, the U.N. Economic Commission for Africa, the U.N. Development Program, and the U.N. Industrial Development Organization. His policy work has focused on the United States, as well as developing countries, primarily in subSaharan Africa, including Ghana, Kenya, Liberia, Gambia, Madagascar, and South Africa. His current work focuses on employment policy and poverty outcomes; public investment; economic policy choices and human rights; informal and atypical employment; financialization and commodity futures markets; macroeconomic policies for sub-Saharan Africa; and the links between economic policies and distributive outcomes, including race and gender dimensions.

Bracken Hendricks is a Senior Fellow at the Center for American Progress and President and CEO of Urban Ingenuity, where he serves as Program Administrator for the DC Property Assessed Clean Energy, or PACE, financing program and as the Multifamily Housing Partner to Connecticut's Green Bank. Hendricks is a long-time strategic advisor to former President Bill Clinton, the Clinton Foundation, and the Clinton Global Initiative on climate solutions, resilient cities, infrastructure finance, and jobs. Hendricks has served as an outside advisor to the campaign and administration of President Barack Obama, and was a key architect of numerous pieces of clean energy and jobs legislation. He served in the Clinton administration as special assistant to the Office of Vice President Al Gore, with the U.S. Department of Commerce's National Oceanic and Atmospheric Administration, and with the President's Council on Sustainable Development. He was founding executive director of the labor and environmental partnership, the Apollo Alliance-now the Blue Green Alliance-and has served as an advisor to federal, state, and local policymakers and elected officials, and to the utility industry's Electric Power Research Institute, or EPRI. Hendricks' publications include the book Apollo's Fire: Igniting America's Clean Energy Economy, which he co-authored with Gov. Jay Inslee (D-WA). 
The Center for American Progress is a nonpartisan research and educational institute dedicated to promoting a strong, just and free America that ensures opportunity for all. We believe that Americans are bound together by a common commitment to these values and we aspire to ensure that our national policies reflect these values. We work to find progressive and pragmatic solutions to significant domestic and international problems and develop policy proposals that foster a government that is "of the people, by the people, and for the people."

Center for American Progress 